NIST NCSTAR 1-6C

Federal Building and Fire Safety Investigation of the World Trade Center Disaster

\title{
Component, Connection, and Subsystem Structural Analysis
}

Mehdi S. Zarghamee,

Said Bolourchi

Daniel W. Eggers

Ömer O. Erbay

Frank W. Kan

Yasuo Kitane

Peter R. Barrett

John L. Gross

Therese P. McAllister
Atis A. Liepins

Michael Mudlock

Wassim I. Naguib

Rasko P. Ojdrovic

Andrew T. Sarawit 



\section{Federal Building and Fire Safety Investigation of the World Trade Center Disaster}

\section{Component, Connection, and Subsystem Structural Analysis}

Mehdi S. Zarghamee

Said Bolourchi, Daniel W. Eggers, Ömer O. Erbay, Frank W. Kan, Yasuo Kitane, Atis A. Liepins, Michael Mudlock, Wassim I. Naguib, Rasko P. Ojdrovic, and Andrew T. Sarawit Simpson Gumpertz \& Heger Inc.

Peter R. Barrett

Computer Aided Engineering Associates, Inc.

John L. Gross

Therese P. McAllister

Building and Fire Research Laboratory

National Institute of Standards and Technology

September 2005

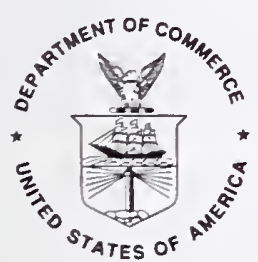

U.S. Department of Commerce

Carlos M. Gutierrez, Secretary

Technology Administration

Michelle O'Neill, Acting Under Secretary for Technology 
Disclaimer No. 1

Certain commercial entities, equipment, products, or materials are identified in this document in order to describe a procedure or concept adequately or to trace the history of the procedures and practices used. Such identification is not intended to imply recommendation, endorsement, or implication that the entities, products, materials, or equipment are necessarily the best available for the purpose. Nor does such identification imply a finding of fault or negligence by the National Institute of Standards and Technology.

\section{Disclaimer No. 2}

The policy of NIST is to use the International System of Units (metric units) in all publications. In this document, however, units are presented in metric units or the inch-pound system, whichever is prevalent in the discipline.

\section{Disclaimer No. 3}

Pursuant to section 7 of the National Construction Safety Team Act, the NIST Director has determined that certain evidence received by NIST in the course of this Investigation is "voluntarily provided safety-related information" that is "not directly related to the building failure being investigated" and that "disclosure of that information would inhibit the voluntary provision of that type of information" (15 USC 7306c).

In addition, a substantial portion of the evidence collected by NIST in the course of the Investigation has been provided to NIST under nondisclosure agreements.

\section{Disclaimer No. 4}

NIST takes no position as to whether the design or construction of a WTC building was compliant with any code since, due to the destruction of the WTC buildings, NIST could not verify the actual (or as-built) construction, the properties and condition of the materials used, or changes to the original construction made over the life of the buildings. In addition, NIST could not verify the interpretations of codes used by applicable authorities in determining compliance when implementing building codes. Where an Investigation report states whether a system was designed or installed as required by a code provision, NIST has documentary or anecdotal evidence indicating whether the requirement was met, or NIST has independently conducted tests or analyses indicating whether the requirement was met.

\section{Use in Legal Proceedings}

No part of any report resulting from a NIST investigation into a structural failure or from an investigation under the National Construction Safety Team Act may be used in any suit or action for damages arising out of any matter mentioned in such report (15 USC 281a; as amended by P.L. 107-231).

National Institute of Standards and Technology National Construction Safety Team Act Report 1-6C Natl. Inst. Stand. Technol. Natl. Constr. Sfty. Tm. Act Rpt. 1-6C, 251 pages (September 2005) CODEN: NSPUE2

\section{U.S. GOVERNMENT PRINTING OFFICE WASHINGTON: 2005}

For sale by the Superintendent of Documents, U.S. Government Printing Office Internet: bookstore.gpo.gov — Phone: (202) 512-1800 — Fax: (202) 512-2250

Mail: Stop SSOP, Washington, DC 20402-0001 


\section{ABSTRACT}

Simpson Gumpertz \& Heger, Inc. (SGH) developed finite element models of the components, connections and subsystems of the World Trade Center (WTC) towers to study their structural performance in the fire environment that followed the aircraft impact to the towers. The results of this study were used to develop global models that captured with numerical efficiency the important failure modes and sequential failures of components and subsystems and to determine the probable sequence of structural responses that let to the global collapse initiation. The study was conducted as part of the investigation on the WTC disaster by the National Institute of Standards and Technology (NIST).

The structural response to the fire environment was established by hand calculations and finite element analyses (FEA) for: connections including interior and exterior truss seats, knuckles, column splices, and spandrel splices; components including a section of the floor system, including concrete slab and a single truss and a single column, and subsystems including full floors and a section exterior wall. The key structural responses, failure modes, and failure loads were identified.

The finite element models, developed in ANSYS, captured the nonlinear responses of the connections, components, and subsystems, including temperature-dependent material properties such as thermal expansion, plasticity and creep of metals, large deflection and the resulting instability, and failure modes of members and connections, modeled by break elements developed for this purpose. The models were subjected to gravity and thermal loads. Construction sequence was included in componcnt models. NIST provided temperature-dependent nonlinear material propcrties, aircraft impact damage to structural members, and temperature time histories of structural elements for subsystems, which were used as input in this study.

The nonlinear analysis of a section of floor system, including break elements that represented the structural performance of interior and exterior truss seats and knuckles, showed that the floor sagged when subjected to high temperatures beyond $600{ }^{\circ} \mathrm{C}$; the main cause of the floor sagging was buckling of truss web diagonals. The sagging floors pulled in the exterior walls. Floor/wall disconnections occurred by the truss walking off their seats after failure of all horizontal connections between the floor and the exterior wall, or by the vertical shear failure of the truss seat, as its capacity was reduced by heat.

The column analysis showed that exterior columns spanning a single floor at low tempcraturcs wcre susceptible to premature buckling initiated by local buckling of plates with rapid reduction of load carrying capacity in the post-buckling regime. This failure mode did not exist when the column was spanning more than one floor or was at high temperatures.

The nonlinear model of the full floor system was developed in ANSYS by converting the existing linear SAP2000 model and by modifying the model to capture the failure modes and the failure loads calculated in the study of components in the fire environment and to enhance computational efficiency. The enhancement was achieved for example by combining double trusses into a single truss to enhance computational efficiency. The model was subjected to the gravity loads and the temperature time histories provided by NIST. The results of analyses performed for all floors with thermal loads showed that the key structural responses of the floors under fire were 1) floor sagging resulting in pull-in forces between the floor and the exterior wall, and 2) disconnections of the floors from the exterior walls. 
A nonlinear model of a section of the exterior wall subsystem consisting of nine floors in height and nine columns in width was developed, including large deflection and inelastic buckling of columns and spandrels and failure of their splices. The model was subjected to gravity loads, including the column loads and NIST provided temperature time histories. The results of the analyses showed that instability of the wall system did not occur when the wall was braced at every floor or when the floor did not restrain the out-of-plane motion of the exterior wall for up to three floors. Bowing and buckling occurred when the wall was subjected to increased column loads or to floor/wall pull-in forces. Furthermore, the exterior column splice failure was rare and occurred by opening of the splices in bending; only in one case was sliding experienced without bolt failure at high temperatures and high vertical loads. Large deformation and buckling of spandrels and partial separations of the spandrel splices were also found in the analysis, but they did not significantly affect the stability of the exterior columns.

Keywords: Collapse, creep, large deflection, nonlinear finite element analysis, plasticity, structural response to damage, structural response to fire, stability, World Trade Center. 


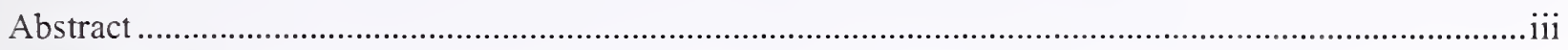

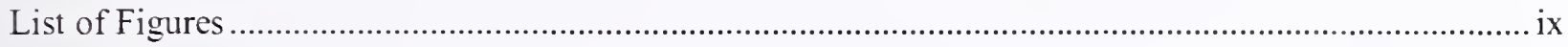

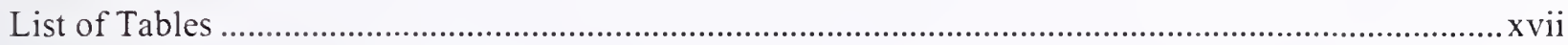

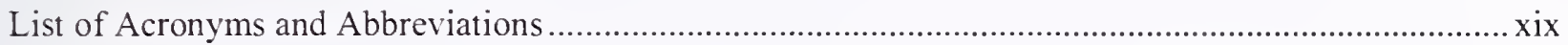

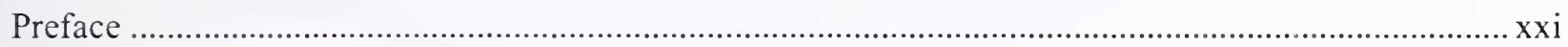

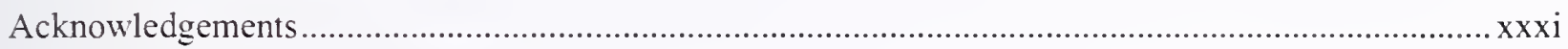

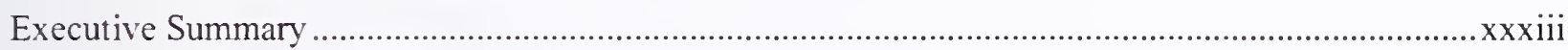

\section{Chapter 1}

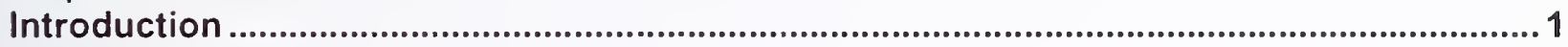

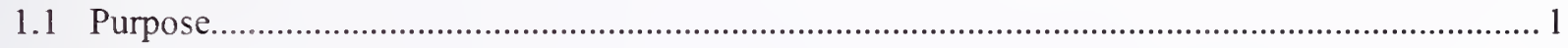

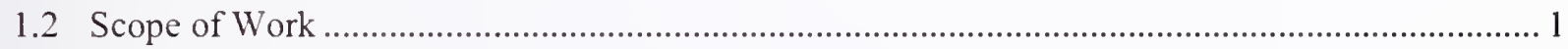

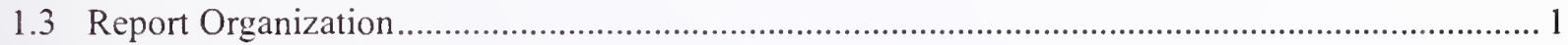

\section{Chapter 2}

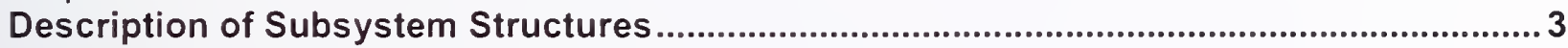

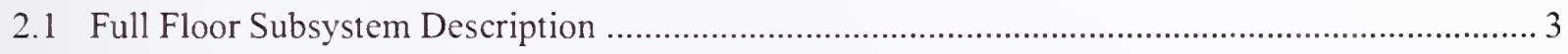

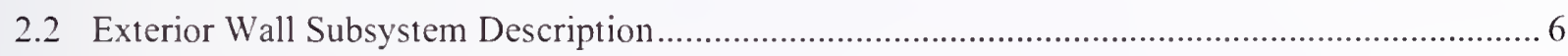

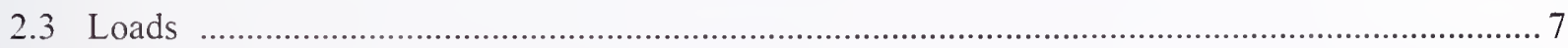

\section{Chapter 3}

Materials

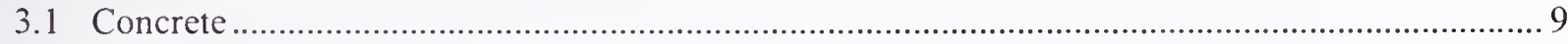

3.1.1 Concrete Properties ................................................................................................... 9

3.1.2 Concrete Stress-Strain Relationships...................................................................... 10

3.1.3 Concrete Failure Criteria ................................................................................... 13

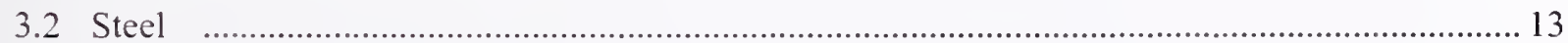

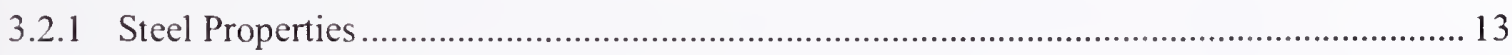

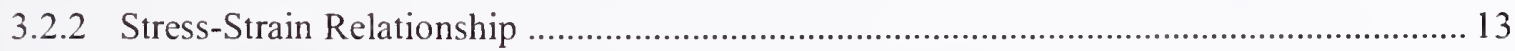

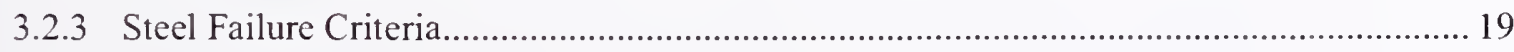

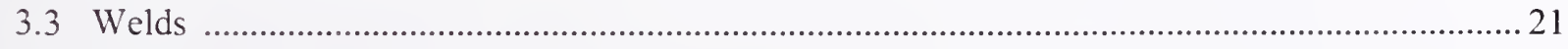

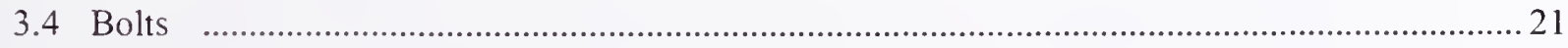

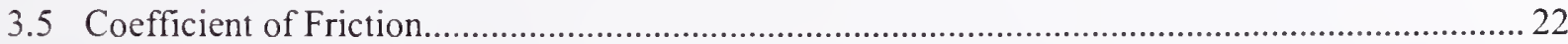


3.6 Symbols

\section{Chapter 4}

Model Conversion From SAP to ANSYS .............................................................. 25

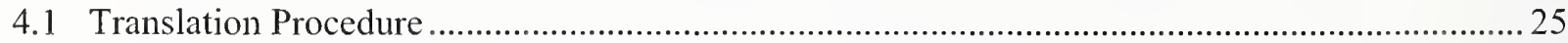

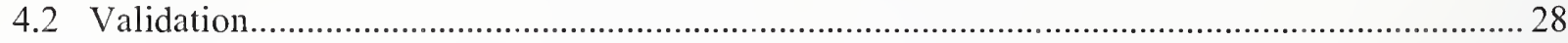

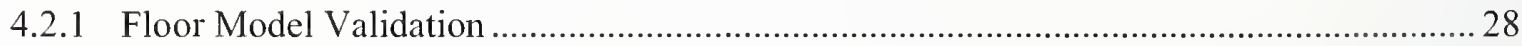

4.2.2 Global Model Validation ..................................................................................... 33

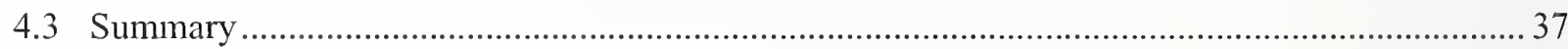

\section{Chapter 5}

Full Floor Subsystem .................................................................................... 39

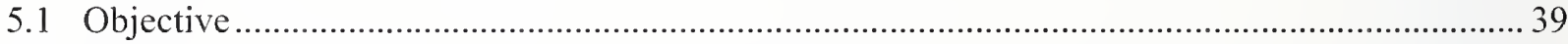

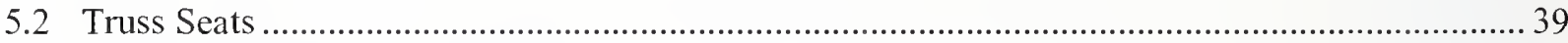

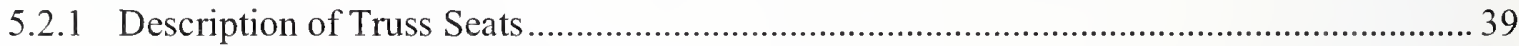

5.2.2 Truss Seat Material Properties.................................................................................. 41

5.2.3 Truss Seat Failure Modes and Sequence ............................................................. 42

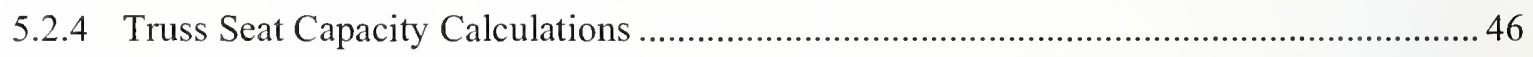

5.2.5 Modeling Failure by Break Elements ........................................................................ 53

5.2.6 Summary of Failure Modes and Finite Element Models of Truss Seats ......................... 55

5.2.7 Summary of Failure Modes and Finite Element Models of the Stud on Strap Anchor and

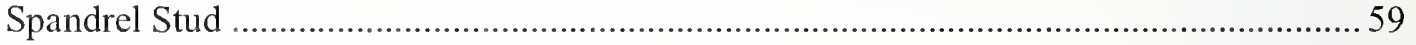

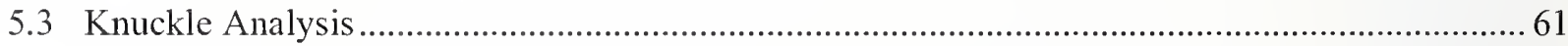

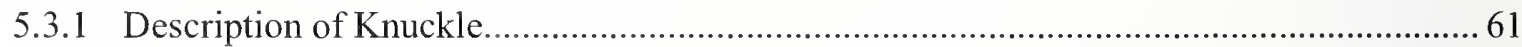

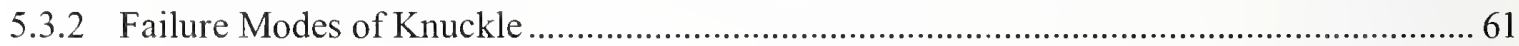

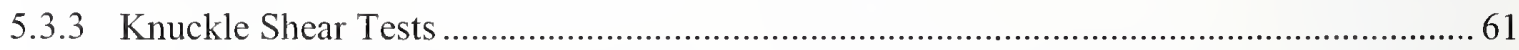

5.3.4 Finite Element Model for Knuckle Test ...................................................................... 63

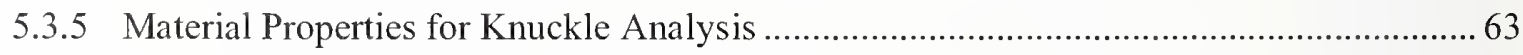

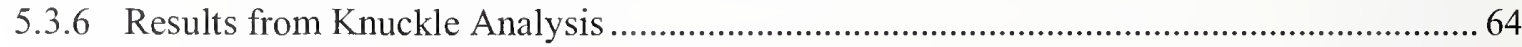

5.3.7 Summary of Failure Modes and Finite Element Models of Knuckle Model for Truss

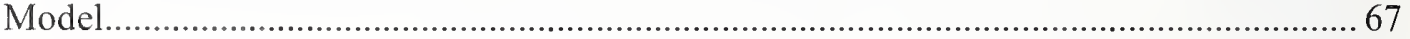

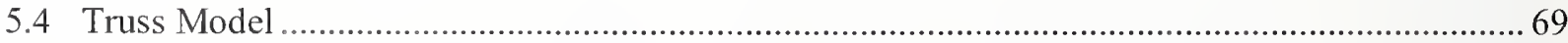

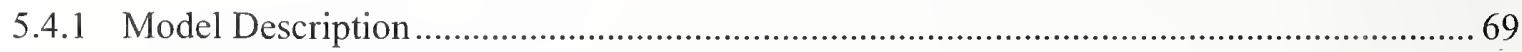

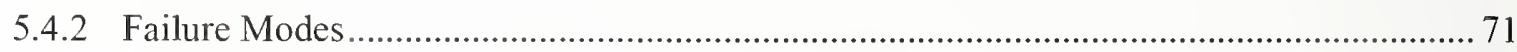

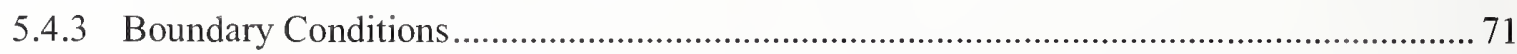

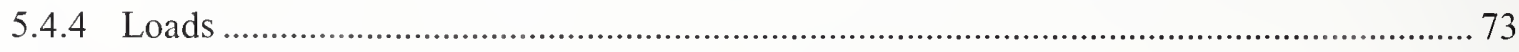

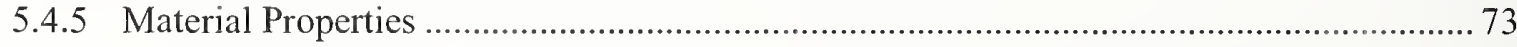




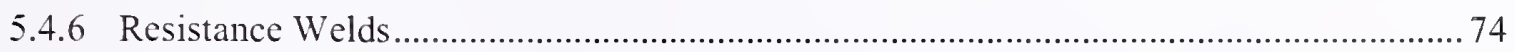

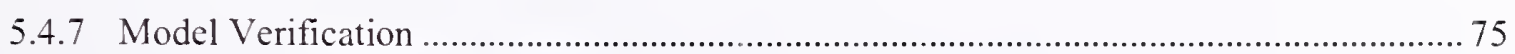

5.4.8 Truss Analysis for Debris Load........................................................................... 75

5.4.9 Truss Analysis for Gravity and Thermal Loads ....................................................... 77

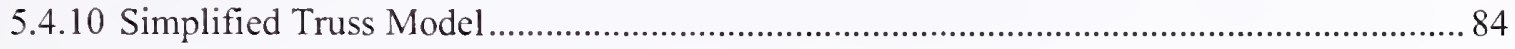

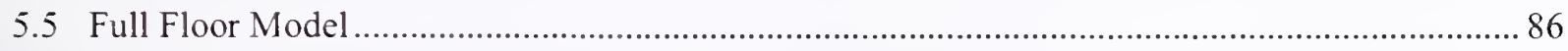

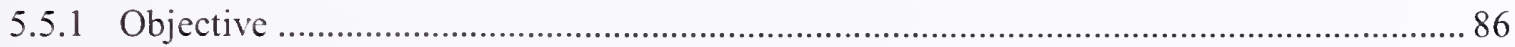

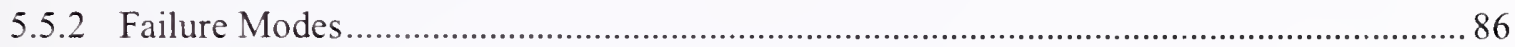

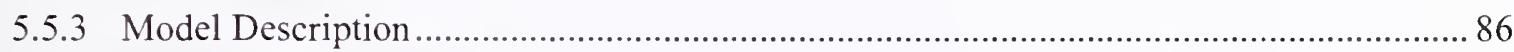

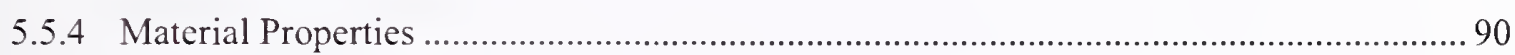

5.5.5 User-Defined Break Elements ...................................................................... 91

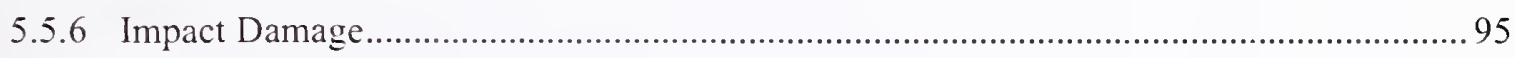

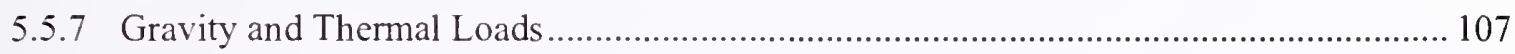

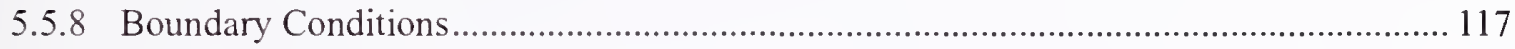

5.5.9 Results from WTC 1 Floor 96 under Case $\mathrm{A}_{\mathrm{i}}$ Temperature Condition ......................... 117

5.5.10 Results from Other WTC 1 Floors under Case $\mathrm{A}_{\mathrm{i}}$ Temperature Condition..................... 122

5.5.11 Results from WTC 1 Floors under Case $B_{i}$ Temperature Condition ............................. 127

5.5.12 Results from WTC 2 Floor 82 under Case $C_{i}$ Temperature Condition........................... 133

5.5.13 Results from Other WTC 2 Floors under Case $C_{i}$ Temperature Condition..................... 138

5.5.14 Results from WTC 2 Floors under Case $D_{1}$ Temperature Condition............................. 142

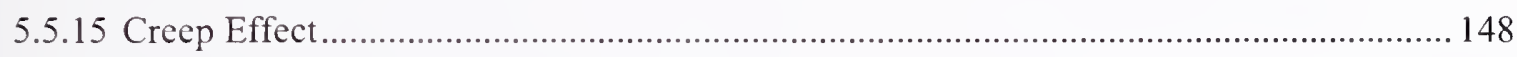

5.5.16 Effect of Column Boundary Conditions ............................................................. 148

5.5.17 Floor Subsystem in Global Models .................................................................. 149

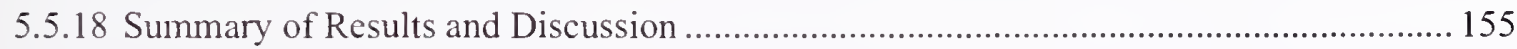

\section{Chapter 6}

Exterior Wall Subsystem ................................................................................. 157

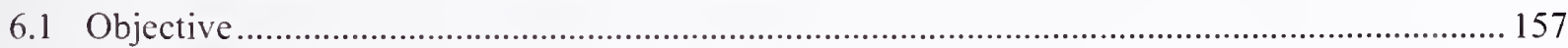

6.2 Exterior Wall Subsystem Description .......................................................................... 157

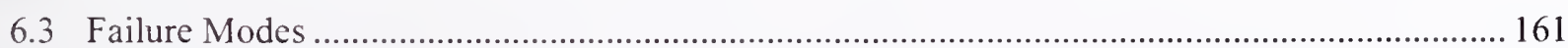

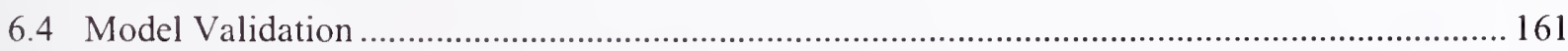

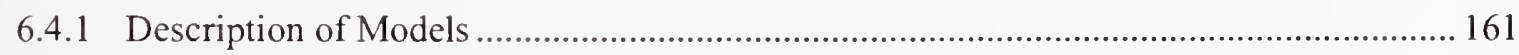

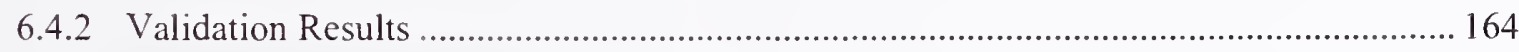

6.5 Finite-Element Model of Exterior Wall Subsystem............................................................ 165

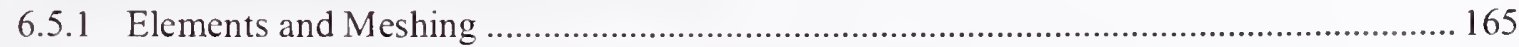




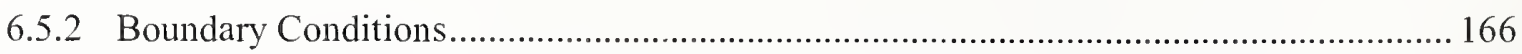

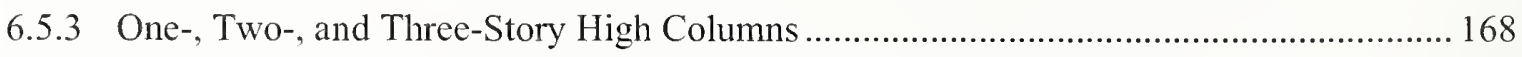

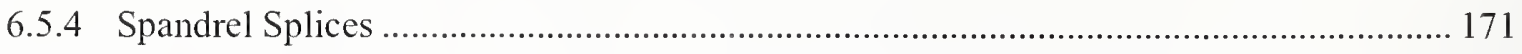

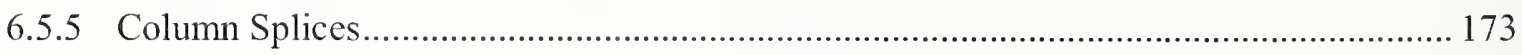

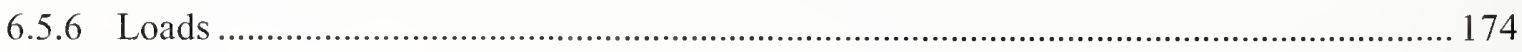

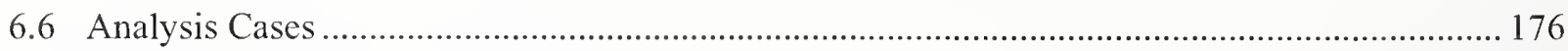

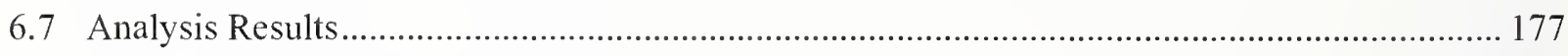

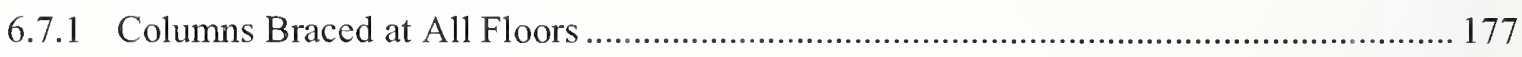

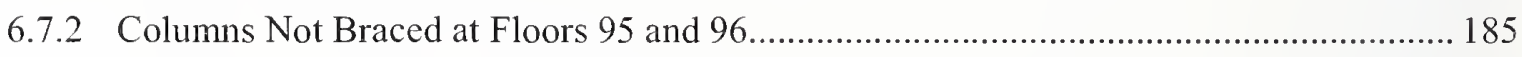

6.7.3 Columns Not Braced at Floors 95, 96, and 97..................................................... 186

6.7.4 Columns Not Braced and Pulled at Unbraced Floors 95, 96, and 97 .......................... 188

6.7.5 Columns Not Braced at Floors 95, 96, and 97 and Pushed Down at Top ..................... 191

6.8 Summary and Discussion of Exterior Wall Analysis Results ............................................. 196

6.8.1 Columns Braced at All Floors ........................................................................ 196

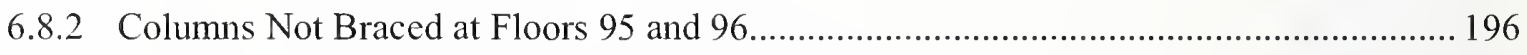

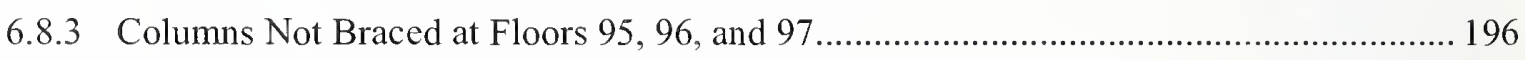

6.8.4 Columns Not Braced and Pulled in at Floors 95, 96, and 97................................... 197

6.8.5 Columns Not Braced at Floors 95, 96, and 97 and Columns Pushed Down at Top ........ 197

6.8.6 Summary of Analysis Results ........................................................................... 198

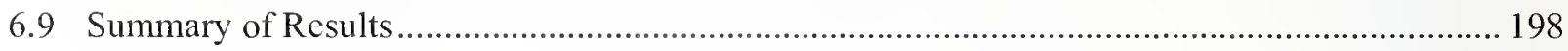

\section{Chapter 7}

Modeling Details for Subsystems in Global Models..................................................... 201

\section{Chapter 8}

References. 


\section{LIST OF FIGURES}

Figure $\mathrm{P}-1$. The eight projects in the federal building and fire safety investigation of the WTC disaster. .xxiii

Figure 2-1. Mock up of office floor framing system (Photograph from about 1967 provided by Laclede Steel Co.). 4

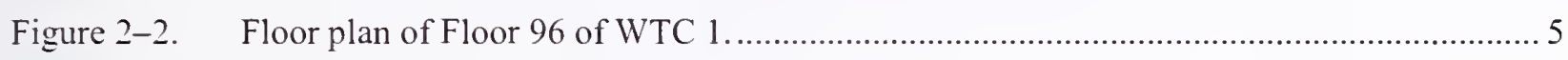

Figure 2-3. Exterior wall construction with prefabricated wall panels......................................... 7

Figure $3-1 . \quad$ Properties of concrete that vary with temperature ................................................ 11

Figure 3-2. Concrete stress-strain relationships at different temperatures...................................... 12

Figure 3-3. Properties for all steel types that vary with temperature ............................................. 14

Figure 3-4. Steel (Material ID 1) stress-strain relationships at different temperatures......................... 16

Figure 3-5. Comparison of creep strains with $a(T)$ given by (7-a) and (7-d) for Material ID 1 steel subject to $15 \mathrm{ksi}$ for $1,800 \mathrm{~s}$ at a given temperature. ........................................... 18

Figure 3-6. Creep behavior at elevated temperatures for Material ID 1 steel................................... 19

Figure 3-7. Maximum plastic strain from the finite element analysis and limiting plastic strain.......... 21

Figure 3-8. $\quad 7 / 8$ in. A325 bolt load-elongation curves at elevated temperatures................................. 22

Figure 4-1. Converted ANSYS model for Floor 96 of WTC 1: overall view....................................28

Figure 4-2. Converted ANSYS model for Floor 96 of WTC 1: partial view near corner of building.

Figure 4-3. Converted ANSYS model for Floor 96 of WTC 1: close-up view at corner of building.

Figure 4-4. Converted ANSYS model for Floor 96 of WTC 1: view of floor beams and columns......30

Figure 4-5. Deformed shape (x100) of gravity load case for SAP floor model (downward displacement is negative). 30

Figure 4-6. Deformed shape (x100) of gravity load case for ANSYS floor model (total displacements are shown).

Figure 4-7. Dominant mode shape (frequency $=4.32 \mathrm{~Hz}$ ) of floor structure for SAP floor model. ...... 32

Figure 4-8. Dominant mode shape (frequency $=4.43 \mathrm{~Hz}$ ) of floor structure for ANSYS floor

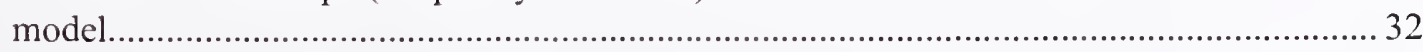

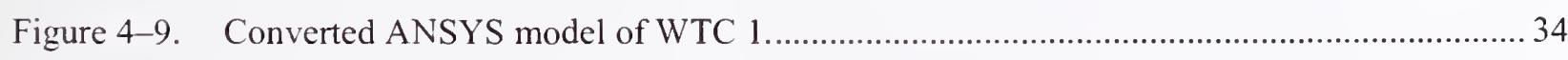

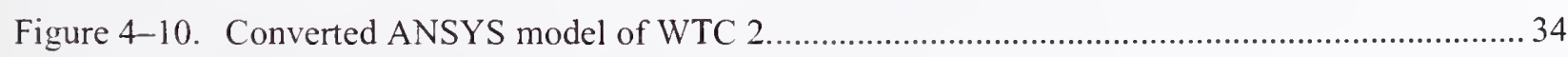

Figure 4-11. Displaced shape of WTC 1 at the end of gravity analysis. ..........................................35 
Figure 4-12. Displaced shape of WTC 2 at the end of gravity analysis. 35

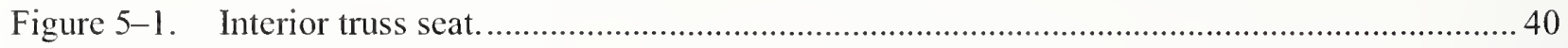

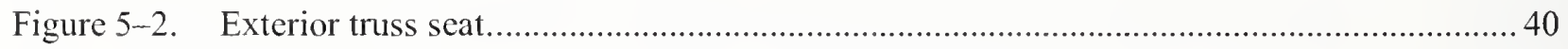

Figure 5-3. Truss seat detail location on northeast quadrant of Floor 96 of WTC 1 .........................4 41

Figure 5-4. Finite element model of exterior truss seat. .......................................................... 43

Figure 5-5. Failure sequence of the exterior truss seats against tensile force......................................4 44

Figure 5-6. Capacity of exterior truss seat for tensile force (Path (A) in Fig. 5-5 for Dctail

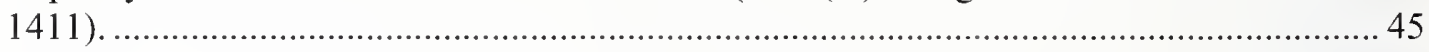

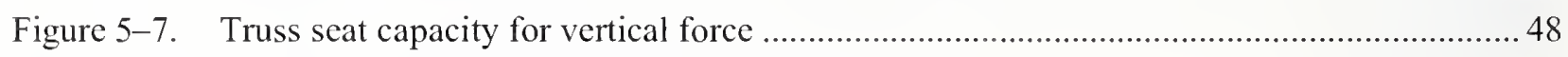

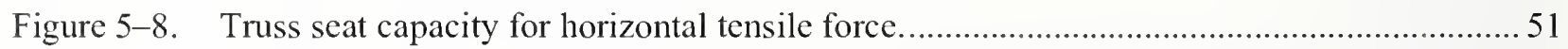

Figure 5-9. Capacity of interior truss seat against vertical and horizontal force (for Detail 22).......... 52

Figure 5-10. Basic mathematical model of connection failure....................................................5 54

Figure 5-11. Representation of interior truss seat by break clements........................................... 56

Figure 5-12. Results of interior truss seat model capturing failure from truss walking off the seat at $500{ }^{\circ} \mathrm{C}$.

Figure 5-13. Results of interior truss seat modcl capturing failure from exceeding the vertical shear capacity at $500{ }^{\circ} \mathrm{C}$.

Figure 5-14. Representation of exterior truss seat by break elements. ..............................................5 58

Figure 5-15. Location of stud on strap anchor and spandrel stud....................................................59

Figure 5-16. Representation of stud shear connector by break elements............................................ 60

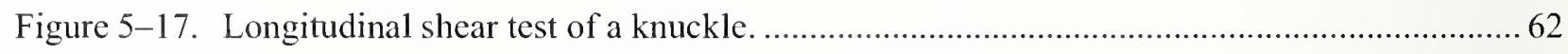

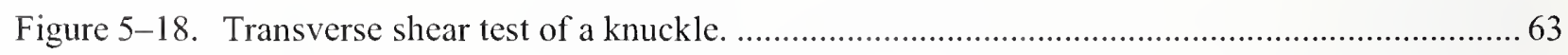

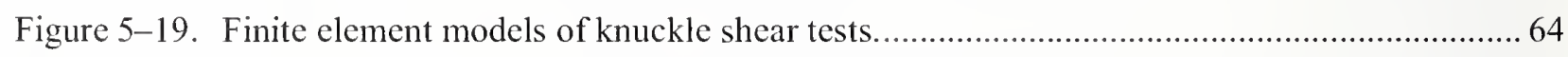

Figure 5-20. Compressive stresses in longitudinal shear finite element model $(4,100$ psi concrete) .....65

Figure 5-21. Shear force versus displacement from finite element model for longitudinal shear of

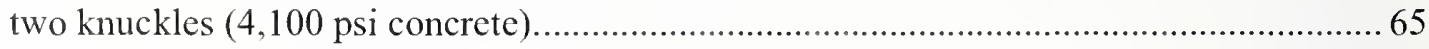

Figure 5-22. Compressive stresses in transverse shear finite elcment model (2,500 psi concrete)........66

Figure 5-23. Shear force versus displacement from finite element model for transverse shear of two knuckles (2,500 psi concrete). 66

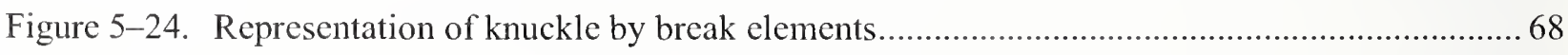

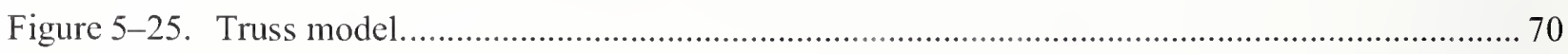

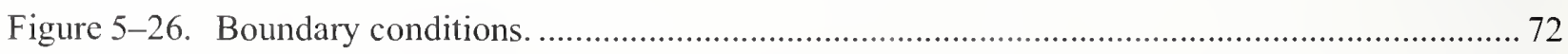

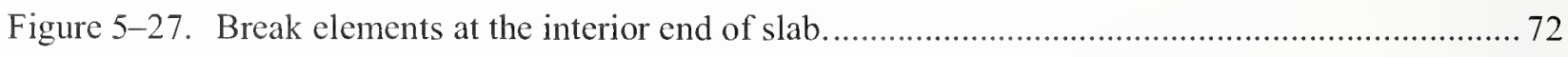

Figure 5-28. Assumed Temperature Distribution in the Truss Model at 30 min.................................. 73 
Figure 5-29. Comparison of resistance weld strength and yield strength of web member at

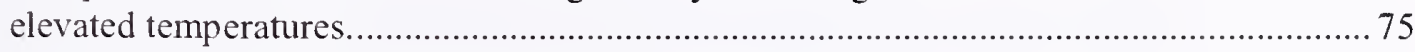

Figure 5-30. Finite element analysis results from increasing gravity............................................. 76

Figure 5-31. Vertical displacement at $700{ }^{\circ} \mathrm{C}$ (downward displacement is negative).......................... 77

Figure 5-32. Displacement versus temperature of steel.............................................................. 78

Figure 5-33. Element numbers and locations of elements examined for axial force............................. 79

Figure 5-34. Axial force in truss members versus temperature of steel. ............................................ 80

Figure 5-35. Axial stress contour in the truss members at $700{ }^{\circ} \mathrm{C}$ (tension is positive; $1.0 \mathrm{x}$ displacement magnification).

Figure 5-36. Force in the knuckles versus temperature of steel. ................................................... 82

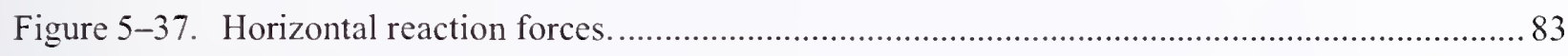

Figure 5-38. Comparison of detailed and simplified truss models................................................. 85

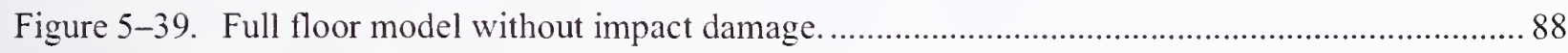

Figure 5-40. Full floor model after removal of deck support angles, spandrel studs, bridging trusses outside of two-way zones, and strap anchors................................................... 90

Figure 5-41. Bilinear material model for concrete slab in the full floor model.................................. 91

Figure 5-42. Bilinear material model in the spandrel. ............................................................... 91

Figure 5-43. Summary of user-defined break element locations in the full floor model.......................93

Figure 5-44. User-defined break element locations in the full floor model (Floor 96, WTC 1).............94

Figure 5-45. Case $A_{i}$ insulation damage condition for WTC 1 floor trusses and beams. .....................96

Figure 5-46. Case $A_{i}$ structural damage condition for WTC 1 floors..............................................97

Figure 5-47. Structural damage to exterior walls of WTC 1 for Case $A_{i}$ and Case $B_{i}$ impact

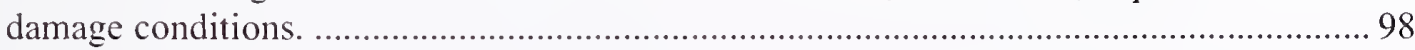

Figure 5-48. Structural damage to core columns of WTC 1 for Case $A_{i}$ impact damage condition........ 99

Figure 5-49. Case $C_{i}$ insulation damage condition for WTC 2 floor trusses and beams.................... 100

Figure 5-50. Case $\mathrm{C}_{\mathrm{i}}$ structural damage condition for WTC 2 floors. .............................................. 101

Figure 5-51. Case $D_{1}$ insulation damage condition for WTC 2 floor trusses and beams................... 102

Figure 5-52. Case $D_{1}$ structural damage condition for WTC 2 floors............................................... 103

Figure 5-53. Structural damage to exterior walls of WTC 2 for Case $C_{i}$ and Case $D_{i}$ impact

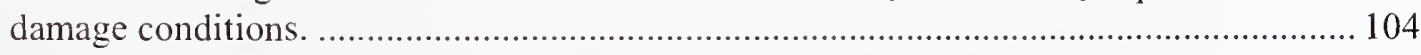

Figure 5-54. Structural damage to core columns of WTC 2 for Case $C_{i}$ impact damage condition...... 104

Figure 5-55. Case $A_{i}$ structural impact damage condition for exterior columns of the north face in the WTC 1 Floor 96 model. 105

Figure 5-56. Case $A_{i}$ structural impact damage condition for exterior columns of the south face in the WTC 1 Floor 96 model. 105

Figure 5-57. Case $A_{i}$ structural impact damage condition for floor trusses in the WTC 1 Floor 96 model. 
Figure 5-58. Case $A_{i}$ structural impact damage condition for the concrete slab in the WTC 1 Floor 96 model.

Figure 5-59. Case $A_{i}$ structural impact damage condition for core beams in the WTC 1 Floor 96 model

Figure 5-60. Case $A_{i}$ structural impact damage condition for core columns in the WTC 1 Floor 96 model.

Figure 5-61. Design live load distribution in Floor 96 of WTC 1 108

Figure 5-62. Case $A_{i}$ temperature condition for Floor 96 of WTC 1 at $10 \mathrm{~min}, 50 \mathrm{~min}$, and $100 \mathrm{~min}$.

Figure 5-63. Case $A_{i}$ temperature distribution in the slab for Floor 96 of WTC 1 at 10 min, $50 \mathrm{~min}$, and $100 \mathrm{~min}$.

Figure 5-64. Case $\mathrm{B}_{\mathrm{i}}$ temperature condition for Floor 96 of WTC 1 at $10 \mathrm{~min}, 50 \mathrm{~min}$, and $100 \mathrm{~min}$.

Figure 5-65. Case $\mathrm{B}_{\mathrm{i}}$ temperature distribution in the slab for Floor 96 of WTC 1 at $10 \mathrm{~min}, 50 \mathrm{~min}$, and $100 \mathrm{~min}$.

Figure 5-66. Case $C_{i}$ temperature condition for Floor 82 of WTC 2 at $10 \mathrm{~min}, 30 \mathrm{~min}$, and $60 \mathrm{~min} . \ldots .113$

Figure 5-67. Case $C_{i}$ temperature distribution in the slab for Floor 82 of WTC 2 at $10 \mathrm{~min}, 30 \mathrm{~min}$, and $60 \mathrm{~min}$

Figure 5-68. Case $D_{1}$ temperature condition for Floor 82 of WTC 2 at $10 \mathrm{~min}, 30 \mathrm{~min}$, and $60 \mathrm{~min} \ldots . .115$

Figure 5-69. Case $D_{i}$ temperature distribution in the slab for Floor 82 of WTC 2 at $10 \mathrm{~min}$, $30 \mathrm{~min}$, and $60 \mathrm{~min}$.

Figure 5-70. Vertical displacement of WTC 1 Floor 96 for Case $A_{i}$ temperature condition at $10 \mathrm{~min}, 50 \mathrm{~min}$, and $100 \mathrm{~min}$ (downward displacement is negative; $5 \mathrm{x}$ displacement magnification).

Figure 5-71. Horizontal displacement of exterior columns of Floor 96 of WTC 1 for Case $A_{i}$ temperature condition at $10 \mathrm{~min}, 50 \mathrm{~min}$, and $100 \mathrm{~min}$.

Figure 5-72. Horizontal reaction force per column of WTC 1 Floor 96 for Case $A_{1}$ temperature condition.

Figure 5-73. User-defined break elements that failed by $100 \mathrm{~min}$ in the model of WTC 1 Floor 96 for Case $A_{i}$ temperature condition.

Figure 5-74. Vertical displacement of WTC 1 Floor 93 for Case $A_{i}$ temperature condition at $30 \mathrm{~min}$ (downward displacement is negative; $5 \mathrm{x}$ displacement magnification).

Figure 5-75. Vertical displacement of WTC 1 Floor 94 for Case $A_{i}$ temperature condition at 100 min (downward displacement is negative; $5 \mathrm{x}$ displacement magnification).

Figure 5-76. Vertical displacement of WTC 1 Floor 95 for Case $A_{1}$ temperature condition at $10 \mathrm{~min}$ (downward displacement is negative; $5 \mathrm{x}$ displacement magnification).

Figure 5-77. Vertical displacement of WTC 1 Floor 97 for Case $A_{i}$ temperature condition at $60 \mathrm{~min}$ (downward displacement is negative; $5 \mathrm{x}$ displacement magnification).

Figure 5-78. Vertical displacement of WTC 1 Floor 98 for Case $A_{j}$ temperature condition at $30 \mathrm{~min}$ (downward displacement is negative; $5 \mathrm{x}$ displacement magnification). 
Figure 5-79. Vertical displacement of WTC 1 Floor 99 for Case $\mathrm{A}_{\mathrm{i}}$ tcmperature condition at $50 \mathrm{~min}$ (downward displacement is negative; $5 \mathrm{x}$ displaccment magnification).

Figure 5-80. Average thermal expansion of WTC 1 floors at $100 \mathrm{~min}$ for Case $\mathrm{A}_{i}$ temperature condition.

Figure 5-81. Horizontal reaction force per column of WTC 1 Floor 97 for Case $A_{i}$ temperature condition.

Figure 5-82. Vertical displacement of WTC 1 Floor 93 for Case $\mathrm{B}_{\mathrm{i}}$ tempcrature condition at $100 \mathrm{~min}$ (downward displacement is negative; $5 \mathrm{x}$ displacement magnification).

Figure 5-83. Vertical displacement of WTC 1 Floor 94 for Case $\mathrm{B}_{i}$ temperature condition at $100 \mathrm{~min}$ (downward displacement is negative; $5 \mathrm{x}$ displacement magnification).

Figure 5-84. Vertical displacement of WTC 1 Floor 95 for Case $\mathrm{B}_{\mathrm{i}}$ temperature condition at $10 \mathrm{~min}$ (downward displacement is negative; $5 \mathrm{x}$ displacement magnification).

Figure 5-85. Vertical displacement of WTC 1 Floor 96 for Case $B_{i}$ temperature condition at $10 \mathrm{~min}$ (downward displacement is negative; $5 \mathrm{x}$ displacement magnification).

Figure 5-86. Vertical displacement of WTC 1 Floor 97 for Case $\mathrm{B}_{1}$ temperature condition at $100 \mathrm{~min}$ (downward displacement is negative; $5 \mathrm{x}$ displacement magnification).

Figure 5-87. Vertical displacement of WTC 1 Floor 98 for Case $B_{i}$ tempcrature condition at $100 \mathrm{~min}$ (downward displacement is negative; $5 \mathrm{x}$ displacement magnification).

Figure 5-88. Vertical displacement of WTC 1 Floor 99 for Case $\mathrm{B}_{i}$ temperature condition at $100 \mathrm{~min}$ (downward displacement is negative; $5 \mathrm{x}$ displacement magnification).

Figure 5-89. Loss of vertical supports in Floor 97 and Floor 98 of WTC 1 for Case $\mathrm{B}_{1}$ temperature condition at $100 \mathrm{~min}$ ( $1 \mathrm{x}$ displacement magnification).....

Figure 5-90. Thermal expansion of WTC 1 floors at $100 \mathrm{~min}$ for Case $\mathrm{B}_{\mathrm{i}}$ conditions.

Figure 5-91. Horizontal reaction force per column of WTC 1 Floor 96 for Case $B_{i}$ temperature condition.

Figure 5-92. Horizontal reaction force per column of WTC 1 Floor 98 for Case $B_{i}$ temperature condition.

Figure 5-93. Vertical displacement of WTC 2 Floor 82 for Case $\mathrm{C}_{\mathrm{i}}$ temperature condition at $10 \mathrm{~min}, 30 \mathrm{~min}$, and $60 \mathrm{~min}$ (downward displacement is negative; 5x displacement magnification).

Figure 5-94. Horizontal displacement of exterior columns of WTC 2 Floor 82 for Case $C_{i}$ temperature condition at $10 \mathrm{~min}, 30 \mathrm{~min}$, and $60 \mathrm{~min}$.

Figure 5-95. Total horizontal reaction at exterior columns on east and west faces of WTC 2 Floor 82 for Case $\mathrm{C}_{\mathrm{i}}$ conditions.

Figure 5-96. User-defined break elements that failed by $60 \mathrm{~min}$ in the model of WTC 2 Floor 82 for Case $\mathrm{C}_{\mathrm{i}}$ temperature condition.

Figure 5-97. Loss of vertical supports in Floor 82 of WTC 2 for Case $C_{i}$ temperature condition at 60 min (1x displacement magnification).

Figure 5-98. Vertical displacement of WTC 2 Floor 79 for Case $C_{i}$ temperature condition at $60 \mathrm{~min}$ (downward displacement is negative; $5 \mathrm{x}$ displacement magnification). 
Figure 5-99. Vertical displacement of WTC 2 Floor 80 for Case $C_{i}$ temperature condition at $60 \mathrm{~min}$ (downward displacement is negative; $5 \mathrm{x}$ displacement magnification).

Figure 5-100. Vertical displacement of WTC 2 Floor 81 for Case $C_{i}$ temperature condition at $60 \mathrm{~min}$ (downward displacement is negative; $5 \mathrm{x}$ displacement magnification).

Figure 5-101. Vertical displacement of WTC 2 Floor 83 for Case $C_{i}$ temperature condition at $60 \mathrm{~min}$ (downward displacement is negative; $5 \mathrm{x}$ displacement magnification).

Figure 5-102. Average thermal expansion of WTC 2 floors at 60 min under Case $C_{i}$ temperature condition.

Figure 5-103. Horizontal reaction force per column of WTC 2 Floor 81 for Case $C_{1}$ temperature condition.

Figure 5-104. Loss of vertical supports in Floor 83 of WTC 2 for Case $C_{i}$ temperature condition at $60 \mathrm{~min}$ (3X displacement magnification).

Figure 5-105. Vertical displacement of WTC 2 Floor 79 for Case $D_{i}$ temperature condition at $60 \mathrm{~min}$ (downward displacement is negative; 5x displacement magnification).

Figure 5-106. Vertical displacement of WTC 2 Floor 80 for Case $\mathrm{D}_{\mathrm{i}}$ temperature condition at $40 \mathrm{~min}$ (downward displacement is negative; $5 \mathrm{x}$ displacement magnification).

Figure 5-107. Vertical displacement of WTC 2 Floor 81 for Case $\mathrm{D}_{\mathrm{i}}$ temperature condition at $50 \mathrm{~min}$ (downward displacement is negative; $5 \mathrm{x}$ displacement magnification).

Figure 5-108. Vertical displacement of WTC 2 Floor 82 for Case $\mathrm{D}_{\mathrm{i}}$ temperature condition at $60 \mathrm{~min}$ (downward displacement is negative; $5 \mathrm{x}$ displacement magnification).

Figure 5-109. Vertical displacement of WTC 2 Floor 83 for Case $\mathrm{D}_{1}$ temperature condition at $60 \mathrm{~min}$ (downward displacement is negative; $5 \mathrm{x}$ displacement magnification).

Figure 5-110. Horizontal reaction force per column of WTC 2 Floor 80 for Case $D_{1}$ temperature condition.

Figure 5-111. Horizontal reaction force per column of WTC 2 Floor 82 for Case $\mathrm{D}_{\mathrm{i}}$ temperature condition.

Figure 5-112. Average thermal expansion of WTC 2 floors at $60 \mathrm{~min}$ for Case $\mathrm{D}_{\mathrm{i}}$ temperature condition.

Figure 5-113. Vertical displacement of a simplified truss model at Column 333 extracted from the full floor model of Floor 96 of WTC 1 under Case $B_{i}$ temperature condition at $40 \mathrm{~min}$ (downward displacement is negative).

Figure 5-114. Conditions of connections between the exterior wall and the floors of WTC 1 for Case $\mathrm{A}_{\mathrm{i}}$ temperature condition at $100 \mathrm{~min}$.

Figure 5-1 15. Conditions of connections between the exterior wall and the floors of WTC 1 for

Case $\mathrm{B}_{\mathrm{i}}$ temperature condition at $100 \mathrm{~min}$.

Figure 5-116. Conditions of connections between the exterior wall and the floors of WTC 2 for

Case $\mathrm{C}_{\mathrm{i}}$ temperature condition at $60 \mathrm{~min}$.

Figure 5-117. Conditions of connections between the exterior wall and the floors of WTC 2 for Case $\mathrm{D}_{1}$ temperature condition at $60 \mathrm{~min}$.

Figure 6-1. Exterior wall subsystem structure. 158 
Figure 6-2. Columns, spandrels, and splices: type and material assignments.

Figure 6-3. Schematic of column cross section.

Figure 6-4. SAP2000 model of prefabricated panel.

Figure 6-5. ANSYS model of prefabricated panel showing meshing.

Figure 6-6. ANSYS model of prefabricated panel showing boundary conditions and loading (loads applied separately).

Figure 6-7. Deflection of prefabricated panel under $100 \mathrm{kip} \mathrm{lateral} \mathrm{load.}$

Figure 6-8. Deflection of prefabricated panel under $100 \mathrm{kip}$ transverse load. 164

Figure 6-9. Deflection of prefabricated panel under $10 \mathrm{kip}$ vertical load. 165

Figure 6-10. Exterior wall subsystem model with boundary conditions. 166

Figure 6-11. Typical meshing of exterior wall model components. 167

Figure 6-12. Schematic representation of columns used in the exterior wall model. 167

Figure 6-13. One-story exterior column model. 169

Figure 6-14. Load-deflection of column at room temperature and $700^{\circ} \mathrm{C}$. 169

Figure 6-15. Local buckling of column at room temperature. 170

Figure 6-16. Plastic hinge in column at room temperature. 170

Figure 6-17. Deformed shape of column at maximum axial load at $700{ }^{\circ} \mathrm{C}$. 171

Figure 6-18. Typical spandrel splice layout for exterior wall subsystem. 172

Figure 6-19. Modeling of a typical interior spandrel splice in the exterior wall model. 172

Figure 6-20. Column splice model used in exterior wall model. 173

Figure 6-21. Exterior wall model temperature time-histories. 175

Figure 6-22. Structural response for temperature time history D with all floors supported................. 178

Figure 6-23. Structural response for temperature time history DBARE with all floors supported. ....... 179

Figure 6-24. Structural response for temperature time history E (hot bolts) with all floors supported.

Figure 6-25. Structural response for temperature time history E1 19 with all floors supported. 182

Figure 6-26. Structural response for temperature time history F with all floors supported..... 184

Figure 6-27. Structural response for temperature time history DBARE with two unbraced floors. 185

Figure 6-28. Structural response for time history DBARE with three unbraced floors. 187

Figure 6-29. Structural response for temperature time history DBARE with pull-in forces at three floors (10X displacement magnification).

Figure 6-30. Column splice bolt stresses for temperature time history and DBARE with pull-in forces at three floors.

Figure 6-31. Column splice contact element status for temperature time history and DBARE with pull-in forces at three floors. 
Figure 6-32. Structural response for temperature time history DBARE and push-down with three unbraced floors (10X displacement magnification).

Figure 6-33. Column splice response for temperature time history DBARE and push-down with three unbraced floors.

Figure 6-34. Sum of total column reaction forces at base during push-down after application of temperature DBARE with three unbraced floors.

Figure 6-35. Sum of additional vertical reaction forces at base induced by imposed displacement during push-down after application of temperature DBARE with three unbraced floors.

Figure 6-36. Individual total column reaction forces at base during push-down after application of temperature DBARE with three unbraced floors.

Figure 6-37. Individual additional column reaction forces at base induced by imposed vertical displacement during push-down after application of temperature DBARE with three unbraced floors.

Figure 6-38. Difference between the additional individual column reaction forces at base and the vertical force applied at the top of each column during push-down after application of tempcrature DBARE with three unbraced floors.

Figure 6-39. Transverse deflection during push-down after application of temperature DBARE with three unbraced floors 


\section{LIST OF TABLES}

Table P-1. Federal building and fire safety investigation of the WTC disaster................................x

Table P-2. Public meetings and briefings of the WTC Investigation. ........................................... xxv

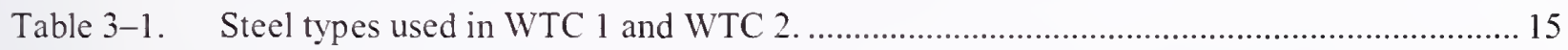

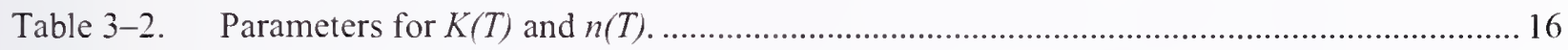

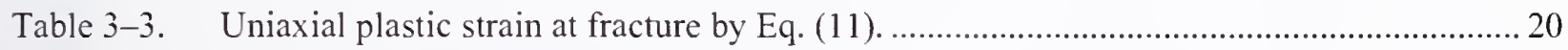

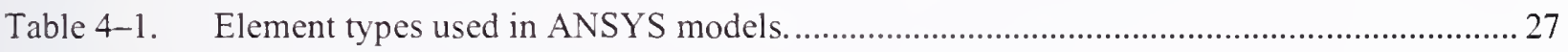

Table 4-2. Comparison of SAP and ANSYS results for gravity load case.....................................2 28

Table 4-3. Comparison of SAP and ANSYS floor model modal analysis results............................. 31

Table 4-4. Comparison of maximum displacements and base reactions of WTC 1 from

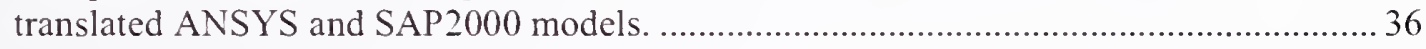

Table 4-5. Comparison of maximum displacements and base reactions of WTC 2 obtained from

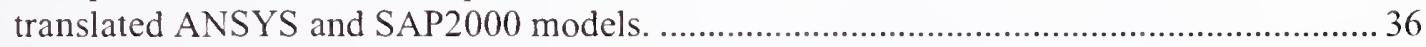

Table 4-6. Comparison of axial forces in randomly selected elements from WTC 1 model at the

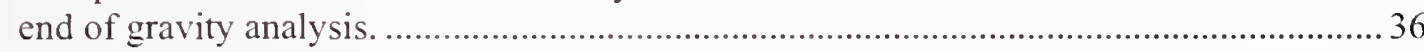

Table 4-7. Comparison of axial forces in randomly selected elements from WTC 2 model at the

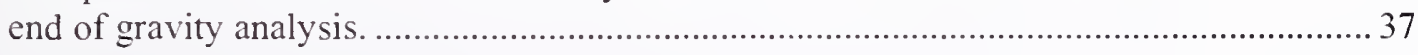

Table 5-1. Materials used for truss seat calculations.............................................................. 42

Table 5-2. Exterior truss seat capacity for vertical force........................................................ 47

Table 5-3. Interior truss seat capacity for vertical force............................................................. 47

Table 5-4. Exterior truss seat capacity for horizontal tensile force ................................................ 50

Table 5-5. Interior truss seat capacity against horizontal tensile force .......................................... 50

Table 5-6. Compression strength of gusset plate.................................................................... 52

Table 5-7. Temperature-dependent knuckle capacity for assumed temperatures............................. 67

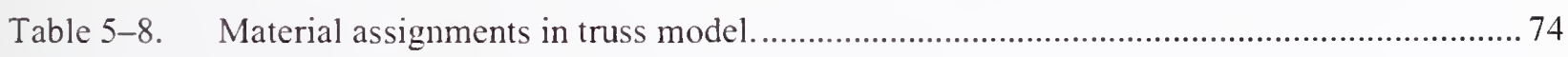

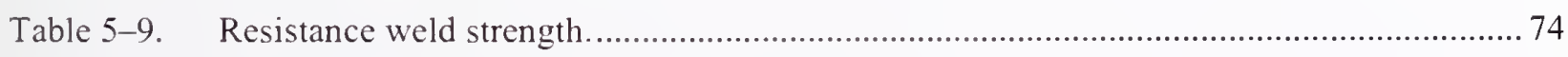

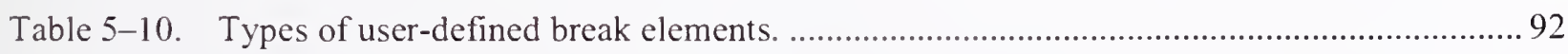

Table 5-11. Number of user-defined break elements in the full floor model (Floor 96, WTC 1).......... 94

Table 5-12. List of full floor model analyses performed............................................................. 117

Table 5-13. Number of failed user-defined break elements in the model of WTC 1 Floor 96 for Case $\mathrm{A}_{i}$ temperature condition. 
Table 5-14. Maximum vertical displacement of WTC 1 floors for Case $A_{i}$ temperature condition. ... 123

Table 5-15. Maximum vertical displacement of WTC 1 floors for Case $B_{i}$ temperature condition...... 128

Table 5-16. Number of failed user-defined break elements in the model of WTC 2 Floor 82 for Case $\mathrm{C}_{\mathrm{i}}$ temperature condition. 138

Table 5-17. Maximum vertical displacement of WTC 2 floors for Case $\mathrm{C}_{\mathrm{i}}$ temperature condition...... 139

Table 5-18. Maximum vertical displacement of WTC 2 floors for Case $\mathrm{D}_{\mathrm{i}}$ temperature condition. .... 143

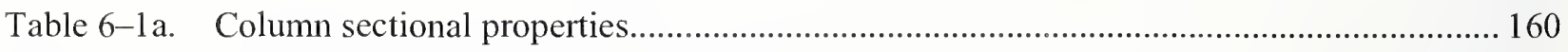

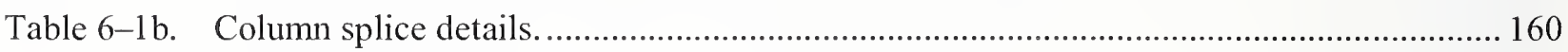

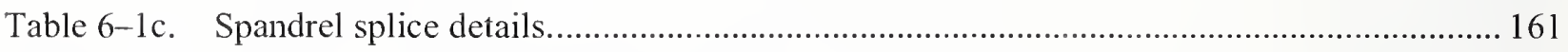

Table 6-2. Prefabricated panel validation results. ................................................................. 165

Table 6-3. Thermal loading conditions used in the exterior wall model........................................ 175

Table 6-4. Analysis cases for exterior wall subsystem model...................................................... 177

Table 6-5. Summary of spandrel splice break elements for temperature time history D with all floors supported.

Table 6-6. Summary of spandrel splice break elements for temperature time history DBARE with all floors supported.

Table 6-7. Summary of spandrel splice break elements for temperature time-history E (hot bolts) with all floors supported.

Table 6-8. Summary of spandrel splice break elements for temperature time history E1 19 with all floors supported.

Table 6-9. Summary of spandrel splice break elements for temperature time history $\mathrm{F}$ with all floors supported.

Table 6-10. Summary of spandrel splice break elements for temperature time history DBARE with 2 unbraced floors.

Table 6-11. Spandrel splice break elements for temperature time history DBARE with 3 unbraced floors. 187

Table 6-12. Summary of exterior wall model results. 198 


\section{LIST OF ACRONYMS AND ABBREVIATIONS}

\section{Acronyms}

$\begin{array}{ll}\text { ARA } & \text { Applied Research Associates, Inc. } \\ \text { ASTM } & \text { American Society for Testing and Materials } \\ \text { BPS } & \text { Building Performance Study } \\ \text { CAEAI } & \text { Computer Aided Engineering Associates, Inc. } \\ \text { FEMA } & \text { Federal Emergency Management Agency } \\ \text { FEA } & \text { Finite element analysis } \\ \text { LERA } & \text { Leslie E. Robertson Associates } \\ \text { NIST } & \text { National Institute of Standards and Technology } \\ \text { PANYNJ } & \text { The Port Authority of New York and New Jersey } \\ \text { SEAoNY } & \text { Structural Engineers Association of New York } \\ \text { SGH } & \text { Simpson Gumpertz \& Heger Inc. } \\ \text { USC } & \text { United States Code } \\ \text { WTC } & \text { World Trade Center } \\ \text { WTC 1 } & \text { World Trade Center 1 (North Tower) } \\ \text { min } & \text { minc } 2\end{array}$


kip kilo pounds

pef pound per cubic foot

psf pound per square foot

psi pound per square inch

ksi kilo pounds per square inch 


\section{PREFACE}

\section{Genesis of This Investigation}

Immediately following the terrorist attack on the World Trade Center (WTC) on September 11, 2001, the Federal Emergency Management Agency (FEMA) and the American Society of Civil Engineers began planning a building performance study of the disaster. The week of October 7 , as soon as the rescue and search efforts ceased, the Building Performance Study Team went to the site and began its assessment. This was to be a brief effort, as the study team consisted of experts who largely volunteered their time away from their other professional commitments. The Building Performance Study Team issued its report in May 2002, fulfilling its goal "to determine probable failure mechanisms and to identify areas of future investigation that could lead to practical measures for improving the damage resistance of buildings against such unforeseen events."

On August 21, 2002, with funding from the U.S. Congress through FEMA, the National Institute of Standards and Technology (NIST) announced its building and fire safety investigation of the WTC disaster. On October 1, 2002, the National Construction Safety Team Act (Public Law 107-231), was signed into law. The NIST WTC Investigation was conducted under the authority of the National Construction Safety Team Act.

The goals of the investigation of the WTC disaster were:

- To investigate the building construction, the materials used, and the technical conditions that contributed to the outcome of the WTC disaster.

- To serve as the basis for:

- Improvements in the way buildings are designed, constructed, maintained, and used;

- Improved tools and guidance for industry and safety officials;

- Recommended revisions to current codes, standards, and practices; and

- Improved public safety.

The specific objectives were:

1. Determine why and how WTC 1 and WTC 2 collapsed following the initial impacts of the aircraft and why and how WTC 7 collapsed;

2. Determine why the injuries and fatalities were so high or low depending on location, including all technical aspects of fire protection, occupant behavior, evacuation, and emergency response;

3. Determine what procedures and practices were used in the design, construction, operation, and maintenance of WTC 1,2, and 7; and

4. Identify, as specifically as possible, areas in current building and fire codes, standards, and practices that warrant revision. 
NIST is a nonregulatory agency of the U.S. Department of Commerce's Technology Administration. The purpose of NIST investigations is to improve the safety and structural integrity of buildings in the United States, and the focus is on fact finding. NIST investigative teams are authorized to assess building performance and emergency response and evacuation procedures in the wake of any building failure that has resulted in substantial loss of life or that posed significant potential of substantial loss of life. NIST does not have the statutory authority to make findings of fault nor negligence by individuals or organizations. Further, no part of any report resulting from a NIST investigation into a building failure or from an investigation under the National Construction Safety Team Act may be used in any suit or action for damages arising out of any matter mentioned in such report (15 USC 281a, as amended by Public Law 107-231).

\section{Organization of the Investigation}

The National Construction Safety Team for this Investigation, appointed by the then NIST Director, Dr. Arden L. Bement, Jr., was led by Dr. S. Shyam Sunder. Dr. William L. Grosshandler served as Associate Lead Investigator, Mr. Stephen A. Cauffman served as Program Manager for Administration, and Mr. Harold E. Nelson served on the team as a private sector expert. The Investigation included eight interdependent projects whose leaders comprised the remainder of the team. A detailed description of each of these eight projects is available at http://wtc.nist.gov. The purpose of each project is summarized in Table $\mathrm{P}-1$, and the key interdependencies among the projects are illustrated in Fig. $\mathrm{P}-1$.

Table P-1. Federal building and fire safety investigation of the WTC disaster.

\begin{tabular}{|c|c|}
\hline Technical Area and Project Leader & Project Purpose \\
\hline $\begin{array}{l}\text { Analysis of Building and Fire Codes and } \\
\text { Practices; Project Leaders: Dr. H. S. Lew } \\
\text { and Mr. Richard W. Bukowski }\end{array}$ & $\begin{array}{l}\text { Document and analyze the code provisions, procedures, and } \\
\text { practices used in the design, construction, operation, and } \\
\text { maintenance of the structural, passive fire protection, and } \\
\text { emergency access and evacuation systems of WTC } 1,2 \text {, and } 7 .\end{array}$ \\
\hline $\begin{array}{l}\text { Baseline Structural Performance and } \\
\text { Aircraft Impact Damage Analysis; Project } \\
\text { Leader: Dr. Fahim H. Sadek }\end{array}$ & $\begin{array}{l}\text { Analyze the baseline performance of WTC } 1 \text { and WTC } 2 \text { under } \\
\text { design, service, and abnormal loads, and aircraft impact damage on } \\
\text { the structural, fire protection, and egress systems. }\end{array}$ \\
\hline $\begin{array}{l}\text { Mechanical and Metallurgical Analysis of } \\
\text { Structural Steel; Project Leader: Dr. Frank } \\
\text { W. Gayle }\end{array}$ & $\begin{array}{l}\text { Determine and analyze the mechanical and metallurgical properties } \\
\text { and quality of steel, weldments, and connections from steel } \\
\text { recovered from WTC } 1,2 \text {, and } 7 \text {. }\end{array}$ \\
\hline $\begin{array}{l}\text { Investigation of Active Fire Protection } \\
\text { Systems; Project Leader: Dr. David } \\
\text { D. Evans; Dr. William Grosshandler }\end{array}$ & $\begin{array}{l}\text { Investigate the performance of the active fire protection systems in } \\
\text { WTC } 1,2 \text {, and } 7 \text { and their role in fire control, emergency response, } \\
\text { and fate of occupants and responders. }\end{array}$ \\
\hline $\begin{array}{l}\text { Reconstruction of Thermal and Tenability } \\
\text { Environment; Project Leader: Dr. Richard } \\
\text { G. Gann }\end{array}$ & $\begin{array}{l}\text { Reconstruct the time-evolving temperature, thermal environment, } \\
\text { and smoke movement in WTC } 1,2 \text {, and } 7 \text { for use in evaluating the } \\
\text { structural performance of the buildings and behavior and fate of } \\
\text { occupants and responders. }\end{array}$ \\
\hline $\begin{array}{l}\text { Structural Fire Response and Collapse } \\
\text { Analysis; Project Leaders: Dr. John } \\
\text { L. Gross and Dr. Therese P. McAllisier }\end{array}$ & $\begin{array}{l}\text { Analyze the response of the WTC towers to fires with and without } \\
\text { aircraft damage, the response of WTC } 7 \text { in fires, the performance } \\
\text { of composite steel-trussed floor systems, and determine the most } \\
\text { probable structural collapse sequence for WTC } 1.2 \text {. and } 7 \text {. }\end{array}$ \\
\hline $\begin{array}{l}\text { Occupant Behavior, Egress, and Emergency } \\
\text { Communications; Project Leader: Mr. Jason } \\
\text { D. Averill }\end{array}$ & $\begin{array}{l}\text { Analyze the behavior and fate of occupants and responders, both } \\
\text { those who survived and those who did not, and the performance of } \\
\text { the evacuation system. }\end{array}$ \\
\hline $\begin{array}{l}\text { Emergency Response Technologies and } \\
\text { Guidelines; Project Leader: Mr. J. Randall } \\
\text { Lawson }\end{array}$ & $\begin{array}{l}\text { Document the activities of the emergency responders from the time } \\
\text { of the terrorist attacks on WTC } 1 \text { and WTC } 2 \text { until the collapse of } \\
\text { WTC } 7 \text {, including practices followed and technologies used. }\end{array}$ \\
\hline
\end{tabular}




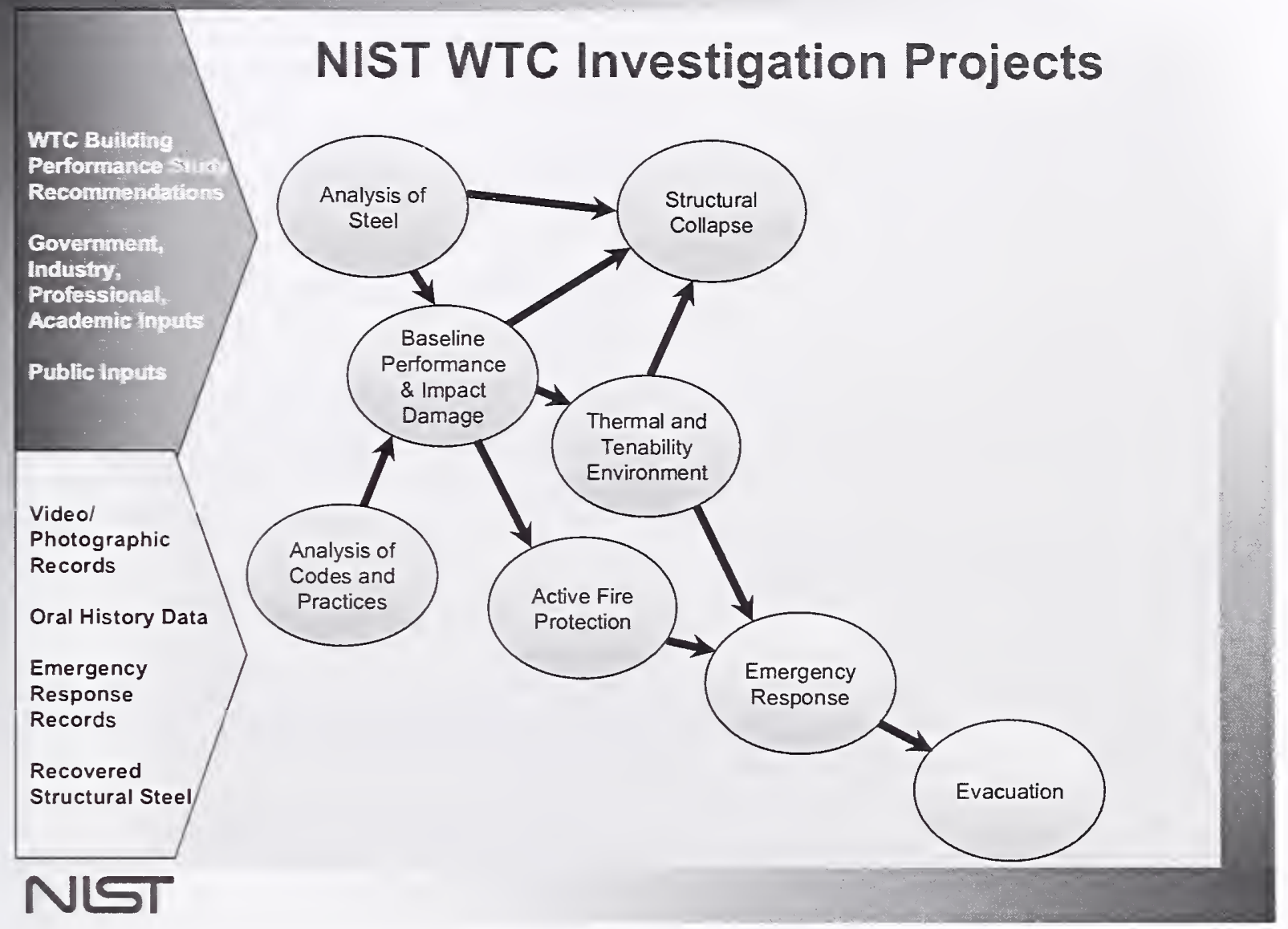

Figure P-1. The eight projects in the federal building and fire safety investigation of the WTC disaster.

\section{National Construction Safety Team Advisory Committee}

The NIST Director also established an advisory committee as mandated under the National Construction Safety Team Act. The initial members of the committee were appointed following a public solicitation. These were:

- Paul Fitzgerald, Executive Vice President (retired) FM Global, National Construction Safety Team Advisory Committee Chair

- John Barsom, President, Barsom Consulting, Ltd.

- John Bryan, Professor Emeritus, University of Maryland

- David Collins, President, The Preview Group, Inc.

- Glenn Corbett, Professor, John Jay College of Criminal Justice

- Philip DiNenno, President, Hughes Associates, Inc. 
- Robert Hanson, Professor Emeritus, University of Michigan

- Charles Thornton, Co-Chairman and Managing Principal, The Thornton-Tomasetti Group, Inc.

- Kathleen Tierney, Director, Natural Hazards Research and Applications Information Center, University of Colorado at Boulder

- Forman Williams, Director, Center for Energy Research, University of California at San Diego

This National Construction Safety Team Advisory Committee provided technical advice during the Investigation and commentary on drafts of the Investigation reports prior to their public release. NIST has benefited from the work of many people in the preparation of these reports, including the National Construction Safety Team Advisory Committee. The content of the reports and recommendations, however, are solely the responsibility of NIST.

\section{Public Outreach}

During the course of this Investigation, NIST held public briefings and meetings (listed in Table P-2) to solicit input from the public, present preliminary findings, and obtain comments on the direction and progress of the Investigation from the public and the Advisory Committee.

NIST maintained a publicly accessible Web site during this Investigation at http://wtc.nist.gov. The site contained extensive information on the background and progress of the Investigation.

\section{NIST's WTC Public-Private Response Plan}

The collapse of the WTC buildings has led to broad reexamination of how tall buildings are designed, constructed, maintained, and used, especially with regard to major events such as fires, natural disasters, and terrorist attacks. Reflecting the enhanced interest in effecting necessary change, NIST, with support from Congress and the Administration, has put in place a program, the goal of which is to develop and implement the standards, technology, and practices needed for cost-effective improvements to the safety and security of buildings and building occupants, including evacuation, emergency response procedures, and threat mitigation.

The strategy to meet this goal is a three-part NIST-led public-private response program that includes:

- A federal building and fire safety investigation to study the most probable factors that contributed to post-aircraft impact collapse of the WTC towers and the 47-story WTC 7 building, and the associated evacuation and emergency response experience.

- A research and development (R\&D) program to (a) facilitate the implementation of recommendations resulting from the WTC Investigation, and (b) provide the technical basis for cost-effective improvements to national building and fire codes, standards, and practices that enhance the safety of buildings, their occupants, and emergency responders. 
Table P-2. Public meetings and briefings of the WTC Investigation.

\begin{tabular}{|c|c|c|}
\hline Date & Location & Principal Agenda \\
\hline June 24,2002 & New York City, NY & $\begin{array}{l}\text { Public meeting: Public comments on the Draft Plan for the } \\
\text { pending WTC Investigation. }\end{array}$ \\
\hline August 21.2002 & Gaithersburg. MD & Media briefing announcing the formal start of the Investigation. \\
\hline December 9.2002 & Washington, DC & $\begin{array}{l}\text { Media briefing on release of the Public Update and NIST request } \\
\text { for photographs and videos. }\end{array}$ \\
\hline April 8, 2003 & New York City, NY & $\begin{array}{l}\text { Joint public forum with Columbia University on first-person } \\
\text { interviews. }\end{array}$ \\
\hline April 29-30, 2003 & Gaithersburg, MD & $\begin{array}{l}\text { NCST Advisory Committee meeting on plan for and progress on } \\
\text { WTC Investigation with a public comment session. }\end{array}$ \\
\hline May 7.2003 & New York City, NY & Media briefing on release of May 2003 Progress Report. \\
\hline August 26-27, 2003 & Gaithersburg, MD & $\begin{array}{l}\text { NCST Advisory Committee meeting on status of the WTC } \\
\text { investigation with a public comment session. }\end{array}$ \\
\hline September 17,2003 & New York City, NY & $\begin{array}{l}\text { Media and public briefing on initiation of first-person data } \\
\text { collection projects. }\end{array}$ \\
\hline December 2-3, 2003 & Gaithersburg, MD & $\begin{array}{l}\text { NCST Advisory Committee meeting on status and initial results } \\
\text { and release of the Public Update with a public comment session. }\end{array}$ \\
\hline February 12.2004 & New York City, NY & $\begin{array}{l}\text { Public meeting on progress and preliminary findings with public } \\
\text { comments on issues to be considered in formulating final } \\
\text { recommendations. }\end{array}$ \\
\hline June 18,2004 & New York City, NY & Media/public briefing on release of June 2004 Progress Report. \\
\hline June $22-23,2004$ & Gaithersburg, MD & $\begin{array}{l}\text { NCST Advisory Committee meeting on the status of and } \\
\text { preliminary findings from the WTC Investigation with a public } \\
\text { comment session. }\end{array}$ \\
\hline August 24,2004 & Northbrook, $1 \mathrm{~L}$ & $\begin{array}{l}\text { Public viewing of standard fire resistance test of WTC floor } \\
\text { system at Underwriters Laboratories, lnc. }\end{array}$ \\
\hline October 19-20, 2004 & Gaithersburg, MD & $\begin{array}{l}\text { NCST Advisory Committee meeting on status and near complete } \\
\text { set of preliminary findings with a public comment session. }\end{array}$ \\
\hline November 22, 2004 & Gaithersburg, MD & $\begin{array}{l}\text { NCST Advisory Committee discussion on draft annual report to } \\
\text { Congress, a public comment session, and a closed session to } \\
\text { discuss pre-draft recommendations for WTC Investigation. }\end{array}$ \\
\hline April 5, 2005 & New York City, NY & $\begin{array}{l}\text { Media and public briefing on release of the probable collapse } \\
\text { sequence for the WTC towers and draft reports for the projects on } \\
\text { codes and practices, evacuation, and emergency response. }\end{array}$ \\
\hline June 23,2005 & New York City, NY & $\begin{array}{l}\text { Media and public briefing on release of all draft reports for the } \\
\text { WTC towers and draft recommendations for public comment. }\end{array}$ \\
\hline $\begin{array}{l}\text { September 12-13, } \\
2005\end{array}$ & Gaithersburg, MD & $\begin{array}{l}\text { NCST Advisory Committee meeting on disposition of public } \\
\text { comments and update to draft reports for the WTC towers. }\end{array}$ \\
\hline $\begin{array}{l}\text { September } 13-15 \text {. } \\
2005\end{array}$ & Gaithersburg, MD & $\begin{array}{l}\text { WTC Technical Conference for stakeholders and technical } \\
\text { community for dissemination of findings and recommendations } \\
\text { and opportunity for public to make technical comments. }\end{array}$ \\
\hline
\end{tabular}

- A dissemination and technical assistance program (DTAP) to (a) engage leaders of the construction and building community in ensuring timely adoption and widespread use of proposed changes to practices, standards, and codes resulting from the WTC Investigation and the R\&D program, and (b) provide practical guidance and tools to better prepare facility owners, contractors, architects, engineers, emergency responders, and regulatory authorities to respond to future disasters.

The desired outcomes are to make buildings, occupants, and first responders safer in future disaster events. 


\section{National Construction Safety Team Reports on the WTC Investigation}

A final report on the collapse of the WTC towers is being issued as NIST NCSTAR 1. A companion report on the collapse of WTC 7 is being issued as NIST NCSTAR 1A. The present report is one of a set that provides more detailed documentation of the Investigation findings and the means by which these technical results were achieved. As such, it is part of the archival record of this Investigation. The titles of the full set of Investigation publications are:

NIST (National Institute of Standards and Technology). 2005. Federal Building and Fire Safety Investigation of the World Trade Center Disaster: Final Report on the Collapse of the World Trade Center Towers. NIST NCSTAR 1. Gaithersburg, MD, September.

NIST (National Institute of Standards and Technology). 2006. Federal Building and Fire Safety Investigation of the World Trade Center Disaster: Final Report on the Collapse of World Trade Center 7. NIST NCSTAR 1A. Gaithersburg, MD.

Lew, H. S., R. W. Bukowski, and N. J. Carino. 2005. Federal Building and Fire Safety Investigation of the World Trade Center Disaster: Design, Construction, and Maintenance of Structural and Life Safety Systems. NIST NCSTAR 1-1. National Institute of Standards and Technology. Gaithersburg, MD, September.

Fanella, D. A., A. T. Derecho, and S. K. Ghosh. 2005. Federal Building and Fire Safety Investigation of the World Trade Center Disaster: Design and Construction of Structural Systems. NIST NCSTAR 1-1A. National Institute of Standards and Technology. Gaithersburg, MD, September.

Ghosh, S. K., and X. Liang. 2005. Federal Building and Fire Safety Investigation of the World Trade Center Disaster: Comparison of Building Code Structural Requirements. NIST

NCSTAR 1-1B. National Institute of Standards and Technology. Gaithersburg, MD, September.

Fanella, D. A., A. T. Derecho, and S. K. Ghosh. 2005. Federal Building and Fire Safety Investigation of the World Trade Center Disaster: Maintenance and Modifications to Structural Systems. NIST NCSTAR 1-1C. National Institute of Standards and Technology. Gaithersburg, MD, September.

Grill, R. A., and D. A. Johnson. 2005. Federal Building and Fire Safety Investigation of the World Trade Center Disaster: Fire Protection and Life Safety Provisions Applied to the Design and Construction of World Trade Center 1, 2, and 7 and Post-Construction Provisions Applied after Occupancy. NIST NCSTAR 1-1D. National Institute of Standards and Technology. Gaithersburg, $\mathrm{MD}$, September.

Razza, J. C., and R. A. Grill. 2005. Federal Building and Fire Safety Investigation of the World Trade Center Disaster: Comparison of Codes, Standards, and Practices in Use at the Time of the Design and Construction of World Trade Center 1, 2, and 7. NIST NCSTAR 1-1E. National Institute of Standards and Technology. Gaithersburg, MD, September.

Grill, R. A., D. A. Johnson, and D. A. Fanella. 2005. Federal Building and Fire Safety Investigation of the World Trade Center Disaster: Comparison of the 1968 and Current (2003) New 
York City Building Code Provisions. NIST NCSTAR 1-1F. National Institute of Standards and Technology. Gaithersburg, MD. September.

Grill, R. A., and D. A. Johnson. 2005. Federal Building and Fire Safety Investigation of the World Trade Center Disaster: Amendunents to the Fire Protection and Life Safety Provisions of the New York City Building Code by Local Law's Adopted While World Trade Center 1, 2, and 7 Were in Use. NIST NCSTAR 1-1G. National Institute of Standards and Technology. Gaithersburg, MD, September.

Grill, R. A., and D. A. Johnson. 2005. Federal Building and Fire Safety Investigation of the World Trade Center Disaster: Post-Construction Modifications to Fire Protection and Life Safety Systeuns of World Trade Center 1 and 2. NIST NCSTAR 1-1H. National Institute of Standards and Technology. Gaithersburg, MD, September.

Grill, R. A., D. A. Johnson, and D. A. Fanella. 2005. Federal Building and Fire Safety Investigation of the World Trade Center Disaster: Post-Construction Modifications to Fire Protection, Life Safety, and Structural Systems of World Trade Center 7. NIST NCSTAR 1-1I. National Institute of Standards and Technology. Gaithersburg, MD, September.

Grill, R. A., and D. A. Johnson. 2005. Federal Building and Fire Safety Investigation of the World Trade Center Disaster: Design, Installation, and Operation of Fuel Systen for Emergency Power in World Trade Center 7. NIST NCSTAR 1-1J. National Institute of Standards and Technology. Gaithersburg, MD, September.

Sadek, F. 2005. Federal Building and Fire Safety Imvestigation of the World Trade Center Disaster: Baseline Structural Performance and Aircraft Impact Damage Analysis of the World Trade Center Towers. NIST NCSTAR 1-2. National Institute of Standards and Technology. Gaithersburg, MD, September.

Faschan, W. J., and R. B. Garlock. 2005. Federal Building and Fire Safety Investigation of the World Trade Center Disaster: Reference Structural Models and Baseline Performance Analysis of the World Trade Center Towers. NIST NCSTAR 1-2A. National Institute of Standards and Technology. Gaithersburg, MD, September.

Kirkpatrick, S. W., R. T. Bocchieri, F. Sadek. R. A. MacNeill, S. Holmes, B. D. Peterson, R. W. Cilke, C. Navarro. 2005. Federal Building and Fire Safety Investigation of the World Trade Center Disaster: Analysis of Aircraft Impacts into the World Trade Center Towers, NIST

NCSTAR 1-2B. National Institute of Standards and Technology. Gaithersburg, MD, September.

Gayle, F. W., R. J. Fields, W. E. Luecke, S. W. Banovic, T. Foecke, C. N. McCowan, T. A. Siewert, and J. D. McColskey. 2005. Federal Building and Fire Safety Investigation of the World Trade Center Disaster: Mechanical and Metallurgical Analysis of Structural Steel. NIST NCSTAR 1-3. National Institute of Standards and Technology. Gaithersburg, MD, September.

Luecke, W. E., T. A. Siewert, and F. W. Gayle. 2005. Federal Building and Fire Safety Investigation of the World Trade Center Disaster: Contemporaneous Structural Steel Specifications. NIST Special Publication 1-3A. National Institute of Standards and Technology. Gaithersburg, MD, September. 
Banovic, S. W. 2005. Federal Building and Fire Safety Investigation of the World Trade Center Disaster: Steel Inventory and Identification. NIST NCSTAR 1-3B. National Institute of Standards and Technology. Gaithersburg, MD, Septembcr.

Banovic, S. W., and T. Foecke. 2005. Federal Building and Fire Safety Investigation of the World Trade Center Disaster: Damage and Failure Modes of Structural Steel Components. NIST NCSTAR 1-3C. National Institute of Standards and Technology. Gaithersburg, MD, September.

Luecke, W. E., J. D. McColskey, C. N. McCowan, S. W. Banovic, R. J. Fields, T. Foecke, T. A. Siewert, and F. W. Gayle. 2005. Federal Building and Fire Safety Investigation of the World Trade Center Disaster: Mechanical Properties of Structural Steels. NIST NCSTAR 1-3D. National Institute of Standards and Technology. Gaithersburg, MD, September.

Banovic, S. W., C. N. McCowan, and W. E. Luecke. 2005. Federal Building and Fire Safety Investigation of the World Trade Center Disaster: Physical Properties of Structural Steels. NIST NCSTAR 1-3E. National Institute of Standards and Technology. Gaithersburg, MD, September.

Evans, D. D., R. D. Peacock, E. D. Kuligowski, W. S. Dols, and W. L. Grosshandler. 2005. Federal Building and Fire Safety Investigation of the World Trade Center Disaster: Active Fire Protection Systems. NIST NCSTAR 1-4. National Institute of Standards and Technology. Gaithersburg, MD, September.

Kuligowski, E. D., D. D. Evans, and R. D. Pcacock. 2005. Federal Building and Fire Safety Ilvestigation of the World Trade Center Disaster: Post-Construction Fires Prior to September 11, 2001. NIST NCSTAR 1-4A. National Institute of Standards and Technology. Gaithersburg, MD, September.

Hopkins, M., J. Schoenrock, and E. Budnick. 2005. Federal Building and Fire Safety Investigation of the World Trade Center Disaster: Fire Suppression Systems. NIST NCSTAR 1-4B. National Institute of Standards and Technology. Gaithersburg, MD, September.

Keough, R. J., and R. A. Grill. 2005. Federal Building and Fire Safety Investigation of the World Trade Center Disaster: Fire Alarm Systems. NIST NCSTAR 1-4C. National Institute of Standards and Technology. Gaithersburg, MD, September.

Ferreira, M. J., and S. M. Strege. 2005. Federal Building and Fire Safety Imvestigation of the World Trade Center Disaster: Smoke Management Systems. NIST NCSTAR 1-4D. National Institute of Standards and Technology. Gaithersburg, MD, September.

Gann, R. G., A. Hamins, K. B. McGrattan, G. W. Mulholland, H. E. Nelson, T. J. Ohlemiller, W. M. Pitts, and K. R. Prasad. 2005. Federal Building and Fire Safety Investigation of the World Trade Center Disaster: Reconstruction of the Fires in the World Trade Center Towers. NIST NCSTAR 1-5. National Institute of Standards and Technology. Gaithersburg, MD, September.

Pitts, W. M., K. M. Butler, and V. Junker. 2005. Federal Building and Fire Safety Investigation of the World Trade Center Disaster: Visual Evidence, Damage Estimates, and Timeline Analysis. NIST NCSTAR 1-5A. National Institute of Standards and Technology. Gaithersburg, MD, September. 
Hamins, A., A. Maranghides, K. B. McGrattan, E. Johnsson, T. J. Ohlemiller, M. Donnelly, J. Yang, G. Mulholland, K. R. Prasad, S. Kukuck, R. Anleitner and T. McAllister. 2005. Federal Building and Fire Safety Investigation of the World Trade Center Disaster: Experiments and Modeling of Structural Steel Elements Exposed to Fire. NIST NCSTAR 1-5B. National Institute of Standards and Technology. Gaithersburg, MD, September.

Ohlemiller, T. J., G. W. Mulholland, A. Maranghides, J. J. Filliben, and R. G. Gann. 2005. Federal Building and Fire Safety Investigation of the World Trade Center Disaster: Fire Tests of Single Office Workstations. NIST NCSTAR 1-5C. National Institute of Standards and Technology. Gaithersburg, MD, September.

Gann, R. G., M. A. Riley, J. M. Repp, A. S. Whittaker, A. M. Reinhorn, and P. A. Hough. 2005. Federal Building and Fire Safety Investigation of the World Trade Center Disaster: Reaction of Ceiling Tile Systems to Shocks. NIST NCSTAR 1-5D. National Institute of Standards and Technology. Gaithersburg, MD, September.

Hamins, A., A. Maranghides, K. B. McGrattan, T. J. Ohlemiller, and R. Anleitner. 2005. Federal Building and Fire Safety Investigation of the World Trade Center Disaster: Experiments and Modeling of Multiple Workstations Burming in a Compartment. NIST NCSTAR 1-5E. National Institute of Standards and Technology. Gaithersburg, MD, September.

McGrattan, K. B., C. Bouldin, and G. Forney. 2005. Federal Building and Fire Safety Investigation of the World Trade Center Disaster: Computer Simulation of the Fires in the World Trade Center Towers. NIST NCSTAR 1-5F. National Institute of Standards and Technology. Gaithersburg, MD, September.

Prasad, K. R., and H. R. Baum. 2005. Federal Building and Fire Safety Investigation of the World Trade Center Disaster: Fire Structure Interface and Thernal Response of the World Trade Center Towers. NIST NCSTAR 1-5G. National Institute of Standards and Technology. Gaithersburg, MD, September.

Gross, J. L., and T. McAllister. 2005. Federal Building and Fire Safety Investigation of the World Trade Center Disaster: Structural Fire Response and Probable Collapse Sequence of the World Trade Center Towers. NIST NCSTAR 1-6. National Institute of Standards and Technology. Gaithersburg, MD, September.

Carino, N. J., M. A. Starnes, J. L. Gross, J. C. Yang, S. Kukuck, K. R. Prasad, and R. W. Bukowski. 2005. Federal Building and Fire Safety Investigation of the World Trade Center Disaster: Passive Fire Protection. NIST NCSTAR I-6A. National Institute of Standards and Technology. Gaithersburg, MD, September.

Gross, J., F. Hervey, M. Izydorek, J. Mammoser, and J. Treadway. 2005. Federal Building and Fire Safety Investigation of the World Trade Center Disaster: Fire Resistance Tests of Floor Truss Systems. NIST NCSTAR 1-6B. National Institute of Standards and Technology. Gaithersburg, MD, September.

Zarghamee, M. S., S. Bolourchi, D. W. Eggers, Ö. O. Erbay, F. W. Kan, Y. Kitane, A. A. Liepins, M. Mudlock, W. I. Naguib, R. P. Ojdrovic, A. T. Sarawit, P. R Barrett, J. L. Gross, and T. P. McAllister. 2005. Federal Building and Fire Safety Investigation of the World Trade Center 
Disaster: Component, Connection, and Subsysten Structural Analysis. NIST NCSTAR 1-6C. National Institute of Standards and Technology. Gaithersburg, MD, September.

Zarghamee, M. S., Y. Kitane, Ö. O. Erbay, T. P. McAllister, and J. L. Gross. 2005. Federal Building and Fire Safety Investigation of the World Trade Center Disaster: Global Structmal Analysis of the Response of the World Trade Center Towers to Impact Damage and Fire. NIST NCSTAR 1-6D. National Institute of Standards and Technology. Gaithersburg, MD, September.

McAllister, T., R. W. Bukowski, R. G. Gann, J. L. Gross, K. B. McGrattan, H. E. Nelson, L. Phan, W. M. Pitts, K. R. Prasad, F. Sadek. 2006. Federal Building and Fire Safety Investigation of the World Trade Center Disaster: Structural Fire Response and Probable Collapse Sequence of World Trade Center 7. (Provisional). NIST NCSTAR 1-6E. National Institute of Standards and Technology. Gaithersburg, MD.

Gilsanz, R., V. Arbitrio, C. Anders, D. Chlebus, K. Ezzeldin, W. Guo, P. Moloney, A. Montalva, J. Oh, K. Rubenacker. 2006. Federal Building and Fire Safety Investigation of the World Trade Center Disaster: Structwral Analysis of the Response of World Trade Center 7 to Debris Danage and Fire. (Provisional). NIST NCSTAR 1-6F. National Institute of Standards and Technology. Gaithersburg, MD.

Kim, W. 2006. Federal Building and Fire Safety Investigation of the World Trade Center Disaster: Analysis of Septenber 11, 2001, Seismogram Data. (Provisional). NIST NCSTAR 1-6G. National Institute of Standards and Technology. Gaithersburg, MD.

Nelson, K. 2006. Federal Building and Fire Safety Investigation of the World Trade Center Disaster: The Con Ed Substation in World Trade Center 7. (Provisional). NIST NCSTAR 1-6H. National Institute of Standards and Technology. Gaithersburg, MD.

Averill, J. D., D. S. Mileti, R. D. Peacock, E. D. Kuligowski, N. Groner, G. Proulx, P. A. Reneke, and H. E. Nelson. 2005. Federal Burilding and Fire Safety Investigation of the World Trade Center Disaster: Occupant Behavior, Egress, and Emergency Conmmication. NIST NCSTAR 1-7. National Institute of Standards and Technology. Gaithersburg, MD, September.

Fahy, R., and G. Proulx. 2005. Federal Building and Fire Safety Investigation of the World Trade Center Disaster: Analysis of Published Acconts of the World Trade Center Evacuation. NIST NCSTAR 1-7A. National Institute of Standards and Technology. Gaithersburg, MD, September.

Zmud, J. 2005. Federal Building and Fire Safety Investigation of the World Trade Center Disaster: Techuical Docmmentation for Survey Adninistration. NIST NCSTAR 1-7B. National Institute of Standards and Technology. Gaithersburg, MD, September.

Lawson, J. R., and R. L. Vettori. 2005. Federal Building and Fire Safety Investigation of the World Trade Center Disaster: The Energency Response Operations. NIST NCSTAR 1-8. National Institute of Standards and Technology. Gaithersburg, MD, September. 


\section{ACKNOWLEDGEMENTS}

The assistance of SGH internal Structural Performance Review Committee (Glenn R. Bell, Ronai O. Hamburger, and Pedro J. Sifre) is gratefully acknowledged. Authors would also like to thank the technical staff of Computer Aided Engineering Associates, Inc., for their effort at converting SAP2000 finite element models to ANSYS and for their assistance in finite element modeling in ANSYS. 
This page intentionally left blank. 


\section{EXECUTIVE SUMMARY}

\section{E.1 INTRODUCTION}

Simpson Gumpertz \& Heger Inc. (SGH) developed finite-element models of the components, connections and subsystems of the World Trade Center (WTC) towers to study their structural performance in the fire environment that followed the aircraft impact to the towers. The results of this study were used to develop global models that ran efficiently and captured the important failure modes and sequential failures of components and subsystems and to determine the probable sequence of structural responses that let to the global collapse initiation.

SGH performed this study under a NIST contract as part of Project 6 of the investigation on the WTC disaster by the National Institute of Standards and Technology (NIST). This report constitutes SGH report on Task 1 of the SGH contract with NIST and Part 1 of the SGH two-part report.

This study completed the following:

- Developed and validated ANSYS models of the full floor and exterior wall subsystems.

- Evaluated structural responses of components, connections, and subsystems to service loads due to gravity (dead and live loads) and elevated temperatures.

- Identified the likely failure modes and failure sequences of components, connections, and subsystems.

- Identified modeling details of the floor and exterior wall subsystems for the global models of the WTC towers.

All analyses used the nominal dimensions and design details shown on the WTC design and construction drawings. Material properties were based on information provided from NIST Project 3 study.

\section{E.2 FULL FLOOR SUBSYSTEM}

Floor 96 of WTC 1 was identified as an office floor with typical floor construction and loading; therefore, it was selected as the basis for modeling floor response. Figure E-1 shows a floor plan of Floor 96 of WTC 1. The full floor subsystem included office area and core area floor framing, as well as core and exterior columns extending to floors immediately above and below this floor.

The floor system in the office area consisted of lightweight concrete slab supported by steel floor trusses. The steel trusses for the floor system were manufactured by Laclede Steel Co. in Saint Louis, Missouri. Steel trusses spanned nominally $60 \mathrm{ft}$ in the long-span area and $36 \mathrm{ft}$ in the short-span area between exterior walls and the central core. Typically, a pair of primary trusses was supported at odd-numbered columns at $6 \mathrm{ft} 8 \mathrm{in}$. on center. Each of these primary trusses consisted of top and bottom chords fabricated from double steel angles and web diagonals fabricated from round bars (see Fig. E-2). Web diagonals extended $3 \mathrm{in}$. above the top chord at the panel points into the concrete slab to form a knuckle and to provide shear transfer between the truss and the concrete slab (see Fig. E-2). 


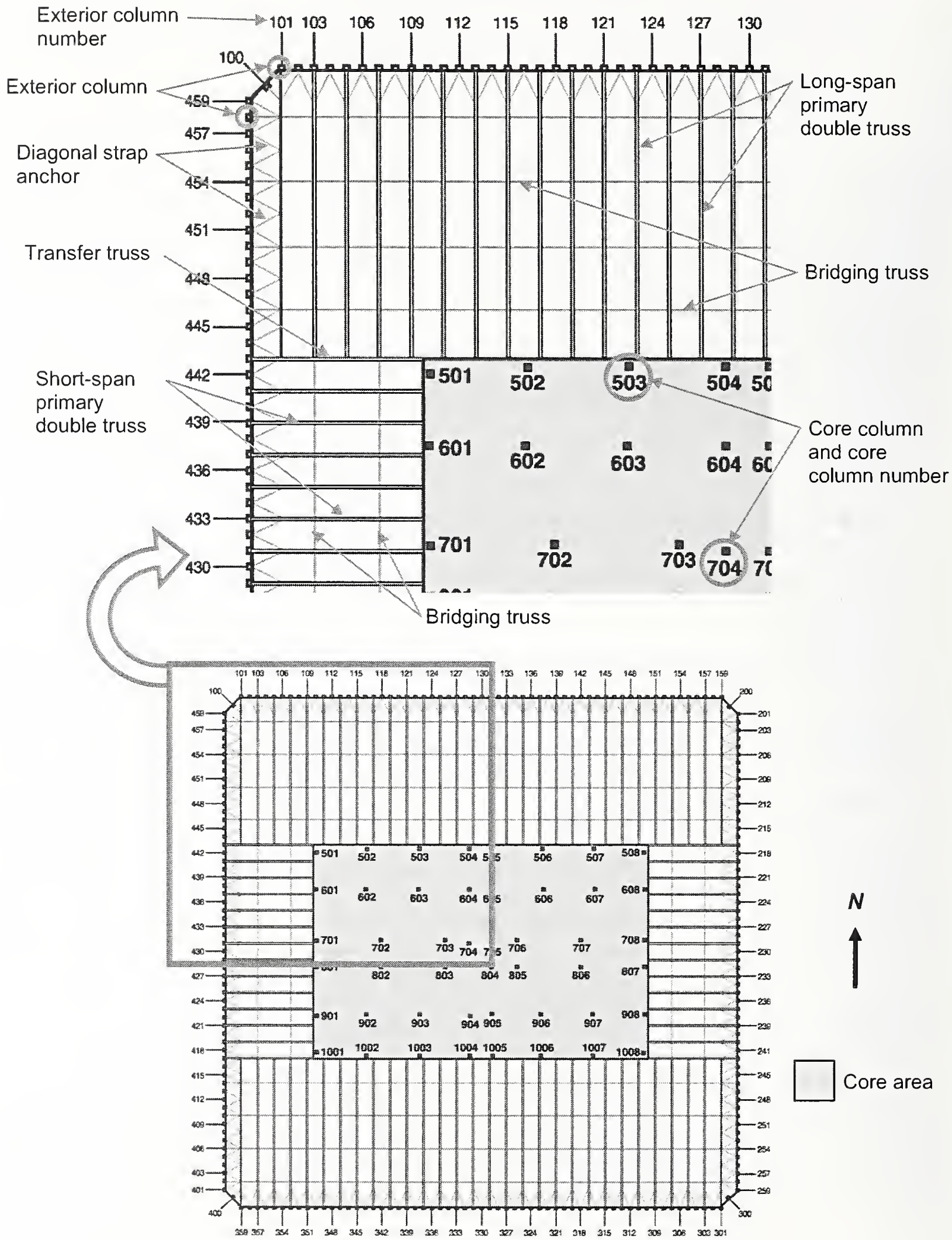

Figure E-1. Floor plan of Floor 96 of WTC 1. 


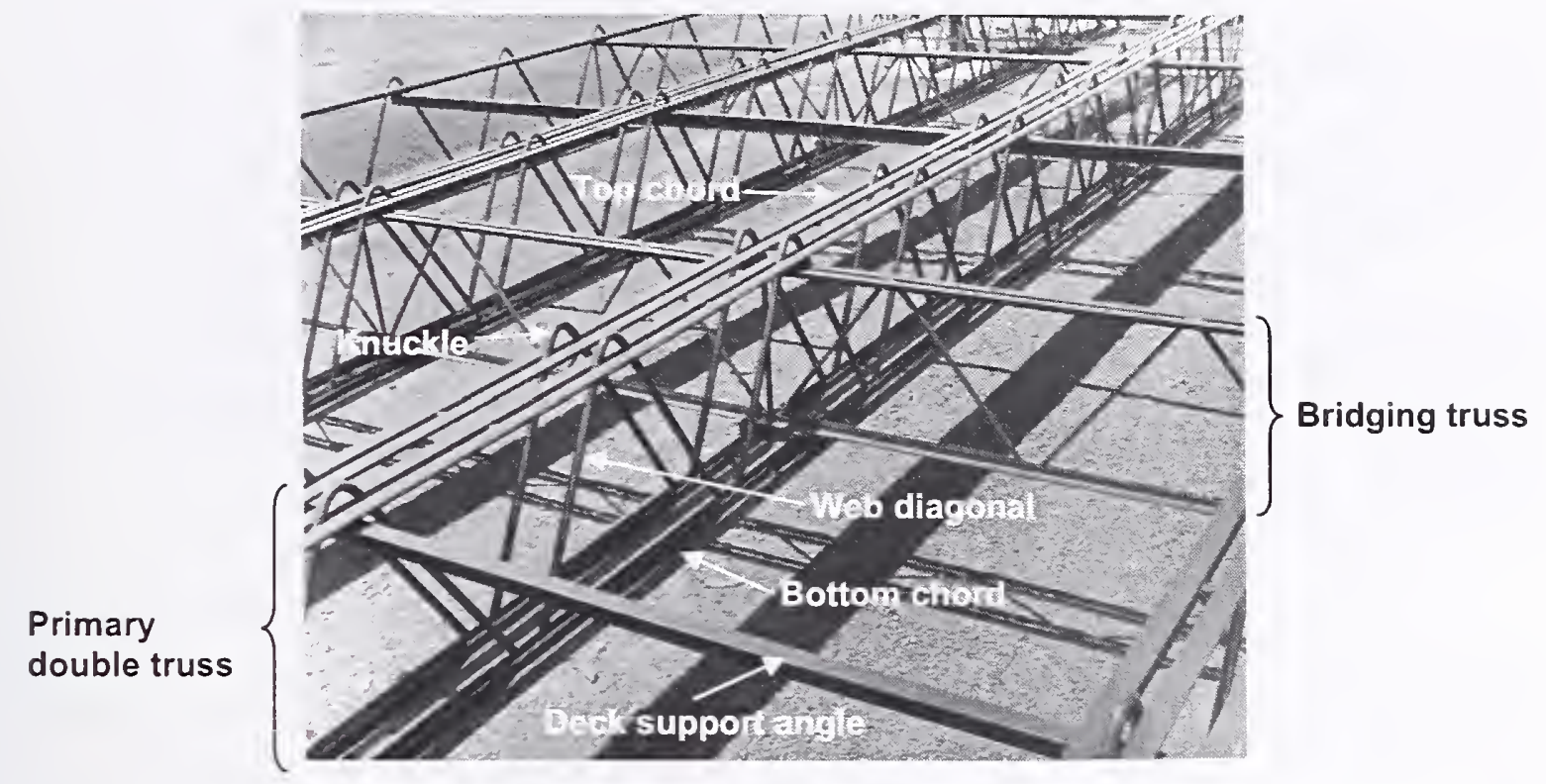

Figure E-2. Mock up of office floor framing system (Photograph from about 1967 provided by Laclede Steel Co.).

The top chords of a pair of trusses (double truss) were supported at the central core by an interior truss seat (Fig. E-3) welded to steel channels that ran continuously around the core floor area. Each pair of trusses was fastened to a horizontal plate of the interior truss seat by two $5 / 8 \mathrm{in}$. bolts (one bolt in each truss) in $13 / 4 \mathrm{in}$. long slotted holes. At the exterior wall, each pair of trusses was supported by an exterior truss seat (Fig. E-4), which fastened to a seat angle with two 5/8 in. diameter bolts in 2 in. long slotted holes. A pair of stand-off plates welded the seat angle to the spandrel. In addition, a gusset plate welded to the spandrel and to the truss top chord tied the truss to the supporting column, and a pair of diagonal strap anchors, welded to the top chords and to the adjacent columns, tied these columns to the primary trusses. Diagonal strap anchors will be referred to as "strap anchors" hereafter.

Primary trusses were interconnected by a transverse system of bridging trusses and deck support angles. These bridging trusses were of similar construction to the primary trusses, except the knuckles did not project above the top chords. The top chord of the bridging trusses sat $11 / 2 \mathrm{in}$. below the top chord of the primary trusses and provided support for the $4 \mathrm{in}$. thick lightweight concrete slab on the $11 / 2 \mathrm{in} ., 22$ gauge steel deck with 2 in. wide at the top, $1.25 \mathrm{in}$. wide at the bottom, and $1.5 \mathrm{in}$. high flutes at $6.8 \mathrm{in}$. on center running parallel to the primary trusses. At each corner of the building core, a $36 \mathrm{ft}$ long transfer truss extended out from the corner core column to the exterior wall and supported the $60 \mathrm{ft}$ long primary trusses. The floor in the core consisted of a $4.5 \mathrm{in}$. thick lightweight concrete slab supported by wide flange girders and beams connected to the core columns with bolted connections. Reinforcement between the core area floor and the office area floor (\#3 bars at $10 \mathrm{in}$. at the top and \#4 bars at $12 \mathrm{in}$. at the bottom, respectively) provided continuity between the two areas and restrained the truss from walking off the interior seat. 


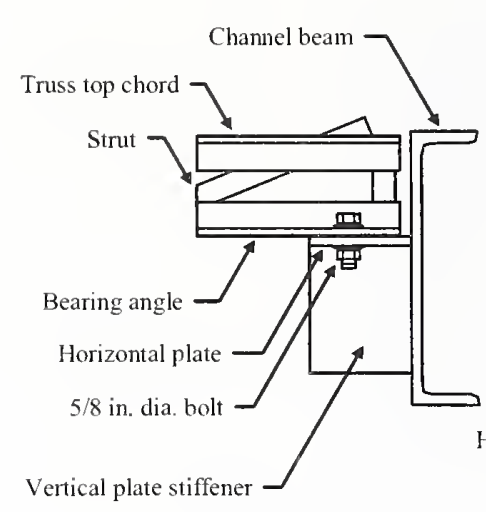

Side View

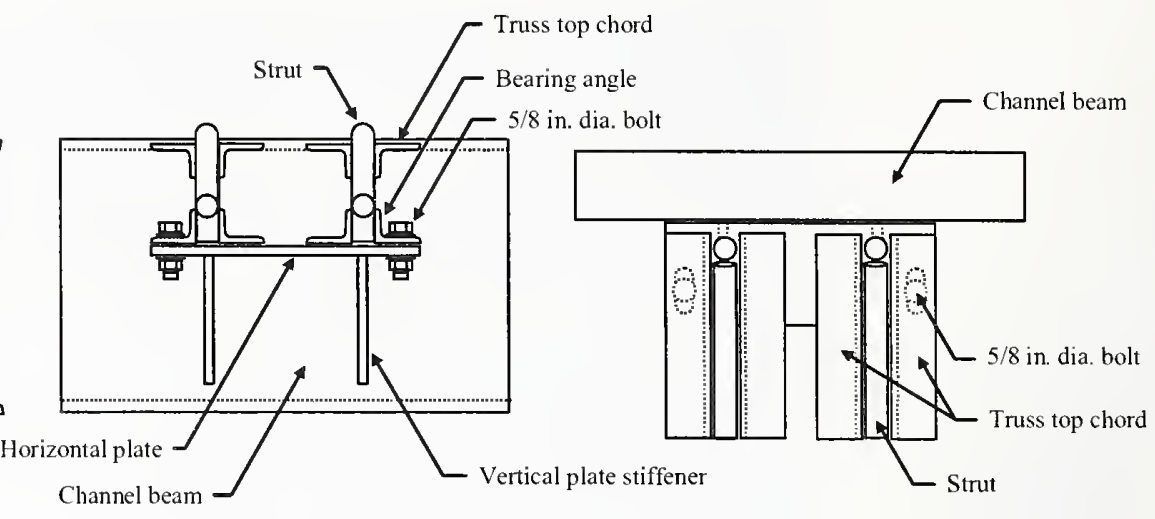

Front View $\underline{\text { Top View }}$

Figure E-3. Interior truss seat.

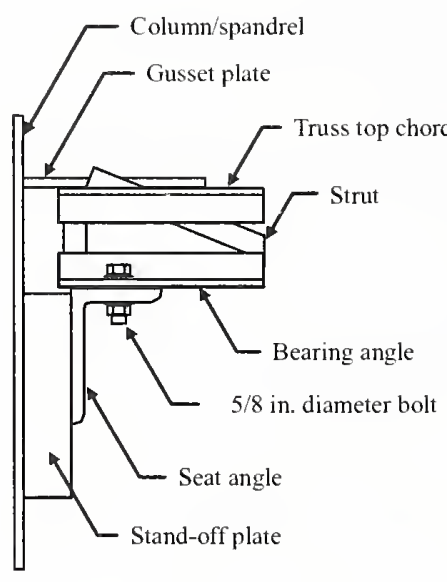

$\underline{\text { Side View }}$

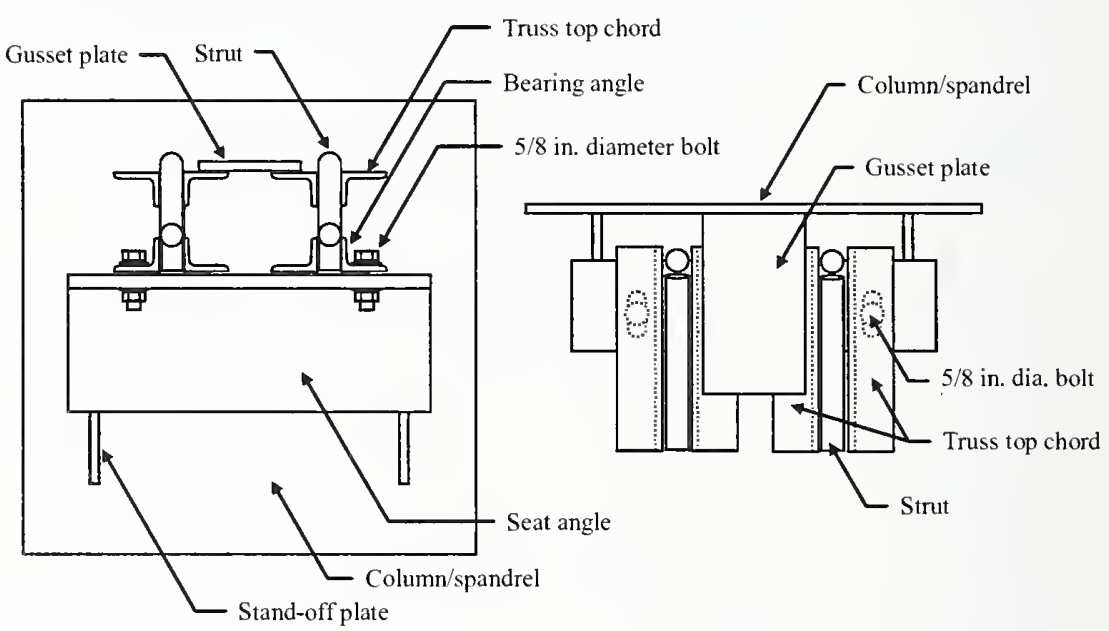

Front View
Top View

Figure E-4. Exterior truss seat.

\section{E.2.1 Truss Seat Analysis}

Failure Modes: The failure modes for truss seats were identified for vertical force, horizontal tensile force, horizontal compressive force, and combined vertical and horizontal force, and the corresponding capacities were calculated for different temperatures as follows:

- Vertical Force: The failure mode of exterior truss seats for vertical force was identified as fracture of the fillet welds between the stand-off plates and spandrel, which resulted in loss of truss vertical support. The failure mode of interior truss seats for vertical force was fracture of the fillet welds at the vertical plate to the channel beam. This failure mode results in loss of truss vertical support.

- Horizontal Tensile Force: The failure sequence of the exterior truss seats for horizontal tensile force differed for different seat details at different temperatures although the final failure mode was truss walk-off for all details. The typical failure sequence of the exterior truss seat was as follows: the gusset plate yielded, the groove weld yielded, the groove weld fractured, the truss bearing angle slid, seat bolts came to bear against the slotted hole, the 
bolts sheared off, and finally the truss walked off the seat angle. The failure sequence of the interior truss seats for horizontal tensile force was bolt shear-off, resulting in truss walk-off.

- Horizontal Compressive Force: Even after the concrete slab failed in compression, additional resistance was developed from the spandrel at the exterior seat or from the channel beam at the interior seat after contact. Under compressive force, the truss did not lose its vertical support.

- Combined Vertical and Horizontal Forces: Under combined vertical and horizontal forces, the failure modes were a combination of the failure modes for vertical and horizontal forces. The vertical shear strength of the truss seats was reduced due to the additional horizontal tensile force. The horizontal tensile strength was not reduced by the additional vertical force on the seat.

Truss Seat Model for Truss Model: Truss seat capacities corresponding to the failure modes were computed for the different types of the truss seats at different temperatures. Finite element models of the exterior and interior truss seats were developed for incorporation in the floor truss analysis using "break elements." Break elements are unidirectional linear springs that were turned off and did not resist any force after the connection forces reached predefined temperature-dependent capacities.

\section{E.2.2 Knuckle Analysis}

Failure Modes: The failure modes of knuckles are:

- Horizontal shear failure due to shear crack or crushing of concrete

- Pullout failure due to vertical tension

The capacities of knuckles were determined based on shear test results conducted by Laclede Steel Co., the results of finite element analysis simulating the shear tests, and hand calculations. Knuckle shear and pullout capacity at room temperature were determined as $30 \mathrm{kip}$ and $15 \mathrm{kip}$, respectively. Capacities at elevated temperatures were calculated based on knock-down factor on concrete strength at given temperatures.

Knuckle Model for Truss Model: A model of knuckle was also developed for the truss model, using break elements.

\section{E.2.3 Truss Analysis}

A finite element model of a section of a floor system, which consisted of a single floor truss and a section of concrete slab with a tributary width, was developed in ANSYS to capture the potential failure modes and failure sequence of the truss under gravity load and thermal load. The model is referred to as "truss model" in this report.

Failure Modes: Two possible failure modes were identified for the truss model: 1) softening and sagging of the truss caused by plasticity, creep, and buckling of web diagonal members at high temperatures; and 2) loss of truss vertical support resulting either from seat failure caused by loss of vertical shear capacity at high temperatures or from truss walking-off truss seat due to large sagging.

Model Description: The truss model included the following: 
- A single typical long-span truss (C32T1) of the primary double truss at Column 143 at Floor 96 of WTC 1. All steel truss members were modeled by 3-D quadratic finite strain beam elements.

- Two exterior columns (Columns 143 and 144) with half the area and bending properties, and a length of $24 \mathrm{ft}$ ( $12 \mathrm{ft}$ above and below the floor level), using elastic beam elements.

- The portion of the spandrel between the two exterior columns, using elastic shell elements.

- The portion of the slab (40 in. wide) between the two exterior columns. The concrete slab was modeled with 4 layers of 3-D, 8-node structural solid elements for an equivalent thickness of 4.35 in.

- One strap anchor connected to the truss top chord, concrete slab, and the adjacent exterior column (Column 144). 3-D quadratic finite strain beam elements were used.

- Exterior and interior truss seats and the gusset plate at the exterior end. Break elements were used to model failures of these connections.

- Spandrel studs, studs on the strap anchor, and knuckles. Break elements were used to model failures of these connections.

Materials: Temperature-dependent elastic, plastic, and creep properties were included in steel members except for columns and spandrels. The Hjelm plasticity model was used for the solid elements of the concrete slab that allowed different "yield strengths" in tension and compression.

Boundary Conditions: The entire top chord of the truss was restrained against the movement transverse to the truss axis. The bottom chord was restrained against the movement transverse to the truss axis at four bridging truss locations. The two edges of the concrete slab parallel to the truss were restrained against rotations about the truss axis and the vertical axis, but were free in the translation along the truss axis. The interior truss seat was fixed in all directions. The exterior truss seat was attached to the spandrel. The truss was pinned at both exterior and interior truss seats. The interior end of the slab was fixed in the vertical direction. In the truss axis direction at the interior end of slab, break elements were implemented to represent temperature-dependent tensile capacities of steel reinforcement.

Loads: The loading on the truss model consisted of dead load and 13.75 psf of live load (equal to 25 percent of design live load for the WTC towers) and temperature time-histories for all truss components including the truss seats and concrete slab. Thermal loads were assumed for exercising the truss model. The temperature was ramped from $20{ }^{\circ} \mathrm{C}$ to $700{ }^{\circ} \mathrm{C}$ in steel members, from $20{ }^{\circ} \mathrm{C}$ to $700{ }^{\circ} \mathrm{C}$ at the bottom of the slab, and from $20{ }^{\circ} \mathrm{C}$ to $300{ }^{\circ} \mathrm{C}$ at the top of the slab for the period from 0 min to $30 \mathrm{~min}$; thereafter, the temperatures were linearly increased by an additional $200^{\circ} \mathrm{C}$ at $40 \mathrm{~min}$. A linear temperature gradient through the thickness of the slab was assumed. Temperature was not applied to the columns and spandrel.

Summary of Results: Key structural response of the truss model to "assumed temperature conditions" can be summarized as follows:

- The stud on the spandrel and studs on the strap anchor failed in shear below $275^{\circ} \mathrm{C}$.

- The first knuckle from the interior end failed in vertical tension at around $100{ }^{\circ} \mathrm{C}$.

- Top chords yielded above $300{ }^{\circ} \mathrm{C}$ due to the difference in coefficients of thermal expansion of steel and concrete. 
- The floor sagged into a catenary shape as four compression diagonals buckled due to high axial compressive force at $565^{\circ} \mathrm{C}$.

- The interior truss seat bolts sheared off, and the second and third knuckles from the interior end failed in the horizontal shear at $566{ }^{\circ} \mathrm{C}$.

- The gusset plate fractured, and the exterior truss seat bolts sheared off at around $680{ }^{\circ} \mathrm{C}$.

- The truss walked off the exterior truss seat at $730{ }^{\circ} \mathrm{C}$.

Simplified Truss Model: The truss model was modified for use in the full floor subsystem model to enhance computational efficiency. Characteristics captured by the simplified truss model were: (1) total horizontal reaction force under the thermal loading and (2) vertical deflection under the thermal loading. The simplified truss model had the following features:

- Double primary truss was combined into a single truss. Areas of truss members were doubled.

- The top and bottom chords and diagonals were modeled by 3-D linear finite strain beam elements. Only one element was used for a member between two panel points.

- Break elements were used to model the following failure modes: (a) seat bolt shear-off, (b) gusset plate fracture, (c) truss walk-off, (d) web diagonal buckling/resistance weld failure, (e) failure of spandrel studs and studs on strap anchors, and (f) weld failure between strap anchors and top chords. Knuckles were not modeled by break elements.

- Temperature-dependent elastic and plastic material properties of steel were used.

- Creep in steel was included in the simplified truss model; however, it was not included when the simplified truss model was incorporated in the full floor model because of convergence problems inherent to 3-D linear finite strain beam elements.

- The concrete slab was modeled by 4-node finite strain shell elements with a temperaturedependent bilinear material model that had the same yield strength in both tension and compression. The yield strength was set to the compressive strength.

\section{E.2.4 Full Floor Analysis}

The full floor models were developed and analyzed using ANSYS to identify the most likely failure modes and the fire-induced damage to be incorporated in the global model along with impact damage and to modify the floors in the global models to enhance computational efficiency.

Failure Modes: Possible failure modes of the floor subsystem were identified as follows:

- Sagging of the Floor System: Floor sagging caused by loss of stiffness, plastic bending, or buckling of web diagonal members resulted in tension in the floor subsystem, tension in the connections to the exterior walls, and lateral forces (pull-in forces) on columns.

- Loss of Support: Loss of a truss support could be caused by (1) vertical shear load due to debris and/or impact load of the dropping floor above, (2) reduced resistance of truss seats under elevated temperatures, (3) tension acting on truss seats caused by floor sagging, (4) cooling of a truss already shortened due to plastic deformation resulting from thermal 
loading, and (5) aircraft impact. Loss of support will reduce buckling strength of exterior columns.

Model Description: The base floor model developed was for Floor 96 of WTC 1 with columns extending from Floor 95 to Floor 97. The full floor model included the following structural members:

- Both exterior and core columns extending from one floor below to one floor above, modeled by 3-D quadratic finite strain beam elements.

- Spandrels of the floor of interest, modeled by four-node finite strain shell elements (eight elements bctween two columns and four elements along the height), which were tied to exterior columns by rigid beam elements.

- Floor slab was modeled by four-node finite strain shell elements with four layers through the thickness.

- Floor trusses including primary and bridging trusses. Two primary trusses supported by the same column were combined into a single truss. Truss members (top and bottom chords and web diagonals) were modeled by 3-D linear finite strain beam elements.

- Strap anchors, modeled by 3-D linear finite strain beam elements.

- Core beams, modeled by 3-D linear finite strain beam elements. They were placed at their centroids and were connected to the slab by rigid beam elements.

- Deck support angles, modeled by 3-D linear finite strain beam elements.

Break elements were incorporated into the model to represent: 1) buckling of web diagonals, 2) gusset plate fracture, 3) truss seat bolt shear-off, 4) truss seat failure, 5) failure of connections between primary and bridging trusses, 6) failure of connections between primary long-span and transfer trusses, 7) failure of studs connecting the slab and the spandrel, and 8) failure of welds between strap anchors and top chords of primary trusses. Break elements were not used for representing knuckle failure as the truss analysis found that buckling of web diagonal members preceded knuckle failures. The concrete slab was always attached to primary trusses at knuckle locations in the full floor model.

Subsequent to the initial thermal response analysis, the following members were removed from the model to enhance computational efficiency: 1) deck support angles, 2) bridging trusses outside of the two-way zones, 3) spandrel studs connecting the slab and the spandrel, and 4) strap anchors. These members were found to fail in the carly stage of thermal loading, caused the analysis to slow down due to the large residual nonlinearities in the subsequent stages of analysis. Deck support angles and bridging trusses buckled between primary trusses due to thermal expansion. Most spandrel studs and welds between strap anchors and truss top chords failed due to lateral shear force in the plane of slab caused by the difference in the thermal expansion between the floor and the exterior wall in the direction transverse to the truss axis. As a result of the removal of strap anchors and spandrel studs, the only connections between the exterior wall and the floor were gusset plates and exterior truss seats in the full floor models.

Materials: Temperature-dependent elastic and plastic material properties of steel provided by NIST were assigned to each structural member according to the PANYNJ drawings. It was found that creep in 3-D linear/quadratic finite strain beam elements would causc convergence problems when those elements experience thermally-induced buckling. Therefore, creep could not be included in the full floor models. For the concrete slab, a bilinear stress-strain relationship with a yield point at its compressive strength was used, where the yield strength was the same in both tension and compression. 
Impact Damage: Elements corresponding to structural members that sustained severe structural damage were removed from the model. Based on the aircraft impact analysis, NIST identified two sets of structural and thermal insulation impact damage for each floor. These impact cases were designated as "Case $A_{i}$ impact damage condition" and "Case $B_{i}$ impact damage condition" for WTC 1 , and "Case $C_{i}$ impact damage condition" and "Case $\mathrm{D}_{\mathrm{i}}$ impact damage condition" for WTC 2.

Boundary Conditions: Both core and exterior columns were fixed in the vertical direction at the bottom. When the column below the floor was severed by aircraft impact, the top of the column above the floor was supported in the vertical direction. Core columns were free in the horizontal directions and fixed for all rotations at the top and bottom ends. Exterior columns were fixed for translation perpendicular to the face of building and from rotating about the axis parallel to the face of the building at the top and bottom. They were also fixed in torsion at the top and bottom.

Loads: The full floor model was first analyzed for dead load and 25 percent of design live load of the WTC towers, and then temperature time histories representative of the WTC fire conditions were applied. Vertical loads to columns were not applied. NIST provided temperatures of structural components from reconstructed fires in the WTC towers based on the impact damage conditions; therefore, the impact damage condition and the temperature condition had one-to-one correspondence. Temperature cases provided were "Case $A_{i}$ temperature condition" and "Case $B_{i}$ temperature condition" for WTC 1, and "Case $C_{i}$ temperature condition" and "Case $D_{1}$ temperature condition" for WTC 2. Temperature data sets were provided at $10 \mathrm{~min}$ time intervals up to $100 \mathrm{~min}$ for WTC 1 and up to $60 \mathrm{~min}$ for WTC 2 for each temperature condition.

Summary of Results: The behaviors of the floor subsystem found in the full floor models subjected to impact damage and fire conditions can be summarized as follows:

- Bridging trusses subjected to elevated temperatures buckled between primary trusses.

- When significant differences in the thermal expansion occurred between the floors and the exterior wall in the direction transverse to the primary trusses, spandrel studs, strap anchors, gusset plates, and seat bolts failed due to lateral shear force.

- Floor sagged as the wcb diagonals of floor trusses buckled in the heated area where the thermal insulation was damaged.

- The floors were disconnected from the exterior wall in some areas due to failure of exterior truss seats.

Pull-in forces were expected to develop whenever the floor sagged. Although the floor sagging was captured by the full floor models, the pull-in force was not captured in most of the full floor model analyses. To accurately calculate pull-in forces between the floor and the exterior columns in the full floor model, much more detailed modeling was required. Such modeling included accurate boundary conditions on columns, creep in steel, friction at the truss seats, and accurate evaluation of failure of strap anchors and stud, and concrete cracking and spalling. In addition, temperatures of structural members might be low due to conservative assumption of limiting the insulation damage to debris abrasion and neglecting the effect of aircraft shock and vibration.

Floor Subsystem in Global Models: To enhance computational efficiency, floors in the global models were modeled by shell elements to have the following functions: 1) diaphragm action and 2) transfer of the load from the core to the exterior wall system by a membrane action. Since the floors modeled by shell elements cannot capture key failure modes under elevated temperatures, including sagging of floors 
and disconnection of floors from the exterior wall, their effects need to be implemented in the global model as fire-induced damage at appropriate points in time.

\section{E.3 EXTERIOR WALL SUBSYSTEM}

The exterior wall subsystem was a nine-column (three-panel) wide by nine-story (three-panel) high section of WTC 1 between Floor 91 and Floor 100 and Column 150 and Column 158 as shown Fig. E-5. This area, typical of the exterior walls of the towers, connected to a part of the floor system near the corner.

Each face of the towers' exterior wall consisted of fifty-nine 14 in. square box columns spaced at $3 \mathrm{ft} 4 \mathrm{in}$. on center, with $52 \mathrm{in}$. deep spandrel plates at each floor level. The exterior wall was constructed with shop-welded prefabricated panels, each consisting of three columns and three spandrel beams, $13 \mathrm{ft} 4 \mathrm{in}$. wide by $36 \mathrm{ft}$ high. Except at mechanical floors and the base and top of the structure, vertical splices (column splices) in prefabricated panels were staggered such that within any story, every third prefabricated panel had a column splice (see Fig. E-5). Exterior column splices at the upper stories typically consisted of four 7/8 in. diameter ASTM A325 bolts fastened through the welded butt plates at the tops and bottoms of adjoining columns. Special prefabricated panels existed for the mechanical floors where no stagger existed at Floors 7, 41,75, and 108. At these mechanical floors, the column splice detail included supplemental field welding in addition to the bolted connection. Horizontal (spandrel-tospandrel) connections between prefabricated panels were all field-bolted using splice plates. Corner panels that connected the orthogonal walls at corners were two-story tall ( $24 \mathrm{ft}$ ) and consisted of two columns, two spandrel plates, and a third column midway between the two columns on alternate floors. Various grades of steel, having yield strengths ranging between $42 \mathrm{ksi}$ and $100 \mathrm{ksi}$, were specified for the exterior column and spandrel plates. Column plate thickness also varied, both vertically and around the building perimeter. Column plate thickness was as thin as $1 / 4 \mathrm{in}$. at the upper stories and increased toward the base of the building.

\section{E.3.1 Single Column Analysis}

A single exterior column model was developed to examine column behavior under compression at different temperatures. The model included a one story high portion of Column 151 extending from Floor 95 to Floor 96 and portions of spandrels at Floor 95 and Floor 96 . Four-node finite strain shell elements were used to model the plates of the column and the spandrels. Nodes of column plates at the top and the bottom of the model were rigidly tied to the center of gravity of the column cross section. The column was pinned at the bottom and fixed in the two horizontal directions at the top. Increments of axial displacement were applied at the top of the model at room temperature and $700{ }^{\circ} \mathrm{C}$.

The calculated capacity of the columns spanning a single floor occurred after local buckling of plates and the subsequent kinking of the cross section at 1,030 kip at room temperature, well below the inelastic buckling strength of the column, and $270 \mathrm{kip}$ for $700{ }^{\circ} \mathrm{C}$. Since the compressive force demand on this particular column was estimated at $175 \mathrm{kip}$, the compressive strength of the column is greater than the demand even at $700{ }^{\circ} \mathrm{C}$. The column underwent kink-type buckling at room temperature, and the loadcarrying capacity in the post-buckling regime decreased rapidly; however, it decreased much more gradually at $700{ }^{\circ} \mathrm{C}$. 
Axial load-displacement behaviors of two and three-story single column models were also examined. As the unsupported length became longer and temperature increased, local buckling of plates and the resulting kinking of the cross section did not occur, and the negative slope of the axial load-deflection curve in the post-buckling regime became less steep.

\section{E.3.2 Column Splices}

Failure Modes: Failure modes identified for column splices were: (1) failure of bolts in tension, (2) failure of bolts in shear, (3) bending failure controlled by tension in bolts. Tension capacity was calculated as the ultimate tension capacity of four bolts. Shear capacity was calculated as the addition of bolt shear capacity and splice friction. The ultimate moment capacity was obtained prior to failure of two bolts with some capacity remaining on other two bolts.

Column Splice Model for Exterior Wall Model: Two 3-D quadratic finite strain beam elements for each of the four bolts. four pairs of 3-D node-to-node contact elements at the faying (contact) surfaces, and rigid beam elements, modeled by $3-\mathrm{D}$ elastic beam elements, connecting the tops of the bolts to the contact elements, were used to model the column splice. Break elements were used to model the fracture of the column splice bolts based on data from bolt tests provided by NIST and on shear failure of the splice. A coefficient of friction of 0.35 was used for the contact elements. The $7 / 8$ in. diameter column splice bolts were preloaded to $36.05 \mathrm{kip}$ at $20^{\circ} \mathrm{C}$.

\section{E.3.3 Spandrel Splices}

Failure Modes: Failure modes identified for spandrel splices were: (1) bolt shear, (2) tearing of the spandrel plate, and (3) tearing of the splice plates at the bolt holes. Capacities of these failure modes at different temperatures were estimated by hand calculations.

Spandrel Splice Model for Exterior Wall Model: Break elements were used to model the spandrel splice connections in the model. At each splice location, eleven break elements were used. Nodal couples were used to model the spandrel splice connections on the boundaries of the model. 


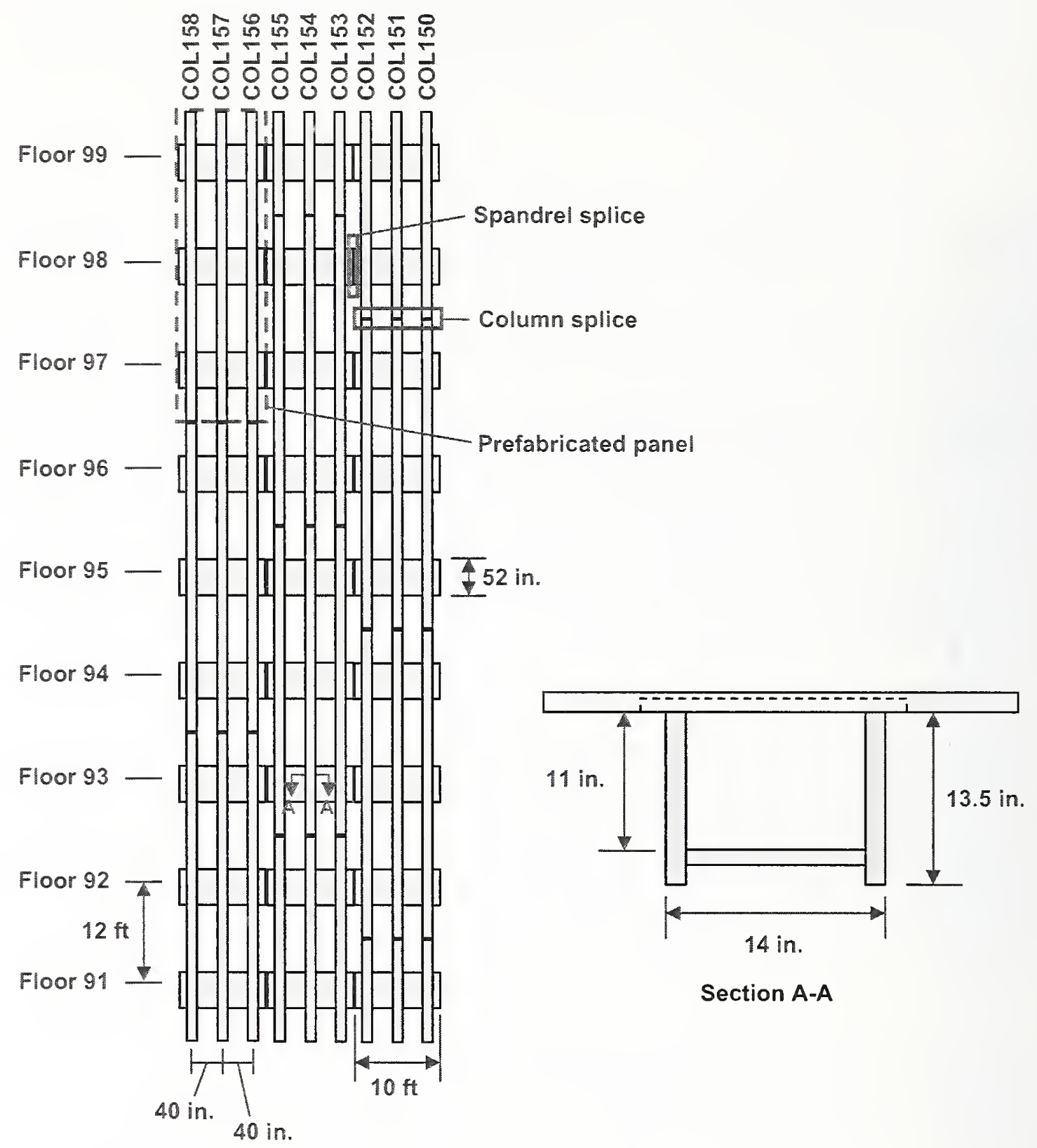

Figure E-5. Exterior wall subsystem.

\section{E.3.4 Exterior Wall Analysis}

Failure Modes: The exterior wall subsystem model captured the following failure modes:

- Inelastic buckling of columns from large lateral deformations,

- Inelastic buckling of columns from loss of support at floor truss seats and diagonal straps,

- Failure of column splice bolts, and

- Failure of spandrel splice bolts or tearing of spandrel or splice plates at bolt holes. 
The model did not capture the local buckling of the column plates and the resulting kinking of the cross section. This was justified because the exterior walls were observed to have bowcd inward over more than three floors prior to the collapse, and temperatures of the columns of these walls were high. In these cases, the kink-type buckling of columns did not occur.

Model Description: BEAM189 elements modeled the columns. Above and below spandrels, 3-D quadratic finite strain beam elements modeled the complete cross sections of the columns. Four-node finite strain shell elements modeled the spandrels. Rigid beam elements connected nodes on the axis of the columns to nodes located in the mid-plane of the spandrels.

Materials: Temperature-dependent elastic and plastic material properties of steel provided by NIST were assigned to each structural member according to the drawings. Creep in steel was included unless the analysis was a displacement-controlled analysis.

Boundary Conditions: The bottoms of all columns in the model were restrained in the vertical direction. The top and the bottom of all columns in the model were restrained in the direction normal to the wall. In addition, the bottom of central column was restrained in the plane of the wall. Symmetry boundary conditions were imposed on the spandrels at the boundaries of the model, except that the spandrels were free to expand in the plane of the wall. Motion out of the plane of the wall was restrained at all floor truss seats and straps. In several analyses, such restraints were removed at two or three floors (either Floors 95 and 96 or Floors 95, 96, and 97) to investigate the effect of floor sagging and floor/wall disconnection on stability of the exterior wall system.

Loads: The loads on the model were applied sequentially in the following order:

- Self weight of the exterior wall components,

- Column splice bolt preload,

- Dead load of the floor system, including 8 psf superimposed dead load,

- 25 percent of WTC floor design live loads,

- Temperatures of fire scenarios provided by NIST, and

- Transverse pull loading from sagging trusses or additional vertical deflection from a potential redistribution of forces to this portion of the exterior wall.

To represent a rangc of thermal conditions expected in the WTC towers, NIST provided five thermal load conditions: D. DBARE, E, E119, and F. These load conditions differed in fire behavior, intensity, location in the towers, and time. Thermal load DBARE assumed steel without insulation. Thermal load E119 corresponded to the standard ASTM E1 19 fire load.

Summary of Results: The response of the exterior wall model subjected to thermal loads can be summarized as follows:

- Large inelastic buckling of spandrels occurred at elevatcd temperatures.

- Although partial separations of the spandrel splices occurred at elevated tempcraturcs, complete separation did not occur.

- Instability of the exterior wall subsystem did not occur at elevated temperatures when the wall was supported laterally at every floor. Instability of the exterior wall subsystem occurred when at least three floors were unbraced and the exterior wall subsystem was subjected to additional vertical load or pull-in force. 
- All column splices remained closed, except near the points of instability of the exterior wall with three floors unbraced and subjected to additional vertical load or pull-in force where calculations showed opening and sliding of the splice with no bolt fracture.

Exterior Wall Subsystem in Global Models: The analyses of the exterior wall model support the following conclusions for modeling the towers:

1. Large inelastic deformations and buckling of the spandrels do not significantly affect the stability of the exterior columns and need not be accurately modeled in the global models.

2. Partial separations of the spandrel splices do not significantly affect the stability of the exterior columns and need not be accurately modeled in the global models.

3. Exterior column splices can be expected to fail by sliding or opening at elevated temperatures when subjected to increased vertical loading or pull-in forces. Since complete failure was not found before the exterior wall became unstable, column splice failure may not be modeled in the global models to enhance computational efficiency.

\section{E.4 RECOMMENDED MODELING DETAILS FOR SUBSYSTEMS IN GLOBAL MODELS}

Based on the results of finite-element analyses performed on components, connections, and subsystems, the following recommendations can be made for modeling of the subsystems in the global models to enhance numerical efficiency.

\section{Floor Subsystem}

Floors in the global model may be modeled by shell elements, which have their membrane stiffness equal to that of the full floor system. Floors in the global model function as diaphragms and transfer load between the exterior wall system and the core.

The global model cannot be constructed with the same level of detail in all floors subjected to thermal loading as the full floor model developed here. To enhance computational efficiency, the pull-in forces and disconnections of floors from the exterior walls may be implemented in the global models as "fireinduced damage" at appropriate times. Since the full floor models could not be used to calculate accurately the pull-in forces at floor/wall connections, the fire-induced damage obtained from the full floor model analyses needs to be modified by the results of "actual observations" obtained from the examination of photographs and videos performed by NIST (NIST NCSTAR 1-5A).

\section{Exterior Wall Subsystem}

The exterior and interior columns must be modeled with fidelity of their inelastic buckling behavior. To capture the premature buckling of the single span exterior columns at low temperatures, which occurs at the onset of plate buckling and results in kinking of the cross section, a fine mesh is needed. However, observations of photographs and videos show that bowing is extended over several floors and column temperatures are not low. Therefore, kink-type buckling of the exterior columns may be neglected.

Exterior column splices need not be modeled in the global models.

Spandrels can be modeled by beam elements capable of resisting shear and bending moment. The spandrel splices need not be modeled in the global analyses. 


\section{Chapter 1 \\ INTRODUCTION}

\subsection{PURPOSE}

Simpson Gumpertz \& Heger Ine. (SGH) developed finite-element models of the eomponents, connections, and subsystems of the World Trade Center (WTC) towers to study their structural performanee in the fire environment that followed the aireraft impaet to the towers. The results of this study were used to develop global models that ran efficiently and eaptured the important failure modes and sequential failures of eomponents and subsystems and to determine the probable sequenee of structural responses that let to the global eollapse initiation.

SGH performed this study as part of Projeet 6 of the investigation on the WTC disaster by the National Institute of Standards and Teehnology (NIST). This report eonstitutes the SGH's report on Task 1 of the SGH eontraet with NIST and Part 1 of the SGH two-part report. The Task 2 and 3 report deals with the global analysis of the WTC towers (NIST NCSTAR 1-6D').

\subsection{SCOPE OF WORK}

SGH in Task 1 performed the following:

- Developed and validated ANSYS models of the full floor and exterior wall subsystems.

- Evaluated structural responses of eomponents, eonneetions, and subsystems to serviee loads due to gravity (dead and live loads) and elevated temperatures.

- Identified the likely failure modes and failure sequences of components, eonneetions, and subsystems.

- Identified modeling details of the floor and exterior wall subsystems in the global models of the WTC towers.

The analyses performed as part of this Task 1 report used the nominal dimensions and design details shown on the PANYNJ drawings ${ }^{2}$. Material properties were based on information provided from the NIST Projeet 3 study (NIST NCSTAR 1-3, NIST NCSTAR 1-3D).

\subsection{REPORT ORGANIZATION}

This report consists of eight ehapters:

- Chapter 1 serves as an introduetion to this report and describes purpose and scope of this study.

1 This reference is to one of the companion documents from this Investigation. A list of these documents appears in the Preface to this report.

2 The technical data required to conduct the analyses of the WTC towers reported herein were obtained from drawings that were provided by the Port Authority of New York and New Jersey (PANYNJ) and their contractors. 
- Chapter 2 introduces a floor subsystem and an exterior wall subsystem of the WTC towers and provides descriptions of their structural details.

- Chapter 3 summarizes temperature-dependent material properties of steel and concrete used in this study.

- Chapter 4 describes a conversion process from SAP2000 reference models to ANSYS models and presents validation studies of the converted ANSYS models.

- Chapter 5 presents results from a study on the full floor subsystem.

- Chapter 6 presents results from a study on the exterior wall subsystem.

- Chapter 7 summarizes recommendations for modeling details of the full floor subsystem and the exterior wall subsystem in the global models.

- Chapter 8 provides a list of refcrences. 


\section{Chapter 2 \\ DESCRIPTION OF SUBSYSTEM STRUCTURES}

The finite-element models of the full floor subsystem and the exterior wall subsystem of the World Trade Center (WTC) towers were developed to calculate the structural response of these subsystems to impact damage and to the fire environments that followed the aircraft impact. The full floor subsystem is a model of Floor 96 of WTC 1. The model is believed to be typical of the upper floors in both towers. The exterior wall subsystem is a nine-column (three-panel) wide by nine-story (three-panel) high section of WTC 1 between Floor 91 and Floor 100 and Column 150 and Column 158. This area is typical of the exterior walls of the towers and connects to a part of the floor system near the corner with different types of trusses.

\subsection{FULL FLOOR SUBSYSTEM DESCRIPTION}

Floor 96 of WTC 1 was identified as an office floor with typical floor construction and loading; therefore, it was selected as the basis for modeling floor response. The full floor subsystem included office area and core area floor framing, as well as core and exterior columns extending to floors immediately above and below this floor. The floor system in the office area consisted of lightweight concrete slab supported by steel floor trusses. Steel trusses spanned nominally $60 \mathrm{ft}$ in the long-span area and $36 \mathrm{ft}$ in the short-span area between exterior walls and the central core. Typically, a pair of primary trusses (double truss) was supported at odd-numbered columns at $6 \mathrm{ft} 8 \mathrm{in}$. on center.

Each of these primary trusses consisted of top and bottom chords fabricated from double steel angles and web diagonals fabricated from round bars (see Fig. 2-1). Web diagonals extended 3 in. above the top chord at the panel points into the concrete slab to form a knuckle and to provide shear transfer between the truss and the concrete slab (see Fig. 2-1).

Hand calculations and finite-element analyses of components of the full floor subsystem and their connections were performed under gravity loads and fire-induced temperature time-histories to capture the different failure modes and loads at failure. Then the results of these calculations and analyses were used to develop the full floor subsystem model.

The top chords of a pair of trusses were supported at the central core by an interior truss seat (Fig. 2-1) welded to steel channels that ran continuously around the core floor area. Each pair of trusses was fastened to a horizontal plate of the interior truss seat by two $5 / 8$ in. bolts (one bolt in each truss) in $13 / 4$ in. long slotted holes. At the exterior wall, each pair of trusses was supported by an exterior truss seat (Fig. 2-1), which fastened to a seat angle with two 5/8 in. diameter bolts in 2 in. long slotted holes. A pair of stand-off plates welded the seat angle to the spandrel. In addition, a gusset plate welded to the spandrel and to the truss top chord tied the truss to the supporting column, and a pair of diagonal strap anchors, welded to the top chords and to the adjacent columns, tied these columns to the primary trusses.

Figure 2-2 shows a floor plan of Floor 96 of WTC 1. Primary trusses were interconnected by a transverse system of bridging trusses and deck support angles. These bridging trusses were of similar construction to the primary trusses, except the knuckles did not project above the top chords. The top chord of the bridging trusses sat $11 / 2 \mathrm{in}$. below the top chord of the primary trusses and provided support for the 4 in. thick lightweight concrete slab on the $11 / 2$ in., 22 gauge steel deck with 2 in. wide at the top, 1.25 in. 
wide at the bottom, and $1.5 \mathrm{in}$. high flutes at $6.8 \mathrm{in}$. on center running parallel to the primary trusses. At each corner of the building core, a $36 \mathrm{ft}$ long transfer truss extended out from the corner core column to the exterior wall and supported the $60 \mathrm{ft}$ long primary trusses. The floor in the core consisted of a $4.5 \mathrm{in}$. thick lightweight concrete slab supported by wide flange girders and beams connected to the core columns with bolted connections. Reinforcement between the core area floor and the office area floor (\#3 bars at $10 \mathrm{in}$. at the top and \#4 bars at $12 \mathrm{in}$. at the bottom) provided continuity between the two areas and restrained the truss from walking off the interior seat.

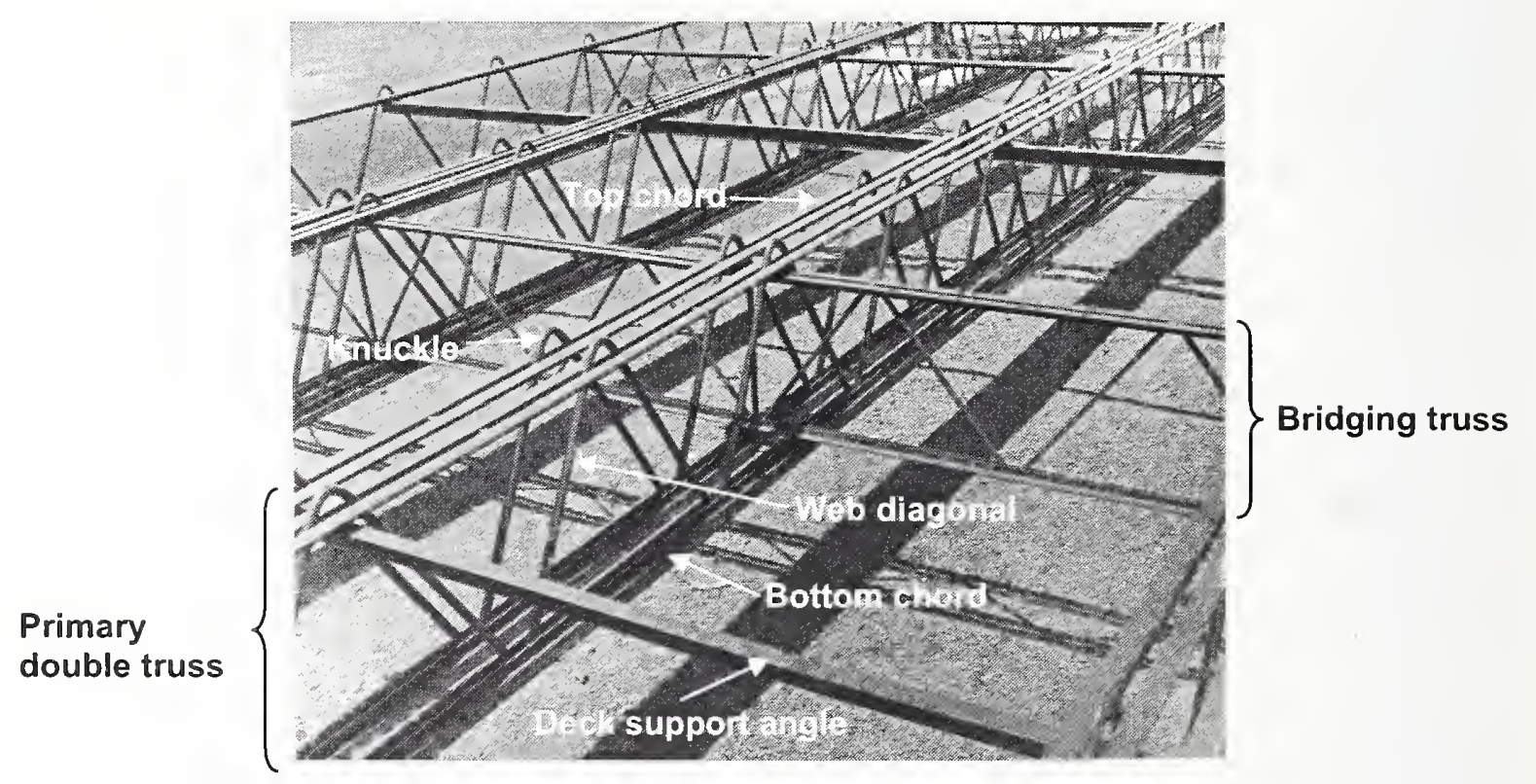

Figure 2-1. Mock up of office floor framing system (Photograph from about 1967 provided by Laclede Steel Co.). 

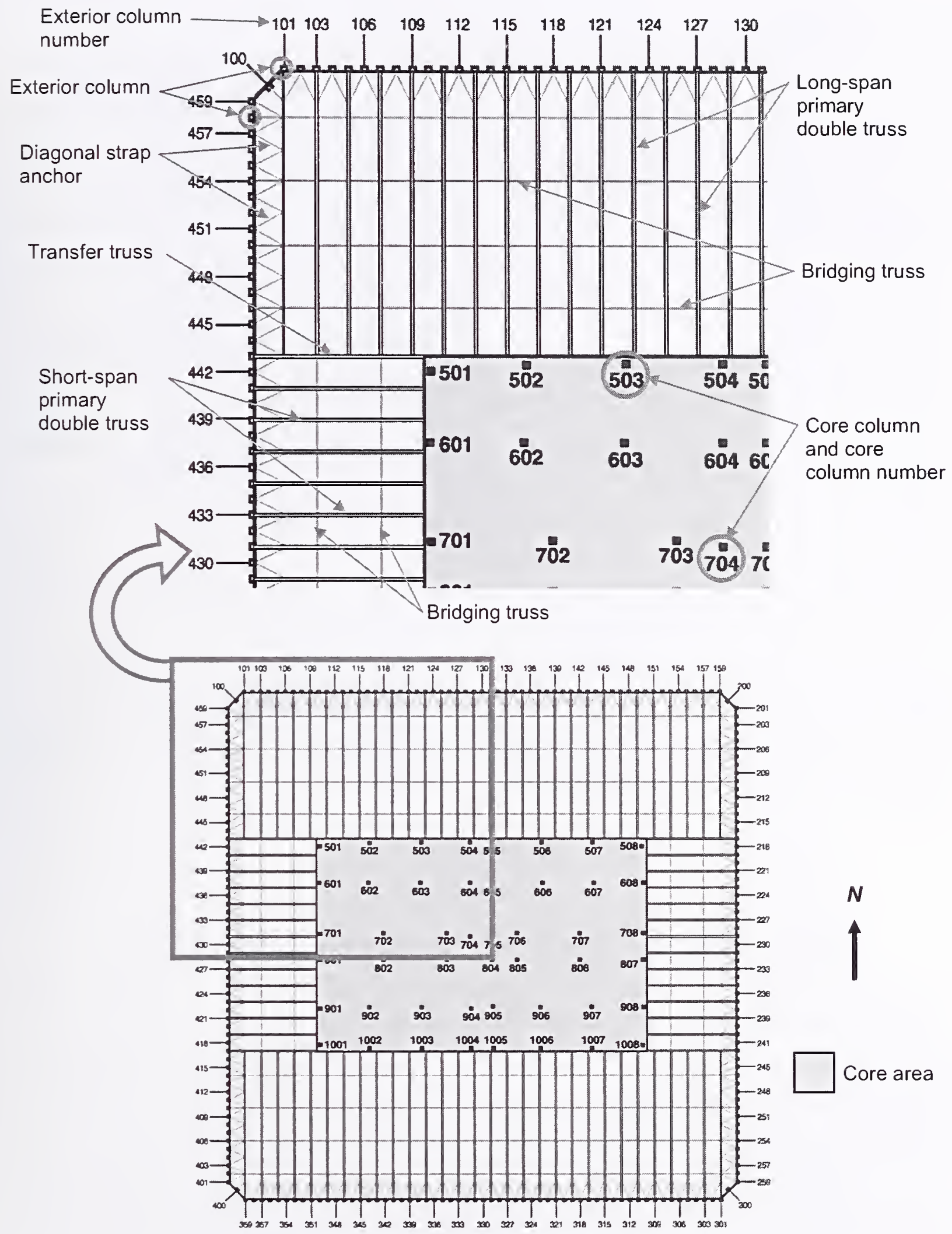

Figure 2-2. Floor plan of Floor 96 of WTC 1. 


\subsection{EXTERIOR WALL SUBSYSTEM DESCRIPTION}

Each exterior wall of the towers consisted of fifty-nine $14 \mathrm{in}$. square box columns spaced at $3 \mathrm{ft} 4 \mathrm{in}$. on center, with 52 in. deep spandrel plates at each floor level. The exterior wall was constructed with shopwelded prefabricated panels, each consisting of three columns and three spandrel beams, $13 \mathrm{ft} 4 \mathrm{in}$. wide by $36 \mathrm{ft}$ high. Except at mechanical floors and the base and top of the structure, vertical splices (column splices) in prefabricated panels were staggered such that within any story, every third prefabricated panel had a column splice (see Fig. 2-3). Exterior column splices at the upper stories typically consisted of four 7/8 in. diameter ASTM A325 bolts fastened through the welded butt plates at the tops and bottoms of adjoining columns. Special prefabricated panels existed for the mechanical floors where no stagger existed at Floors 7, 41, 75, and 108. At these mechanical floors, the column splice detail included supplemental field welding in addition to the bolted connection. Horizontal (spandrel-to-spandrel) connections between prefabricated panels were all field-bolted using splice plates. Corner panels that connected the orthogonal walls at corners were two-story tall $(24 \mathrm{ft})$ and consisted of two columns, two spandrel plates, and a third column midway between the two columns on alternate floors.

Various grades of steel, having yield strengths ranging between $42 \mathrm{ksi}$ and $100 \mathrm{ksi}$, were specified for the exterior column and spandrel plates. However, fewer grades were actually used than specified by supplying a single grade steel for the 3 highest specified yield strengths. Column plate thickness also varied, both vertically and around the building perimeter. Column plate thickness was as thin as $1 / 4 \mathrm{in}$. at the upper stories and increased toward the base of the building. The specified plate thickness and material yield strength for each column differed between the two towers primarily due to the 90-degree change in the building orientation between the two towers and computed wind loads (NIST NCSTAR 1-2).

The model of the exterior wall subsystem was a nine-column (three-panel) wide by nine-story (threepanel) high section of WTC 1 between Floor 91 and Floor 100 and Column 150 and Column 158 as shown Fig. 2-3. This area, typical of the exterior walls of the towers, connected to a part of the floor system near the corner. (Column 159 is at the corner of the north face of WTC 1, see Fig. 2-3). Using this model, the structural behavior and failure modes of the exterior wall system were evaluated in the fire environment. 

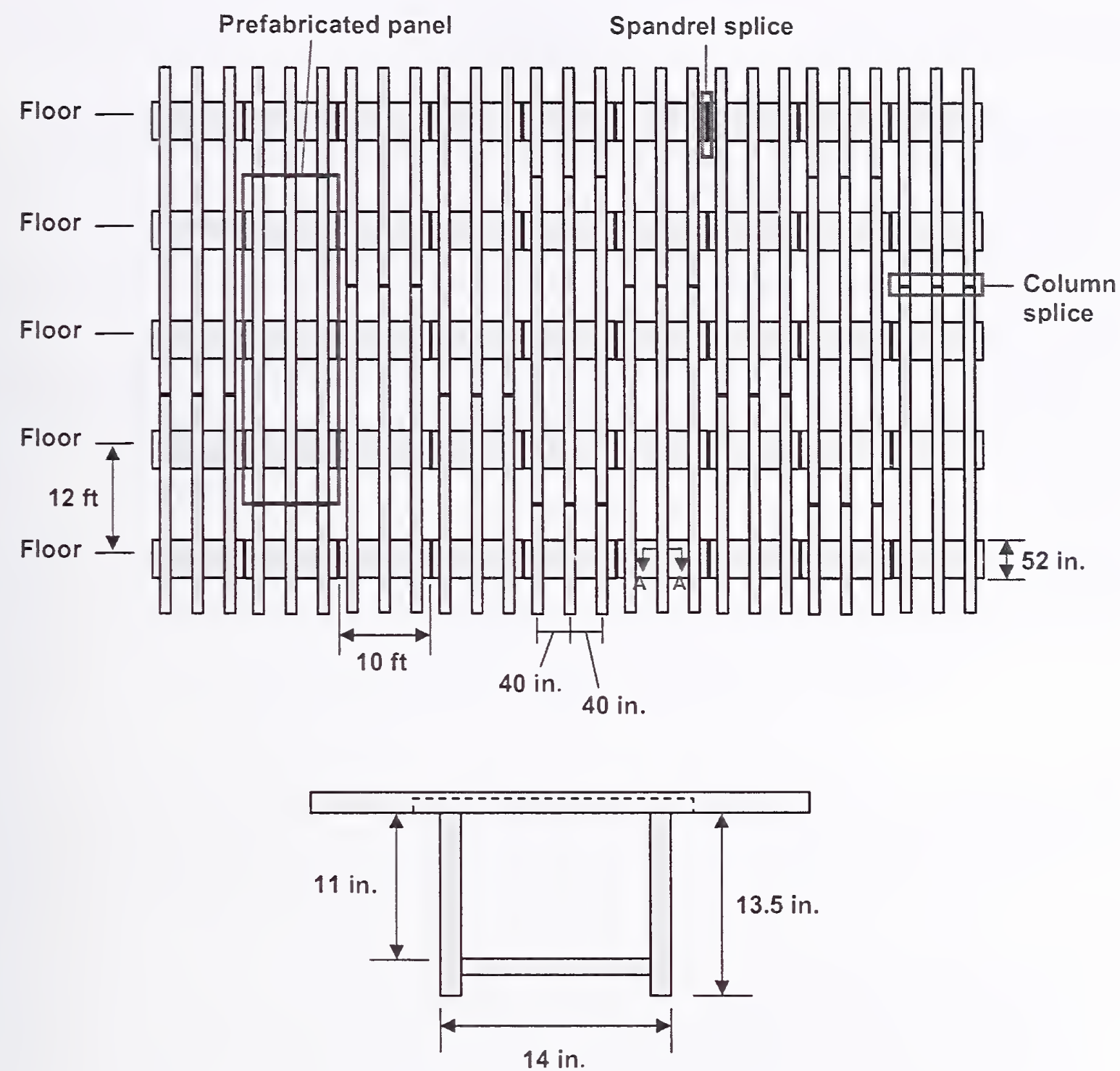

Section A-A

Figure 2-3. Exterior wall construction with prefabricated wall panels.

\subsection{LOADS}

The subsystems and components were analyzed for dead (D), live ( $L)$, and thermal $\left(T_{a}\right)$ loads. The dead load consisted of structural weight and superimposed dead loads. The superimposed dead load and design live load were defined in the World Trade Center Design Criteria (LERA 2003). The superimposed dead loads for floors outside the core consisted of the weights of ceiling, mechanical and electrical equipment, passive fire protection (also referred to as thermal insulation or fireproofing), and floor finish, and were estimated at 8 psf. Twenty five (25) percent of the design live load was selected as a reasonable approximation of the load that likely existed at the time of the collapse. (For example, 25 percent of the design live load resulted in a load of 13.75 psf for the long-span trusses in the two way zone of Floor 96 
with 55 psf design live load.) The service dead and live loads were applied first, followed by the thermal loads.

The dead and live loads were defined as weights, so that during the collapse process, the gravity loads remained acting on the structure. The weight of debris from the plane provided by Project 2 (NIST NCSTAR 1-2) was found to be negligible relative to the dead and service live loads and was not included in the analysis.

The thermal loads, $T_{a}$, were temperature time histories for all structural members provided by Project 5 (NIST NCSTAR 1-5, NIST NCSTAR 1-5G).

For analysis of some of the components, discrete values of temperature or temperature distributions were linearly ramped from $20^{\circ} \mathrm{C}$ to $700{ }^{\circ} \mathrm{C}$ (or to a temperature below $700{ }^{\circ} \mathrm{C}$ that results in the failure of the component) over $30 \mathrm{~min}$. Failure modes of the components were evaluated at room temperature and at different elevated temperatures, as failure modes and failure loads may change with increasing temperature.

Although wind may have had a minor role in the collapse of the towers, all analyses performed in this study did not include wind load effects. 


\section{Chapter 3 \\ MATERIALS}

The mechanical properties of both steel and concrete are affected significantly by temperature. In the following sections, the material properties used in this study are specified as a function of temperature. For finite element analysis (FEA) of components, subsystems, and global models of the World Trade Center (WTC) towers, a material properties catalog was developed. Each material model was identified with a number in ANSYS; steels were Material ID 1 through Material ID 29, and concretes were Material ID 51 through Material ID 83. The details of different materials are discussed for concrete and steel separately in this chapter.

\subsection{CONCRETE}

Two types of concrete were generally used for the flooring inside the towers: lightweight concrete and normal weight concrete. Thermal properties of normal weight concrete depend on the type of aggregate. Petrographic inspection by Simpson Gumpertz \& Heger Inc. of two samples of concrete taken from the debris at NIST showed siliceous sand. Because the source of coarse and fine aggregates for a construction site is usually the same, available data for siliceous aggregates were used.

\subsubsection{Concrete Properties}

The unit weight of the lightweight concrete was specified at $100 \mathrm{pcf}$ by the WTC Design Criteria (LERA 2003); however, 110 pcf was used in the analysis based on the density of the two concrete samples examined by SGH. The unit weight of the normal weight concrete was specified at 150 pcf by the WTC Design Criteria (LERA 2003).

Poisson's ratio, $v_{c}$, of 0.17 was used for both normal weight and lightweight concrete at all temperatures.

The specified concrete strength was 3.000 psi for the lightweight concrete, and either 3,000 psi or 4,000 psi for the normal weight concrete, as shown on Drawing Book 8, Sheet ABl-2.1 (SHCR 1973). The actual strength, $f_{a}$, of in-place concrete at room temperature was calculated from the specified strength, $f_{c}^{\prime}$, as follow's:

$$
f_{a}=f_{c}^{\prime} \cdot F_{1} \cdot F_{2} \cdot F_{3}
$$

where the factor $F_{1}=$ the ratio of the average strength of 28-day cylinders to specified strength, $F_{2}=$ the ratio of in-situ 28-day strength to 28-day cylinder strength, and $F_{3}=$ factor that accounts for the change in concrete strength with age.

By using $F_{l}=1.25$ and $F_{2}=0.95$ (Bartlett and MacGregor 1996) and $F_{3}=1.16$, based on the formula specified in Section 2.2.1 of American Concrete Institute (ACI) 209 for the change of concrete strength with age, the mean of the ratio of actual strength of in-place concrete to the specified concrete strength was determined to be $f_{a} / f_{c}^{\prime}=1.38$. Based on this mean value, the actual strengths of in-place concretes are $f_{a}=5,500$ psi for the specified 4,000 psi normal weight concrete, 4,100 psi for the specified 3,000 psi normal weight concrete, and 4,100 psi for the specified 3,000 psi lightweight concrete. 
Temperature-dependent properties of concrete used in this study were modulus of elasticity, instantaneous coefficient of thermal expansion, compressive strength, and tensile strength.

Modulus of elasticity at room temperature was evaluated by the following formula:

$$
E_{c}(R T)=33 \gamma_{c}^{1.5} \sqrt{f_{a}}
$$

For the compressive strength, the actual strength, $f_{a}$, was used as the compressive strength at room temperature. The tensile strength at room temperature was evaluated by:

$$
f_{t}(R T)=5 \sqrt{f_{a}}
$$

The effects of elevated temperature on concrete properties are based on the work of Phan (1996) as shown in Fig. 3-1.

\subsubsection{Concrete Stress-Strain Relationships}

The compressive stress-strain relationship for concrete, formulas expressed by Seanz (1964), is given by

$$
\sigma=\frac{K_{c} f_{a}\left(\frac{\varepsilon}{\varepsilon_{c 1}}\right)}{1+a\left(\frac{\varepsilon}{\varepsilon_{c 1}}\right)+b\left(\frac{\varepsilon}{\varepsilon_{c 1}}\right)^{2}+c\left(\frac{\varepsilon}{\varepsilon_{c 1}}\right)^{3}}
$$

Where,

$$
\begin{aligned}
& c=\frac{K_{s}-1}{\left(K_{e}-1\right)^{2}} K_{c}-\frac{1}{K_{e}}, \quad b=1-2 c, \quad a=c+K_{c}-2, \\
& K_{c}=2, \quad K_{s}=\frac{1}{0.85}, \quad K_{e}=1.41, \quad \text { and } \quad \varepsilon_{\mathrm{cl}}=K_{c} \frac{f_{a}}{E_{c}}
\end{aligned}
$$

In tension, stress increases linearly up to the tensile strength. When concrete is strained in tension beyond its strength, it softens, and the stress drops. However, the descending branch of stress-strain relationship caused significant numerical problems which were avoided by assuming, with little error, that concrete becomes plastic in tension. The assumption of concrete plasticity after the onset of micro-cracking is valid for reinforced concrete with a reinforcement ratio of about a ratio of the tensile strength of concrete to the yield strength of reinforcement, which is 0.46 percent. The reinforcement ratio in the typical concrete slab in the WTC towers was 0.21 percent in the primary truss direction and 0.74 percent in the direction transverse to the primary trusses. Although the reinforcement ration in the truss direction was smaller than 0.46 percent, the resulting error was not significant. Figure 3-2 shows stress-strain curves of concrete with 3,000 psi specified compressive strength at room and elevated temperatures. 


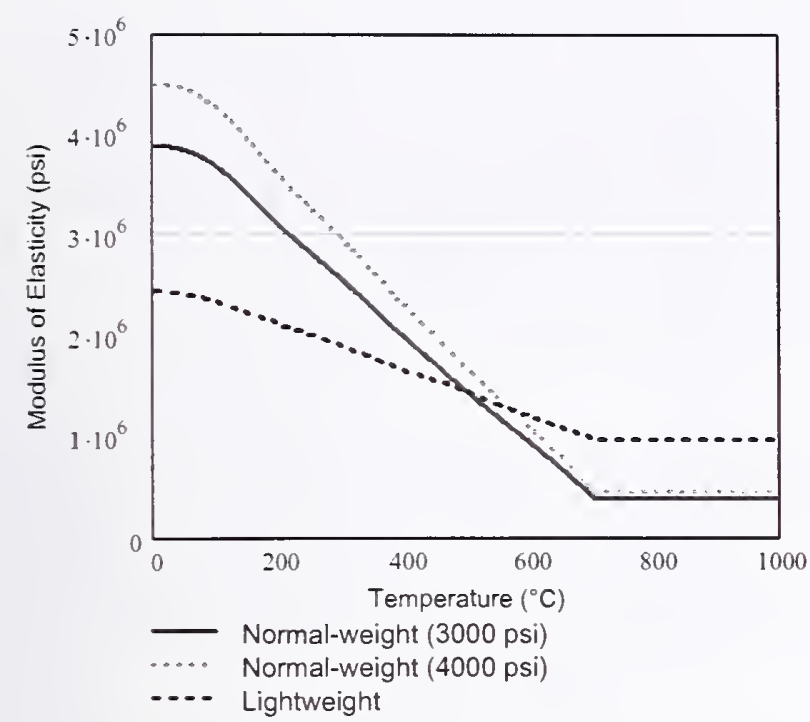

(a) Modulus of elasticity

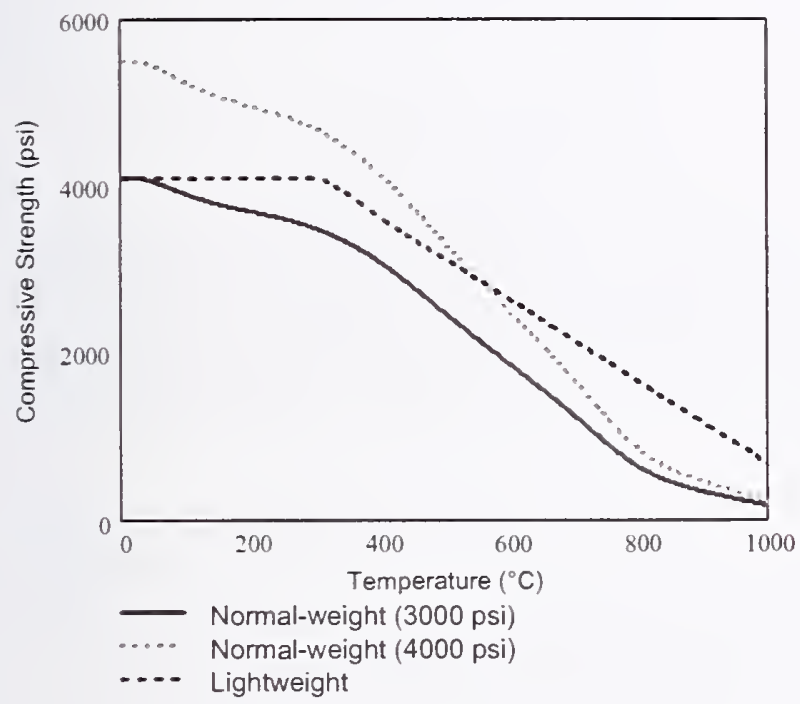

(c) Compressive strength

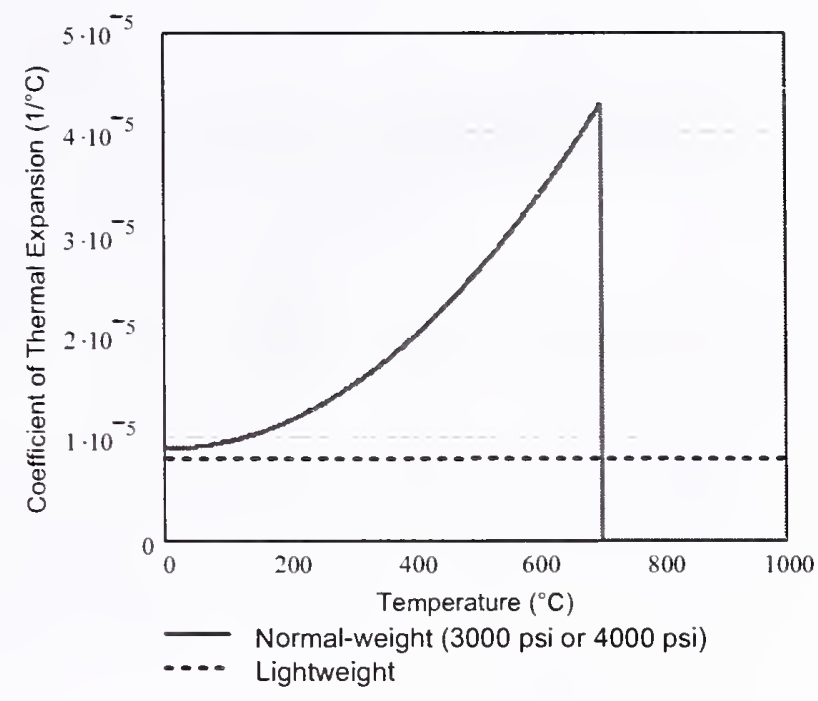

(b) Instantaneous coefficient of thermal expansion

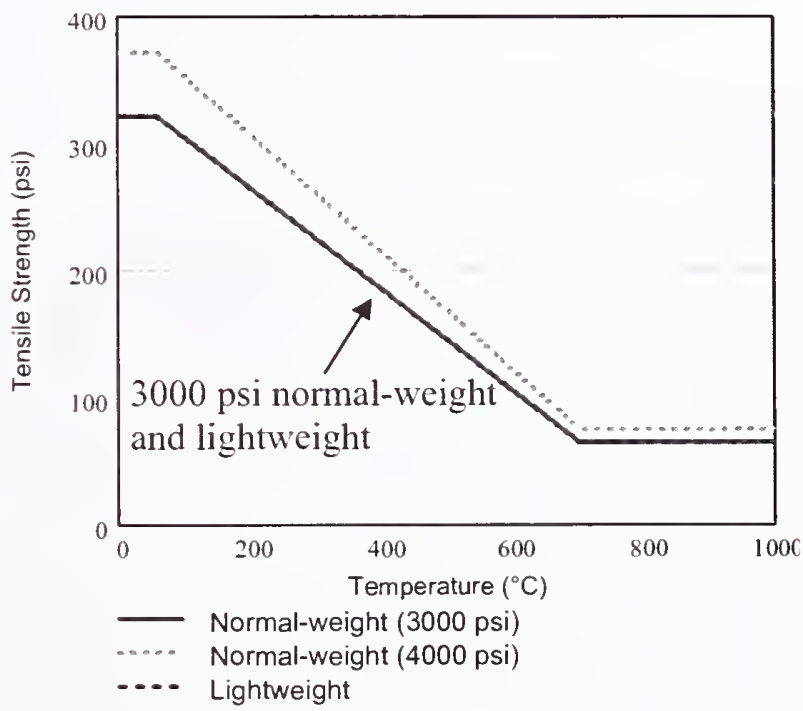

(d) Tensile strength

Figure 3-1. Properties of concrete that vary with temperature. 


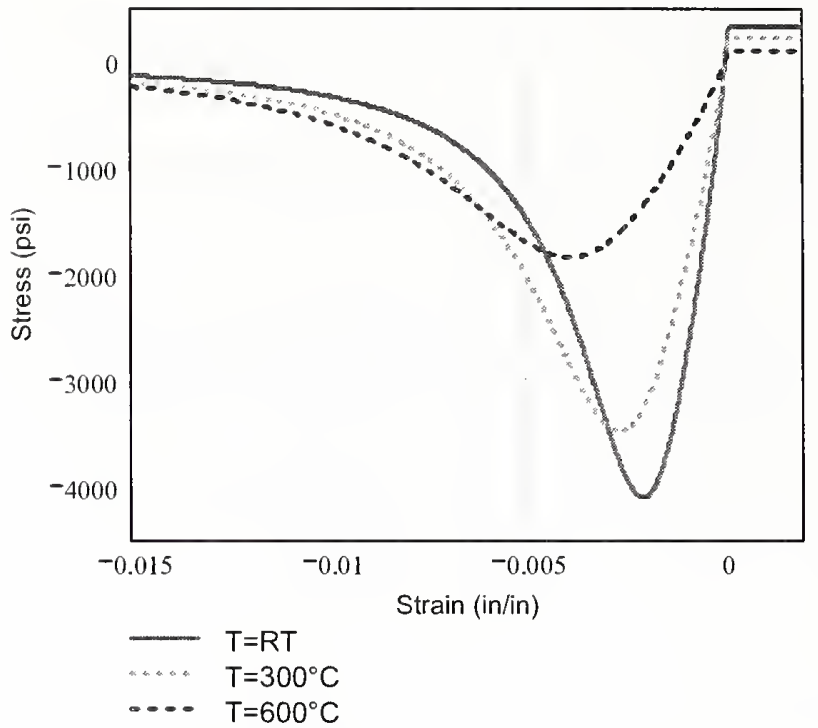

(a) Normal-weight concrete (3,000 psi)

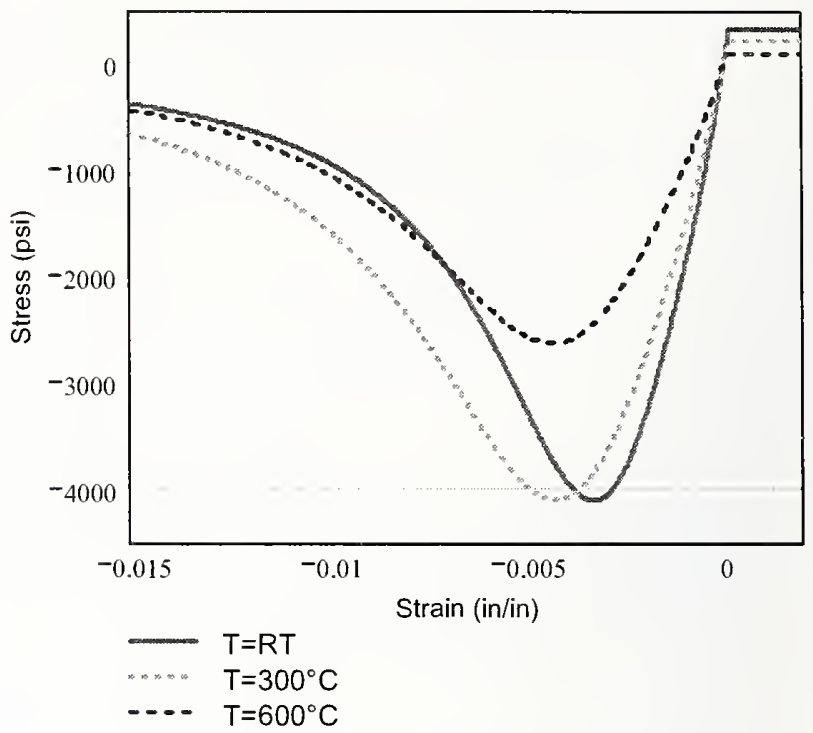

(b) Lightweight concrete

Figure 3-2. Concrete stress-strain relationships at different temperatures.

For the knuckle model in LS-DYNA, solid concrete elements were used with Pseudo Tensor material model (Livermore Software Technology Corporation 2003). The response mode II default concrete option was used. Properties of welded wire fabric were smeared into the concrete material properties, assuming a steel reinforcement of 0.47 percent and a yield strength of wire of $70 \mathrm{ksi}$, where 0.47 percent steel reinforcement was the average of the reinforcement in the two horizontal directions. Since material properties cannot be defined as temperature-dependent properties in this model, different material types were specified for the lightweight concrete at $20^{\circ} \mathrm{C}, 150{ }^{\circ} \mathrm{C}, 300{ }^{\circ} \mathrm{C}, 450{ }^{\circ} \mathrm{C}, 600{ }^{\circ} \mathrm{C}$, and $750{ }^{\circ} \mathrm{C}$ (Material IDs 51 through 56) with different stress-strain relationships.

The concrete floor slab in the truss model was modeled with eight-node solid elements (SOLID185) with a material model that accounts for different behaviors in tension and compression. One such material model in ANSYS is the Hjelm plasticity model with different yield properties in tension and compression. A low "yield stress in tension" was used to simulate cracking of concrete. The Hjelm model uses the Rankine maximum stress criterion in tension and the von Mises yield criterion in compression (ANSYS, Inc. 2004). Concrete material models with the Hjelm model for the specified 3,000 psi normal weight concrete, the specified 4,000 psi normal weight concrete, and the specified 3,000 psi lightweight concrete were assigned to Material ID 81, 82, and 83, respectively. To improve convergence in analysis, the negative slope in the stress-strain relationship after cracking or crushing in compression was removed, and the concrete was assumed to be plastic after cracking or crushing.

Isotropic hardening von Mises plasticity with a bilinear stress-strain relationship was used for the shell element modeling of the concrete slab in the full floor model. The model was elastic until the stress reached the compressive strength. It has the same yield strength in both tension and compression and, thus, did not accurately represent the tensile softening of concrete. This model did have temperaturedependent material properties. 


\subsubsection{Concrete Failure Criteria}

The Mohr-Coulomb failure surface with end caps (a tensile cut-off stress and a compressivc failure end cap) was used in the Pseudo Tensor material model in the knuckle analysis (Livermore Software Technology Corporation 2003). The cut-off stress for tensile failure was set as

$$
\sigma_{c u t}=1.7\left(f_{a}\right)^{2 / 3}
$$

\subsection{STEEL}

Steel types used in WTC 1 and WTC 2 are listed in Table 3-1 along with the actual yield and tensile strengths used in analysis. NIST examined the WTC steels in Project 3 and determined their material properties (NIST NCSTAR 1-3). There were a number of steel suppliers and the multiple sources for steel components of the same grade resulted in different strengths.

\subsubsection{Steel Properties}

Figure 3-3 shows mechanical properties of steel that are affected by elevated temperatures: (a) modulus of elasticity, (b) Poisson's ratio, (c) yield strength reduction factor, (d) tensile strength reduction factor, and (e) instantaneous coefficient of thermal expansion. All steel properties, except yicld and tensile strength reduction factors for bolt steels, are the same for all steels shown in Table 3-1.

\subsubsection{Stress-Strain Relationship}

Plasticity: Stress-strain relationships at room temperature were provided by Project 3. They were constructed from mill reports, actual test data, and literature information using the Voce hardening law.

Stress-strain relationships at elevated temperatures, without consideration of creep, were obtained from the power law:

$$
\sigma=R_{T S} R_{C} K(T) \varepsilon_{c p}^{n(T)}
$$

where:

$$
\begin{aligned}
& K(T)=(k 4-k 0) \exp \left\{-0.5\left[\left(\frac{T}{t k 1}\right)^{k 1}+\left(\frac{T}{t k 2}\right)^{k 2}\right]\right\}+k 0 \\
& n(T)=(n 4-n 0) \exp \left\{-0.5\left[\left(\frac{T}{t n 1}\right)^{n 1}+\left(\frac{T}{t n 2}\right)^{n 2}\right]\right\}+n 0
\end{aligned}
$$

The steel stress-strain relationships at different temperatures varied depending on the typc of steel used in the construction of the towers. Values for $R_{T S}$ and $R_{C}$ are given in Table 3-1, and parameters of functions $K(T)$ and $n(T)$, which were provided by Project 3, are given in Table 3-2. The stress-strain curve is linear with Young's modulus up to the "lincarity limit." At the lincarity limit, the linear stressstrain curve intersects the power law stress strain curve. (Stress at the linearity limit at elcvated temperature was not necessarily equal to the yield stress at the given temperature. The linearity limit was required for ANSYS input.) 


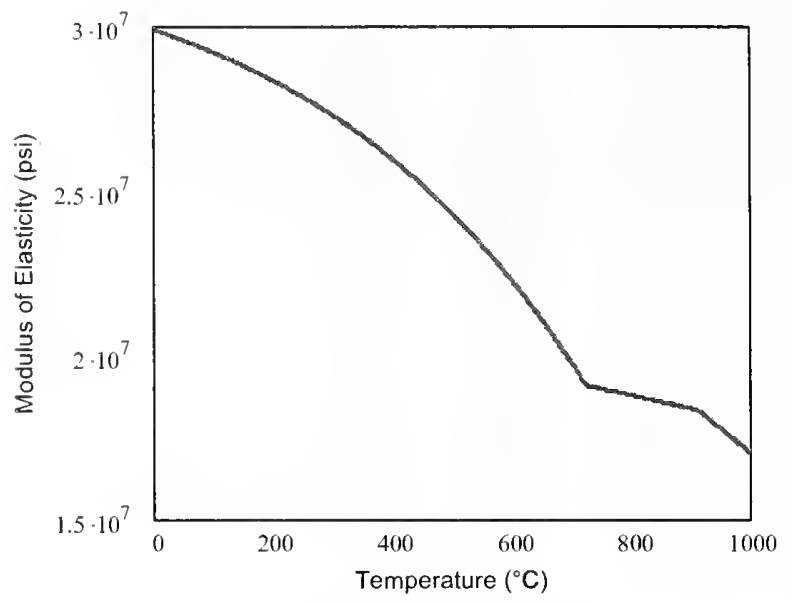

(a) Modulus of elasticity

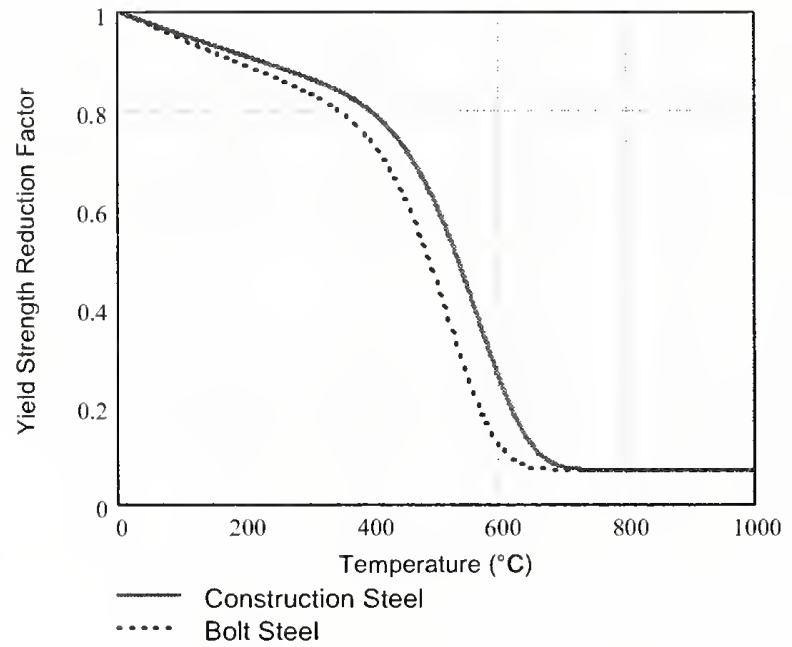

(c) Yield strength reduction factor

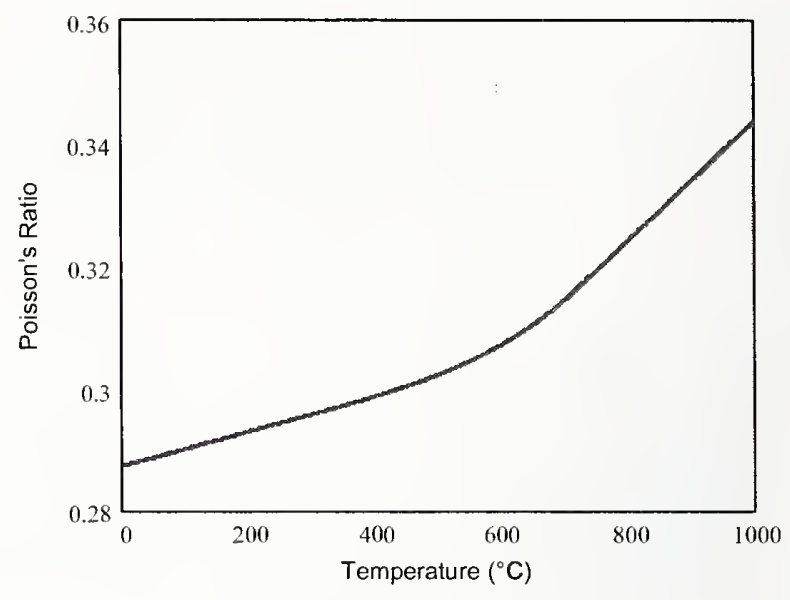

(b) Poisson's ratio

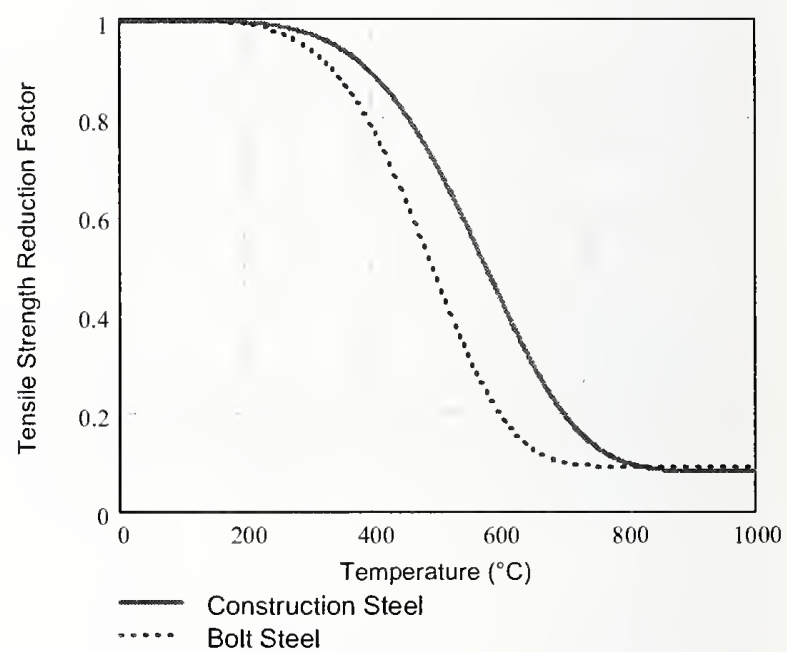

(d) Tensile strength reduction factor

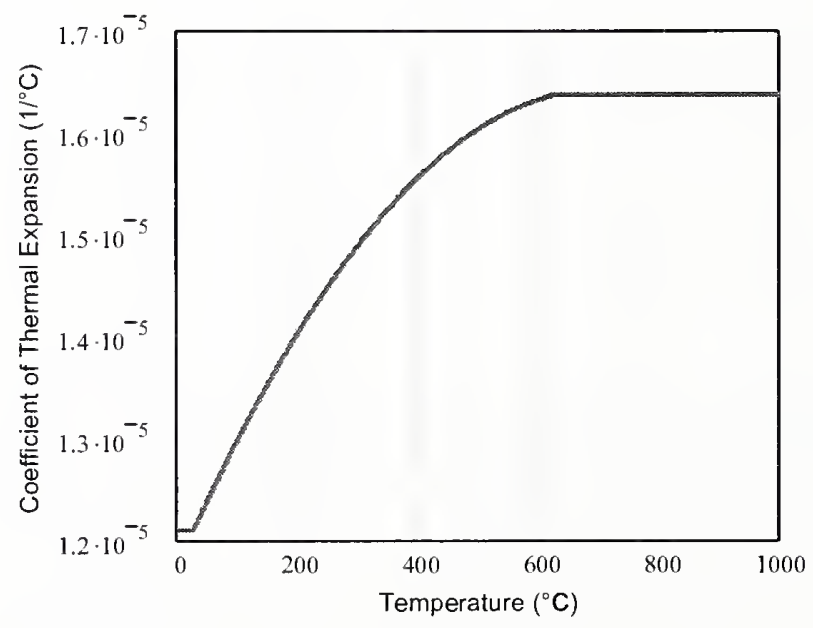

(e) Instantaneous coefficient of thermal expansion

Figure 3-3. Properties for all steel types that vary with temperature. 
Table 3-1. Steel types used in WTC 1 and WTC 2.

\begin{tabular}{|c|c|c|c|c|c|}
\hline Material ID & Description & $\begin{array}{r}\sigma_{y R T} \\
(\mathrm{psi})\end{array}$ & $\begin{array}{l}\sigma_{u R T} \\
(\mathrm{psi})\end{array}$ & $\mathbf{R}_{\mathrm{TS}}$ & $\mathbf{R}_{\mathrm{C}}$ \\
\hline 1 & All 36 ksi core box columns, plates, straps ${ }^{a}$ & 36,720 & 64.470 & 1.086 & 0.857 \\
\hline 2 & $\begin{array}{l}\text { All } 36 \mathrm{ksi} \text { core WF, channels, and tubes } 36 \mathrm{ksi} \text { large area } \\
\text { and large inertia "rigid" beams in SAP2000 model }{ }^{\mathrm{a}}\end{array}$ & 37,000 & 63,450 & 1.069 & 0.954 \\
\hline 3 & All $42 \mathrm{ksi}$ box columns $(1<=0.75$ in. $)$ & 51,400 & 79,200 & 1.070 & 0.884 \\
\hline 4 & All $42 \mathrm{ksi}$ box columns ( 0.75 in. $<\mathrm{t}<=1.5$ in.) & 47.000 & 74,800 & 1.010 & 0.884 \\
\hline 5 & All 42 ksi box columns ( $\mathrm{t}>1.5$ in.) & 42.600 & 70,400 & 0.951 & 0.880 \\
\hline 6 & $42 \mathrm{ksi}$ or $45 \mathrm{ksi}$ Group 3 WF core columns & 53,800 & 74,400 & 1.005 & 0.977 \\
\hline 7 & $42 \mathrm{ksi}$ or $45 \mathrm{ksi}$ Group 3 WF core columns & 49,000 & 71,040 & 0.960 & 0.954 \\
\hline 8 & 42 ksi Group $4 \& 5$ WF core columns & 44.200 & 66,640 & 0.900 & 0.948 \\
\hline 9 & 45 ksi Group $4 \& 5$ WF core columns & 47,800 & 71,074 & 0.960 & 0.939 \\
\hline 10 & All 36 ksi Plates 1,2 , and 4 in perimeter columns & 35.630 & 61,170 & 1.031 & 0.875 \\
\hline 11 & $\begin{array}{l}\text { All }(42.45 \text {, or } 46) \text { ksi Plates } 1,2, \text { and } 4 \text { in. perimeter } \\
\text { columns }\end{array}$ & 53,051 & 74,864 & 1.011 & 0.948 \\
\hline 12 & $\begin{array}{l}\text { All } 50 \text { ksi Plates } 1,2 \text {, and } 4 \text { in. perimeter columns. All } \\
50 \mathrm{ksi} \text { channels and plates }\end{array}$ & 53,991 & 75,618 & 1.021 & 0.978 \\
\hline 13 & $\begin{array}{l}\text { All } 55 \mathrm{ksi} \text { Plates 1, 2, and } 4 \text { with } \mathrm{t}<=1.5 \text { in. in perimeter } \\
\text { columns }\end{array}$ & 60,817 & 82,558 & 1.115 & 0.903 \\
\hline 14 & $\begin{array}{l}\text { All } 60 \text { ksi Plates } 1,2 \text {, and } 4 \text { with } t<=1.25 \text { in. in perimeter } \\
\text { columns }\end{array}$ & 62,027 & 87.250 & 1.178 & 0.894 \\
\hline 15 & $\begin{array}{l}\text { All } 65 \mathrm{ksi} \text { Plates 1, 2, and } 4 \text { with } \mathrm{t}<=0.5 \text { in. in perimeter } \\
\text { columns } \mathrm{s}^{\mathrm{b}}\end{array}$ & 69,642 & 90,442 & 1.221 & 0.979 \\
\hline 16 & All $70 \mathrm{ksi}$ Plates 1. 2. and 4 in. perimeter columns & 76,735 & 91,951 & 1.242 & 0.955 \\
\hline 17 & All 75 ksi Plates 1,2 , and 4 in perimeter columns & 82,469 & 96,821 & 1.308 & 0.936 \\
\hline 18 & All $80 \mathrm{ksi}$ perimeter columns steels, regardless of plate & 91.517 & 99,442 & 1.343 & 0.987 \\
\hline 19 & $\begin{array}{l}\text { All }(85,90.100) \text { ksi perimeter column steels, regardless } \\
\text { of plate }\end{array}$ & 104,783 & 115,983 & 1.566 & 0.976 \\
\hline 20 & Laclede truss web bar rounds specified as A36 & 38,067 & 59,567 & 1.004 & 0.935 \\
\hline 21 & $\begin{array}{l}\text { Laclede truss chord angels (regardless of ASTM Spec) } \\
\text { and all rounds specified as A242 }\end{array}$ & 55.332 & 74,050 & 1.000 & 0.959 \\
\hline 22 & $\mathrm{~A} 325$ bolts $^{\mathrm{c}}$ & 104,783 & 115,983 & 1.566 & 0.976 \\
\hline 23 & All $42 \mathrm{ksi}$ Plate 3 in perimeter columns & 42.600 & 67,216 & 0.900 & 0.912 \\
\hline 24 & All $45 \mathrm{ksi}$ Plate 3 in perimeter columns & 45,900 & 69,831 & 0.940 & 0.921 \\
\hline 25 & All $50 \mathrm{ksi}$ Plate 3 in perimeter columns & 51,400 & 74,188 & 1.000 & 0.935 \\
\hline 26 & All $55 \mathrm{ksi}$ Plate 3 in perimeter columns & 56,900 & 78,546 & 1.070 & 0.906 \\
\hline 27 & All $60 \mathrm{ksi}$ Plate 3 in perimeter columns & 62,400 & 83,903 & 1.130 & 0.949 \\
\hline 28 & All 65 ksi Plate 3 in perimeter columns & 67.900 & 87.261 & 1.190 & 0.975 \\
\hline 29 & All $70 \mathrm{ksi}$ and $75 \mathrm{ksi}$ Plate 3 in perimeter columns & 78,900 & 95,976 & 1.310 & 0.997 \\
\hline
\end{tabular}

a. Steels in the following members are assumed to have the properties shown in the table:

36 ksi plates and straps (Material 1).

36 ksi channels, tubes, and "rigid" beams (Material 2).

$50 \mathrm{ksi}$ channels and plates (Material 12).

b. $65 \mathrm{ksi}$ steels in perimeter columns with $\downarrow>0.5$ in. are assumed to have the same properties as those in Material 15.

c. In the column model, stress-strain relationships of bolts are used.

Note: Bolt properties are assumed to be the same as those in Material 19. 
Table 3-2. Parameters for $K(T)$ and $n(T)$.

\begin{tabular}{|l|cc|}
\hline & $\sigma_{\mathbf{y} R}=\mathbf{3 6 , 0 0 0} \mathbf{p s i}$ & $\sigma_{\mathbf{y} R T}>\mathbf{3 6 , 0 0 0} \mathbf{p s i}$ \\
\hline $\mathrm{tk} 1,{ }^{\circ} \mathrm{C}$ & 524.1812 & 511.8266 \\
$\mathrm{tk} 2,{ }^{\circ} \mathrm{C}$ & 523.6799 & 511.8938 \\
$\mathrm{k} 0, \mathrm{psi}$ & 29049.2 & 26472.1 \\
$\mathrm{k} 1$ & 9.4346 & 6.5764 \\
$\mathrm{k} 2$ & 9.3532 & 6.5971 \\
$\mathrm{k} 4, \mathrm{psi}$ & 121605.6 & 122516.7 \\
\hline $\mathrm{tn} 1,{ }^{\circ} \mathrm{C}$ & 524.4304 & 519.634 \\
$\mathrm{tn} 2,{ }^{\circ} \mathrm{C}$ & 521.241 & 499.6031 \\
$\mathrm{n} 0, \mathrm{psi}$ & 0.1235 & 0.0342 \\
$\mathrm{n} 1$ & 19.0000 & 10.0000 \\
$\mathrm{n} 2$ & 19.0000 & 10.0000 \\
$\mathrm{n} 4, \mathrm{psi}$ & 0.2168 & 0.1511 \\
\hline
\end{tabular}

Figure 3-4 shows stress-strain curves of Material ID 1 (see Table 3-1 for the material description) at room and elevated temperatures. Figure 3-4 (a) is a close-up view of the lower strain range, while Fig. 3-4 (b) shows strain levels up to 0.3 .

The elastic-plastic behavior of steels was modeled with ANSYS material model "Multi-linear isotropic hardening von Mises plasticity."

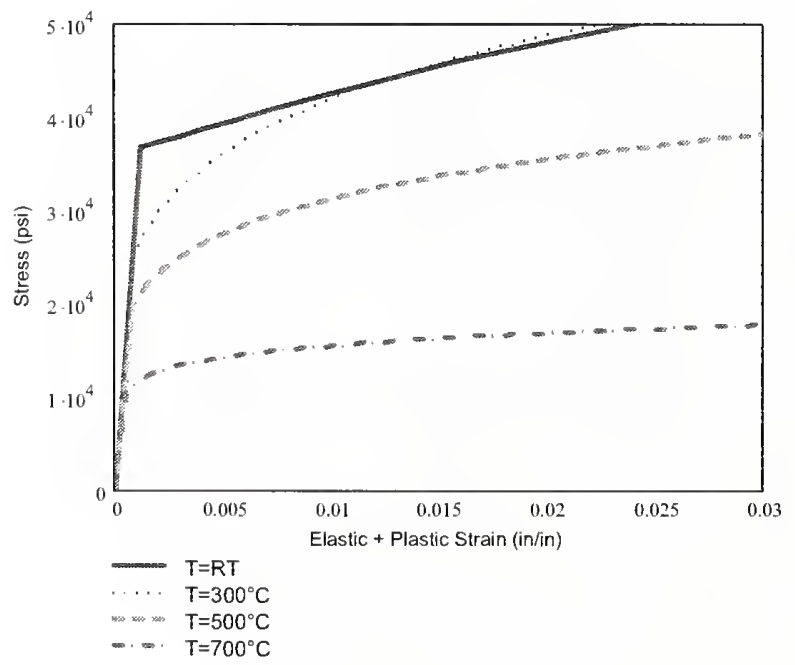

(a) Strain $<0.03$

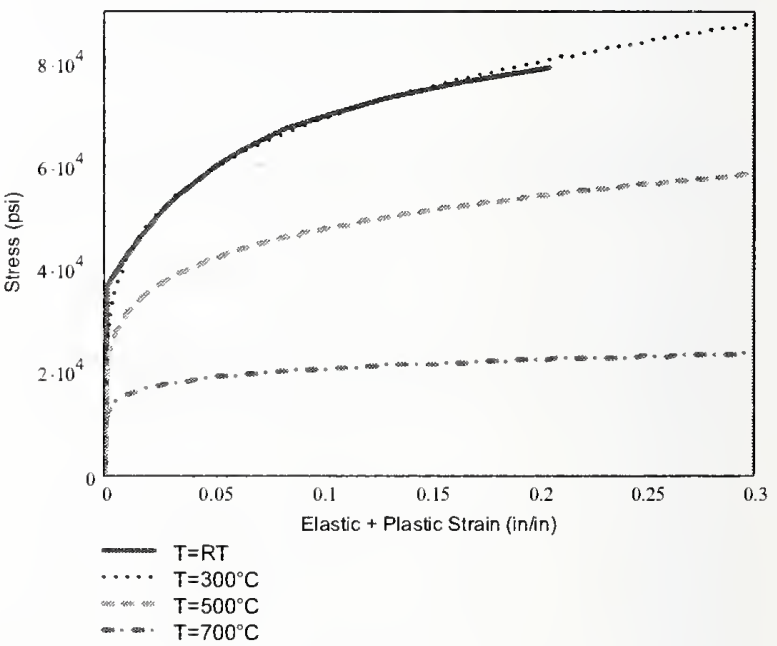

(b) Strain $<0.3$

Figure 3-4. Steel (Material ID 1) stress-strain relationships at different temperatures. 
Creep: Steel creeps at elevated temperatures $\left(T \geq 350{ }^{\circ} \mathrm{C}\right)$. The creep behavior of the steels in the WTC towers was expressed by NIST as follows:

$$
\varepsilon_{c r}(t, T, \sigma)=\frac{1}{100} a(T)\left(\frac{t}{60}\right)^{b(T)}\left(70.5 \frac{\sigma}{\sigma_{t / R T}}\right)^{c(T)}
$$

where:

$$
\begin{aligned}
& a(T)=\left\{\begin{array}{lll}
0 & \text { for } \quad T<350^{\circ} \mathrm{C} \\
10^{-(6.1+0.00573 T)} & \text { for } \quad 350^{\circ} \mathrm{C} \leq T<500^{\circ} \mathrm{C} \\
10^{-(13.25-0.00851 T)} & \text { for } \quad 500^{\circ} \mathrm{C} \leq T<725^{\circ} \mathrm{C}
\end{array}\right. \\
& b(T)=-1.1+0.0035 T \text { for } T<725^{\circ} \mathrm{C} \\
& c(T)=2.1+0.0064 T \text { for } T<725^{\circ} \mathrm{C}
\end{aligned}
$$

The creep model was validated against experimental data by NIST (NIST NCSTAR 1-3D). The creep model was derived by modifying the creep model already developed by Fields and Fields (1991). In this original model, the stress was scaled by yield strength at room temperature. The original model was used in the truss model and the exterior wall model.

The function, $a(T)$, is not smooth at $T=500^{\circ} \mathrm{C}$. To enhance numerical efficiency, $a(T)$ was modified by smoothing it as follows:

$$
a(T)=\left\{\begin{array}{lll}
10^{-(13.25-0.00851 \times 20)} & \text { for } & T<20^{\circ} \mathrm{C} \\
10^{-(13.25-0.00851 T)} & \text { for } \quad 20^{\circ} \mathrm{C} \leq T<725^{\circ} \mathrm{C}
\end{array}\right.
$$

A comparison of creep strains calculated from Eq. (7) with $a(T)$ given by Eqs. (7-a) and (7-d) is shown in Fig. 3-5. For $350{ }^{\circ} \mathrm{C} \leq T \leq 500^{\circ} \mathrm{C}$, creep strain is underestimated with $a(T)$ by Eq. (7-d).

However, the difference is small, and creep strains for temperatures below $500{ }^{\circ} \mathrm{C}$ are usually negligible. Figure 3-6 illustrates creep behavior of steel at elevated temperatures for Material ID 1. Figure 3-6 (a) shows creep strain rate at different stress levels and different temperatures, and Fig. 3-6 (b) compares elastic, plastic, creep, elastic plus plastic, and total strains at $T=600^{\circ} \mathrm{C}$ and after loading at a constant stress level for $1,800 \mathrm{~s}$. The creep model expressed by Eq. (7) with $a(T)$ given by Eq. (7-d) was used in the global models.

In ANSYS analysis, the "time hardening" implicit creep model was used for BEAM188 and BEAM189 elements, where creep strain rate was given by:

$$
\frac{d \varepsilon_{c r}}{d t}=C_{1}(T) \sigma^{C_{2}(T)} t^{C_{3}(T)}
$$

and $C_{1}(T), C_{2}(T)$, and $C_{3}(T)$ are temperature-dependent parameters derived from the creep model expressed by Eq. (7) with the following relationships: 


$$
\begin{aligned}
& C_{1}(T)=\frac{1}{100} a(T) b(T)\left(\frac{1}{60}\right)^{b(T)}\left(\frac{70.5}{\sigma_{u R T}}\right)^{c(T)} \\
& C_{2}(T)=c(T) \\
& C_{3}(T)=b(T)-1
\end{aligned}
$$

For BEAM24 elements in ANSYS, the primary explicit creep model was used. Creep strain rate was specified by

$$
\frac{d \varepsilon_{c r}}{d t}=M(T) K(T) \sigma^{N(T)} t^{M(T)-1}
$$

where

$$
\begin{aligned}
& M(T)=b(T) \\
& N(T)=c(T) \\
& K(T)=\frac{1}{100} a(T)\left(\frac{1}{60}\right)^{b(T)}\left(\frac{70.5}{\sigma_{u R T}}\right)^{c(T)}
\end{aligned}
$$

The truss model and the exterior wall subsystem model included creep with BEAM188 and 189 elements. The global model included creep with BEAM24 elements, as they were more numerically stable for creep and post-buckling behaviors.

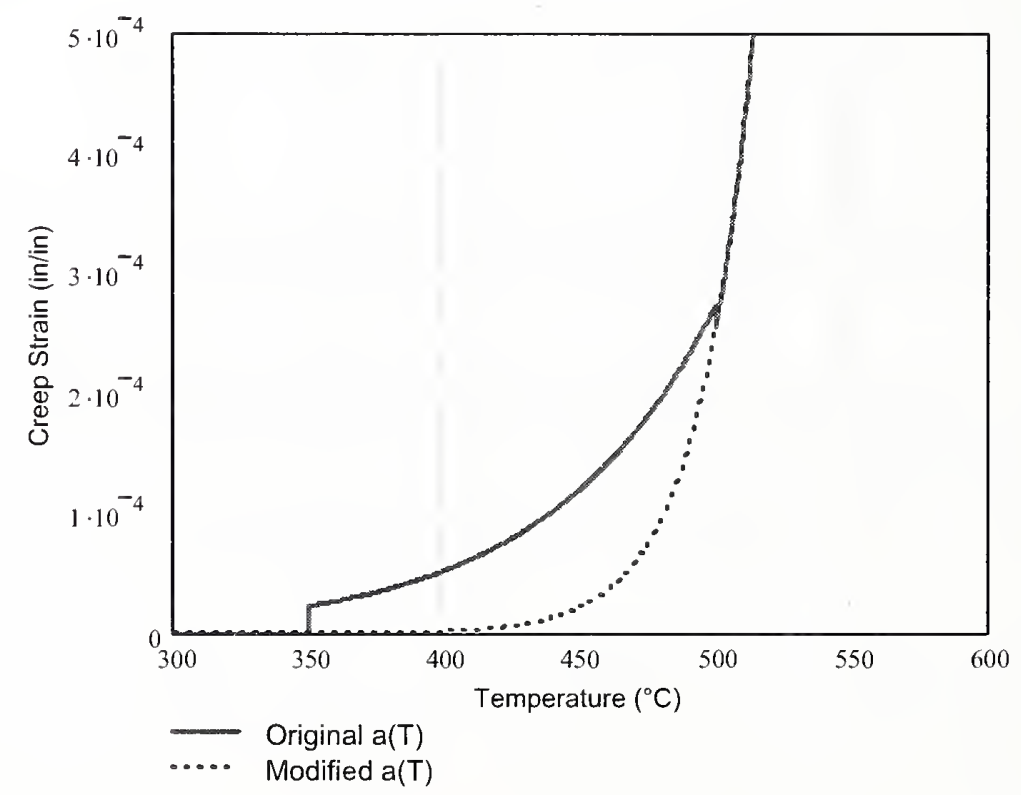

Figure 3-5. Comparison of creep strains with $a(T)$ given by (7-a) and (7-d) for Material ID 1 steel subject to $15 \mathrm{ksi}$ for $1,800 \mathrm{~s}$ at a given temperature. 


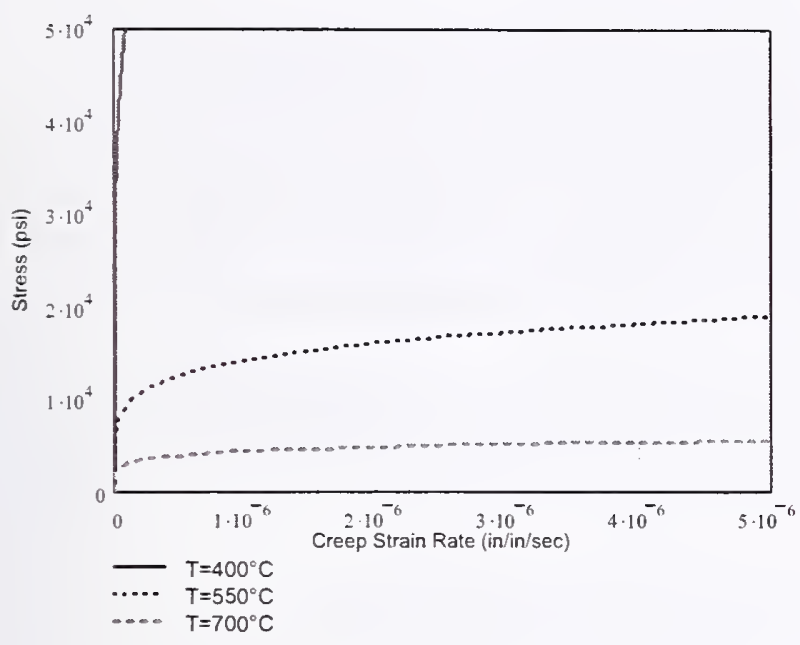

(a) Creep strain rate

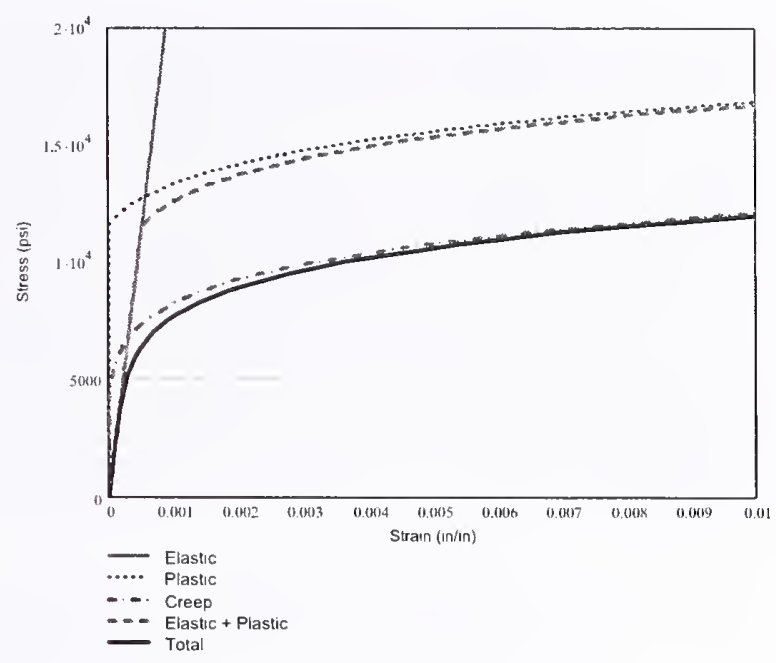

(b) Comparison of different strains at $T=600{ }^{\circ} \mathrm{C}$ and $t=1,800 \mathrm{~s}$

Figure 3-6. Creep behavior at elevated temperatures for Material ID 1 steel.

\subsubsection{Steel Failure Criteria}

The tensile failure criteria for steel were defined in terms of plastic strains. The multi-axial fracture strain criterion for different steels and temperatures in terms of true stress and true strain (NIST NCSTAR 1-3D) can be expressed as follows:

$$
\bar{\varepsilon}_{f}=\alpha(T) \exp \left[-\frac{3}{2} \frac{\sigma_{m}}{\bar{\sigma}}\right]
$$

$\alpha(T)$ is a temperature dependent material property, values of which can be calculated from Table 3-3 by using Eq. (11). For the uniaxial stress condition, where $\bar{\sigma}=\sigma$ and $\sigma_{m}=\sigma / 3$, the plastic strain at fracture reduces to:

$$
\bar{\varepsilon}_{f_{-} \iota m i}=\alpha(T) \exp (-0.5)
$$

Table 3-3 shows the uniaxial plastic strain at fracture, $\bar{\varepsilon}_{f_{-} u m i}$, calculated by Eq. (11) for different temperatures. This criterion is valid for a finite element analysis (FEA) with a very fine mesh. For a coarser mesh, the equivalent steel fracture criterion was determined numerically as follows. A standard tension test specimen was modeled in ANSYS. The gauge length, width, and thickness of the specimen were $8 \mathrm{in}, 1.5 \mathrm{in}$, and $1 \mathrm{in}$., respectively, and steel properties of Material ID 1 were used. Six different models (Model 0 to 5 ) were created, each having a different mesh size. Element sizes of Models 0 to 5 were $0.025 \mathrm{in.,} 0.050 \mathrm{in.,} 0.0125 \mathrm{in.,} 0.250 \mathrm{in.,} 0.375 \mathrm{in}$., and $0.75 \mathrm{in}$. It was assumcd that Model 0 was a fine mesh that was able to capture tensile fracture in uniaxial tension.

Model 0 was subjected to tension until the maximum plastic strain in the direction of applied displacement reached the uniaxial fracture strain determined by Eq. (11) for uniaxial stress condition, and the corresponding elongation of the specimen, $\Delta_{0}$, was obtained. Models 1 to 5 were then subjected to the same elongation, $\Delta_{0}$, and the maximum plastic strain in the direction of applied displacement was measured for each model. The maximum plastic strain due to the elongation of $\Delta_{0}$ was defined as the limiting plastic strain (equivalent fracture plastic strain) for the corresponding element size. 
From these six cases, a relationship between element size and equivalent uniaxial fracture plastic strain was established. This process was repeated for temperatures $20^{\circ} \mathrm{C}, 100{ }^{\circ} \mathrm{C}, 300{ }^{\circ} \mathrm{C}, 500{ }^{\circ} \mathrm{C}$, and $700{ }^{\circ} \mathrm{C}$. Figure 3-7 (a) shows the ratio of the maximum plastic strain in the direction of applied displacement due to displacement $\Delta_{0}$ to uniaxial plastic strain by Eq. (11) vs. element size at different temperatures. The FEA results were extrapolated up to the element size of 50 in. Plastic strain shown in Fig. 3-7 (b) was used as the failure criterion for the corresponding element size in the FEA. Note that Fig. 3-7 (b) shows the failure criterion for element size larger than $0.375 \mathrm{in}$.

The compressive failure criteria for steel were not specified explicitly in terms of plastic strains because the information was not available. However, failure of compressive members was expressed by elastic buckling and plastic kink-type buckling (see Chapter 6) of compression members.

Table 3-3. Uniaxial plastic strain at fracture by Eq. (11).

\begin{tabular}{|c|c|c|c|c|c|c|}
\hline \multirow[b]{2}{*}{ Material ID } & \multicolumn{6}{|c|}{ Plastic Strain at Fracture in the Uniaxial Test, $\bar{\varepsilon}_{f_{-} u n i}$} \\
\hline & $20^{\circ} \mathrm{C}$ & $100^{\circ} \mathrm{C}$ & $300^{\circ} \mathrm{C}$ & $500^{\circ} \mathrm{C}$ & $700^{\circ} \mathrm{C}$ & $1000^{\circ} \mathrm{C}$ \\
\hline 1 & 0.8411 & 0.6989 & 0.6610 & 1.0446 & 1.8100 & 3.5862 \\
\hline 2 & 0.8411 & 0.6989 & 0.6610 & 1.0446 & 1.8100 & 3.5862 \\
\hline 3 & 0.4908 & 0.4078 & 0.3857 & 0.6095 & 1.0561 & 2.0924 \\
\hline 4 & 0.4908 & 0.4078 & 0.3857 & 0.6095 & 1.0561 & 2.0924 \\
\hline 5 & 0.4908 & 0.4078 & 0.3857 & 0.6095 & 1.0561 & 2.0924 \\
\hline 6 & 0.4908 & 0.4078 & 0.3857 & 0.6095 & 1.0561 & 2.0924 \\
\hline 7 & 0.4908 & 0.4078 & 0.3857 & 0.6095 & 1.0561 & 2.0924 \\
\hline 8 & 0.4908 & 0.4078 & 0.3857 & 0.6095 & 1.0561 & 2.0924 \\
\hline 9 & 0.4908 & 0.4078 & 0.3857 & 0.6095 & 1.0561 & 2.0924 \\
\hline 10 & 0.8891 & 0.7388 & 0.6987 & 1.1042 & 1.9142 & 3.7907 \\
\hline 11 & 0.4908 & 0.4078 & 0.3857 & 0.6095 & 1.0561 & 2.0924 \\
\hline 12 & 0.4908 & 0.4078 & 0.3857 & 0.6095 & 1.0561 & 2.0924 \\
\hline 13 & 0.2846 & 0.2364 & 0.2236 & 0.3534 & 0.6123 & 1.2132 \\
\hline 14 & 0.3774 & 0.3136 & 0.2965 & 0.4686 & 0.8120 & 1.6088 \\
\hline 15 & 0.5338 & 0.4436 & 0.4195 & 0.6629 & 1.1486 & 2.2758 \\
\hline 16 & 0.5623 & 0.4672 & 0.4418 & 0.6983 & 1.2099 & 2.3972 \\
\hline 17 & 0.7752 & 0.6442 & 0.6092 & 0.9628 & 1.6681 & 3.3051 \\
\hline 18 & 0.6545 & 0.5439 & 0.5143 & 0.8129 & 1.4084 & 2.7906 \\
\hline 19 & 0.4254 & 0.3535 & 0.3343 & 0.5283 & 0.9154 & 1.8137 \\
\hline 20 & 0.8411 & 0.6989 & 0.6610 & 1.0446 & 1.8100 & 3.5862 \\
\hline 21 & 0.4908 & 0.4078 & 0.3857 & 0.6095 & 1.0561 & 2.0924 \\
\hline
\end{tabular}




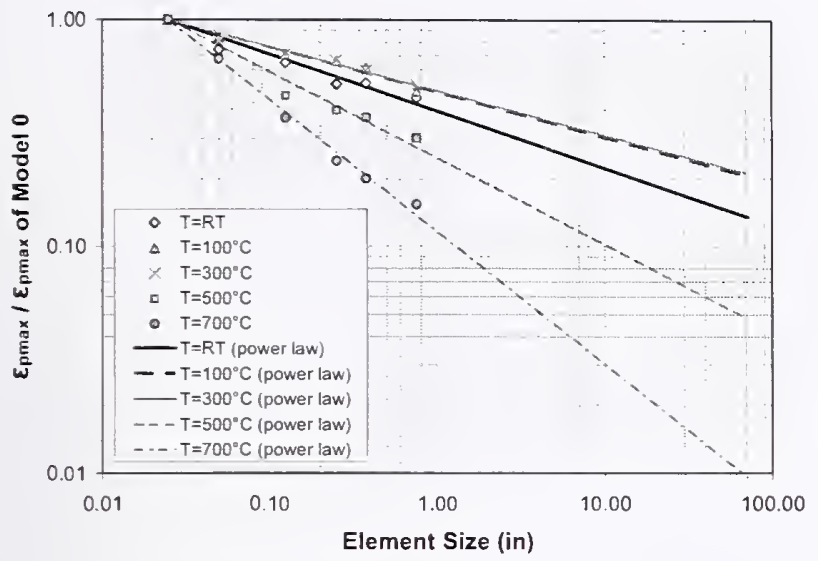

(a) FEA results and extrapolation

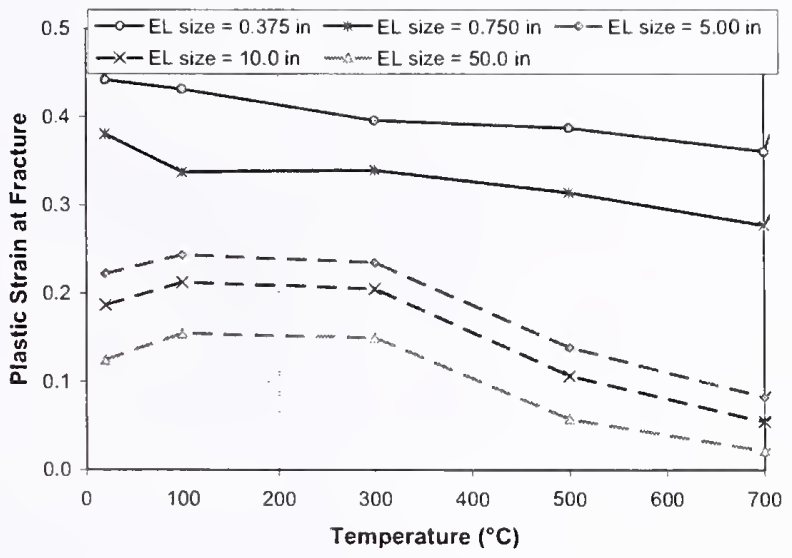

(b) Recommended limiting plastic strain

\section{Figure 3-7. Maximum plastic strain from the finite element analysis and limiting plastic strain.}

\subsection{WELDS}

The weld properties at all temperatures were assumed to be the same as those of the base metal of the same ultimate tensile strength as determined by Project 3. High temperature properties of the weld metals were not found in the literature. Susceptibility of existing cracks in the welds to growth (fracture toughness) does not increase with temperature (Stevick 1994). This assumption was supporter by the following observations in the recovered WTC steel: the exterior column welds were strong enough to fail the base metal, the observed fractures in the exterior columns were mostly through the base metal, and the welds in trusses were resistance welds with no filler added. For the core columns, the area of the welds was significantly less than that of the base metal, and several fractures through the welds were observed. Fractures in the truss seats and truss connections were also observed.

\section{$3.4 \quad$ BOLTS}

A load-elongation relationship for a 7/8 in. A325 bolt with 4 in. length at room temperature was provided by Project 3. Load-elongation relationships at elevated temperatures are constructed by scaling the loads by the yield and ultimate tensile strength reduction factors for bolt steels shown in Fig. 3-3 (c) and (d). Figure 3-8 shows the load-elongation relationships of a 7/8 in. bolt at different temperatures. Loadelongation relationships of $\mathrm{A} 325$ bolts of different size were created by proportioning the load by the net area.

The load-elongation relationship for bolts with a different length than $4.0 \mathrm{in}$. is expected to be very similar to the load-elongation relationship for $4.0 \mathrm{in}$. length since bolt deformations are localized.

Based on the AISC formulas (AISC 2003), C-J3-2 to C-J3-4, the shear strength for a single shear plane is calculated as 0.67 of the tensile strength given in Fig. 3-8 when threads are excluded from the shear plane. When threads are not excluded from the shear plane, the nominal shear strength for a single shear plane is 0.53 of the tensile strength given in Fig. 3-8. These factors were obtained by a ratio between the shear strength and the tensile strength evaluated by the AISC formulas. No shear ductility was assumed at failure. 


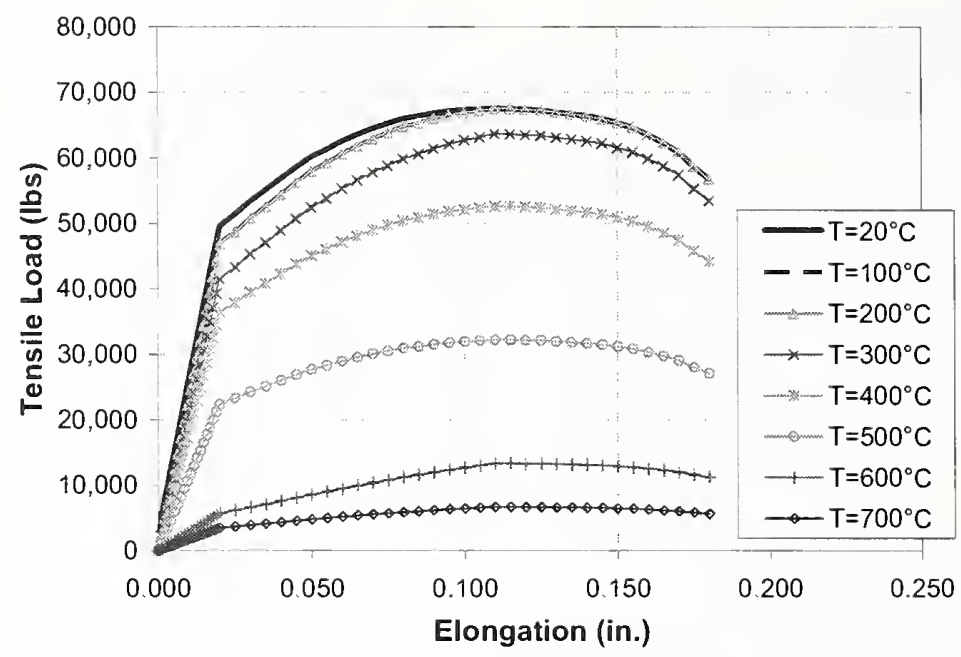

Figure 3-8. 7/8 in. A325 bolt load-elongation curves at elevated temperatures.

\subsection{COEFFICIENT OF FRICTION}

The coefficient of friction of 0.33 for calculation of shear in friction-type connections was used. This value was taken from the AISC LRFD (2003) friction coefficient for uncoated clean mill scale steel surfaces, or surfaces with Class A coatings on blast-cleaned steel surfaces.

\subsection{SYMBOLS}

$\alpha(T)=\quad$ temperature-dependent material property that defines fracture criterion

$\alpha_{c}(T)=\quad$ instantaneous coefficient of thermal expansion of concrete

$\alpha_{s}(T)=\quad$ instantaneous coefficient of thermal expansion of steel

$\beta_{y}(T)=\quad$ steel yield sírength reduction factor due to elevated temperature

$\beta_{u}(T)=\quad$ steel ultimate strength reduction factor due to elevated temperature

$\gamma_{c}=\quad$ unit weight of concrete $(110 \mathrm{pcf}$ and $150 \mathrm{pcf}$ for lightweight and normal weight concrete, respectively)

$\gamma_{s}=\quad$ unit weight of steel $(490 \mathrm{pcf}=0.284 \mathrm{pci}$ for all steel types at any temperature $)$

$\varepsilon_{c 1}=$ concrete strain at maximum compressive stress

$\varepsilon_{c r}=\quad$ creep strain of steel

$\varepsilon_{e} \quad=\quad$ elastic strain

$\varepsilon_{e p} \quad=\quad$ elastic plus plastic strain

$\bar{\varepsilon}_{f} \quad=\quad$ effective plastic strain at fracture

$\bar{\varepsilon}_{f_{-} \text {uni }}=\quad$ uniaxial plastic strain at fracture

$\varepsilon_{p} \quad=\quad$ plastic strain

$\varepsilon_{t} \quad=\quad$ concrete strain at maximum tensile stress

$\varepsilon_{t u}=$ concrete strain at full crack formation (separation) in tension 


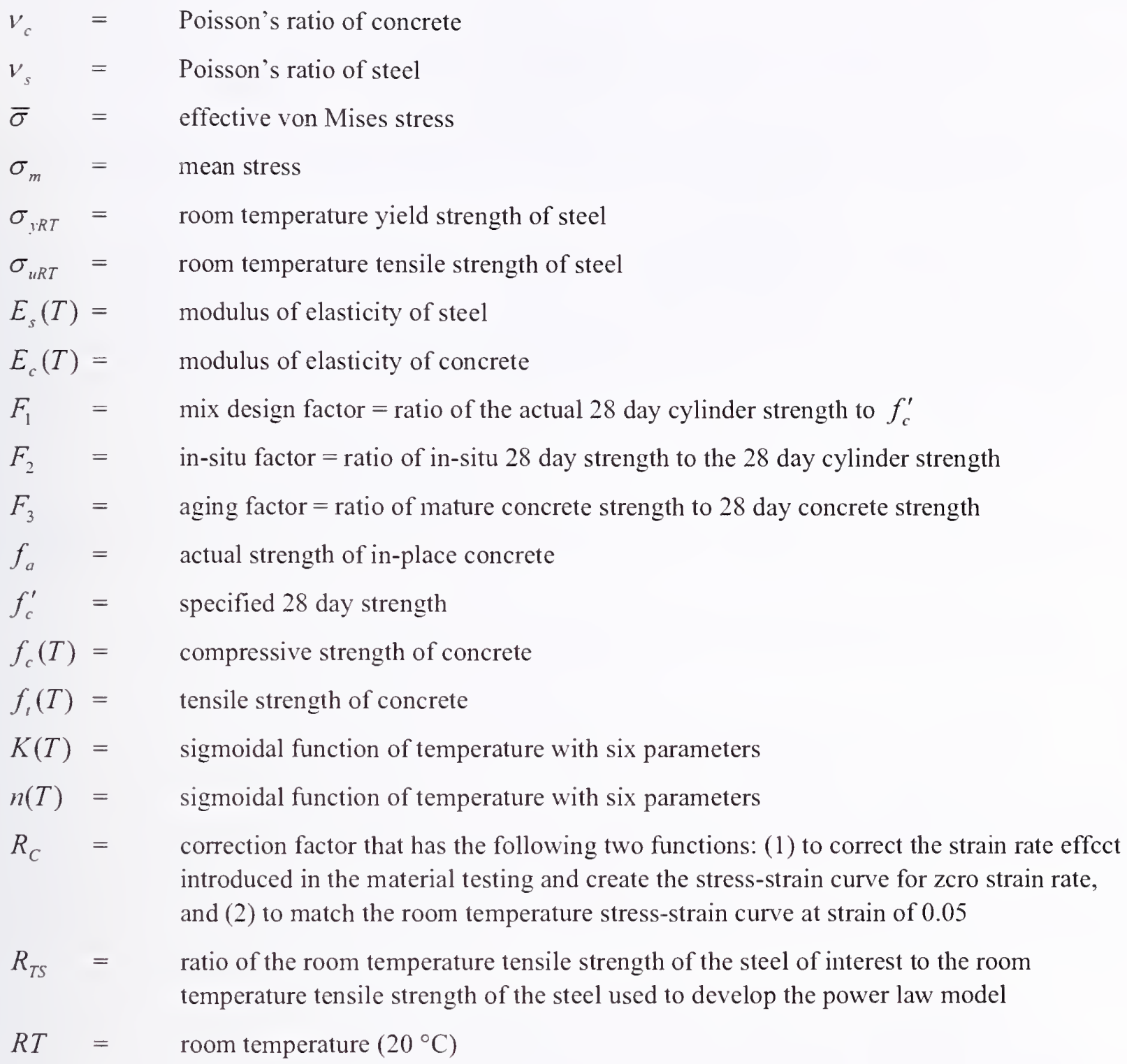


This page intentionally left blank. 


\section{Chapter 4 \\ MOdEL CONVERSION FROM SAP TO ANSYS}

Reference structural models were developed under Project 2 in SAP2000 (SAP) for traceability to a verified data set (NIST NCSTAR 1-2, NIST NCSTAR 1-2A). The SAP2000 Floor 96 model of WTC 1 and the SAP global models of WTC 1 and WTC 2 were converted into ANSYS 8.1 (ANSYS) and used as a foundation for developing detailed structural models. The converted ANSYS models were modified to incorporate the nonlinear behaviors of the components for the thermal/structural evaluation of collapse initiation.

\subsection{TRANSLATION PROCEDURE}

An automatic translation software was developed to partially convert the floor model and global models from SAP to ANSYS:

- The Joints, Frames, and Shells in the SAP model were translated into ANSYS Keypoints, Lines, and Areas. Translation using geometry definition, instead of nodes and elements, allowed for easy mesh refinement, where needed.

- Lines were meshed with both section properties and real constants so that a translation between 3-D elastic beam (BEAM44) elements and 3-D inelastic finite strain beam (BEAM188/BEAM189) elements was achieved by simply changing element types. Areas were meshed with elastic shell (SHELL63) elements in ANSYS to match the Shell elements in SAP. Lines and Areas were able to be changed to nonlinear beam (BEAM188) and nonlinear shell (SHELL181) elements simply by changing an element type.

- Material properties were assigned as described in Chapter 3 based on the material definitions and Frame section properties in SAP.

- Frame section properties in SAP were converted into Real Constants for BEAM44 in ANSYS. Cross section properties in SAP were retained for future conversion into cross section data for BEAM188 elements. Shell thicknesses in SAP were converted into Real Constants for SHELL63 in ANSYS.

- Joint restraints in SAP were translated into DOF constraints in ANSYS.

- Frame distributed loads and area uniform loads were translated into surface loads on Lines and Areas in ANSYS.

- The ANSYS BEAM44 elements support element moment releases, but the ANSYS nonlinear BEAM 188 elements do not. Therefore, Frame releases in SAP were modeled by coincident nodes with coupled (CP) degrees of freedom in ANSYS.

- The ANSYS BEAM44 elements allow beam end offsets in three directions, but the ANSYS nonlinear BEAM188 elements only allow beam end offsets perpendicular to the element axis through section offset (SECOFFSET) command. Frame insertion points in SAP were converted in two ways. For offsets along the element axis, additional nodes and rigid MPC184 elements with the proper lengths werc used in ANSYS. For offsets perpendicular to 
the element axis, beam end offsets were defined using Real Constants for BEAM44, and were defined using SECOFFSET command for BEAM188.

- Frame offsets and rigid panel factor in SAP were modeled by adding additional nodes and rigid beam MPC184 elements with the proper lengths in ANSYS.

During the conversion of the SAP floor model, the following conditions were encountered and were resolved:

- The SAP floor model allowed automatic division of the frames at joints. This caused problems in the translation software, because the frame connectivities in the Graphical User Interface did not show the actual internal element connectivities used in the SAP analysis engine. In order to resolve this problem, the translation software was modified to use the internal element connectivities. The table of internal connectivities was exported from the SAP model after the execution of the SAP analysis.

- Information on automatic offsets in the SAP model were not available in the SAP input file. The table of element offsets was exported after the execution of the SAP analysis.

- There were both intentional and unintentional duplicate elements in the SAP floor model that led to problems in the translator since ANSYS cannot have duplicate lines sharing the same keypoints. Some duplicate elements were used to model additional steel plates at the ends of trusses. The duplicate elements were manually deleted, and the section properties of the remaining elements were modified to account for the additional steel. Some duplicate elements were from frame elements with different lengths that overlapped. These were manually corrected.

Those parts of the model that were not converted by the translation software were converted manually.

Table 4-1 presents the descriptions of finite elements used in ANSYS models, such as BEAM188 (ANSYS, Inc. 2004). All structural elements listed in the table including link, beam, shell, and solid elements can be used with temperature-dependent material properties. 
Table 4-1. Element types used in ANSYS models.

\begin{tabular}{|c|c|c|}
\hline Name & Element Type & Description \\
\hline LINK8 & $3-\mathrm{D}$ truss & $\begin{array}{l}\text { LINK8 is a uniaxial tension-compression element with three degrees of freedom } \\
\text { at each node. It has plasticity, creep, and large deflection capabilities. }\end{array}$ \\
\hline BEAM4 & $\begin{array}{l}3 \text {-D elastic } \\
\text { beam }\end{array}$ & $\begin{array}{l}\text { BEAM4 is a 3-D elastic Euler beam element. The element has six degrees of } \\
\text { freedom at each node. Large deflection capability is included. }\end{array}$ \\
\hline BEAM44 & $\begin{array}{l}\text { 3-D elastic } \\
\text { tapered } \\
\text { unsymmetric } \\
\text { beam }\end{array}$ & $\begin{array}{l}\text { BEAM44 is a 3-D elastic Euler beam element and allows a different } \\
\text { unsymmetrical geometry at each end. The element has six degrees of freedom } \\
\text { at each node. Large deflection capability is included. }\end{array}$ \\
\hline BEAM 188 & $\begin{array}{l}3-\mathrm{D} \text { linear } \\
\text { finite strain } \\
\text { beam }\end{array}$ & $\begin{array}{l}\text { BEAM1 } 88 \text { is a linear ( } 2 \text {-node) or a quadratic beam element in 3-D based on } \\
\text { Timoshenko beam theory. Each node has six degrees of freedom or seven } \\
\text { degrees of freedom ( } 6+\text { warping). Shear deformation effects are included. This } \\
\text { element is supported for plasticity, creep, large deflection. A cross section can } \\
\text { be a built-up section referencing more than one material. Creep strain is } \\
\text { calculated by implicit time integration method. }\end{array}$ \\
\hline BEAM 189 & $\begin{array}{l}\text { 3-D quadratic } \\
\text { finite strain } \\
\text { beam }\end{array}$ & $\begin{array}{l}\text { BEAM1 } 89 \text { is a quadratic (3-node) beam element in 3-D based on Timoshenko } \\
\text { beam theory. Each node has six degrees of freedom or seven degrees of } \\
\text { freedom ( } 6+\text { warping). This element is supported for plasticity, creep, large } \\
\text { deflection. A cross section can be a built-up section referencing more than one } \\
\text { material. Creep strain is calculated by implicit time integration method. }\end{array}$ \\
\hline SHELL63 & $\begin{array}{l}\text { 4-node elastic } \\
\text { shell }\end{array}$ & $\begin{array}{l}\text { SHELL } 63 \text { has both bending and membrane capabilities. The element has six } \\
\text { degrees of freedom at each node: three translations and three rotations. Large } \\
\text { deflection capability is also included. }\end{array}$ \\
\hline SHELL 181 & $\begin{array}{l}\text { 4-node finite } \\
\text { strain shell }\end{array}$ & $\begin{array}{l}\text { SHELL181 is a 4-node shell element with six degrees of freedom at each node: } \\
\text { three translations and three rotations. Plasticity, creep, and large deflection } \\
\text { capabilities are supported. In nonlinear analyses, change in shell thickness is } \\
\text { accounted for. SHELL181 may be used for layered applications. }\end{array}$ \\
\hline SOLID 185 & $\begin{array}{l}\text { 3-D 8-node } \\
\text { structural solid }\end{array}$ & $\begin{array}{l}\text { SOLID185 is an 8-node structural solid element and has three degrees of } \\
\text { freedom at each node (three translations). Plasticity, creep, and large deflection } \\
\text { capabilities are supported. }\end{array}$ \\
\hline COMBIN37 & $\begin{array}{l}\text { Control } \\
\text { element }\end{array}$ & $\begin{array}{l}\text { COMBIN } 37 \text { is a unidirectional element with the capability of turning on and off } \\
\text { during an analysis. The element has one degree of freedom at each node. }\end{array}$ \\
\hline $\mathrm{MPC} 184$ & $\begin{array}{l}\text { Multipoint } \\
\text { constraint } \\
\text { element }\end{array}$ & $\begin{array}{l}\text { MPC } 184 \text { comprises a general class of multi constraint elements that implement } \\
\text { kinematic constraints using Lagrange multipliers. Depending on the option that } \\
\text { the user selects, the element can be used as a rigid link element, a rigid beam } \\
\text { element, a slider element, a spherical element, a revolute joint element, and a } \\
\text { universal joint element. }\end{array}$ \\
\hline
\end{tabular}




\subsection{VALIDATION}

\subsubsection{Floor Model Validation}

Figures 4-1 through 4-4 show the converted floor model.

The following analyses were performed to validate the converted ANSYS floor model against the original SAP model.

- One static analysis with gravity loads, defined in SAP as Load Case "DEAD," included selfweight plus 3.5 psf uniform load in the office area.

- One modal analysis, using structural mass only.

Table 4-2 summarizes the comparison of the SAP and ANSYS results for the gravity load case. The total reactions for the SAP and ANSYS models were within 0.1 percent of each other. The maximum slab displacement predicted by the ANSYS model was 3.2 percent smaller than that obtained from the SAP model. The deformed shapes of the gravity load case for the SAP and ANSYS models are shown in Figs. $4-5$ and $4-6$.

Table 4-2. Comparison of SAP and ANSYS results for gravity load case.

\begin{tabular}{|l|c|c|}
\hline & SAP & ANSYS \\
\hline Total reaction, kip & $2,212.81$ & $2,210.85(-0.09 \%)$ \\
\hline Maximum slab displacement, in. & 0.718 & $0.695(-3.2 \%)$ \\
\hline
\end{tabular}

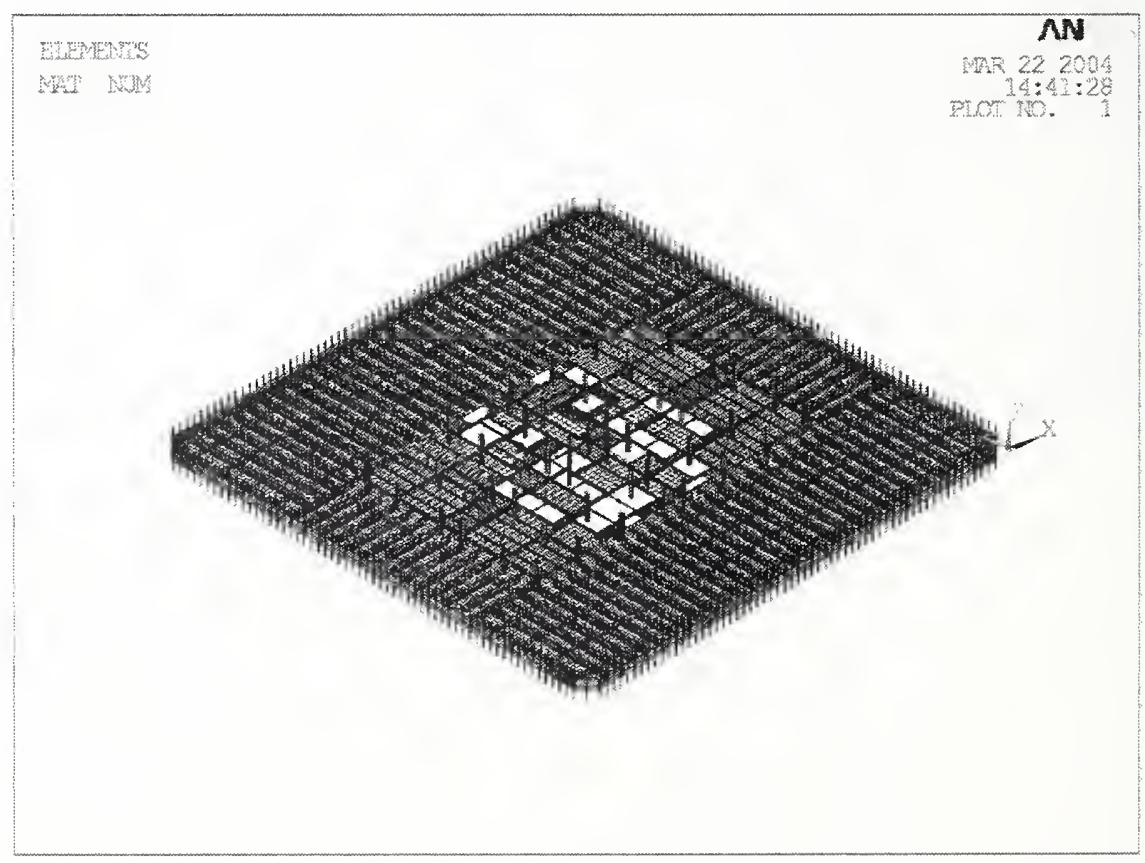

Figure 4-1. Converted ANSYS model for Floor 96 of WTC 1: overall view. 


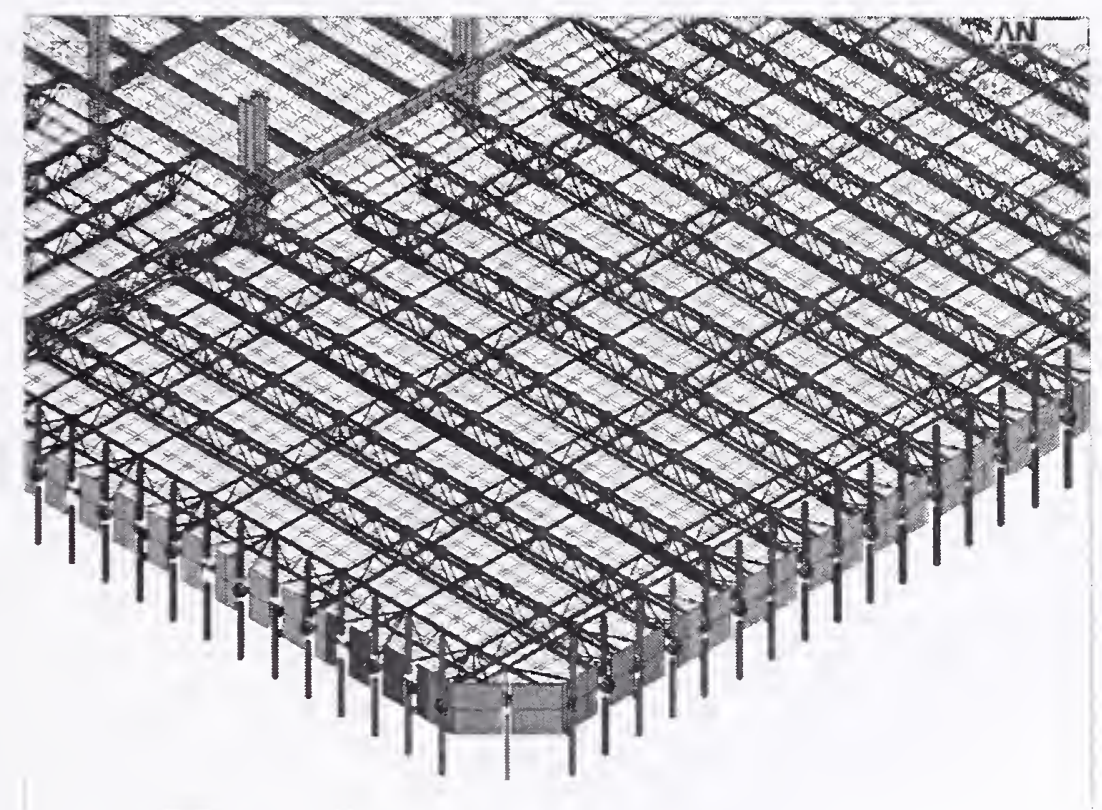

Figure 4-2. Converted ANSYS model for Floor 96 of WTC 1: partial view near corner of building.

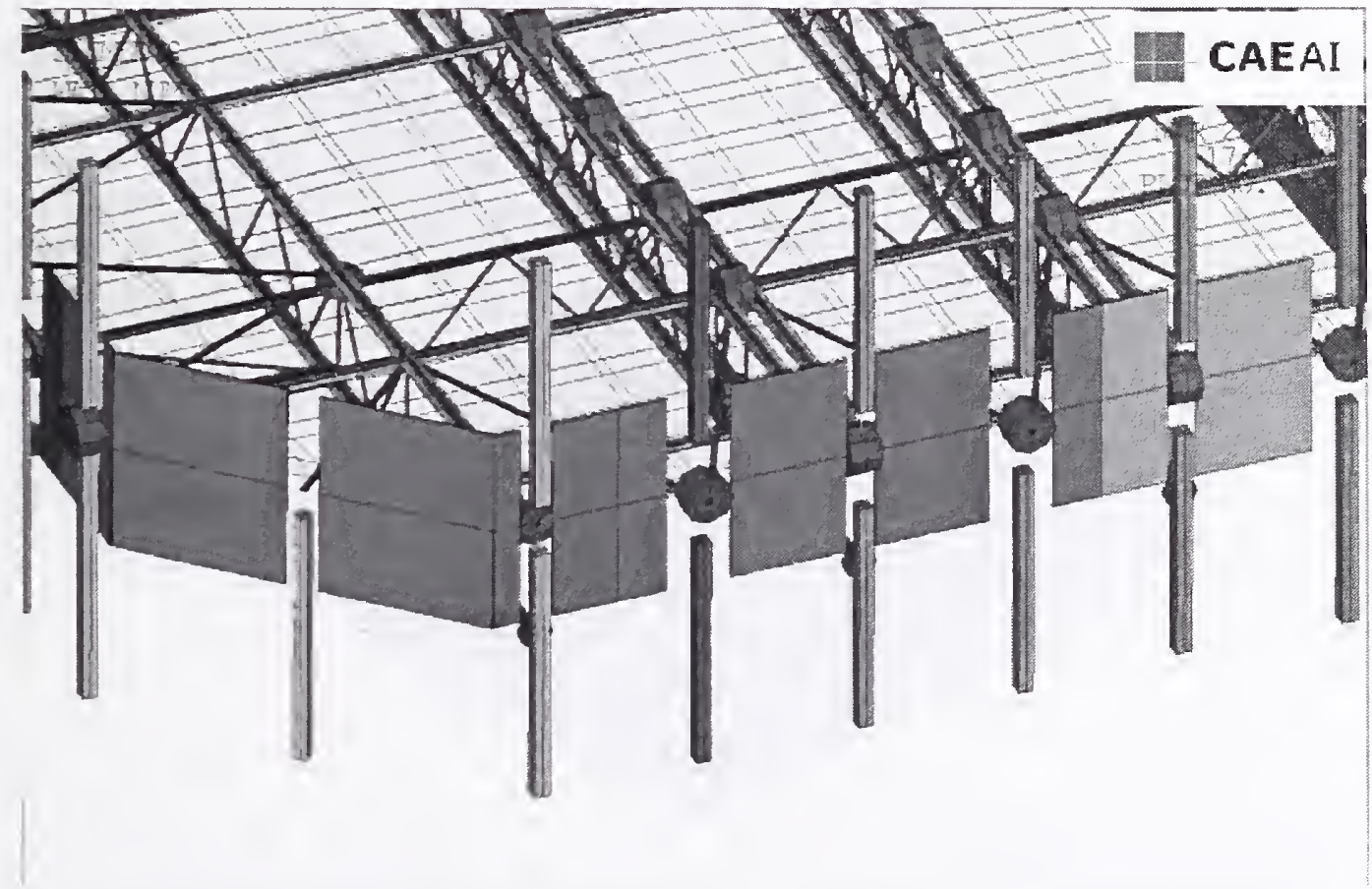

Figure 4-3. Converted ANSYS model for Floor 96 of WTC 1: close-up view at corner of building. 


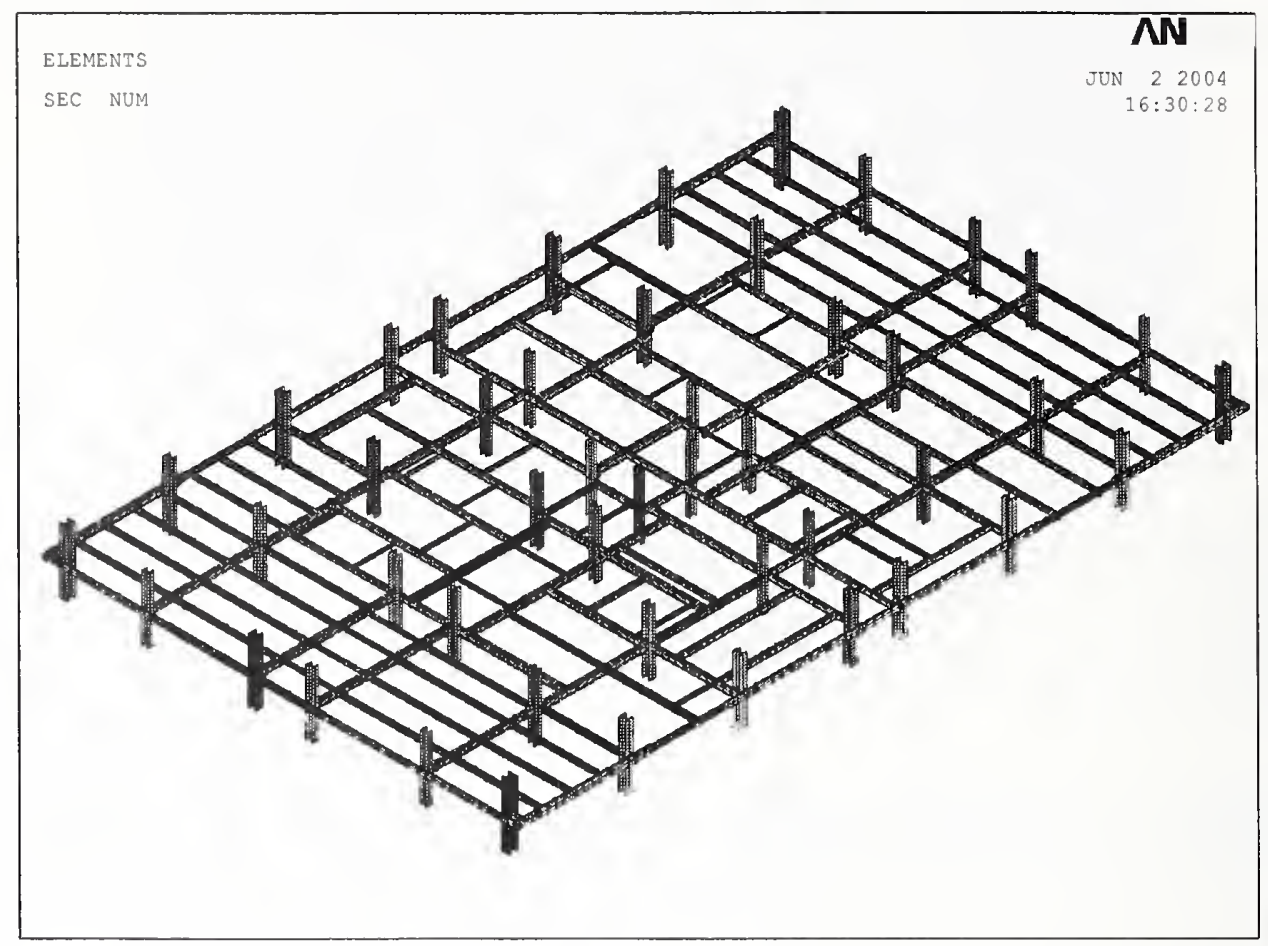

Figure 4-4. Converted ANSYS model for Floor 96 of WTC 1: view of floor beams and columns.

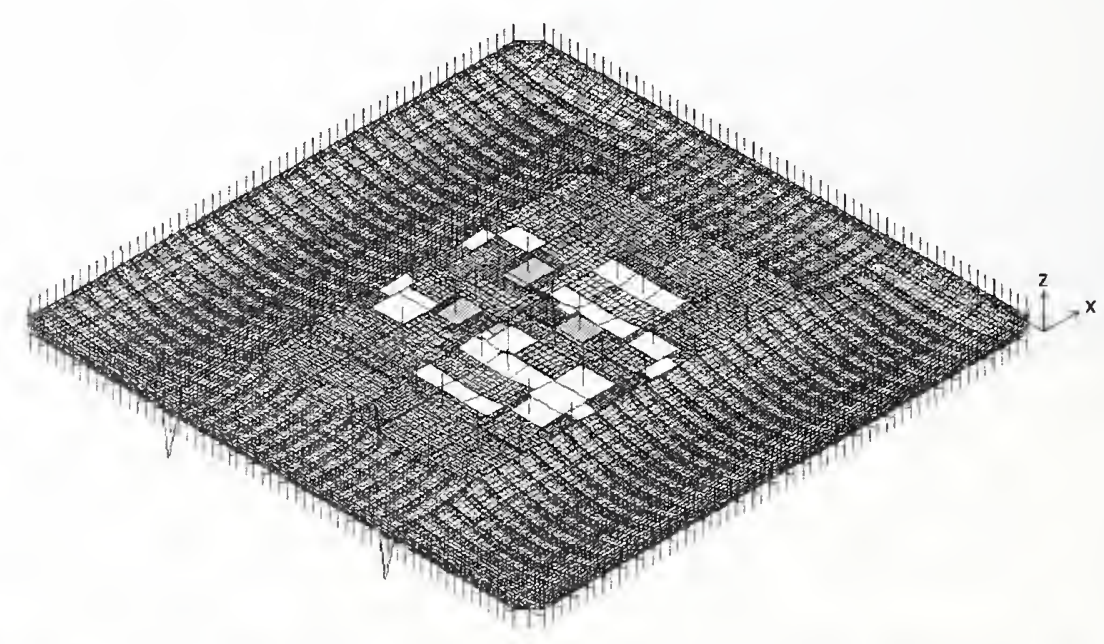

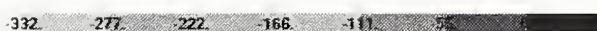

(in.)

Figure 4-5. Deformed shape (x100) of gravity load case for SAP floor model (downward displacement is negative). 


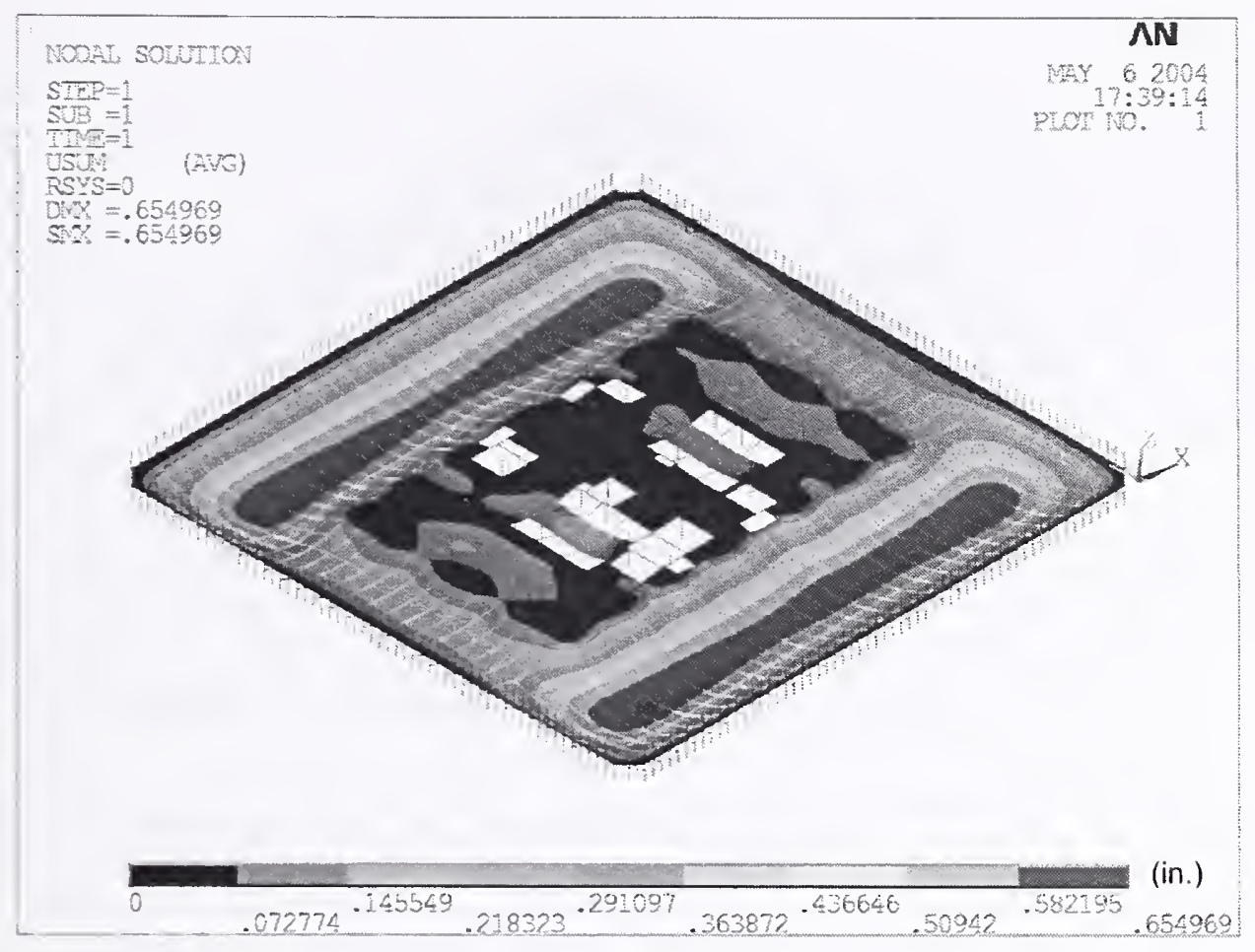

Figure 4-6. Deformed shape $(\times 100)$ of gravity load case for ANSYS floor model (total displacements are shown).

Table 4-3 summarizes the comparison of the SAP and ANSYS results for the modal analysis of the floor models. The total masses of the SAP and ANSYS models were within 0.02 percent of each other. The dominant natural frequency of the floor predicted by the ANSYS model was 2.5 percent higher than that obtained from the SAP model. This discrepancy is consistent with the discrepancy observed for gravity displacement. The dominant mode shapes of the floor for SAP and ANSYS models are shown in Figs. 4-7 and 4-8.

Table 4-3. Comparison of SAP and ANSYS floor model modal analysis results.

\begin{tabular}{|l|c|c|}
\hline & SAP & ANSYS \\
\hline Total mass, lb·sec 2 /in. & 5448.7 & $5447.7(-0.02 \%)$ \\
\hline Dominant natural frequency of floor, $\mathrm{Hz}$ & 4.32 & $4.43(+2.5 \%)$ \\
\hline
\end{tabular}




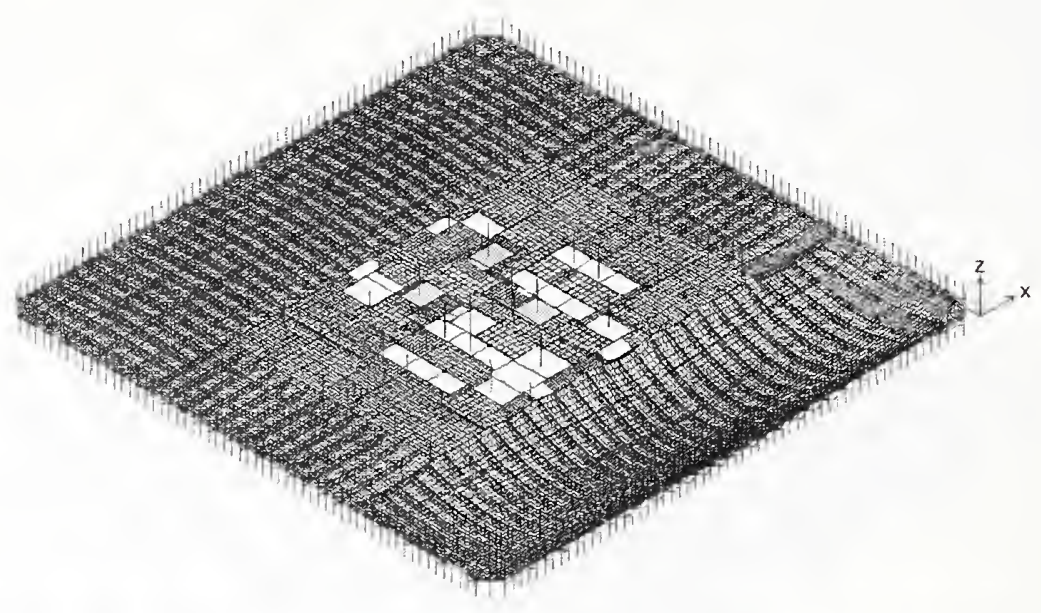

Figure 4-7. Dominant mode shape (frequency $=4.32 \mathrm{~Hz}$ ) of floor structure for SAP floor model.

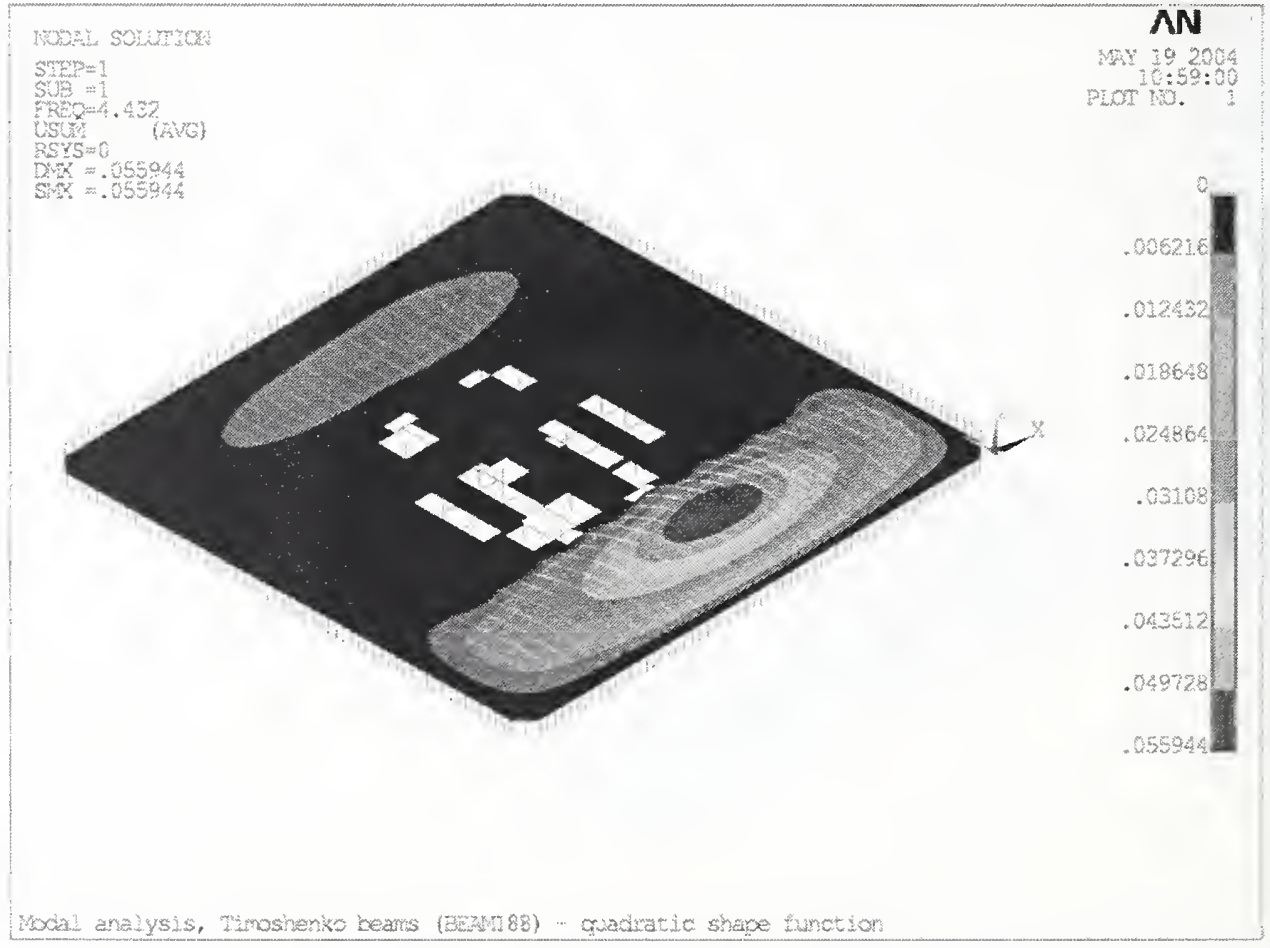

Figure 4-8. Dominant mode shape (frequency $=4.43 \mathrm{~Hz}$ ) of floor structure for ANSYS floor model. 


\subsubsection{Global Model Validation}

The translated ANSYS models were subjected to gravity dead and live loads and the results were compared to the results of SAP2000 global models (Figures 4-9 and 4-10). This comparison was performed to verify the accuracy of the translation of the SAP2000 models into ANSYS. The overall displaced shapes, the maximum displacements and vertical base reactions at each construction stage, and element forces for a set of randomly selected members from different parts of the buildings were compared.

The gravity analysis consisted of three stages that simulated the construction sequence of the buildings. Stage 1 was the analysis of the parts of the towers up to and including Floor 106 under their self weight. In Stage 2, the members above Floor 106 in unstressed states were added to the parts of the towers up to and including Floor 106, which had already deformed under their self-weight, and the towers were subjected to and analyzed for the dead load of the newly added members. In Stage 3, the towers were subjected to and analyzed for the additional load consisting of the superimposed dead load and 25 percent of the design live loads were added to the existing dead loads.

Figures 4-11 and 4-12 compare the deformed shapes of WTC 1 and WTC 2 obtained from the translated ANSYS models to the ones obtained from the SAP models at the end of Stage 3 of the gravity analysis. Table 4-4 and Table 4-5 summarize the maximum displacement and vertical reactions at the base for all stages of the gravity analysis. As can be seen, the deformed shapes and the maximum displacements and vertical reactions obtained from the analyses performed with the translated ANSYS models agree well with the results of the SAP analyses. The maximum differences between the two models were less than 1.4 percent for WTC 1 and 0.7 percent for WTC 2 for the displacements, and 1.2 percent for WTC 1 and 0.3 percent for WTC 2 for the base reactions.

Table 4-6 and Table 4-7 show the comparisons of the axial forces computed from ANSYS and SAP2000 for a randomly selected set of elements from different parts of each building. In Table 4-6 and Table 47 , the axial force values that are less then $0.5 \mathrm{kip}$ are shown as $0.0 \mathrm{kip}$. There is good agreement between the results obtained from ANSYS and SAP models. 


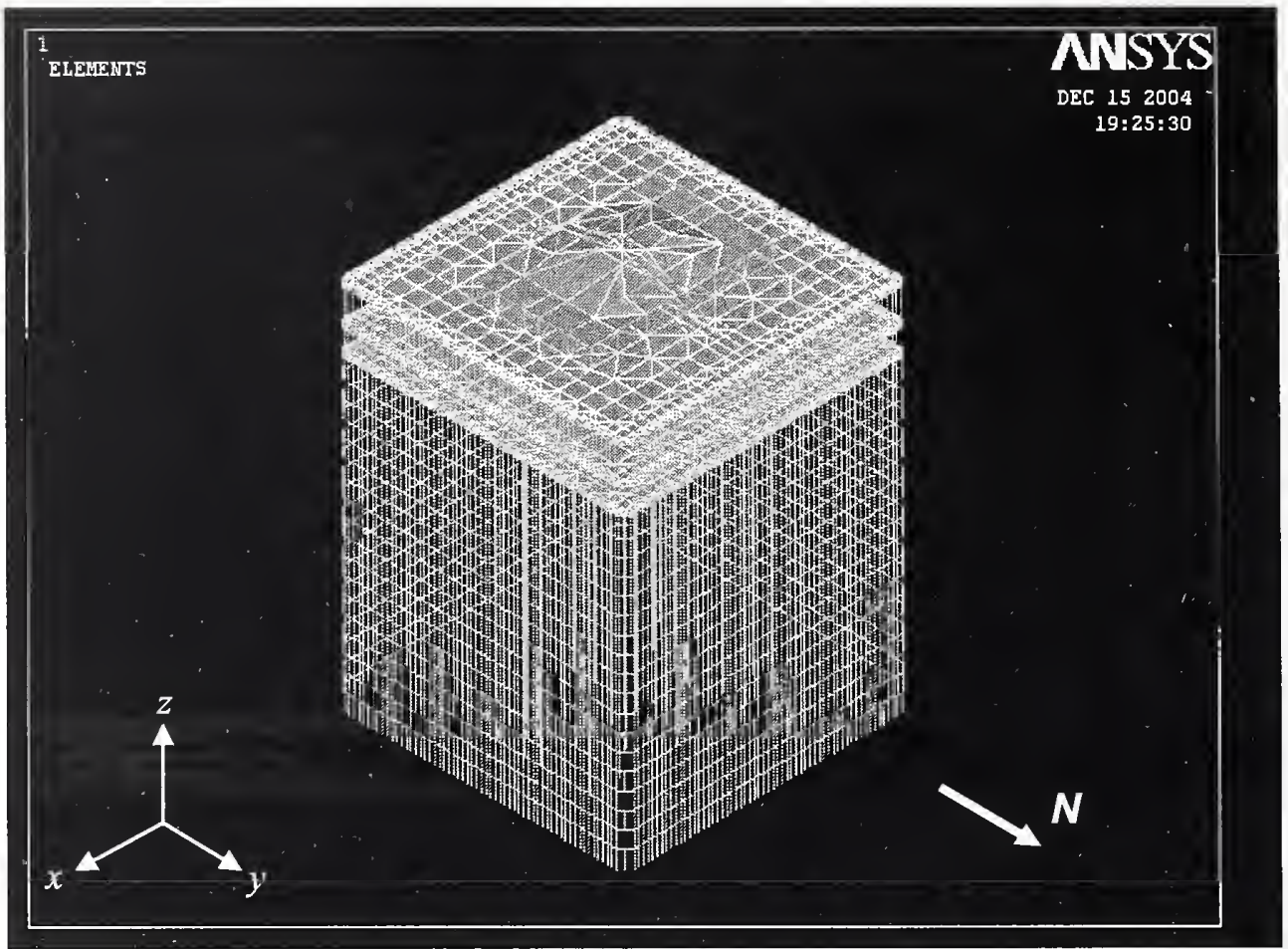

Figure 4-9. Converted ANSYS model of WTC 1.

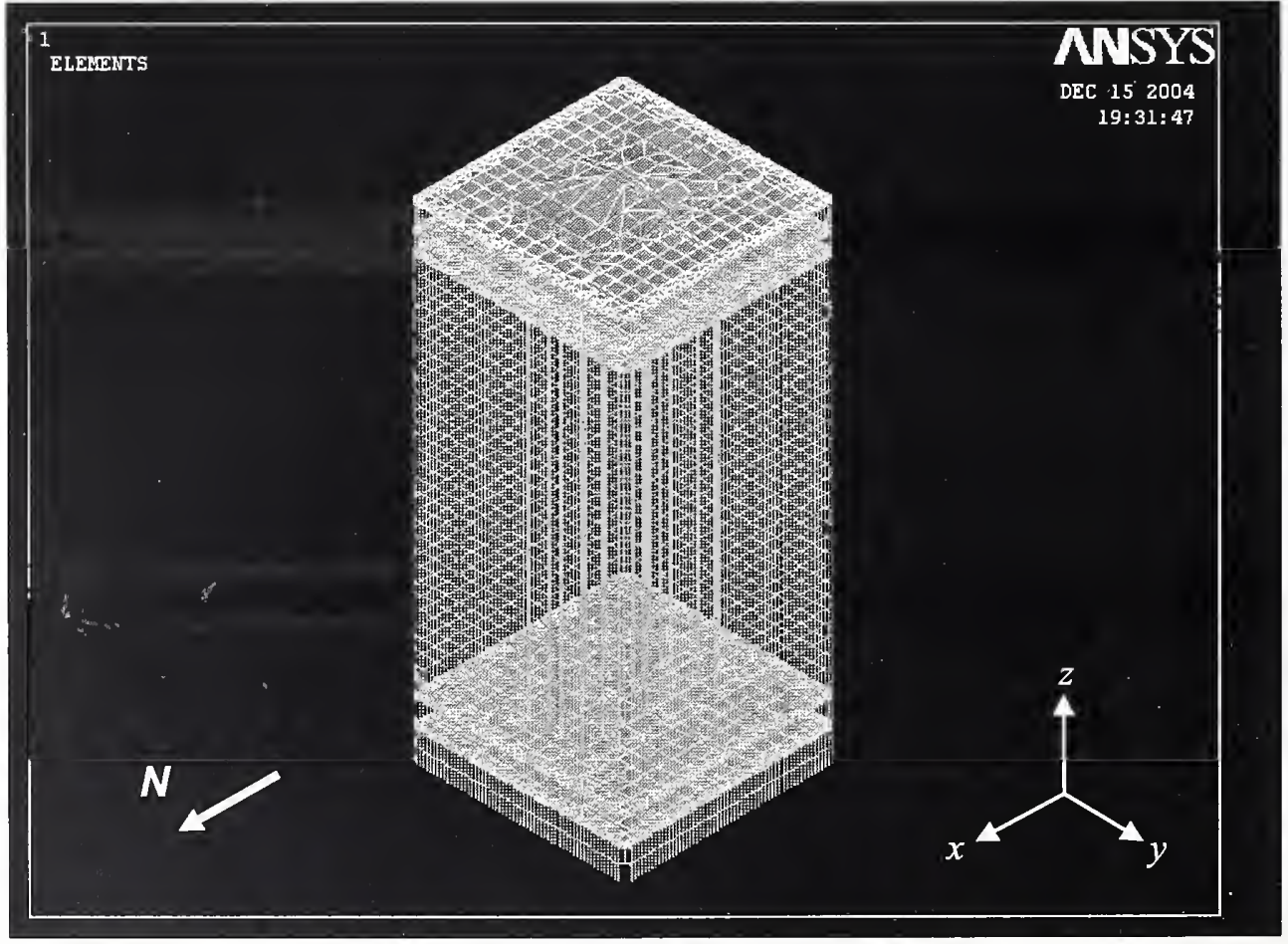

Figure 4-10. Converted ANSYS model of WTC 2. 


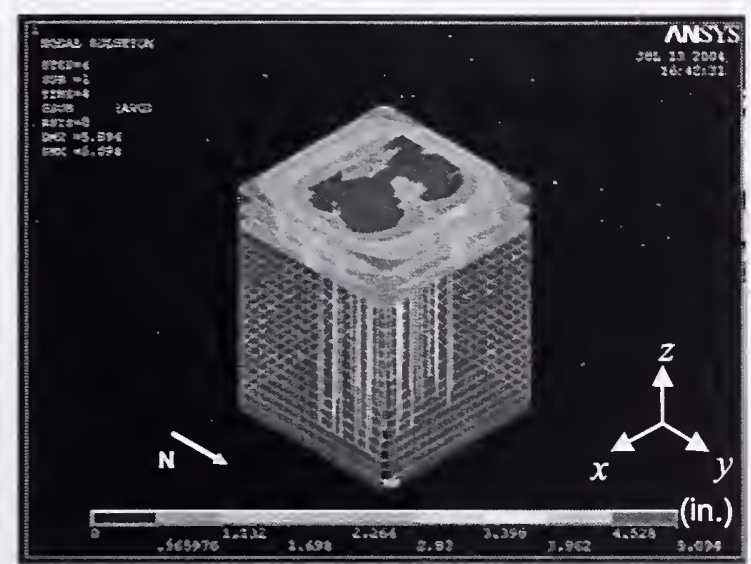

(a) WTC 1 ANSYS Model at Stage 3

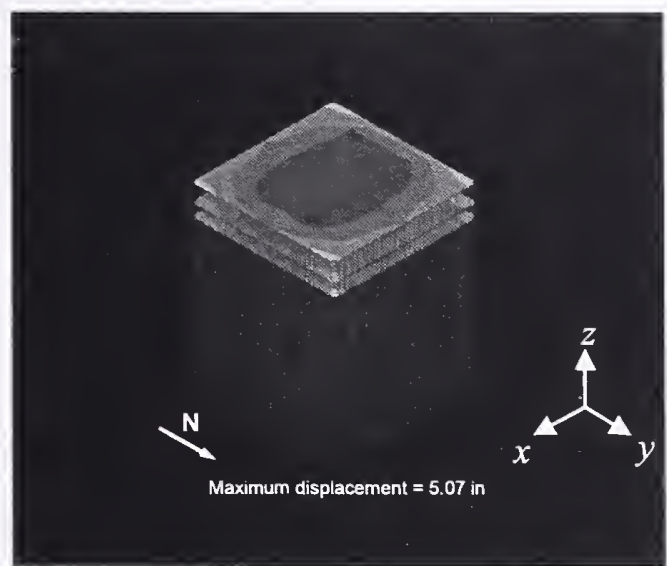

(b) WTC 1 SAP2000 Model at Stage 3 (Displacement contour is only shown on floor (shell) elements.)

Figure 4-11. Displaced shape of WTC 1 at the end of gravity analysis.

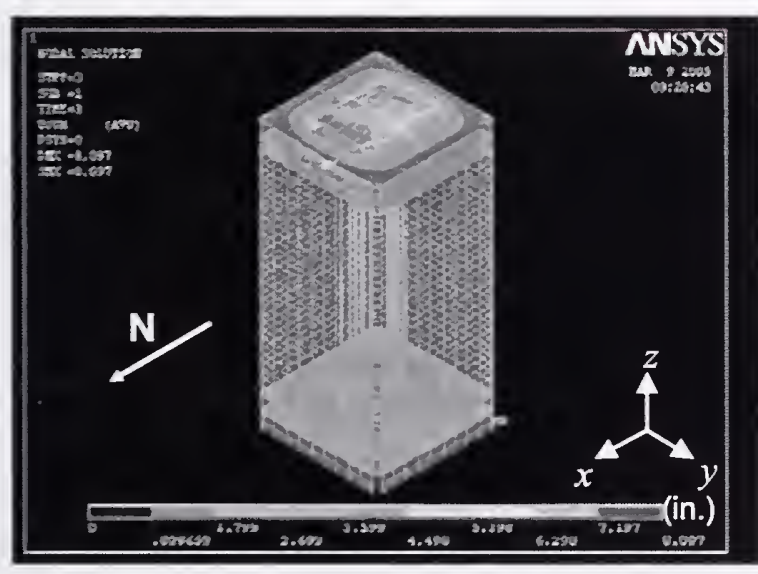

(a) WTC 2 ANSYS Model at Stage 3

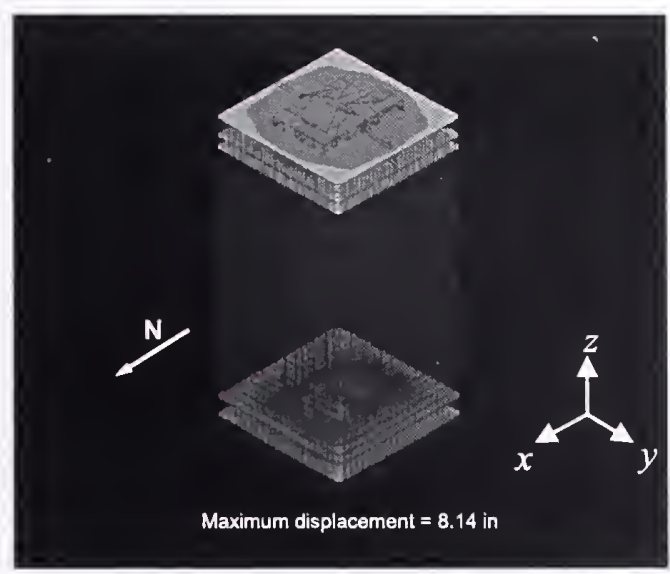

(b) WTC 2 SAP2000 Model at Stage 3 (Displacement contour is only shown on floor (shell) elements.)

Figure 4-12. Displaced shape of WTC 2 at the end of gravity analysis. 
Table 4-4. Comparison of maximum displacements and base reactions of WTC 1 from translated ANSYS and SAP2000 models.

\begin{tabular}{|c|c|c|c|c|c|c|}
\hline \multirow{2}{*}{ Stage } & \multicolumn{2}{|c|}{ Maximum Vertical Displacement (in.) } & \multicolumn{3}{c|}{ Base Reaction Sum (kip) } \\
\cline { 2 - 7 } & ANSYS & SAP2000 & $\begin{array}{c}\text { Percent } \\
\text { Difference }\end{array}$ & ANSYS & SAP2000 & $\begin{array}{c}\text { Percent } \\
\text { Difference }\end{array}$ \\
\hline 1 & -2.87 & -2.83 & 1.4 & 55,600 & 54,940 & 1.2 \\
\hline 2 & -4.76 & -4.74 & 0.4 & 98,470 & 97,850 & 0.6 \\
\hline 3 & -5.09 & -5.07 & 0.4 & 107,040 & 106,450 & 0.6 \\
\hline
\end{tabular}

Table 4-5. Comparison of maximum displacements and base reactions of WTC 2 obtained from translated ANSYS and SAP2000 models.

\begin{tabular}{|c|c|c|c|c|c|c|}
\hline \multirow{2}{*}{ Stage } & \multicolumn{2}{|c|}{ Maximum Vertical Displacement (in.) } & \multicolumn{3}{c|}{ Base Reaction Sum (kip) } \\
\cline { 2 - 7 } & ANSYS & SAP2000 & $\begin{array}{c}\text { Percent } \\
\text { Difference }\end{array}$ & ANSYS & SAP2000 & $\begin{array}{c}\text { Percent } \\
\text { Difference }\end{array}$ \\
\hline 1 & -5.87 & -5.91 & -0.7 & 125,050 & 124,680 & 0.3 \\
\hline 2 & -7.67 & -7.71 & -0.5 & 166,950 & 166,980 & 0.0 \\
\hline 3 & -8.10 & -8.14 & -0.5 & 180,250 & 180,360 & -0.1 \\
\hline
\end{tabular}

Table 4-6. Comparison of axial forces in randomly selected elements from WTC 1 model at the end of gravity analysis.

\begin{tabular}{|l|c|c|}
\hline \multicolumn{1}{|c|}{ Location and Type of Selected Element } & \multicolumn{2}{c|}{ Axial Force (kip) } \\
\cline { 2 - 3 } & ANSYS & SAP2000 \\
\hline Exterior Column 302 at Floor 104 & -77 & -69 \\
Spandrel between Columns 124 and 125 at Floor 102 & 0 & 0 \\
Outrigger member between at Floor 110 & -39 & -48 \\
Vertical hat-truss member at 1005 core column line at Floor 109 & -74 & -91 \\
Horizontal hat-truss member at Floor 107 & 21 & 19 \\
Horizontal hat-truss member at Floor 108 & 170 & 150 \\
Core Column 602 at Floor 97 & -738 & -745 \\
Core Column 501 at Floor 93 & $-2,180$ & $-2,190$ \\
Core Column 1001 at Floor 89 & $-2,570$ & $-2,590$ \\
Spandrel between Columns 339 and 340 at Floor 100 & 0 & 0 \\
\hline
\end{tabular}

* Axial force values less than $0.5 \mathrm{kip}$ are shown as $0.0 \mathrm{kip}$. 
Table 4-7. Comparison of axial forces in randomly selected elements from WTC 2 model at the end of gravity analysis.

\begin{tabular}{|l|c|c|}
\hline \multirow{2}{*}{\multicolumn{1}{|c|}{ Location and Type of Selected Element }} & \multicolumn{2}{c|}{ Axial Force (kip) } \\
\cline { 2 - 3 } & ANSYS & SAP2000 \\
\hline Core beam at Floor 107 & 11 & 6 \\
Inclined truss member at hat-truss at Floor 107 & -34 & -4 \\
Inclined truss member at hat-truss at Floor 108 & 36 & 8 \\
Inclined truss member at hat-truss at Floor 108 & -580 & -670 \\
Core Column 502 at Floor 87 & $-1,930$ & 1,940 \\
Core Column 1001 at Floor 82 & $-3,270$ & $-3,290$ \\
Core Column 1002 at Floor 87 & $-1,910$ & $-1,920$ \\
Core Column 1008 at Floor 82 & $-3,400$ & 3,520 \\
Core Column 1003 at Floor 107 & -590 & -608 \\
Exterior Column 122 at Floor 82 & -313 & -313 \\
Exterior Column 329 at Floor 82 & -228 & -230 \\
Exterior Column 130 at Floor 107 & -222 & -202 \\
Spandrel between Columns 138 and 139 at Floor 83 & 0 & 0 \\
Spandrel between Columns 447 and 448 at Floor 87 & 0 & 0 \\
\hline
\end{tabular}

"Axial force values less than 0.5 kip are shown as 0.0 kip.

\subsection{SUMMARY}

In general, the results from the translated ANSYS floor and global models showed good agreement with the results obtained form the SAP models. For the floor model, the calculated base reactions and displacements due to gravity load showed a 3 percent difference between the ANSYS and SAP models. Similarly, the modal analysis results showed a 3 percent difference in calculated total mass and the fundamental frequency between the ANSYS and SAP floor models.

For the global models, the comparison of base reactions and the maximum displacements in the vertical direction showed that the maximum differences between the ANSYS and the SAP models were less than 1.4 percent for WTC 1 and 0.7 percent for WTC 2 for displacements, and 1.2 percent for WTC 1 and 0.3 percent for WTC 2 for base reactions. Comparison of axial forces for both global models showed good agreement between ANSYS and SAP models.

Based on these comparisons it was concluded that the translation of the floor and global models from SAP to ANSYS was acceptable, and the translated models were used to investigate the component and building responses under the presence of non-linear material properties and thermal effects. 
This page intentionally left blank. 


\section{Chapter 5 \\ FULL FLOOR SUBSYSTEM}

\subsection{OBJECTIVE}

The failure modes and the corresponding failure loads of key components of the full floor subsystem were identified and were evaluated at elevated temperatures through analysis of detailed models of these components, using either hand calculations or finite element analysis. Key floor components analyzed included truss seats, knuckle (truss-to-slab shear connector), and a 3-D model of a single truss and a corresponding section of concrete slab. Finite element models that can capture the failure modes with efficiency and determine the failure loads were then developed. These models of key components were incorporated in the full floor subsystem model.

\section{$5.2 \quad$ TRUSS SEATS}

Likely failure modes of truss seats were identified, and the corresponding failure loads were determined and are reported in this section. The following loading conditions were considered: vertical force, horizontal tensile force, horizontal compressive force, and combined vertical and horizontal force.

\subsubsection{Description of Truss Seats}

The floor truss was supported at the exterior wall and at the core by truss seats. The truss seats at the exterior wall and at the core are referred to as exterior truss seat and interior truss seat, respectively.

The interior truss seat consisted of a horizontal plate with two vertical plate stiffeners as shown in Fig. 5-1. These plates were fillet welded together and fillet welded to the core channel beam. Two $5 / 8$ in. diameter A325 bolts (one bolt in each truss) connected the truss to the seat. The bolted connection was a friction type with $3 / 4$ in. $\times 13 / 4$ in. (width $\times$ length) long slotted holes in the seat horizontal plate and $7 / 8$ in. oversize holes in the bearing angles.

The exterior truss seat consisted of a seat angle attached to the spandrel with two vertical plates (stand-off plates), and a gusset plate as shown in Fig. 5-2. Fillet welds connected the seat angle to the stand-off plates, the stand-off plates to the column/spandrel, and the gusset plate to truss top chord. A completejoint-penetration groove weld connected the gusset plate to the column/spandrel. Similar to the interior truss seat, each pair of trusses was attached to the exterior truss seat by two $5 / 8 \mathrm{in}$. A325 bolts. The bolted connection was a friction type with $3 / 4 \mathrm{in.} \times 2 \mathrm{in.} \mathrm{long} \mathrm{slotted} \mathrm{holes} \mathrm{in} \mathrm{the} \mathrm{seat} \mathrm{angle} \mathrm{and} 7 / 8 \mathrm{in}$. oversize holes in the truss bearing angle.

In Floor 96 of WTC 1, there were seven types of interior truss seats and eight types of exterior truss seats. The different types of interior truss seats were identified with Detail Numbers 15, 17, 20,21, 22, 23, and 226A; and the exterior truss seats with Detail Numbers 1013, 1111, 1212, 1311, 1313,1411, 1511, and 1611, as shown in Fig. 5-3.

All interior truss seat types were similar in their design geometry, but with different sizes of vertical and horizontal plates, locations of the bolt holes, and sizes of the fillet welds. The thicknesses of plates ranged from $3 / 8 \mathrm{in}$. to $3 / 4 \mathrm{in}$; t the distance between bolt holes ranged from $81 / 2 \mathrm{in}$. to $101 / 2 \mathrm{in}$; and the size of the fillet welds ranged from $1 / 4$ in. to $3 / 8$ in. All exterior truss seat types were also similar in their 
design geometry, but with different sizes of stand-off plates, sizes of seat angles, sizes and shapes of gusset plates, locations of bolt holes, and sizes of fillet welds. The vertical heights of the stand-off plate ranged from $8 \mathrm{in}$. to $11 \mathrm{in}$. The seat angle sizes ranged from L4 $4 \times 1 / 2$ to L6 $\times 4 \times 3 / 4$. The gusset plates were rectangular and trapezoidal and ranged in width from $41 / 2 \mathrm{in}$. to $6 \mathrm{in}$. The distance between bolt holes ranged from $31 / 4 \mathrm{in}$. to $101 / 2 \mathrm{in}$.; where it was $31 / 4 \mathrm{in}$., the seat was supporting a single truss in lieu of a pair of trusses. The size of the fillet welds ranged from $5 / 16 \mathrm{in}$. to $3 / 8 \mathrm{in}$.

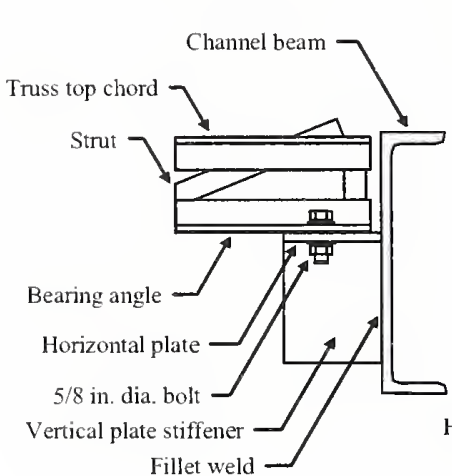

$\underline{\text { Side View }}$

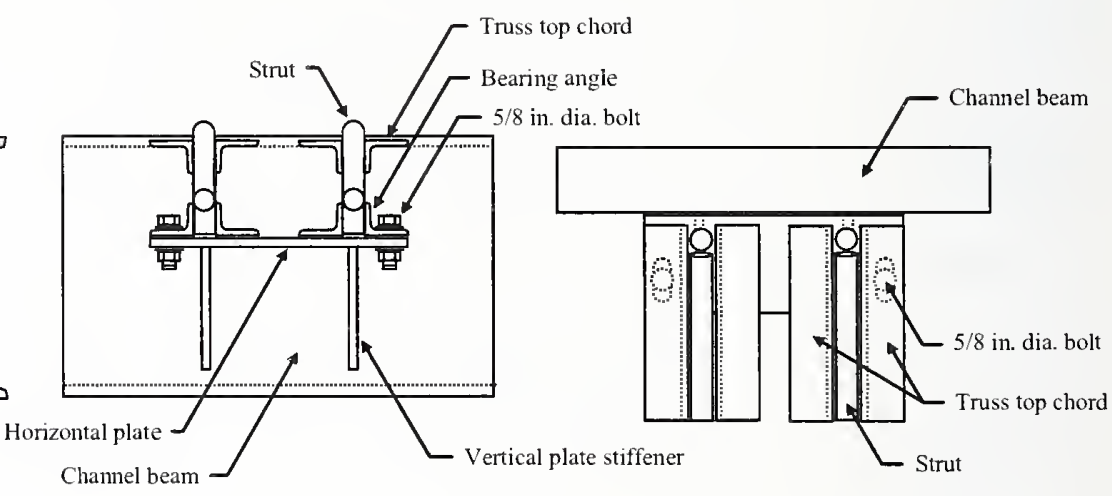

$\underline{\text { Front View }}$ $\underline{\text { Top View }}$

Figure 5-1. Interior truss seat.

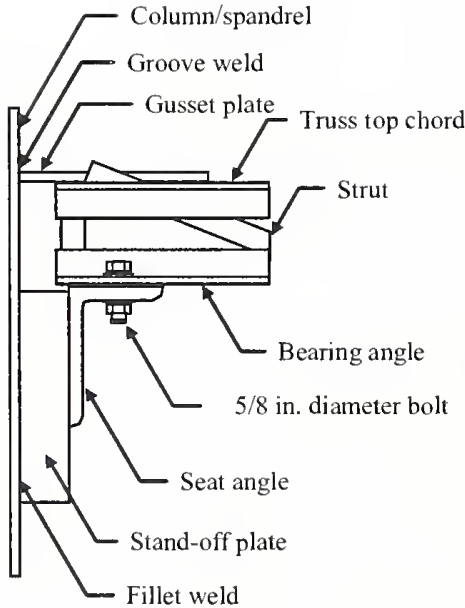

$\underline{\text { Side View }}$

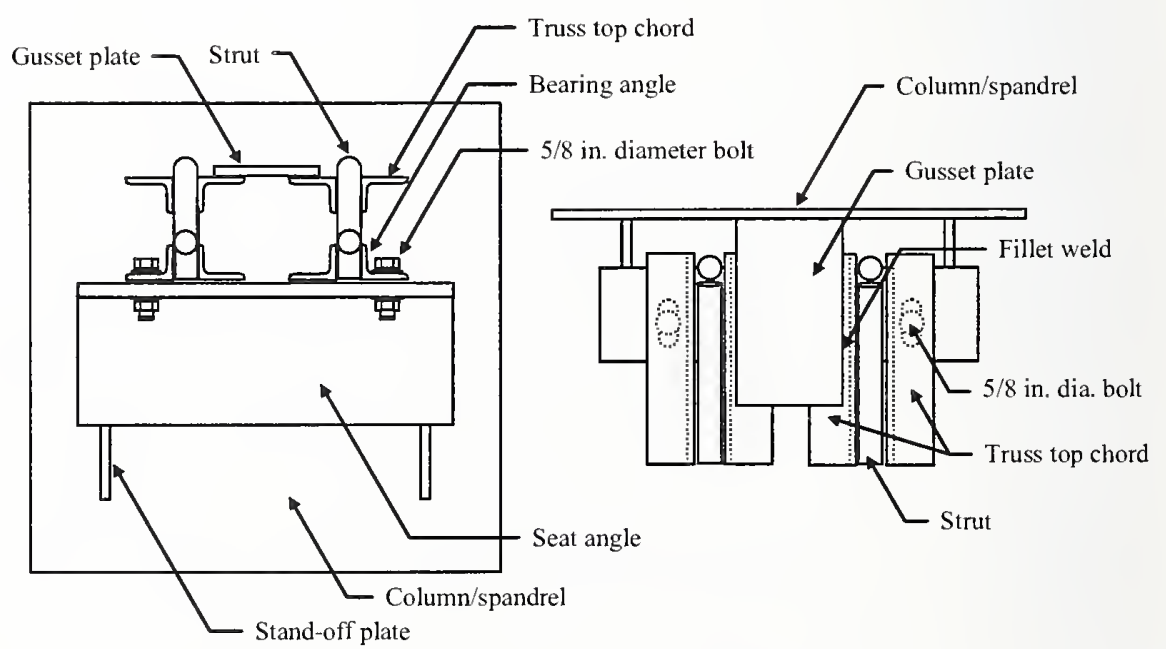

Front View $\underline{\text { Top View }}$

Figure 5-2. Exterior truss seat. 


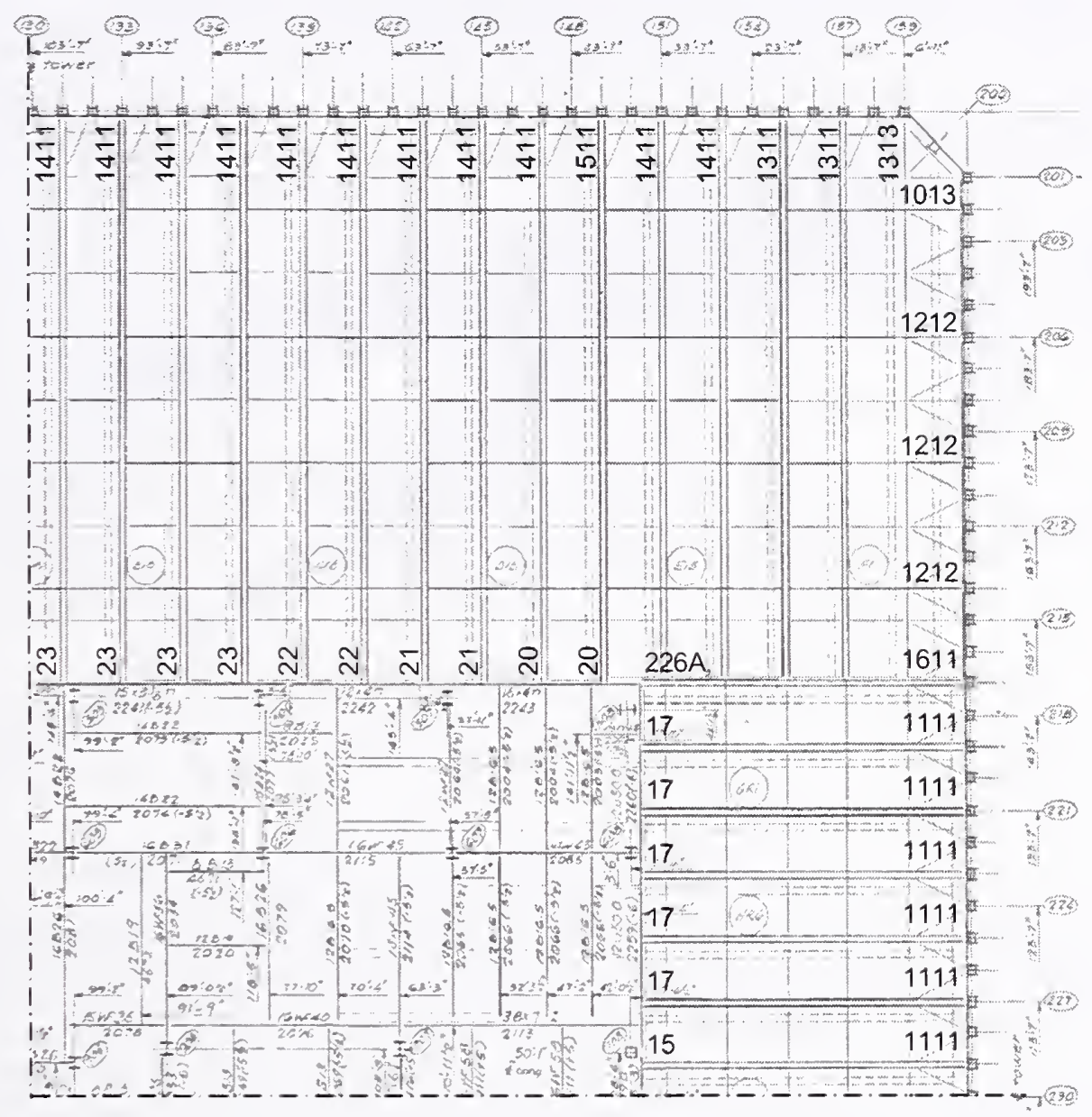

Reproduced with permission of The Port Authority of New York and New Jersey.

Figure 5-3. Truss seat detail location on northeast quadrant of Floor 96 of WTC 1.

\subsubsection{Truss Seat Material Properties}

The material properties used in the calculations were selected from Table 3-1 to best match the material properties indicated on the design drawings. Figure $3-3$ was used to determine the mechanical properties at high temperature. The materials used for truss seat calculations are shown in Table 5-1. 
Table 5-1. Materials used for truss seat calculations.

\begin{tabular}{|c|c|c|}
\hline \multirow{2}{*}{$\begin{array}{c}\text { Exterior and interior } \\
\text { truss seat }\end{array}$} & $\begin{array}{c}\text { Delected Material } \\
\text { ID }\end{array}$ \\
\cline { 2 - 3 } & A325 bolts & Material 22 \\
\cline { 2 - 3 } & Fillet welds & Material 7 \\
\hline \multirow{3}{*}{ Exterior truss seat } & Truss bearing angles & Material 21 \\
\cline { 2 - 3 } & Seat angle & Material 1 \\
\cline { 2 - 3 } & Gusset plate & Material 12 \\
\cline { 2 - 3 } & Stand-off & Material 23 \\
\cline { 2 - 3 } & Truss top chord angles & Material 21 \\
\cline { 2 - 3 } & Cover plate for bridging truss top chord & Material 1 \\
\hline Interior truss seat & Vertical plate stiffener & Material 12 \\
\cline { 2 - 3 } & Horizontal plate & Material 12 \\
\hline
\end{tabular}

\subsubsection{Truss Seat Failure Modes and Sequence}

Possible failure modes for truss seats were identified for vertical force, horizontal tensile force, horizontal compressive force, and combined vertical and horizontal force. For each failure mode, the truss seat capacity was determined at different temperatures.

Failure Modes of Exterior Truss Seats for Vertical Force: The vertical load on the seat was eccentric to the plane of connection between the seat and the spandrel. Because of this eccentricity, the truss seat resisted to combined effect of both shear and bending. Finite element analysis of the truss seat was performed to determine load paths and evaluate the behavior of the seat connection.

Figure 5-4 shows the finite element model of the exterior truss seat connection. Half of the truss seat was modeled and symmetry boundary conditions were applied to all nodes in the plane of symmetry. The results of the finite element analysis showed that shear force was carried primarily by the stand-off plates, while the bending moment was resisted by tensile force in the gusset plate and compressive force in the stand-off plate. The seat angle restrained the moment until horizontal force in the connection caused slippage between the seat angle and bearing angle. The truss seat capacity was governed by the capacities of fillet welds at the stand-off plate to spandrel connection subjected to shear, bending, and compression. The failure mode was the fracture of the fillet welds between the stand-off plates and spandrel, resulting in loss of vertical support.

Failure Modes of Interior Truss Seats for Vertical Force: The vertical load on the truss seat was eccentric to the plane of fillet weld connection between the truss seat vertical plate stiffeners and the channel beam. Calculations showed that the truss seat capacity was governed by the capacities of the fillet welds at this joint subjected to shear and bending. The failure mode was the fracture of the fillet welds between the vertical plate stiffeners and the channel beam, resulting in loss of vertical support. 


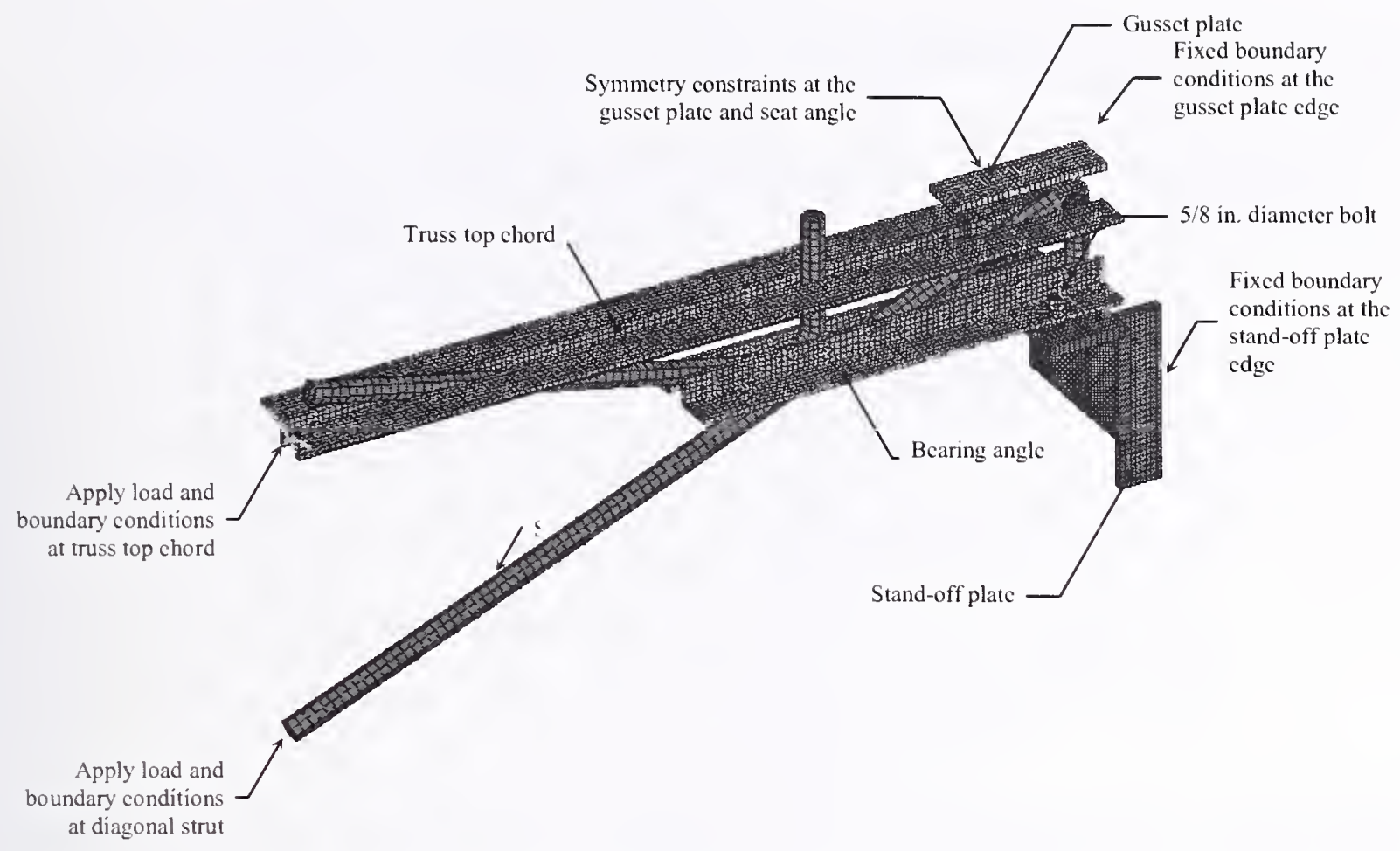

Figure 5-4. Finite element model of exterior truss seat.

Failure Modes of Exterior Truss Seats for Hori-ontal Tensile Force: The failure of exterior truss seats subjected to a horizontal tensile force can occur in the following modes: (1) fracture of the groove weld between the gusset plate and spandrel, (2) fracture of the fillet weld between the gusset plate and the truss top chord, (3) tensile fracture of the gusset plate, and (4) shear failure of the bolted connection by bolt shear, bolt bearing, tear-out, and block shear. For calculation purposes, the bolts were assumed to be centered in the slotted holes. The typical failure sequence of the exterior truss seat was as follows: (1) the gusset plate yielded, (2) the groove weld fractured, (3) the truss bearing angle slid so that the bolts were bearing against the slotted holes and then the bolts sheared off, and (4) the truss walked off the seat angle. The travel distance for the truss to walk off the seat angle was $45 / 8 \mathrm{in}$. This failure sequence is illustrated in Fig. 5-5 as path (A). The relationship between the tensile force rcsistance and the truss travel distance is plotted in Fig. 5-6 for path (A) in Fig. 5-5. In this figure, frictional resistance between the seat angle and bearing angle was not included.

Seat details 1212 and 1313 had a wider gusset plate and followed path (D), where the bolts bore against the slotted hole then sheared off before the gusset plate connection failed. The failure scquence of seat detail 1013 was temperature-dependent. At temperatures below $100{ }^{\circ} \mathrm{C}$, the fillet weld connection between the gusset plate and the truss top chord fractured before the bolts sheared off. At temperatures greater than or equal to $100{ }^{\circ} \mathrm{C}$, the failure sequence was the same as that for Details 1212 and 1313 .

Failure Modes of Interior Truss Seats for Horizontal Tensile Force: The failure of interior truss seats subjected to a horizontal tensile force can occur in the following modes: (1) shear failure of the bolted connection by bolt shear, bolt bearing, tear-out, block shear, and (2) fracture of fillet weld connection between the truss seat and the channel beam. Calculations showed that the bolt shear strength controlled the truss seat capacity. Bolt shear by itself, however, did not cause the truss to lose its vertical support, 
but it was the prerequisite to the truss walking off the seat. The travel distance required for the truss to walk off the seat was $4 \mathrm{in}$.

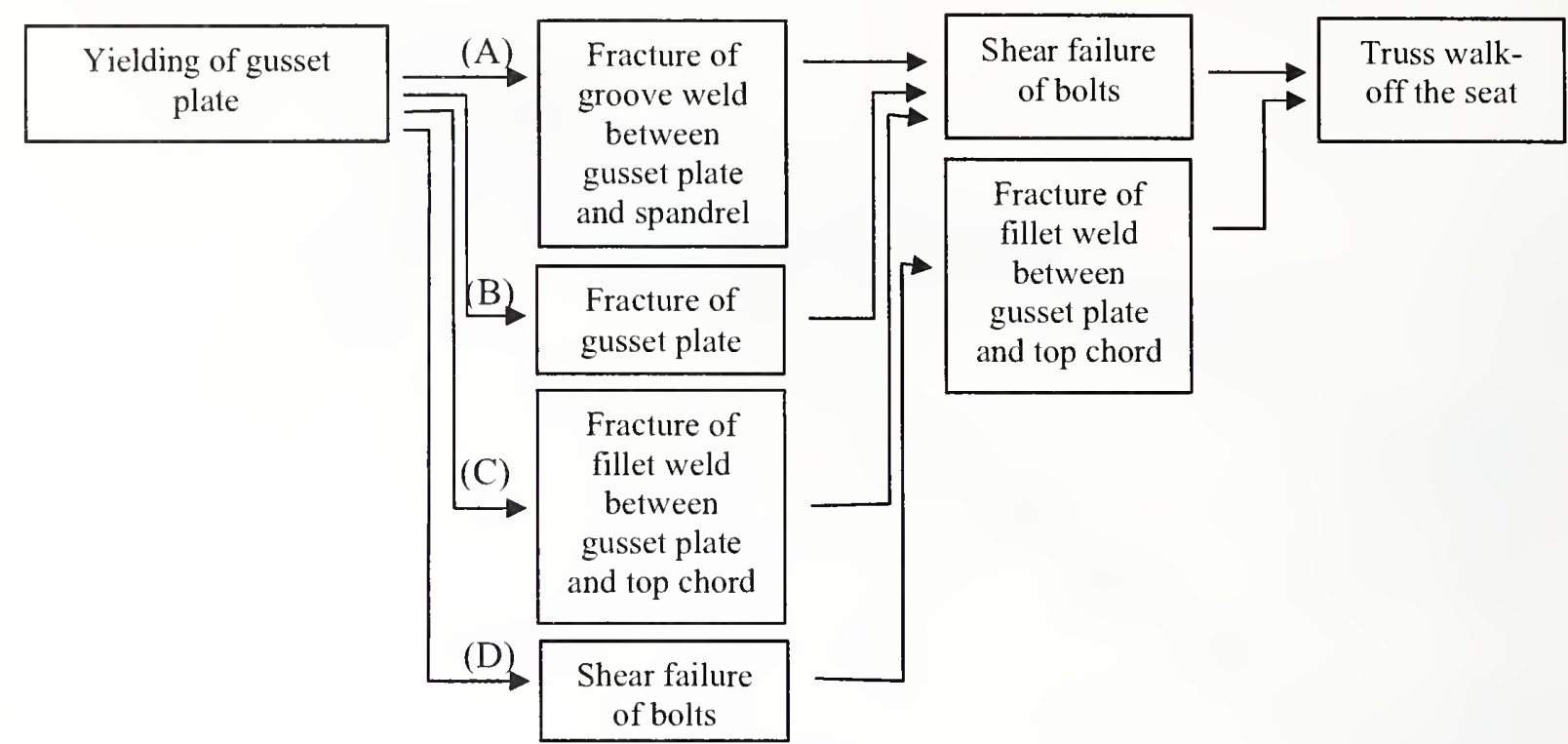

(A) Seat details $1311,1411,1511$, and 1611 at all temperatures.

(B) Seat detail 1111 at all temperatures.

(C) Seat detail 1013 at temperatures below $100^{\circ} \mathrm{C}$.

(D) Seat details 1212 and 1313 at all temperatures, and detail 1013 at temperatures more than or equal to $100{ }^{\circ} \mathrm{C}$.

Figure 5-5. Failure sequence of the exterior truss seats against tensile force. 


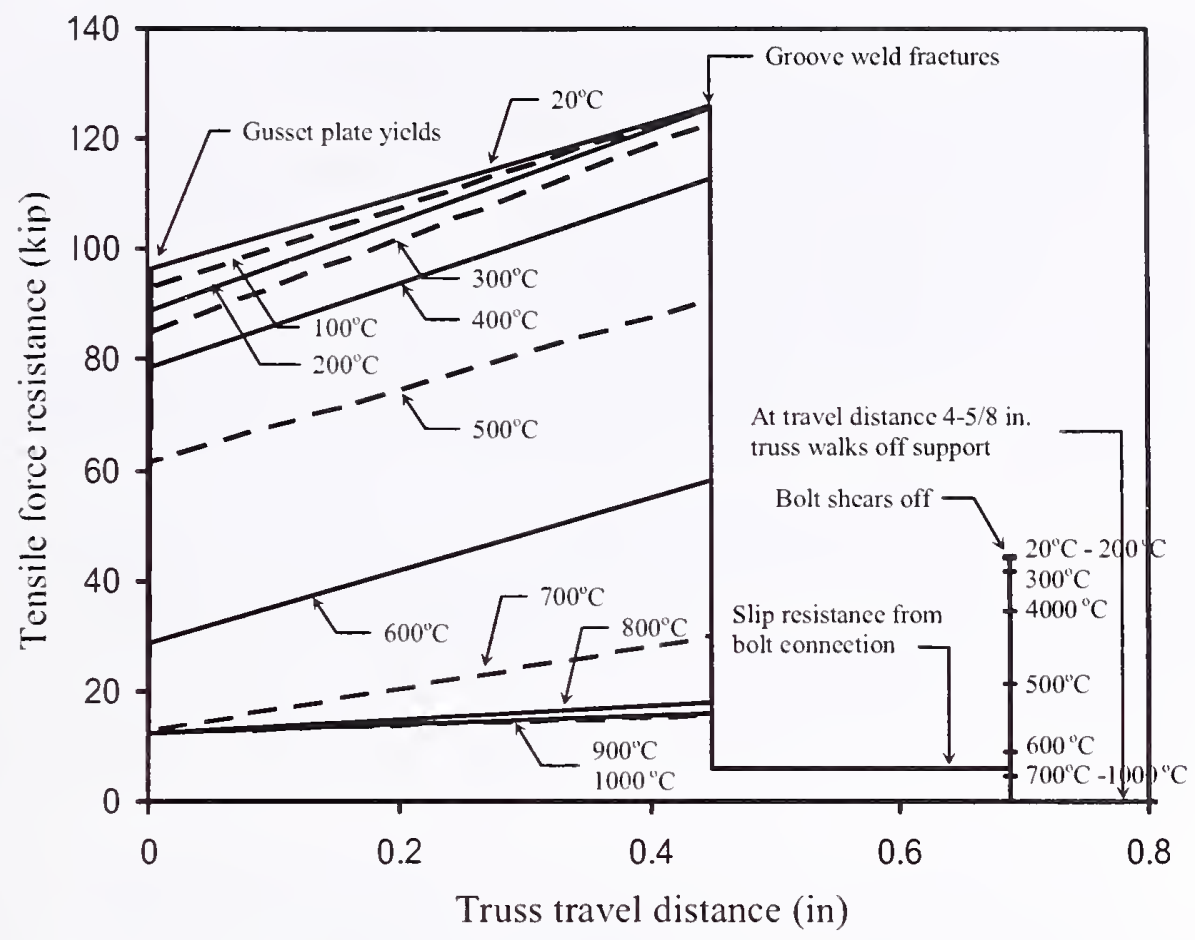

Figure 5-6. Capacity of exterior truss seat for tensile force (Path (A) in Fig. 5-5 for Detail 1411).

Failure Modes of Exterior Truss Seats for Horizontal Compressive Force: The concrete slab above the truss seat connection provided the compressive force resistance. In the absencc of the concrete slab, the truss seat resistance against compressive force was provided by the gusset plate until it buckled, and by bolt shear when the bolt bore against the slotted hole. Surface friction between the seat angle and bearing angles also provided some resistance. Additional resistance developed when the truss came into contact with the spandrel. Travel distance for the truss to contact the column spandrel was $11 / 2 \mathrm{in}$. Under compressive force, the truss did not lose its vertical support.

Failure Modes of Interior Truss Seats for Horizontal Compressive Force: The reinforced concrete slab above the truss seat connection provided the compressive force resistance. In the absence of the concrete slab, the truss seat resistance against compressive force came from surface friction between the seat horizontal plate and bearing angles. Additional resistance was developed when the truss came into contact with the channel beam. Travel distance for the truss to contact the channel beam was $1 / 2$ in. Under compressive force, the truss did not lose its vertical support.

Failure Modes of Interior and Exterior Truss Seats for Combined Vertical and Horizontal Forces: The failure modes of the interior and exterior truss seats when subjected to combined vertical and horizontal forces were a combination of the failure modes for vertical and horizontal forces. The vertical shear strengths of fillet welds in both the interior and exterior truss seats were reduced by the horizontal tensile force. This fillet weld was between the vertical plate and channel beam for interior truss seats and between the stand-off plate and spandrel for exterior truss seats. The horizontal tensile strengths of the truss seats were not reduced by the additional vertical forces on the truss seats. 


\subsubsection{Truss Seat Capacity Calculations}

In this section, truss seat capacities corresponding to the failure modes described in the previous section are given. The capacities were computed for different types of truss seats at different temperatures.

Calculation of the capacities was performed using the methods in the Manual of Steel Construction: Load and Resistance Factor Design (AISC 2001) with the resistance factor, $\phi$, assumed to be equal to one.

Capacity of Exterior Truss Seats for Vertical Force: The failure mode of the truss seat against vertical force was fracture of the fillet welds at the stand-off plate to spandrel connection. Strength of the fillet welds at this connection is summarized in Table 5-2 and Fig. 5-7. The symbol \# in this table refers to seat detail number.

Capacity of Iuterior Truss Seats for Vertical Force: Failure mode of the truss seat against vertical force was fracture of the fillet welds between the seat vertical plate stiffener and channel beam. Strengths of the fillet welds at this joint are summarized in Table 5-3 and Fig. 5-7. 
Table 5-2. Exterior truss seat capacity for vertical force.

\begin{tabular}{|c|c|c|c|c|c|c|c|c|}
\hline \multirow{2}{*}{$\begin{array}{c}\text { Temp. } \\
\left({ }^{\circ} \mathbf{C}\right)\end{array}$} & \multicolumn{6}{|c|}{ Connection Detail Capacity for Vertical Force (kip) } \\
\hline & $\# \mathbf{1 0 1 3}$ & $\# \mathbf{1 1 1 1}$ & $\mathbf{\# 1 2 1 2}$ & $\mathbf{\# 1 3 1 1}$ & \#1313 & \#1411 & \#1511 & \#1611 \\
\hline 20 & 94 & 94 & 111 & 94 & 94 & 140 & 193 & 207 \\
\hline 100 & 94 & 94 & 111 & 94 & 94 & 140 & 193 & 207 \\
\hline 200 & 93 & 93 & 110 & 93 & 93 & 139 & 192 & 206 \\
\hline 300 & 91 & 91 & 108 & 91 & 91 & 136 & 187 & 201 \\
\hline 400 & 84 & 84 & 100 & 84 & 84 & 126 & 172 & 184 \\
\hline 500 & 69 & 69 & 81 & 69 & 69 & 102 & 136 & 146 \\
\hline 600 & 45 & 58 & 53 & 60 & 45 & 78 & 84 & 90 \\
\hline 700 & 29 & 26 & 34 & 27 & 29 & 35 & 38 & 41 \\
\hline 800 & 14 & 13 & 17 & 13 & 14 & 17 & 19 & 20 \\
\hline 900 & 12 & 11 & 14 & 11 & 12 & 14 & 16 & 17 \\
\hline 1000 & 12 & 11 & 14 & 11 & 12 & 14 & 15 & 17 \\
\hline
\end{tabular}

Table 5-3. Interior truss seat capacity for vertical force.

\begin{tabular}{|c|c|c|c|c|c|c|c|}
\hline \multirow{2}{*}{$\begin{array}{c}\text { Temp. } \\
(\mathbf{C})\end{array}$} & \multicolumn{6}{|c|}{ Connection Detail Capacity for Vertical Force (kip) } \\
\cline { 2 - 8 } & $\mathbf{\# 1 5}$ & $\# \mathbf{1 7}$ & $\mathbf{\# 2 0}$ & $\mathbf{\# 2 1}$ & $\mathbf{\# 2 2}$ & $\mathbf{\# 2 3}$ & \#226A \\
\hline 20 & 233 & 233 & 274 & 229 & 194 & 194 & 395 \\
\hline 100 & 233 & 233 & 274 & 229 & 194 & 194 & 395 \\
\hline 200 & 232 & 232 & 273 & 228 & 194 & 194 & 393 \\
\hline 300 & 226 & 226 & 267 & 223 & 189 & 189 & 384 \\
\hline 400 & 207 & 207 & 244 & 204 & 173 & 173 & 352 \\
\hline 500 & 164 & 164 & 194 & 162 & 137 & 137 & 279 \\
\hline 600 & 101 & 101 & 119 & 100 & 85 & 85 & 172 \\
\hline 700 & 46 & 46 & 54 & 45 & 39 & 39 & 78 \\
\hline 800 & 23 & 23 & 27 & 22 & 19 & 19 & 38 \\
\hline 900 & 19 & 19 & 22 & 18 & 16 & 16 & 32 \\
\hline 1000 & 19 & 19 & 22 & 18 & 16 & 16 & 32 \\
\hline
\end{tabular}




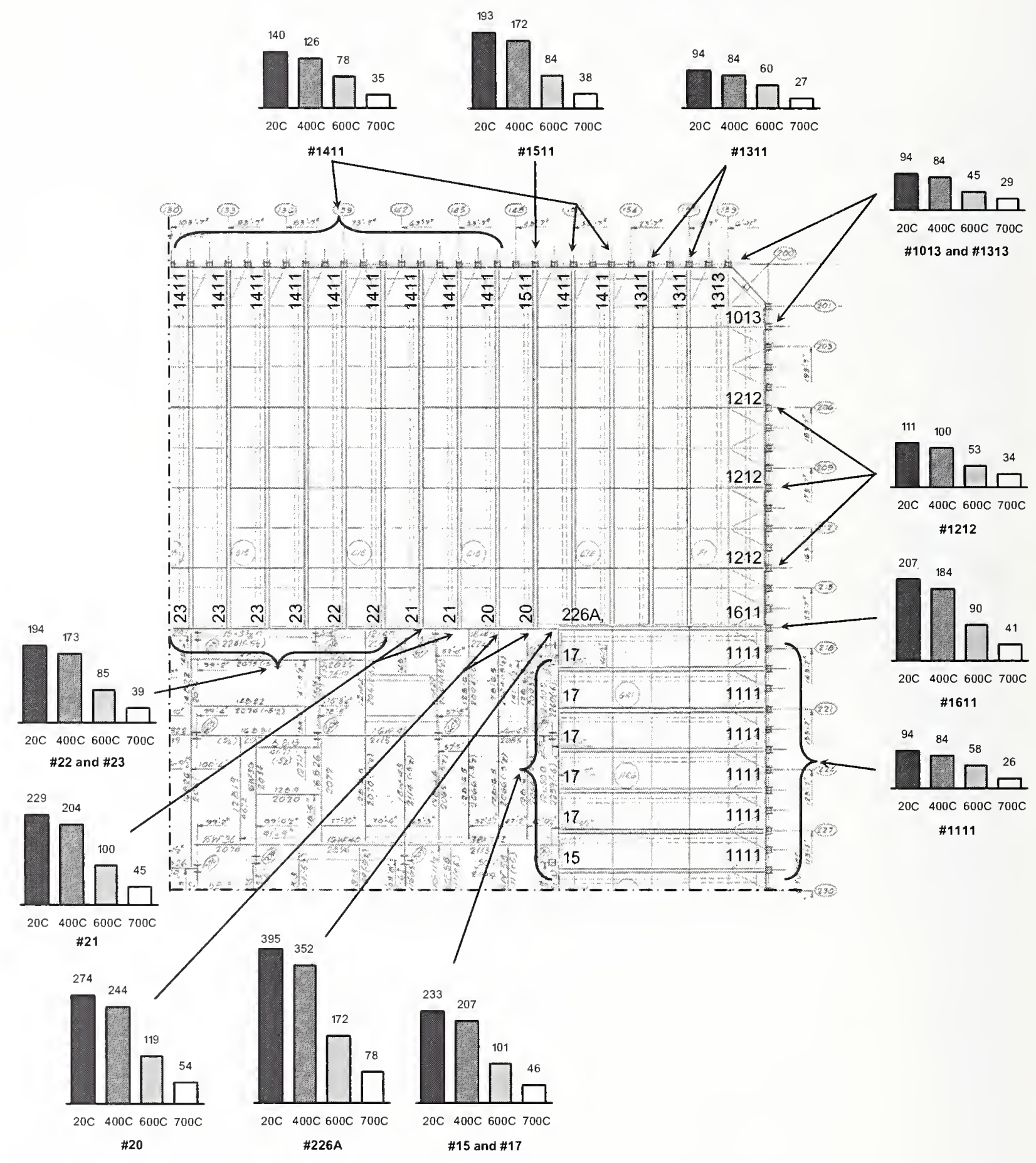

Original document reproduced with permission of The Port Authority of New York and New Jersey.

Figure 5-7. Truss seat capacity for vertical force 
Capacity of Exterior Truss Seats for Horizontal Tensile Force: The capacities of truss seats that followed failure sequence (A), as shown in Fig. 5-5, were governed by the fracture strength of the groove weld between the gusset plate and the spandrel. The capacities of truss seats that followed failure sequence (B) were governed by the tensile fracture strength of the gusset plate, and truss seats that followed failure sequence $(C)$ were governed by the fracture strength of the fillet weld between the gusset plate and the truss top chord. The capacities of truss seats that followed failure sequence (D) were governed by a combination of shear strength of bolts and tension developed in the gusset plate. The results of the exterior truss seat capacity calculations are summarized in Table 5-4 and Fig. 5-8. Note that the strength of the truss seat $\# 1013$ at $100{ }^{\circ} \mathrm{C}$ is higher than that at $20{ }^{\circ} \mathrm{C}$ by about 38 percent. For temperatures less than $100^{\circ} \mathrm{C}$. the capacity was controlled by the fillet weld strength, and for temperatures in excess of $100{ }^{\circ} \mathrm{C}$, the bolt reached the end of its travel in the elongated bolt hole, thus providing a stiffer load path and higher load capacity of the connection.

Capacity of Interior Truss Seats for Horizontal Tensile Force: Failure loads were computed for the failure modes described above, including shear failure of the bolted connection by bolt shear, bolt bearing, tear-out, block shear, and fracture of fillet weld connection between the truss seat and the channel beam. The results showed that the shear strength of the two bolts controlled the horizontal tensile strength of the truss seat connection for all seat details including $15,17,20,21,23$, and $226 \mathrm{~A}$. Table 5-5 and Fig. 5-8 summarize the capacities of interior truss seats for horizontal tensile force. As can be seen from this table, at temperature $500^{\circ} \mathrm{C}$, bolt shear capacity was reduced by half, and at $600{ }^{\circ} \mathrm{C}$ it was reduced to less than a quarter of the original capacity at room temperature.

Capacity of Exterior Truss Seats for Horizontal Compressive Force: Under compressive force, the gusset plate buckled before the bolts sheared off. Compression strength of the gusset plate governed the exterior truss seat capacity. The compressive strength of gusset plate is summarized in Table 5-6.

Capacity of Interior Truss Seats for Horizontal Compressive Force: Under compressive force, the truss came into contact with the channel beam before the bolt bore against the slotted hole. The interior truss seat did not fail under compressive force.

Capacity of Interior Truss Seats for Combined Vertical and Horizontal Force: A typical interaction relationship for the combined vertical and horizontal tensile force is shown in Fig. 5-9. 
Table 5-4. Exterior truss seat capacity for horizontal tensile force.

\begin{tabular}{|c|c|c|c|c|c|c|c|c|}
\hline \multirow[b]{3}{*}{$\begin{array}{l}\text { Temp. } \\
\left({ }^{\circ} \mathrm{C}\right)\end{array}$} & \multicolumn{8}{|c|}{ Connection Detail Capacity for Horizontal Tensile Force (kip) } \\
\hline & \#1013 & \#1111 & $\# 1212$ & \#1311 & \#1313 & \#1411 & \#1511 & \#1611 \\
\hline & $\begin{array}{l}\text { Fracture of } \\
\text { Fillet Weld/ } \\
\text { Shear Failure } \\
\text { of Bolts }\end{array}$ & $\begin{array}{l}\text { Fracture of } \\
\text { Gusset Plate }\end{array}$ & $\begin{array}{l}\text { Shear Failure } \\
\text { of Bolts }\end{array}$ & $\begin{array}{l}\text { Fracture of } \\
\text { Groove Weld }\end{array}$ & $\begin{array}{l}\text { Shear Failure } \\
\text { of Bolts }\end{array}$ & $\begin{array}{l}\text { Fracture of } \\
\text { Groove Weld }\end{array}$ & $\begin{array}{l}\text { Fracture of } \\
\text { Groove Weld }\end{array}$ & $\begin{array}{l}\text { Fracture of } \\
\text { Groove Weld }\end{array}$ \\
\hline 20 & 100 & 104 & 182 & 126 & 182 & 126 & 126 & 126 \\
\hline 100 & 138 & 104 & 181 & 126 & 181 & 126 & 126 & 126 \\
\hline 200 & 135 & 103 & 180 & 126 & 180 & 126 & 126 & 126 \\
\hline 300 & 130 & 101 & 174 & 123 & 174 & 123 & 123 & 123 \\
\hline 400 & 115 & 93 & 156 & 113 & 156 & 113 & 113 & 113 \\
\hline 500 & 84 & 75 & 117 & 91 & 117 & 91 & 91 & 91 \\
\hline 600 & 42 & 49 & 67 & 58 & 67 & 58 & 58 & 58 \\
\hline 700 & 20 & 25 & 32 & 30 & 32 & 30 & 30 & 30 \\
\hline 800 & 14 & 16 & 19 & 18 & 19 & 18 & 18 & 18 \\
\hline 900 & 13 & 14 & 17 & 16 & 17 & 16 & 16 & 16 \\
\hline 1000 & 13 & 14 & 17 & 16 & 17 & 16 & 16 & 16 \\
\hline
\end{tabular}

Table 5-5. Interior truss seat capacity against horizontal tensile force.

\begin{tabular}{|c|c|}
\hline \multirow{2}{*}{$\begin{array}{c}\text { Temp. } \\
\left({ }^{\circ} \mathbf{C}\right)\end{array}$} & \begin{tabular}{c} 
Capacity (kip) \\
\cline { 2 - 2 }
\end{tabular} \\
\hline 20 & 44 \\
\hline 100 & 44 \\
\hline 200 & 44 \\
\hline 300 & 42 \\
\hline 400 & 34 \\
\hline 500 & 21 \\
\hline 600 & 9 \\
\hline 700 & 4 \\
\hline 800 & 4 \\
\hline 900 & 4 \\
\hline 1000 & 4 \\
\hline
\end{tabular}




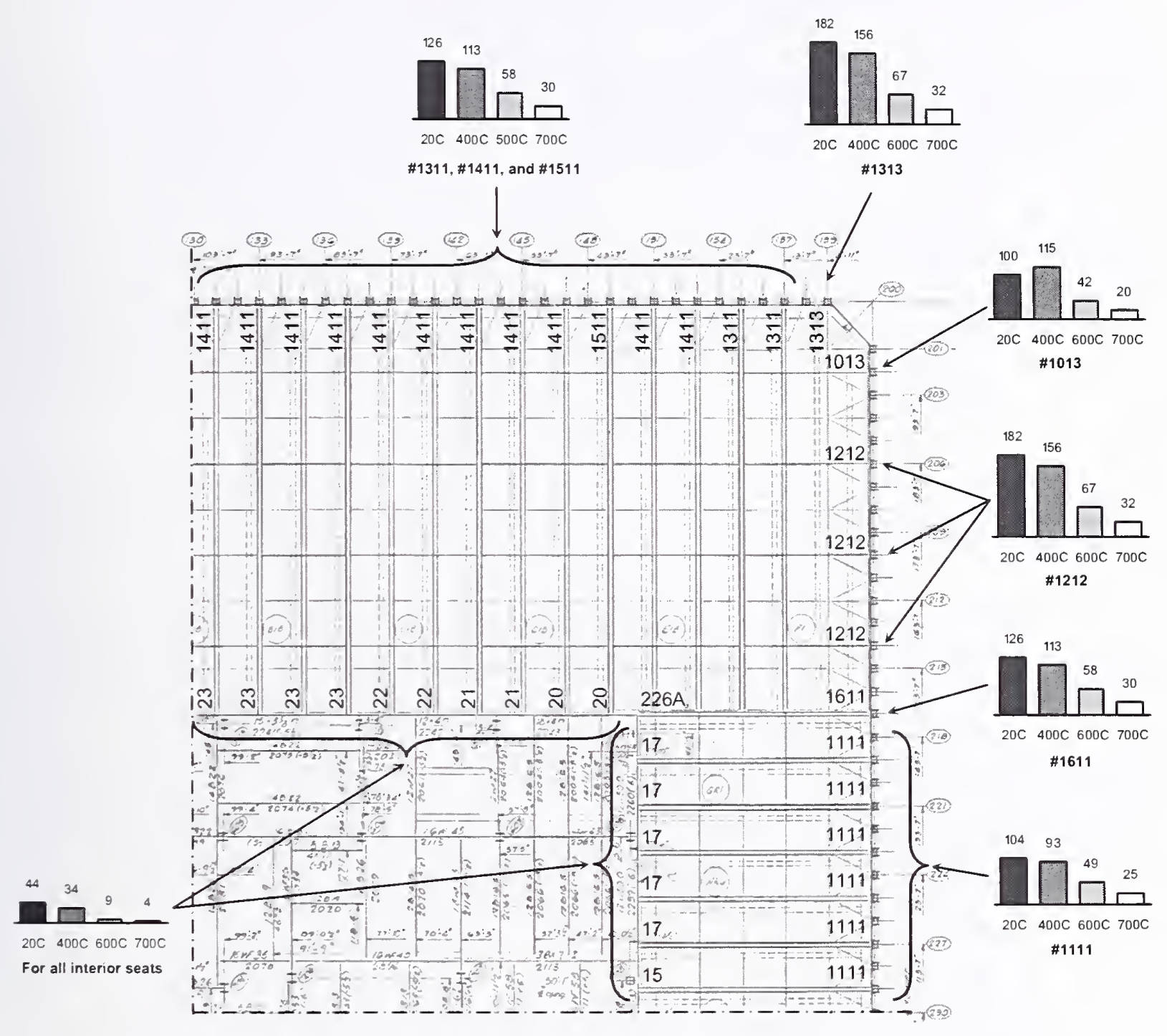

Original document reproduced with permission of The Port Authority of New York and New Jersey.

Figure 5-8. Truss seat capacity for horizontal tensile force. 
Table 5-6. Compression strength of gusset plate.

\begin{tabular}{|c|c|c|c|c|c|c|c|c|}
\hline \multirow{2}{*}{$\begin{array}{c}\text { Temp. } \\
\left({ }^{\circ} \mathbf{C}\right)\end{array}$} & \multicolumn{7}{|c|}{ Compression Strength of Gusset Plate (kip) } \\
\hline 20 & 74 & 68 & 98 & 90 & 98 & 90 & 90 & 90 \\
\hline 100 & 71 & 66 & 95 & 86 & 95 & 86 & 86 & 86 \\
\hline 200 & 68 & 63 & 90 & 82 & 90 & 82 & 82 & 82 \\
\hline 300 & 65 & 60 & 86 & 78 & 86 & 78 & 78 & 78 \\
\hline 400 & 60 & 55 & 79 & 72 & 79 & 72 & 72 & 72 \\
\hline 500 & 46 & 42 & 60 & 55 & 60 & 55 & 55 & 55 \\
\hline 600 & 19 & 17 & 25 & 22 & 25 & 22 & 22 & 22 \\
\hline 700 & 6 & 5 & 8 & 7 & 8 & 7 & 7 & 7 \\
\hline 800 & 6 & 5 & 7 & 6 & 7 & 6 & 6 & 6 \\
\hline 900 & 6 & 5 & 7 & 6 & 7 & 6 & 6 & 6 \\
\hline 1000 & 6 & 5 & 7 & 6 & 7 & 6 & 6 & 6 \\
\hline
\end{tabular}

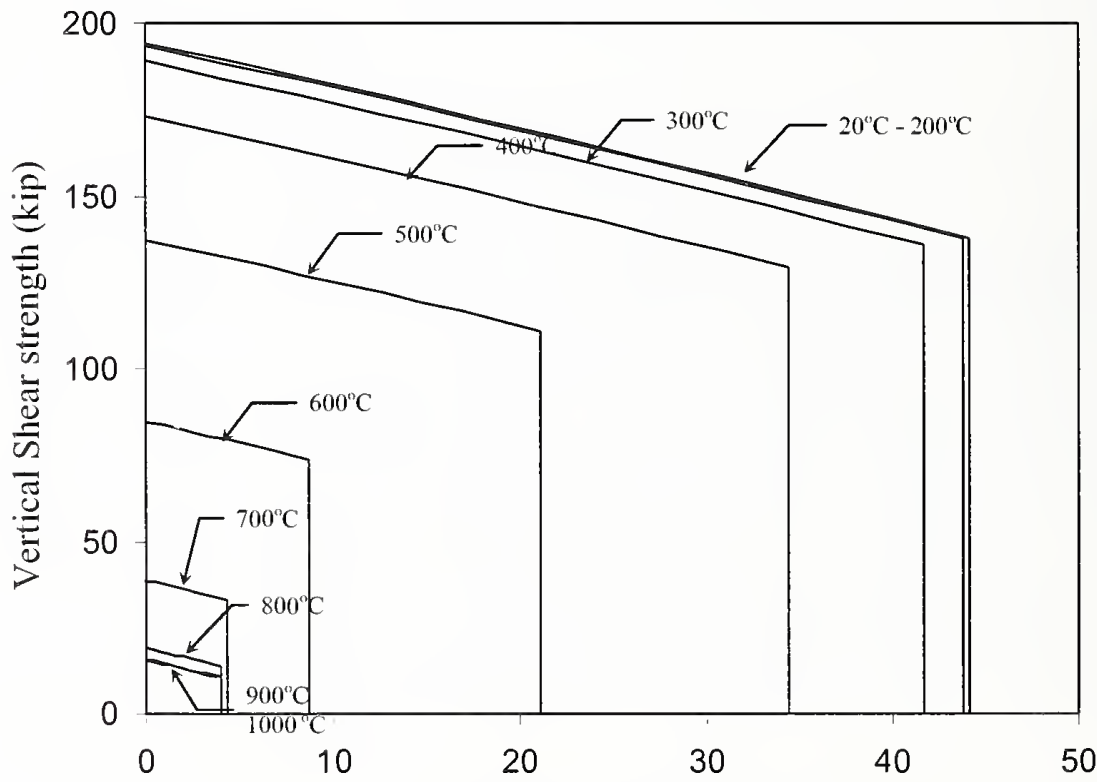

Horizontal tensile strength (kip)

Figure 5-9. Capacity of interior truss seat against vertical and horizontal force (for Detail 22). 


\subsubsection{Modeling Failure by Break Elements}

In this section, the finite element models developed to capture failure modes of the exterior and interior truss seats, studs on strap anchors, and studs on spandrels are described. These models were developed for incorporation in the floor truss analysis to capture the connection failure modes, failure loads as a function of temperature, and failure sequences.

The models of these connections simulated the loss of connection resistance after their failure either from exceeding the connection force capacity or from exceeding the allowable deformation (for example, truss walking off the seat). The connection capacity was also temperature-dependent. The finite element modeling assumptions are as follows:

A control element (COMBIN37), a unidirectional linear spring element with the capability of turning on and off during an analysis, was used for modeling connection failure. The element is referred to as "break element" in this report. The element is a part of the structure that connects two "active" nodes in the "on" mode and disconnects them in the "off" mode, depending on the relative displacement of two "control" nodes. The break element is defined as follows:

$$
B_{m}\left[\left(i, j, d o f_{i j}\right) ;\left(k, l, d o f_{k l}\right) ;\left(K, \Delta_{0}\right)\right]
$$

where $m$ is the break element number, $i$ and $j$ are the active nodes, $d o f_{i j}$ is the degree of freedom for the active nodes, $k$ and $l$ are the control nodes, dof $f_{k l}$ is the degree of freedom for the control nodes, $K$ is the elastic stiffness of the break element, and $\Delta_{0}$ is the differential displacement limit of the control nodes.

To make the connection capacity temperature-dependent, a beam element with temperature-dependent coefficient of thermal expansion was added to the break element. This was done by using the deformation of a beam element from thermal expansion to control the status (on/off) of the break element. Figure 5-10 illustrates the basic mathematical model of the connection using break elements.

Multiple connection failure modes require use of different break elements that are connected together in a logical manner. For example, to model independent failure modes, that is, one failure mode that does not cause other failures, break elements are connected in parallel so that when one break element turns "off", the other break elements remain "on". For dependent failure modes, break elements are connected in series so that when one break element turns "off', all elements turn "off". 


\section{Basic mathematical model:}

- Let node $l$ and $i$ have same displacement.

- In this example, control nodes $k$ and $l$ relative displacement has the form:

$$
U_{k}-U_{l}=\frac{P}{K}+\alpha L \Delta T
$$

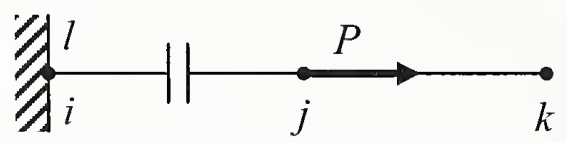

Break element Beam element

- Stiffness, $K$

- Break element status is by definition

$$
\begin{aligned}
& U_{k}-U_{l} \leq \Delta_{0}, \text { status: on } \\
& U_{k}-U_{l}>\Delta_{0}, \text { status : off }
\end{aligned}
$$

- Define break element to turn off when capacity, $P_{u}$, has been reached

$$
\Delta_{0}=\frac{P_{u}}{K}+\alpha L \Delta T
$$

- Element capacity at room temperature is given as

$$
P_{u, r m}=K \Delta_{0}
$$

- Hence for a given $P_{u}$ and $\Delta T$ relationship, the required thermal expansion to turn the break element off can be found by

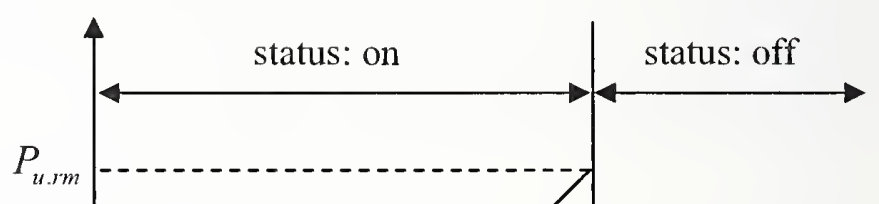

$$
\alpha=\frac{P_{u, r m}-P_{u}}{K L \Delta T}
$$

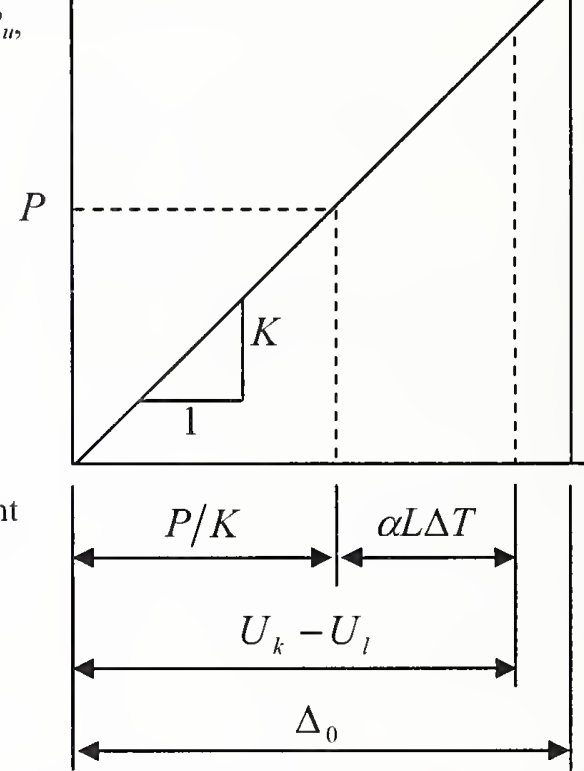

Figure 5-10. Basic mathematical model of connection failure. 


\subsubsection{Summary of Failure Modes and Finite Element Models of Truss Seats}

The failure modes of the interior truss seats include (1) truss walking off the seat, (2) exceeding the vertical temperature-dependent shear capacity of the fillet welds between the seat vertical plate stiffeners and channel beam, and (3) exceeding temperature-dependent shear capacity of bolts when they bear against the slotted holes. These failure modes were modeled by using four break elements and two beam elements as shown in Fig. 5-11. The interior seat model was tested in ANSYS, and results are shown in Figs. 5-12 and 5-13. These figures depict the relationship between the horizontal and vertical seat forces and the horizontal truss travel distance.

Figure 5-12 shows the results from analysis where the truss seat was subjected to a constant vertical load and horizontal displacement increments at $500{ }^{\circ} \mathrm{C}$. When a truss seat is subjected to a large horizontal tension and small vertical shear, the failure is by two bolts shearing off followed by the truss walking off the seat, as shown in Fig. 5-12. The shear strength of the bolts controls the truss seat horizontal tension capacity. The bolt shear by itself does not cause the truss to lose its vertical support, but it is the prerequisite for the truss walking off the seat. The travel distance for a truss to walk off a truss seat is $4 \mathrm{in}$. for an interior seat and $45 / 8 \mathrm{in}$. for an exterior seat.

Figure 5-13 shows the results from analysis where the truss seat was subjected to a constant horizontal load and vertical displacement increments at $500{ }^{\circ} \mathrm{C}$. When a truss seat is subjected to a large vertical shear and small horizontal tension, the failure is by the fracture of fillet welds between the vertical plate stiffeners and the channel beam at an interior seat and between the stand-off plates and the spandrel at an exterior seat, resulting in loss of both vertical and horizontal support, as shown in Fig. 5-13.

The finite element models of the exterior truss seats were similar to those for the interior truss seats, except for an additional beam element and a break element to model failure of the gusset plate, as shown in Fig. 5-14. 


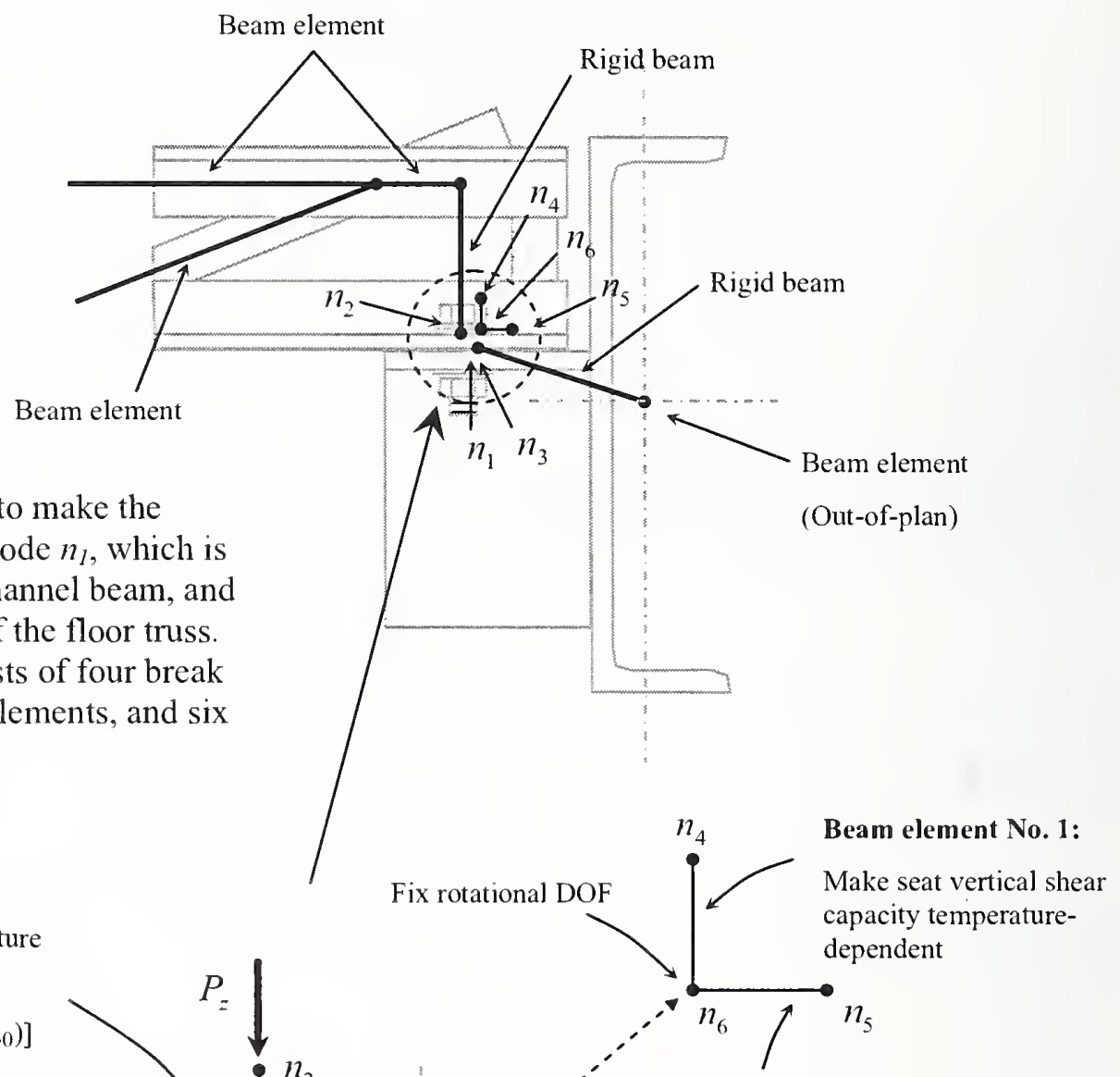

Seat model was used to make the connection between node $n_{l}$, which is part of the seat and channel beam, and node $n_{2}$, which part of the floor truss. The seat model consists of four break elements, two beam elements, and six nodes.

Break element No. 1: Capture walk-off support

$\mathrm{B}_{\mathrm{I}}\left[(2,3, \mathrm{UZ}) ;(2,1, \mathrm{UY}) ;\left(\mathrm{K}, \Delta_{0}\right)\right]$

Break element No. 2:

Capture seat vertical shear capacity

$\mathrm{B}_{2}\left[(1,3, \mathrm{UZ}) ;(4,2, \mathrm{UZ}) ;\left(\mathrm{K}, \Delta_{0}\right)\right]$

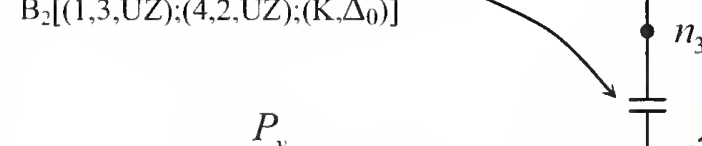

Beam element No. 2:

Make bolt shear capacity temperature-dependent

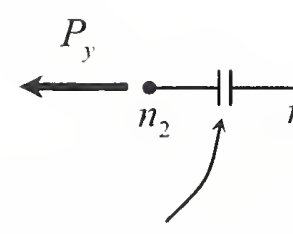

Break element No. 3:

Capture loss of horizontal resistance if seat fails vertically

$\mathrm{B}_{3}\left[(2,3, \mathrm{UY}) ;(4,2, \mathrm{UZ}) ;\left(\mathrm{K}, \Delta_{0}\right)\right]$

Break element No. 4:

Capture bolt shear capacity

Constraint equations

Coupling displacement DOF of node 1 and 6

$\mathrm{B}_{4}\left[(1,3, \mathrm{UY}) ;(2,5, \mathrm{UY}) ;\left(\mathrm{K}, \Delta_{0}\right)\right]$

Figure 5-11. Representation of interior truss seat by break elements. 


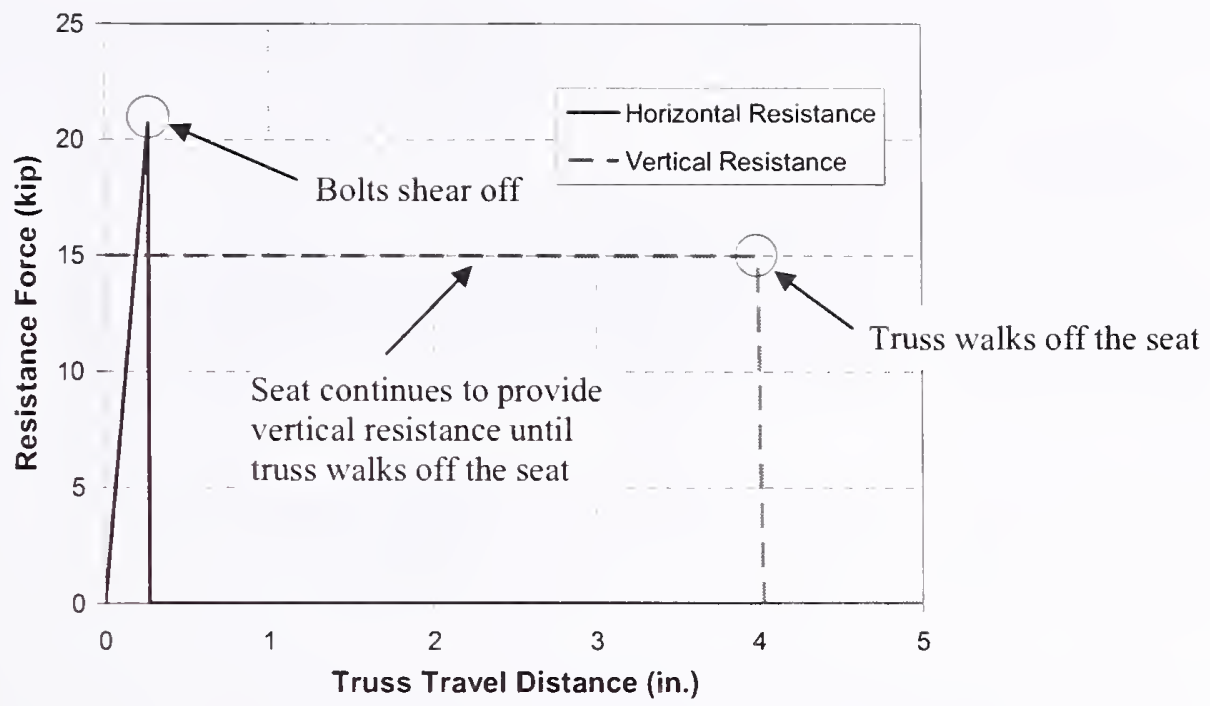

Figure 5-12. Results of interior truss seat model capturing failure from truss walking off the seat at $500^{\circ} \mathrm{C}$.

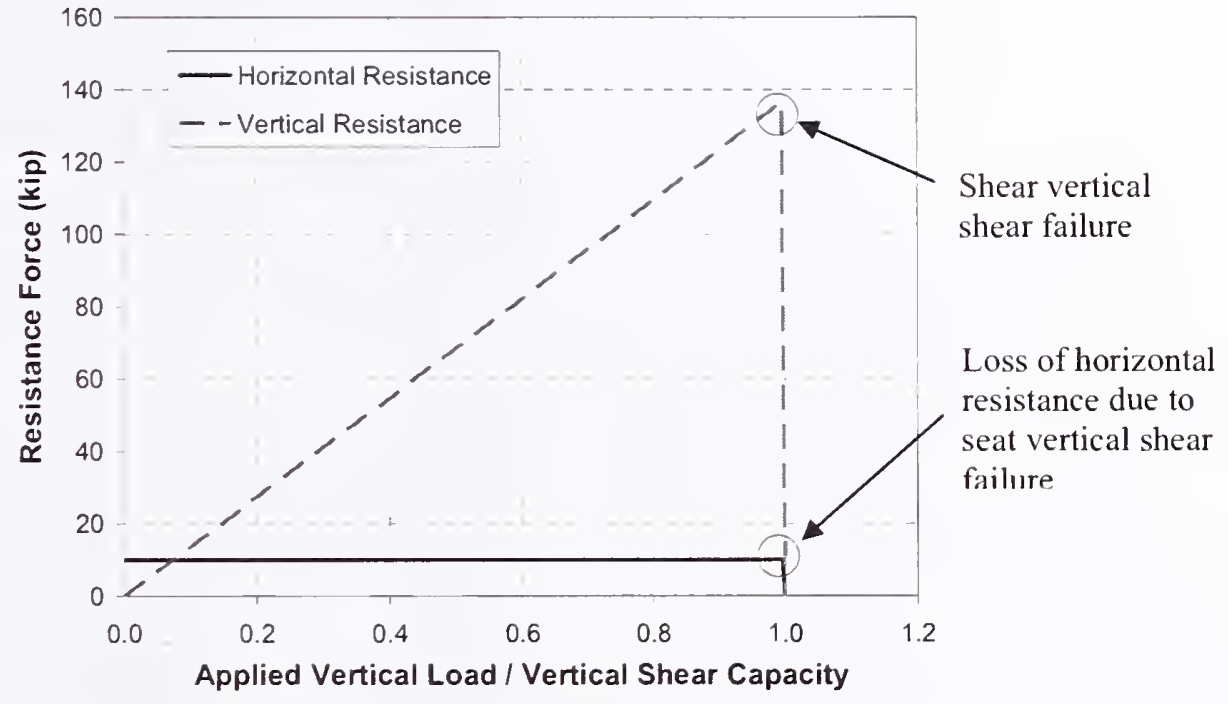

Figure 5-13. Results of interior truss seat model capturing failure from exceeding the vertical shear capacity at $500^{\circ} \mathrm{C}$. 


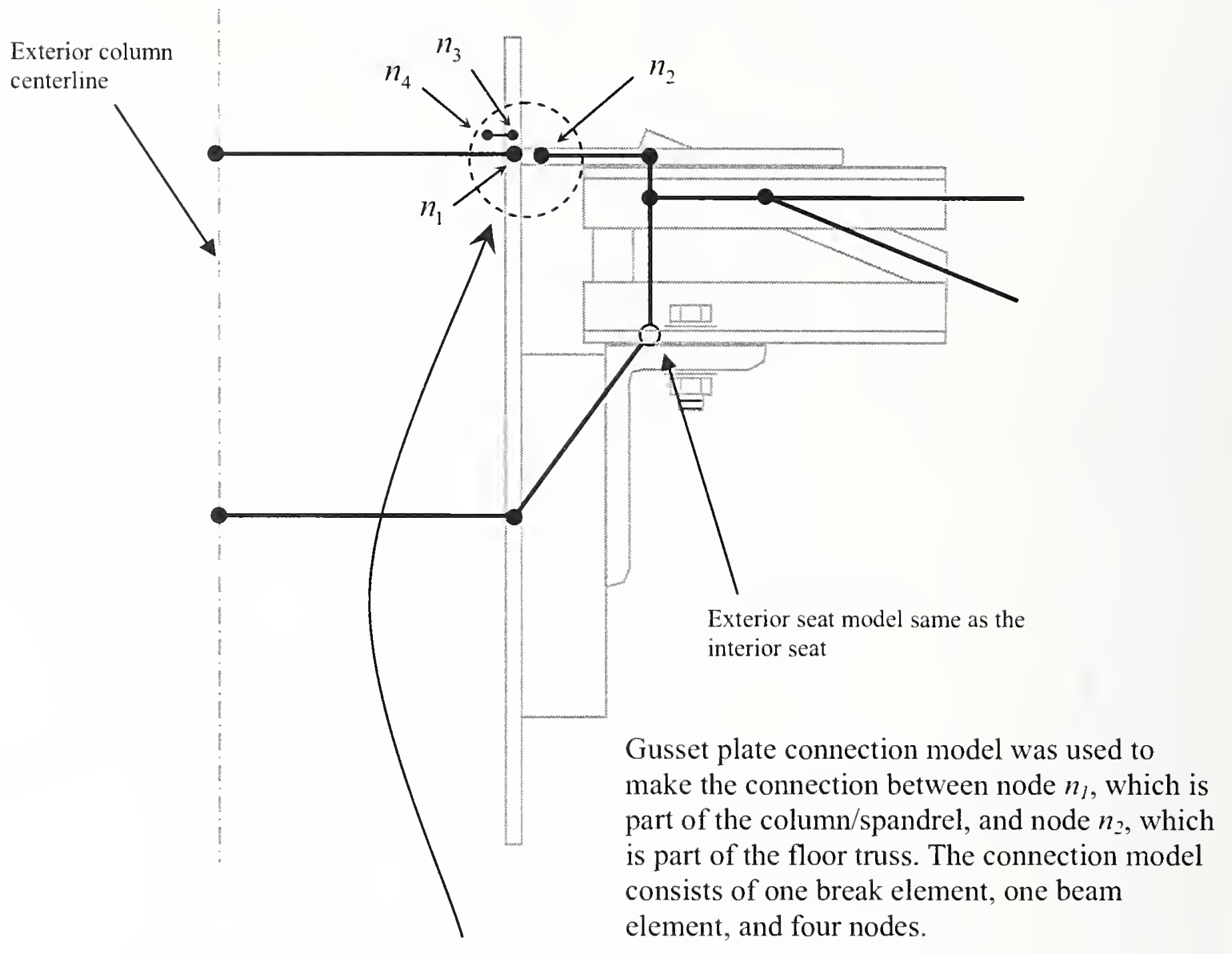

Beam element:

Make gusset plate tensile strength temperature-dependent

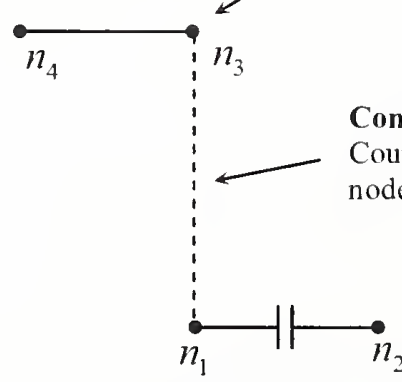

Fix rotational DOF

Break element:

Capture failure of gusset plate under tensile force

$\mathrm{B}_{\mathrm{I}}\left[(1,2, \mathrm{UY}) ;(4,2, \mathrm{UY}) ;\left(\mathrm{K}, \Delta_{0}\right)\right]$

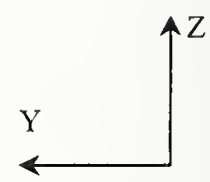

Coordinate system

Figure 5-14. Representation of exterior truss seat by break elements. 


\subsubsection{Summary of Failure Modes and Finite Element Models of the Stud on Strap Anchor and Spandrel Stud}

Stud on Strap Anchor: There were four 5/8 in. $\times 2.5$ in. studs on each strap anchor as shown in

Fig. 5-15. Calculations were carried out to compute the lateral shear capacity of these stud shear connectors using the procedure in Building Code Requirements for Structural Concrete (ACI 318-02) at different temperatures. The following failure modes were considered in the calculation: steel shear failure, concrete pryout, and concrete breakout. The capacity of the stud close to the edge of the slab was governed by concrete breakout at all temperatures, while those of the other three studs located farther from the concrete edge were governed by concrete pryout at temperatures below $700{ }^{\circ} \mathrm{C}$ and steel shear failure at temperature equal to and above $700{ }^{\circ} \mathrm{C}$.

Spandrel Stud: There was one 3/4 in. $\times 6$ in. spandrel stud located between two adjacent exterior columns as shown in Fig. 5-15. Calculations were carried out to compute the shear capacity and tensile capacity of the spandrel stud at different temperatures. For shear capacity, the following failure modes were considered: steel shear failure, concrete pryout, and concrete breakout. For tensile capacity, the following failure modes were considered: steel tensile failure, concrete breakout, pullout strength, and concrete sideface blowout. The shear and tensile capacities of the spandrel stud were both governed by concrete breakout strength.

Finite element models of studs on strap anchors and studs on spandrels were developed using break elements. The stud model included 8 break elements and 4 beam elements, as shown in Fig. 5-16.

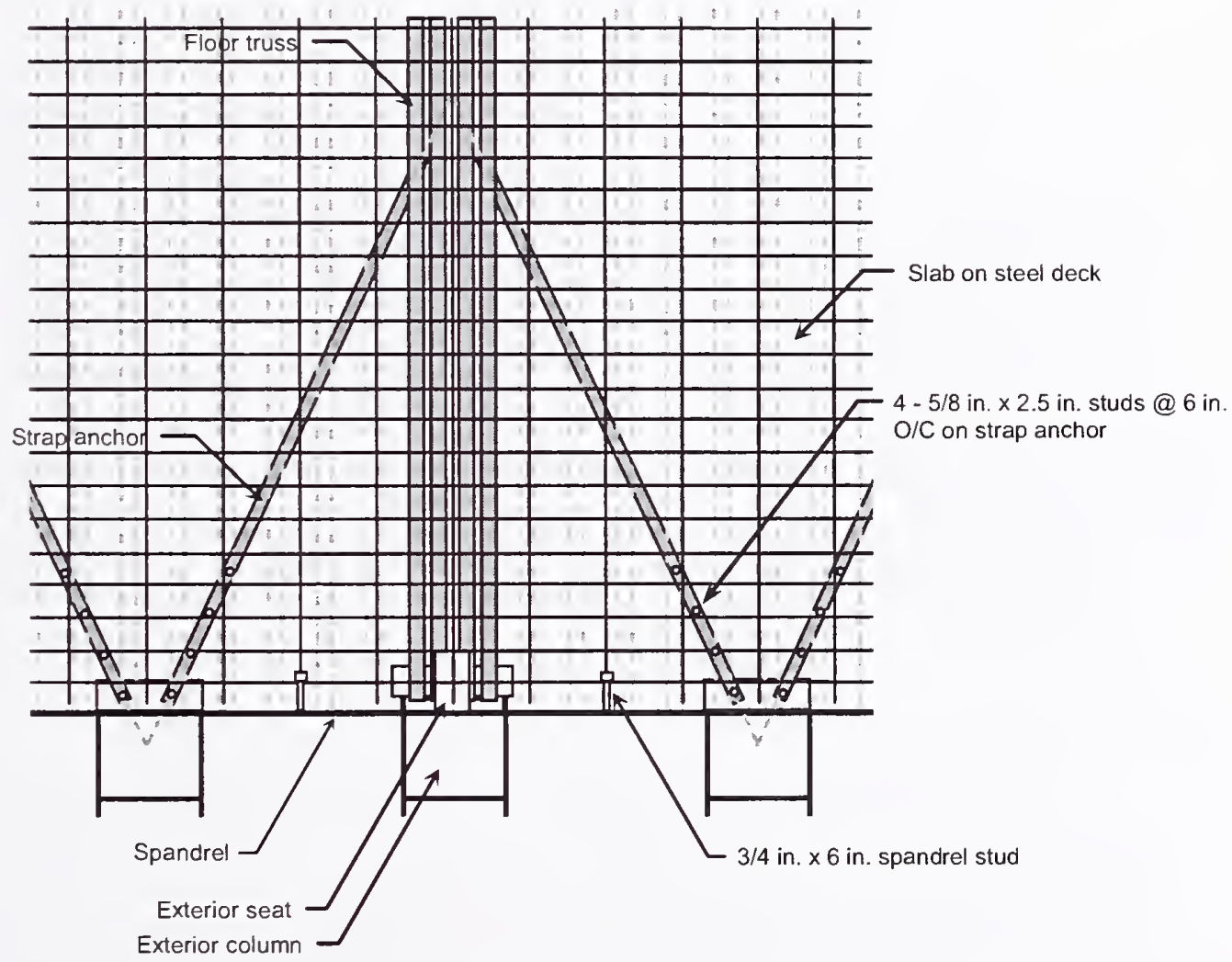

Figure 5-15. Location of stud on strap anchor and spandrel stud. 
Four beam elements were used to make the stud shear connector temperature-dependent

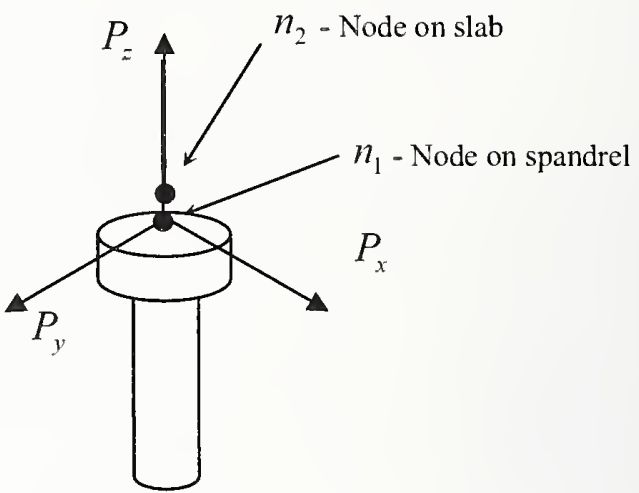

Break element No. 4:
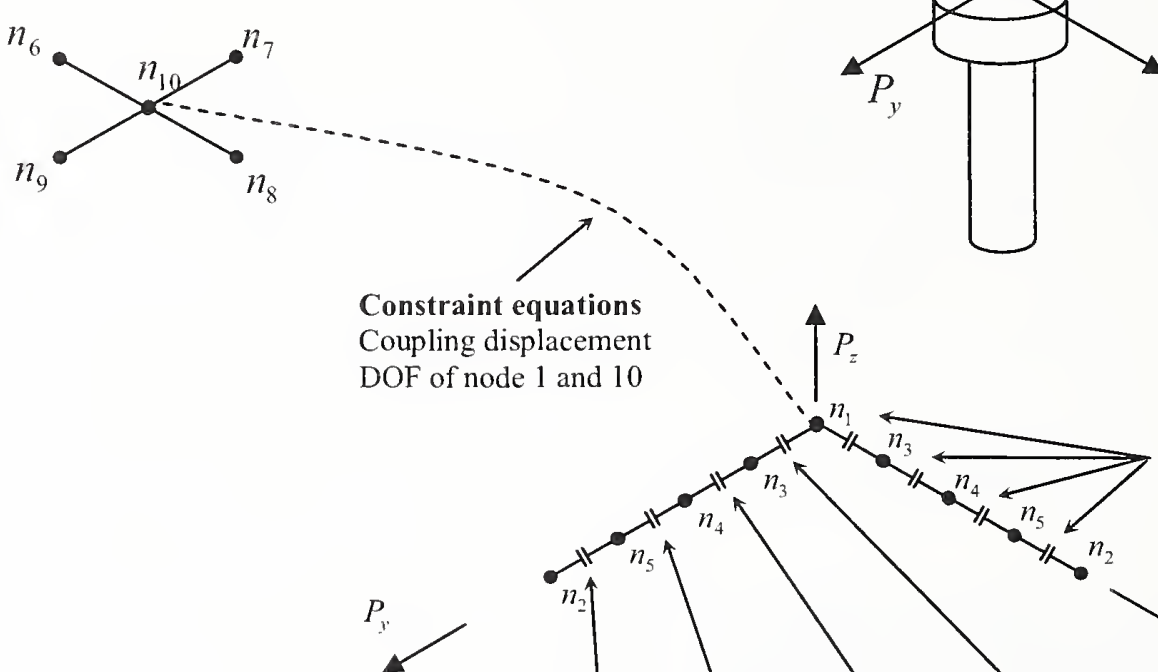

Capture loss of lateral resistance in the $\mathrm{Y}$ direction if failure occurs in the negative $\mathrm{X}$ direction

$\mathrm{B}_{4}\left[(2,5, \mathrm{UY}) ;(8,2, \mathrm{UX}) ;\left(\mathrm{K}, \Delta_{0}\right)\right]$

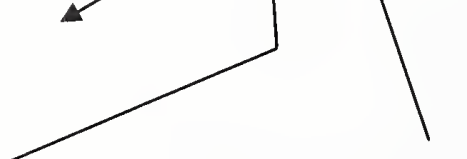

Break element No. 3:

Capture loss of lateral resistance in the $\mathrm{Y}$ direction if failure occurs in the positive $\mathrm{X}$ direction

$\mathrm{B}_{3}\left[(4,5, \mathrm{UY}) ;(2,6, \mathrm{UX}) ;\left(\mathrm{K}, \Delta_{0}\right)\right]$
The purpose of break elements No. 5-8 is similar to break elements No. $1-4$
Break element No. 1:

Capture lateral shear failure in the positive $\mathrm{Y}$ direction

\section{$\mathrm{B}_{1}\left[(1,3, \mathrm{UY}) ;(2,7, \mathrm{UY}) ;\left(\mathrm{K}, \Delta_{0}\right)\right]$}

Break element No. 2:

Capture lateral shear failure in the negative $\mathrm{Y}$ direction

$\mathrm{B}_{2}\left[(3,4, \mathrm{UY}) ;(9,2, \mathrm{UY}) ;\left(\mathrm{K}, \Delta_{0}\right)\right]$

Figure 5-16. Representation of stud shear connector by break elements. 


\subsection{KNUCKLE ANALYSIS}

The objective of this analysis was to predict the capacity of the knuckle subjected to loads between the truss and the concrete slab and to develop a finite element model of the knuckle to be included in the full floor subsystem model.

\subsubsection{Description of Knuckle}

The "knuckle" was formed by the extension of the truss web diagonals into the concrete slab. It provides for composite action of the steel truss and concrete slab (see Fig. 2-1) as it allows shear transfer in both the transverse and longitudinal directions.

\subsubsection{Failure Modes of Knuckle}

Failure modes of knuckles are:

- Horizontal shear failure due to crack or crushing of concrete

- Pullout failure due to vertical tension

\subsubsection{Knuckle Shear Tests}

Two sets of experiments were performed in 1967 at Laclede Steel Company in Saint Louis, Missouri, to determine the transverse and longitudinal shear capacities of the knuckle.

The longitudinal shear test consisted of double knuckles cast into two concrete blocks as shown in Fig. 5-17. The test specification showed corner angles confining the concrete blocks and no reinforcement in concrete. However, the test pictures showed reinforcement in both directions for each concrete block, with the corner angles dismantled. The test specification called for concrete density of $152 \mathrm{pcf}$, which corresponds to a normal weight concrete. The slab in the office areas was made from lightweight concrete. Three specimens were tested: two specimens after 28-day curing and one after 96-day curing. The average compressive strength of two 28-day cylinders tested was 4,290 psi. A third sample, tested after 96 days, showed a strength of 2,850 psi. No reason is known for the compressive strength in the third test being less than the other two tests. The test specification did not idcntify the weld size connecting the inner ends of the two knuckles to two channels. However, the primary failure mode observed in the third test was weld failure. Weld failure was not identified as the failure mode of the knuckle for the other two tests. The results of the longitudinal shear strengths of the knuckle based on the first two tests were approximately $28.3 \mathrm{kip}$ per knuckle. The strength of in-place, mature, lightweight concrete is $4,100 \mathrm{psi}$, and the 28 -day corrected average strength of the normal weight concrcte used in the test was 3,707 psi. After adjusting for the strength of in-place, mature, lightwcight concrete by multiplying by the ratio of 4,100 psi to 3,707 psi, the longitudinal shear capacity of the knuckle in the WTC floor systems was determined at approximately 31 kip per knuckle.

The transverse shear test consisted of double knuckles cast into two reinforced concrete blocks that were confined at the corners by angles as shown in Fig. 5-18. The concrete density was $110 \mathrm{pcf}$, corresponding to a lightweight concrete. Two tests were conducted, seven and 27 days after casting concrete. The concrete compressive strengths reported for seven-day and 27 -day cylinder tests were $1,330 \mathrm{psi}$, and 2,600 psi, respectively. The inner ends of the two knuckles were connected through channels to a \#11 rebar, and the rebar was loaded until the concrete failed. The tests were conducted at concrete ages of six and 27 days. The primary failure mode observed was concrcte shear failure. The pictures from the tests showed formation of a shear crack in one of the concrete blocks. The transverse 
shear capacity of the knuckle, as the average of the two reported tests, was 16.9 kip per knuckle. For the WTC floor system, the knuckle transverse shear capacity was determined by adjusting the strength of inplace, mature, lightweight concrete of 4,100 psi relative to the average strength of the lightweight concrete used in the test of 1,965 psi. Multiplying by the ratio of 4,100 to 1,965 psi, the transverse shear capacity of the knuckle in the WTC floor system was determined at approximately 35 kip per knuckle.
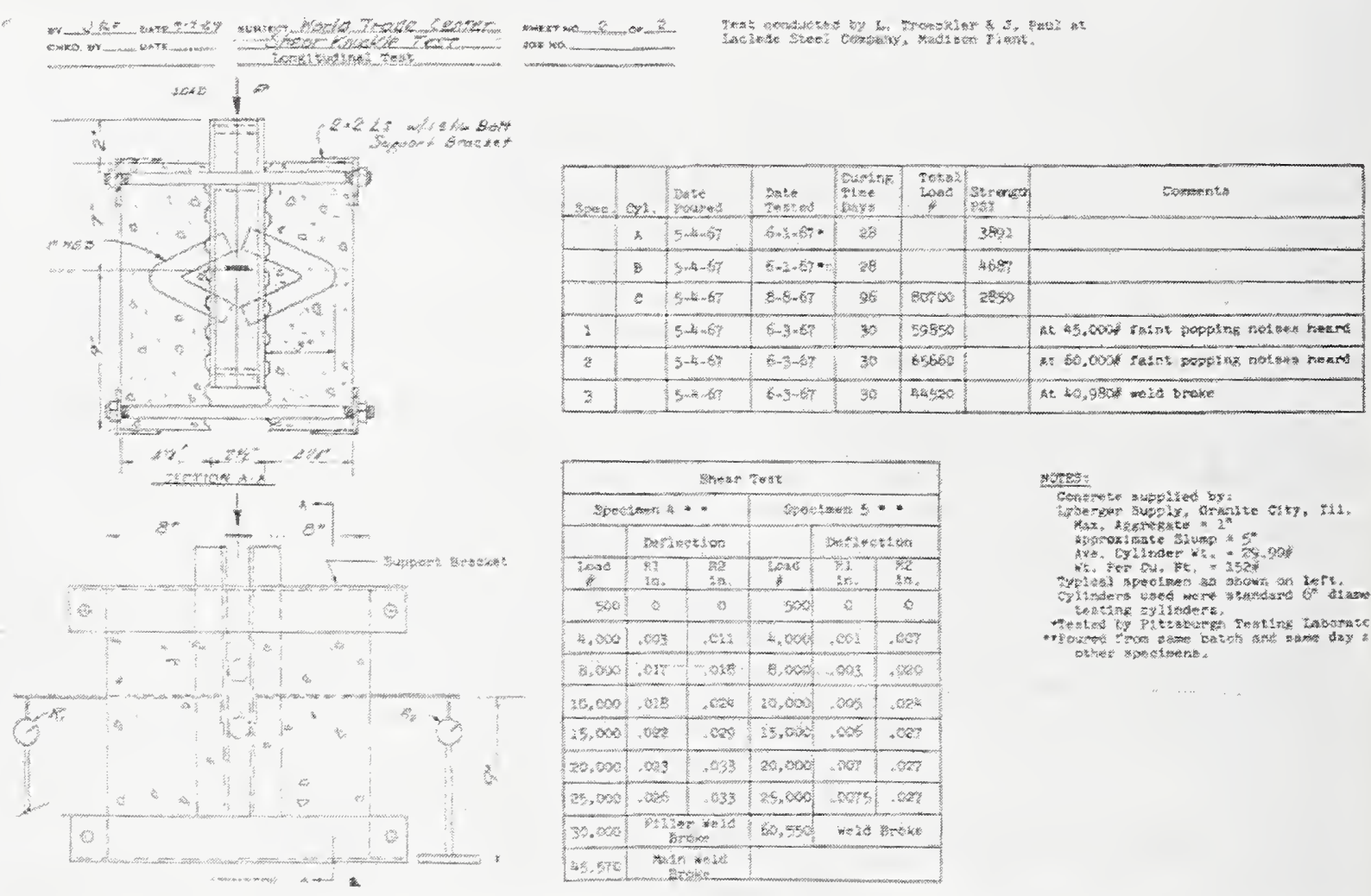

\begin{tabular}{|c|c|c|c|c|c|}
\hline \multicolumn{6}{|c|}{ 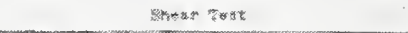 } \\
\hline \multicolumn{3}{|c|}{ 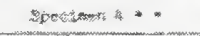 } & \multicolumn{3}{|c|}{ 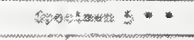 } \\
\hline & \multicolumn{2}{|c|}{ 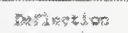 } & & \multicolumn{2}{|c|}{ 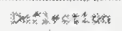 } \\
\hline inese & 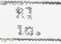 & $\begin{array}{ll}282 \\
23\end{array}$ & Bene & 83 & $\begin{array}{l}y_{2} \\
3 x \\
30\end{array}$ \\
\hline$\leqslant \neq 0$ & 民 & 8 & $\sin x$ & 2 & $\$$ \\
\hline$k_{1}, 0 \times 2$ & .623 & eis & 4,000 & .002 &. $\operatorname{ees}$ \\
\hline$x+\cos c$ & .05 & $-3 x$ & $5,003 x^{2}$ & $\operatorname{sos} 3$ & .86 \\
\hline$x_{0}, 620$ & 028 & . & $a, \infty 2$ & $\cos$ & $\sin$ \\
\hline 23,000$)$ & vise & 6 & $25,502 \%$ & $=006$ &.$+\infty$ \\
\hline$x 2,0021$ & .023 & .435 & $25,20 \times 2$ & Sag? & $.6 \%$ \\
\hline $2 x, 500$ & 20 & .033 & $2 \varepsilon_{m} \times \infty$ & 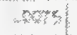 & .28 \\
\hline 32.0025 & \multicolumn{2}{|c|}{ 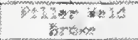 } & $2 \alpha, 5,0$ & \multicolumn{2}{|c|}{ wezts } \\
\hline $3+5.78$ & \multicolumn{2}{|c|}{$* 12 * k^{2}$} & & & \\
\hline
\end{tabular}

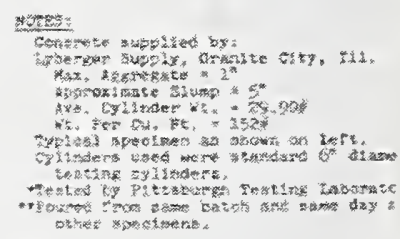

Information provided by Laclede Steel

Figure 5-17. Longitudinal shear test of a knuckle. 


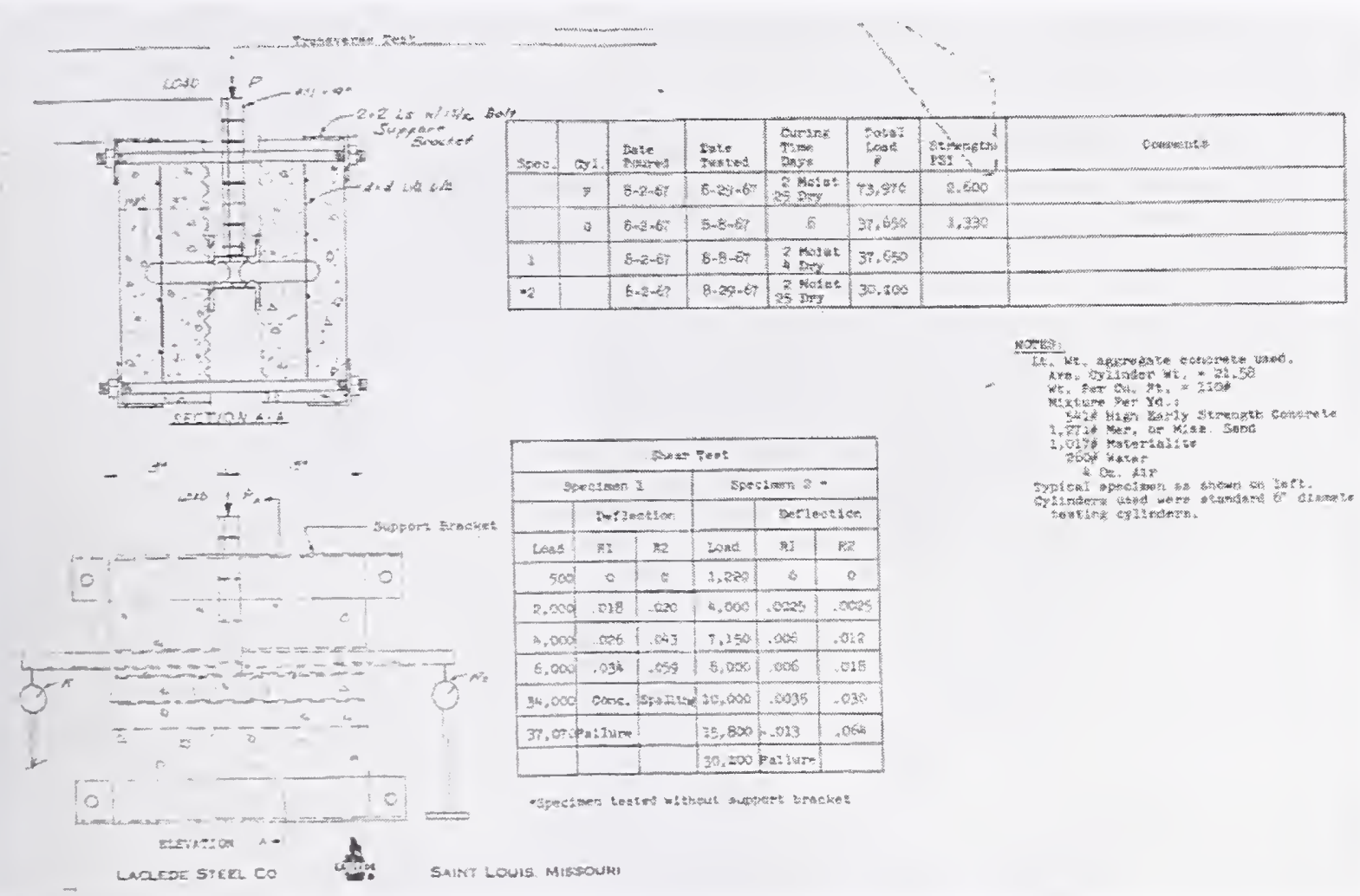

Information provided by Laclede Steel

Figure 5-18. Transverse shear test of a knuckle.

\subsubsection{Finite Element Model for Knuckle Test}

The LS-DYNA computer program was used for the analysis. Finite element models, shown in Fig. 5-19, represent one quarter of the knuckle test specimens. The knuckle and channel members in the test set-up were modeled with solid elements with steel material properties. Concrete was also modeled with solid elements with the Pseudo Tensor material model described in Chapter 3. Two different assumptions were made about the interface condition between the concrete and the steel, namely, fully bonded or frictionless. Boundary conditions are also shown in Fig. 5-19. Displacement was imposed in a form of a ramp to the angles.

\subsubsection{Material Properties for Knuckle Analysis}

The concrete strengths used in the finite element model were 4,100 psi for the longitudinal shear test and 2,500 psi for the transverse shear test. In addition, 0.47 percent steel reinforcement, representing the welded wire reinforcement of the slab, was added in a distributed way to the concrete.

Angles were modeled with Material 21 (see Chapter 3 for description). 


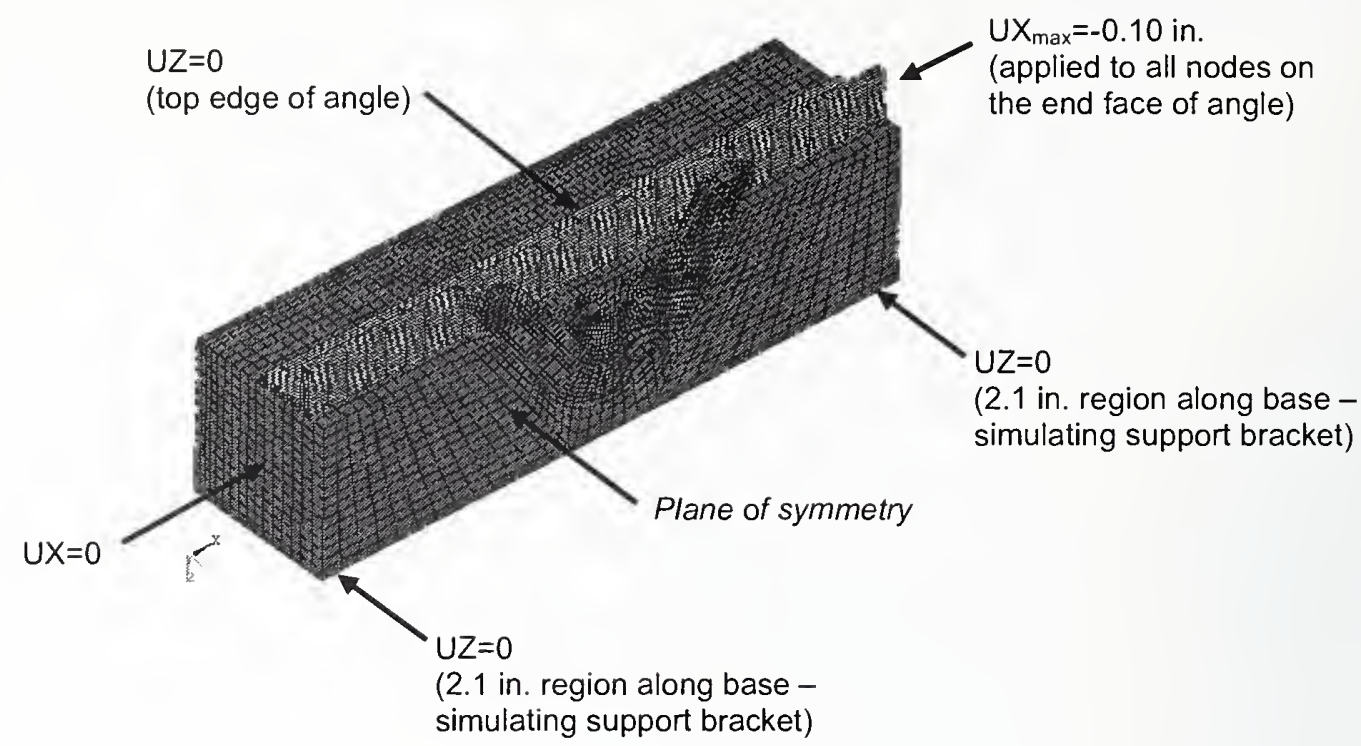

(a) Longitudinal sheat test model

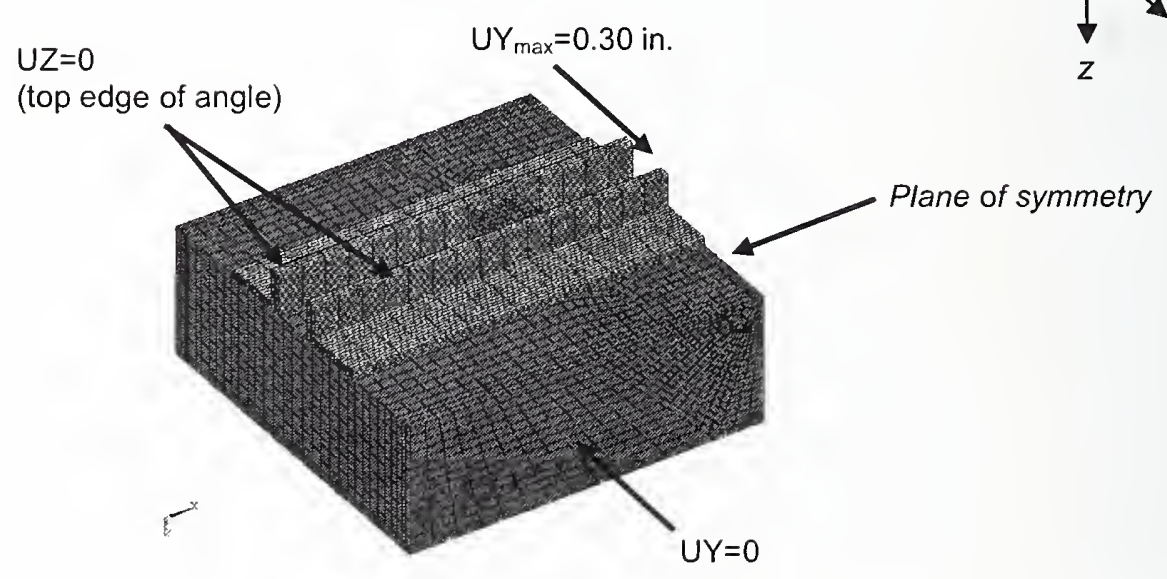

(b) Transverse sheat test model

Figure 5-19. Finite element models of knuckle shear tests.

\subsubsection{Results from Knuckle Analysis}

\section{Finite Element Analysis (FEA) of Tests}

The results of FEA of the tests are shown in Figs. 5-20 through 5-23. The results showed significant dependence on the interface characteristics between the steel and the concrete. The results of FEA of the longitudinal shear test (Fig. 5-21) showed that each knuckle had strength in the range of 15 kip to 35 kip, depending on the interface condition. When the analysis results are compared to the test results, the interface appears to be closer to the fully bonded case.

The transverse shear FEA results (Fig. 5-23) showed that transverse knuckle strength was about 24 kip for the frictionless condition with 2,500 psi concrete, which corresponds to 39 kip for 4,100 psi concrete. For the full bonded case, the analysis was terminated at 20 kip per knuckle before reaching the ultimate 
strength. The transverse shear FEA results (Fig. 5-22) showed that concrete was crushed in a small region next to the knuckle and extended in front of the shear load. Figure 5-22 also shows large regions of crushed concrete at the lower portion of the model. (Note that the boundary condition UY=0, although realistic for the test, would not occur in a pair of transversely loaded knuckles in the two actual trusses.) The small crushed regions indicate that a pair of knuckles can be expected to behave nearly independently of each other and, therefore, have nearly double the capacity of a single knuckle.

Although the analysis showed the sensitivity of the results to the steel-concrete interface assumptions, it supported the shear capacities determined from test results.

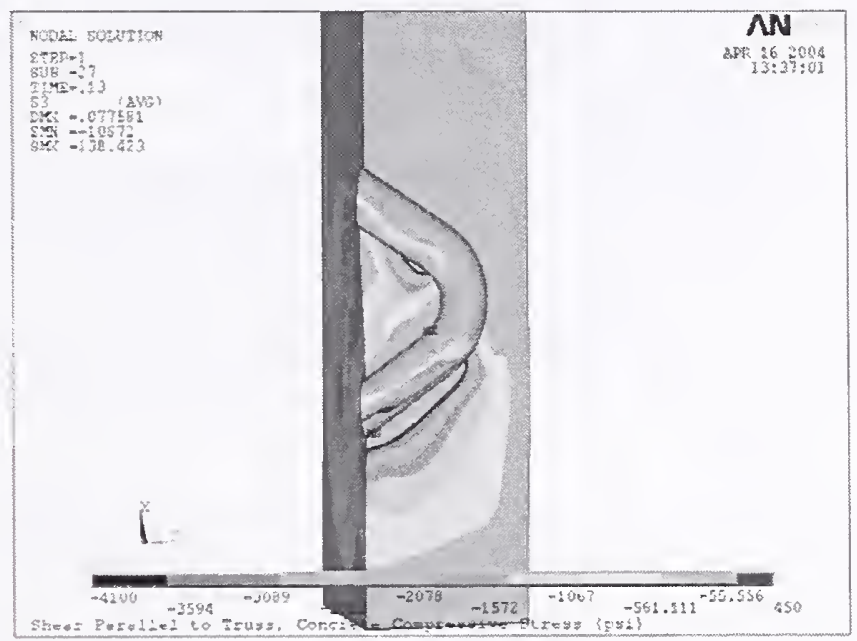

Figure 5-20. Compressive stresses in longitudinal shear finite element model (4,100 psi concrete).

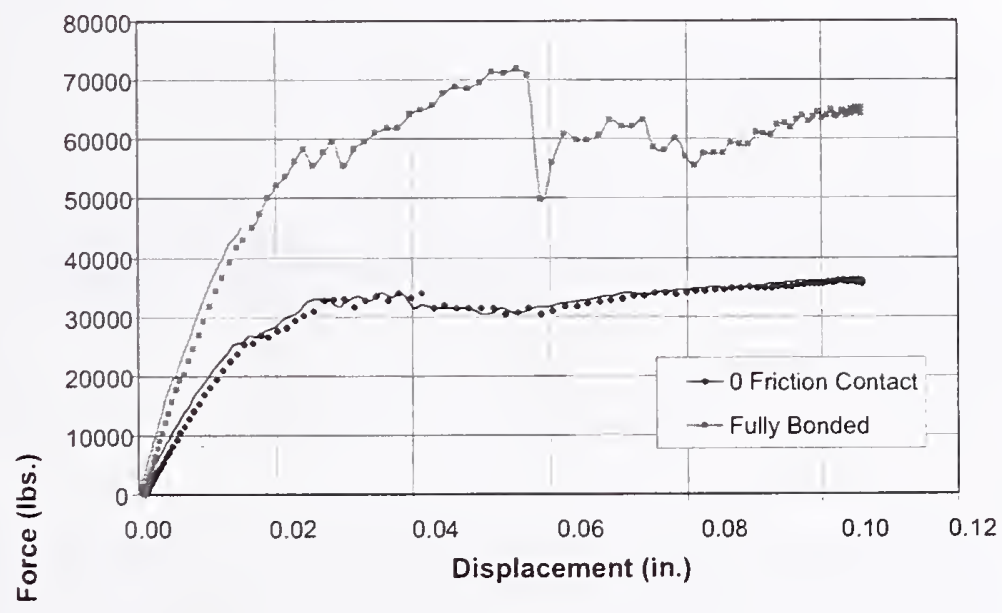

Figure 5-21. Shear force versus displacement from finite element model for longitudinal shear of two knuckles (4,100 psi concrete). 


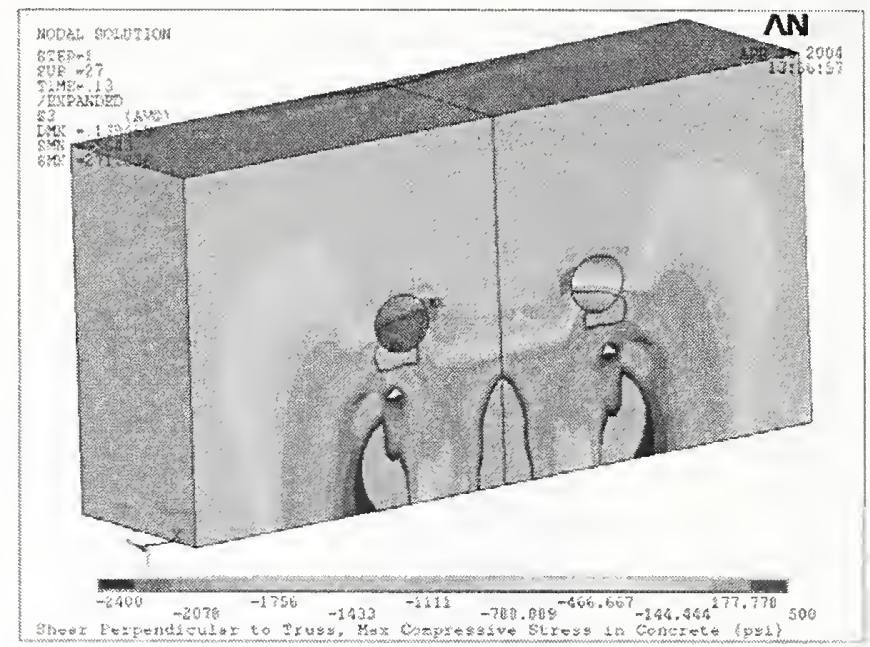

Figure 5-22. Compressive stresses in transverse shear finite element model (2,500 psi concrete).

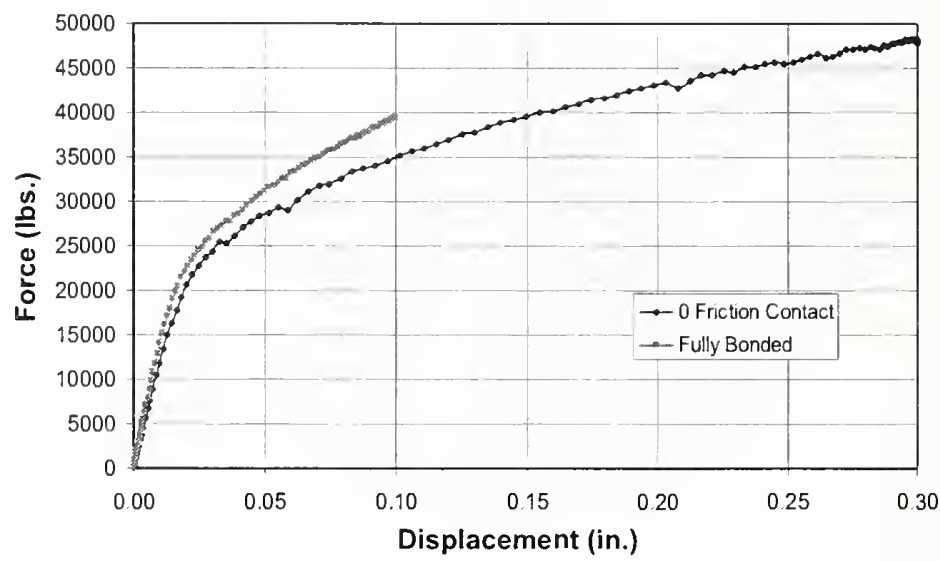

Figure 5-23. Shear force versus displacement from finite element model for transverse shear of two knuckles $(2,500$ psi concrete).

\section{Analysis of Temperature Effects}

Temperature effects on knuckles were evaluated based on hand calculations and engineering judgment.

The effects can be summarized as follows:

- The steel knuckle heated rapidly and reached the temperature of the truss web diagonal member without much loss of heat into the relatively cool concrete slab. Concrete had a low coefficient of conductivity and did not respond as rapidly as steel to the rise of temperature.

- Concrete in the immediate proximity of the steel knuckle heated to a temperature close to that of the steel.

- Shear failure of the knuckle was initiated by the failure of concrete in close proximity to the knuckle. Final failure engaged not only the hot concrete in close proximity to the knuckle, but the cooler concrete farther away. 
- It was assumed that for gas temperatures of $20{ }^{\circ} \mathrm{C}$ to $450{ }^{\circ} \mathrm{C}, 650{ }^{\circ} \mathrm{C}, 850{ }^{\circ} \mathrm{C}$, and $1,050{ }^{\circ} \mathrm{C}$, the knuckle steel temperatures would be lower at $20^{\circ} \mathrm{C}$ to $375^{\circ} \mathrm{C}, 550{ }^{\circ} \mathrm{C}, 725^{\circ} \mathrm{C}$, and $900{ }^{\circ} \mathrm{C}$, and average concrete temperatures would be even lower at $20{ }^{\circ} \mathrm{C}$ to $300{ }^{\circ} \mathrm{C}, 450{ }^{\circ} \mathrm{C}$, $600^{\circ} \mathrm{C}$, and $750^{\circ} \mathrm{C}$, respectivcly.

Neglecting the difference in thermal expansion of concrete and steel, for gas temperatures of $20{ }^{\circ} \mathrm{C}$ to $450{ }^{\circ} \mathrm{C}, 650{ }^{\circ} \mathrm{C}, 850{ }^{\circ} \mathrm{C}$, and $1.050{ }^{\circ} \mathrm{C}$, the expected concrete strength at the knuckle is in the range of 4,100 psi, 3,300 psi, 2,600 psi, and 2,000 psi based on the expected concrete temperature. Based on the results of tests performed and bracketing of test results by the finite element analysis, the knuckle capacities in either longitudinal or transverse direction are $30 \mathrm{kip}, 24 \mathrm{kip}, 19 \mathrm{kip}$, and $15 \mathrm{kip}$ for the average concrete temperature of $20{ }^{\circ} \mathrm{C}$ to $300{ }^{\circ} \mathrm{C}, 450{ }^{\circ} \mathrm{C}, 600{ }^{\circ} \mathrm{C}$, and $750{ }^{\circ} \mathrm{C}$, respectively. Temperaturedependent knuckle shear capacities for the assumed temperatures are summarized in Table 5-7.

For the pullout failure mode, the capacity was estimated at 15 kip at room temperature. Based on concrete temperature and concrete strength, temperature-dependent capacity for pullout was calculated as shown in Table 5-7.

Table 5-7. Temperature-dependent knuckle capacity for assumed temperatures.

\begin{tabular}{|c|c|c|c|c|}
\hline $\begin{array}{c}\text { Gas temperature } \\
\left({ }^{\circ} \mathbf{C}\right)\end{array}$ & $\begin{array}{c}\text { Steel temperature } \\
\left({ }^{\circ} \mathbf{C}\right)\end{array}$ & $\begin{array}{c}\text { Concrete } \\
\text { temperature } \\
\left({ }^{\circ} \mathbf{C}\right)\end{array}$ & $\begin{array}{c}\text { Knuckle shear } \\
\text { capacity } \\
(\text { kip })\end{array}$ & $\begin{array}{c}\text { Knuckle pullout } \\
\text { capacity } \\
\text { (kip) }\end{array}$ \\
\hline $20-450$ & $20-375$ & $20-300$ & 30 & 15 \\
\hline 650 & 550 & 450 & 24 & 12 \\
\hline 850 & 725 & 600 & 19 & 10 \\
\hline 1.050 & 900 & 750 & 15 & 7 \\
\hline
\end{tabular}

\subsubsection{Summary of Failure Modes and Finite Element Models of Knuckle Model for Truss Model}

Knuckle failure modes captured by the finite element models of knuckles in the truss model were the horizontal shear failure and vertical tensile pullout failure, which are both temperature-dependent. Finite element modeling assumptions for the knuckle are: (1) the knuckle has resistance in all translational degree of freedom, (2) the knuckle does not have a vertical compression capacity limit, (3) capacities in the horizontal shear and vertical tension are temperature-dependent, and (4) vertical compression resistance is independent of the capacities in the other directions. A finite elemcnt knuckle model was constructed by using 15 break elements and five beam elements for incorporation into the truss model, as shown in Fig. 5-24. 


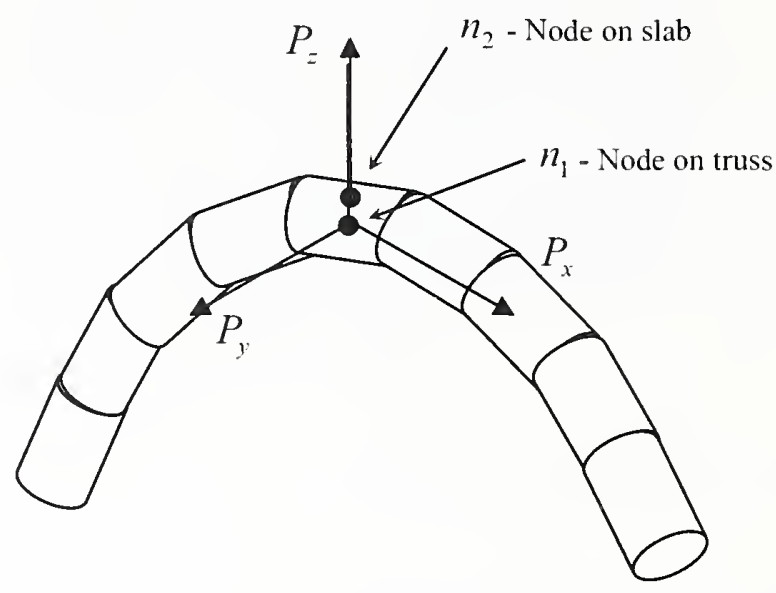

Five beam elements are used to make the knuckle capacity temperature-dependent

Point-to-point contact element to transfer vertical compressive force between node 1 and 2
Break element No. 1-4:

Capture loss of vertical resistance if knuckle fails horizontally
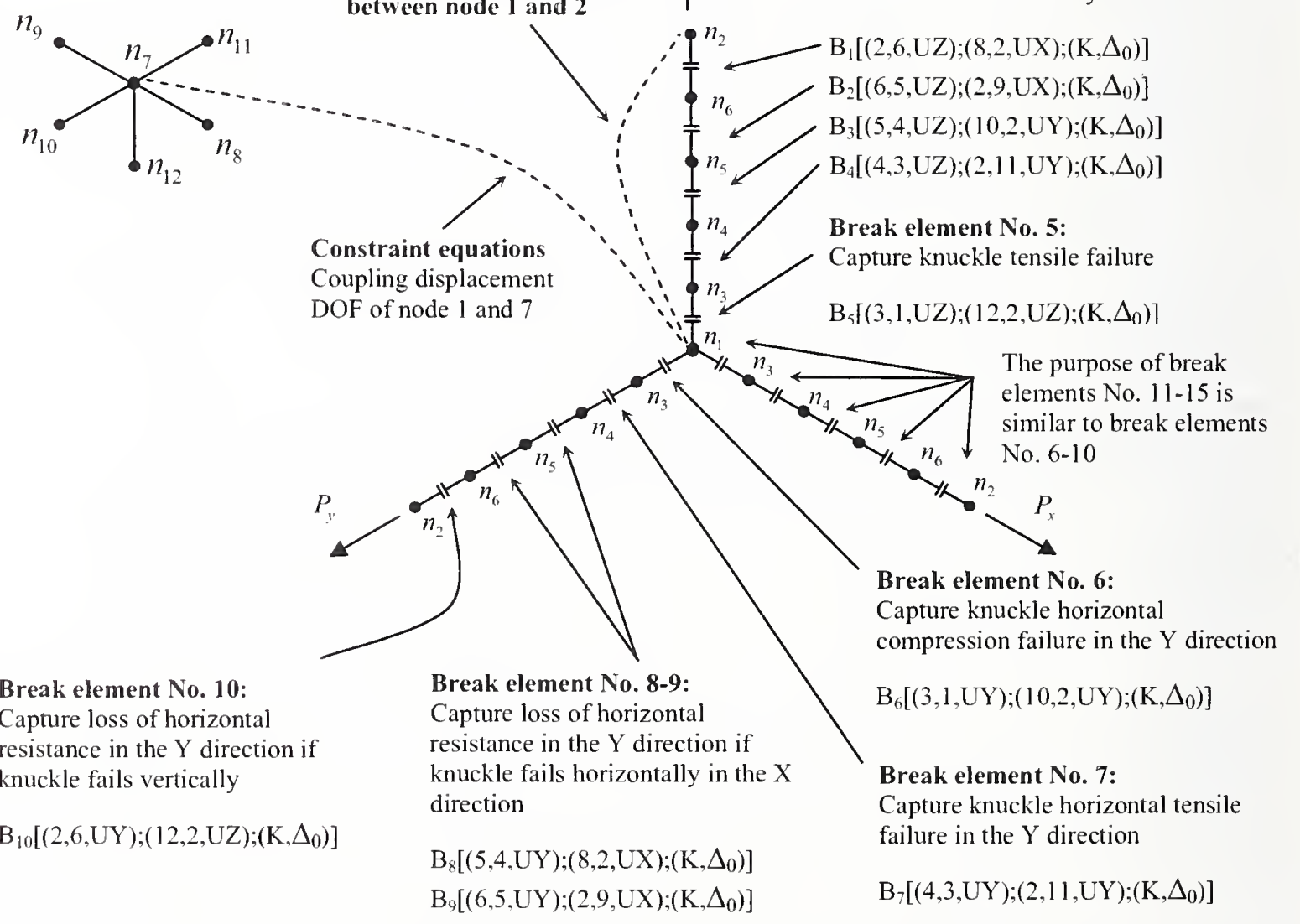

Break element No. 10:

Capture loss of horizontal resistance in the $\mathrm{Y}$ direction if knuckle fails vertically

$\mathrm{B}_{10}\left[(2,6, \mathrm{UY}) ;(12,2, \mathrm{UZ}) ;\left(\mathrm{K}, \Delta_{0}\right)\right]$
$\mathrm{B}_{8}\left[(5,4, \mathrm{UY}) ;(8,2, \mathrm{UX}) ;\left(\mathrm{K}, \Delta_{0}\right)\right]$

$\mathrm{B}_{9}\left[(6,5, \mathrm{UY}) ;(2,9, \mathrm{UX}) ;\left(\mathrm{K}, \Delta_{0}\right)\right]$ elements No. 11-15 is similar to break elements $n_{2}$

Break element No. 6:

Capture knuckle horizontal compression failure in the $Y$ direction

$\mathrm{B}_{6}\left[(3,1, \mathrm{UY}) ;(10,2, \mathrm{UY}) ;\left(\mathrm{K}, \Delta_{0}\right)\right]$

Break element No. 7:

Capture knuckle horizontal tensile in the $Y$ direction

$\mathrm{B}_{7}\left[(4,3, \mathrm{UY}) ;(2,11, \mathrm{UY}) ;\left(\mathrm{K}, \Delta_{0}\right)\right]$

Figure 5-24. Representation of knuckle by break elements. 


\subsection{TRUSS MODEL}

The truss model is a section of a floor system, which consists of a single floor truss and a corresponding section of the concrete slab. The objectives of the truss model study were to:

- Capture the potential failure modes and failure sequence of the truss model subjected to gravity load and temperature time histories,

- Determine failure loads for different failure modes, and

- Develop a simplified model that replicates the expected failure modes of the truss model for use in the full floor subsystem model.

\subsubsection{Model Description}

Figure 5-25 shows the truss model. The truss model is a cut-out section of the office area floor system. A typical long-span truss designated C32T1 (SHCR 1973:WTC Drawing Book 7, Sheet AB1-2) was modeled. The model used symmetry and included the following:

- One of the two primary trusses at Column 143 at Floor 96 of WTC 1,

- Two exterior columns (Columns 143 and 144) at the plane of symmetry with half the area and the moment of inertia and with a length of $24 \mathrm{ft}$ (each column extends over the full height of a floor),

- Part of the spandrel between the two planes of symmetry,

- Part of the slab (40 in. wide) between the two plane of symmetry,

- Strap anchor attached on one end to the truss top chord and the concrete slab and on the other end to the adjacent exterior column (Column 144), and

- Halves of exterior and interior truss seats and the gusset plate at the exterior end.

The slab was 4 in. thick lightweight concrete on 22 gauge steel deck with flutes 6.8 in. on center running parallel to the primary trusses. Two layers of welded wire reinforcement were provided in the slab. The reinforcement ratios were 0.21 percent and 0.735 percent in the directions parallel and transverse to the truss, respectively. A flute was $2 \mathrm{in.}$ wide at the top, $1.25 \mathrm{in}$. wide at the bottom, and $1.47 \mathrm{in}$. high.

The finite element model of the concrete slab had an equivalent thickness of $4.35 \mathrm{in}$. By using the equivalent thickness, the bending stiffness in the direction transverse to the truss became about 15 percent higher than the actual stiffness. However, since the bending in the transverse direction to the truss was small, the concrete slab was modeled as an isotropic plate. The steel deck and the welded wire fabric were not included in the truss model either explicitly or implicitly by modification of concrete stressstrain relationship. The concrete slab was modeled with four layers of 3-D eight-node structural solid (SOLID185) elements. The Hjelm plasticity model as described in Section 3.1.2 was used for the solid elements that allowed different "yield strengths" in tension and compression.

The top chord of truss C32T1 consisted of double angles of $11 / 2 \times 2 \times 0.25$ (long legs horizontal), and the bottom chord consisted of double angles of $3 \times 2 \times 0.37$ (long legs horizontal). Web diagonal members were round bars of either 1.09 in. or 1.14 in. diameter. Most web diagonal members had a 1.09 in. diameter.

The top and bottom chords and the web diagonals were modeled by BEAM189 elements with temperature-dependent elastic, plastic, and creep material properties. Top and bottom chords were 
divided into four elements between panel points; panel points are those where web diagonals attached to chord members. Web diagonals were also divided into four elements between top and bottom chords.

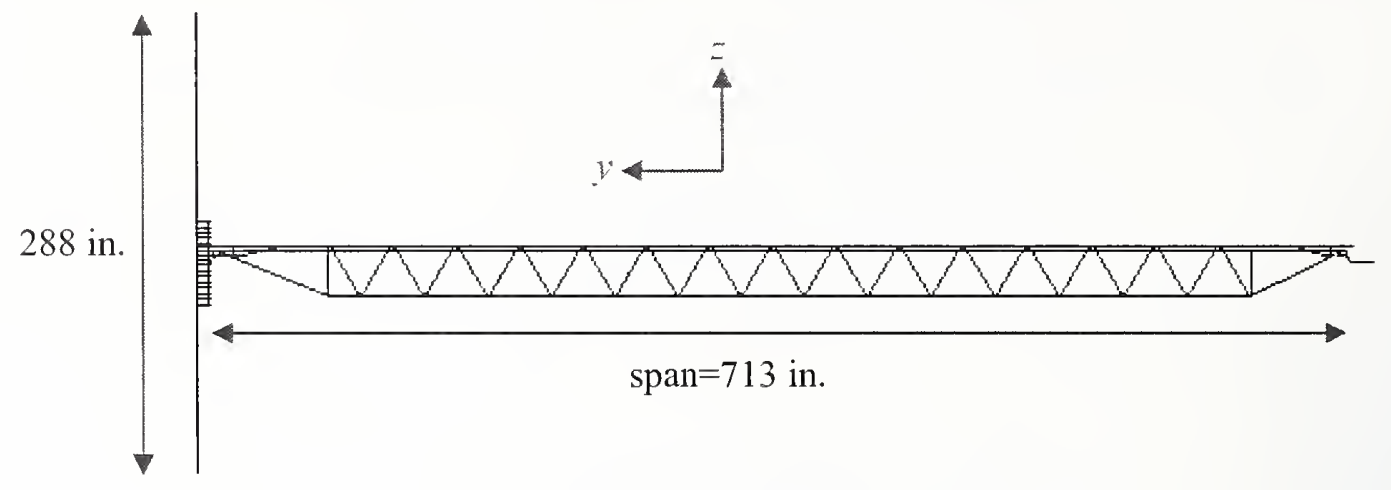

(a) Entire model

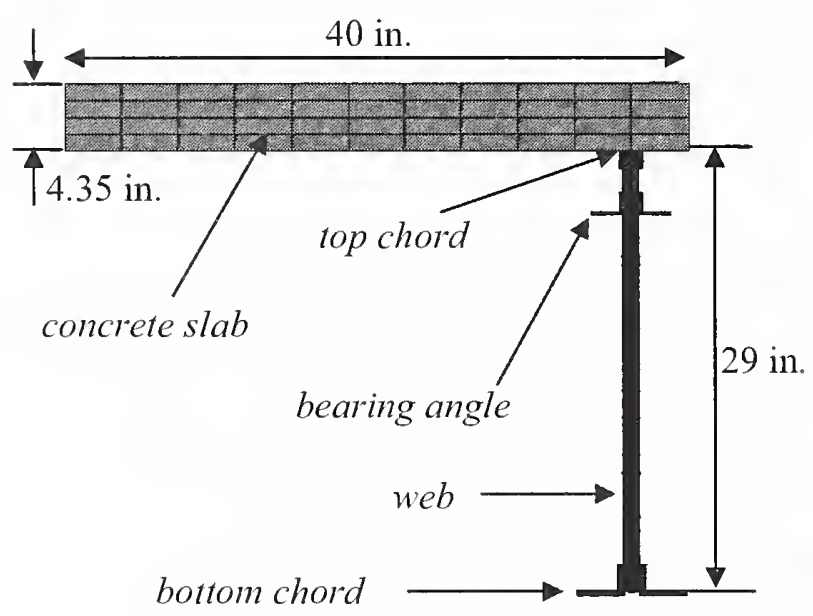

(b) Cross section

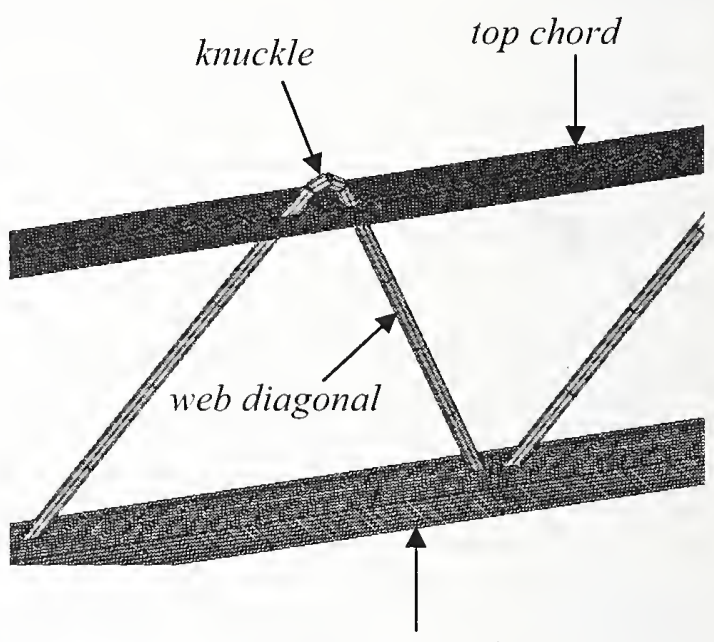

bottom chord

(c) Top and bottom chords and web diagonals

Figure 5-25. Truss model.

At knuckle locations, elements representing the top chord and the concrete slab were connected by break elements (COMBIN37) with capacities determined from the knuckle analysis. By including point-topoint contact (CONTA178) elements, compression was transferred even after failure of knuckles. The studs on the strap anchor between the top chord and column 144 were also modeled by break elements (COMBIN37) that connected the strap anchor to the slab and had temperature-dependent capacities. The slab and the strap anchor were tied by the COMBIN37 break elements horizontally while their vertical displacements were coupled. The exterior and interior truss seats were modeled by COMBIN37 break elements that had temperature-dependent capacities determined from the truss seat analysis. A stud on the spandrel was also modeled by COMBIN37 break elements, which tied the spandrel with the slab and had temperature-dependent capacities.

The visco-elastic damping unit that connected the truss bottom chord to the spandrel plate was not included in the truss model because the dampers were expected to be soft when subjected to very slow loading rates. 
Elastic BEAM44 elements were used to model the exterior columns. Elastic SHELL63 elements were used to model the spandrel.

A camber of 2.0 in. at midspan was not included in the truss model.

\subsubsection{Failure Modes}

Two possible failure modes were identified for the truss model:

Sagging of Truss: The top and bottom chords and web diagonals were exposed to the hot gas layer that accumulated below the floor slab. The steel in the truss exhibited stiffness degradation, yield strength reduction, plastic softening, and creep at high temperatures. A truss with softened chords and diagonals would sag. As the concrete slab was heated, its stiffness and strength were reduced, especially at its bottom layer where temperatures were the highest due to exposure to hot gas and around the knuckles where concrete temperature rose by conduction through the steel.

In addition to direct thermal effects, sagging and weakening of the truss were caused by the following component failures:

- Buckling of web diagonal members,

- Yielding of the chord members,

- Knuckle failure and loss of composite action between the concrete slab and the steel truss (see Section 5.3), and/or

- Weld failure between the web diagonal members and the chord members.

Loss of Truss Support: The truss can fail by loss of support. Loss of support at either the exterior or interior truss seats was caused by the loss of vertical shear capacity of the seats at elevated temperatures or by the truss walking-off the seat due to large sagging.

As discussed in Section 5.4.3, the bottom chord of the truss model was restraincd in the direction transverse to the truss at the bridging truss locations. Although the out-of-plane deformation of the bottom chord due to thermal expansion of bridging trusses may result in a reduction of the vertical load capacity of a primary truss, the use of symmetry in the truss model prevents its application to cases with lateral loads. The interaction between the bridging trusses and the primary trusses was captured in the full floor model.

\subsubsection{Boundary Conditions}

Boundary conditions for the truss model are shown in Fig. 5-26.

The entire top chord of the truss was restrained against lateral movement in the $\mathrm{x}$ direction. The bottom chord was restrained against lateral movement in the $x$ direction at four bridging truss locations. The two edges of the concrete slab parallel to the truss were restrained against rotations about the $y$ and $z$ axes, but were free in the $x$ direction.

The interior truss seat was fixed in all directions. The exterior truss seat was attached to the spandrel. The truss was supported by break elements to capture failure modes of the truss seats, and break elements were connected to beam elements representing the seats.

The exterior end of the slab was tied to the spandrel by contact elements to prevent the slab from penetrating the spandrel and break elements representing tension and shear failures of the spandrel stud. 
The interior end of the slab was fixed in the $z$ direction, but connected to break elements with temperature-dependent tensile capacities of the slab in the $y$ direction, as shown in Fig. 5-27. Therefore, the interior slab end was fixed in the $y$ direction as long as the tensile force was within the tensile capacity of the slab calculated for the actual steel reinforcement in the region between office area and core slabs (\#3@10 in. top and \#4@12 in. bottom).

The top and bottom ends of the columns were restrained against all rotations and against the translation in the $y$-direction. In addition, the lower columns were restrained against the translation in the vertical direction. The end restraint conditions of columns affect the magnitude of the horizontal reaction to thermal expansion of the floor section. A quantitative study of the effect of column boundary conditions is discussed in Section 5.5.16.

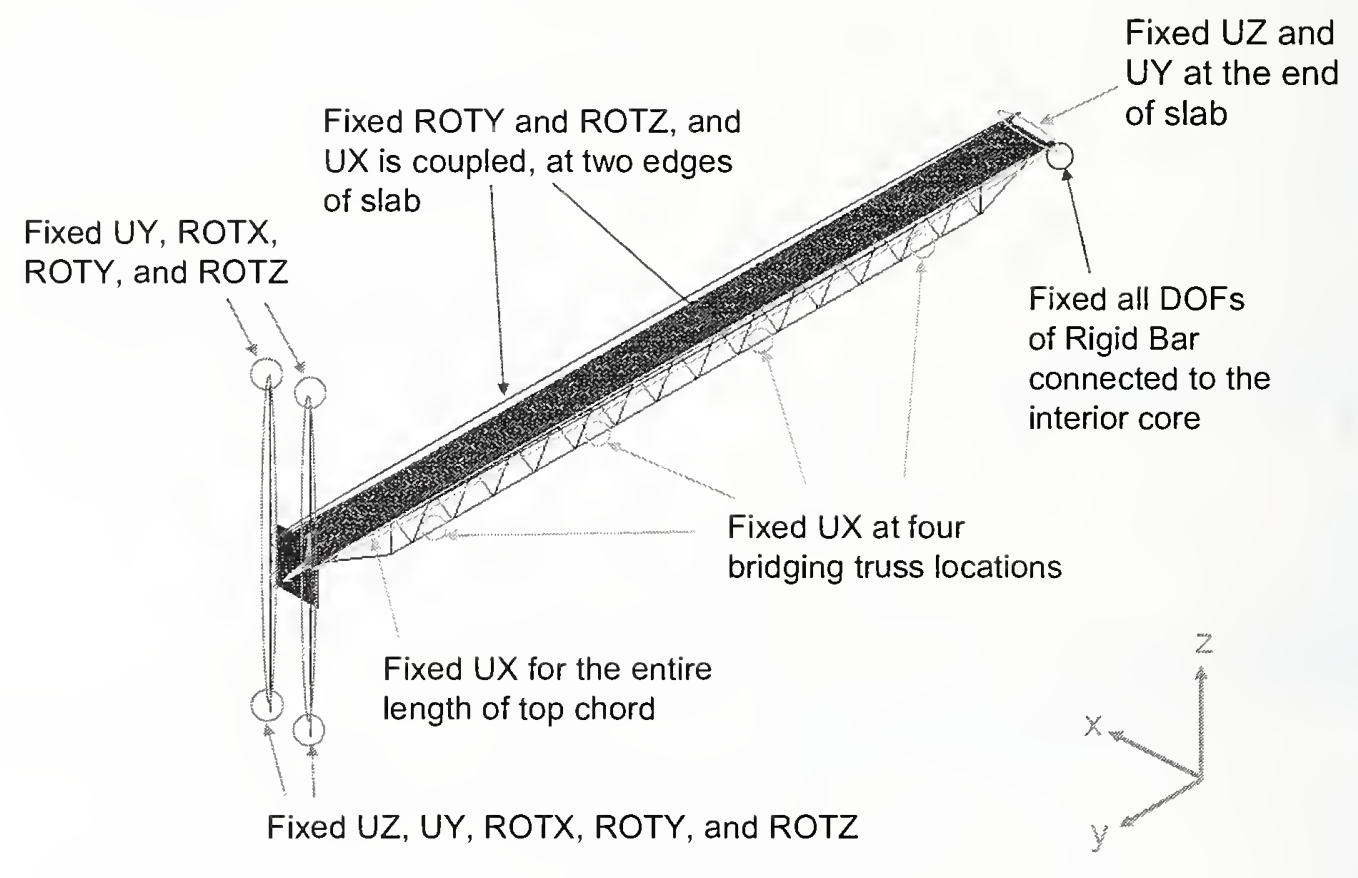

Figure 5-26. Boundary conditions.

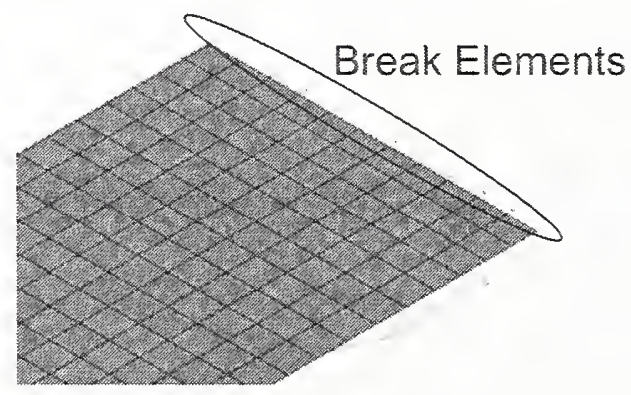

Figure 5-27. Break elements at the interior end of slab. 


\subsubsection{Loads}

Loads on the truss model consisted of dead and live loads and temperature time histories for all truss components including the truss seats and concrete slab. The gravity loads included the weight of the structure, 8 psf superimposed dead load (including nonstructural dead loads due to architectural items and fixed service equipment), and 13.75 psf of live load equal to 25 percent of design live load of $55 \mathrm{psf}$.

A temperature time history was used for exercising the truss model (Figure 5-28). It was not obtained from fire dynamics or heat conduction analyses. The temperature was ramped over the first $30 \mathrm{~min}$ linearly from $20{ }^{\circ} \mathrm{C}$ to $700{ }^{\circ} \mathrm{C}$ in truss members, from $20{ }^{\circ} \mathrm{C}$ to $700{ }^{\circ} \mathrm{C}$ at the bottom surface of the concrete slab, and from $20{ }^{\circ} \mathrm{C}$ to $300{ }^{\circ} \mathrm{C}$ at the top surface of the concrete slab; thereafter, the maximum temperatures were linearly increased at a rate of $20^{\circ} \mathrm{C}$ per min. At 40 min temperatures increased by $200{ }^{\circ} \mathrm{C}$ from those at $30 \mathrm{~min}$. A linear gradient through the thickness of the slab was assumed. No temperature load was applied to the columns or spandrel.

The effects of construction sequence were included by using "element birth and death" for the concrete slab. In the first step, the self-weight of truss members and concrete slab was applied to the truss without the concrete slab. In the second step, the concrete slab was placed stress-free, and the superimposed dead and live load were applied to the model.

To determine the effect of debris load on the truss behavior, the gravity was increased until the analysis failed to converge at room temperature.

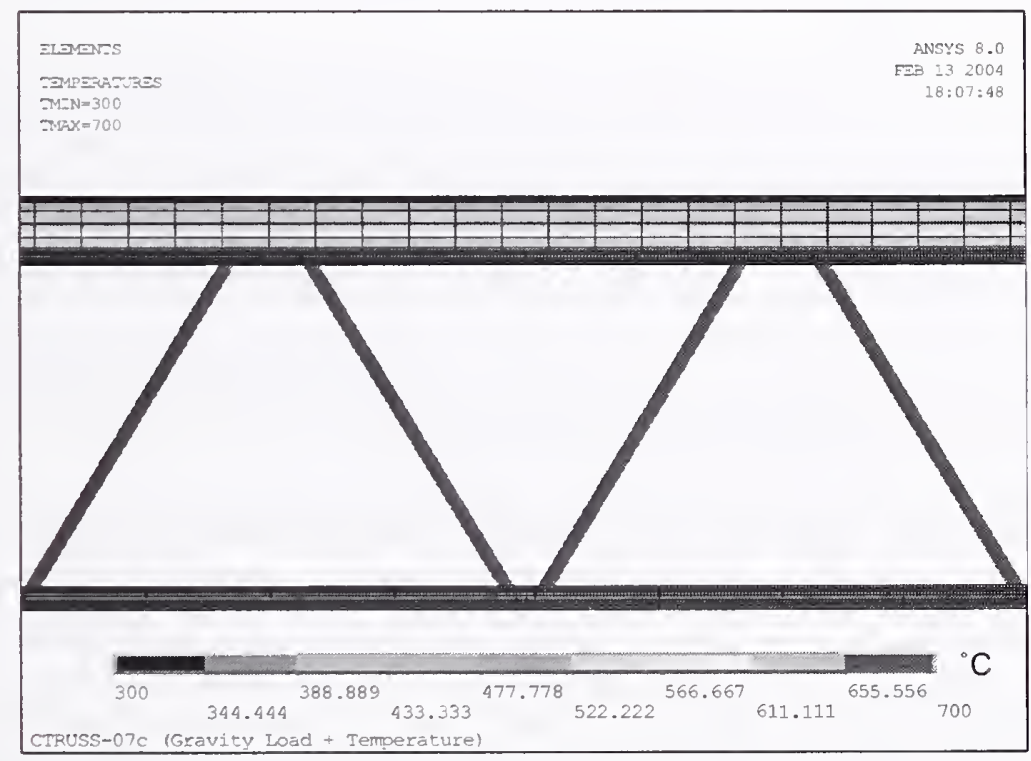

Figure 5-28. Assumed Temperature Distribution in the Truss Model at $30 \mathrm{~min}$.

\subsubsection{Material Properties}

Table 5-8 shows material assignments for structural components in the truss model.

Elastic properties were assigned to the elements for Columns 143 and 144 and the spandrel. As described in Section 3.1.2, the Hjelm material model was used for the concrete model, which allowed different yield strengths for tension and compression. To improve convergence in the analysis, the negative slope after cracking in tension or crushing in compression was removed, and the concrete was assumed to be plastic after cracking or crushing. 
Creep in steel was included in the analysis; however, the creep formulation was slightly different from Eq. (7) in Section 3.2.2. A ratio of room temperature yield strengths (i.e., 35.5/ $\sigma_{y R T}$ ) was used as the scaling factor of stress in the creep formulation for the truss model. NIST later changed the scaling factor from what was used here to the ratio of room temperature ultimate strengths (i.e., $70.5 / \sigma_{u R T}$ ) as shown in Eq. (7).

Table 5-8. Material assignments in truss model.

\begin{tabular}{|c|c|c|}
\hline Structural Component & $\begin{array}{c}\text { Specified Yield } \\
\text { Strength }\end{array}$ & Material ID \\
\hline Top chord & $50 \mathrm{ksi}$ & 21 \\
\hline Bottom chord & $50 \mathrm{ksi}$ & 21 \\
\hline 1.09 in. diameter web & $36 \mathrm{ksi}$ & 20 \\
\hline 1.14 in. diameter web & $50 \mathrm{ksi}$ & 21 \\
\hline Strap & $36 \mathrm{ksi}$ & 1 \\
\hline Column 143 & $65 \mathrm{ksi}$ & 15 \\
\hline Column 144 & $65 \mathrm{ksi}$ & 15 \\
\hline Spandrel & $42 \mathrm{ksi}$ & 11 \\
\hline Lightweight concrete slab & $3,000 \mathrm{psi}(\mathrm{fc})$ & 83 \\
\hline
\end{tabular}

\subsubsection{Resistance Welds}

Table 5-9 shows the resistance weld strength between a double angle chord and a web diagonal ${ }^{3}$. Weld strengths shown in Table 5-9 were the sum of the capacities of two resistance welds, one on each side of the web diagonal to each angle. Figure 5-29 compares resistance weld strength at the top or bottom chord with the yield strength of a web diagonal at elevated temperatures. As shown in Fig. 5-29 (a), a typical web diagonal (1.09 in. diameter) yields before the resistance weld fails. For a 1.14 in. diameter web diagonal, the resistance weld strength is less than the web diagonal yield strength at temperatures below $550{ }^{\circ} \mathrm{C}$, as can be seen in Fig. 5-29 (b). However, shop drawings showed additional arc welds between the chord and 1.14 in. diameter bar at most locations. ${ }^{4}$

Table 5-9. Resistance weld strength.

\begin{tabular}{|c|c|c|}
\hline Chord & $\begin{array}{c}\text { Size of Web Diagonal } \\
\text { (in.) }\end{array}$ & $\begin{array}{c}\text { Average Weld Strength } \\
\text { (kip) }\end{array}$ \\
\hline Top chord & 1.09 & 36.9 \\
\hline Top chord & 1.14 & 37.7 \\
\hline Bottom chord & 1.09 & 41.0 \\
\hline Bottom chord & 1.14 & 40.5 \\
\hline
\end{tabular}

3 Based on the test data from Laclede Steel Co.

4 Based on the test data from Laclede Steel Co. 


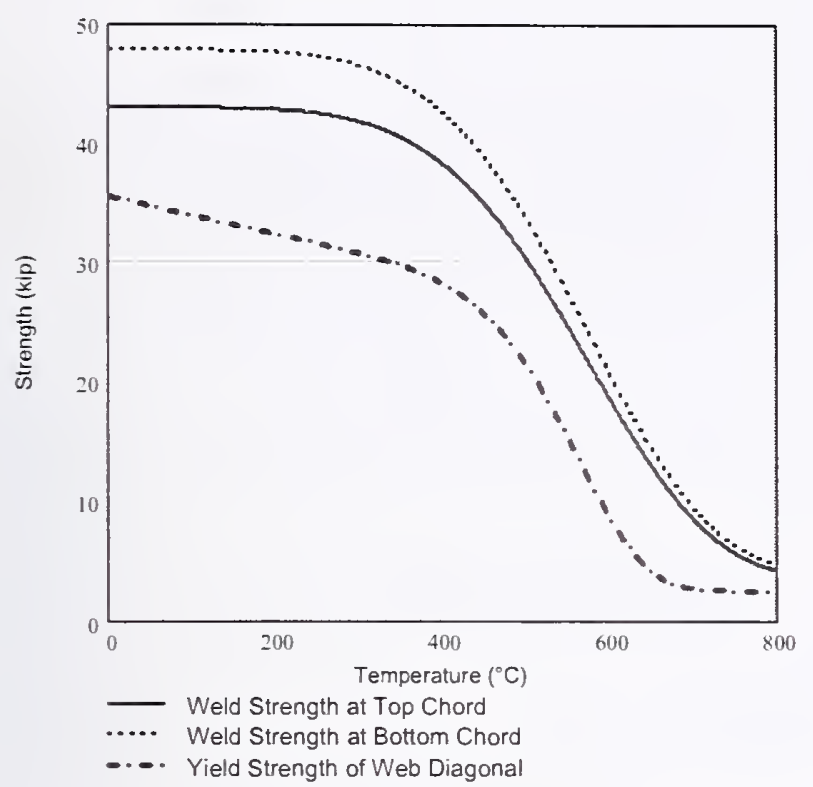

(a) 1.09 in. diameter bar

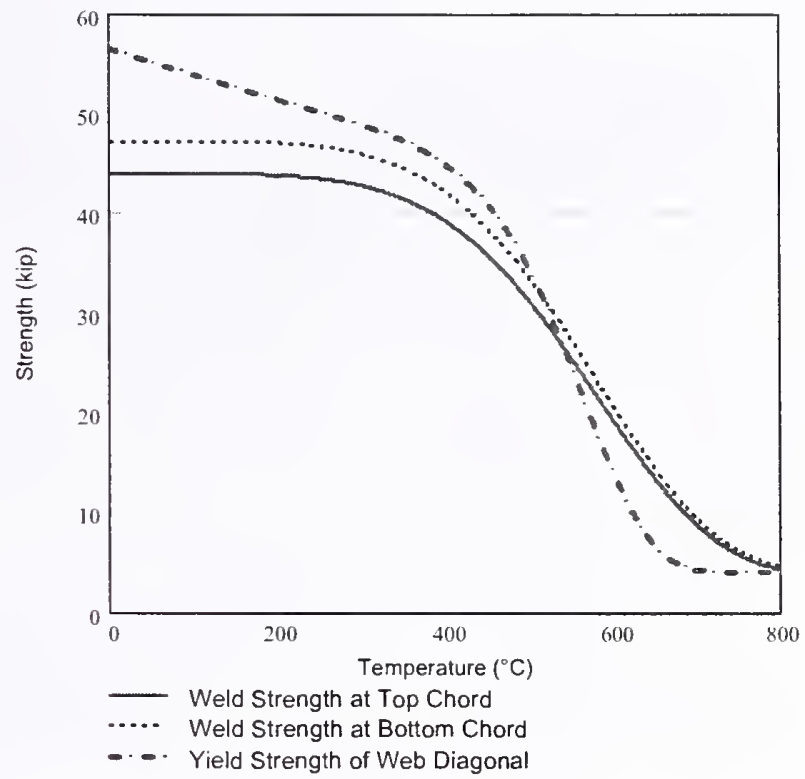

(b) 1.14 in. diameter bar

Figure 5-29. Comparison of resistance weld strength and yield strength of web member at elevated temperatures.

\subsubsection{Model Verification}

Before analyzing the truss model response to elevated temperatures, the maximum vertical displacement under dead and live loads was verified against the single truss model extracted from the ANSYS full floor model. The maximum difference in the vertical displacement was found to be 3.5 percent. In this comparison, the effects of construction sequence were not included in either model.

\subsubsection{Truss Analysis for Debris Load}

The capacity of the truss model against additional debris load was determined by increasing the gravity loads. When this analysis was performed, the truss model was still under development and somewhat different from the model described in Section 5.4.1. Break elements were not used for studs, interior, or exterior truss seats, nor for reinforcement at the interior end of the slab. The slab was modeled by SHELL181 elements with elastic material properties. Boundary conditions of the slab were also slightly different from those described in Section 5.4.3. The exterior end of the slab was tied to the spandrel without break elements and contact elements, and the interior end of the slab was fixed in the $y$ and $z$ directions and against rotations about the $x$ and $z$ axes without break elements.

The analysis was terminated at a load factor of 3.4. Load factor is the ratio of the gravity load plus debris weight to the gravity load. Figure 5-30 (a) shows midspan vertical displacement versus load factor. At a load factor of 2.4 , Knuckles 5 to 15 failed due to horizontal shear in the truss direction. At a load factor of 2.8, Knuckle 4 failed. Figure 5-30 (b) shows the sum of the horizontal reaction forces measured at the exterior columns, where a positive value is used when columns are pulled in by the truss. After twelve of fifteen knuckles failed, the model lost its composite action, and the vertical displacement increased significantly. As a result, horizontal reaction forces at the exterior columns also increased. 


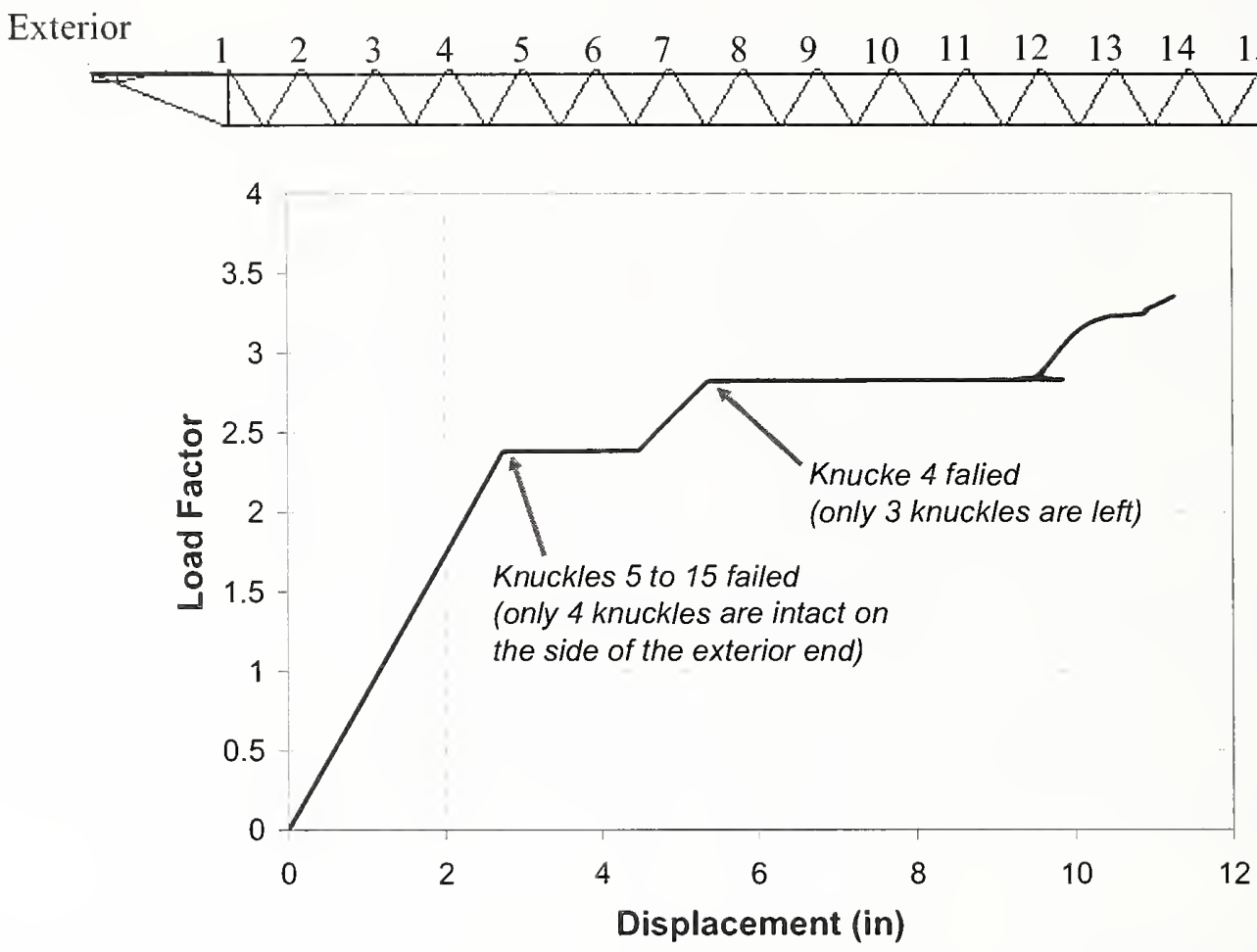

(a) Load factor versus midspan vertical displacement

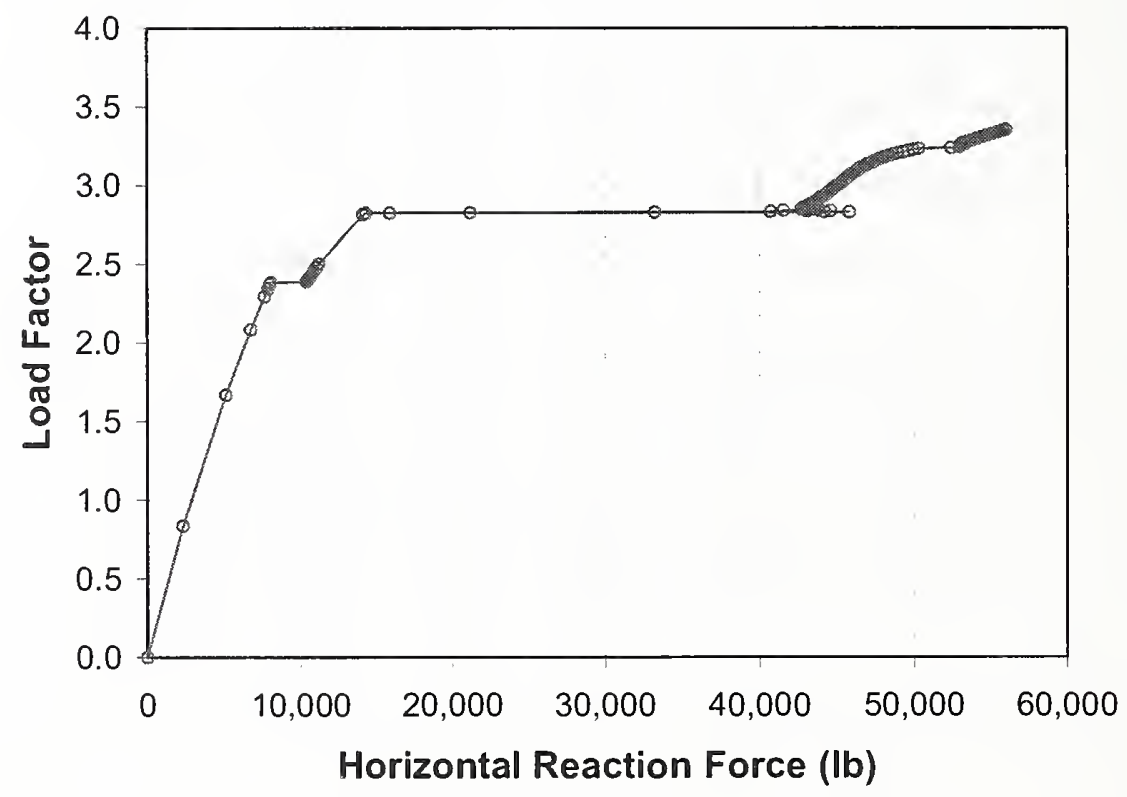

(b) Load factor versus horizontal reaction force

Figure 5-30. Finite element analysis results from increasing gravity. 


\subsubsection{Truss Analysis for Gravity and Thermal Loads}

Gravity Loading: The maximum calculated vertical deflection due to the self-weight of the structure, which occurred when the concrete was still wet, was $1.7 \mathrm{in}$. downward. When the superimposed dead and live loads were applied to the truss with hardened concrete slab, the maximum vertical deflection becamc 2.0 in., and the maximum horizontal column deflection was $0.05 \mathrm{in}$. inward. The maximum forces in the top chord, bottom chord, web diagonal, and end diagonal strut were $-25.7 \mathrm{kip}, 41.3 \mathrm{kip},-6.9 \mathrm{kip}$, and $16.0 \mathrm{kip}$, respectively, which translate to average stresses of $14.8 \mathrm{ksi}, 11.6 \mathrm{ksi}, 6.7 \mathrm{ksi}$, and $15.7 \mathrm{ksi}$, respectively. The yield strength of top and bottom chords and end diagonal struts was $55.3 \mathrm{ksi}$. The yield strength of web diagonals was $38.1 \mathrm{ksi}$, except for the first compressive web diagonal at the interior end, which had a yield strength of $55.3 \mathrm{ksi}$. Therefore, the maximum stress level was about 30 percent of yield strength.

Gravity Plus Thermal Loading: The analysis of the truss model subjected to tcmperature time history was carried out statically; however, when the solution process did not converge, to overcome the convergence problem, the problem was solved dynamically with a 5 pcrcent Rayleigh damping. The static analysis was then resumed when acceleration and velocity became small. The analysis proceeded in this fashion until the temperature of the steel became $727^{\circ} \mathrm{C}$. Figure $5-31$ shows the vertical displacement of the truss at $700{ }^{\circ} \mathrm{C}$, and Fig. 5-32 shows the horizontal displacement of Column 143 at the floor level and vertical displacement of the bottom chord at midspan with temperature of stecl. The zero vertical displacement in this figure represents the initial displacement after the self-weight was applied. A positive horizontal displacement indicates that the exterior columns were pushed out, and a negative vertical displacement indicates that the truss was deflected downward. At $445^{\circ} \mathrm{C}$, when the end diagonal struts began to yield, the horizontal displacement at the exterior column began to decrease. At $565{ }^{\circ} \mathrm{C}$, the truss sag became large due to the buckling of web diagonals, and the exterior columns werc pulled in.

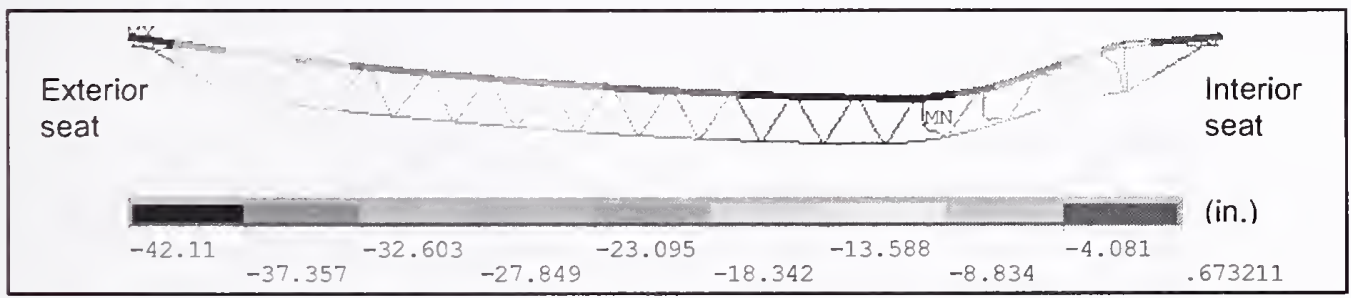

Figure 5-31. Vertical displacement at $700^{\circ} \mathrm{C}$ (downward displacement is negative). 


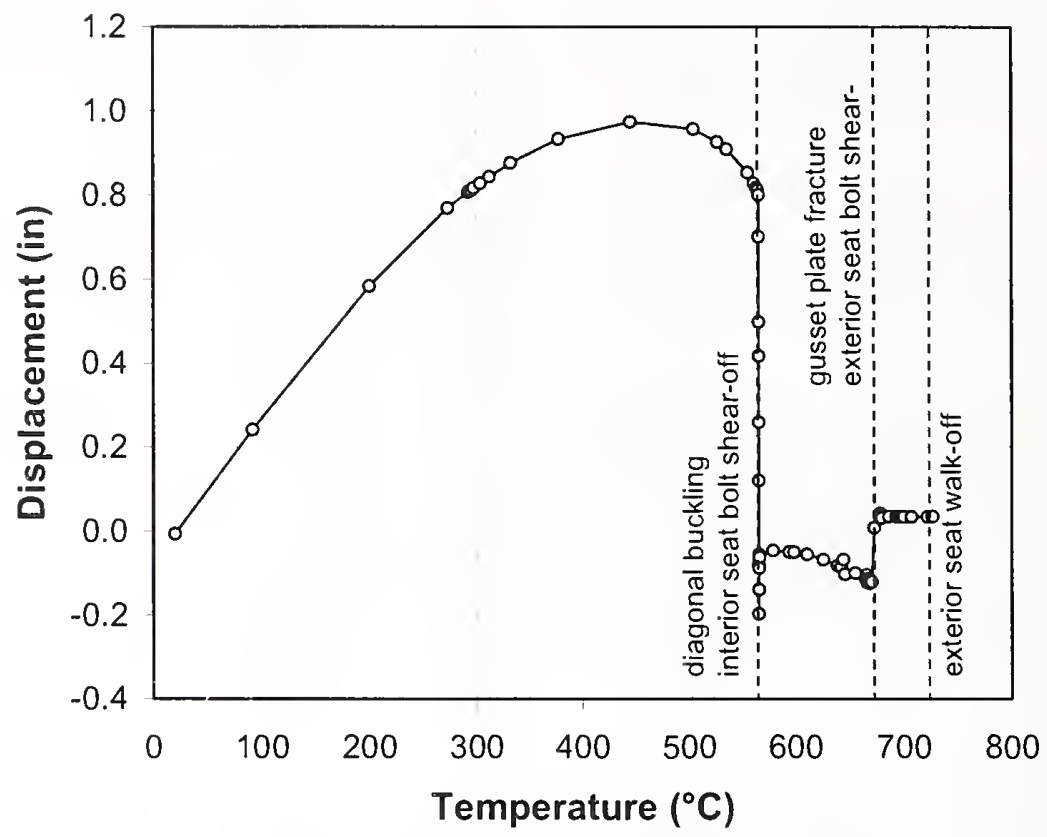

(a) Horizontal displacement at Column 143

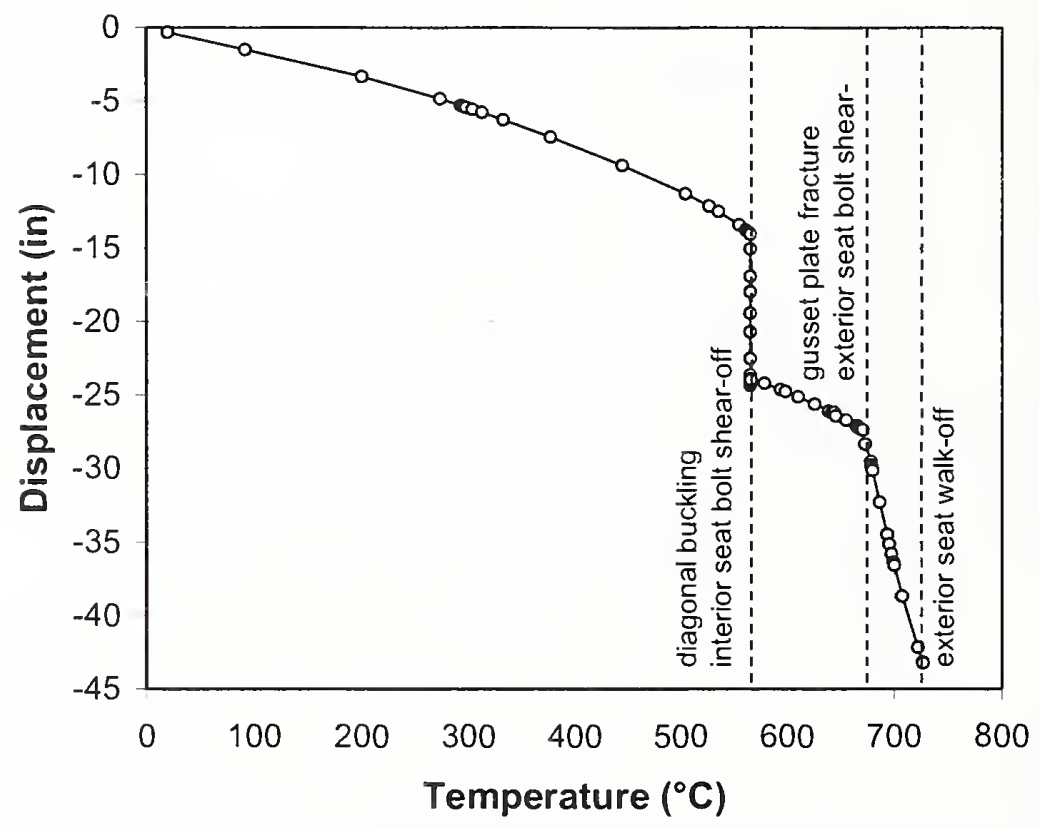

(b) Vertical displacement at midspan

Figure 5-32. Displacement versus temperature of steel. 
Figure 5-33 shows selected truss members. Figure 5-34 shows the axial forces in selected truss members Fig. 5-33. In Fig. 5-34, Py is the axial force at yield and equals the product of the net area of the member and the yield strength which varies with temperature. Pc in Fig. 5-34 (c) is the compressive strength calculated per the American Institute of Steel Construction's Manual of Steel construction, Load and Resistance Factor Design (AISC 2003) for fixed end conditions. Because the top chord was tied to the concrete in the vertical direction and was restrained in the direction transverse to the truss in this model, the failure of the top chord was by yielding, Py, rather than buckling, Pc.

Figure 5-34 (a) shows yielding of the top chords between knuckles beyond $300{ }^{\circ} \mathrm{C}$, resulting from the significant difference in coefficients of thermal expansion between concrete and steel. At $500{ }^{\circ} \mathrm{C}$, the coefficient of thermal expansion of steel was twice that of lightweight concrete. Yielding of the top chord did not play a significant role in the truss response because of its minor contribution to the composite area of the concrete slab and steel truss. Bottom chords were still in the elastic range at the end of analysis. Buckling of web diagonals started at approximately $565^{\circ} \mathrm{C}$. Several web diagonals were bent significantly in the plane of the truss by the high compressive axial force (see Fig. 5-35 for the deformed shape at the interior end).

Figure 5-36 shows knuckle forces in the longitudinal truss direction and the vertical direction. The capacity of a knuckle was $30 \mathrm{kip}$ in shear and $15 \mathrm{kip}$ in tension at room temperature. Knuckle 15 failed due to tension around $100^{\circ} \mathrm{C}$. Knuckles 13 and 14 failed due to shear in the longitudinal truss direction at about $566^{\circ} \mathrm{C}$.

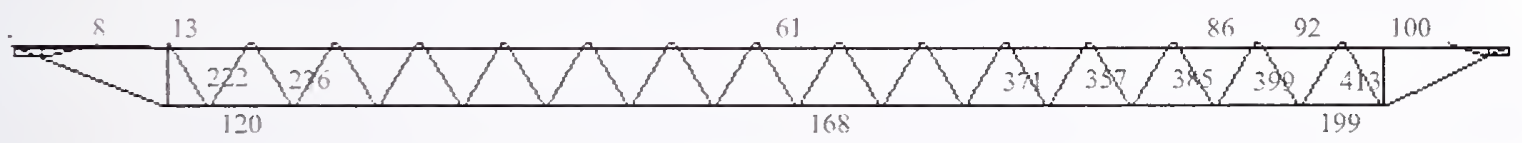

Figure 5-33. Element numbers and locations of elements examined for axial force. 
(a) Top chord

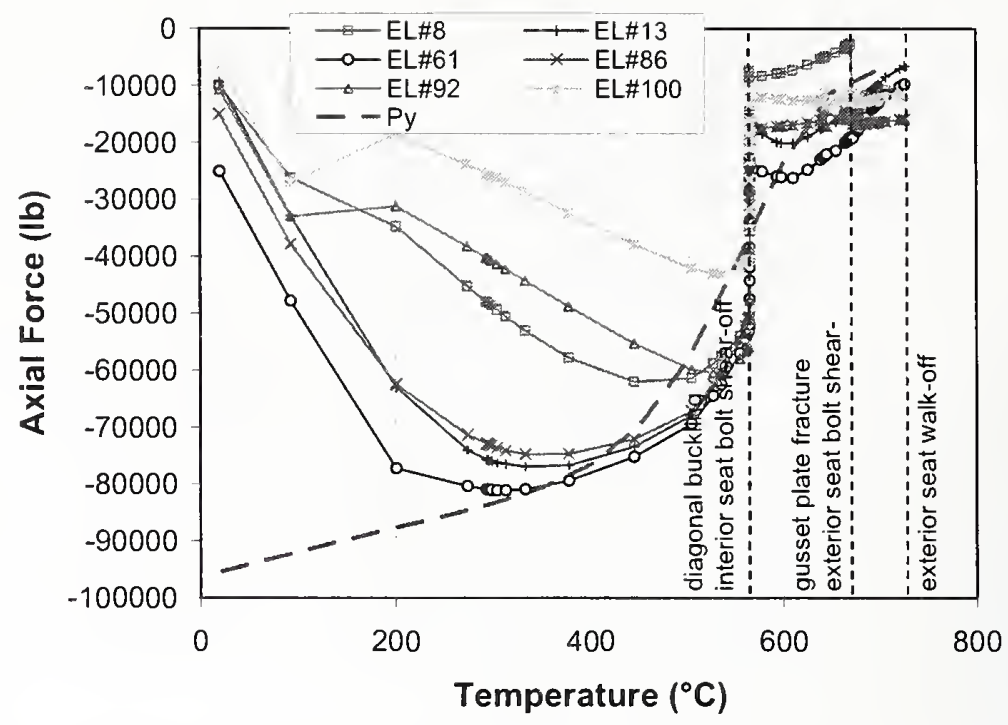

(b) Bottom chord

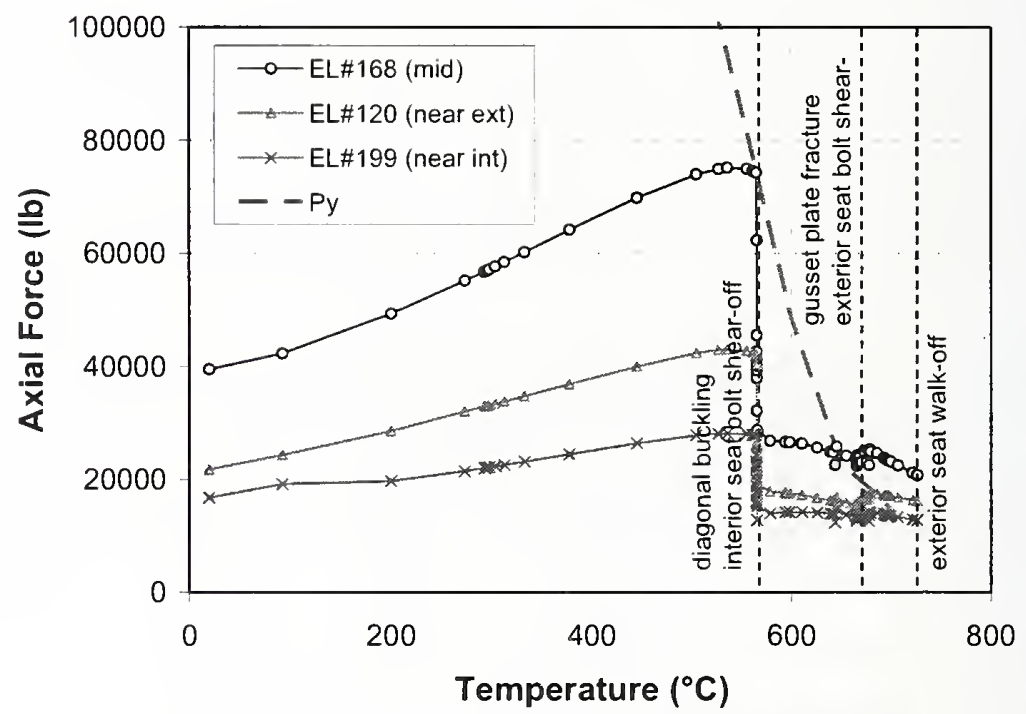

(c) Compression web diagonal

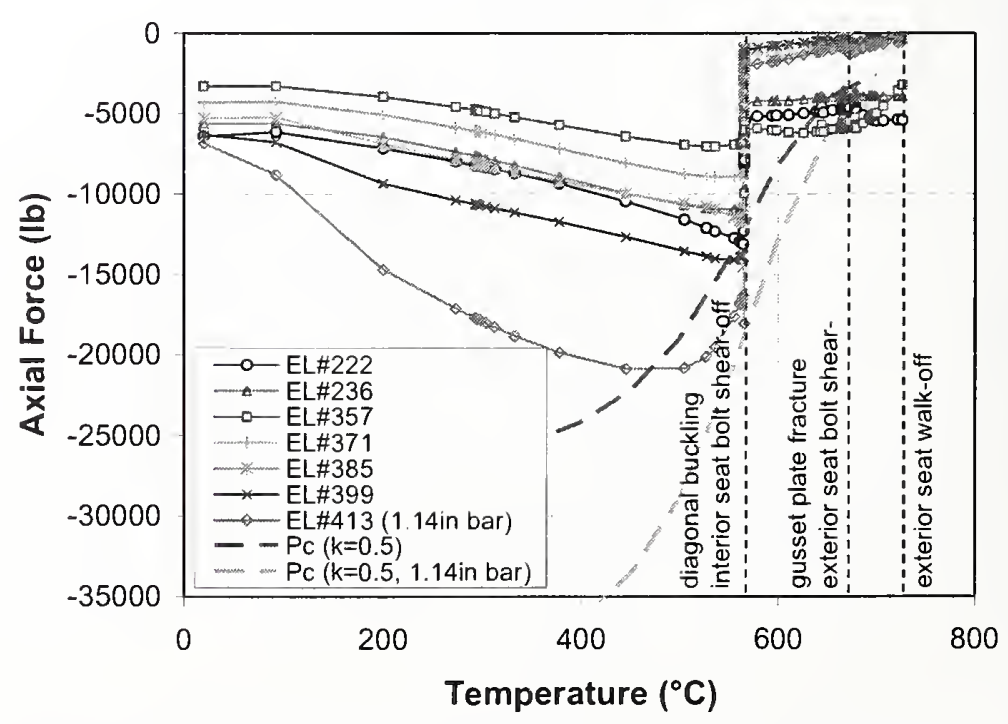

Figure 5-34. Axial force in truss members versus temperature of steel. 


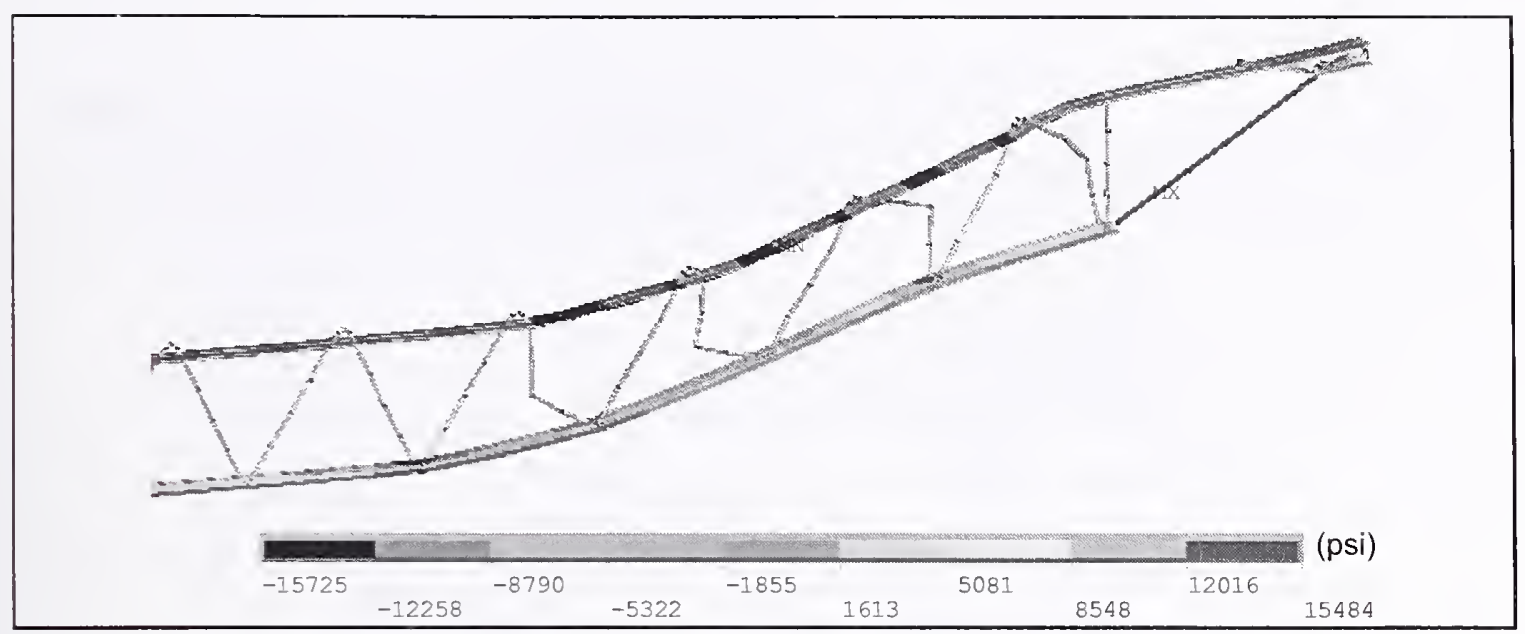

Figure 5-35. Axial stress contour in the truss members at $700{ }^{\circ} \mathrm{C}$ (tension is positive; $1.0 x$ displacement magnification).

Figure 5-37 (a) and (b) show the horizontal reaction forces at exterior and interior truss seats and exterior columns, respectively. At $566{ }^{\circ} \mathrm{C}$, the interior truss seat bolts sheared off, without loss of vertical support. At $670{ }^{\circ} \mathrm{C}$, the gusset plate at the exterior truss seat fractured, followed by shearing of the exterior seat bolt. At $730{ }^{\circ} \mathrm{C}$, the truss walked off the exterior truss seat. At about $600{ }^{\circ} \mathrm{C}$ before failures of the gusset plate and the exterior seat bolts, the tension between the truss and the exterior columns was about $12 \mathrm{kip}$, which was through the gusset plate and the strap anchor. At about $700{ }^{\circ} \mathrm{C}$ after failure of the gusset plate and the exterior truss seat bolts, the tension became about $10 \mathrm{kip}$, which was only through the strap anchor. It was found that $10 \mathrm{kip}$ tension in the strap anchor was larger than the strength at $700{ }^{\circ} \mathrm{C}(7.5$ kip) of the weld (a size of 5/16 in. and a length of 4 in.) between the strap anchor and the top chord. The failure of this weld was not modeled by break elements in the truss model. If the failure of this weld had been modeled in the truss model, the walk-off could have occurrcd at a temperature lower than $730{ }^{\circ} \mathrm{C}$.

Failure modes and failure sequence of the truss model subjected to "assumed tempcrature conditions" were as follows:

- The stud on the spandrel and studs on the strap anchor failed in shear below $275^{\circ} \mathrm{C}$.

- Knuckle 15 failed in vertical tension at around $100{ }^{\circ} \mathrm{C}$, and Knuckles 13 and 14 failed in the horizontal shear at $566^{\circ} \mathrm{C}$.

- Top chords yielded above $300{ }^{\circ} \mathrm{C}$ due to the difference in coefficients of thermal expansion of steel and lightweight concrete.

- Four compression web diagonals buckled due to high axial compressive force at $565^{\circ} \mathrm{C}$.

- The interior truss seat bolts sheared off at $566{ }^{\circ} \mathrm{C}$.

- The gusset plate fractured and the exterior truss seat bolts sheared off at around $680{ }^{\circ} \mathrm{C}$.

- The truss walked off the exterior truss seat at $730^{\circ} \mathrm{C}$.

The actual failure modes and failure sequence in the WTC towers may have been different due to the difference in actual and assumed temperature time histories. The truss model was simplified as described in the next section and incorporated in the full floor model and analyzed for the actual estimates of temperature time histories. 
Exterior

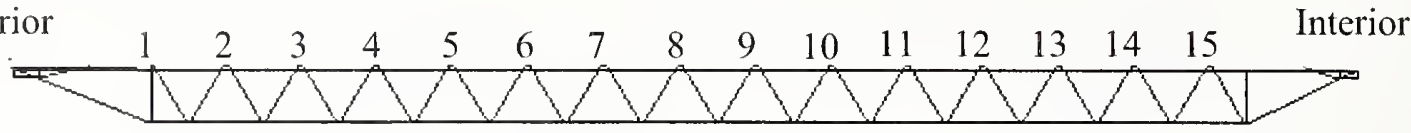

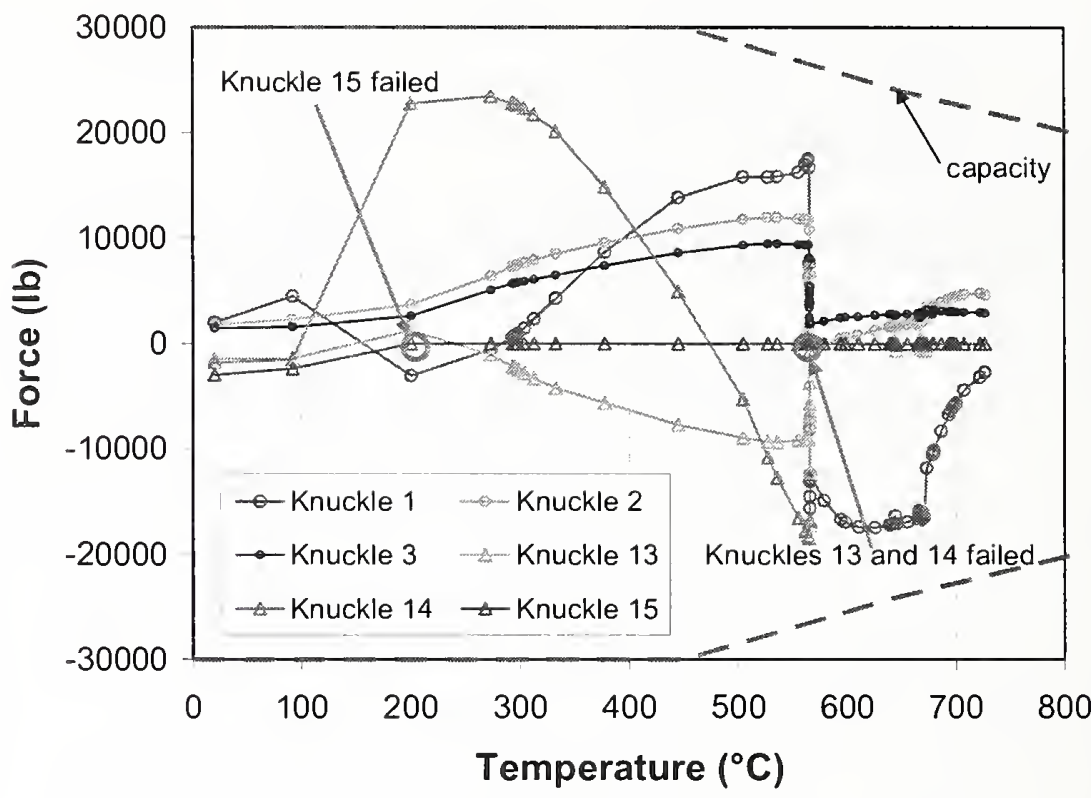

(a) Horizontal force

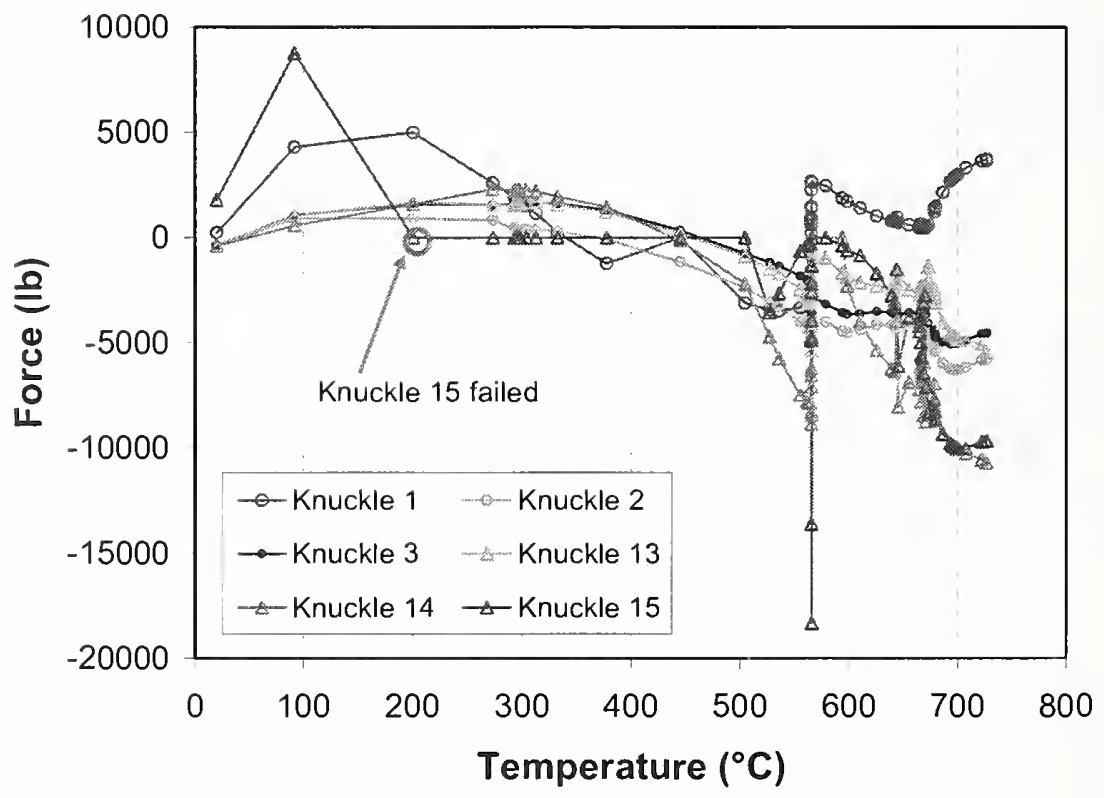

(b) Vertical force

Figure 5-36. Force in the knuckles versus temperature of steel. 


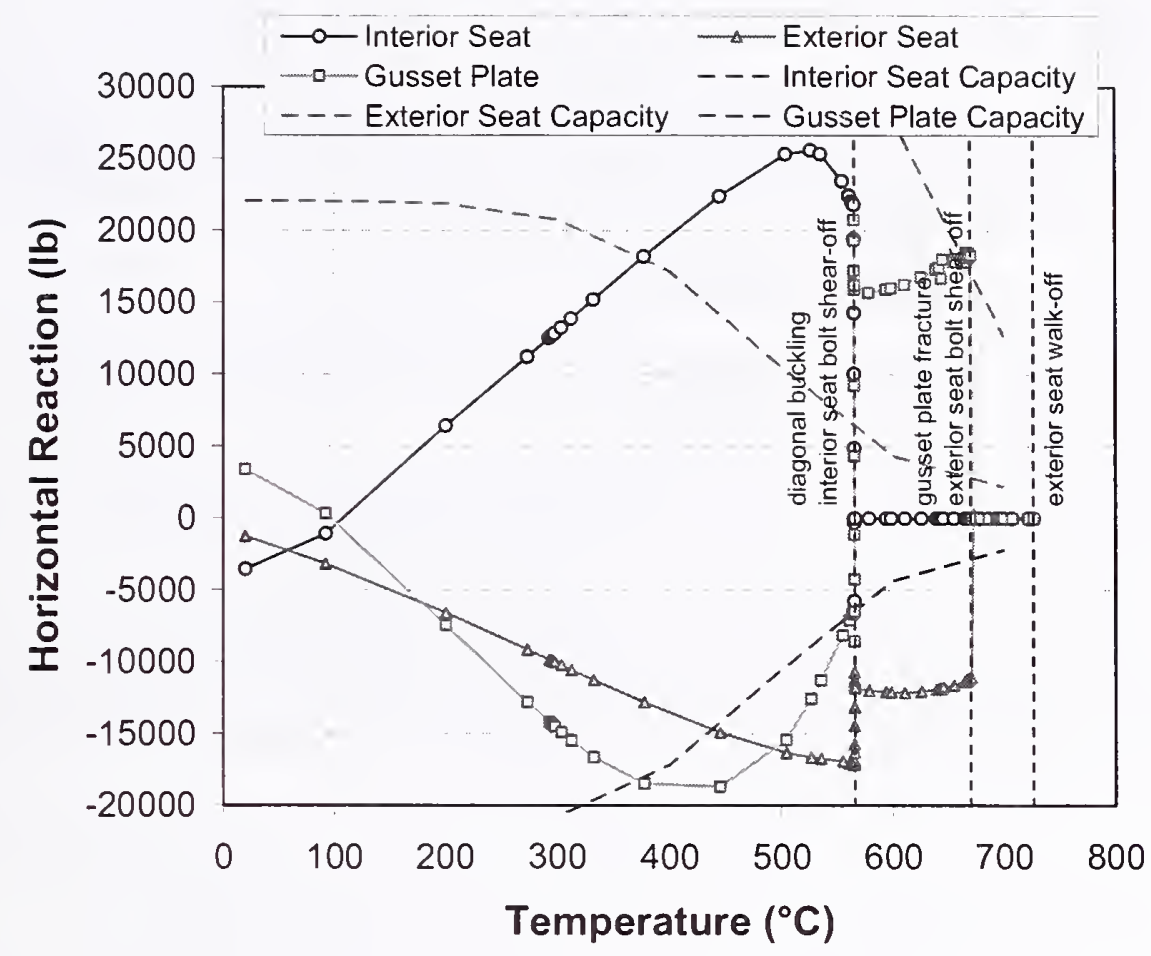

(a) At truss seats

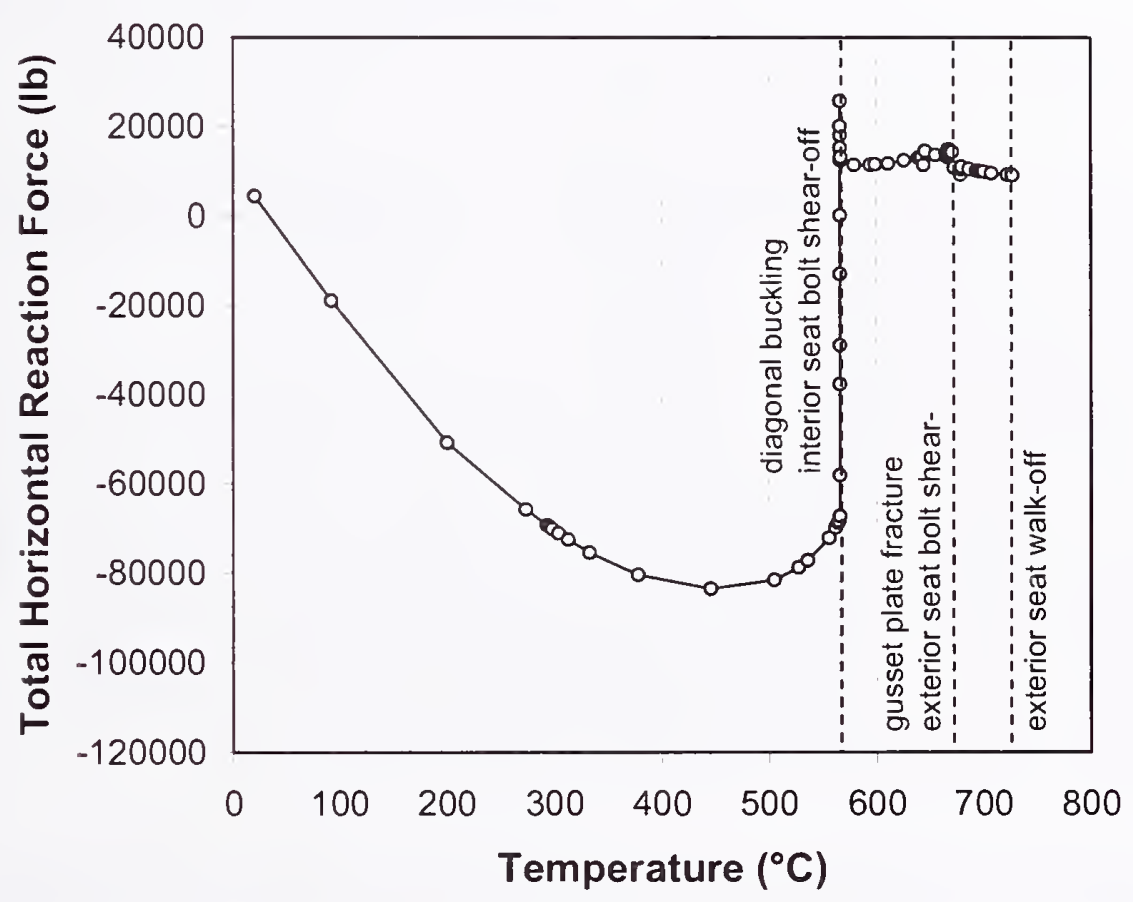

(b) At exterior columns

Figure 5-37. Horizontal reaction forces. 


\subsubsection{Simplified Truss Model}

The truss model was simplified for use in the full floor subsystem model. Characteristics of the truss model captured by the simplified truss model were: (1) total horizontal rcaction force under the thermal loading and (2) vertical deflcction at midspan under the thermal loading. The simplified truss model had the following features:

- The geometry of the truss was preserved.

- A pair of primary trusses at each exterior column was combincd into one truss. Cross scctions of truss members were doubled.

- The top and bottom chords and web diagonals were modeled by BEAM188 elements. A member between two panel points was modeled by one element only.

- Break elements modeled by ANSYS user-defined elements were used to model the following failure modes: (a) seat bolt shear-off, (b) gusset plate fracture, (c) truss walk-off, (d) web diagonal buckling/rcsistance weld failure, (e) failure of studs on the spandrel and strap anchors, and ( $f$ ) weld failure between strap anchors and top chords. User-defined break elements will be further discussed in Section 5.5.5.

- Knuckles were not modeled by break elements. It was found that neglecting knuckle failure did not significantly change truss behavior subjected to thermal loads.

- Steel had temperature-dependent elastic and plastic material properties.

- Creep in steel was included in the simplified truss model; however, it was not included when the simplified truss model was incorporated in the full floor model, because of convergence problems inherent in BEAM188 elements.

- The concrete slab was modeled by SHELL181 elements with a temperature-dependent bilinear material model that had the same yield strength in both tension and compression. The yield strength was set to the compressive strength.

- Construction sequence was not considered.

Figure 5-38 shows the vertical deflection at midspan and the horizontal reaction at exterior columns of the truss model and simplified truss model subjected to the gravity load and the assumed thermal load described in Section 5.4.4. Vertical displacement in this figure is the displacement that occurred during thermal loading. The simplified truss model predicted the buckling of web diagonals at $530{ }^{\circ} \mathrm{C}$, which is about $35^{\circ} \mathrm{C}$ lower than the temperature at which web diagonal buckling was predicted by the truss model. The tension at $700{ }^{\circ} \mathrm{C}$ in the simplified truss model was about $2 \mathrm{kip}$, which was less than $10 \mathrm{kip}$ in the truss model. Overall truss behaviors as predicted by the simplified truss model subjected to gravity and the assumed thermal loading were in good agreement with the truss model. 


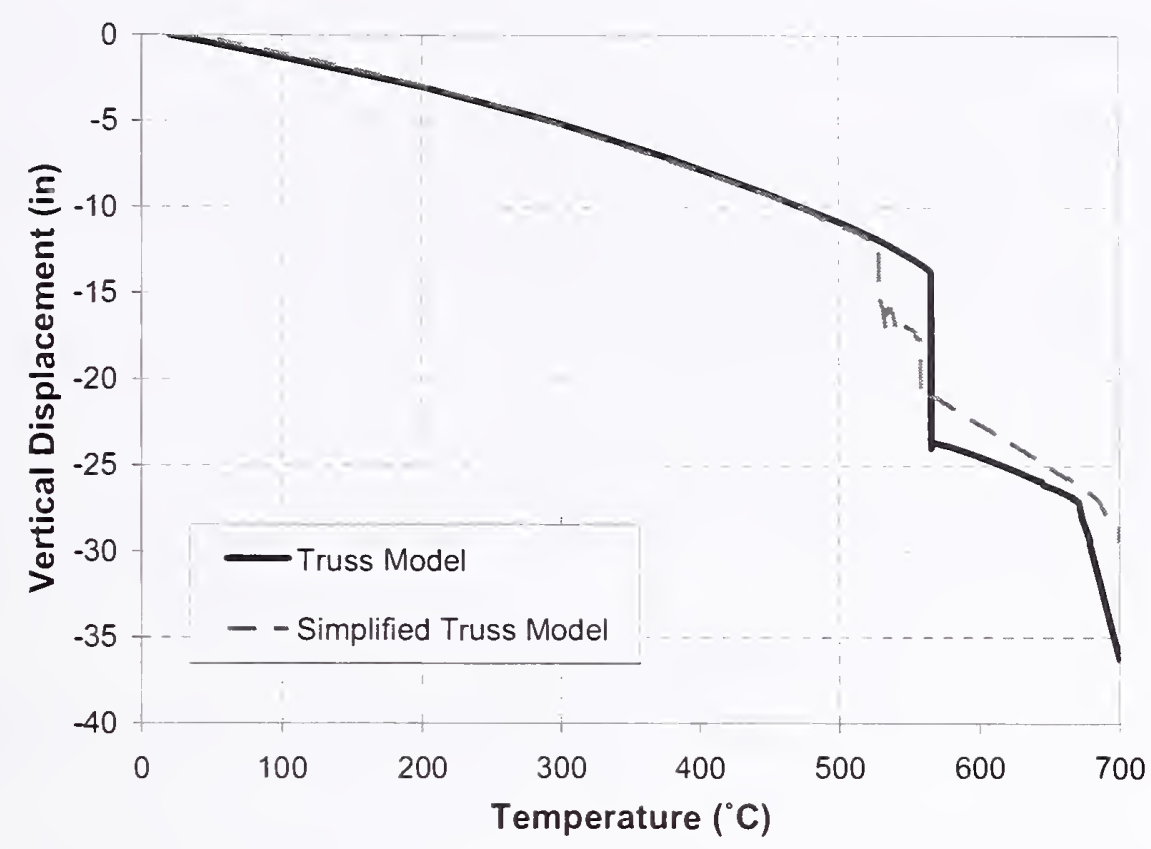

(a) Midspan vertical deflection

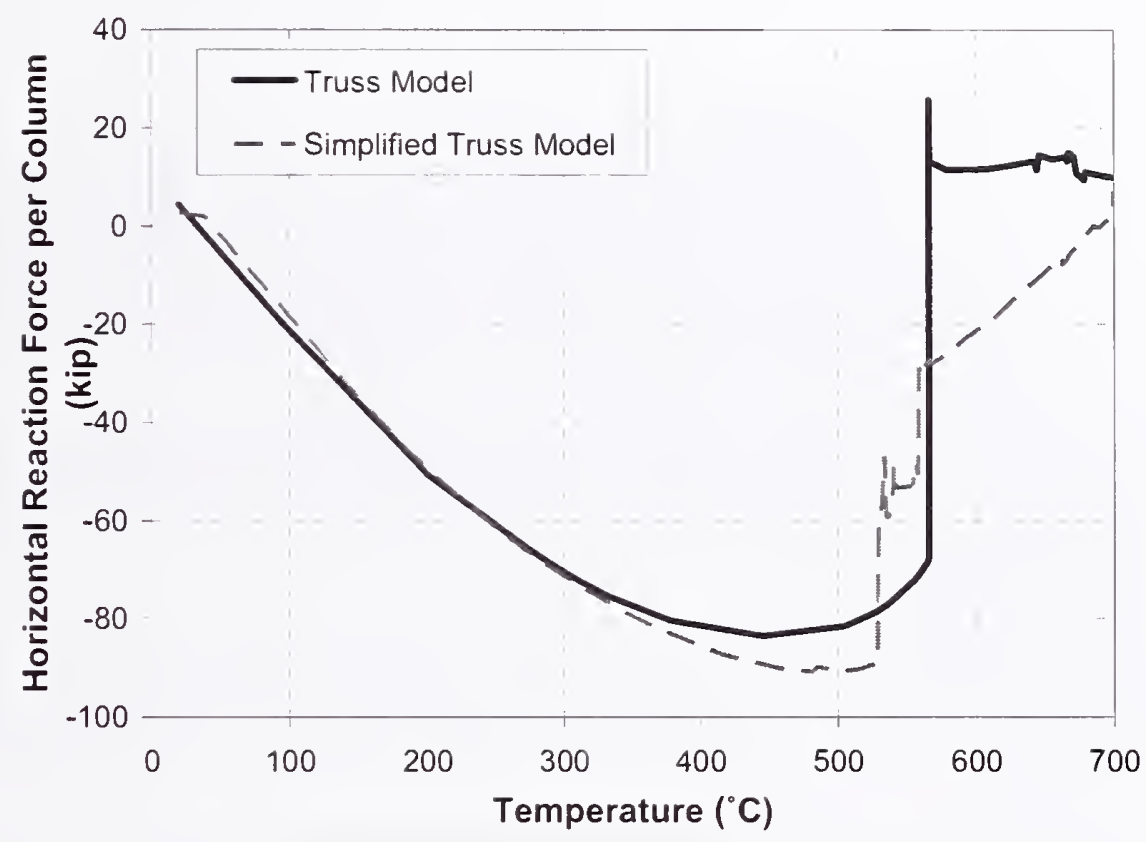

(b) Horizontal reaction force at exterior columns

Figure 5-38. Comparison of detailed and simplified truss models. 


\subsection{FULL FLOOR MODEL}

\subsubsection{Objective}

The full floor model was developed and analyzed using the ANSYS general purpose finite element program Version 8.1. The objectives of the full floor model analysis were:

- To identify the most likely failure modes,

- To evaluate

- Failure loads,

- Temperatures at failure,

- Time-to-failure, and

- Changes in mechanical properties and geometry at failure.

- To identify the fire-induced damage to be incorporated along with impact-induced damage in the global model

- To develop computationally efficient modeling details of the floor subsystem for incorporation into the global model.

\subsubsection{Failure Modes}

Failure modes that the full floor models captured were as follows:

- Floor Sagging: Floor sagging was caused by loss of stiffness and softening of truss at high temperature, by yielding and buckling of truss members, and by the impact damage to truss seats. These were discussed in some detail under truss failure modes. Floor sagging resulted in tension in the floor subsystem, tension on the connections to the exterior walls, and lateral forces (pull-in forces) on exterior columns.

- Loss of Support: Loss of a truss support was caused by reduced vertical shear resistance of truss seats at elevated temperatures, by tension acting on truss seats caused by floor sagging, and by aircraft impact.

\subsubsection{Model Description}

The base floor model developed was for Floor 96 of WTC 1 with columns extending from Floor 95 to Floor 97. The model was developed based on the converted SAP2000 model for Floor 96 of WTC 1, with the following modifications:

1. Two adjacent trusses supported by the same column were combined into a single truss. The areas of members in a truss were doubled to create a combined truss.

2. Spandrels were defined as beam sections in the SAP2000 model, and were replaced with SHELL181 elements (eight elements between two columns and four elements along the height). This modification eliminated the need for defining panel zone stiffness at the interface between spandrel and exterior column.

3. Elastic column elements were changed to BEAM189 elements with user-defined composite sections and nonlinear material properties. 
4. Section offsets of exterior columns were removed, and nodes were placed at centroids of their cross sections.

5. Spandrels were tied to exterior columns by rigid beam elements as described in Section 6.4.1 of this report.

6. Core floor slab was remeshed with a more uniform mesh.

7. Section offsets of core beams were removed to eliminate the end bending moment due to eccentricity. Core beams were placed at their centroids and were connected to the slab by rigid beam elements.

8. Where there was more than one beam element representing a top chord between two adjacent panel points, the beam elements were merged into one to prevent the top chord from buckling upward and penetrating the slab.

9. Web diagonals were modeled by BEAM188 elements.

10. Coincident nodes were provided for user-defined break elements.

11. User-defined break elements were incorporated into the model to represent:
a. buckling of web diagonals,
b. gusset plate fracture,
c. truss seat bolt shear-off,
d. truss seat failure,
e. failure of connections between primary and bridging trusses,
f. failure of connections between primary long-span and transfer trusses,
g. failure of studs connecting the slab and the spandrel, and
h. failure of welds between strap anchors and top chords of primary trusses.

12. The ANSYS floor model translated from the SAP model had the bottom chord connection at every intersection of primary and bridging trusses. Some of the bottom chord connections between primary and bridging trusses were removed according to the PANYNJ drawings.

The full floor model, as shown in Fig. 5-39, included the following structural members:
a. both exterior and core columns extending from one floor below to one floor above,
b. spandrels of the floor modeled,
c. floor slab,
d. floor trusses including primary and bridging trusses,
e. strap anchors,
f. core beams, and
g. deck support angles. 


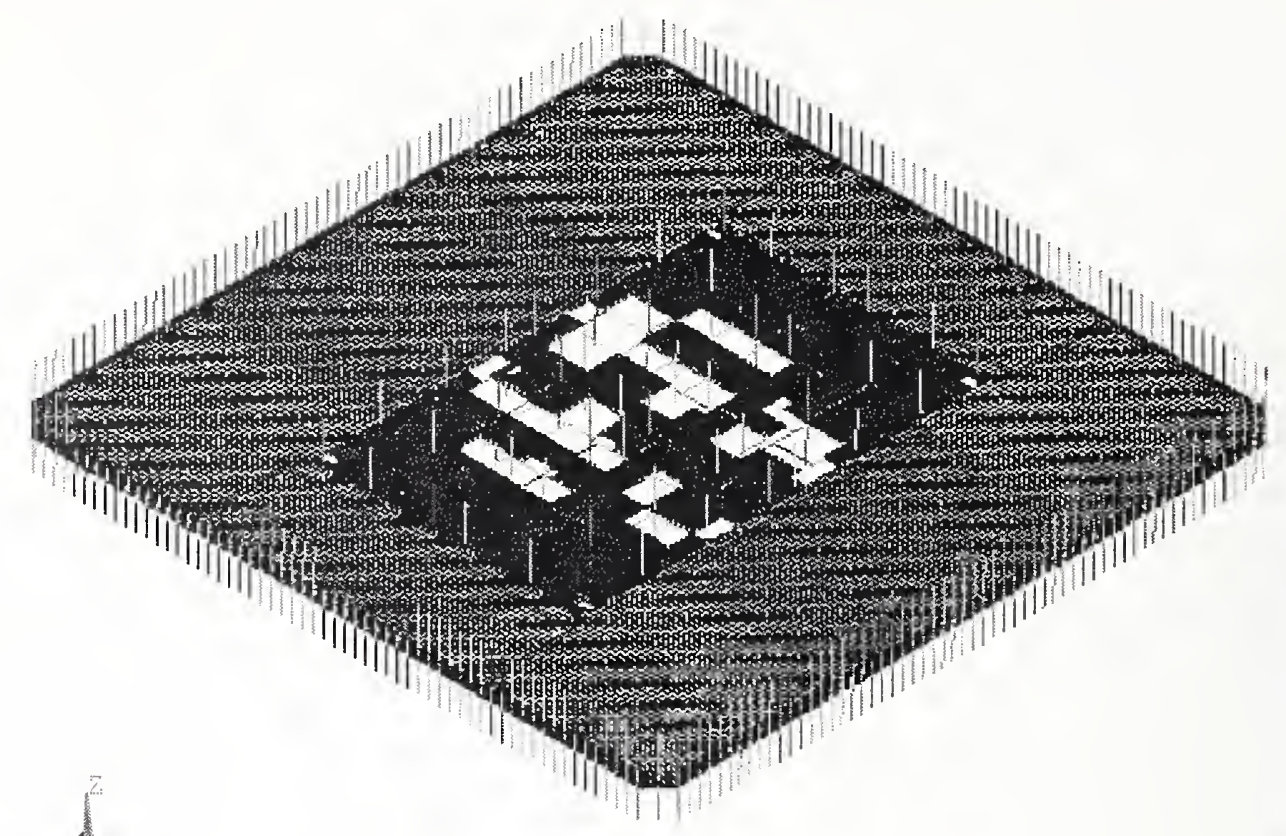

(a) Top view

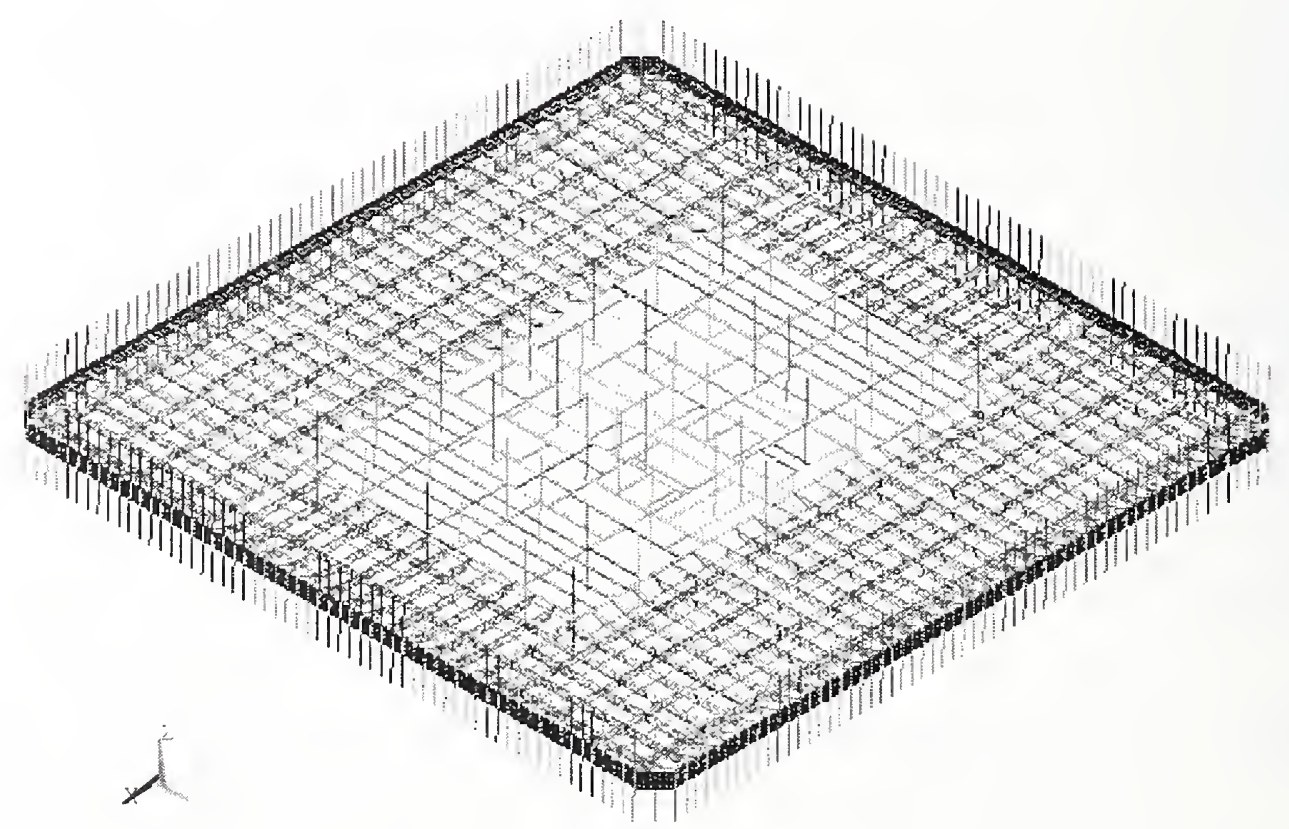

(b) Top view without concrete slab

Figure 5-39. Full floor model without impact damage. 
The size of the full floor model was as follows:

- Number of elements: 46,280

- Number of nodes: 61,251

- Number of degrees of freedom: 269,926

Truss members (top and bottom chords and web diagonals) were modeled by BEAM188 elements.

Columns were modeled by BEAM1 89 elements. Spandrels were modeled by SHELL1 81 elements. The concrete slab was modeled by SHELL181 elements with four layers through the thickness. Each layer of the shell element for the slab had one integration point.

The full floor model was validated against the SAP floor model by performing the two analyses described in Section 4.2.1. To compare the full floor model with the SAP floor model, density of lightweight concrete was changed from $110 \mathrm{pcf}$ to $100 \mathrm{pcf}$. Under gravity loads, the maximum displacement of the full floor model was $0.722 \mathrm{in}$., which is only 0.56 percent smaller than that of the SAP floor model. The first vibration mode of the full floor model was not the vertical deflection of the office floor, but the lateral vibration of the bridging trusses in the short-span truss area. This was a result of removing some of the bottom chord connections between the primary and bridging trusses. The natural frequency of the vertical deflection mode was $4.41 \mathrm{~Hz}$, which is only 2 percent higher than that of the SAP floor model.

Subsequent to initial full floor analysis with thermal loads, the members listed below were removed from the model to enhance computational efficiency without loss of accuracy of prediction of final failure modes and failure sequence, as shown in Fig. 5-40.

- Deck support angles

- Bridging trusses outside of the two-way zones

- Spandrel studs connecting the slab and the spandrel

- Strap anchors

These elements failed in the early stage of thermal loading and caused the analysis to slow down due to large nonlinearities of the failed elements. Deck support angles and bridging trusses buckled between the primary trusses due to thermal expansion. Many shear studs and welds between strap anchors and truss top chords failed due to lateral shear force in the direction transverse to the primary trusses caused by the difference in thermal expansion between the floor and the exterior wall. These members were removed from the model to enhance computational efficiency. As a result of removal of strap anchors and spandrel studs, the only connections between the exterior wall and the floor were gusset plates and exterior truss seats.

The visco-elastic dampers that connected the truss bottom chords to the spandrels were not included in the full floor model because dampers were expected to be soft when subjected to very slow loading rates.

The concrete slab was attached to primary trusses at knuckle locations. Break elements were not used for representing knuckle failure as the truss analysis found that web diagonal buckling rather than knuckle failure caused floors to sag. The concrete slab and trusses were always connected in the analysis. 


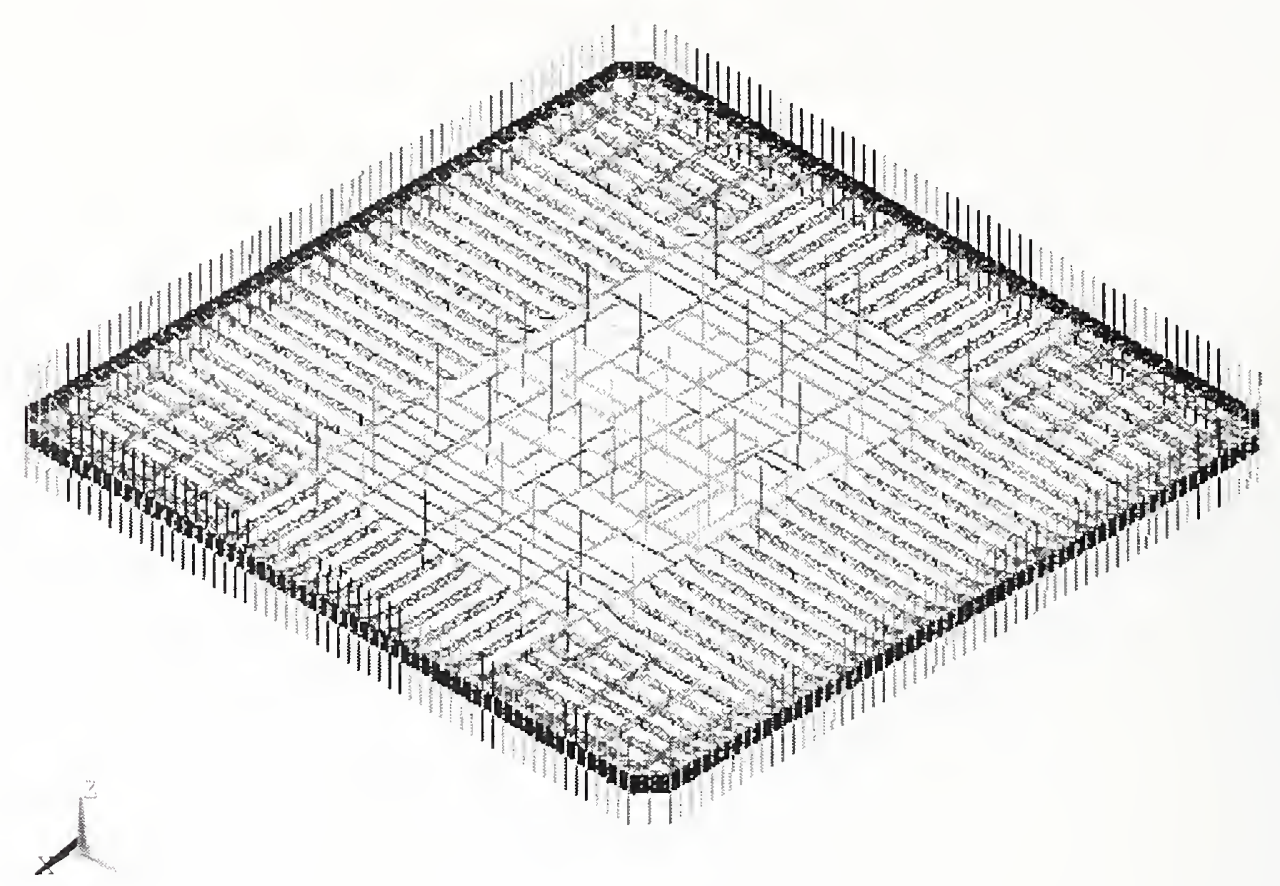

Figure 5-40. Full floor model after removal of deck support angles, spandrel studs, bridging trusses outside of two-way zones, and strap anchors.

\subsubsection{Material Properties}

Material properties from Table 3-1 were assigned to each steel member according to the PANYNJ drawings. The Hjelm plasticity model used for the concrete slab in the truss model can be used only with solid elements. Since the concrete slab in the full floor model was modeled by shell elements to enhance computational efficiency, a bilinear model with a yield point at its compressive strength was created and assigned to the shell elements for the concrete slab. This material model required the same yield strength values in both tension and compression, as shown in Fig. 5-41. With this material model, tensile strength of the concrete slab was not represented accurately, and the actual floor stiffness was overestimated. In the full floor models, bending stresses in the concrete slab that exceeded the actual tensile strength of concrete were found in few locations. This phenomenon was typically observed when the temperature of the top of the slab was higher than the temperature at the bottom of the slab, and the concrete slab still deflected down due to large thermal expansion of the truss. However, when the temperature is higher at the bottom, the simplified truss model with this material model showed a very similar behavior to the detailed truss model, and the key failure modes of the floors were not significantly affected.

Thermal expansion of the spandrel would cause the spandrel to buckle between columns at early stages of thermal loading and slow down the computation, causing severe convergence problems. To enhance computational efficiency, a bilinear material model with a yield strength lower than the elastic buckling strength was incorporated in the spandrel to prevent its elastic buckling. Figure 5-42 shows the bilinear model in the spandrel and the location of elements with this material model.

It was found that creep in BEAM188/189 elements would cause severe convergence problems when those elements experience thermally-induced buckling. Therefore, creep was not included in any of the full floor analyses. 


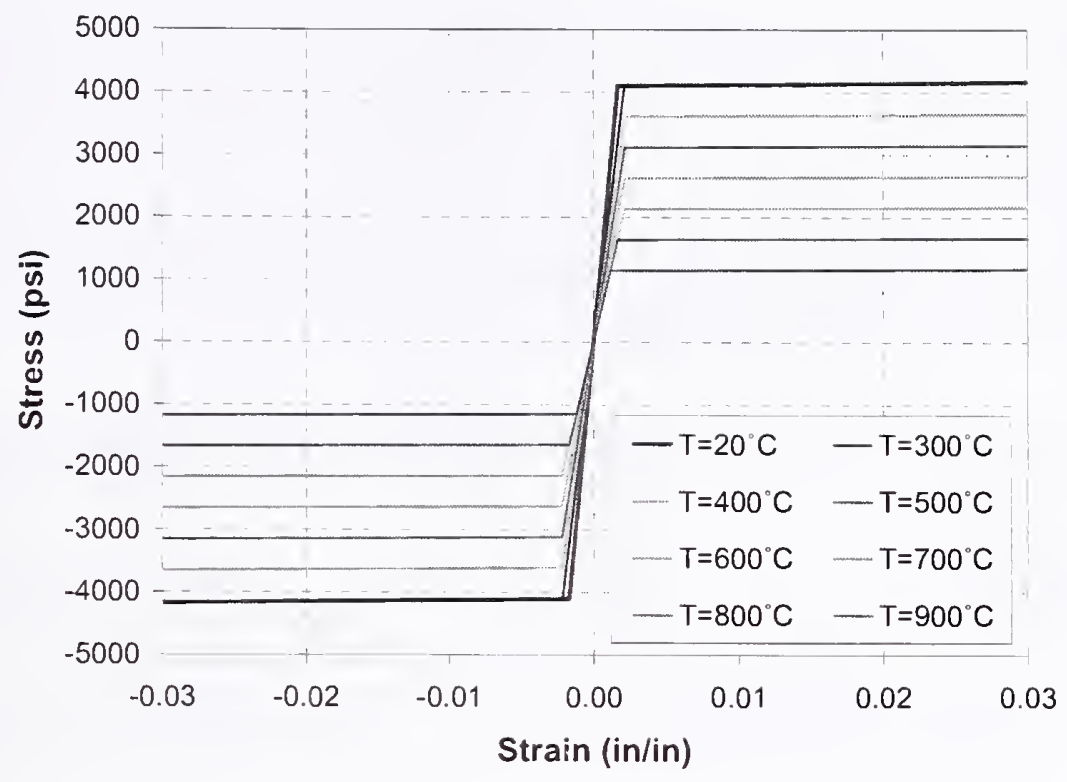

Figure 5-41. Bilinear material model for concrete slab in the full floor model.

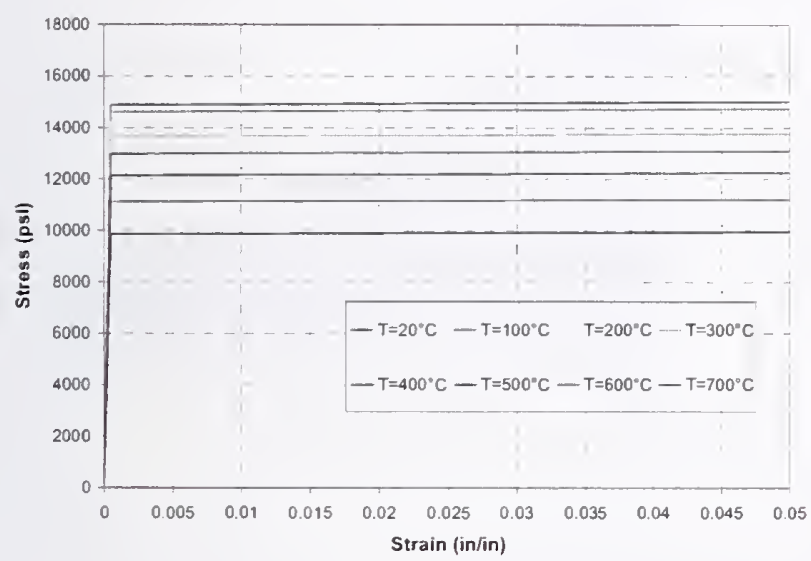

(a) Bilinear material model for spandrel (only tension side is shown)

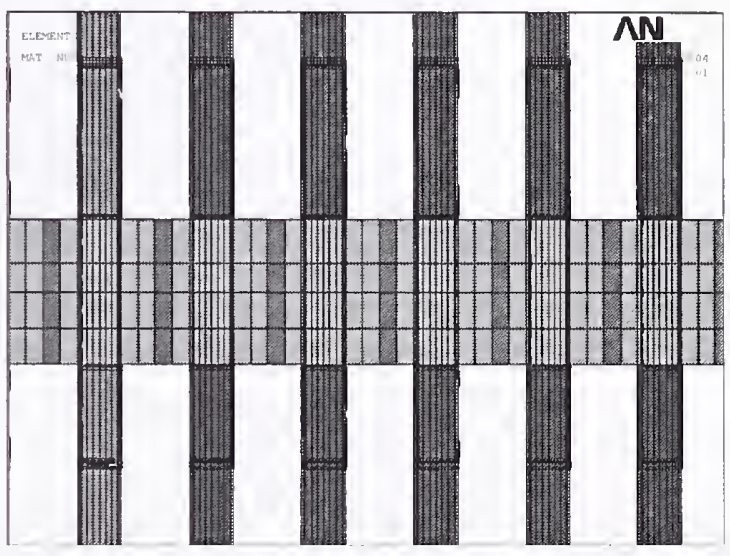

(b) Elements with the bilinear material model (shown in pick)

Figure 5-42. Bilinear material model in the spandrel.

\subsubsection{User-Defined Break Elements}

Break elements were used to represent component failures. Break elements for the full floor model were recreated by using user-defined elements in ANSYS. Basically, a user-defined break element is an elastic spring. When the force or the moment in a certain direction in the element reaches its capacity, the spring stiffnesses in all directions are reduced to the predefined post-failure stiffnesses. Initial and post-failure stiffnesses are defined as temperature-independent properties, while the capacity can be defined as temperature-dependent properties. Different capacities can be assigned to tension and compression. There are differences between the break elements defined by COMBIN37 elements described in Section 5.2.5 and the break elements defined by user-defined elements. First, the user-defined break 
element has stiffness even after failure of the element although the post-failure stiffness is set significantly small, usually $10^{-4}$ to $10^{-6}$ times the initial stiffness. Second, only one user-defined break element is usually required to model one failure mode, while many COMBIN37 break elements along with elastic beam elements are required to model one failure mode.

Four different types of user-defined break elements were developed for the full floor model and the exterior wall model, and their features are summarized in Table 5-10. Figure 5-43 shows a summary of user-defined break element locations in the full floor model.

Table 5-10. Types of user-defined break elements.

\begin{tabular}{|c|c|c|c|c|c|}
\hline Type & $\begin{array}{c}\text { Degrees } \\
\text { of } \\
\text { Freedom. }\end{array}$ & $\begin{array}{c}\text { Capacities } \\
\text { to be } \\
\text { defined }\end{array}$ & Stiffness to be defined & Description & $\begin{array}{l}\text { Usage in the } \\
\text { floor model }\end{array}$ \\
\hline 102 & $\begin{array}{l}\text { UX } \\
\text { UY } \\
\text { UZ } \\
\text { ROTX } \\
\text { ROTY } \\
\text { ROTZ }\end{array}$ & $\begin{array}{l}\text { Positive FX } \\
\text { Negative FX } \\
\text { Positive FY } \\
\text { Negative FY } \\
\text { Positive FZ } \\
\text { Negative FZ } \\
\text { MX } \\
\text { MY } \\
\text { MZ }\end{array}$ & $\begin{array}{l}\text { Initial stiffness for UX } \\
\text { Post-failure stiffness for UX } \\
\text { Initial stiffness for UY } \\
\text { Post-failure stiffness for UY } \\
\text { Initial stiffness for UZ } \\
\text { Post-failure stiffness for UZ } \\
\text { Initial stiffness for ROTX } \\
\text { Post-failure stiffness for ROTX } \\
\text { Initial stiffness for ROTY } \\
\text { Post-failure stiffness for ROTY } \\
\text { Initial stiffness for ROTZ } \\
\text { Post-failure stiffness for ROTZ }\end{array}$ & $\begin{array}{l}\text { All force and moment } \\
\text { components are checked } \\
\text { with corresponding } \\
\text { capacities. }\end{array}$ & $\begin{array}{l}\text { Failure of seats } \\
\text { Fracture of } \\
\text { gusset plates } \\
\text { Failure of } \\
\text { connections } \\
\text { between primary } \\
\text { and bridging } \\
\text { trusses } \\
\text { Failure of } \\
\text { connections } \\
\text { between long- } \\
\text { span and transfer } \\
\text { trusses }\end{array}$ \\
\hline 103 & $\begin{array}{l}\mathrm{UX} \\
\mathrm{UY} \\
\mathrm{UZ}\end{array}$ & $\begin{array}{l}\text { Positive F } \\
\text { Negative F }\end{array}$ & $\begin{array}{l}\text { Initial stiffness for UX, UY, } \\
\text { and UZ } \\
\text { Post-failure stiffness for UX, } \\
\mathrm{UY} \text {, and UZ }\end{array}$ & $\begin{array}{l}\text { SRSS* of three force } \\
\text { components is checked } \\
\text { with the capacity. The } \\
\text { sign of force is } \\
\text { determined by the } \\
\text { direction specified by } \\
\text { the user. }\end{array}$ & $\begin{array}{l}\text { Failure of strap } \\
\text { anchor welds }\end{array}$ \\
\hline 104 & $\begin{array}{l}\text { UX } \\
\text { UY } \\
\text { UZ }\end{array}$ & $\begin{array}{l}\text { Positive FX } \\
\text { Negative FX } \\
\text { Positive FY } \\
\text { Negative FY } \\
\text { Positive FZ } \\
\text { Negative FZ }\end{array}$ & $\begin{array}{l}\text { Initial stiffness for UX } \\
\text { Post-failure stiffness for UX } \\
\text { Initial stiffness for UY } \\
\text { Post-failure stiffness for UY } \\
\text { Initial stiffness for UZ } \\
\text { Post-failure stiffness for UZ }\end{array}$ & $\begin{array}{l}\text { All force components } \\
\text { are checked with } \\
\text { corresponding } \\
\text { capacities. }\end{array}$ & $\begin{array}{l}\text { Failure of studs } \\
\text { connecting the } \\
\text { spandrel and the } \\
\text { slab }\end{array}$ \\
\hline 105 & $\begin{array}{l}\text { UX } \\
\text { UY } \\
\text { UZ } \\
\text { ROTX } \\
\text { ROTZ } \\
\text { ROTZ }\end{array}$ & $\begin{array}{l}\text { Positive F } \\
\text { Negative F }\end{array}$ & $\begin{array}{l}\text { Initial stiffness for UX, UY, } \\
\text { and UZ } \\
\text { Post-failure stiffness for UX, } \\
\text { UY, and UZ } \\
\text { Initial stiffness for ROTX, } \\
\text { ROTY, and ROTZ } \\
\text { Post-failure stiffness for ROTX, } \\
\text { ROTY, and ROTZ }\end{array}$ & $\begin{array}{l}\text { SRSS* of three force } \\
\text { components is checked } \\
\text { with the capacity. The } \\
\text { sign of force is } \\
\text { determined by the } \\
\text { direction specified by } \\
\text { the user. }\end{array}$ & $\begin{array}{l}\text { Buckling of web } \\
\text { diagonals } \\
\text { Failure of } \\
\text { resistance weld } \\
\text { between web } \\
\text { diagonals and } \\
\text { chords }\end{array}$ \\
\hline
\end{tabular}

*SRSS: square-root-of-sum-of-square 
O

0

(a) Web diagonal buckling or weld failure

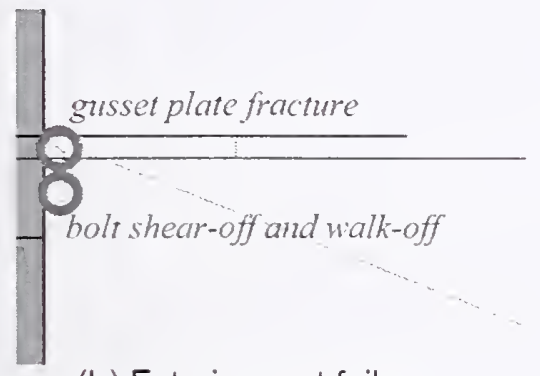

(b) Exterior seat failure

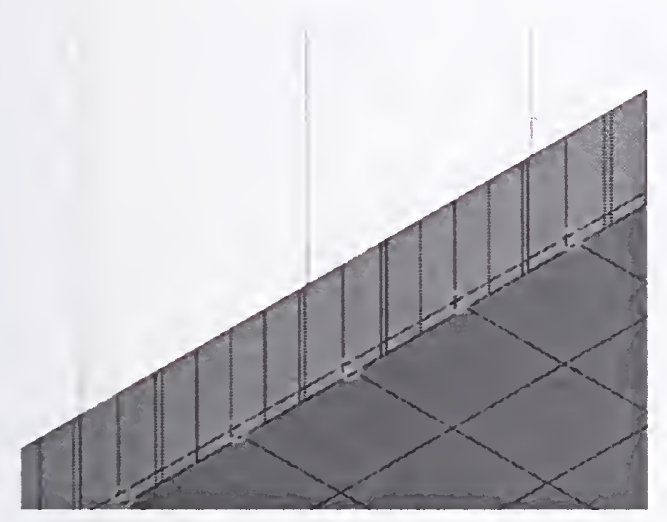

(d) Stud failure

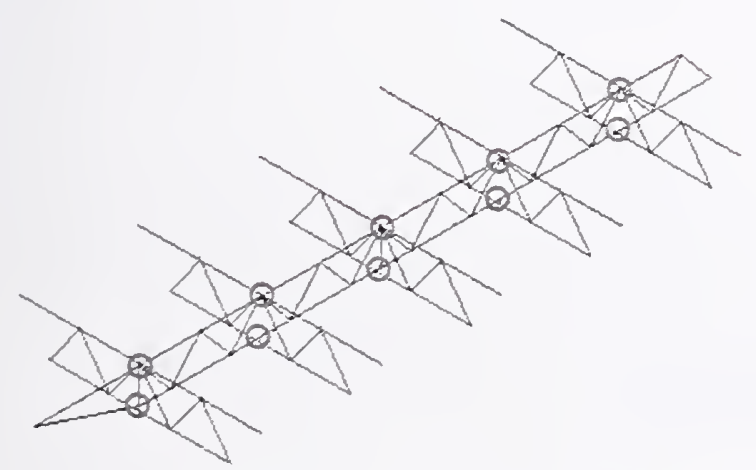

(e) Connection failure between primary and bridging trusses

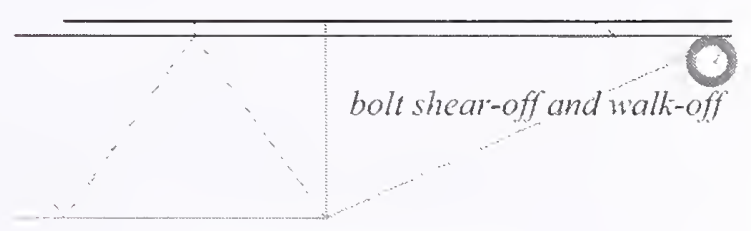

(c) Interior seat failure

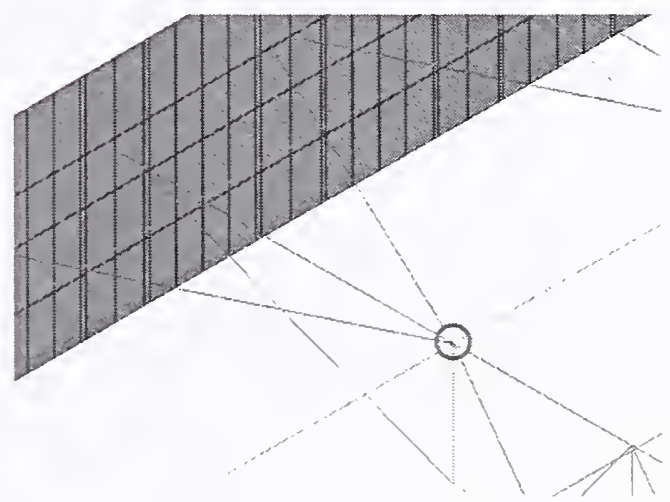

(d) Strap anchor weld failure

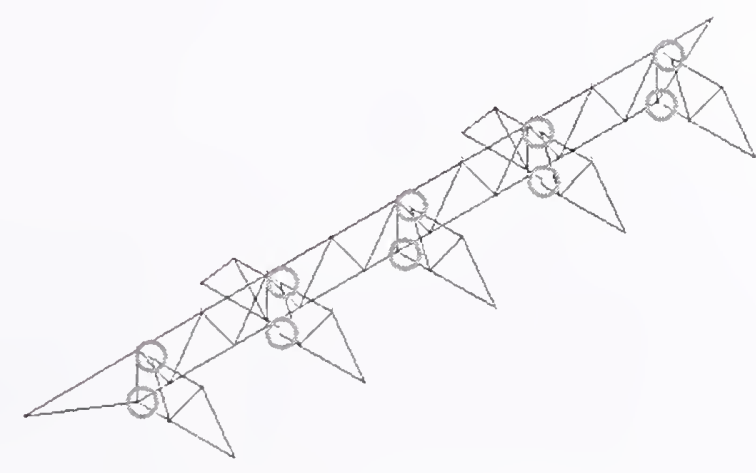

(f) Connection failure between long-span and transfer trusses

Figure 5-43. Summary of user-defined break element locations in the full floor model. 
Table 5-11 gives the number of user-defined break elements in the WTC 1 Floor 96 model after the removal of studs, strap anchors, bridging trusses, and severed members by aircraft impact, and Fig. 5-44 shows locations of the user-defined break elements.

Table 5-11. Number of user-defined break elements in the full floor model (Floor 96, WTC 1).

\begin{tabular}{|l|c|}
\hline & Number of break elements \\
\hline Web diagonals & 1,264 \\
\hline Studs & 0 \\
\hline Strap anchor welds & 0 \\
\hline Seats and gusset plates & 564 \\
\hline Connections between primary and bridging trusses & 200 \\
\hline Connections between long-span and transfer trusses & 40 \\
\hline \hline Total & 2,068 \\
\hline
\end{tabular}

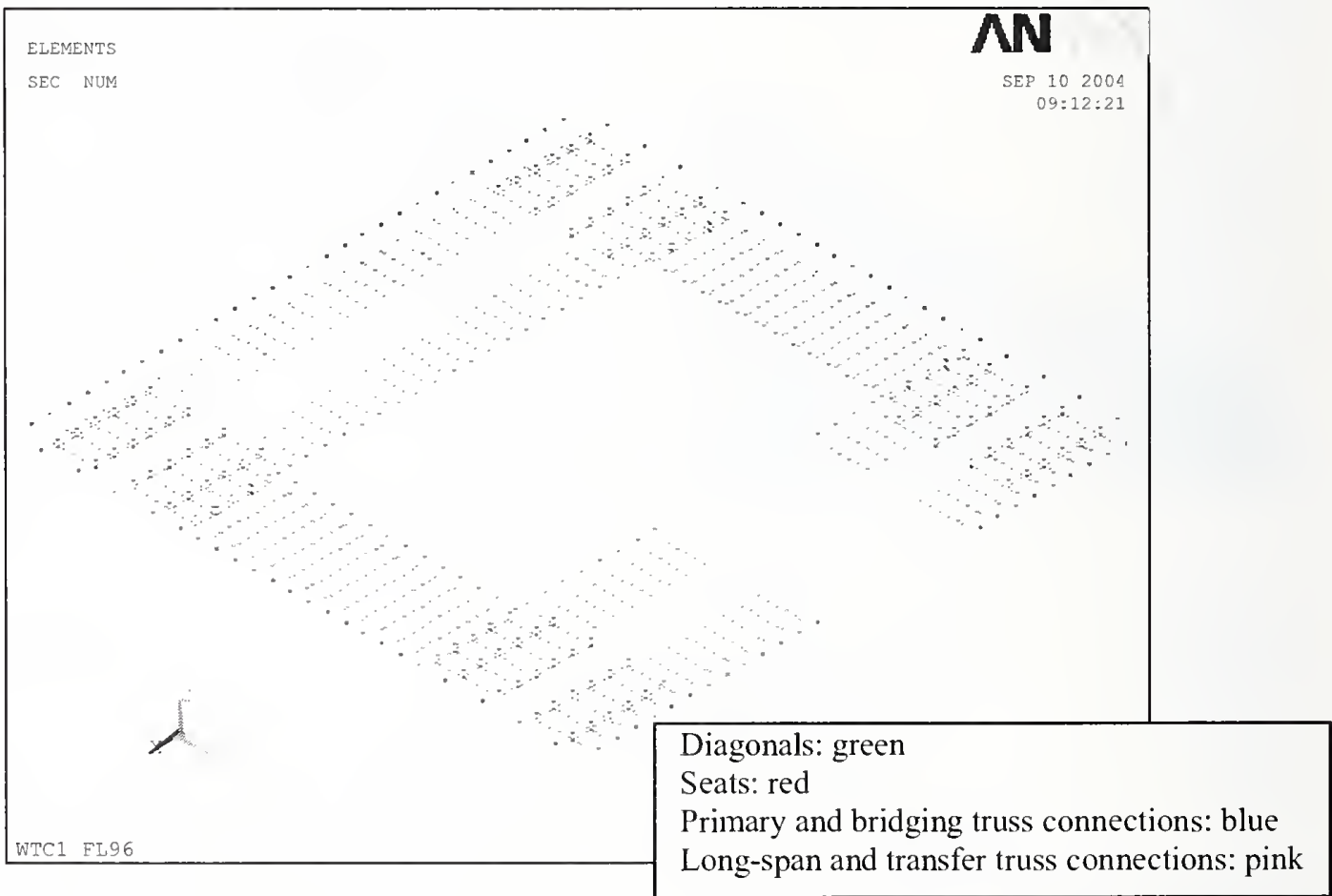

Figure 5-44. User-defined break element locations in the full floor model (Floor 96, WTC 1). 


\subsubsection{Impact Damage}

Elements corresponding to structural members that sustained severe structural damage were removed from the model. Based on the aircraft impact analysis, NIST identified two sets of impact damage (structural damage and insulation damage) for each of the two WTC towers. These two cases represented a base case and a more severe case of damage estimates, and they were designated as "Case $\mathrm{A}_{i}$ impact damage condition" and "Case $\mathrm{B}_{\mathrm{i}}$ impact damage condition" for WTC 1, and "Case $\mathrm{C}_{\mathrm{i}}$ impact damage condition" and "Case $\mathrm{D}_{i}$ impact damage condition" for WTC 2. The floor model analyses were performed by using these impact damage conditions. However, NIST later refined these impact damage conditions, and refined cases are referred to as "Case A impact damage condition" and "Case B impact damage condition" for WTC 1, and "Case C impact damage condition" and "Case D impact damage condition" for WTC 2. Refined impact damage conditions were never used in the full floor model. Figures 5-45 to 5-54 show structural impact damage conditions for different cases. Structural impact damage to exterior columns did not change between Case $A_{i}$ and Case $B_{i}$ or between Case $C_{i}$ and Case $D_{i}$. Only columns that were indicated as "severed" were removed from the model, and those columns that were damaged but not severed were retained as undamaged in the analysis. Figures 5-55 through 5-60 show floor models of WTC 1 Floor 96 with and without impact damage for Case $A_{i}$ impact damage condition.

Using the base floor model (WTC 1 Floor 96) as a basis, seven floor models from Floor 93 to Floor 99 of WTC 1 were created for Case $A_{i}$ structural damage condition. Each model had the same geometry, but different impact damages were incorporated. Since Case $\mathrm{B}_{i}$ structural damage condition was not provided by NIST at the time of computation, the same structural damage as Case $A_{i}$ was assumed for Case $B_{i}$ condition. The WTC 2 Floor 81 model was developed by changing only column properties of the base floor model (WTC 1 Floor 96). Floor models of other floors of WTC 2 (Floor 79, Floor 80, Floor 82, and Floor 83) had the same geometry as the WTC 2 Floor 81 model, but had different impact damage. For WTC 2, a total of ten models were created: five models for Case $C_{i}$ impact damage condition and five for Case $D_{1}$ impact damage condition. 


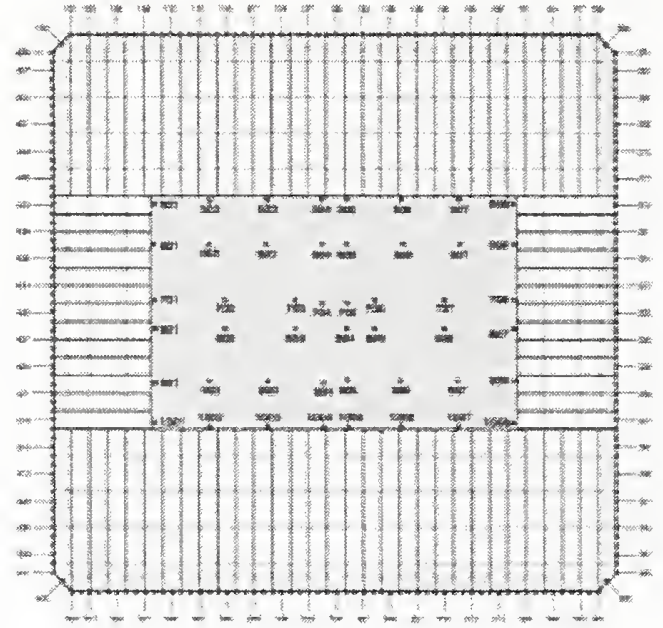

(a) Floor 94

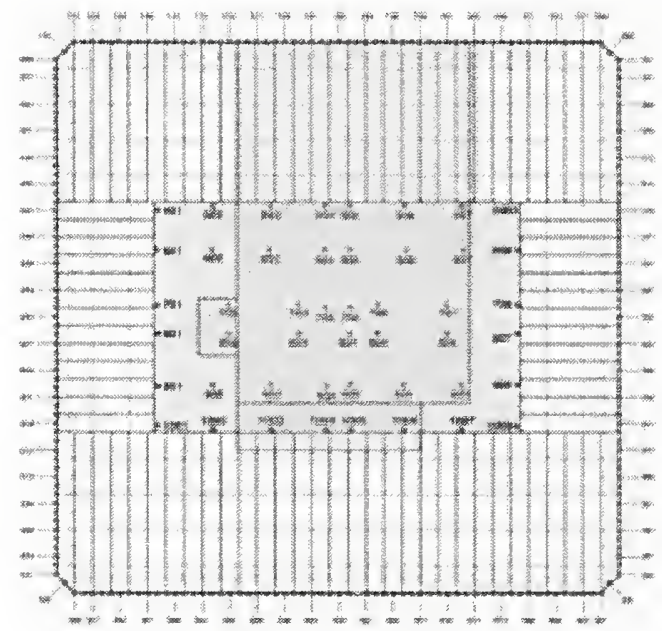

(c) Floor 96

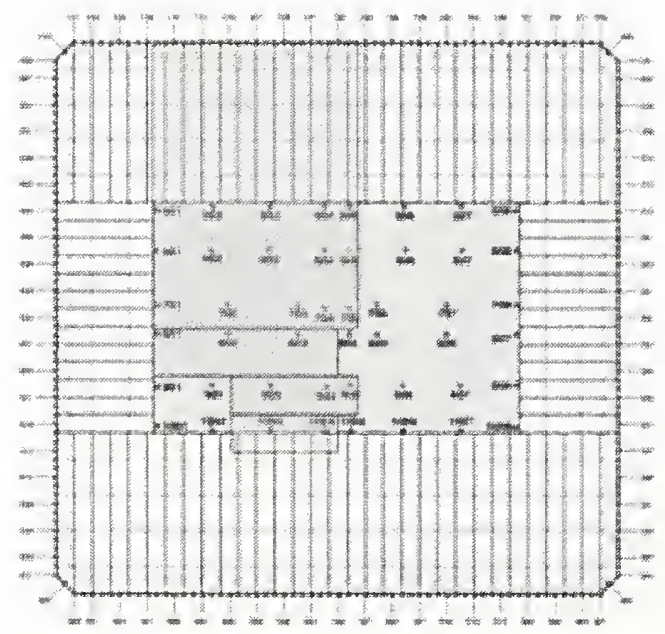

(e) Flong 98

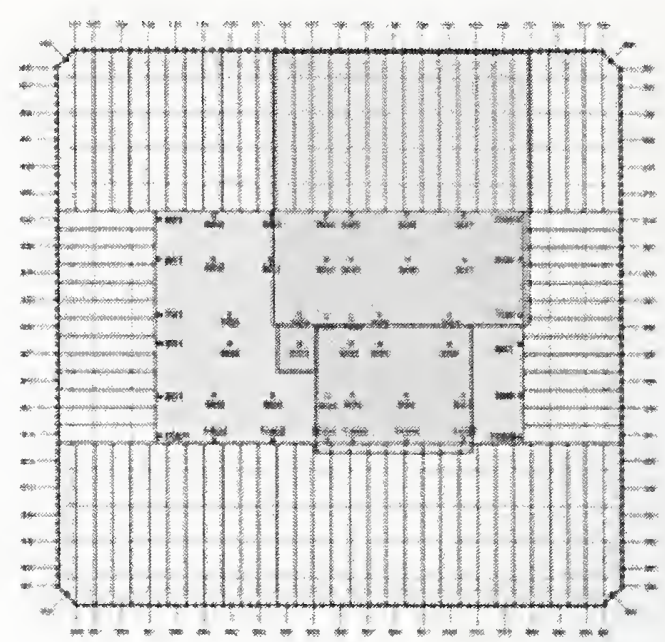

(b) Floor 95

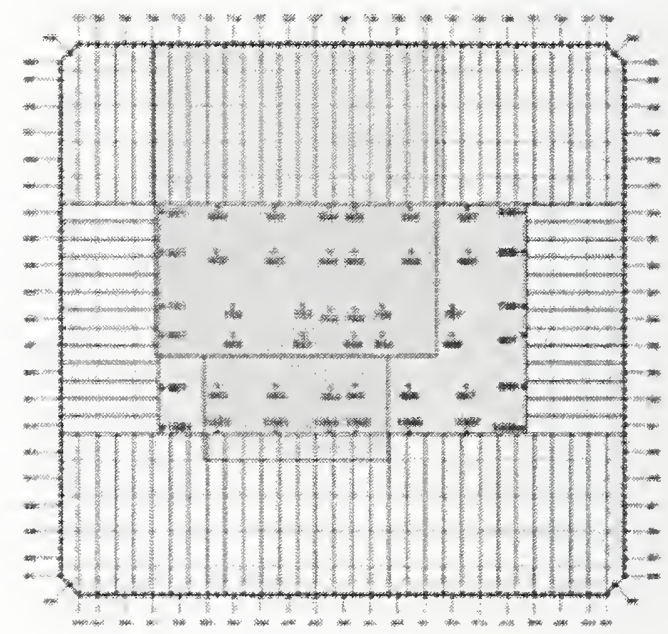

(d) Floor 97

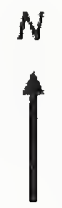

Fireproufing damage to core beams and trusses

Figure 5-45. Case $A_{i}$ insulation damage condition for WTC 1 floor trusses and beams. 


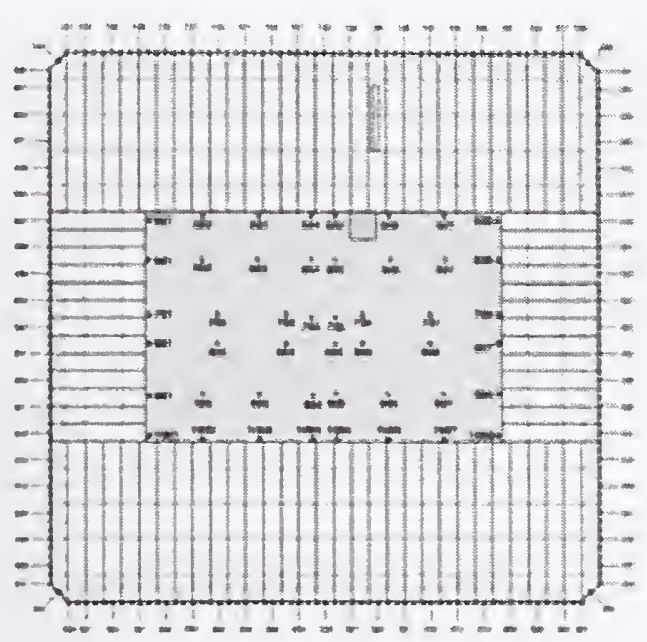

(a) Floor 94

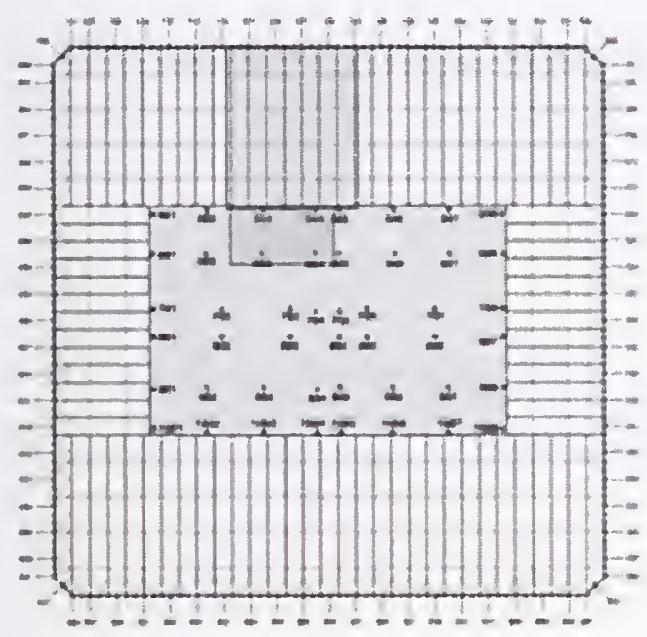

(c) Floor 96

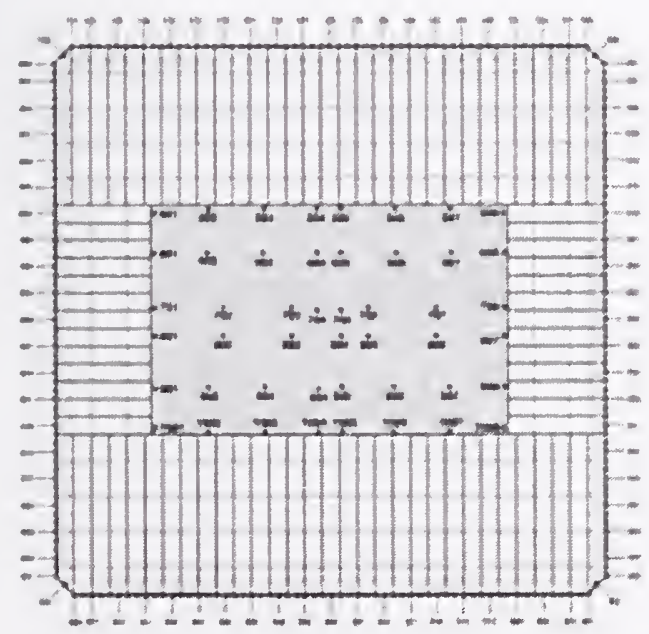

(e) Floor 98

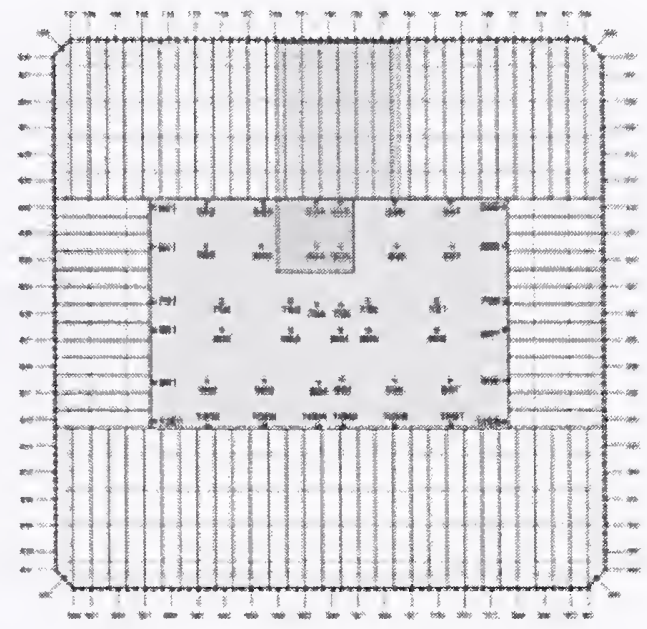

(b) Floor 95

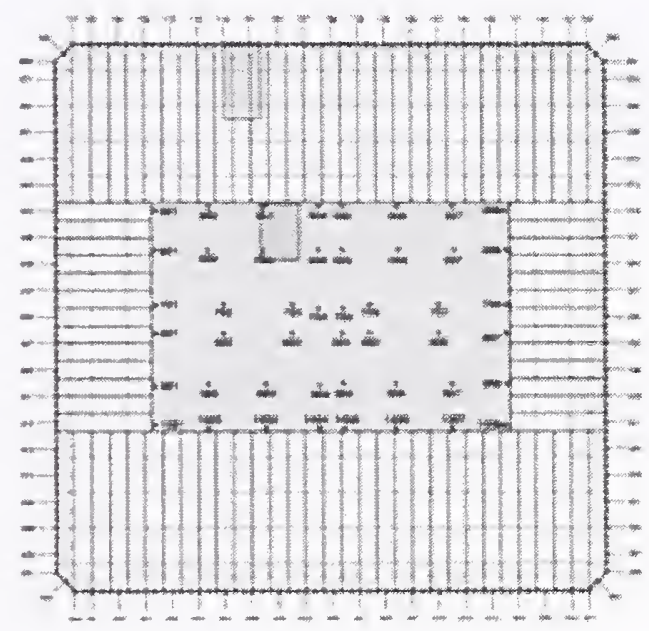

(d) Floor 97

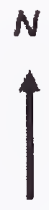

Structural damage to concrete slab, core beams, and trusses

Figure 5-46. Case $A_{i}$ structural damage condition for WTC 1 floors. 


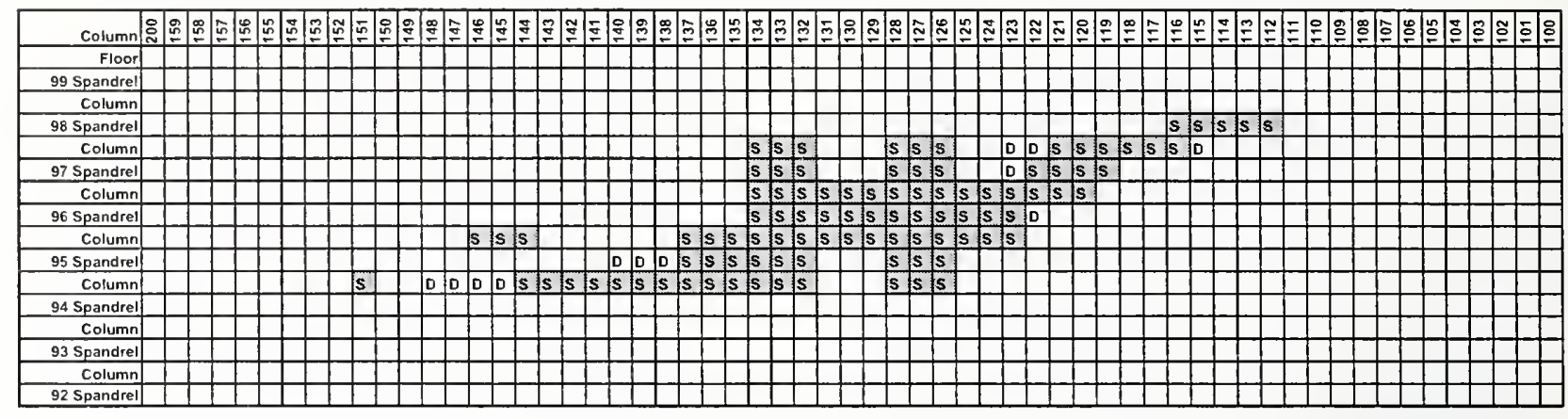

(a) North face

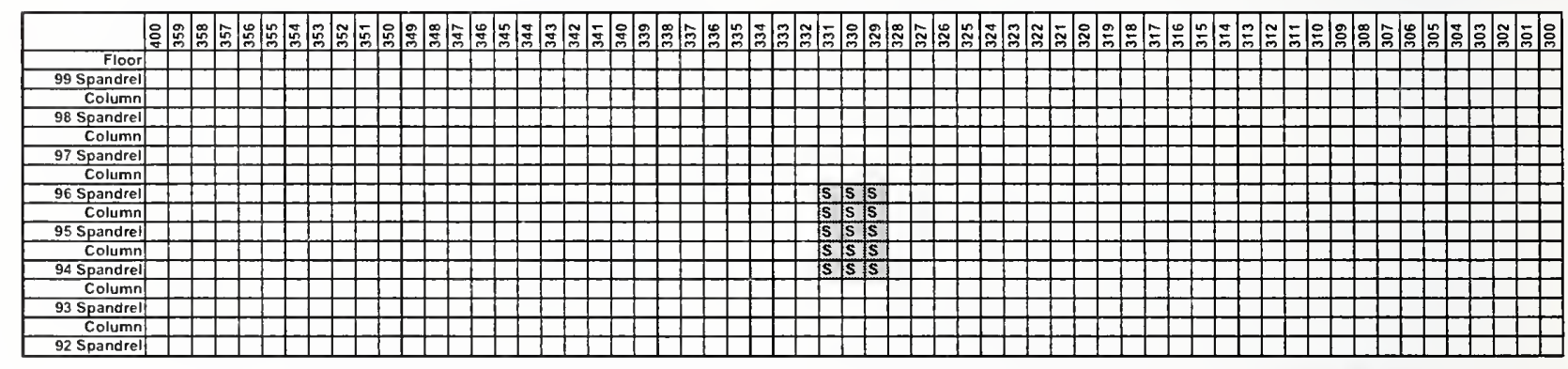

(b) South face

S: severed; D: damaged

Figure 5-47. Structural damage to exterior walls of WTC 1 for Case $A_{i}$ and Case $B_{i}$ impact damage conditions. 


\begin{tabular}{|c|cccccc|}
\hline & COL501 & COL601 & COL701 & COL801 & COL901 & COL1001 \\
\hline FL100 & & & & & & \\
FL99 & $\mathrm{I}$ & $\mathrm{I}$ & $\mathrm{I}$ & $\mathrm{I}$ & $\mathrm{I}$ & $\mathrm{I}$ \\
FL98 & $\mathrm{D}^{*}$ & $\mathrm{I}$ & $\mathrm{I}$ & $\mathrm{I}$ & $\mathrm{I}$ & $\mathrm{D}^{*}$ \\
FL97 & $\mathrm{I}$ & $\mathrm{I}$ & $\mathrm{I}$ & $\mathrm{I}$ & $\mathrm{I}$ & $\mathrm{I}$ \\
FL96 & $\mathrm{I}$ & $\mathrm{I}$ & $\mathrm{I}$ & $\mathrm{I}$ & $\mathrm{I}$ & $\mathrm{I}$ \\
FL95 & $\mathrm{I}$ & $\mathrm{I}$ & $\mathrm{I}$ & $\mathrm{I}$ & $\mathrm{I}$ & $\mathrm{I}$ \\
FL94 & $\mathrm{I}$ & $\mathrm{I}$ & $\mathrm{I}$ & $\mathrm{I}$ & $\mathrm{I}$ & $\mathrm{I}$ \\
FL93 & $\mathrm{I}$ & $\mathrm{I}$ & $\mathrm{I}$ & $\mathrm{I}$ & $\mathrm{I}$ & $\mathrm{I}$ \\
FL92 & $\mathrm{D}^{*}$ & $\mathrm{I}$ & $\mathrm{I}$ & $\mathrm{I}$ & $\mathrm{I}$ & $\mathrm{D}^{*}$ \\
\hline
\end{tabular}

\begin{tabular}{|c|cccccc|}
\hline & COL505 & COL605 & COL705 & COL804 & COL905 & COL1005 \\
\hline FL100 & & & & & & \\
FL99 & $\mathrm{I}$ & $\mathrm{I}$ & $\mathrm{I}$ & $\mathrm{I}$ & $\mathrm{I}$ & $\mathrm{I}$ \\
FL98 & $\mathrm{I}$ & $\mathrm{I}$ & $\mathrm{I}$ & $\mathrm{I}$ & $\mathrm{I}$ & $\mathrm{I}$ \\
FL97 & $\mathrm{I}$ & $\mathrm{I}$ & $\mathrm{I}$ & $\mathrm{I}$ & $\mathrm{I}$ & $\mathrm{I}$ \\
FL96 & $\mathrm{D}$ & $\mathrm{I}$ & $\mathrm{I}$ & $\mathrm{I}$ & $\mathrm{I}$ & $\mathrm{I}$ \\
FL95 & $\mathrm{D}$ & $\mathrm{I}$ & $\mathrm{I}$ & $\mathrm{I}$ & $\mathrm{I}$ & $\mathrm{I}$ \\
FL94 & $\mathrm{I}$ & $\mathrm{I}$ & $\mathrm{I}$ & $\mathrm{I}$ & $\mathrm{I}$ & $\mathrm{I}$ \\
FL93 & $\mathrm{I}$ & $\mathrm{I}$ & $\mathrm{I}$ & $\mathrm{I}$ & $\mathrm{I}$ & $\mathrm{I}$ \\
FL92 & $\mathrm{I}$ & $\mathrm{I}$ & $\mathrm{I}$ & $\mathrm{I}$ & $\mathrm{I}$ & $\mathrm{I}$ \\
\hline
\end{tabular}

\begin{tabular}{|c|cccccc|}
\hline & COL502 & COL602 & COL702 & COL802 & COL902 & COL1002 \\
\hline FL100 & & & & & & \\
FL99 & $\mathrm{I}$ & $\mathrm{I}$ & $\mathrm{I}$ & $\mathrm{I}$ & $\mathrm{I}$ & $\mathrm{I}$ \\
FL98 & $\mathrm{D}^{*}$ & $\mathrm{I}$ & $\mathrm{I}$ & $\mathrm{I}$ & $\mathrm{I}$ & $\mathrm{I}$ \\
FL97 & $\mathrm{I}$ & $\mathrm{I}$ & $\mathrm{I}$ & $\mathrm{I}$ & $\mathrm{I}$ & $\mathrm{I}$ \\
FL96 & $\mathrm{I}$ & $\mathrm{I}$ & $\mathrm{I}$ & $\mathrm{I}$ & $\mathrm{I}$ & $\mathrm{I}$ \\
FL95 & $\mathrm{I}$ & $\mathrm{I}$ & $\mathrm{I}$ & $\mathrm{I}$ & $\mathrm{I}$ & $\mathrm{I}$ \\
FL94 & $\mathrm{I}$ & $\mathrm{I}$ & $\mathrm{I}$ & $\mathrm{I}$ & $\mathrm{I}$ & $\mathrm{I}$ \\
FL93 & $\mathrm{I}$ & $\mathrm{I}$ & $\mathrm{I}$ & $\mathrm{I}$ & $\mathrm{I}$ & $\mathrm{I}$ \\
FL92 & $\mathrm{I}$ & $\mathrm{I}$ & $\mathrm{I}$ & $\mathrm{I}$ & $\mathrm{I}$ & $\mathrm{I}$ \\
\hline
\end{tabular}

\begin{tabular}{|c|cccccc|}
\hline & COL506 & COL606 & COL706 & COL805 & COL906 & COL1006 \\
\hline FL100 & & & & & & \\
FL99 & $\mathrm{I}$ & $\mathrm{I}$ & $\mathrm{I}$ & $\mathrm{I}$ & $\mathrm{I}$ & $\mathrm{I}$ \\
FL98 & $\mathrm{I}$ & $\mathrm{I}$ & $\mathrm{I}$ & $\mathrm{I}$ & $\mathrm{I}$ & $\mathrm{I}$ \\
FL97 & $\mathrm{I}$ & $\mathrm{I}$ & $\mathrm{I}$ & $\mathrm{I}$ & $\mathrm{I}$ & $\mathrm{I}$ \\
FL96 & $\mathrm{I}$ & $\mathrm{I}$ & $\mathrm{I}$ & $\mathrm{I}$ & $\mathrm{I}$ & $\mathrm{I}$ \\
FL95 & $\mathrm{I}$ & $\mathrm{I}$ & $\mathrm{S}$ & $\mathrm{I}$ & $\mathrm{I}$ & $\mathrm{I}$ \\
FL94 & $\mathrm{D}$ & $\mathrm{I}$ & $\mathrm{S}$ & $\mathrm{D}$ & $\mathrm{I}$ & $\mathrm{I}$ \\
FL93 & $\mathrm{I}$ & $\mathrm{I}$ & $\mathrm{S}$ & $\mathrm{I}$ & $\mathrm{I}$ & $\mathrm{I}$ \\
FL92 & $\mathrm{I}$ & $\mathrm{I}$ & $\mathrm{R}$ & $\mathrm{I}$ & $\mathrm{I}$ & $\mathrm{I}$ \\
\hline
\end{tabular}

\begin{tabular}{|c|cccccc|}
\hline & COL503 & COL603 & COL703 & COL803 & COL903 & COL1003 \\
\hline FL100 & & & & & & \\
FL99 & 1 & 1 & 1 & 1 & 1 & 1 \\
FL98 & 1 & $\mathrm{I}$ & $\mathrm{I}$ & $\mathrm{I}$ & $\mathrm{I}$ & $\mathrm{I}$ \\
FL97 & $\mathrm{I}$ & $\mathrm{I}$ & $\mathrm{I}$ & $\mathrm{I}$ & $\mathrm{I}$ & $\mathrm{I}$ \\
FL96 & $\mathrm{D}$ & $\mathrm{I}$ & $\mathrm{I}$ & $\mathrm{I}$ & $\mathrm{I}$ & $\mathrm{I}$ \\
FL95 & $\mathrm{I}$ & $\mathrm{I}$ & $\mathrm{I}$ & $\mathrm{I}$ & $\mathrm{I}$ & $\mathrm{I}$ \\
FL94 & $\mathrm{I}$ & $\mathrm{I}$ & $\mathrm{I}$ & $\mathrm{I}$ & $\mathrm{I}$ & $\mathrm{I}$ \\
FL93 & $\mathrm{I}$ & $\mathrm{I}$ & $\mathrm{I}$ & $\mathrm{I}$ & $\mathrm{I}$ & $\mathrm{I}$ \\
FL92 & $\mathrm{I}$ & $\mathrm{I}$ & $\mathrm{I}$ & $\mathrm{I}$ & $\mathrm{I}$ & $\mathrm{I}$ \\
\hline
\end{tabular}

\begin{tabular}{|c|cccccc|}
\hline & COL507 & COL607 & COL707 & COL806 & COL907 & COL1007 \\
\hline FL100 & & & & & & \\
FL99 & 1 & 1 & 1 & 1 & 1 & 1 \\
FL98 & 1 & 1 & 1 & 1 & $\mathrm{I}$ & $\mathrm{I}$ \\
FL97 & 1 & 1 & 1 & 1 & $\mathrm{I}$ & 1 \\
FL96 & $\mathrm{I}$ & $\mathrm{I}$ & $\mathrm{I}$ & $\mathrm{I}$ & $\mathrm{I}$ & $\mathrm{I}$ \\
FL95 & $\mathrm{I}$ & $\mathrm{I}$ & $\mathrm{I}$ & $\mathrm{I}$ & $\mathrm{I}$ & $\mathrm{I}$ \\
FL94 & $\mathrm{I}$ & $\mathrm{I}$ & $\mathrm{I}$ & $\mathrm{I}$ & $\mathrm{I}$ & $\mathrm{I}$ \\
FL93 & $\mathrm{I}$ & $\mathrm{I}$ & $\mathrm{I}$ & $\mathrm{I}$ & $\mathrm{I}$ & $\mathrm{I}$ \\
FL92 & $\mathrm{I}$ & $\mathrm{I}$ & $\mathrm{I}$ & $\mathrm{I}$ & $\mathrm{I}$ & $\mathrm{I}$ \\
\hline
\end{tabular}

\begin{tabular}{|c|ccccc|}
\hline & COL504 & COL604 & COL704 & COL904 & COL1004 \\
\hline FL100 & & & & & \\
FL99 & I & I & I & I & I \\
FL98 & I & I & I & I & I \\
FL97 & I & I & I & I & I \\
FL96 & S & A & D & D & I \\
FL95 & S & S & D & I & I \\
FL94 & S & S & I & I & I \\
FL93 & S & I & I & I & I \\
FL92 & R & I & I & I & I \\
\hline
\end{tabular}

\begin{tabular}{|c|cccccc|}
\hline & COL508 & COL608 & COL708 & COL807 & COL908 & COL1008 \\
\hline FL100 & & & & & & \\
FL99 & $\mathrm{I}$ & $\mathrm{I}$ & $\mathrm{I}$ & $\mathrm{I}$ & $\mathrm{I}$ & $\mathrm{I}$ \\
FL98 & $\mathrm{D}^{*}$ & $\mathrm{I}$ & $\mathrm{I}$ & $\mathrm{I}$ & $\mathrm{I}$ & $\mathrm{D}^{*}$ \\
FL97 & $\mathrm{I}$ & $\mathrm{I}$ & $\mathrm{I}$ & $\mathrm{I}$ & $\mathrm{I}$ & $\mathrm{I}$ \\
FL96 & $\mathrm{I}$ & $\mathrm{I}$ & $\mathrm{I}$ & $\mathrm{I}$ & $\mathrm{I}$ & $\mathrm{I}$ \\
FL95 & $\mathrm{I}$ & $\mathrm{I}$ & $\mathrm{I}$ & $\mathrm{I}$ & $\mathrm{I}$ & $\mathrm{I}$ \\
FL94 & $\mathrm{I}$ & $\mathrm{I}$ & $\mathrm{I}$ & $\mathrm{I}$ & $\mathrm{I}$ & $\mathrm{I}$ \\
FL93 & $\mathrm{I}$ & $\mathrm{I}$ & $\mathrm{I}$ & $\mathrm{I}$ & $\mathrm{I}$ & $\mathrm{I}$ \\
FL92 & $\mathrm{D}^{*}$ & $\mathrm{I}$ & $\mathrm{I}$ & $\mathrm{I}$ & $\mathrm{I}$ & $\mathrm{D}^{*}$ \\
\hline
\end{tabular}

I: intact

A: alignment affected

D: damaged (plastic strain present)

S: severed

R: rotated

*: column connections show plastic strains

Figure 5-48. Structural damage to core columns of WTC 1 for Case $A_{i}$ impact damage condition. 


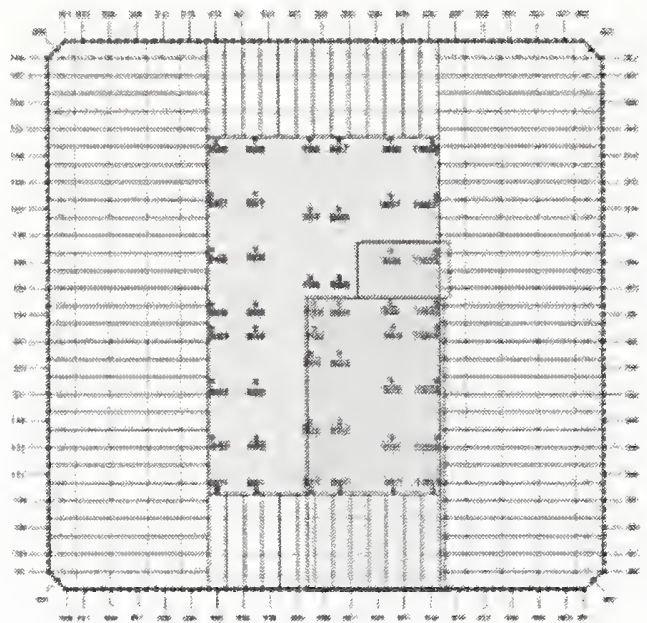

(a) Floor 79

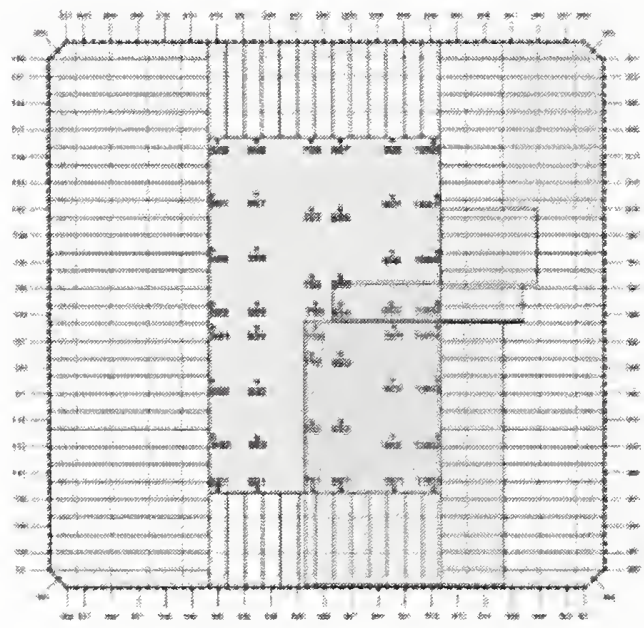

(c) Floor 1

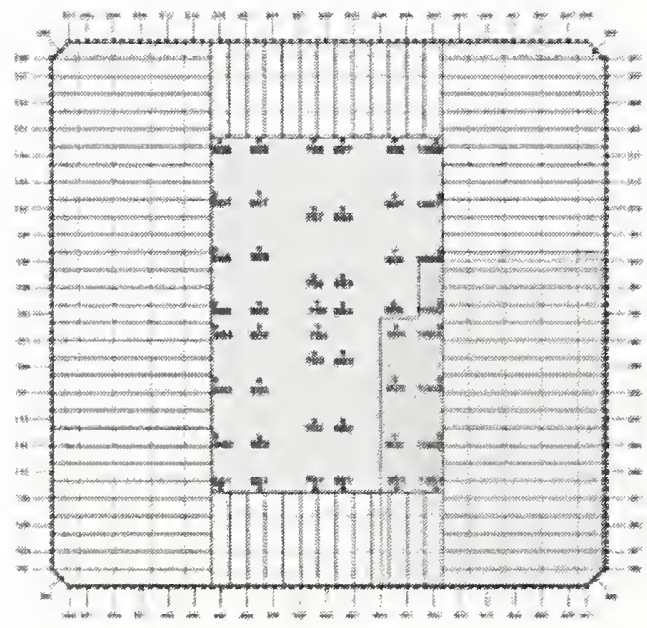

(e) Floor 83

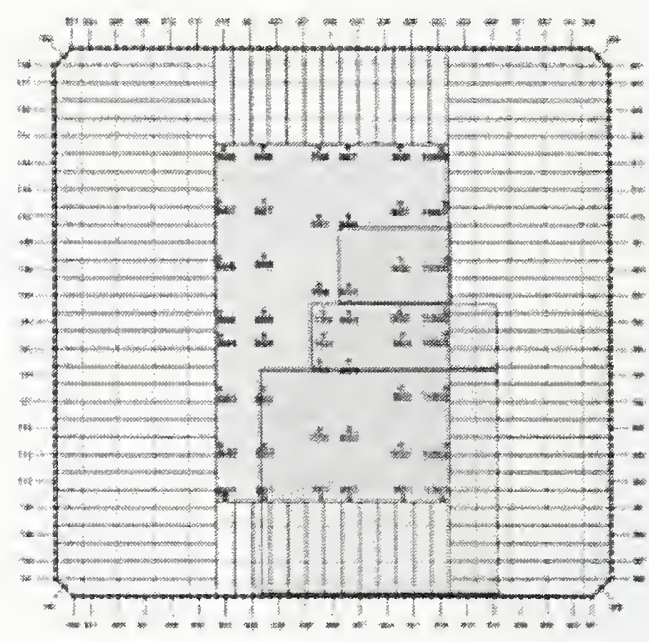

(b) Floor 80

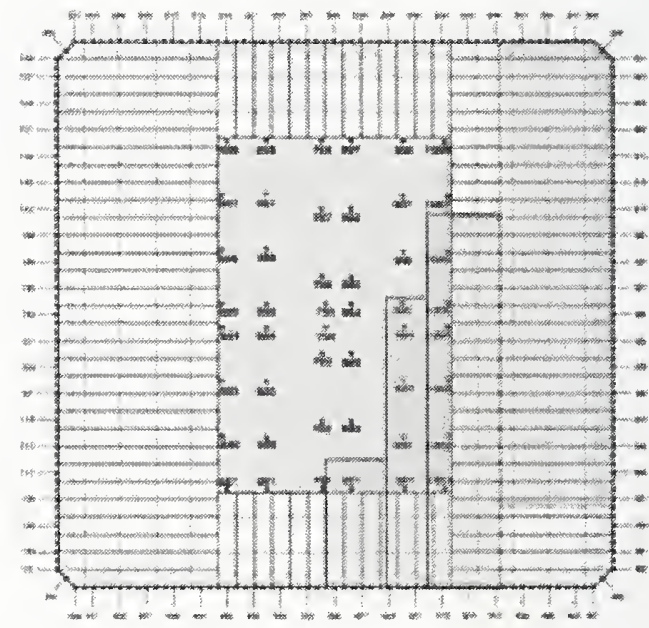

(d) Floor 82

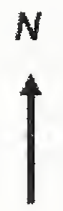

Fireproofing damage to core beams and trusses

Figure 5-49. Case $C_{i}$ insulation damage condition for WTC 2 floor trusses and beams. 


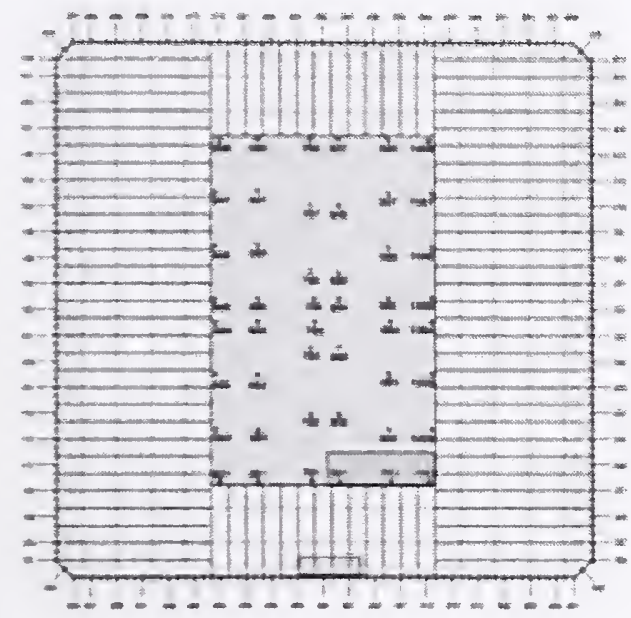

(a) Floor 79

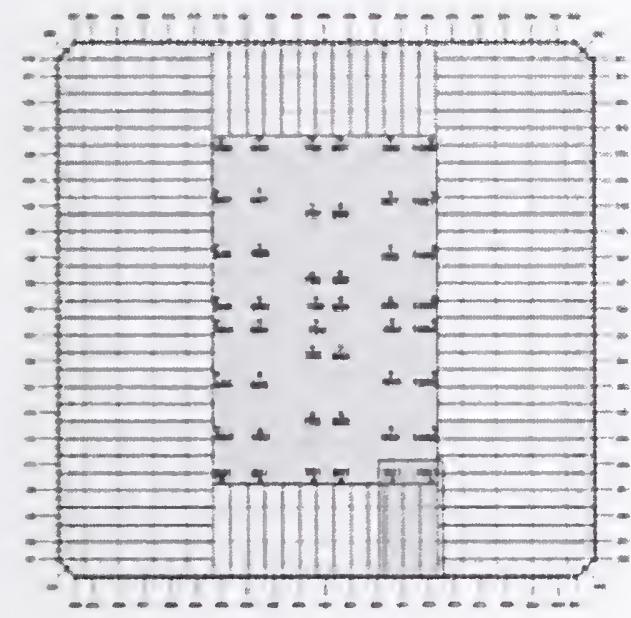

(c) Floor 81

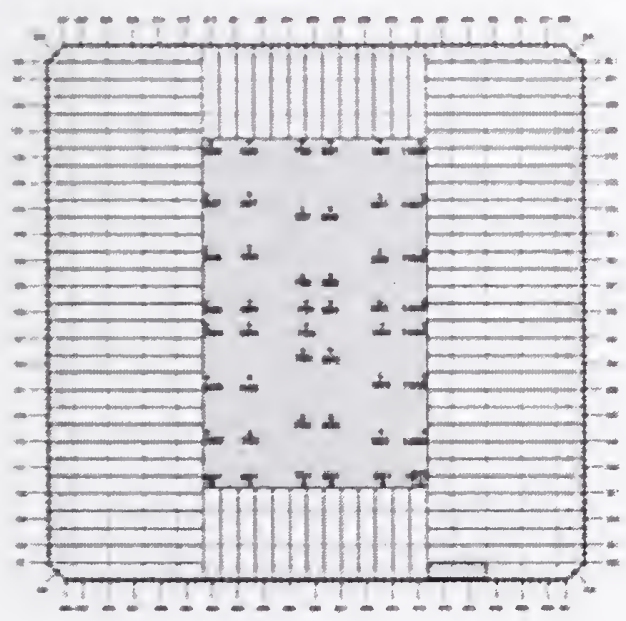

(e) Floor 83

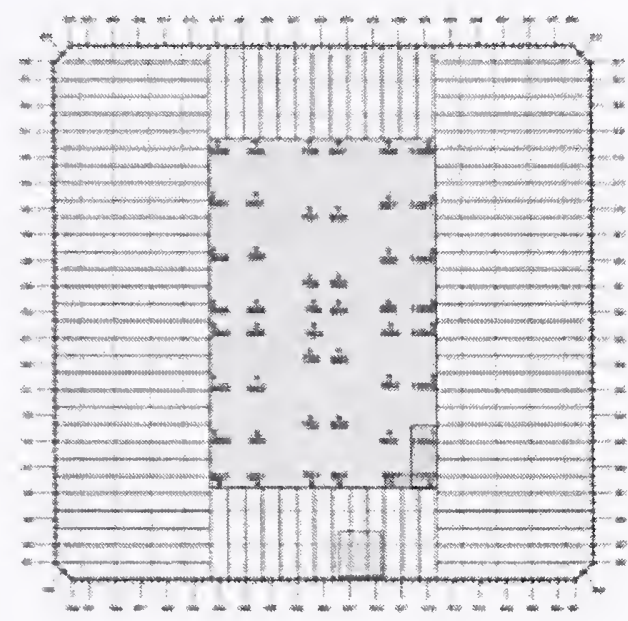

(b) Floor 80

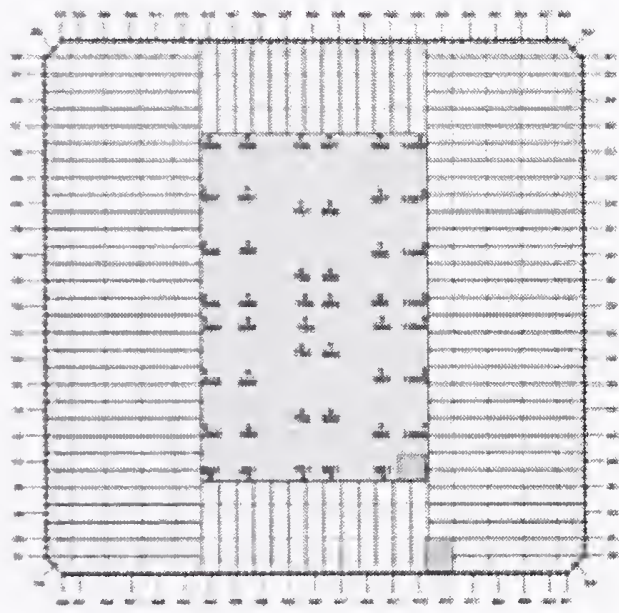

(d) Floor 82

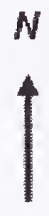

Structural damage to concrete slat, core beams, and trusses

Figure 5-50. Case $C_{i}$ structural damage condition for WTC 2 floors. 


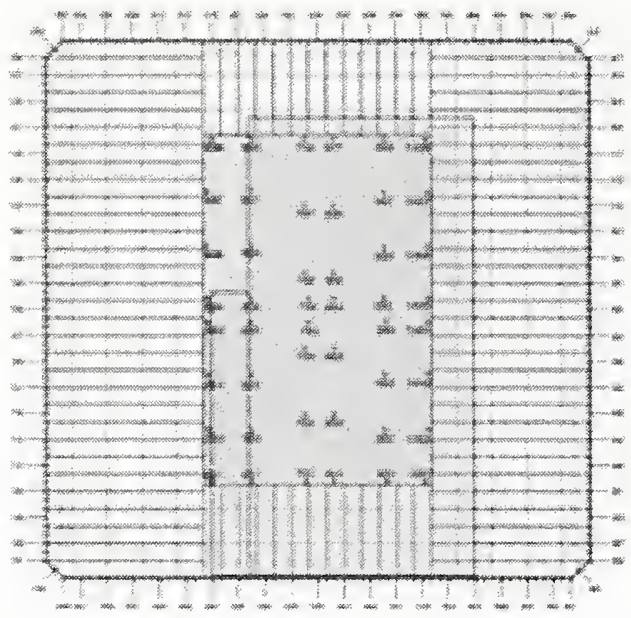

(a) Floor 79

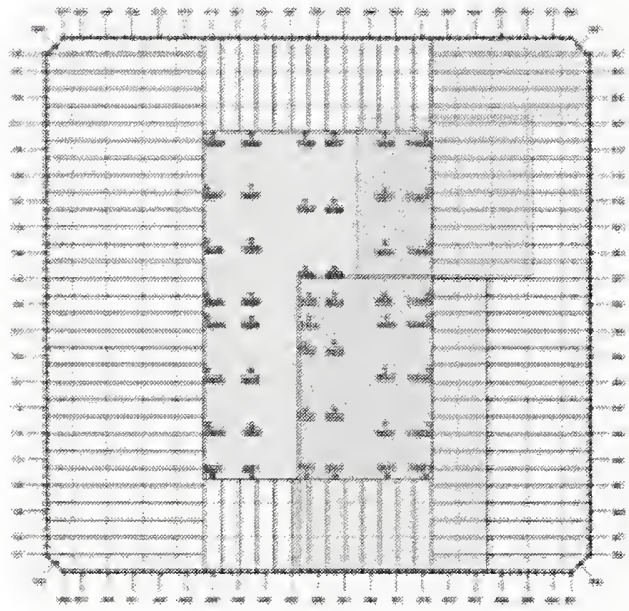

(c) Floor 81

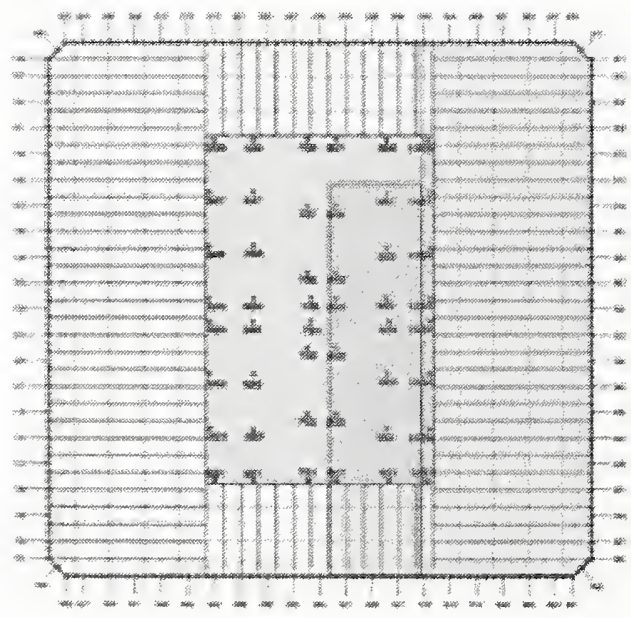

(e) Floor 83

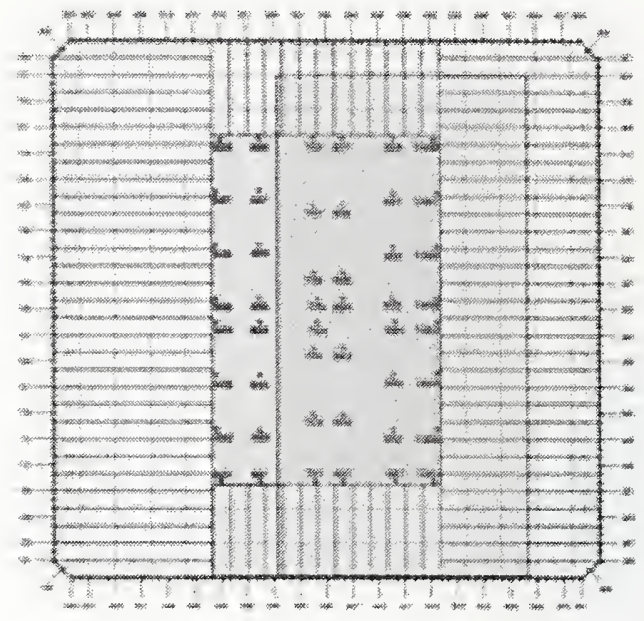

(b) Floor 80

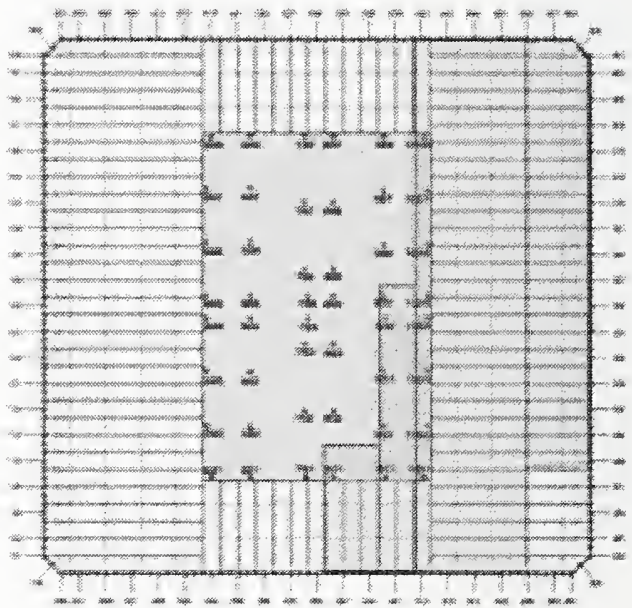

(d) Floor 82

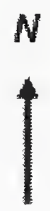

Fireproofing damage to core be ams and trusses

Figure 5-51. Case $D_{i}$ insulation damage condition for WTC 2 floor trusses and beams. 


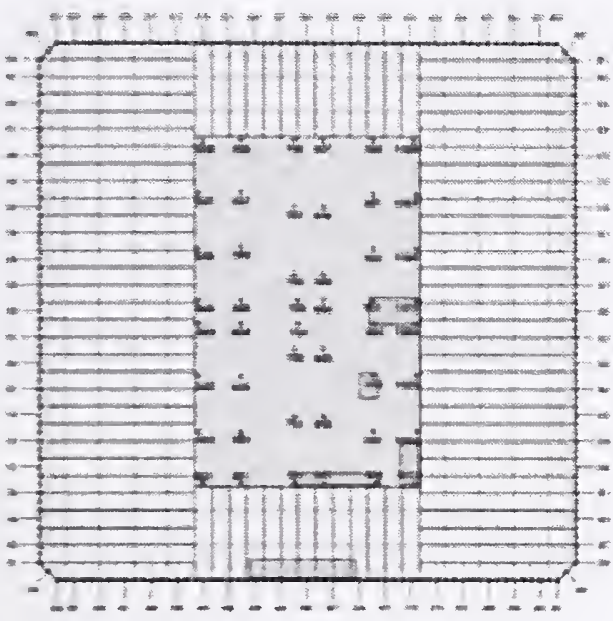

(a) Floor 79

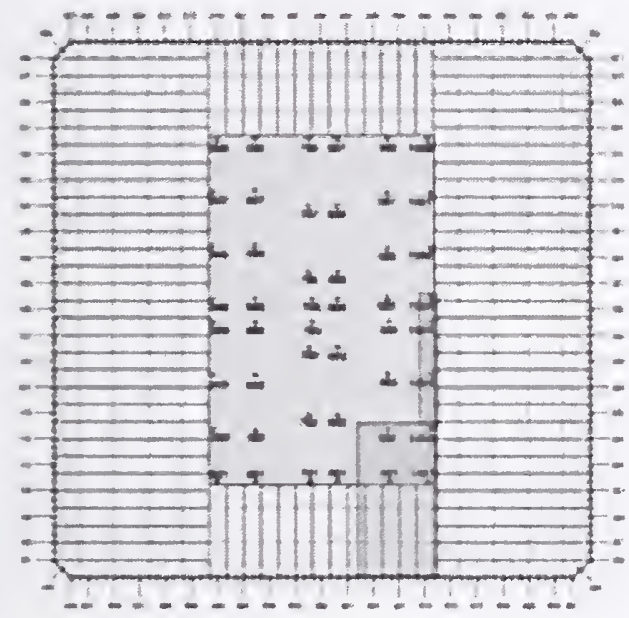

(c) Floor 81

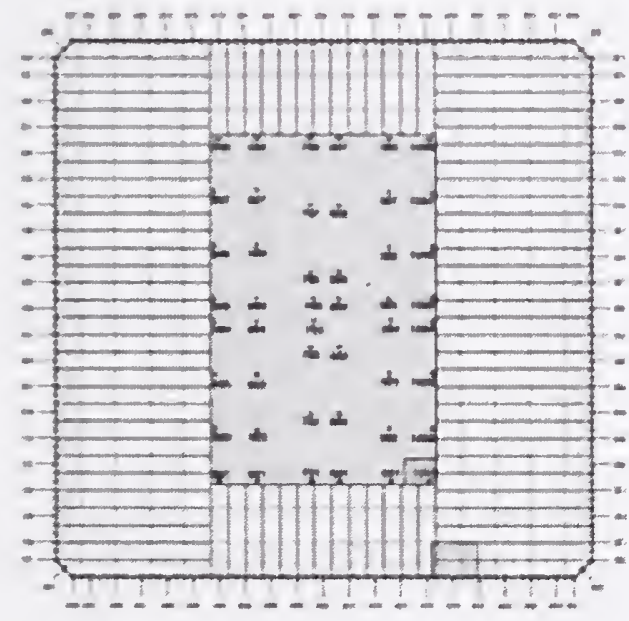

(e) Floor 83

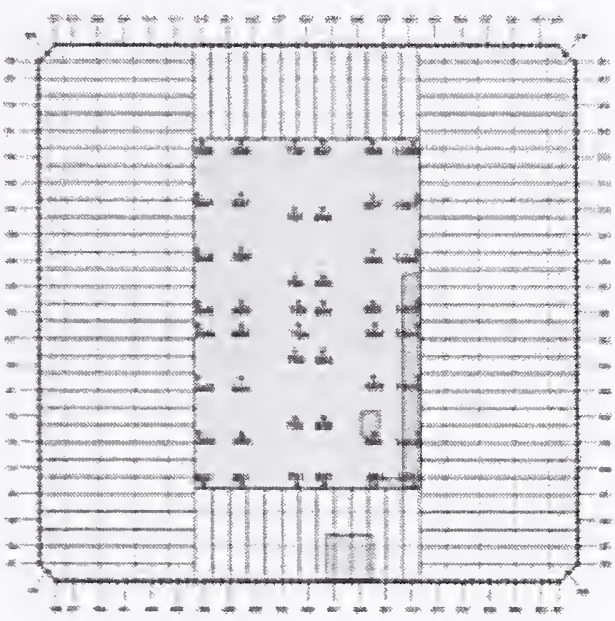

(b) Floor 80

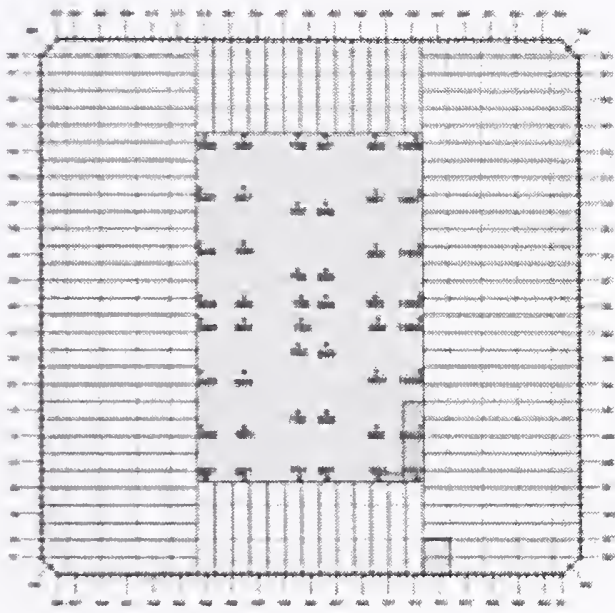

(d) Floor 82

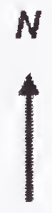

Structural damage to coricrete slab, core beams, and trusses

Figure 5-52. Case $D_{i}$ structural damage condition for WTC 2 floors. 


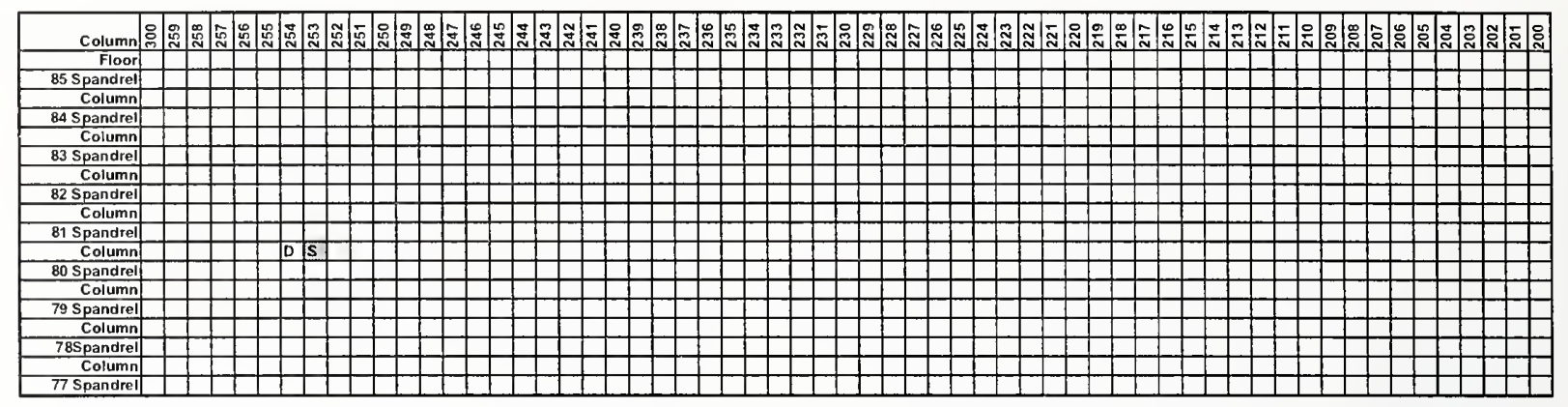

(a) North face

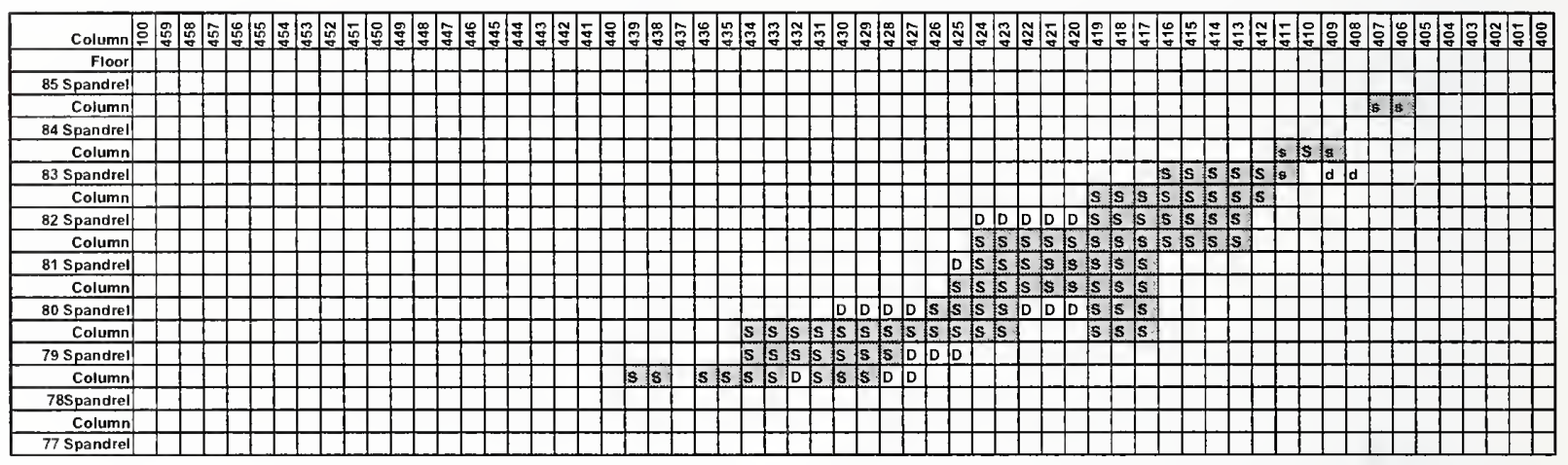

(b) South face

S: severed; D: damaged

Figure 5-53. Structural damage to exterior walls of WTC 2 for Case $C_{i}$ and Case $D_{i}$ impact damage conditions.
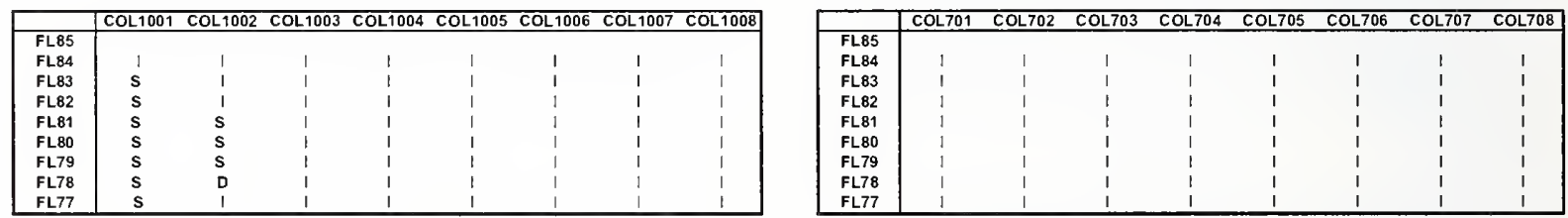

\begin{tabular}{|c|c|c|c|c|c|c|c|c|}
\hline & COL901 & COL902 & COL 903 & COL904 & COL905 & COL906 & COL907 & COL908 \\
\hline FL85 & & & & & & & & \\
\hline FL84 & I & I & I & 1 & 1 & I & 1 & 1 \\
\hline FL83 & I & 1 & I & 1 & I & 1 & I & I \\
\hline FL82 & 1 & I & I & 1 & I & 1 & 1 & 1 \\
\hline FL81 & D & I & 1 & 1 & 1 & 1 & 1 & I \\
\hline FL80 & $\mathbf{s}$ & s & I & 1 & 1 & I & 1 & 1 \\
\hline FL79 & $\mathbf{s}$ & D & 1 & 1 & 1 & 1 & 1 & I \\
\hline FL78 & 1 & D & 1 & I & I & 1 & I & I \\
\hline FL77 & 1 & 1 & 1 & 1 & 1 & 1 & I & 1 \\
\hline
\end{tabular}

\begin{tabular}{|c|c|c|c|c|c|c|c|c|}
\hline & COL601 & COL602 & COL603 & COL604 & COL605 & COL606 & COL607 & COL608 \\
\hline FL85 & & & & & & & & \\
\hline FL84 & 1 & I & I & I & I & I & I & I \\
\hline FL83 & I & I & 1 & 1 & I & I & 1 & I \\
\hline FL82 & I & I & 1 & I & I & 1 & 1 & 1 \\
\hline FL81 & 1 & I & I & I & I & 1 & 1 & 1 \\
\hline FL80 & I & I & I & I & I & I & 1 & 1 \\
\hline FL79 & I & I & I & 1 & I & 1 & I & I \\
\hline FL78 & 1 & I & I & I & I & I & I & I \\
\hline FL77 & i & 1 & 1 & I & I & I & 1 & I \\
\hline
\end{tabular}

\begin{tabular}{|c|c|c|c|c|c|c|c|}
\hline & COL804 & COL802 & COLB03 & COL804 & COL805 & COLB06 & COL807 \\
\hline FL85 & & & & & & & \\
\hline FL84 & I & 1 & I & 1 & । & I & 1 \\
\hline FL83 & I & I & 1 & 1 & I & I & 1 \\
\hline FL82 & I & I & 1 & 1 & 1 & 1 & I \\
\hline FLB1 & I & I & 1 & I & I & I & I \\
\hline FL80 & I & 1 & 1 & 1 & । & I & I \\
\hline FL79 & I & 1 & I & I & 1 & I & I \\
\hline FL78 & I & 1 & I & I & I & I & I \\
\hline FL77 & 1 & i & I & I & 1 & I & i \\
\hline
\end{tabular}

\begin{tabular}{|c|c|c|c|c|c|c|c|c|}
\hline & COL501 & COL502 & COL503 & COL504 & COL505 & COL506 & COL507 & COL508 \\
\hline FL85 & & & & & & & & \\
\hline FL84 & 1 & 1 & 1 & 1 & I & I & I & I \\
\hline FL83 & I & I & i & 1 & 1 & 1 & । & 1 \\
\hline FL82 & i & i & I & i & I & I & i & 1 \\
\hline FL81 & 1 & I & I & I & 1 & I & 1 & 1 \\
\hline FLBO & i & i & i & i & i & i & i & i \\
\hline FL79 & 1 & I & 1 & 1 & 1 & I & 1 & I \\
\hline FL78 & 1 & I & 1 & 1 & 1 & 1 & 1 & I \\
\hline FL77 & $i$ & i & $i$ & i & i & i & i & I \\
\hline
\end{tabular}
I: Intact
D: Damaged (plastic strain present)
R: Rotated

A: Alignment affected

S: Severed

Figure 5-54. Structural damage to core columns of WTC 2 for Case $C_{i}$ impact damage condition. 


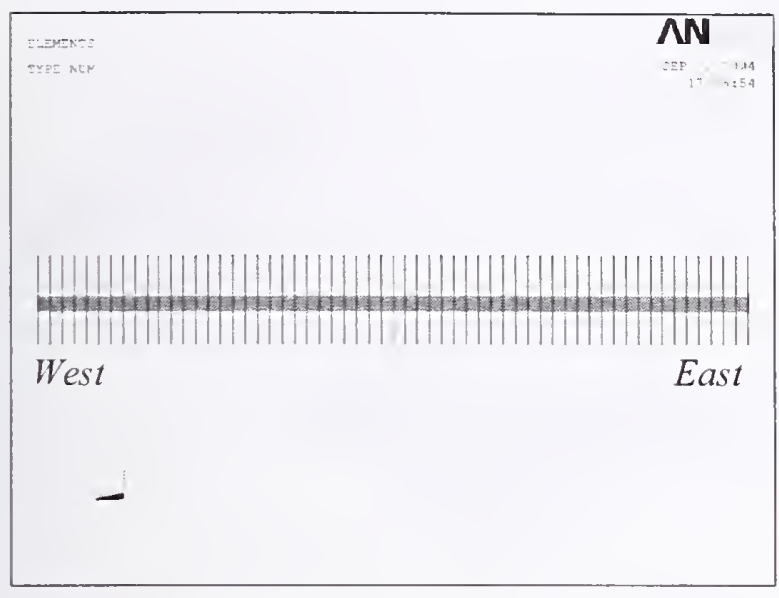

(a) Model without damage

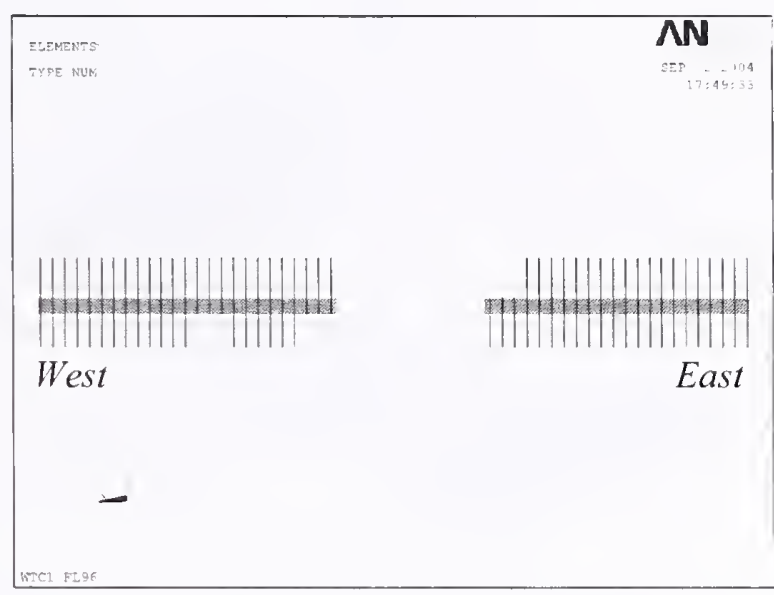

(b) Model with damage

Figure 5-55. Case $A_{i}$ structural impact damage condition for exterior columns of the north face in the WTC 1 Floor 96 model.

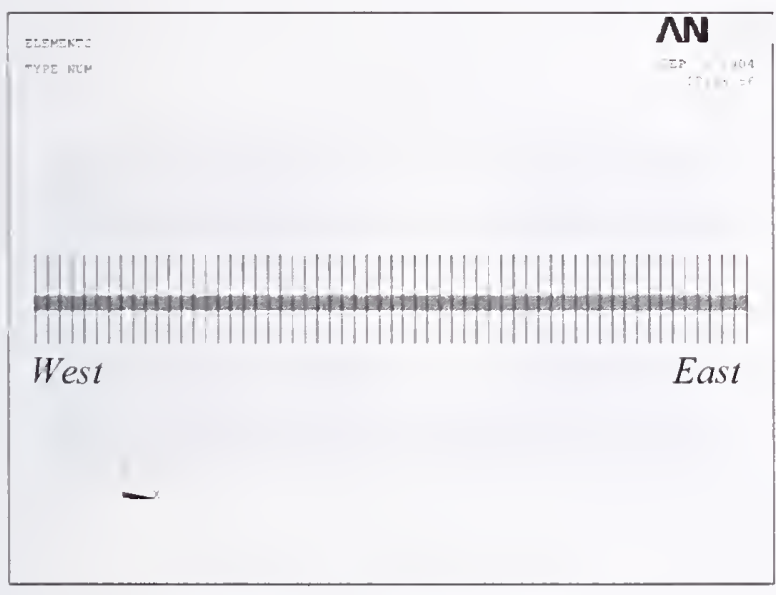

(a) Model without damage

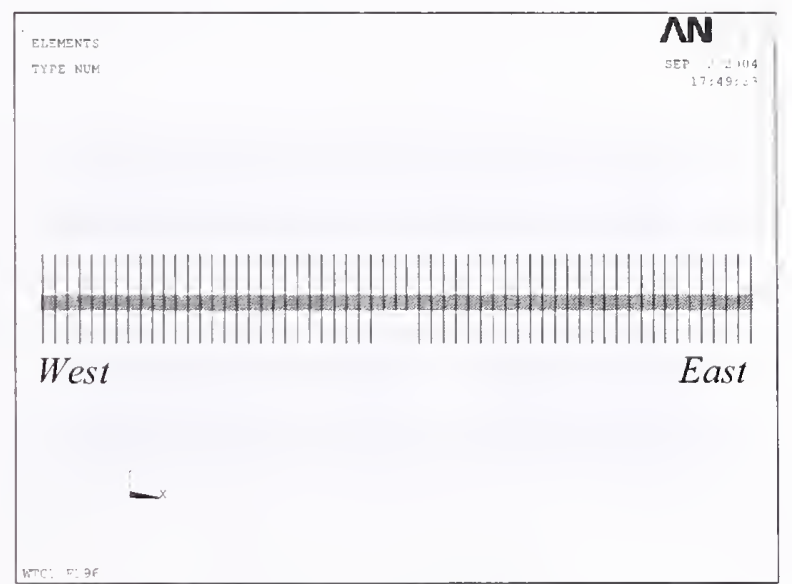

(b) Model with damage

Figure 5-56. Case $A_{i}$ structural impact damage condition for exterior columns of the south face in the WTC 1 Floor 96 model. 


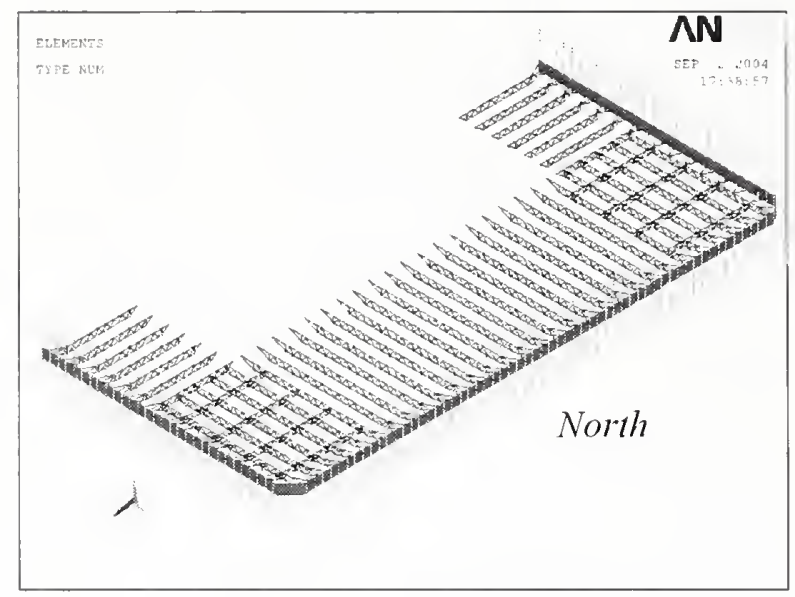

(a) Model without damage

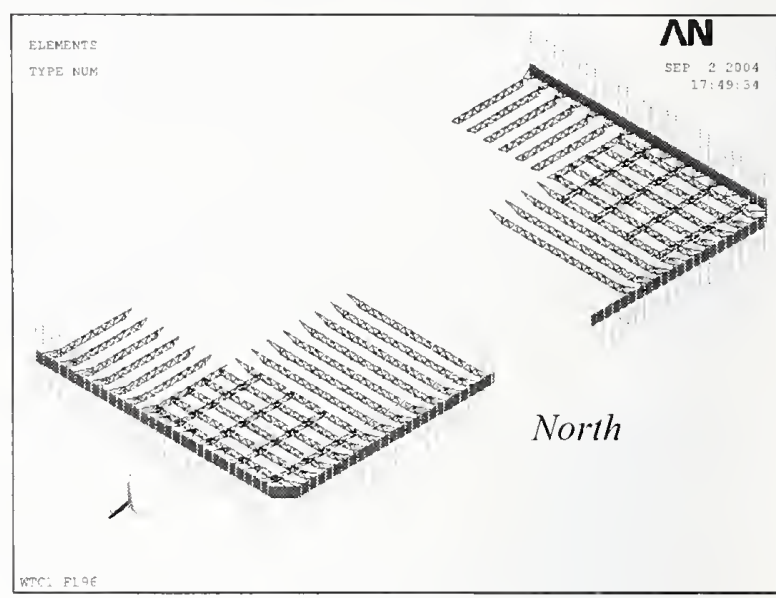

(b) Model with damage

Figure 5-57. Case $A_{i}$ structural impact damage condition for floor trusses in the WTC 1 Floor 96 model.

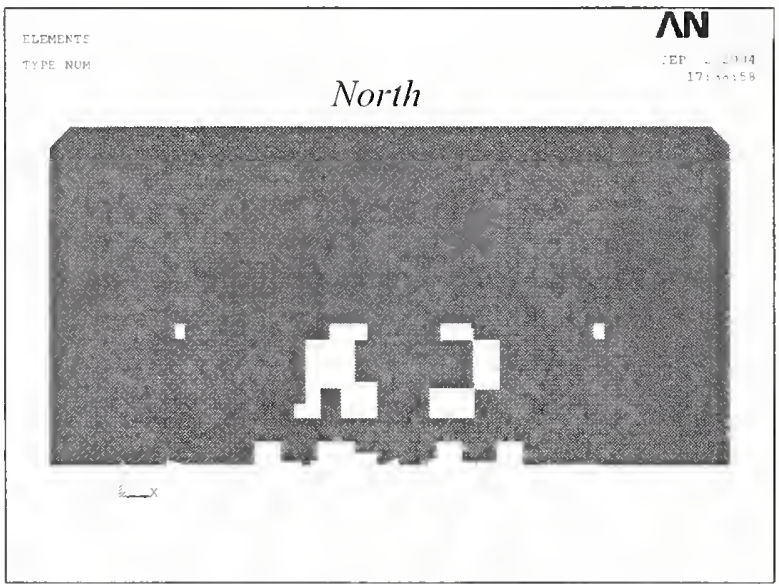

(a) Model without damage

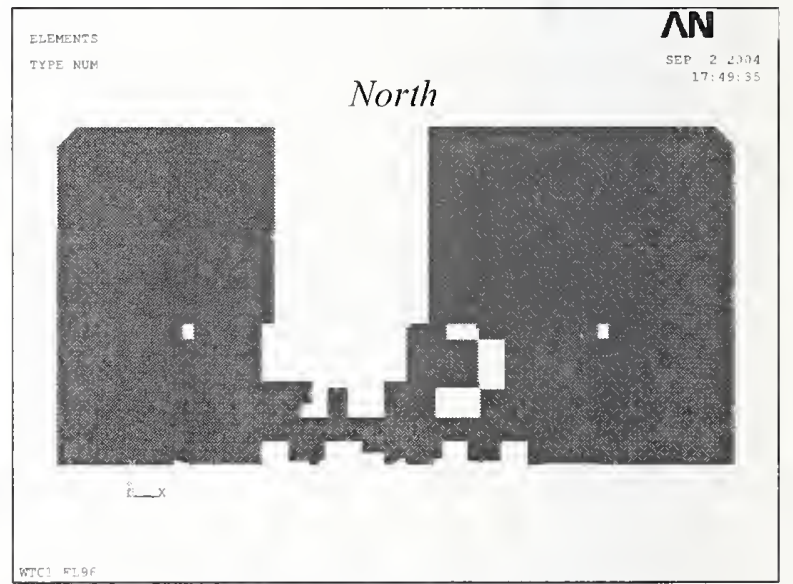

(b) Model with damage

Figure 5-58. Case $A_{i}$ structural impact damage condition for the concrete slab in the WTC 1 Floor 96 model. 


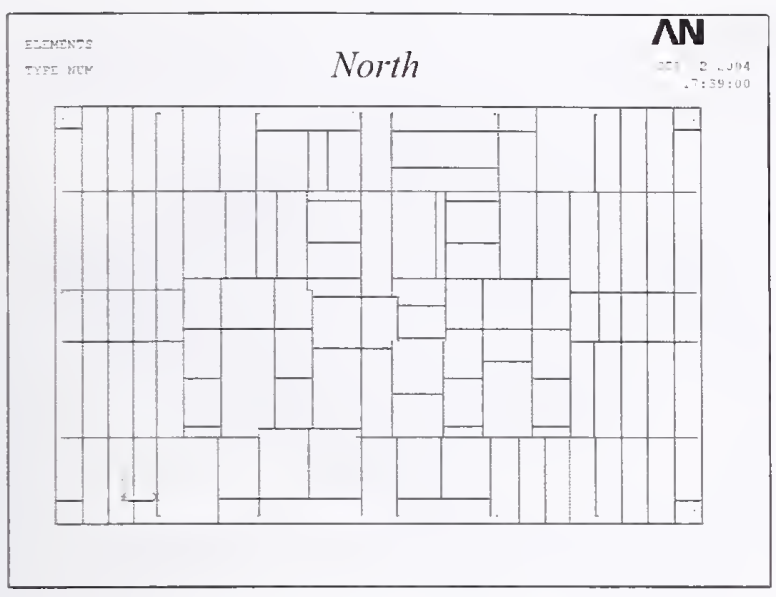

(a) Model without damage

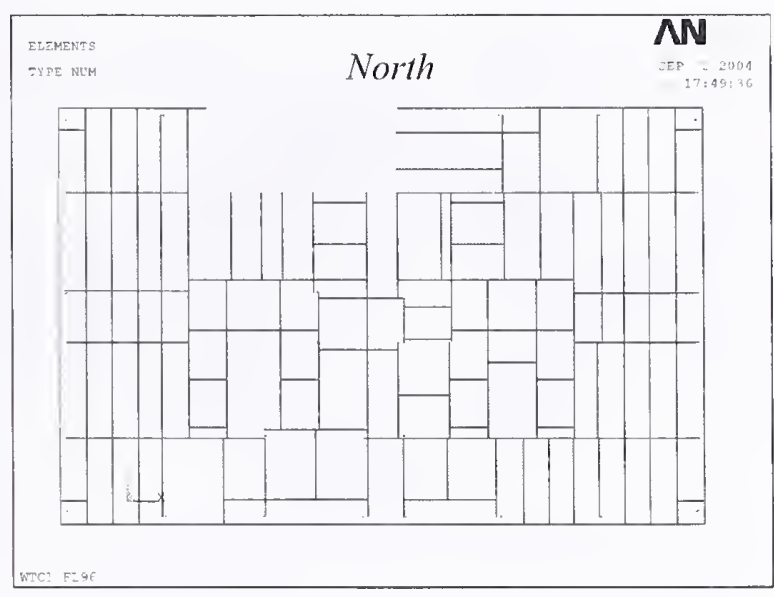

(b) Model with damage

Figure 5-59. Case $A_{i}$ structural impact damage condition for core beams in the WTC 1 Floor 96 model.

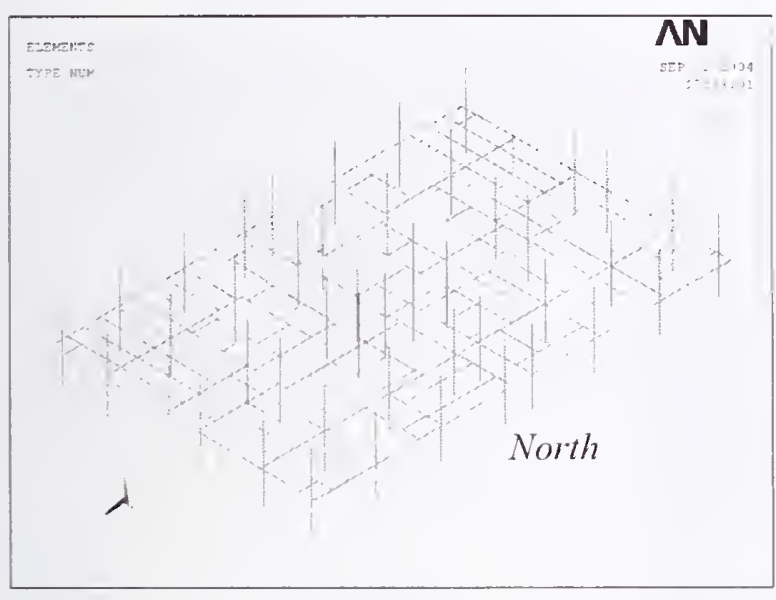

(a) Model without damage

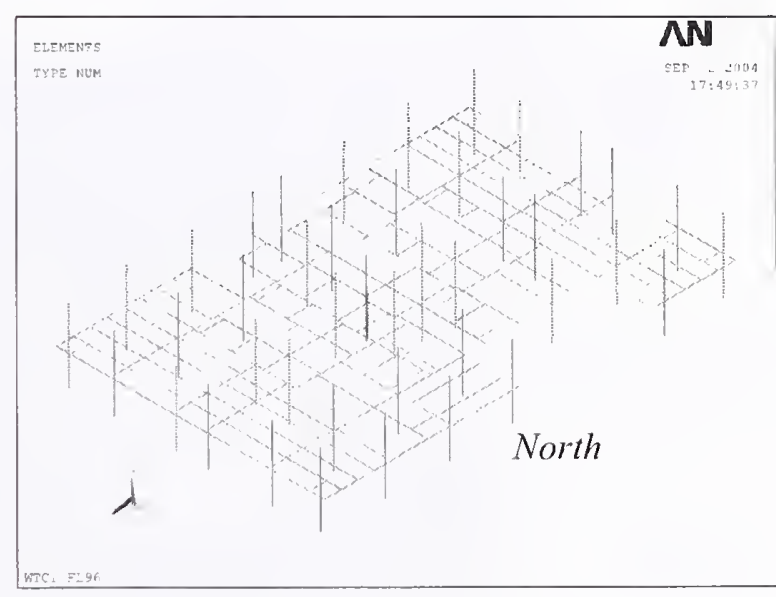

(b) Model with damage

Figure 5-60. Case $A_{i}$ structural impact damage condition for core columns in the WTC 1 Floor 96 model.

\subsubsection{Gravity and Thermal Loads}

The full floor model with impact damage included was first analyzed for gravity dead and live loads, and then temperature time histories representative of the WTC fire conditions were applied to analyze its path-dependent nonlinear structural response. Gravity dead and live loads consisted of self-weight, 8 psf superimposed dead load, and 25 percent of design live loads. Design live loads varied from $55 \mathrm{psf}$ to 85 psf as shown in Fig. 5-61. Vertical loads were not applied to the top of columns.

NIST derived the temperatures of structural components from fire models of the WTC towers and the thermal insulation damage conditions. Temperature cases provided by NIST were "Case $\mathrm{A}_{i}$ temperature condition" and "Case $\mathrm{B}_{\mathrm{i}}$ temperature condition" for WTC 1 , and "Case $\mathrm{C}_{\mathrm{i}}$ temperature condition" and 
"Case $\mathrm{D}_{1}$ temperature condition" for WTC 2. ${ }^{5}$ The floor model analyses were performed by using these temperature conditions. However, NIST later refined these temperature conditions based on the refined impact damage conditions, and the refined cases were "Case A temperature condition" and "Case B temperature condition" for WTC 1, and "Case C temperature condition" and "Case D temperature condition" for WTC 2. For the WTC 1 Floor 97 full floor model only, Case A tcmperature condition was also used. Since the results from the WTC 1 Floor 97 analysis for Case A temperature condition was very similar to those for Case $A_{i}$, it was concluded that the refined temperature cases would not change the floor behavior significantly. Therefore, other floors were not run with the refined temperature conditions. Temperature data sets were provided at $10 \mathrm{~min}$ intervals up to $100 \mathrm{~min}$ for WTC 1 and up to $60 \mathrm{~min}$ for WTC 2 for each temperature condition. In the first step of thermal loading, temperatures were linearly ramped from room temperature $\left(20^{\circ} \mathrm{C}\right)$ to the temperatures specified at $10 \mathrm{~min}$. After the first step, temperatures were varied linearly to the next specified temperatures. Figures 5-62 to 5-65 show Case $A_{i}$ and Case $B_{i}$ temperature conditions for Floor 96 of WTC 1, and Figs. 5-66 to 5-69 show Case $C_{j}$ and Case $\mathrm{D}_{1}$ temperature conditions for Floor 82 of WTC 2. These figures show that high temperature occurs in trusses where there is insulation damage. Severed members are also shown in these figures; however, severed members were not included in the analysis. Table 5-12 shows a list of full floor analyses performed in this study.
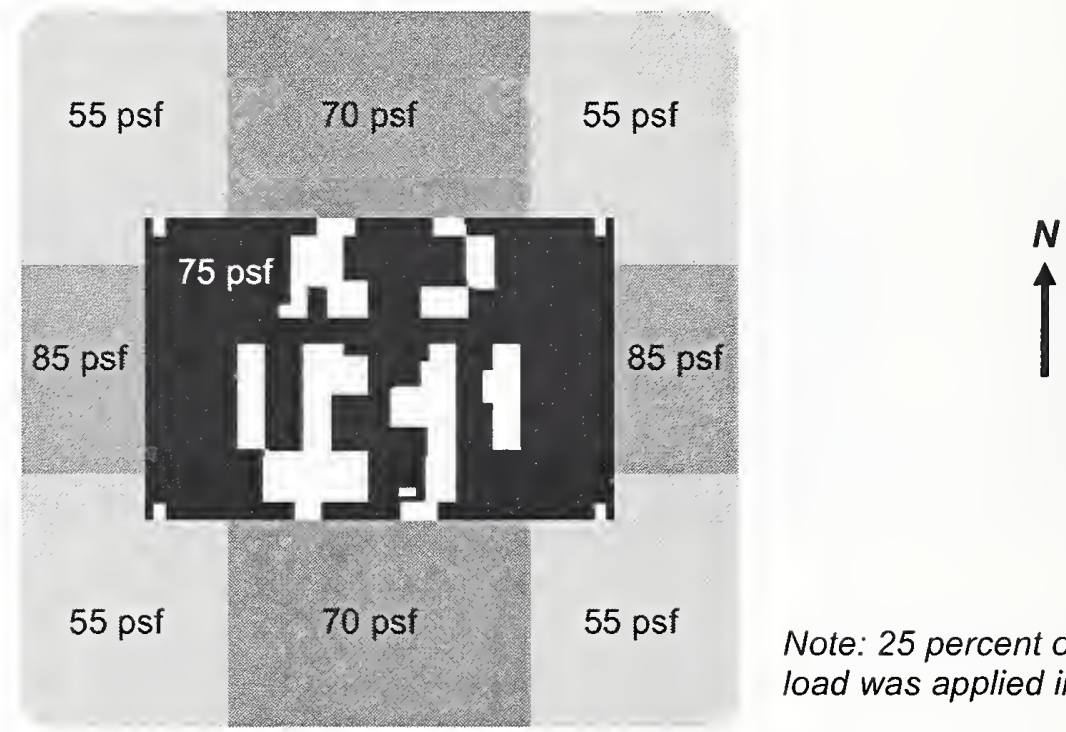

Figure 5-61. Design live load distribution in Floor 96 of WTC 1.

Temperatures were assigned at node locations for beam elements. Only columns had temperature gradients across their cross sections; trusses and spandrels had uniform temperatures within their cross sections. Slab temperatures were assigned at node locations. Shell elements for the slab had four layers through thickness, and there were five points across the thickness to define the temperature distribution through the thickness at each node location.

\footnotetext{
${ }^{5}$ Temperature cases were formerly called by different names. Case $D_{1}$ and Case $C_{i}$ conditions were called "baseline case", and Case $B_{i}$ and Case $D_{1}$ conditions were called "maximum damage case". Case A and Case C conditions were called "best estimate case" or "realistic case", and Case B and Case D conditions were called "upper bound case" or "severe case". These former temperature case names may appear on graphics produced in ANSYS.
} 


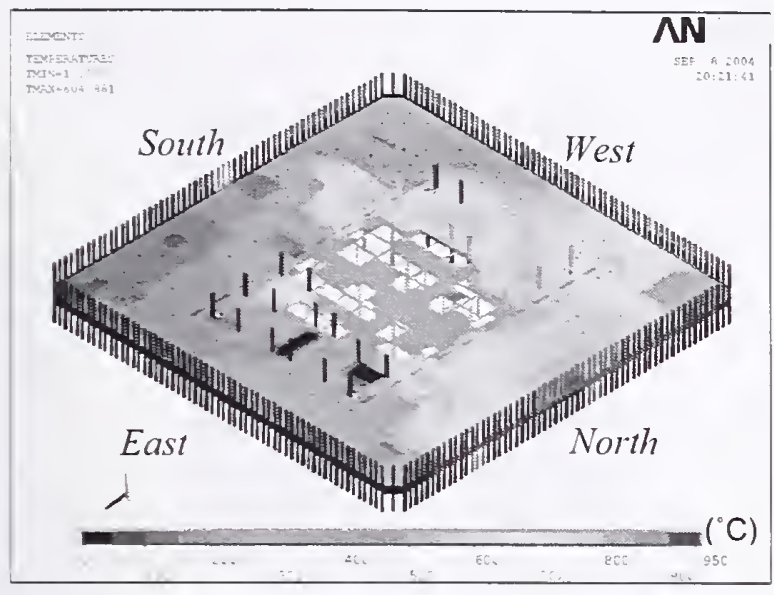

(a) Top view at $10 \mathrm{~min}$

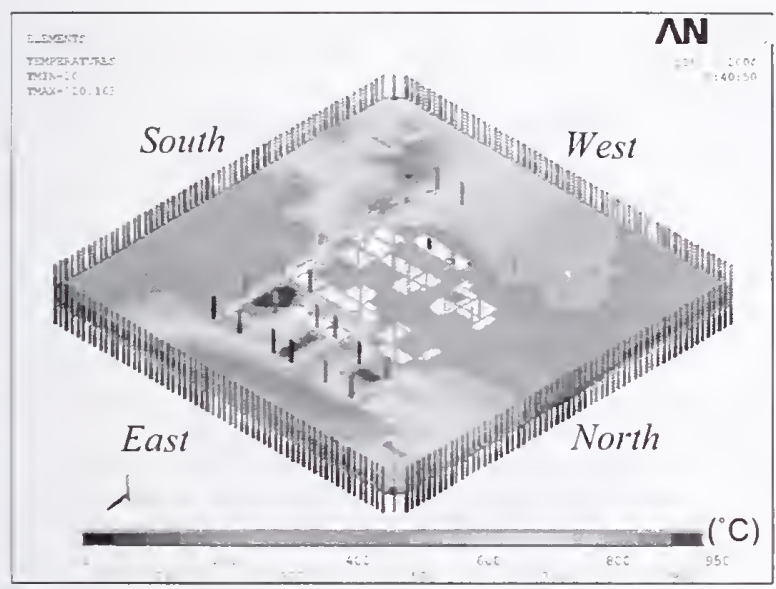

(c) I op view at su min

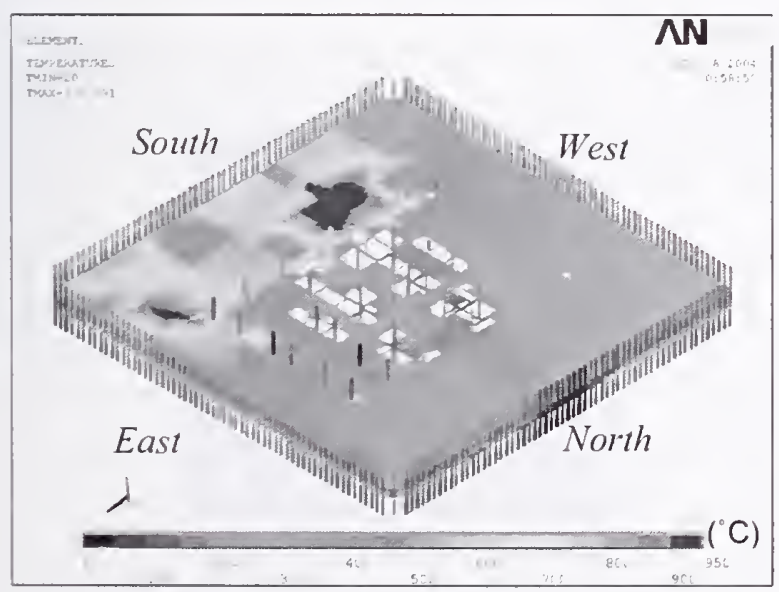

(e) lop view at $100 \mathrm{~m} ı n$

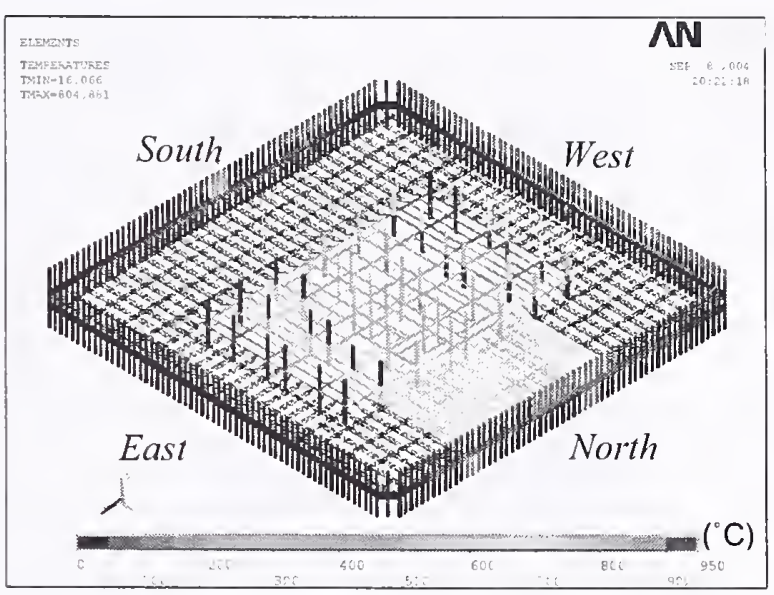

(b) Top view without concrete slab at $10 \mathrm{~min}$

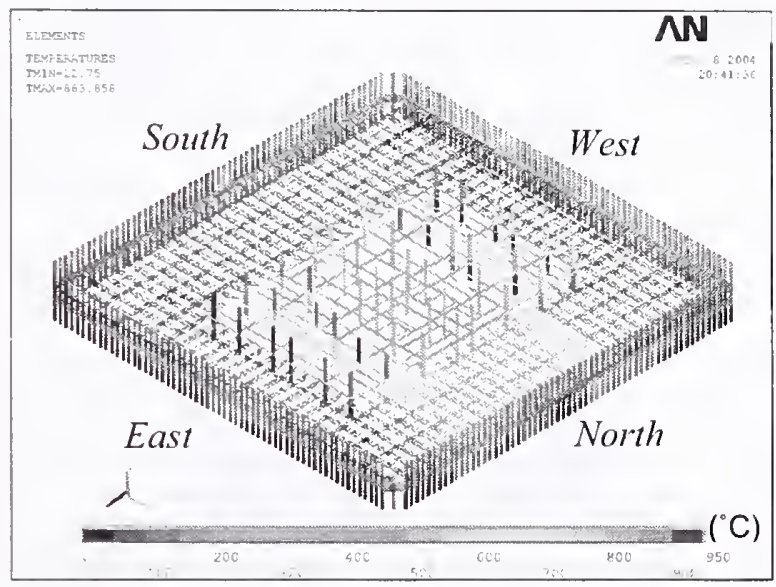

(a) Iop view witnout concrete siap at ou mın

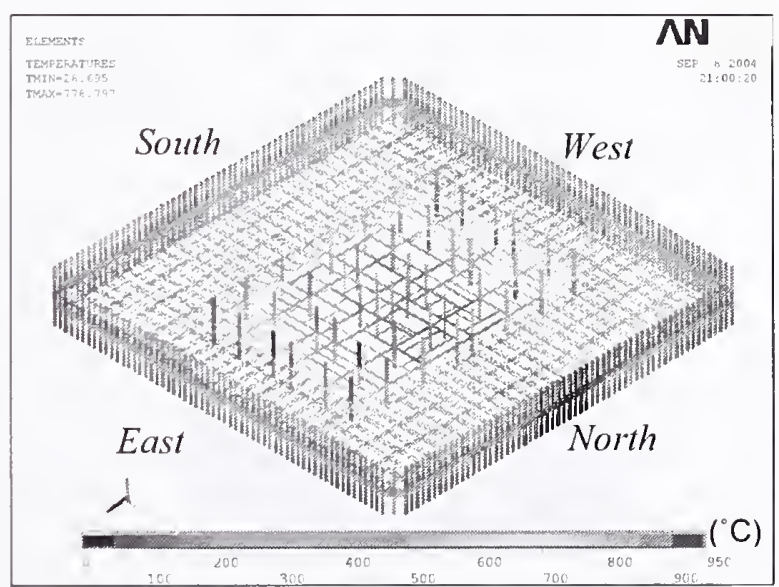

(t) Iop view without concrete slab at 100 mın

Figure 5-62. Case $A_{i}$ temperature condition for Floor 96 of WTC 1 at $10 \mathrm{~min}, 50 \mathrm{~min}$, and $100 \mathrm{~min}$. 


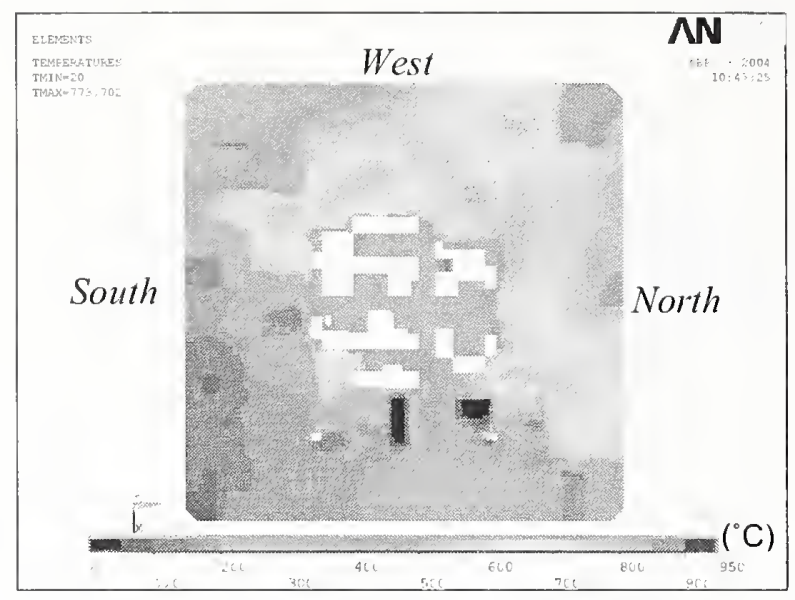

(a) Top surface at $10 \mathrm{~min}$

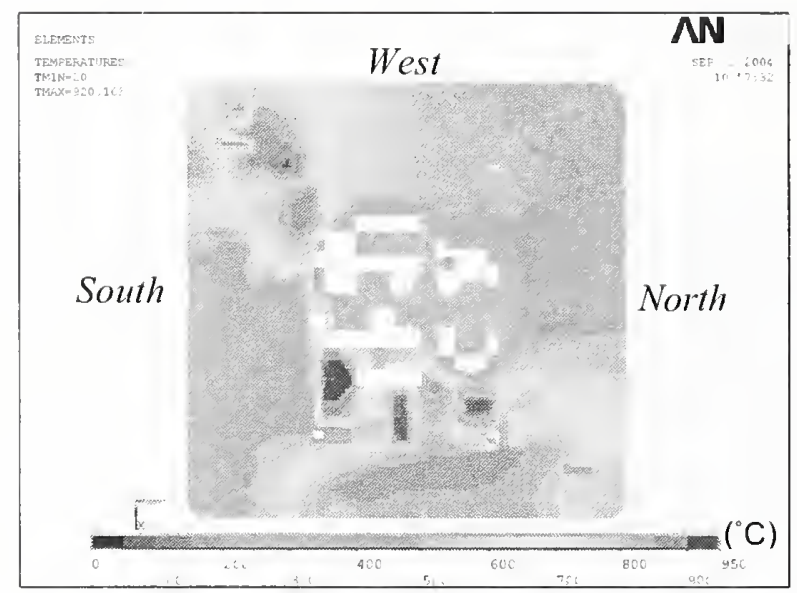

(c) Top surface at $50 \mathrm{~min}$

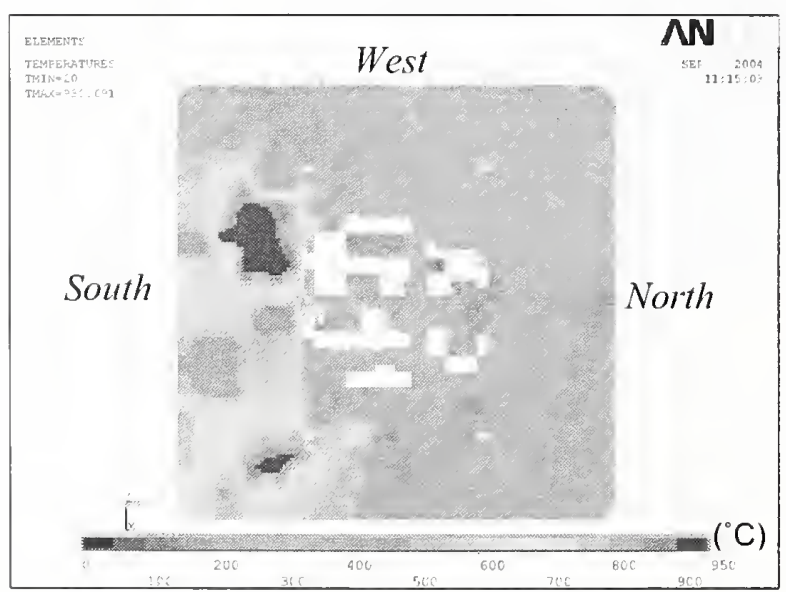

(e) Top surface at $100 \mathrm{~min}$

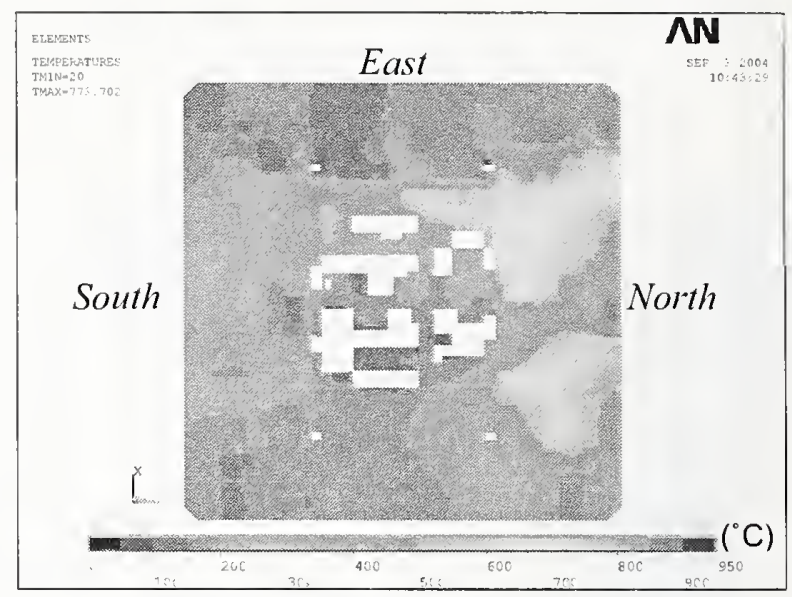

(b) Bottom surface at $10 \mathrm{~min}$

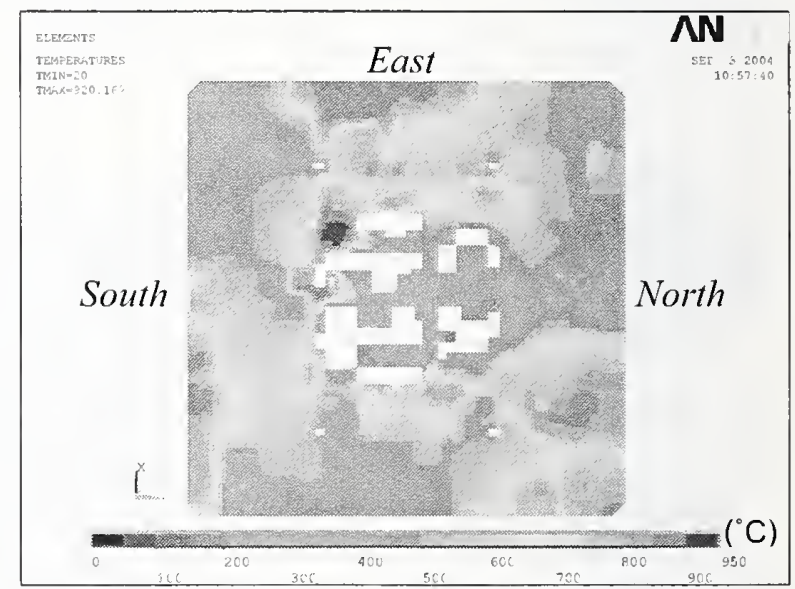

(d) Bottom surface at $50 \mathrm{~min}$

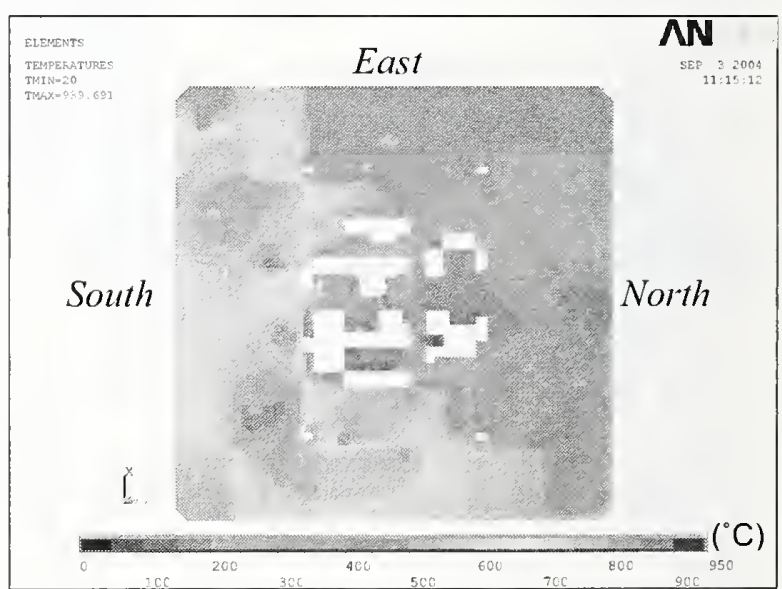

(f) Bottom surface at $100 \mathrm{~min}$

Figure 5-63. Case $A_{i}$ temperature distribution in the slab for Floor 96 of WTC 1 at $10 \mathrm{~min}$, $50 \mathrm{~min}$, and $100 \mathrm{~min}$. 


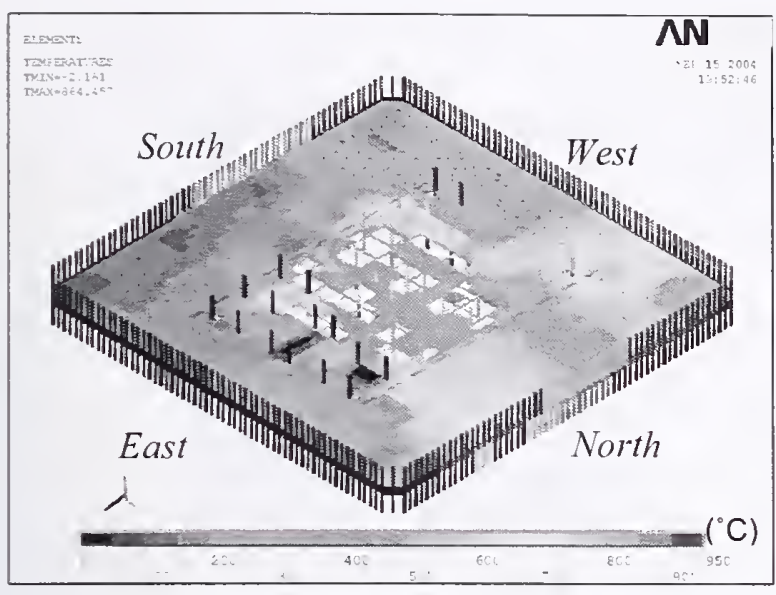

(a) Top view at $10 \mathrm{~min}$

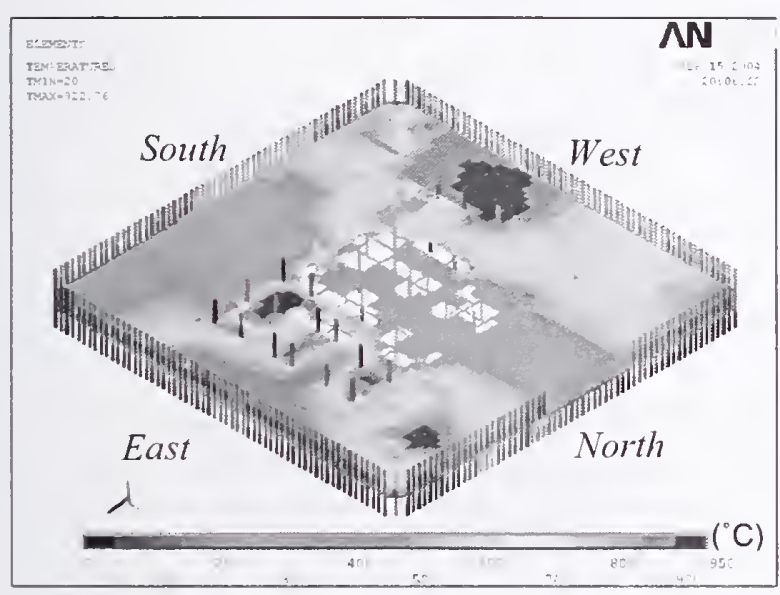

(c) Top view at $50 \mathrm{~min}$

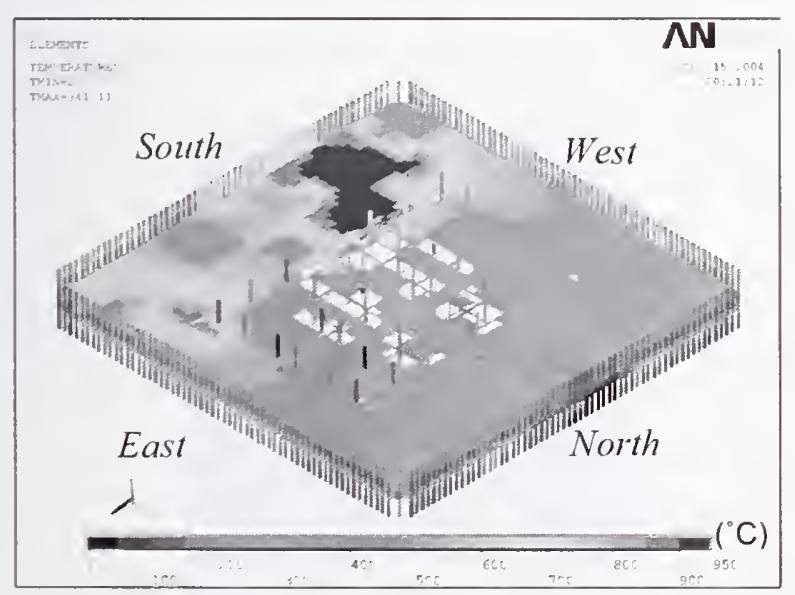

(e) Top view at $100 \mathrm{~min}$

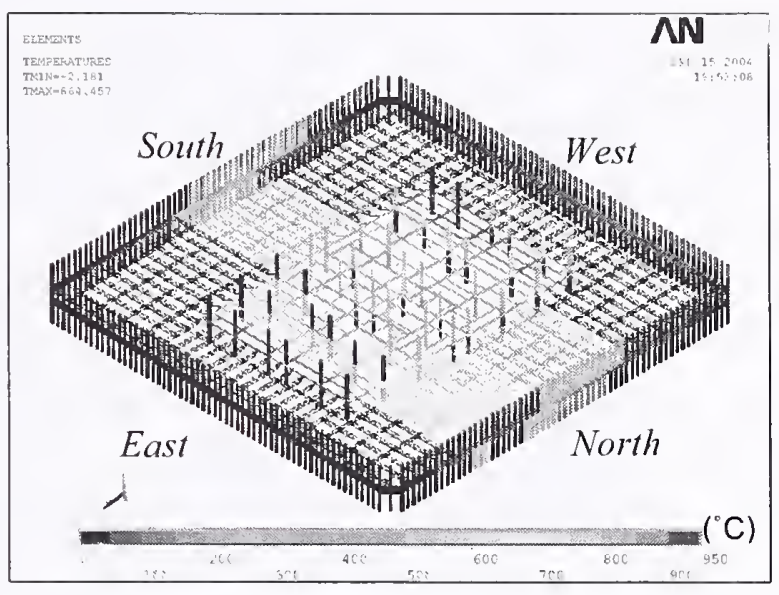

(b) Top view without concrete slab at $10 \mathrm{mir}$

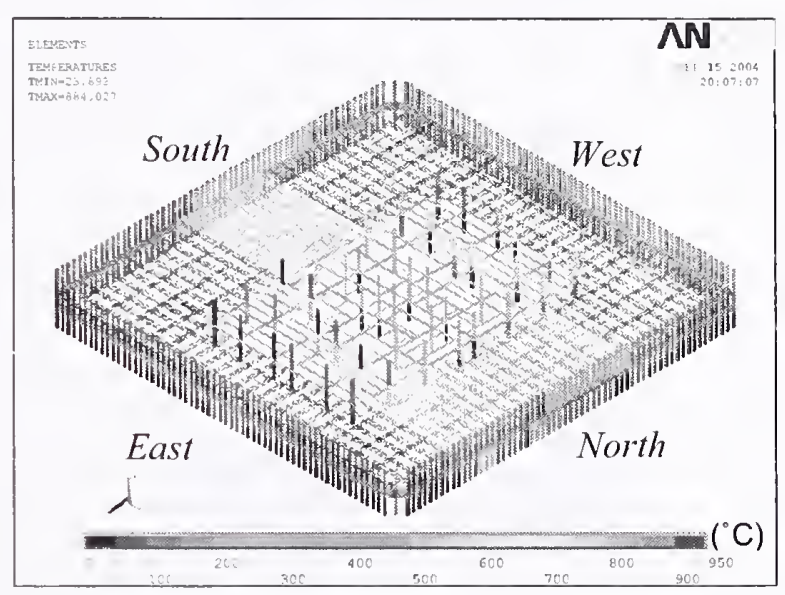

(d) Top view without concrete slab at $50 \mathrm{~min}$

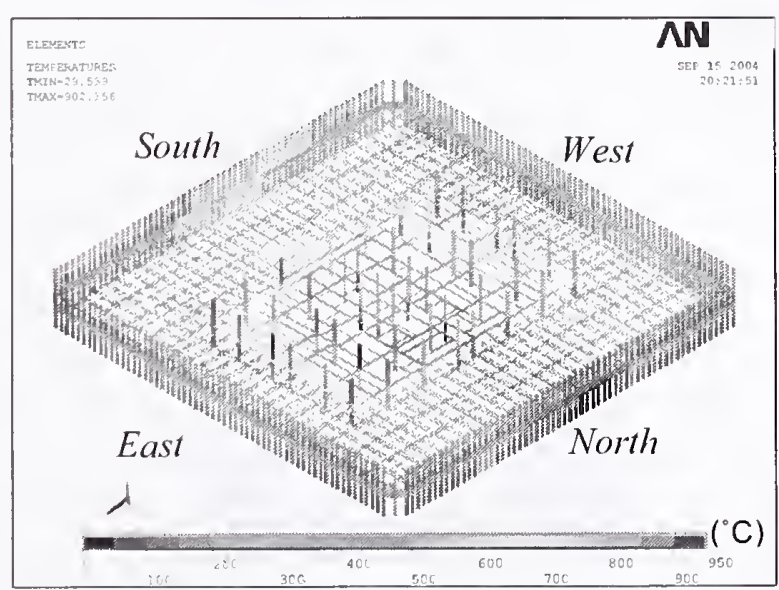

(f) Top view without concrete slab at $100 \mathrm{~min}$

Figure 5-64. Case $B_{i}$ temperature condition for Floor 96 of WTC 1 at $10 \mathrm{~min}, 50 \mathrm{~min}$, and $100 \mathrm{~min}$. 


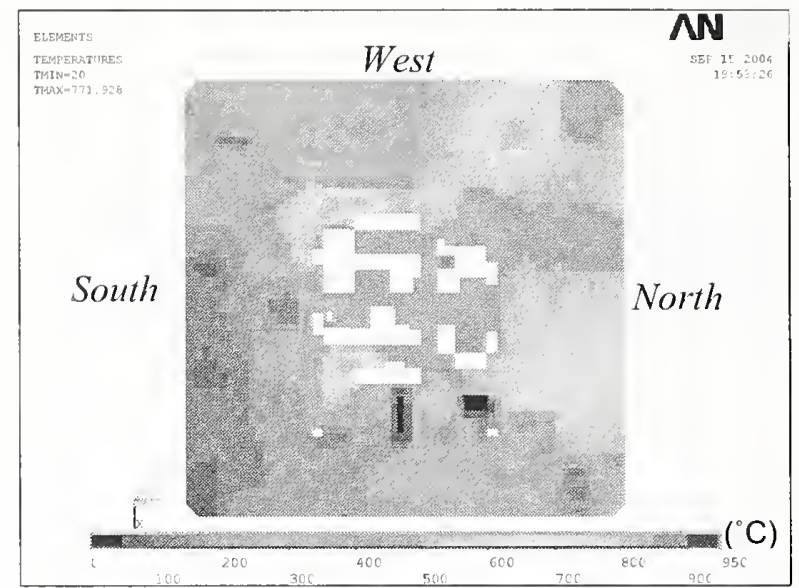

(a) Top surface at $10 \mathrm{~min}$

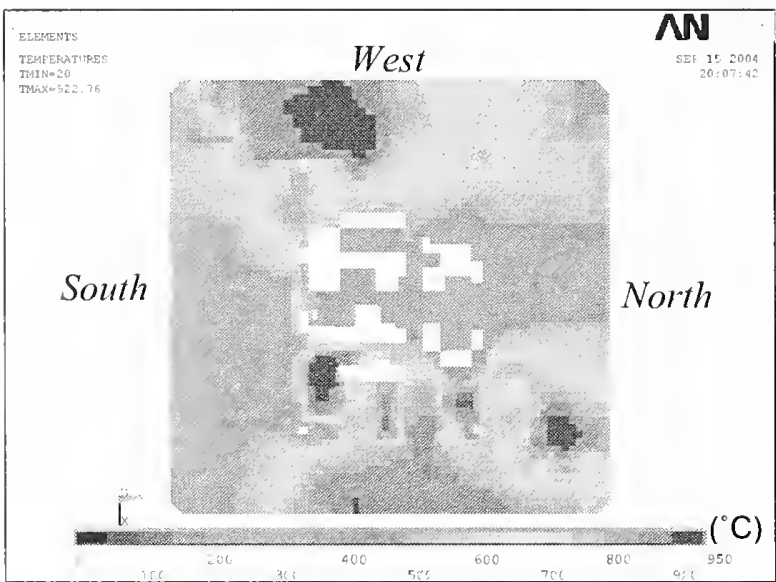

(c) Top surface at $50 \mathrm{~min}$

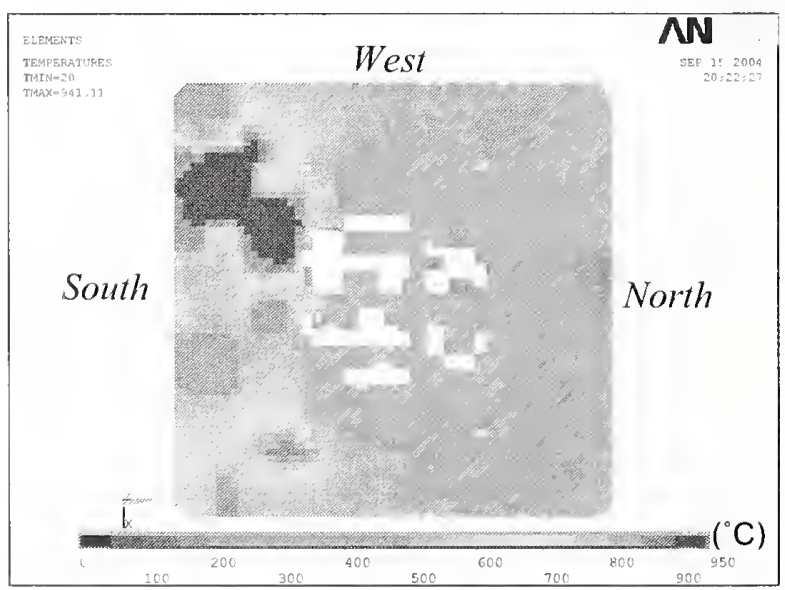

(e) Top surface at $100 \mathrm{~min}$

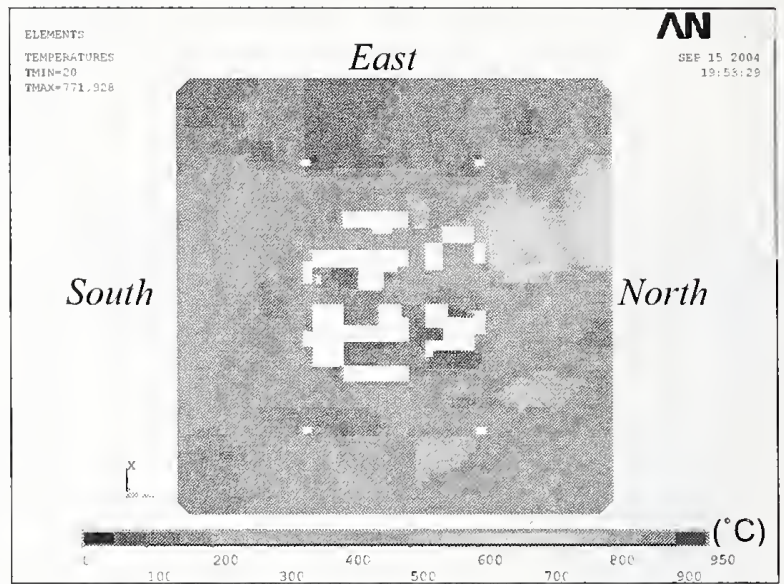

(b) Bottom surface at $10 \mathrm{~min}$

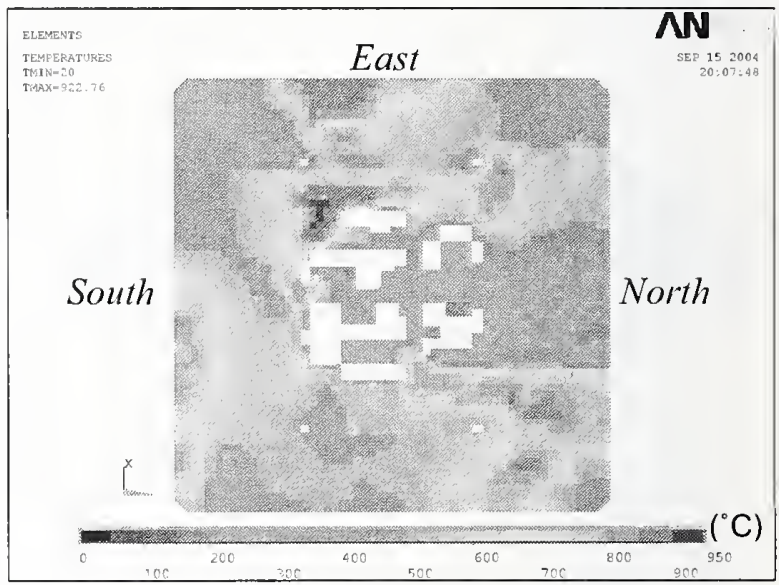

(d) Bottom surface at 50 min

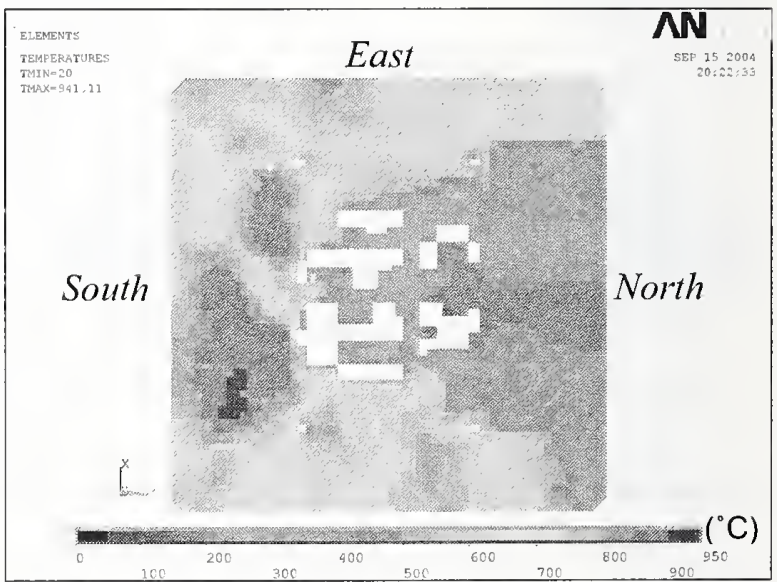

(f) Bottom surface at $100 \mathrm{~min}$

Figure 5-65. Case $B_{i}$ temperature distribution in the slab for Floor 96 of WTC 1 at $10 \mathrm{~min}$, $50 \mathrm{~min}$, and $100 \mathrm{~min}$. 


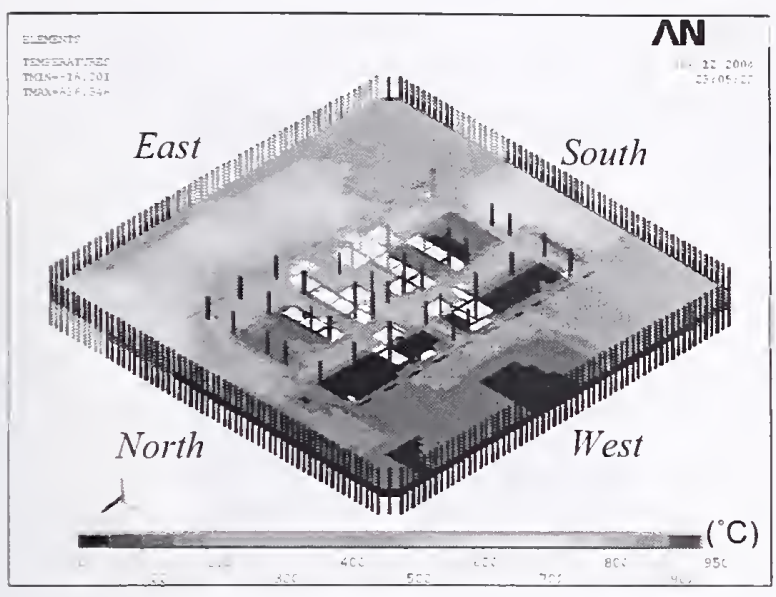

(a) Top view at $10 \mathrm{~min}$

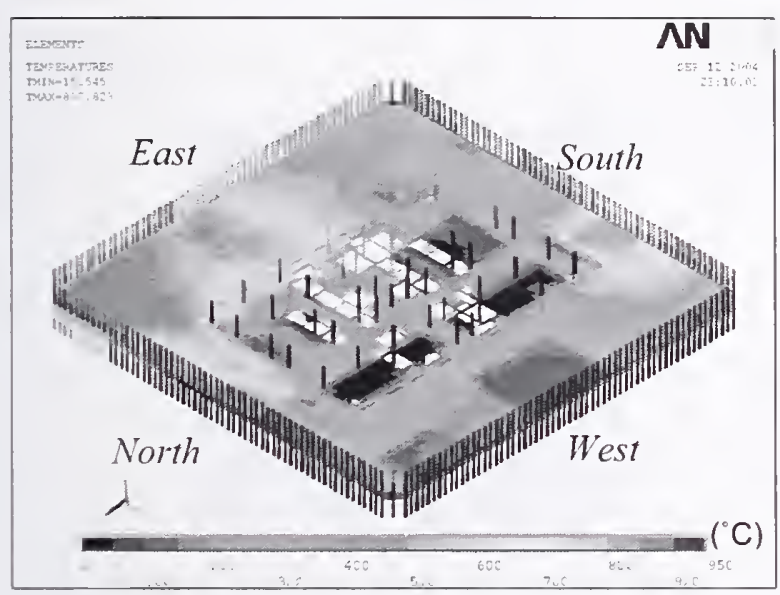

(c) Top view at $30 \mathrm{~min}$

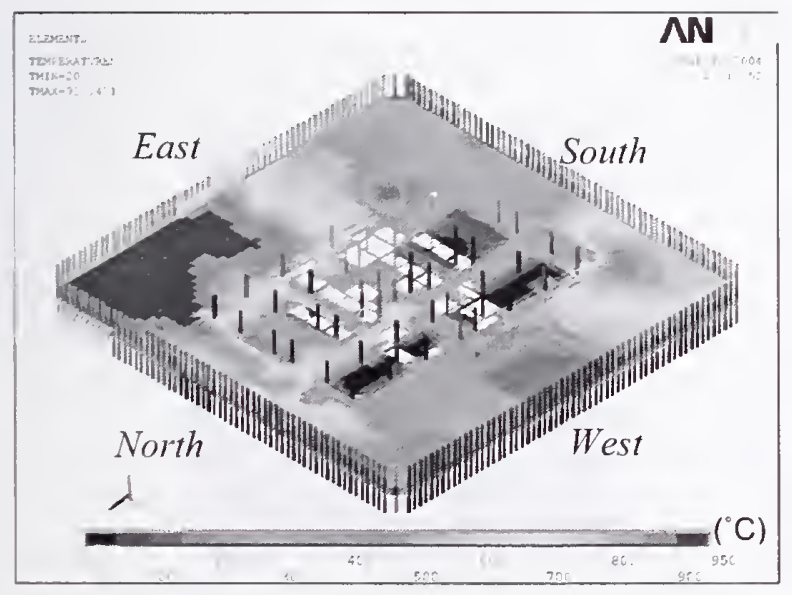

(e) Top view at $60 \mathrm{~min}$

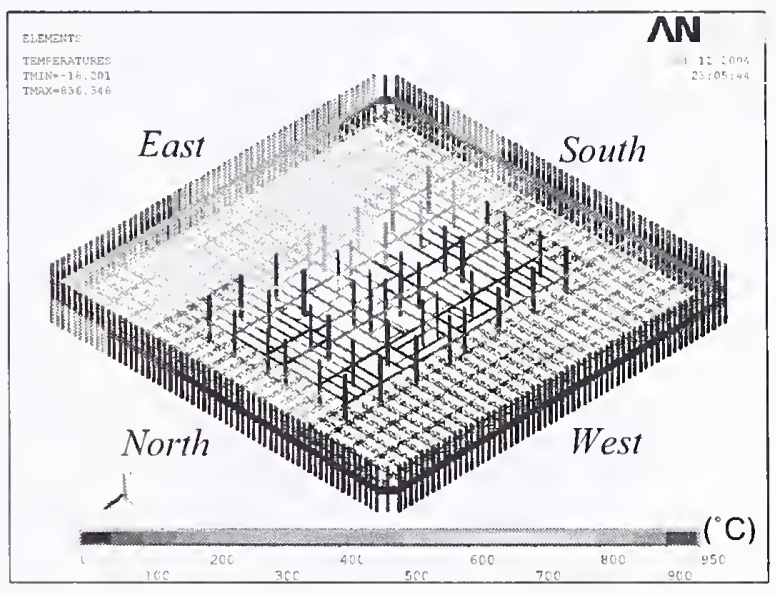

(b) Top view without concrete slab at $10 \mathrm{~min}$

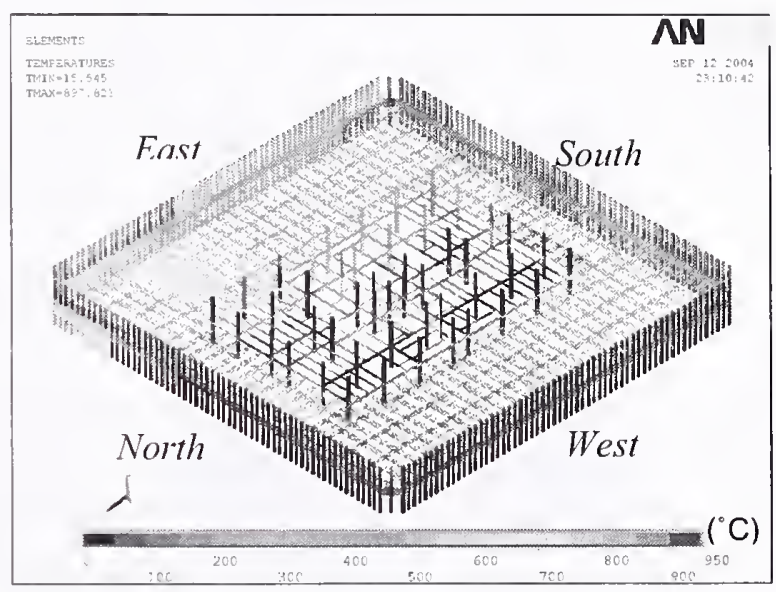

(d) Top view without concrete slab at $30 \mathrm{~min}$

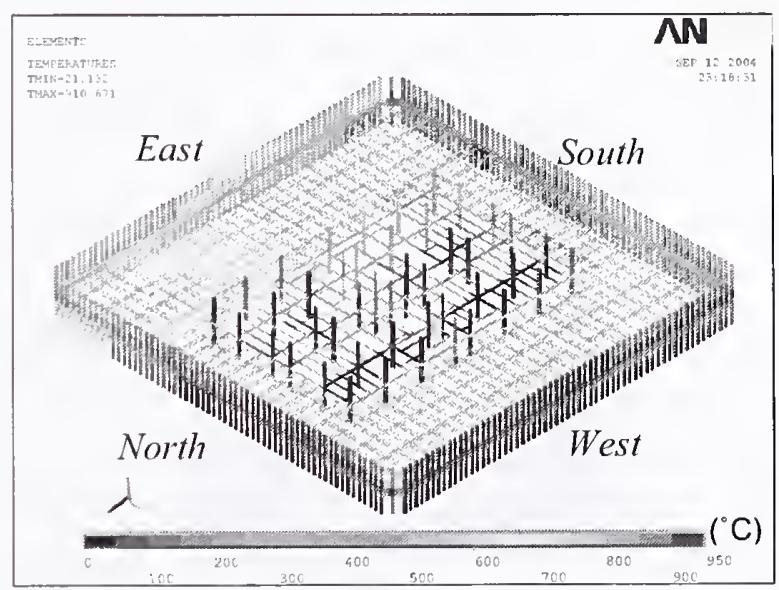

(f) Top view without concrete slab at $60 \mathrm{~min}$

Figure 5-66. Case $C_{i}$ temperature condition for Floor 82 of WTC 2 at $10 \mathrm{~min}, 30 \mathrm{~min}$, and $60 \mathrm{~min}$. 


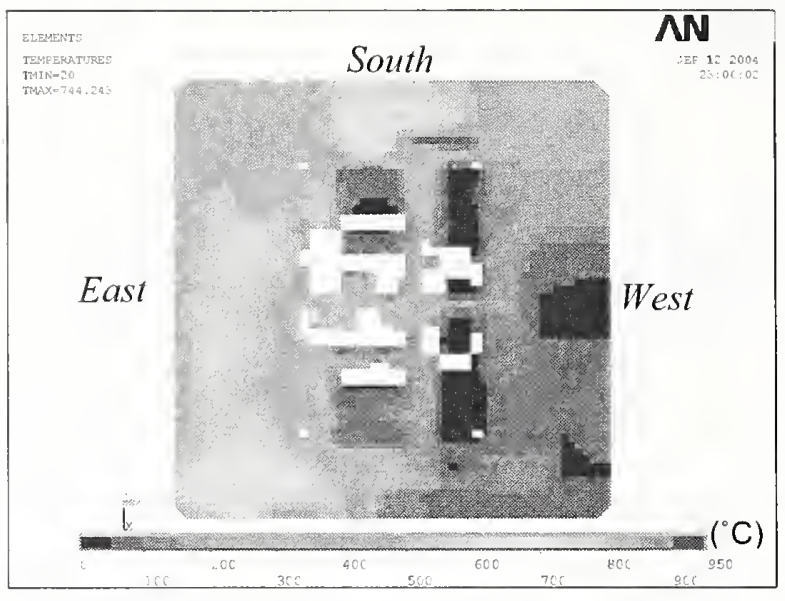

(a) Top surface at $10 \mathrm{~min}$

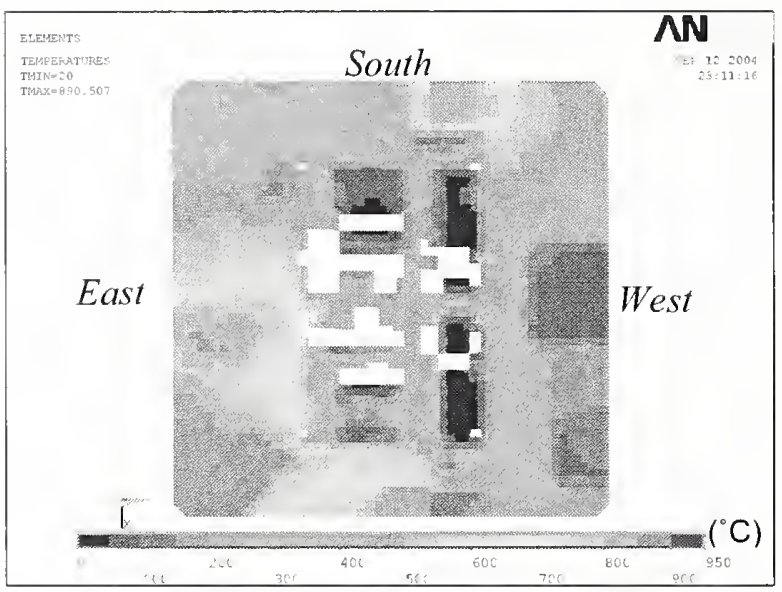

(c) Top surface at $30 \mathrm{~min}$

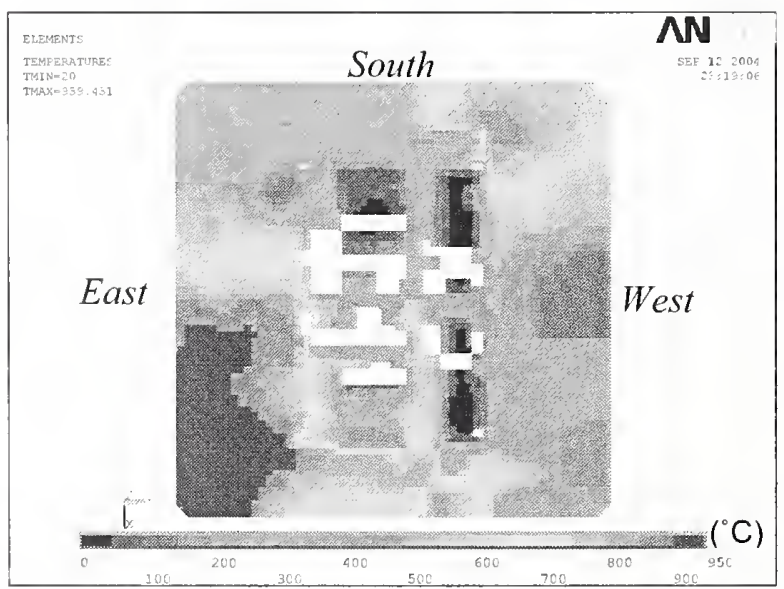

(e) Top surface at $60 \mathrm{~min}$

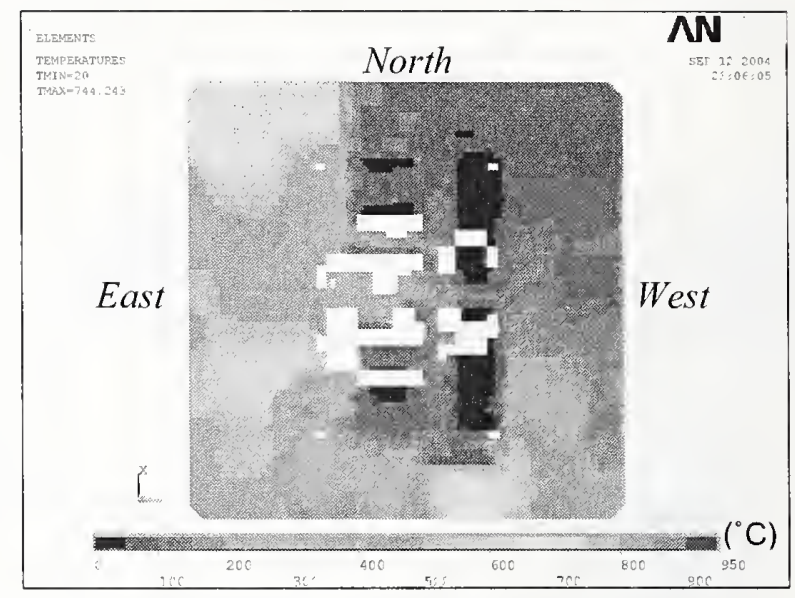

(b) Bottom surface at $10 \mathrm{~min}$

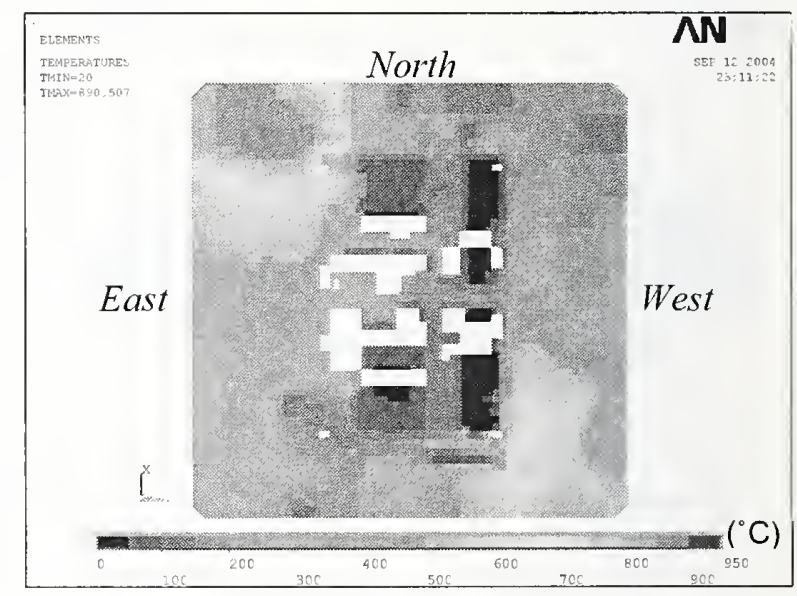

(d) Bottom surface at $30 \mathrm{~min}$

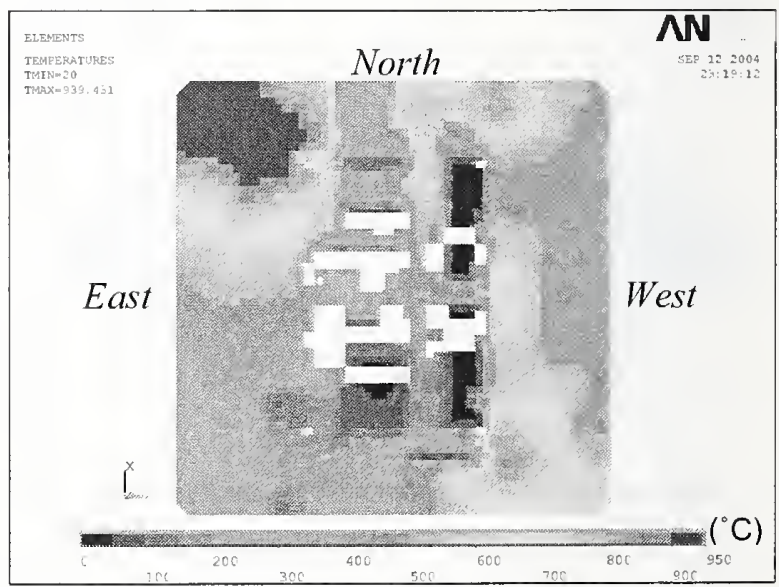

(f) Bottom surface at $60 \mathrm{~min}$

Figure 5-67. Case $C_{i}$ temperature distribution in the slab for Floor 82 of WTC 2 at 10 min, $30 \mathrm{~min}$, and $60 \mathrm{~min}$. 


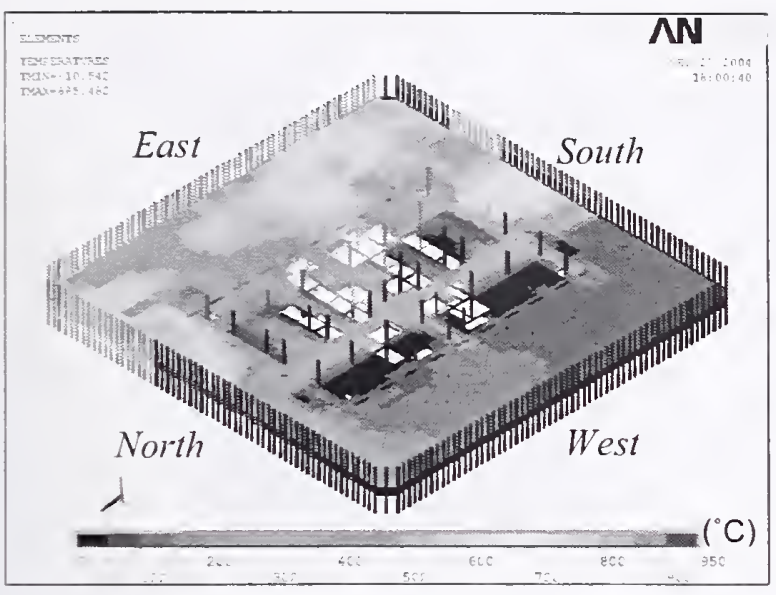

(a) Top view at $10 \mathrm{~min}$

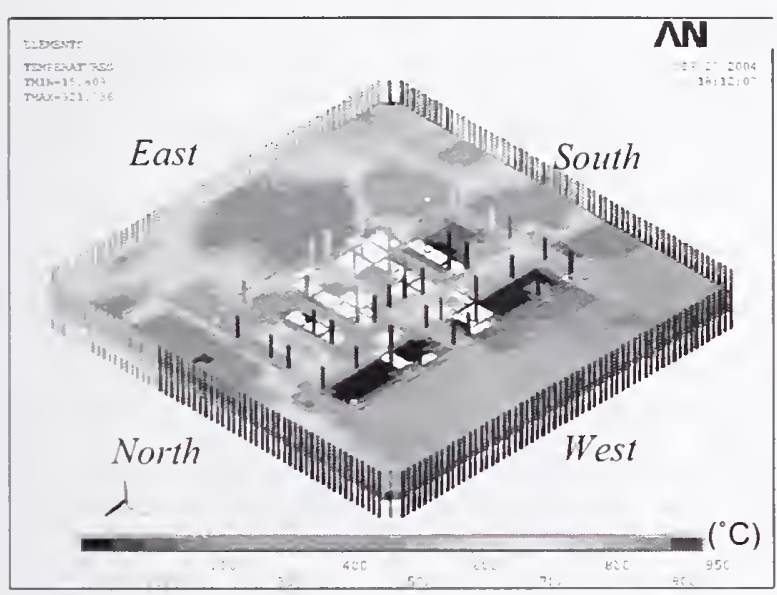

(c) Top view at $30 \mathrm{~min}$

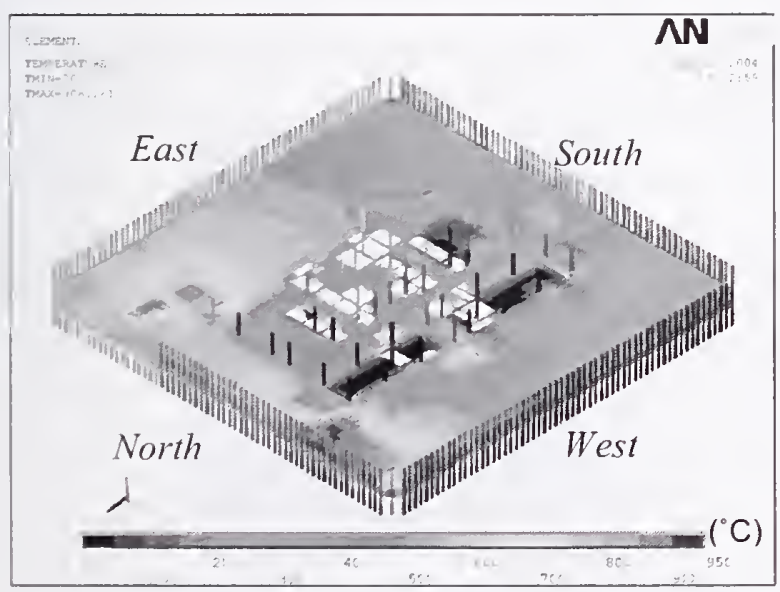

(e) Top view at $60 \mathrm{~min}$

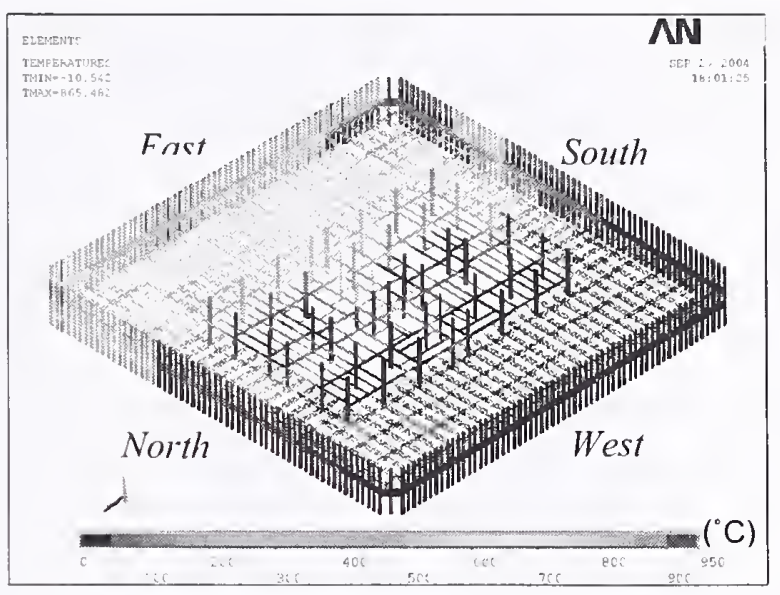

(b) Top view without concrete slab at $10 \mathrm{~min}$

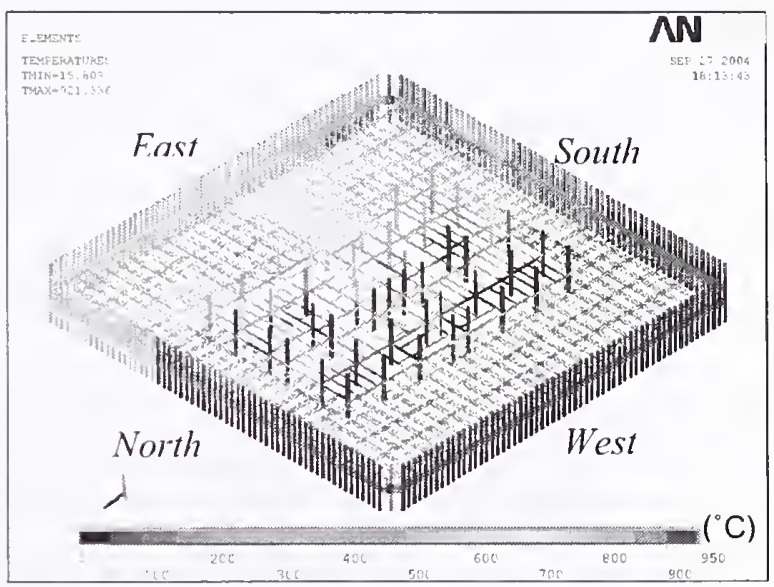

(d) Top view without concrete slab at $30 \mathrm{~min}$

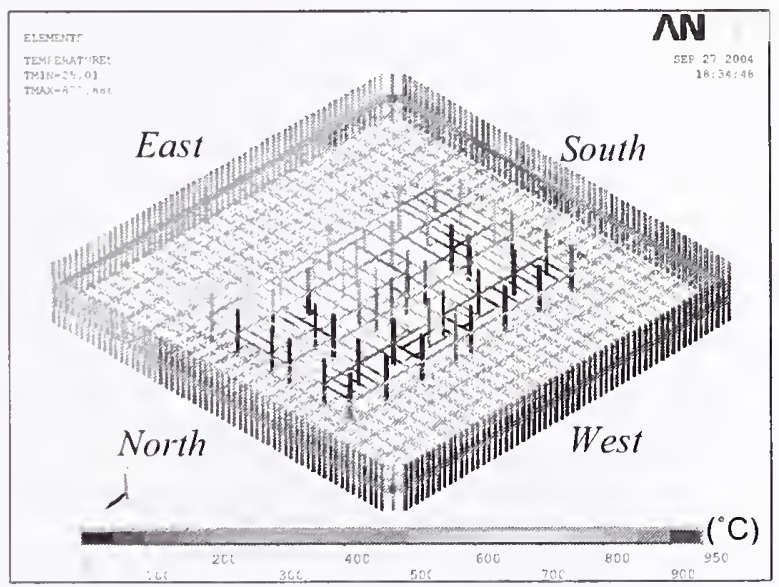

(f) Top view without concrete slab at $60 \mathrm{~min}$

Figure 5-68. Case $D_{i}$ temperature condition for Floor 82 of WTC 2 at $10 \mathrm{~min}, 30 \mathrm{~min}$, and $60 \mathrm{~min}$. 


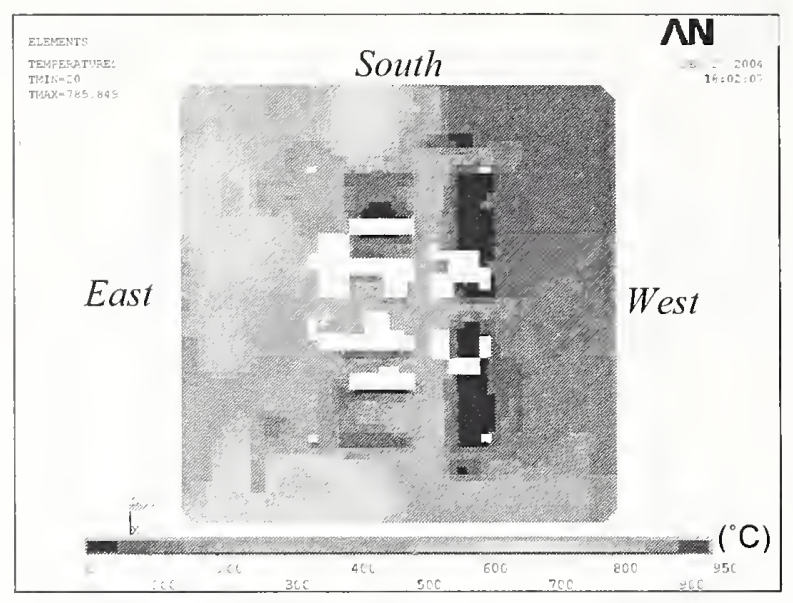

(a) Top surface at $10 \mathrm{~min}$

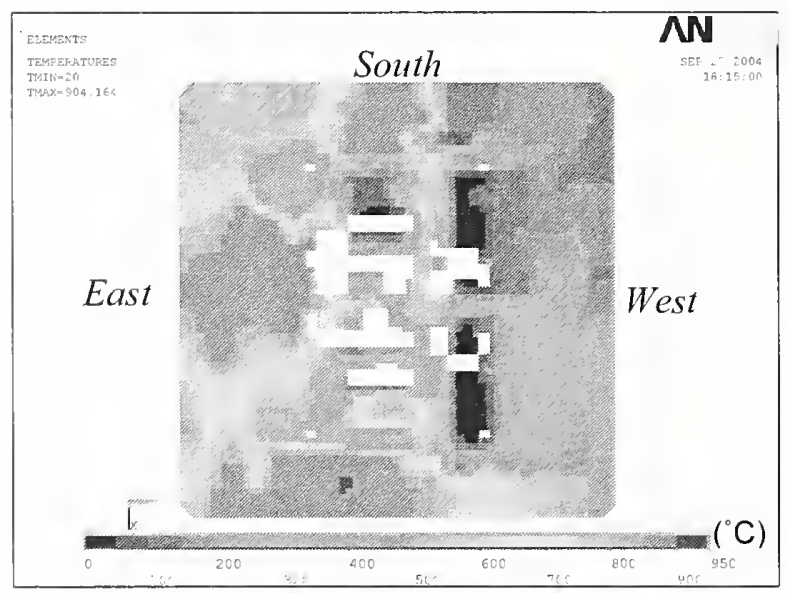

(c) Top surface at 30 min

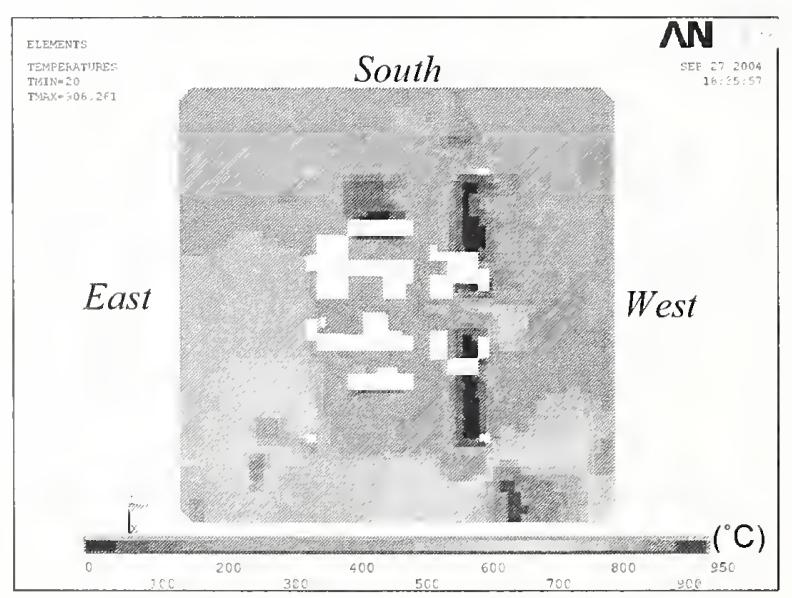

(e) Top surface at $60 \mathrm{~min}$

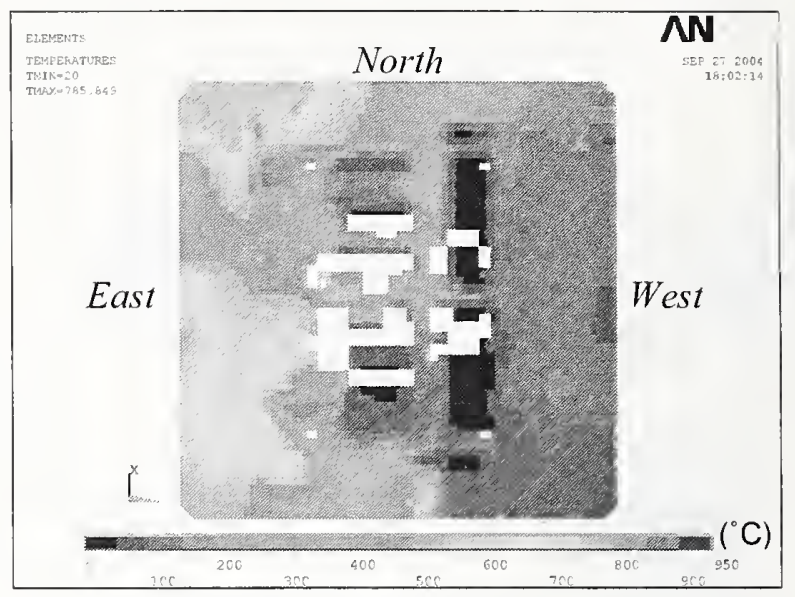

(b) Bottom surface at $10 \mathrm{~min}$

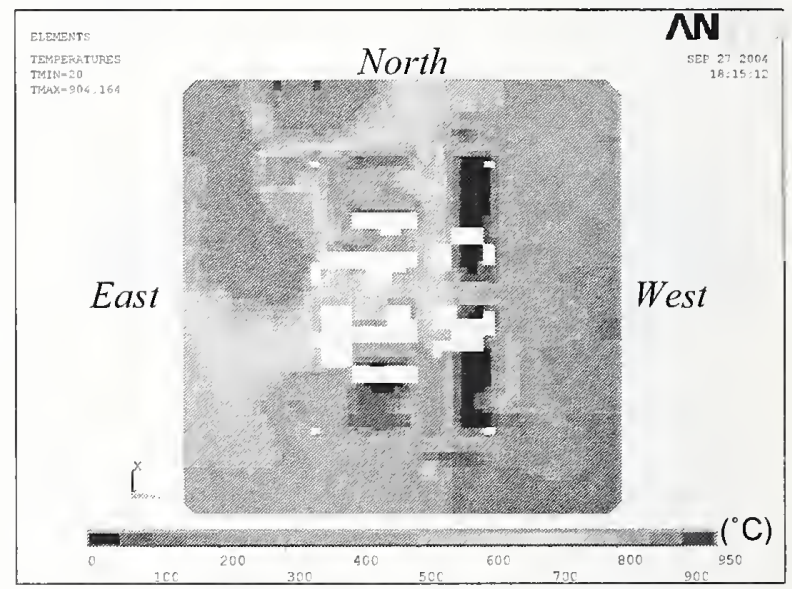

(d) Bottom surface at $30 \mathrm{~min}$

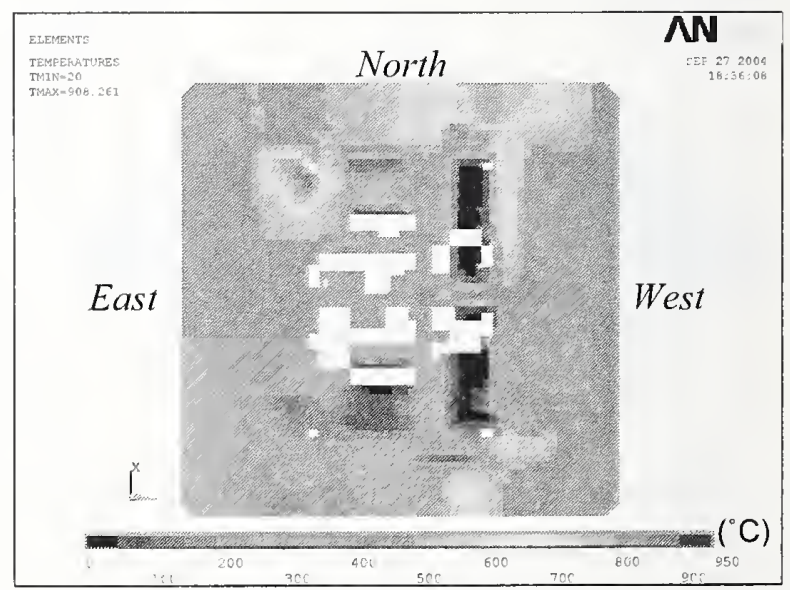

(f) Bottom surface at $60 \mathrm{~min}$

Figure 5-69. Case $D_{i}$ temperature distribution in the slab for Floor 82 of WTC 2 at $10 \mathrm{~min}$, $30 \mathrm{~min}$, and $60 \mathrm{~min}$. 
Table 5-12. List of full floor model analyses performed.

\begin{tabular}{|c|c|c|c|c|}
\hline Analysis \# & Tower & Floor & Impact Damage & Temperature \\
\hline 1 & WTC 1 & Floor 93 & Case $A_{i}$ & Case $A_{i}$ \\
\hline 2 & WTC 1 & Floor 94 & Case $A_{i}$ & Case $\mathrm{A}_{\mathrm{i}}$ \\
\hline 3 & WTC 1 & Floor 95 & Case $A_{i}$ & Case $A_{i}$ \\
\hline 4 & WTC 1 & Floor 96 & Case $A_{i}$ & Case $A_{i}$ \\
\hline 5 & WTC 1 & Floor 97 & Case $A_{i}$ & Case $A_{i}$ \\
\hline 6 & WTC 1 & Floor 98 & Case $A_{i}$ & Case $A_{1}$ \\
\hline 7 & WTC 1 & Floor 99 & Case $A_{i}$ & Case $A_{i}$ \\
\hline 8 & WTC 1 & Floor 93 & Case $A_{i}$ & Case $B_{1}$ \\
\hline 9 & WTC 1 & Floor 94 & Case $A_{i}$ & Case $\mathrm{B}_{1}$ \\
\hline 10 & WTC 1 & Floor 95 & Case $A_{i}$ & Case $B_{i}$ \\
\hline 11 & WTC 1 & Floor 96 & Case $A_{i}$ & Case $B_{i}$ \\
\hline 12 & WTC 1 & Floor 97 & Case $A_{i}$ & Case $B_{i}$ \\
\hline 13 & WTC 1 & Floor 98 & Case $A_{i}$ & Case $B_{i}$ \\
\hline 14 & WTC 1 & Floor 99 & Case $\mathrm{A}_{\mathrm{i}}$ & Case $B_{i}$ \\
\hline 15 & WTC 2 & Floor 79 & Case $C_{i}$ & Case $C_{i}$ \\
\hline 16 & WTC 2 & Floor 80 & Case $C_{i}$ & Case $C_{i}$ \\
\hline 17 & WTC 2 & Floor 81 & Case $C_{i}$ & Case $\mathrm{C}_{\mathrm{i}}$ \\
\hline 18 & WTC 2 & Floor 82 & Case $C_{i}$ & Case $C_{i}$ \\
\hline 19 & WTC 2 & Floor 83 & Case $\mathrm{C}_{\mathrm{i}}$ & Case $C_{i}$ \\
\hline 20 & WTC 2 & Floor 79 & Case $D_{1}$ & Case $\mathrm{D}_{\mathrm{i}}$ \\
\hline 21 & WTC 2 & Floor 80 & Case $D_{1}$ & Case $\mathrm{D}_{\mathrm{i}}$ \\
\hline 22 & WTC 2 & Floor 81 & Case $\mathrm{D}_{1}$ & Case $\mathrm{D}_{\mathrm{i}}$ \\
\hline 23 & WTC 2 & Floor 82 & Case $\mathrm{D}_{1}$ & Case $D_{i}$ \\
\hline 24 & WTC 2 & Floor 83 & Case $D_{i}$ & Case $\mathrm{D}_{\mathrm{i}}$ \\
\hline 25 & WTC 1 & Floor 97 & Case $A_{i}$ & Case A \\
\hline
\end{tabular}

\subsubsection{Boundary Conditions}

Both core and exterior columns were supported in the vertical direction at the bottom. When the column below the floor was severed by aircraft impact, the top of the column above the floor was supported in the vertical direction. Core columns were free in the horizontal directions and fixed against all rotations at the top and bottom ends. Exterior columns were fixed for translation perpendicular to the face of the building and against rotation about the axis parallel to the face of the building at the top and bottom. They were also fixed in torsion at the top and bottom. A quantitative study of the effect of column boundary conditions is discussed in Section 5.5.16.

\subsubsection{Results from WTC 1 Floor 96 under Case $A_{i}$ Temperature Condition}

Vertical Displacement: Figure 5-70 shows the vertical displacements of Floor 96 for Case $A_{1}$ temperature condition at $10 \mathrm{~min}, 50 \mathrm{~min}$, and $100 \mathrm{~min}$. The maximum displacement of $23 \mathrm{in}$. occurred at $10 \mathrm{~min}$ in the north office area. Then, the vertical displacement decreased in the north office area as the fire moved away from the area. The floor in the south office area started to deflect upward at $20 \mathrm{~min}$, and part of the 
south office area deflected upward at $70 \mathrm{~min}$. Most short-span trusses also deflected upward. In the early stage of Case $A_{i}$ temperature condition, the temperature in the slab was much higher than that in the trusses in the south office area as can be seen in Figs. 5-62 and 5-63 because the insulation was intact on the trusses in the south office area. Although the coefficient of thermal expansion (CTE) of steel is larger than that of concrete ( 50 percent larger at room temperature; the difference increases as temperature becomes higher), when the difference in temperature between the slab and the trusses becomes large enough to cause the thermal expansion of the slab to be greater than that of trusses, the floor deflects upward. At $80 \mathrm{~min}$, several trusses in the south office area started to deflect downward, which was caused by the buckling of the floor due to compression in the east-west direction. At $100 \mathrm{~min}$, the maximum downward displacement of the floor in the north area was 12.8 in., reflecting the cooling that took place, and the maximum vertical displacements in the south office area were 4.8 in. upward and 6.4 in. downward.

Behavior of Exterior Columns on North and South Faces: Figure 5-71 shows the displacements of exterior columns normal to the face of the building at $10 \mathrm{~min}, 50 \mathrm{~min}$, and $100 \mathrm{~min}$. The maximum outward displacements were $5.8 \mathrm{in}$. and $3.7 \mathrm{in}$. for the north and south faces, which occurred at $70 \mathrm{~min}$ and $90 \mathrm{~min}$ after the impact, respectively. Exterior columns were pushed out by the floor throughout the duration of the thermal loading. Figure 5-72 shows the horizontal reaction at each column on the north and south faces. Since even number columns were not connected to trusses and spandrel studs and strap anchors were removed, reaction forces at even number columns were small. In the figure, the reaction force is positive when the floor pulls the exterior column in. Since exterior columns were always pushed out by the floor during the analysis, reaction forces were always negative. Sagged floors did not pull in the exterior wall in this analysis.

Break Elements: Figure 5-73 shows the locations of user-defined break elements that failed by $100 \mathrm{~min}$. Table 5-13 gives the number of failed user-defined break elements. Many web diagonals buckled in the northeast half of the office area where the insulation on the trusses was removed by the aircraft impact. In the south office area, there were only a few web diagonals that buckled because the insulation on the trusses was not damaged by the aircraft impact for Case $A_{i}$ impact damage condition. By 100 min, about 70 percent of all the primary and bridging truss connections in the two-way zones and the long-span and transfer truss connections had failed at their top chord connections, but remained connected at their bottom chord connections at most of these locations. None of the truss seats failed during the analysis; therefore, all trusses were still connected to the exterior wall.

Effect of Vertical Loads to Columns: Another analysis was made with vertical loads applied to columns that were obtained from the SAP2000 floor model without impact damage. Core columns yielded when their temperatures exceeded $600{ }^{\circ} \mathrm{C}$. However, the floor behavior did not change significantly from the analysis without the vertical loads on columns. 


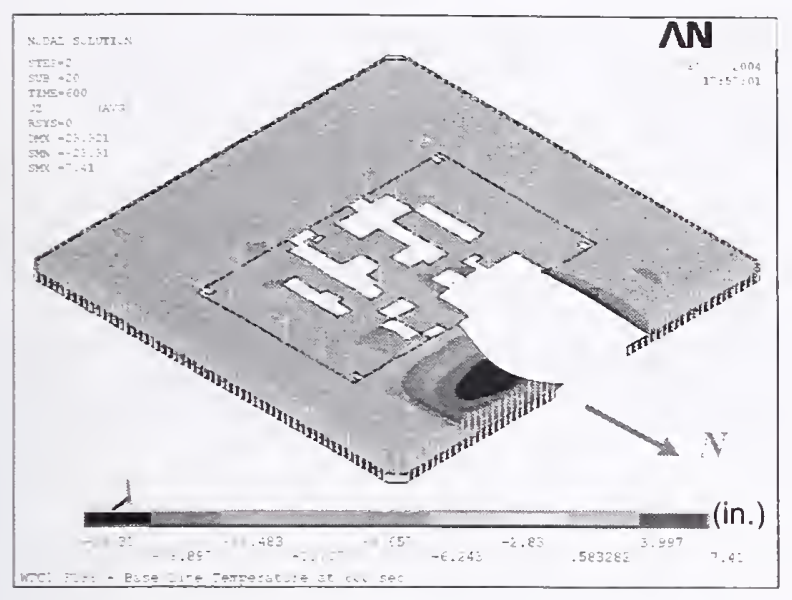

(a) Entıre model at $10 \mathrm{~min}$

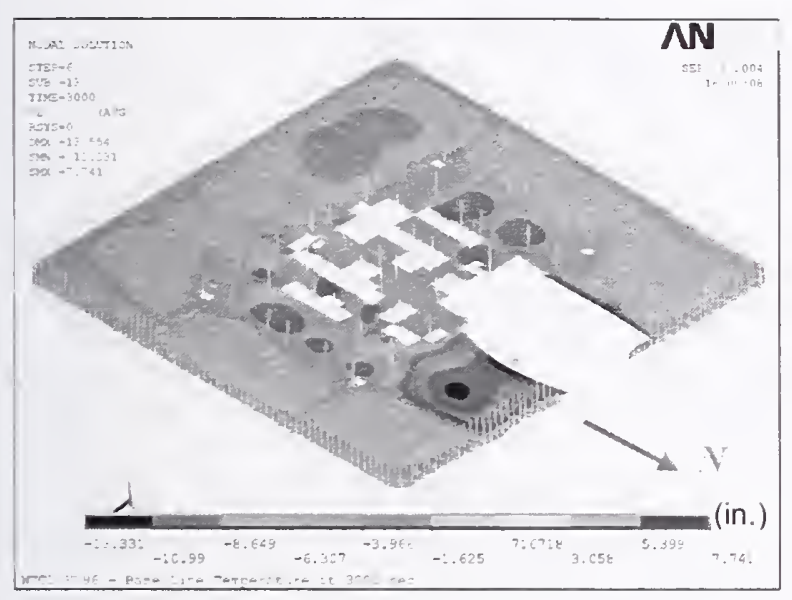

(c) tntıre model at $s u$ mın

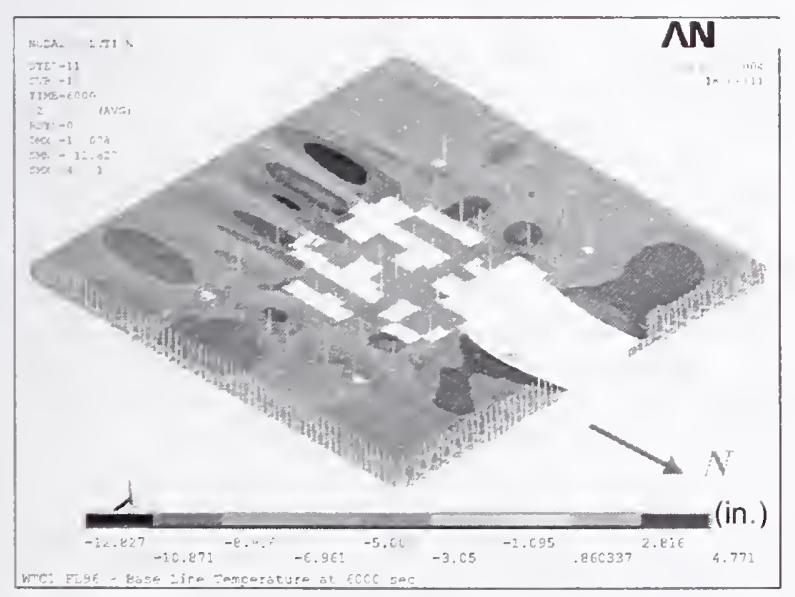

(e) Entire model at $100 \mathrm{~min}$

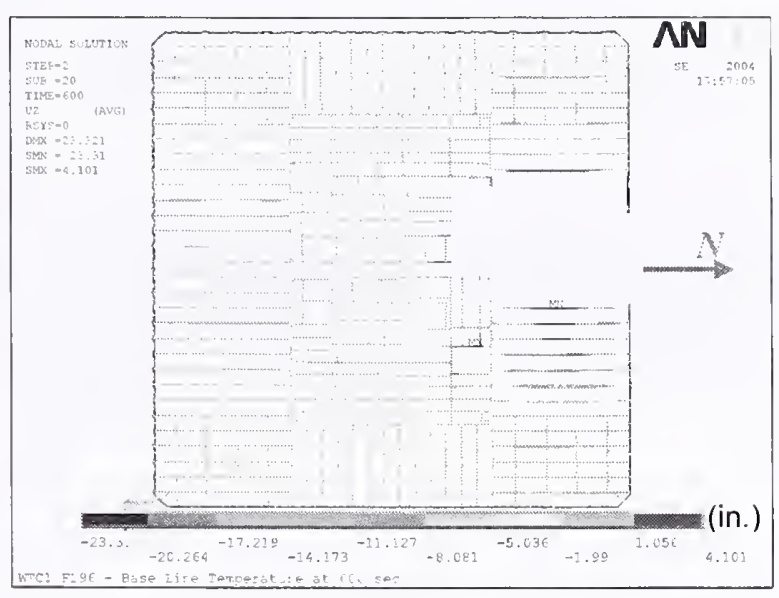

(b) Top view without concrete slab at 10 min

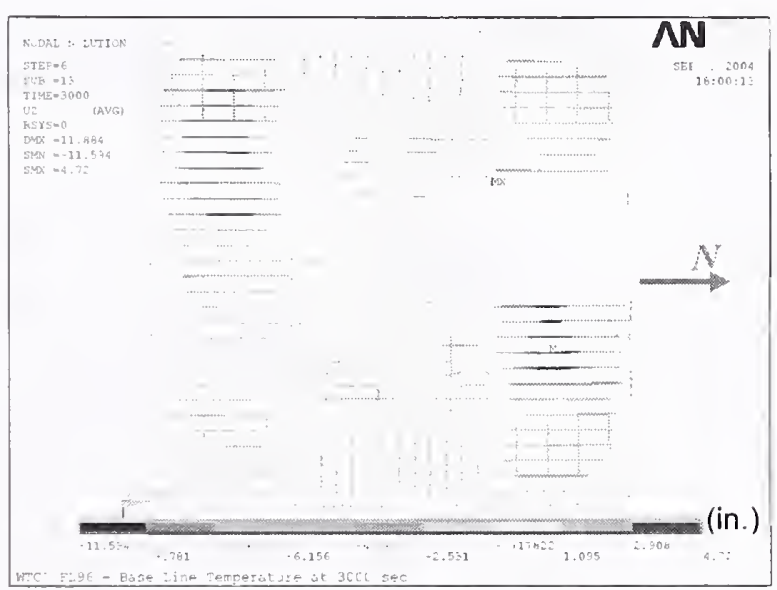

(d) Top view without concrete slab at $50 \mathrm{~min}$

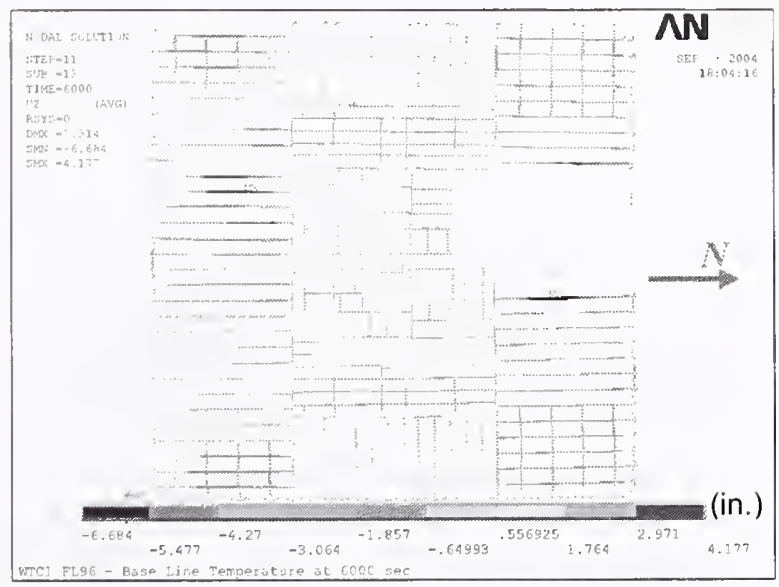

(f) Top view without concrete slab at $100 \mathrm{~min}$

Figure 5-70. Vertical displacement of WTC 1 Floor 96 for Case $A_{i}$ temperature condition at $10 \mathrm{~min}, 50 \mathrm{~min}$, and $100 \mathrm{~min}$ (downward displacement is negative; $5 x$ displacement magnification). 


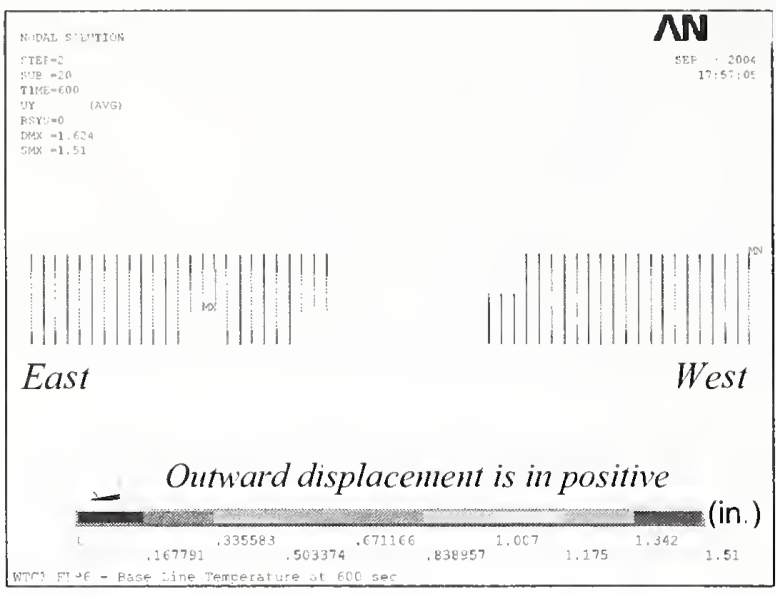

(a) North face at $10 \mathrm{~min}$

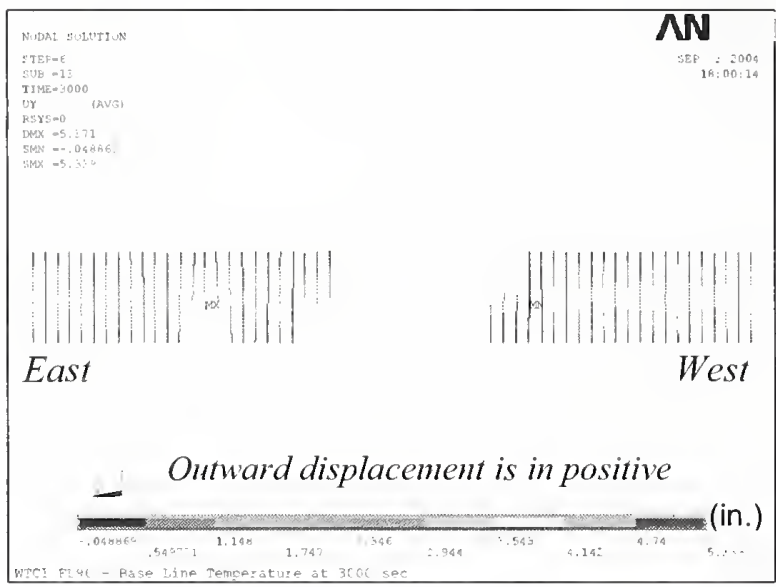

(c) North face at $50 \mathrm{~min}$

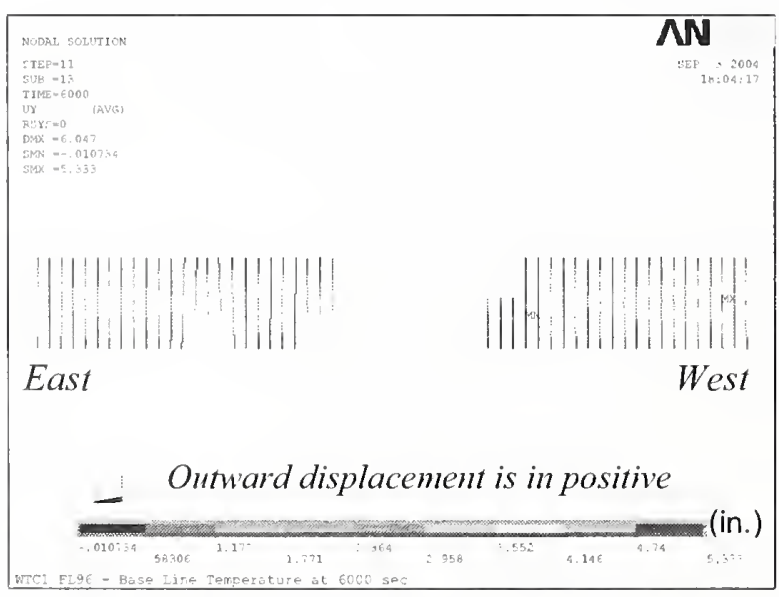

(e) North tace at $100 \mathrm{~min}$

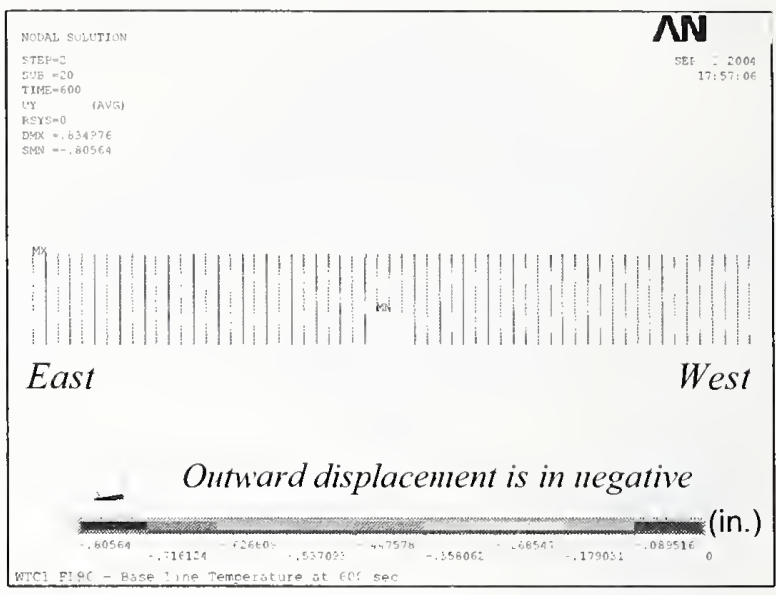

(b) South face at $10 \mathrm{~min}$

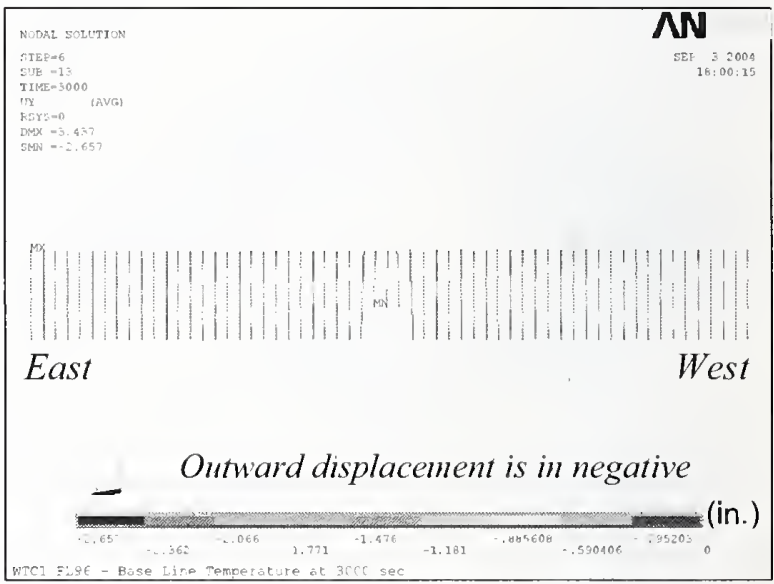

(d) South face at $50 \mathrm{~min}$

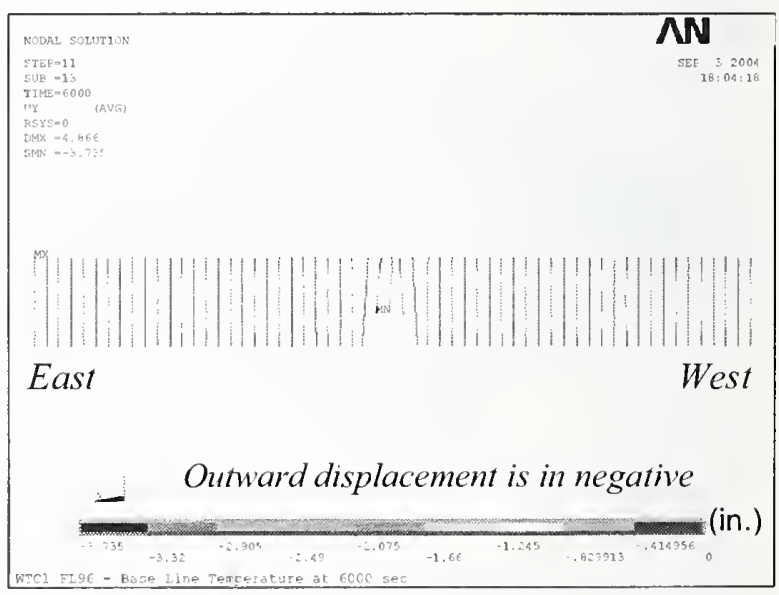

(t) South tace at $100 \mathrm{~m} ! n$

Figure 5-71. Horizontal displacement of exterior columns of Floor 96 of WTC 1 for Case $A_{i}$ temperature condition at $10 \mathrm{~min}, 50 \mathrm{~min}$, and $100 \mathrm{~min}$. 


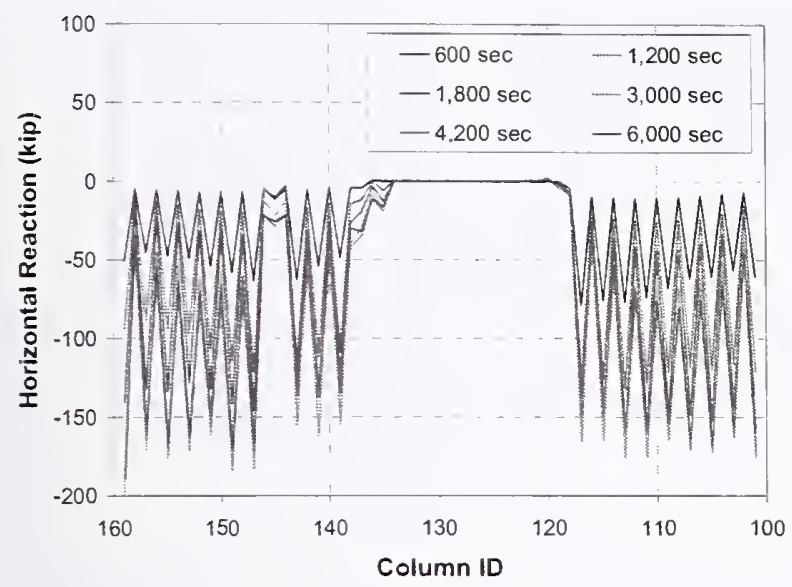

(a) North face

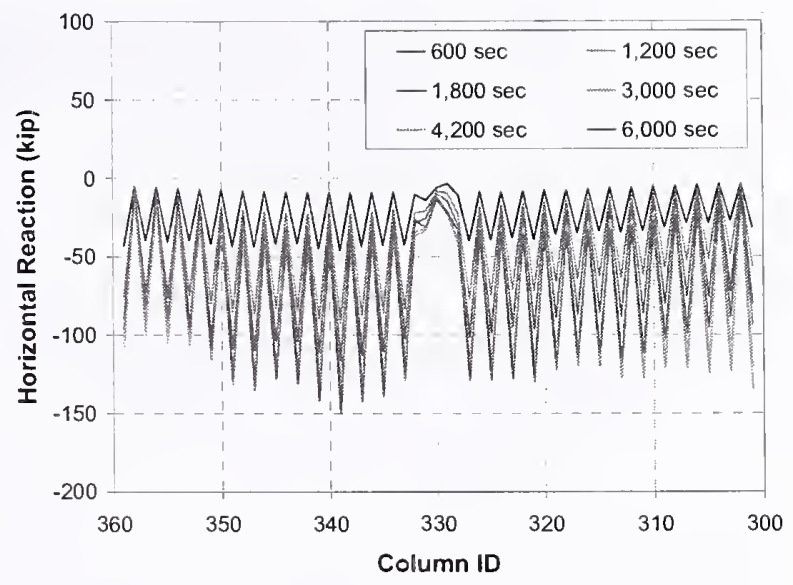

(b) South face

Figure 5-72. Horizontal reaction force per column of WTC 1 Floor 96 for Case $A_{i}$ temperature condition.

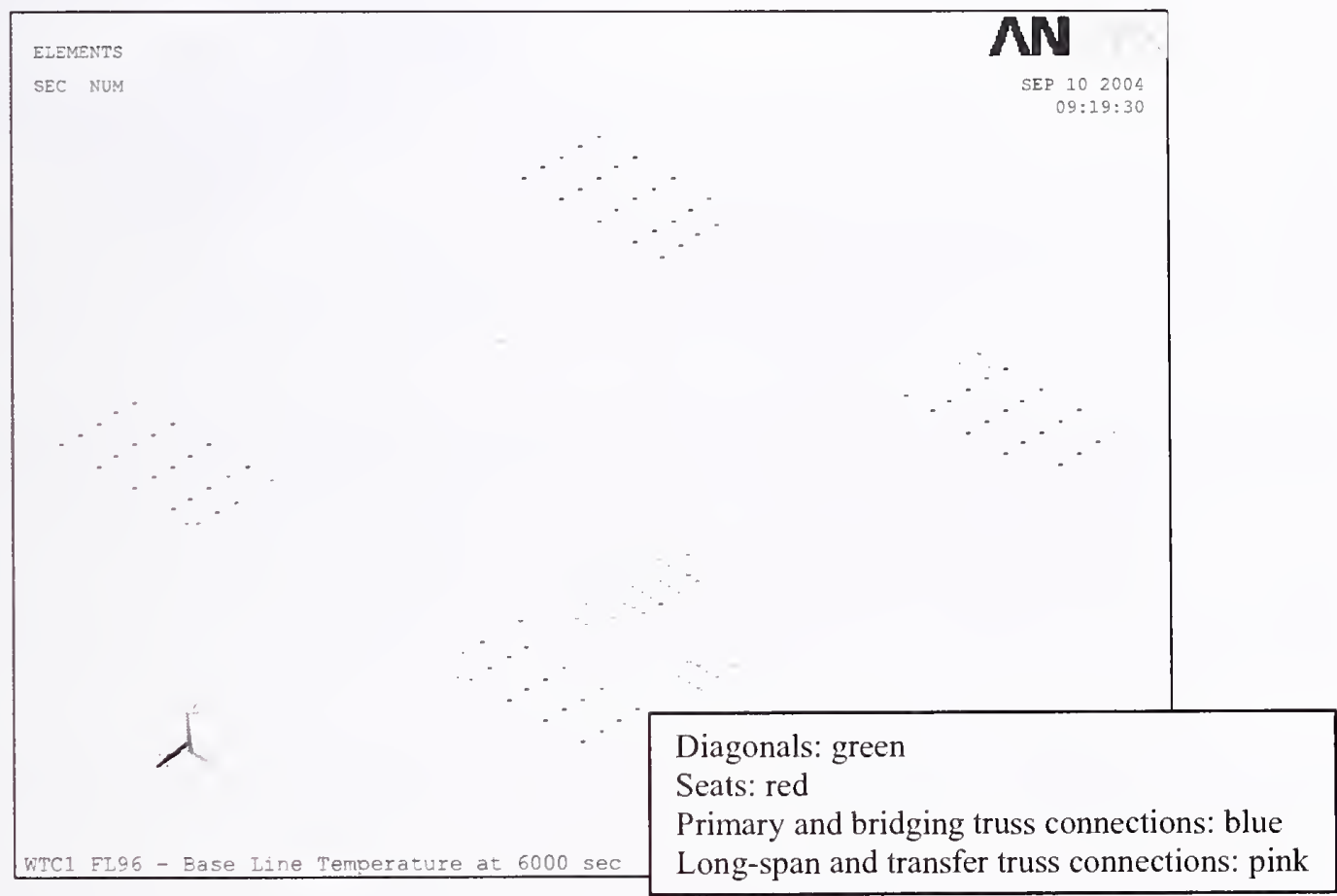

Figure 5-73. User-defined break elements that failed by $100 \mathrm{~min}$ in the model of WTC 1 Floor 96 for Case $A_{i}$ temperature condition. 
Table 5-13. Number of failed user-defined break elements in the model of WTC 1 Floor 96 for Case $A_{i}$ temperature condition.

\begin{tabular}{|l|c|}
\hline & Number of Break Elements \\
\hline Web diagonals & 56 \\
\hline Seats and gusset plates & 0 \\
\hline Connections between primary and bridging trusses & 75 \\
\hline Connections between long-span and transfer trusses & 14 \\
\hline \hline Total & 145 \\
\hline
\end{tabular}

\subsubsection{Results from Other WTC 1 Floors under Case $A_{i}$ Temperature Condition}

Table 5-14 summarizes the maximum vertical displacements of WTC 1 floors for Case $A_{i}$ temperature condition. Figures 5-74 to 5-79 show vertical displacements of WTC 1 floors under Case $A_{i}$ temperature condition when each floor experienced the maximum displacement. Floor 95 to Floor 98 showed a significant vertical displacement in the north office area near the impact damage where truss insulation was damaged. The maximum vertical displacement of all floors was $32 \mathrm{in}$. at Floor 97 at $60 \mathrm{~min}$. The vertical displacement in the south office area was found to be insignificant on all the floors throughout the thermal loading. Note that no truss insulation was damaged in the south office area of WTC 1 floors for Case $\mathrm{A}_{\mathrm{i}}$ temperature condition.

Figure 5-80 (a) shows the average horizontal displacement due to thermal expansion of floors at $100 \mathrm{~min}$ on each face, while Fig. 5-80 (b) shows the average total thermal expansion of floors at $100 \mathrm{~min}$ in two orthogonal directions. The total floor expansion ranged from 4 in. to 8 in. Figure 5-81 shows horizontal reaction force at individual columns of the north and south faces of Floor 97 . In this figure, the reaction is positive when the column is pulled inward by the floor. As can be seen in the figure, almost all the columns were pushed outward by the floor. This was also the case for other floors.

Many web diagonals of Floor 95 to Floor 98 buckled in the hot zones of the north office area where the truss insulation was damaged. Although gusset plates at the exterior truss seats fractured at several locations, a complete disconnection of the floor from the exterior wall was not found in any floor.

Results from WTC 1 Floor 97 under Case A temperature condition were found to be very close to those from WTC 1 Floor 97 under Case $A_{i}$ temperature condition, and, hence, will not be presented separately in this report. 
Table 5-14. Maximum vertical displacement of WTC 1 floors for Case $A_{i}$ temperature condition.

\begin{tabular}{|c|c|c|}
\hline Floor & $\begin{array}{c}\text { Max. Displacement } \\
\text { (in.) }\end{array}$ & $\begin{array}{c}\text { Time at the Maximum } \\
\text { (min) }\end{array}$ \\
\hline 93 & 5.4 & 30 \\
\hline 94 & 13.5 & 100 \\
\hline 95 & 30.9 & 10 \\
\hline 96 & 23.3 & 10 \\
\hline 97 & 31.5 & 60 \\
\hline 98 & 26.4 & 30 \\
\hline 99 & 7.0 & 50 \\
\hline
\end{tabular}

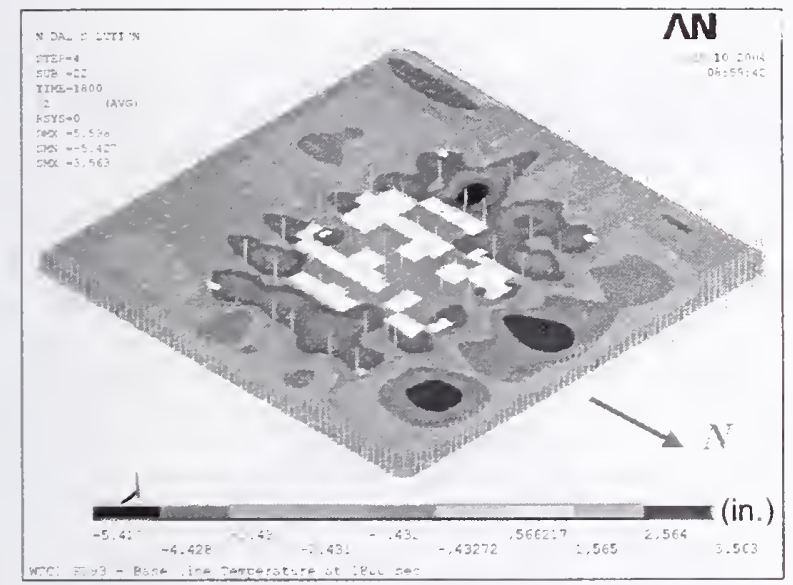

(a) Entire model

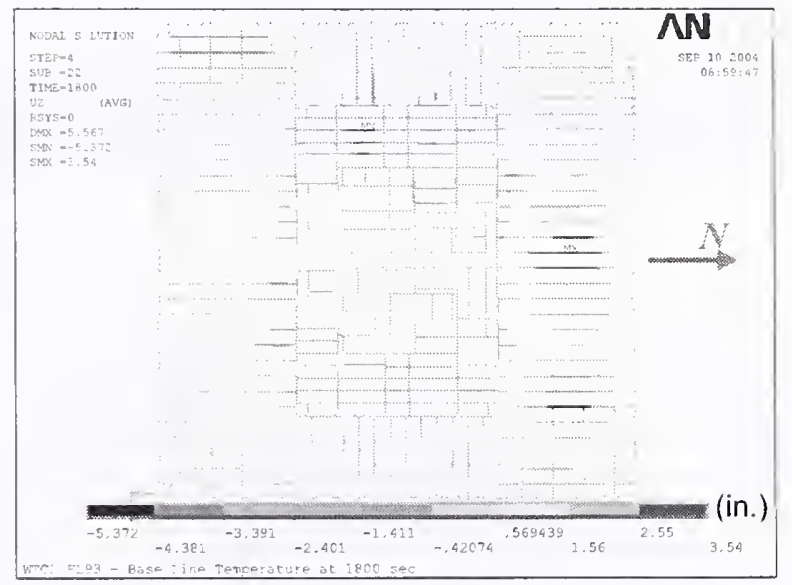

(b) Top view without slab

Figure 5-74. Vertical displacement of WTC 1 Floor 93 for Case $A_{i}$ temperature condition at $30 \mathrm{~min}$ (downward displacement is negative; $5 x$ displacement magnification). 


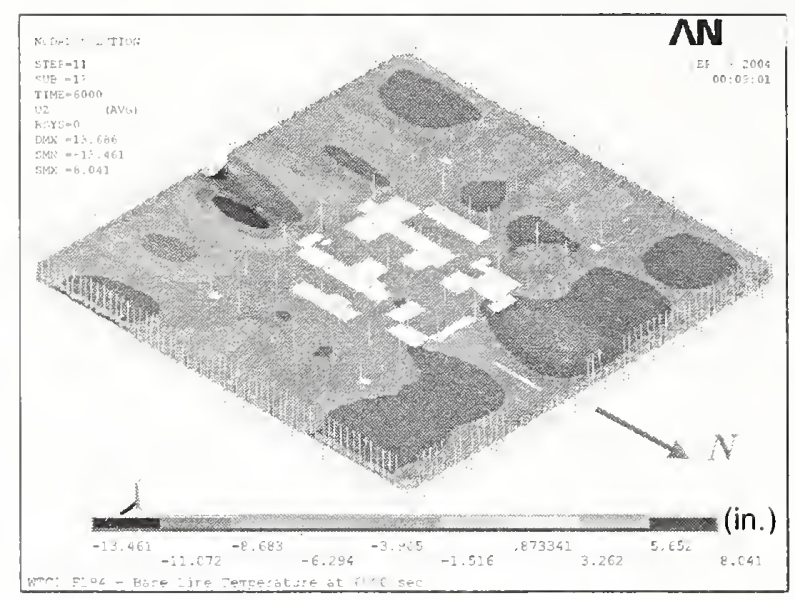

(a) Entire model

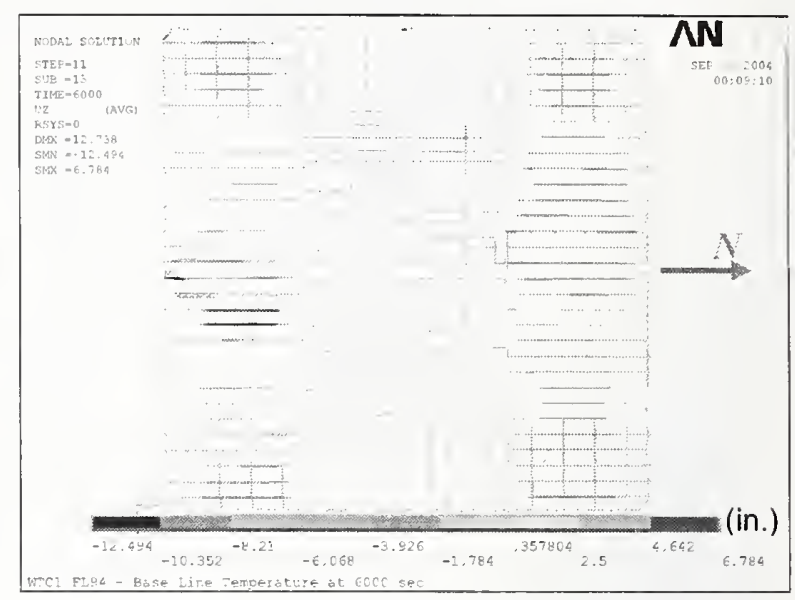

(b) Top view without slab

Figure 5-75. Vertical displacement of WTC 1 Floor 94 for Case $A_{i}$ temperature condition at $100 \mathrm{~min}$ (downward displacement is negative; $5 x$ displacement magnification).

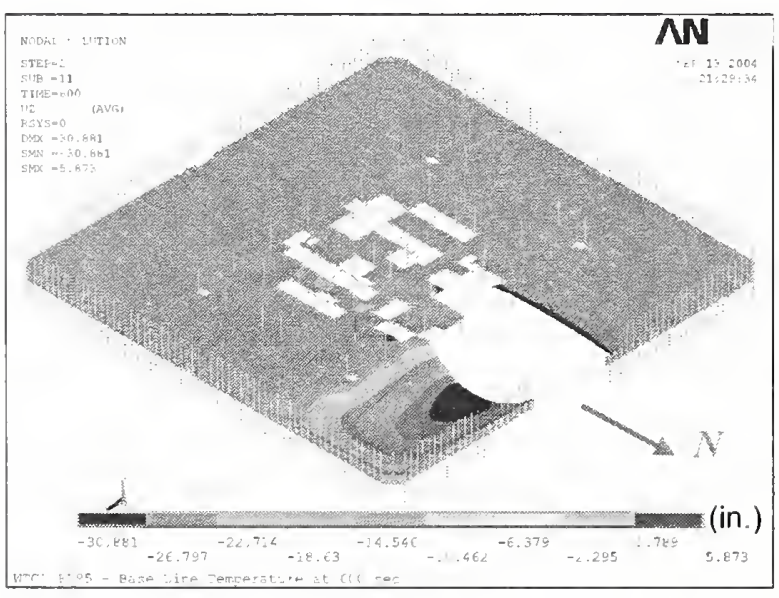

(a) Entire model

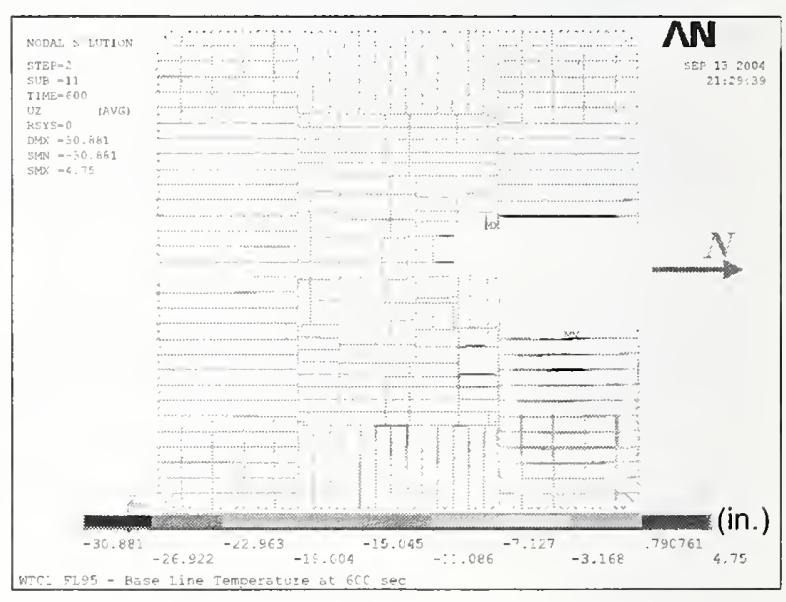

(b) Top view without slab

Figure 5-76. Vertical displacement of WTC 1 Floor 95 for Case $A_{i}$ temperature condition at $10 \mathrm{~min}$ (downward displacement is negative; $5 \mathrm{x}$ displacement magnification). 


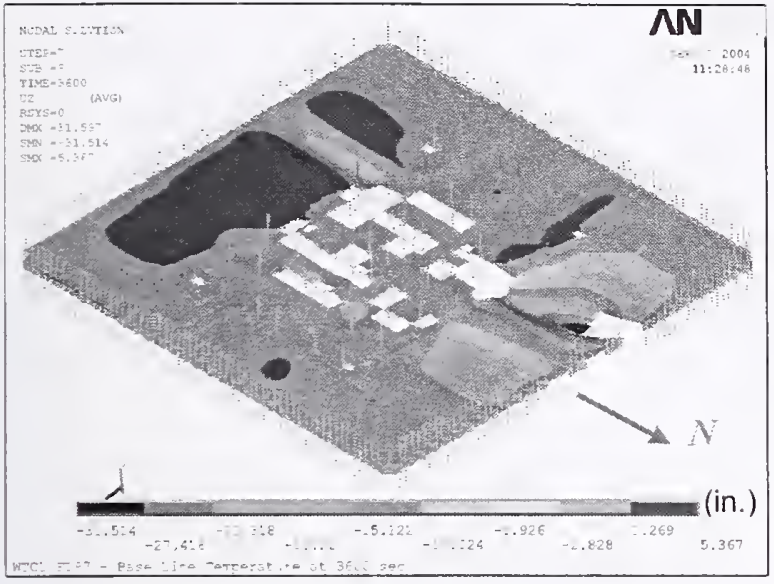

(a) Entire model

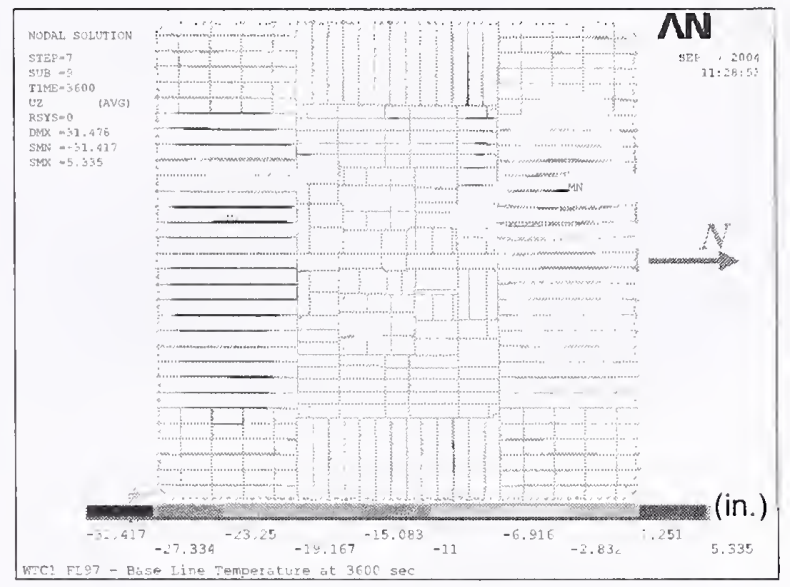

(b) Top view without slab

Figure 5-77. Vertical displacement of WTC 1 Floor 97 for Case $A_{i}$ temperature condition at $60 \mathrm{~min}$ (downward displacement is negative; $5 \mathrm{x}$ displacement magnification).

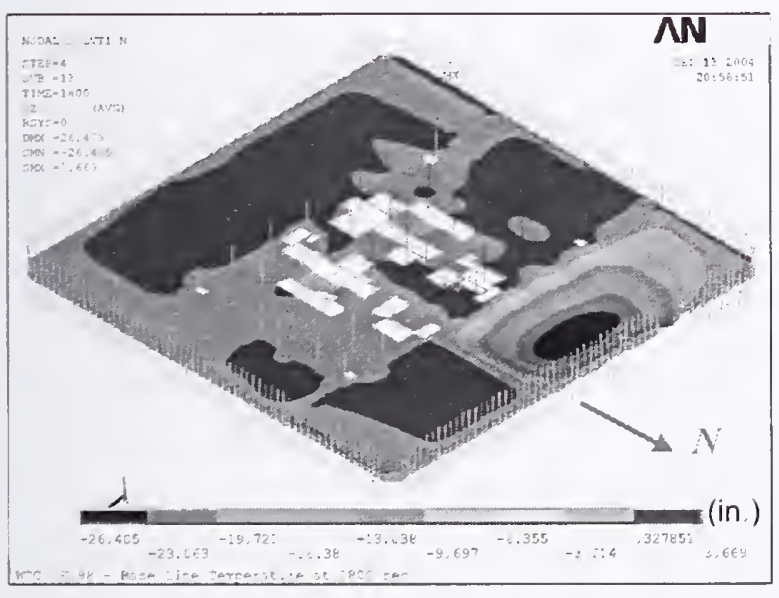

(a) Entire model

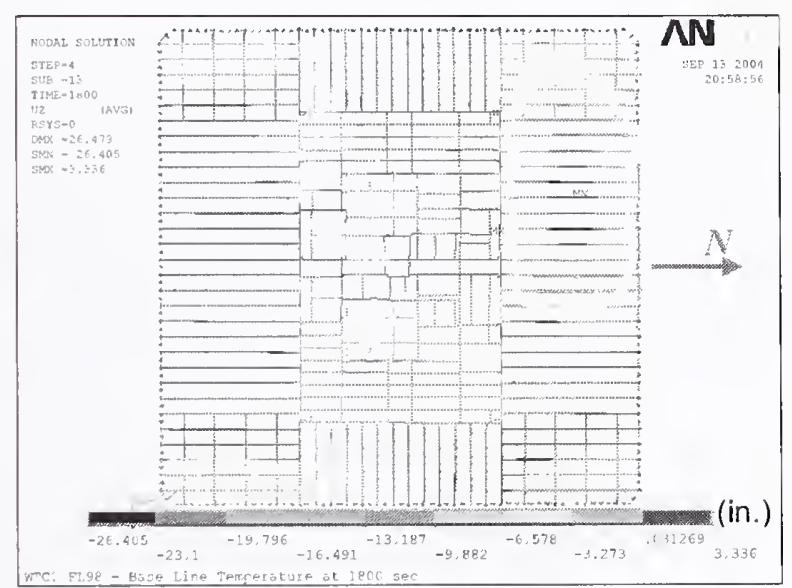

(b) Top view without slab

Figure 5-78. Vertical displacement of WTC 1 Floor 98 for Case $A_{i}$ temperature condition at $30 \mathrm{~min}$ (downward displacement is negative; 5x displacement magnification). 


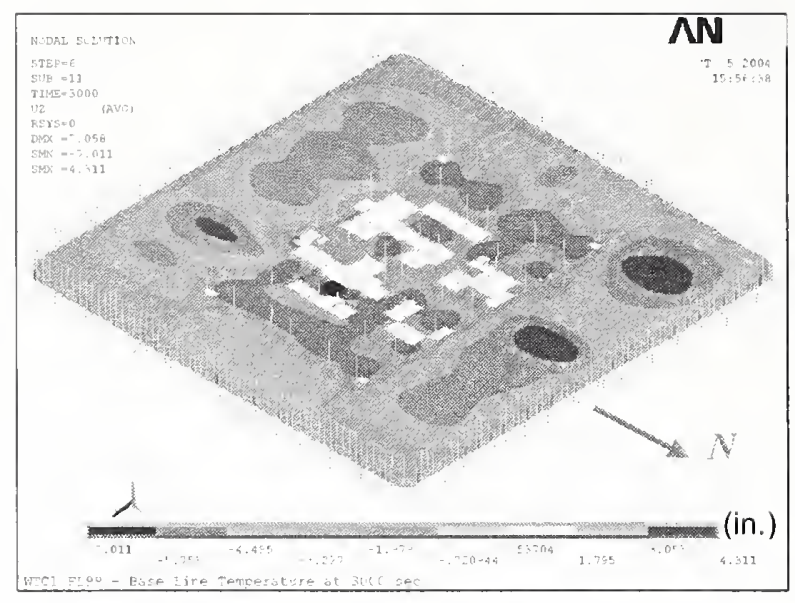

(a) Entire model

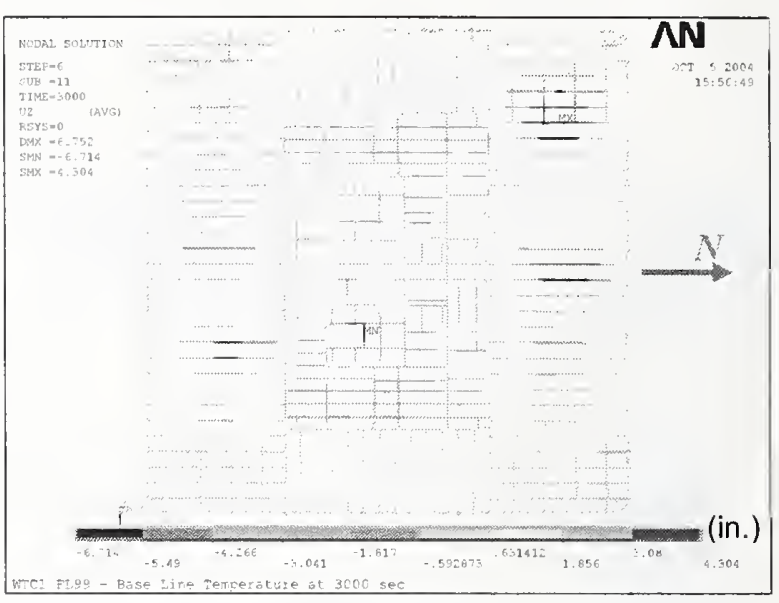

(b) Top view without slab

Figure 5-79. Vertical displacement of WTC 1 Floor 99 for Case $A_{i}$ temperature condition at $50 \mathrm{~min}$ (downward displacement is negative; $5 x$ displacement magnification).

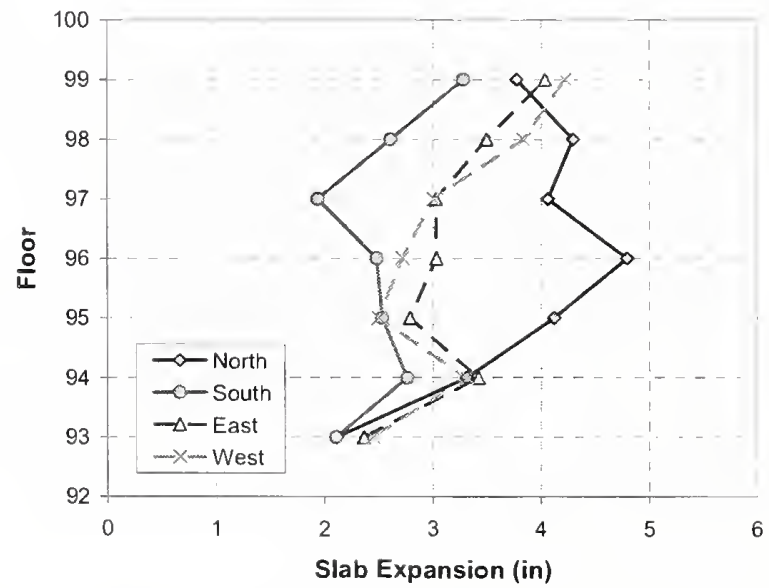

(a) Average displacement of each face

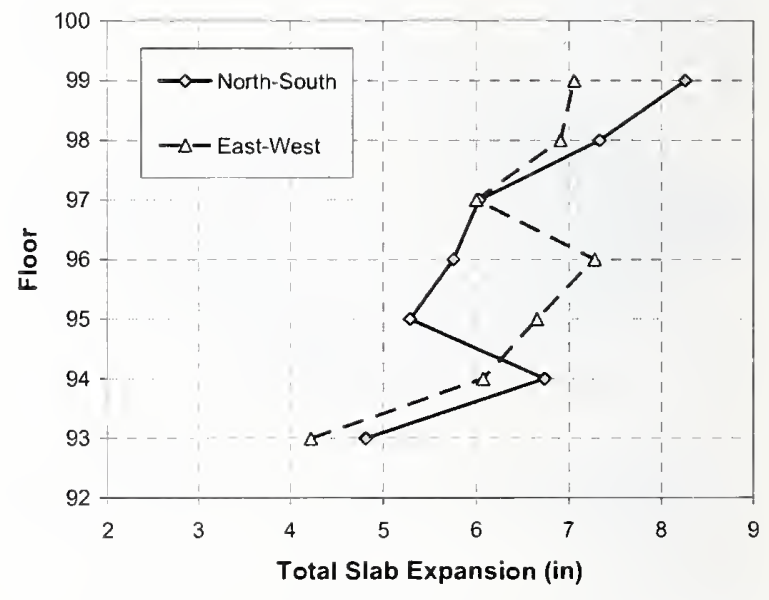

(b) Average slab expansion in each direction

Figure 5-80. Average thermal expansion of WTC 1 floors at $100 \mathrm{~min}$ for Case $A_{i}$ temperature condition. 


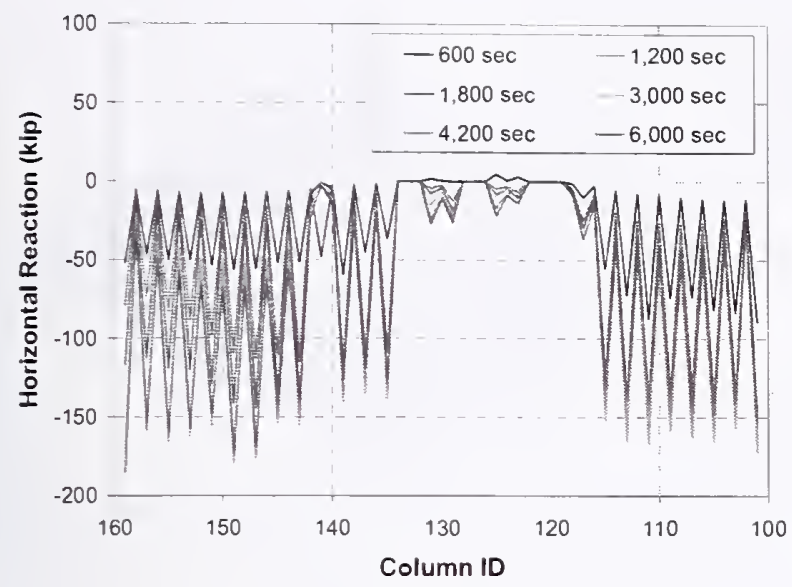

(a) North face

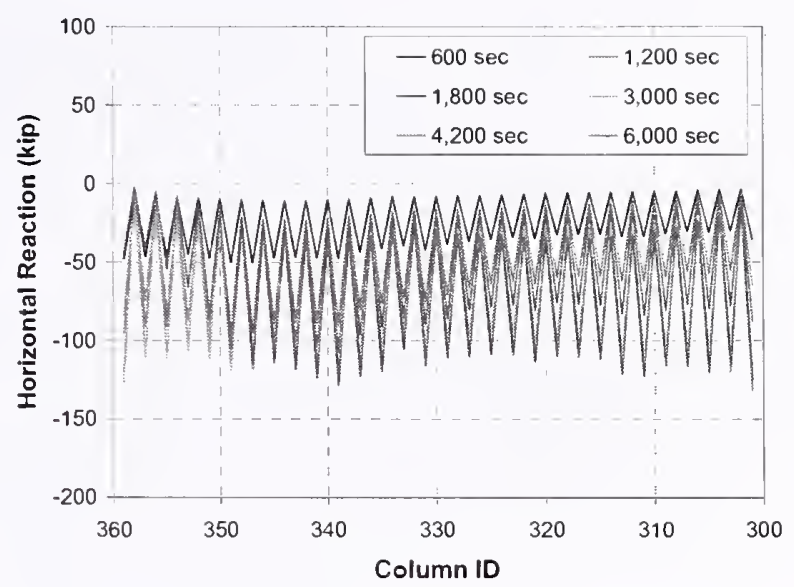

(b) South face

Figure 5-81. Horizontal reaction force per column of WTC 1 Floor 97 for Case $A_{i}$ temperature condition.

\subsubsection{Results from WTC 1 Floors under Case $B_{i}$ Temperature Condition}

Table 5-15 summarizes the maximum vertical displacement of WTC 1 floors for Case $\mathrm{B}_{\mathrm{i}}$ temperature condition, and Figs. 5-82 to 5-88 show the vertical displacements of WTC 1 floors when each floor experienced the maximum displacement. The maximum vertical displacements of Floor 95 to Floor 98 increased due to higher temperatures when compared to those for Case $\mathrm{A}_{\mathrm{i}}$ temperature condition, especially in the south office area. The increase in temperatures in the south office area was a result of impact damage to insulation on floor trusses in the area. The maximum vertical displacement among all floors was 49 in. in the south office area of Floor 98, as shown in Fig. 5-87. The large displacement on the south side of Floor 98 was caused by the exterior truss seat failures between Column 329 and Column 343 that started between $80 \mathrm{~min}$ and $90 \mathrm{~min}$. Exterior truss seats at Column 337 to Column 347 of Floor 97 also failed, which caused 37 in. of vertical displacement in the south office area. These exterior truss seats failed by losing vertical shear strength due to extreme temperatures of greater than $800{ }^{\circ} \mathrm{C}$. Exterior seat failures of Floor 97 and Floor 98 are shown in Fig. 5-89.

Figure 5-90 (a) shows the average horizontal displacement due to thermal expansion of floors at $100 \mathrm{~min}$ on each face, while Fig. 5-90 (b) shows the average total thermal expansion of floors at 100 min in two orthogonal directions. The total floor expansion ranged from 5 in. to 8.5 in. Figures 5-91 and 5-92 show the horizontal reaction force at individual columns of north and south faces of Floor 96 and Floor 98 . In these figures, the reaction is positive when the column is pulled inward by the floor. Although almost all the columns were pushed outward by the floor, it was found that large vertical displacement of the floor would reduce the compression between the floor and the exterior wall. By comparing Fig. 5-72 (b) and Fig. 5-91 (b), one can see that the compressive forces at Columns 323 to 337 on the south face decreased significantly for Case $\mathrm{B}_{\mathrm{i}}$ temperature condition. It should be also noted in Fig. 5-92 (b) that the compressive forces became almost zero at columns where the floor was disconnected.

Many web diagonals of Floor 95 to Floor 98 buckled in the hot zones of the north and south office areas where the truss insulation was damaged. In addition to exterior seat failures (see Fig. 5-89) that occurred on the south face, gusset plates and seat bolts at the exterior truss seats failed at several locations on the north face; however, failures of gusset plates and seat bolts did not cause complete disconnection of the floor from the exterior wall. 
Table 5-15. Maximum vertical displacement of WTC 1 floors for Case $\mathbf{B}_{i}$ temperature condition.

\begin{tabular}{|c|c|c|}
\hline Floor & $\begin{array}{c}\text { Max. Displacement } \\
\text { (in.) }\end{array}$ & $\begin{array}{c}\text { Time at the Maximum } \\
\text { (min) }\end{array}$ \\
\hline 93 & -5.8 & 100 \\
\hline 94 & 12.7 & 100 \\
\hline 95 & 29.2 & 10 \\
\hline 96 & 28.6 & 10 \\
\hline 97 & 37.4 & 100 \\
\hline 98 & 49.0 & 100 \\
\hline 99 & 6.8 & 100 \\
\hline
\end{tabular}

Note: Negative value represents upward displacement in this table.

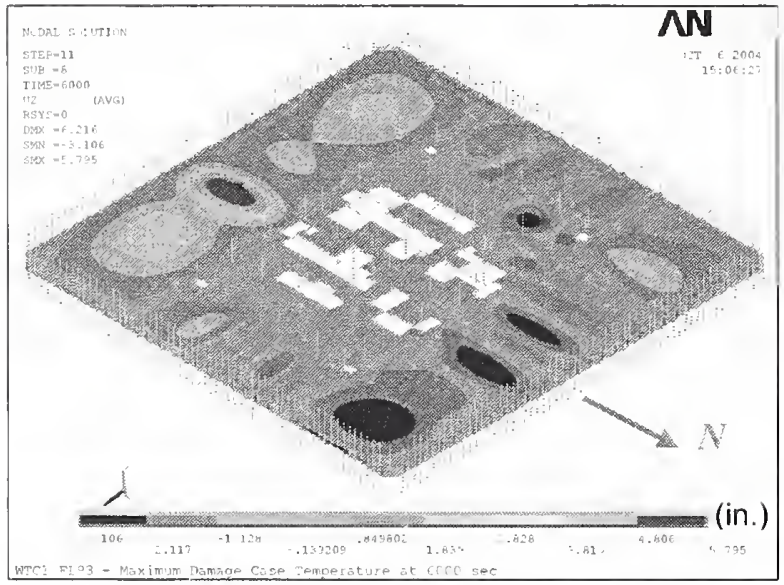

(a) Entire model

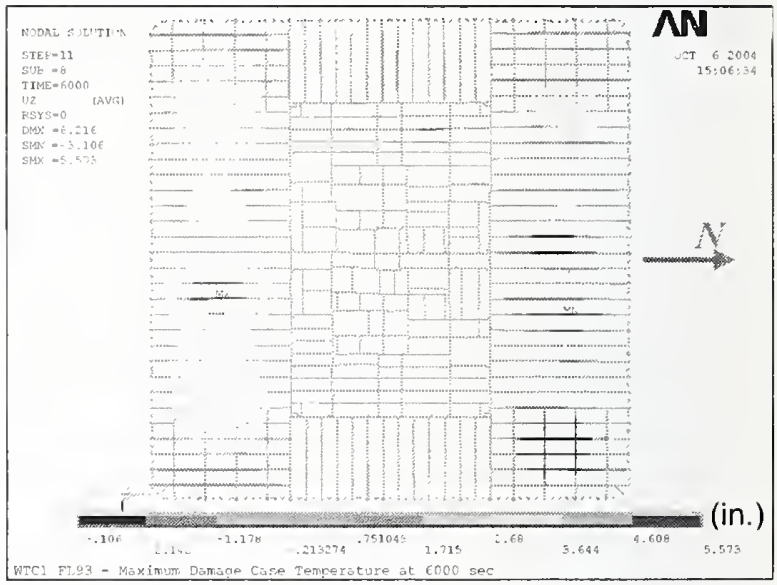

(b) Top view without slab

Figure 5-82. Vertical displacement of WTC 1 Floor 93 for Case $B_{i}$ temperature condition at $100 \mathrm{~min}$ (downward displacement is negative; $5 \mathrm{x}$ displacement magnification). 


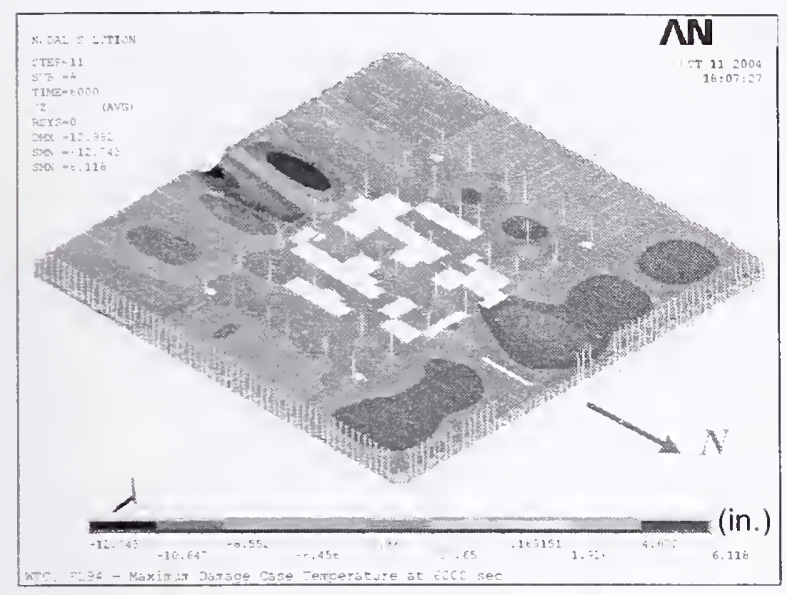

(a) Entire model

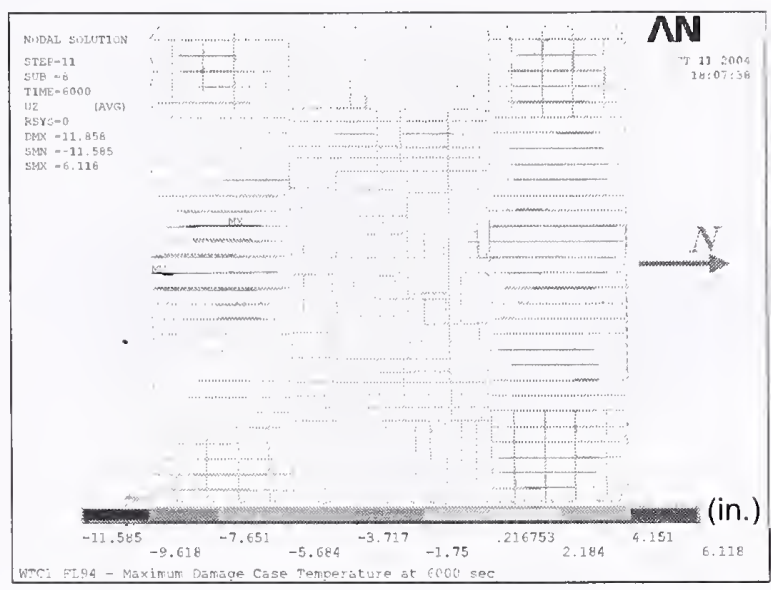

(b) Top view without slab

Figure 5-83. Vertical displacement of WTC 1 Floor 94 for Case $B_{i}$ temperature condition at $100 \mathrm{~min}$ (downward displacement is negative; $5 \mathrm{x}$ displacement magnification).

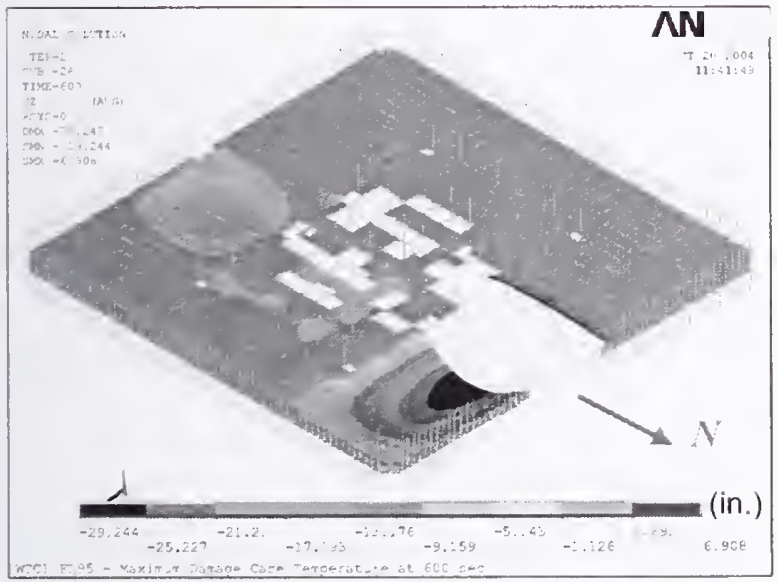

(a) Entire model

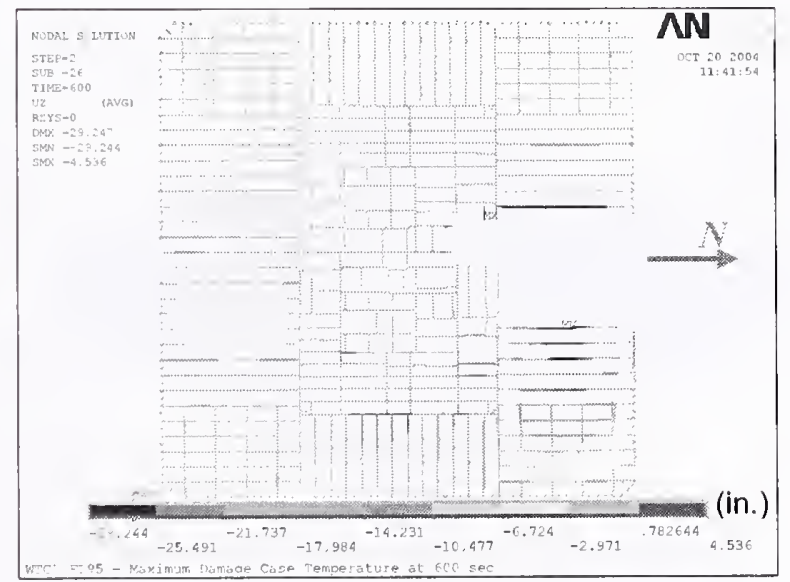

(b) Top view without slab

Figure 5-84. Vertical displacement of WTC 1 Floor 95 for Case $B_{i}$ temperature condition at $10 \mathrm{~min}$ (downward displacement is negative; $5 \mathrm{x}$ displacement magnification). 


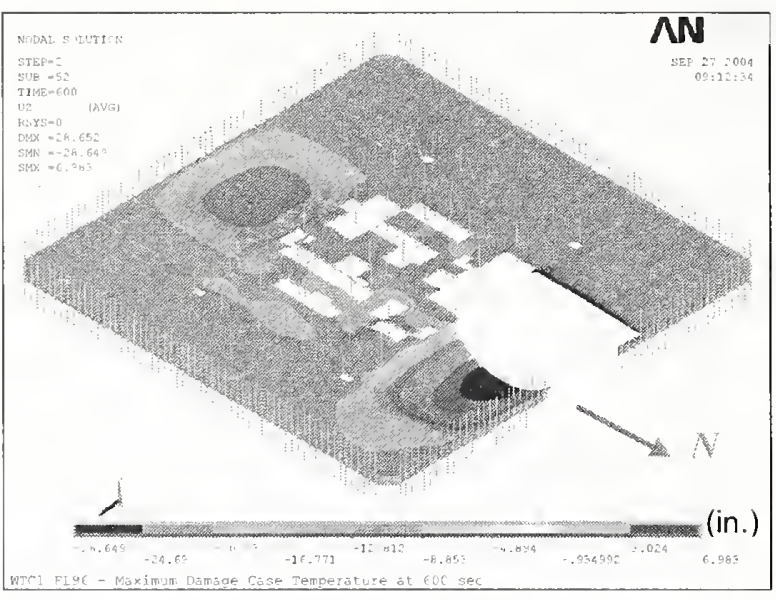

(a) Entire model

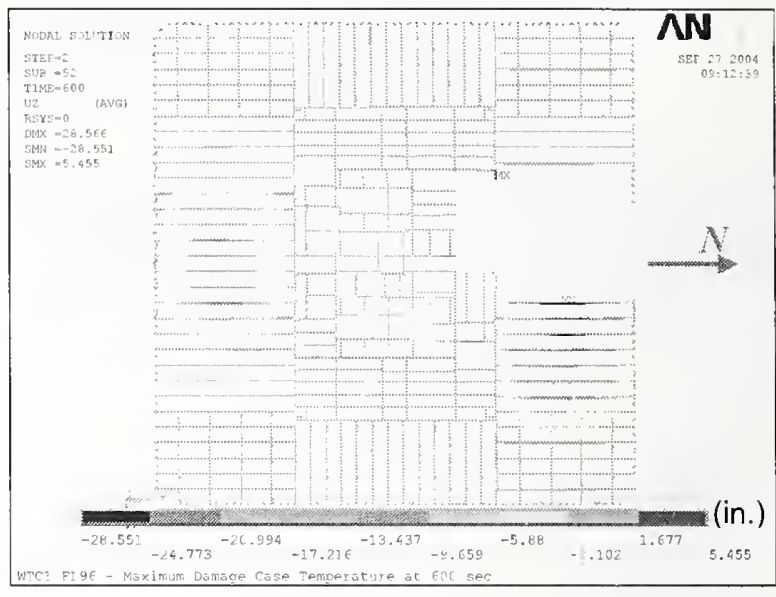

(b) Top view without slab

Figure 5-85. Vertical displacement of WTC 1 Floor 96 for Case $B_{i}$ temperature condition at $10 \mathrm{~min}$ (downward displacement is negative; $5 x$ displacement magnification).

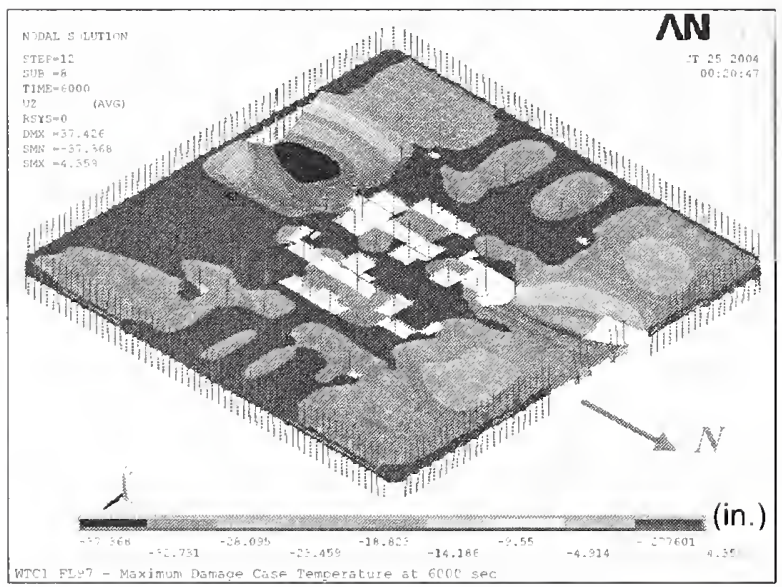

(a) Entire model

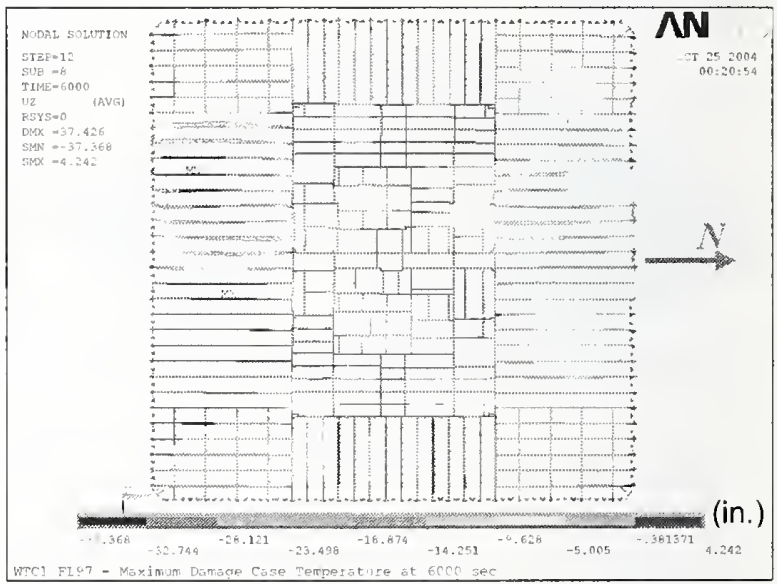

(b) Top view without slab

Figure 5-86. Vertical displacement of WTC 1 Floor 97 for Case $B_{i}$ temperature condition at $100 \mathrm{~min}$ (downward displacement is negative; 5x displacement magnification). 


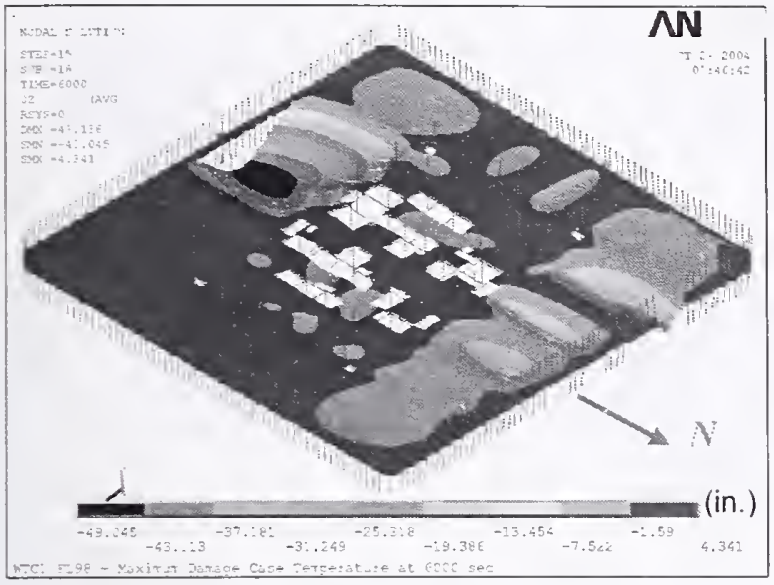

(a) Entire model

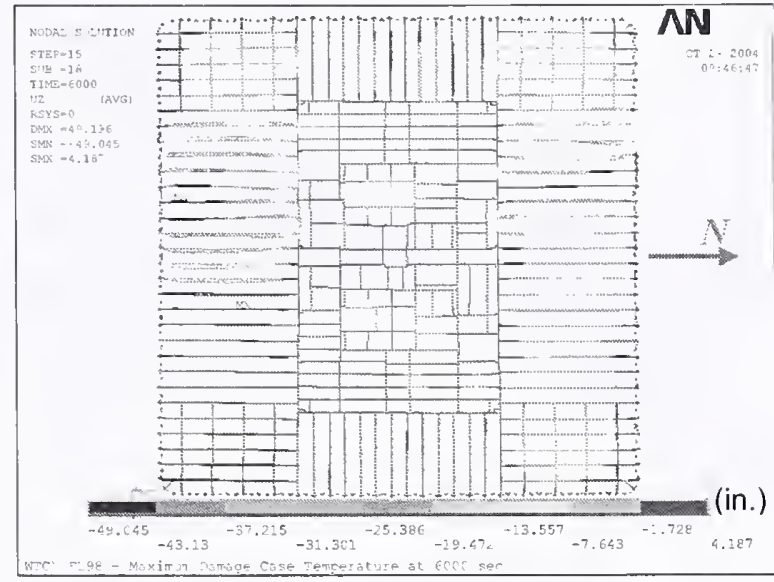

(b) Top view without slab

Figure 5-87. Vertical displacement of WTC 1 Floor 98 for Case $B_{i}$ temperature condition at $100 \mathrm{~min}$ (downward displacement is negative; $5 \mathrm{x}$ displacement magnification).

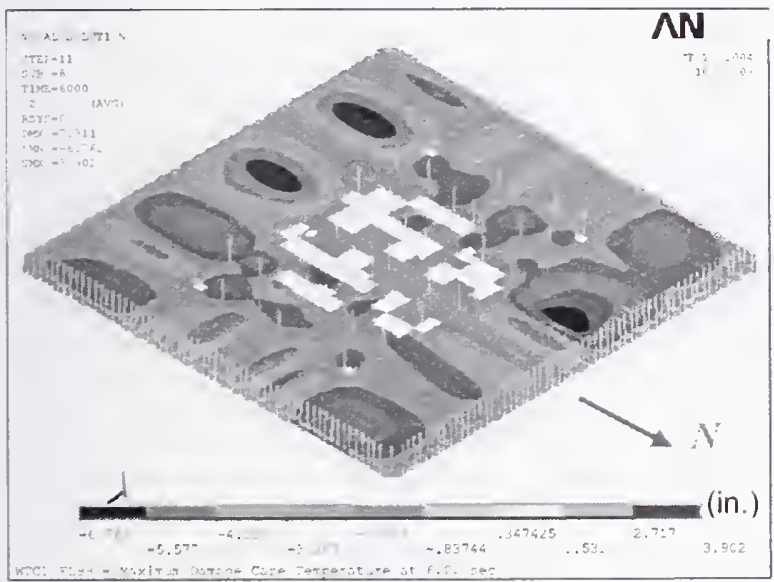

(a) Entire model

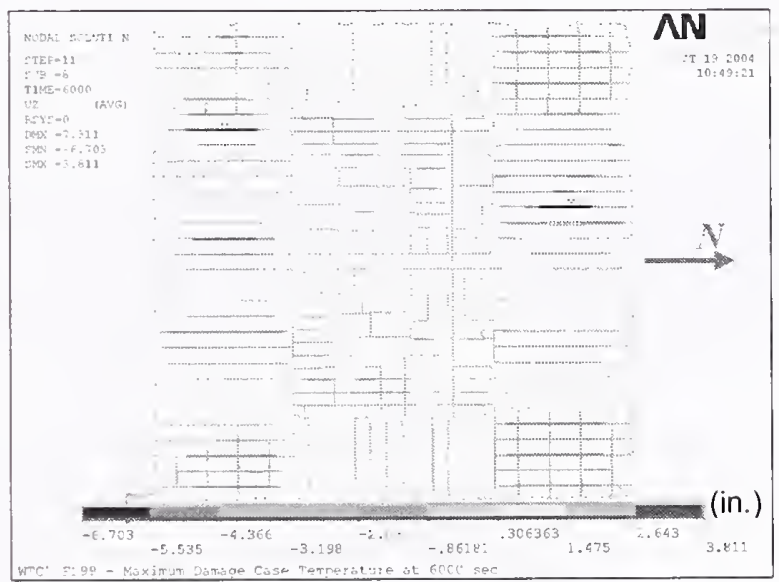

(b) Top view without slab

Figure 5-88. Vertical displacement of WTC 1 Floor 99 for Case $B_{i}$ temperature condition at $100 \mathrm{~min}$ (downward displacement is negative; 5x displacement magnification). 


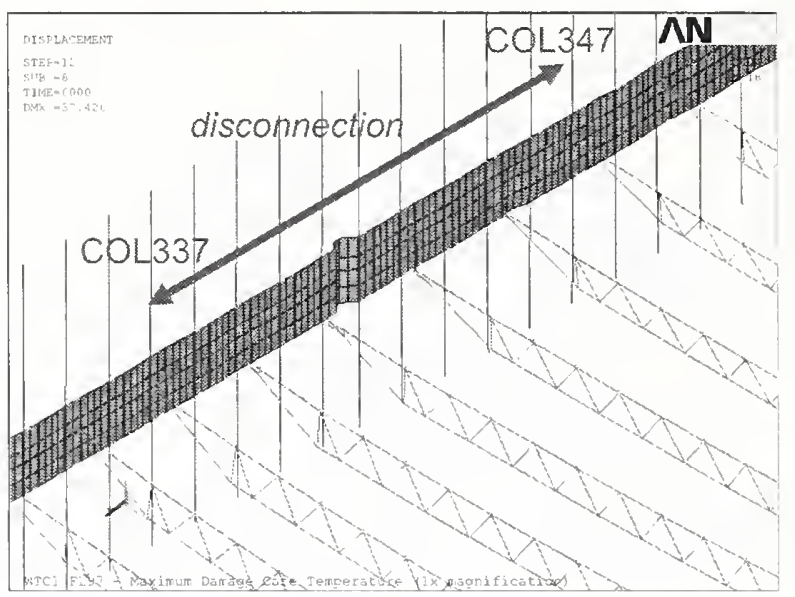

(a) Floor 97

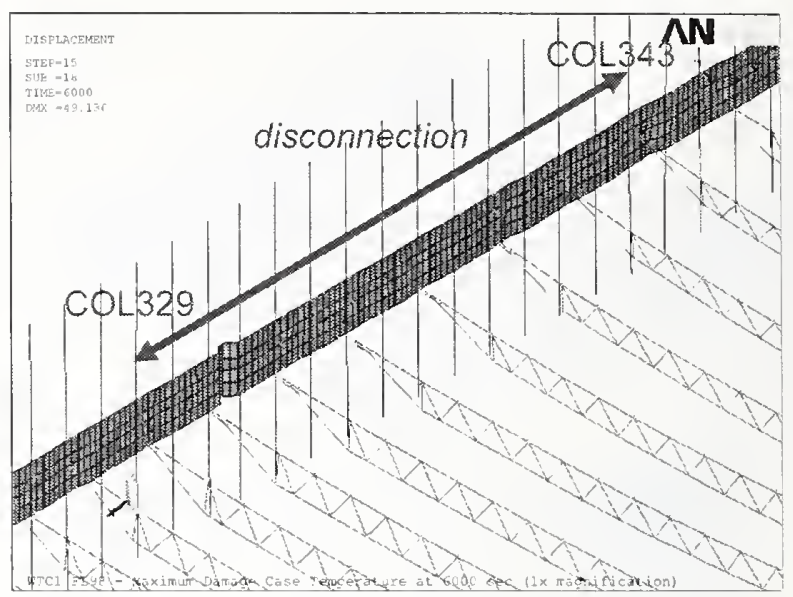

(b) Floor 98

Figure 5-89. Loss of vertical supports in Floor 97 and Floor 98 of WTC 1 for Case $B_{i}$ temperature condition at $100 \mathrm{~min}$ (1x displacement magnification).

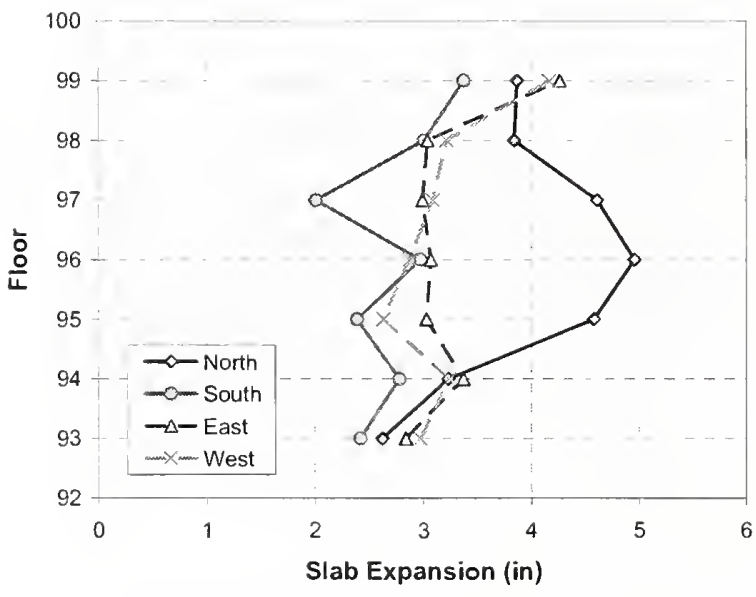

(a) Average displacement of each face

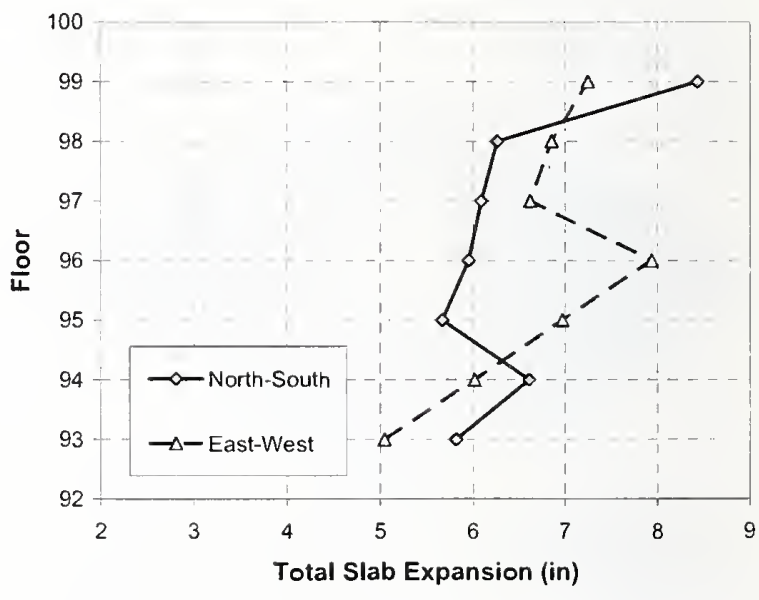

(b) Average slab expansion in each direction

Figure 5-90. Thermal expansion of WTC 1 floors at $100 \mathrm{~min}$ for Case $B_{i}$ conditions. 


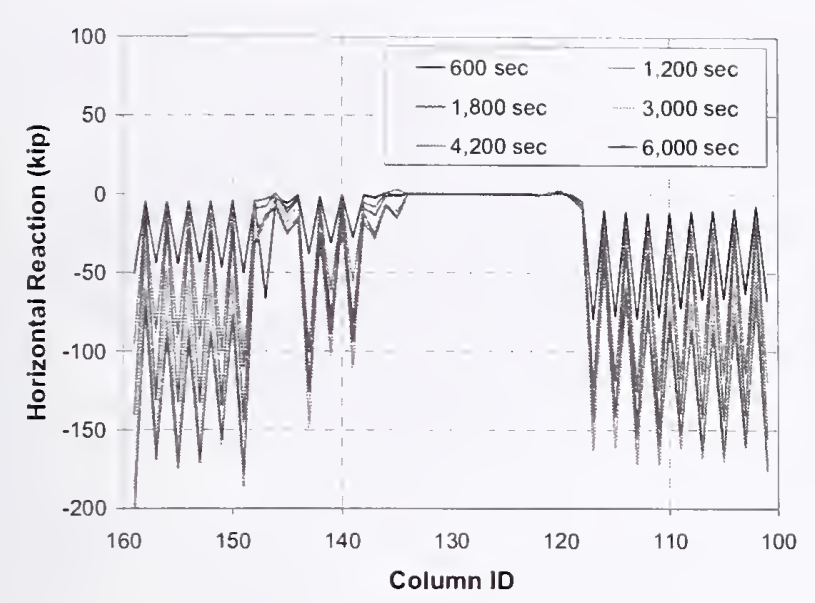

(a) North face

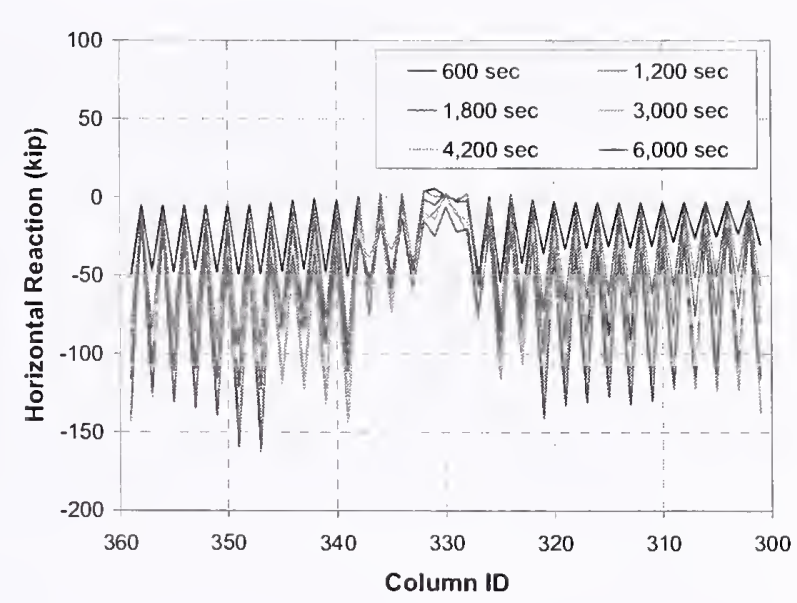

(b) South face

Figure 5-91. Horizontal reaction force per column of WTC 1 Floor 96 for Case $B_{i}$ temperature condition.

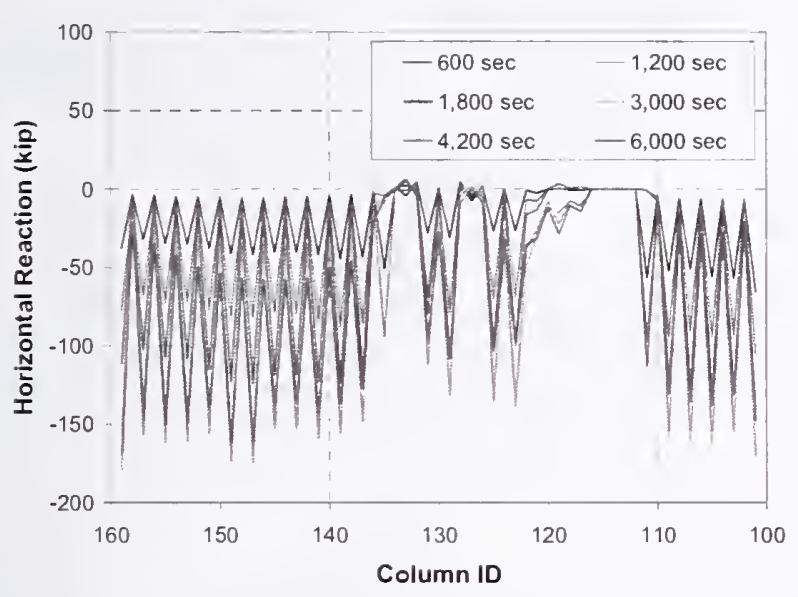

(a) North face

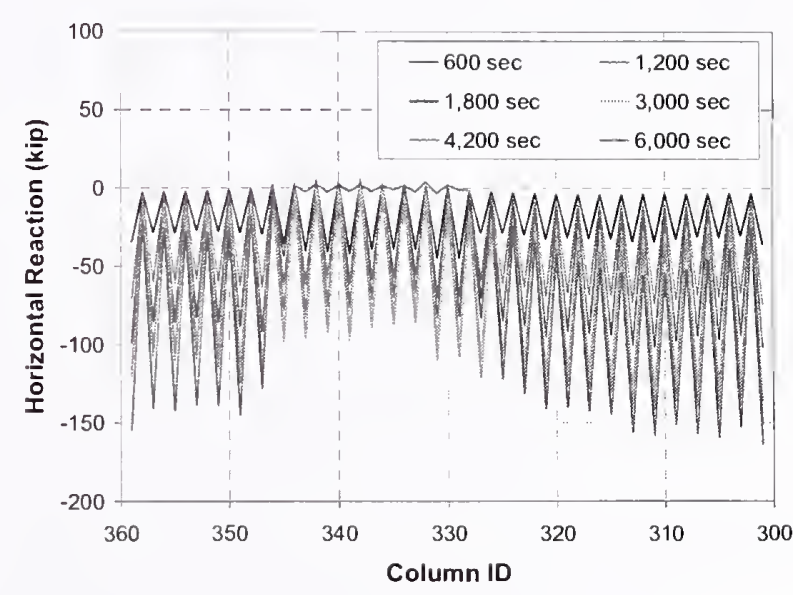

(b) South face

Figure 5-92. Horizontal reaction force per column of WTC 1 Floor 98 for Case $\mathbf{B}_{i}$ temperature condition.

\subsubsection{Results from WTC 2 Floor 82 under Case $C_{i}$ Temperature Condition}

Vertical Displacement: Figure 5-93 shows the vertical displacements of WTC 2 Floor 82 at 10 min, $30 \mathrm{~min}$, and $60 \mathrm{~min}$. The maximum vertical displacement after the impact was $5 \mathrm{in}$. in the southeast area near the impact damage. At 50 min, trusses at Column 301 to Column 317 near the northeast corner lost their vertical support at the exterior truss seats, and the vertical displacement in this area increased significantly. A maximum displacement of $45 \mathrm{in}$. occurred at $60 \mathrm{~min}$ in the northeast corner area. The west office area did not show significant vertical displacement because the insulation on trusses was intact.

Behavior of Exterior Columns on East and West Faces: Figure 5-94 shows the horizontal displacements of the exterior columns normal to the face of the building at $10 \mathrm{~min}, 30 \mathrm{~min}$, and $60 \mathrm{~min}$. 
The maximum outward displacements were $3.8 \mathrm{in}$. and $1.6 \mathrm{in}$. for the east and west faces, respectively, at $60 \mathrm{~min}$ after the impact. In general, the exterior columns had outward displacement except for the north side of the east face where there was an inward displacement of about $0.8 \mathrm{in}$. at $10 \mathrm{~min}$. This inward displacement was caused by the temperature gradient in the cross section of the exterior columns. Figure 5-95 shows the horizontal reaction at each column on the north and south faces. Since even number columns were not connected to trusses and spandrel studs and strap anchors were removed, reaction forces at even number columns were small. In the figure, the reaction force is positive when the floor pulls the exterior column in. It was found that both faces experienced compression from the floor throughout the thermal loading; however, several columns of the east face near the northeast corner lost lateral support from the floor, and the reaction forces at these columns became very small.

Break Elements: Figure 5-96 shows the locations of user-defined break elements that failed by $60 \mathrm{~min}$. Table 5-16 summarizes the number of failed user-defined break elements during the analysis. A significant number of web diagonals buckled in the east office area where insulation on the trusses was damaged by the aircraft impact. By $60 \mathrm{~min}$, about 70 percent of all the primary and bridging truss connections in the two-way zones and the long-span and transfer truss connections failed at their top chord connections; however, at the majority of these locations, they were still connected at their bottom chord connections. By the end of the thermal loading, gusset plates fractured at 19 exterior truss seats, bolts sheared off at 18 exterior truss seats and 1 interior truss seat, and 8 exterior truss seats failed in vertical shear. Figure 5-97 shows the deformed shape of the floor trusses after loss of their vertical support at the exterior truss seats. 


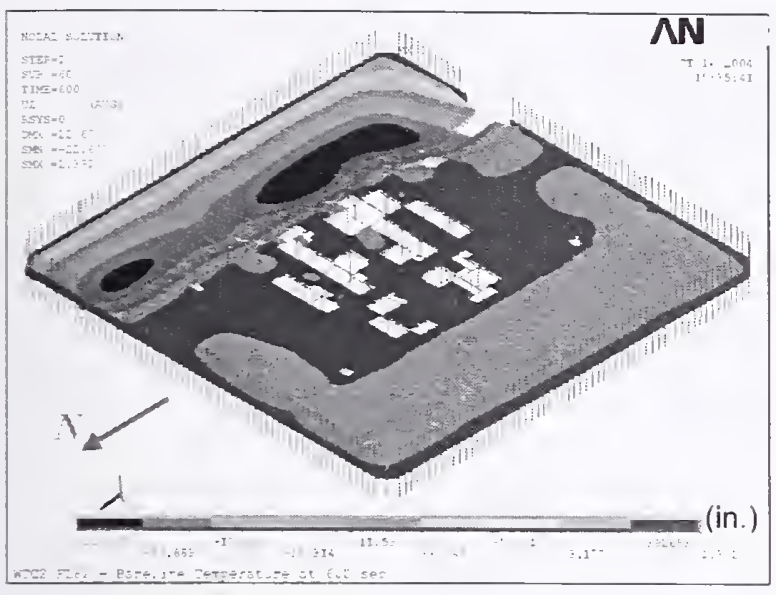

(a) Entire model at $10 \mathrm{~min}$

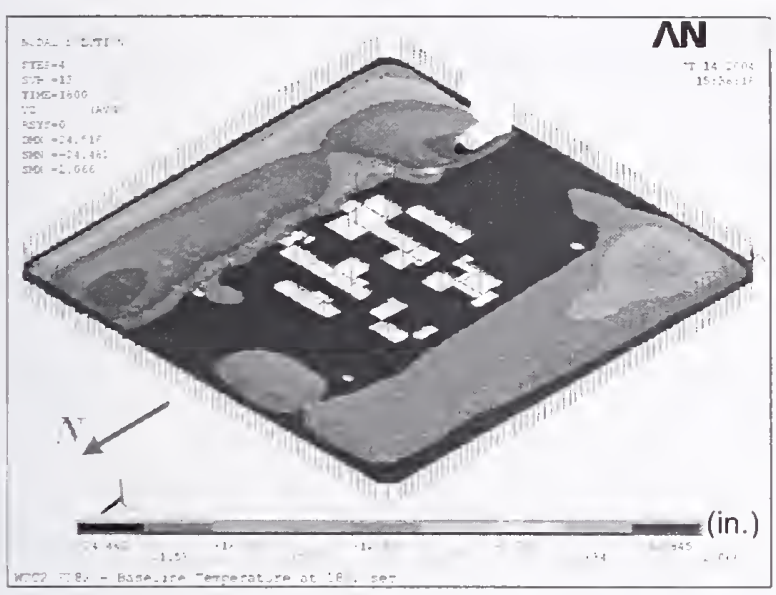

(c) Entire model at $30 \mathrm{~min}$

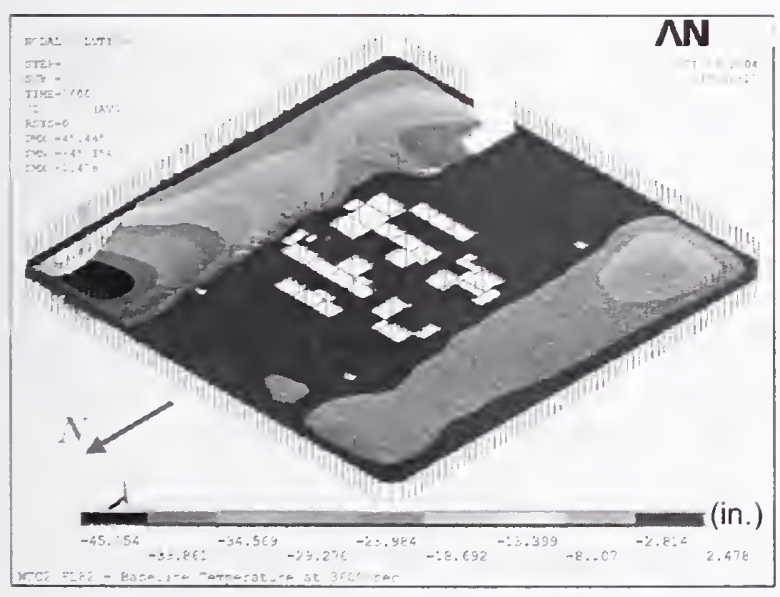

(e) Entire model at $60 \mathrm{~min}$

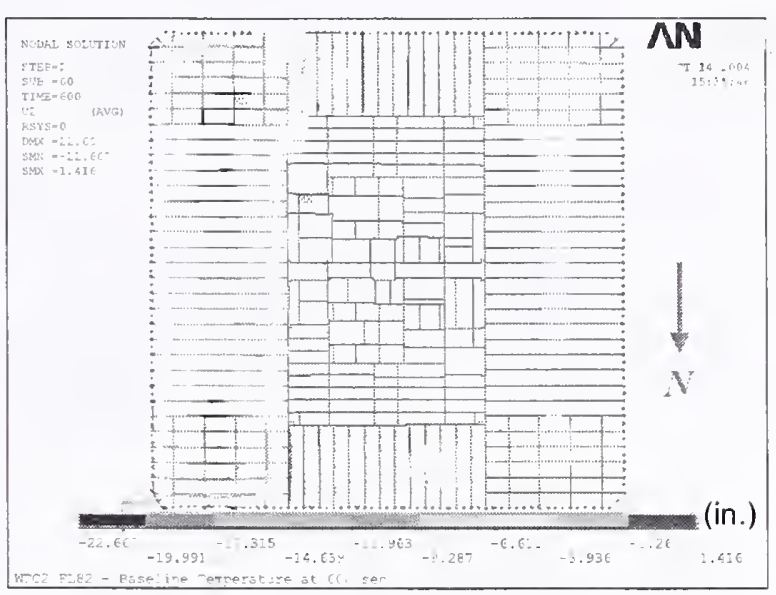

(b) Top view without concrete slab at $10 \mathrm{~min}$

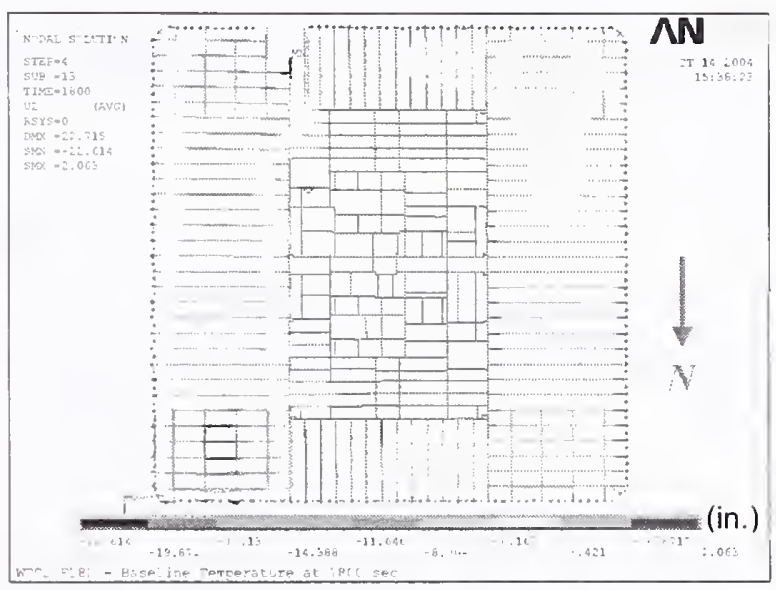

(d) Top view without concrete slab at $30 \mathrm{~min}$

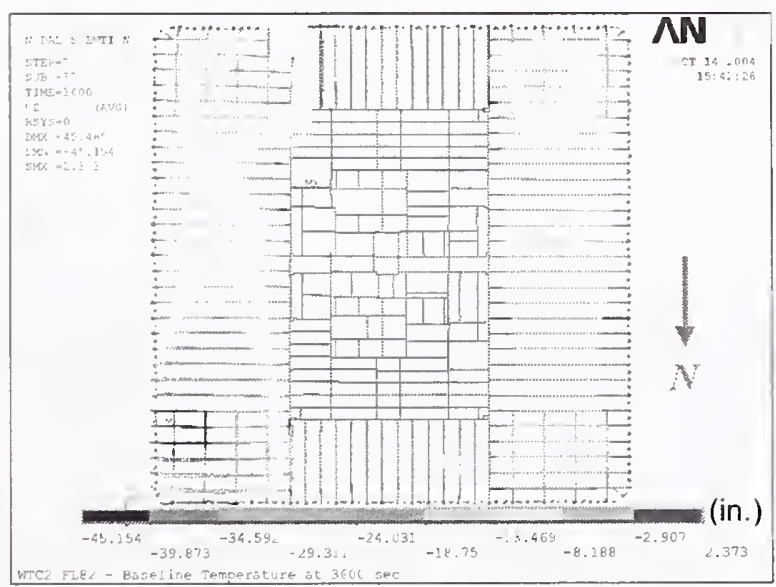

(t) I op view without concrete slab at 60 min

Figure 5-93. Vertical displacement of WTC 2 Floor 82 for Case $C_{i}$ temperature condition at $10 \mathrm{~min}, 30 \mathrm{~min}$, and $60 \mathrm{~min}$ (downward displacement is negative; $5 x$ displacement magnification). 


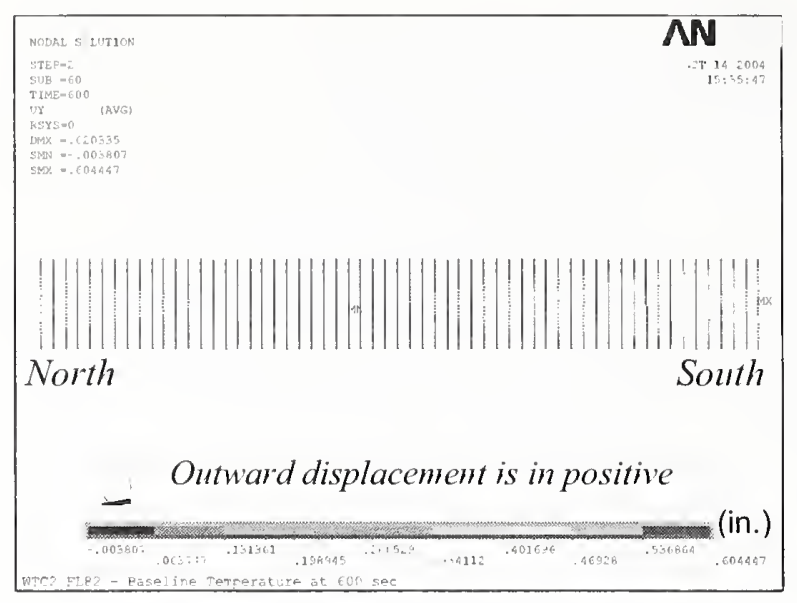

(a) West face at $10 \mathrm{~min}$

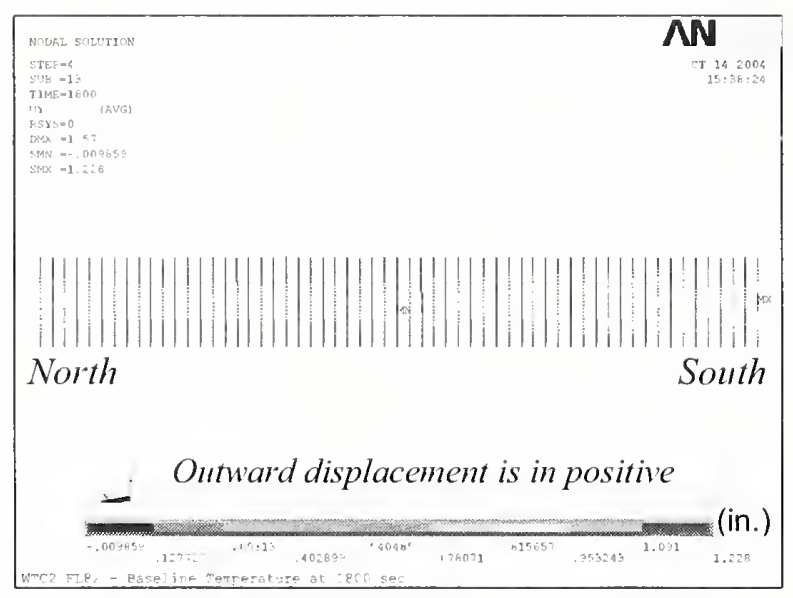

(c) West tace at $30 \mathrm{~m} ı \mathrm{n}$

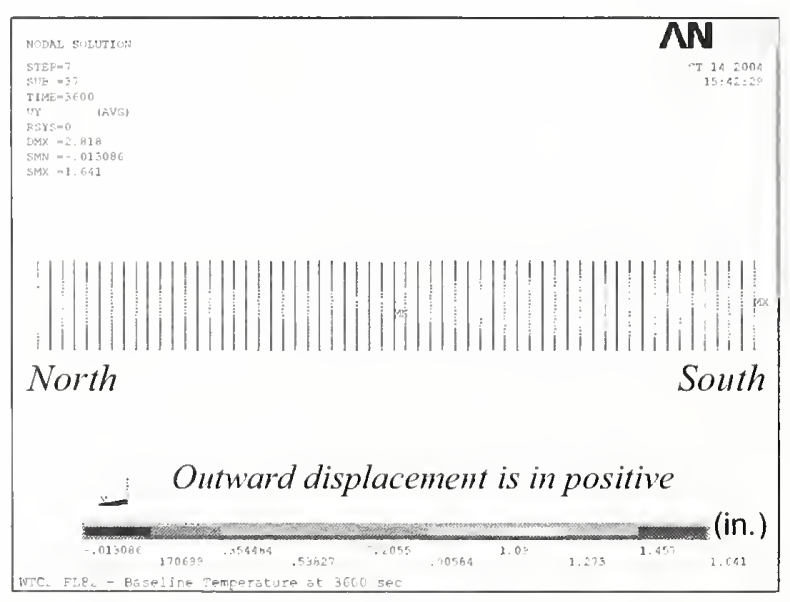

(e) West tace at bu mın

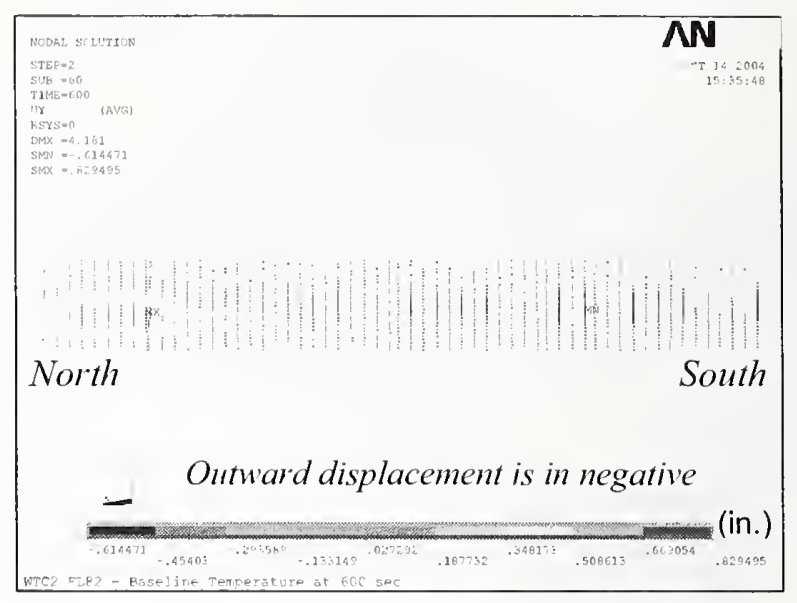

(b) East face at $10 \mathrm{~min}$

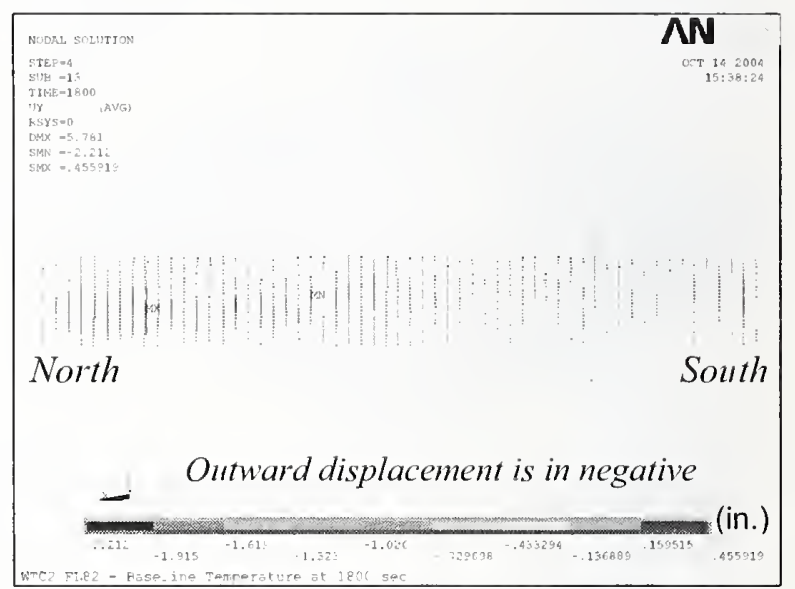

(d) tast tace at $30 \mathrm{~m} ı \mathrm{n}$

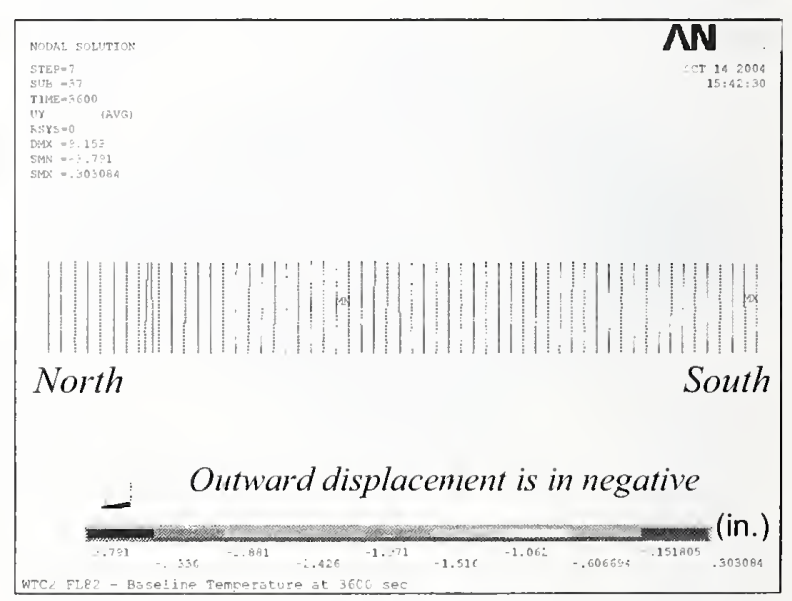

(t) Last tace at $60 \mathrm{~m} ı \mathrm{n}$

Figure 5-94. Horizontal displacement of exterior columns of WTC 2 Floor 82 for Case $C_{i}$ temperature condition at $10 \mathrm{~min}, 30 \mathrm{~min}$, and $60 \mathrm{~min}$. 


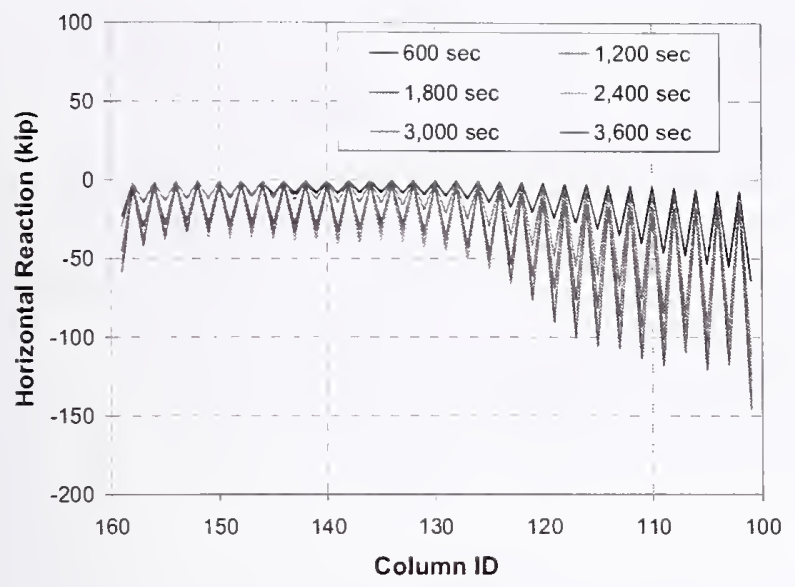

(a) West face

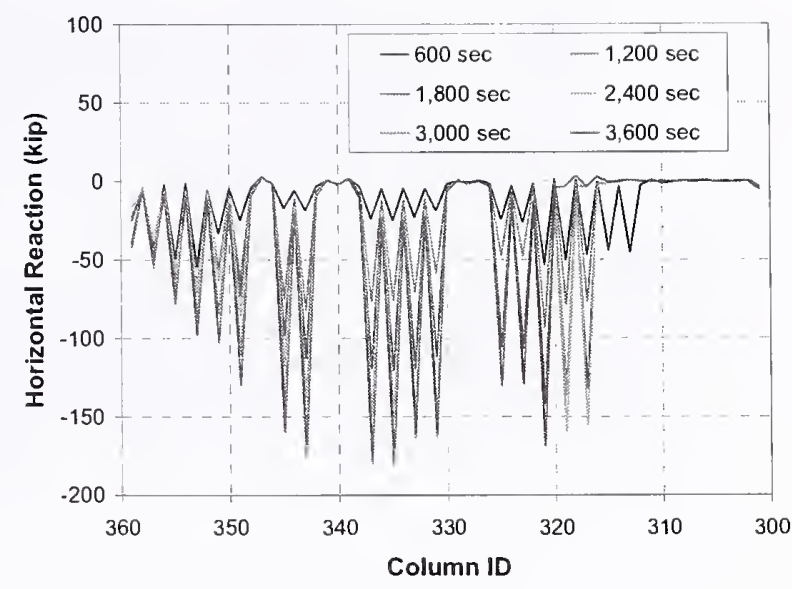

(b) East face

Figure 5-95. Total horizontal reaction at exterior columns on east and west faces of WTC 2 Floor 82 for Case $C_{i}$ conditions.

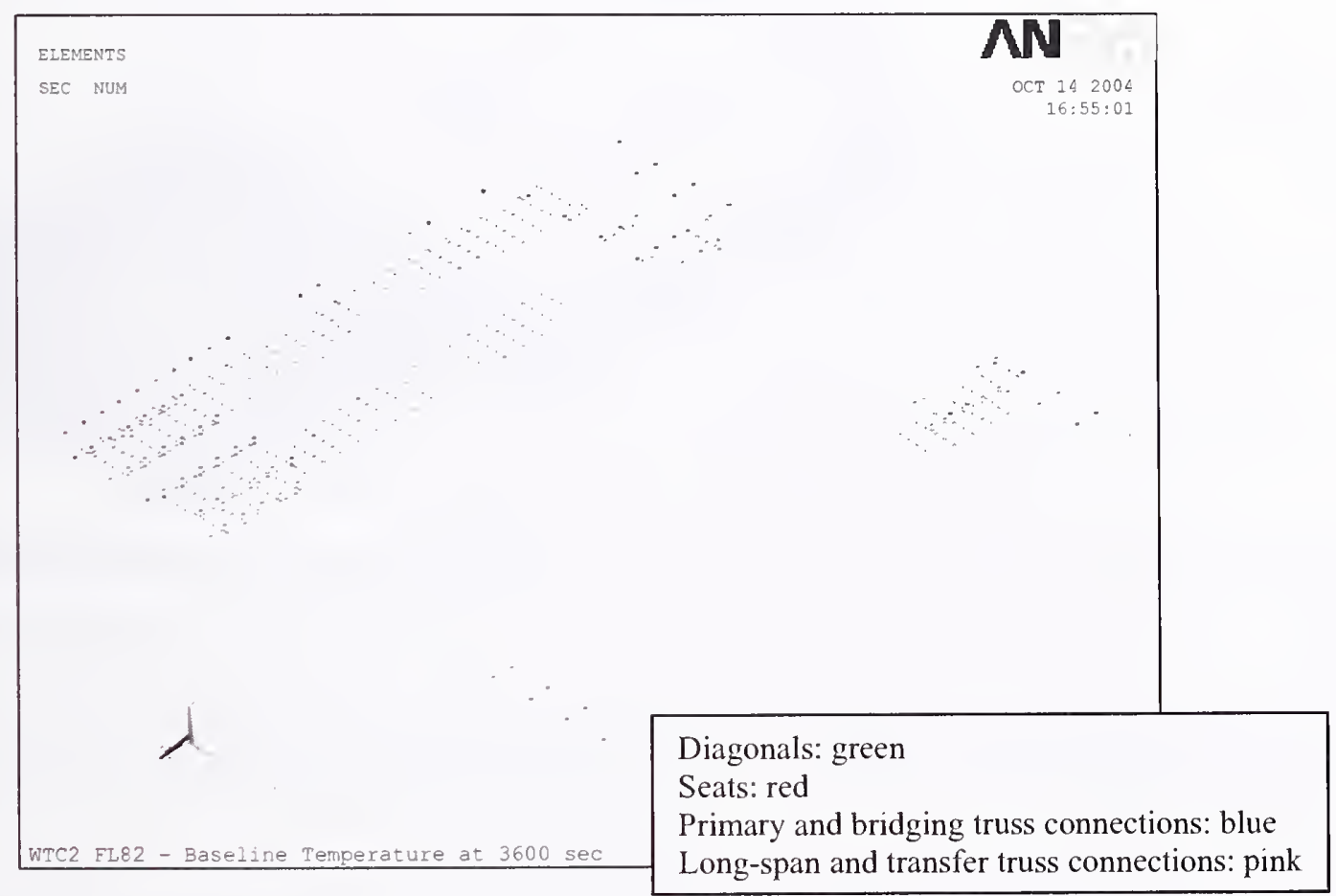

Figure 5-96. User-defined break elements that failed by $60 \mathrm{~min}$ in the model of WTC 2 Floor 82 for Case $\mathrm{C}_{\mathrm{i}}$ temperature condition. 
Table 5-16. Number of failed user-defined break elements in the model of WTC 2 Floor $\mathbf{8 2}$ for Case $\mathrm{C}_{\mathrm{i}}$ temperature condition.

\begin{tabular}{|l|c|}
\hline & Number of Break Elements \\
\hline \hline Web diagonals & 381 \\
\hline Seats and gusset plates & 46 \\
\hline Connections between primary and bridging trusses & 70 \\
\hline Connections between long-span and transfer trusses & 16 \\
\hline \hline Total & 513 \\
\hline
\end{tabular}

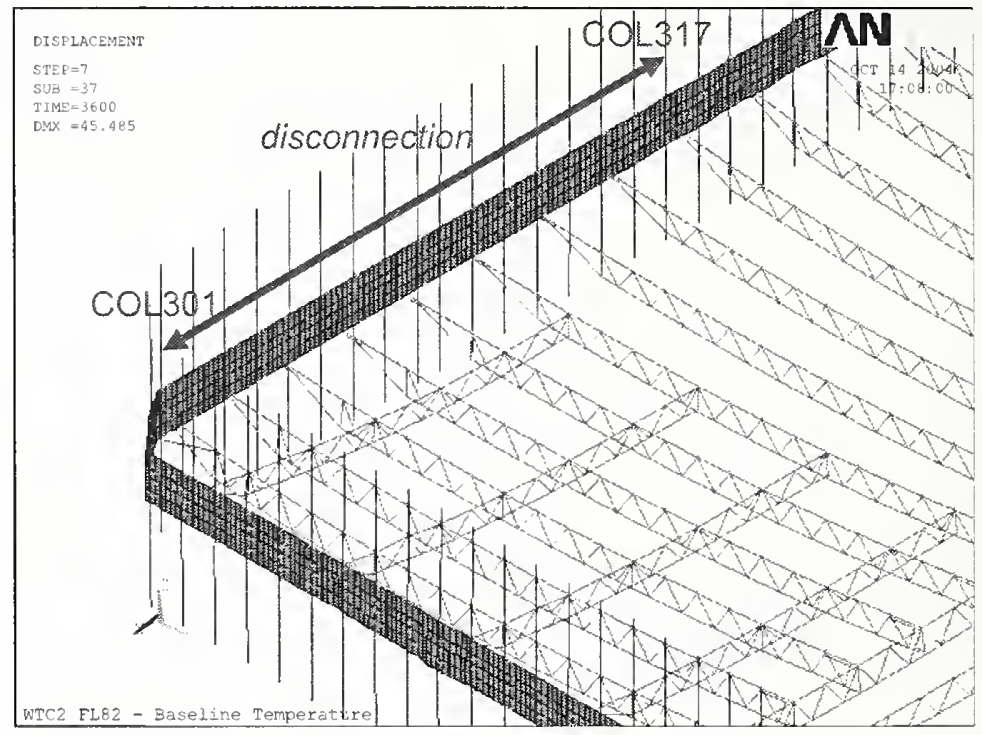

Figure 5-97. Loss of vertical supports in Floor 82 of WTC 2 for Case $C_{i}$ temperature condition at $60 \mathrm{~min}$ ( $1 \mathrm{x}$ displacement magnification).

\subsubsection{Results from Other WTC 2 Floors under Case $C_{i}$ Temperature Condition}

Table 5-17 gives the maximum vertical displacement of WTC 2 floors for Case $\mathrm{C}_{\mathrm{i}}$ temperature condition, and Figs. 5-98 to 5-101 show the vertical displacements of WTC 2 floors when each floor experienced the maximum displacement. Except for Floor 82, the maximum vertical displacement occurred in the southeast area near the impact damage. The maximum displacement occurred at $60 \mathrm{~min}$ on all floors. The vertical displacement in the west office area was found to be insignificant on all the floors except Floor 80 throughout the thermal loading because the insulation on floor trusses was intact in the west office area. In Floor 80, the maximum vertical displacement of the west office area became about 20 in. at $60 \mathrm{~min}$.

Figure 5-102 (a) shows the average thermal expansion of floors at $60 \mathrm{~min}$ on each face, while Fig. 5-102 (b) shows the average total thermal expansion of floors at $60 \mathrm{~min}$ in two orthogonal directions. The total slab expansion ranged from $2.5 \mathrm{in.}$ to $5.5 \mathrm{in}$. Figure 5-103 shows the horizontal reaction at each column on the north and south faces of Floor 82. (The reaction force is positive when the floor pulls the exterior column in.) It was found that Columns 353 to 359 were pulled in by the floor due to the 
significant sag in the southeast area caused by the impact damage to the transfer truss and interior truss seats in this area.

Web diagonals of Floor 81 to Floor 83 buckled in the hot zones of the east office area where the insulation on the trusses was damaged. Failures of the exterior truss seats, gusset plates, or seat bolts were not observed on Floor 79 to Floor 81. Trusses at Column 325 to Column 333 on the east face of Floor 83 lost their vertical support at the exterior truss seats at $50 \mathrm{~min}$, as shown in Fig. 5-104.

Table 5-17. Maximum vertical displacement of WTC 2 floors for Case $\mathrm{C}_{\mathrm{i}}$ temperature condition.

\begin{tabular}{|c|c|c|}
\hline Floor & $\begin{array}{c}\text { Max. Displacement } \\
\text { (in.) }\end{array}$ & $\begin{array}{c}\text { Time at the Maximum } \\
(\mathbf{m i n})\end{array}$ \\
\hline 79 & 19.0 & 60 \\
\hline 80 & 30.1 & 60 \\
\hline 81 & 31.0 & 60 \\
\hline 82 & 45.2 & 60 \\
\hline 83 & 38.9 & 60 \\
\hline
\end{tabular}

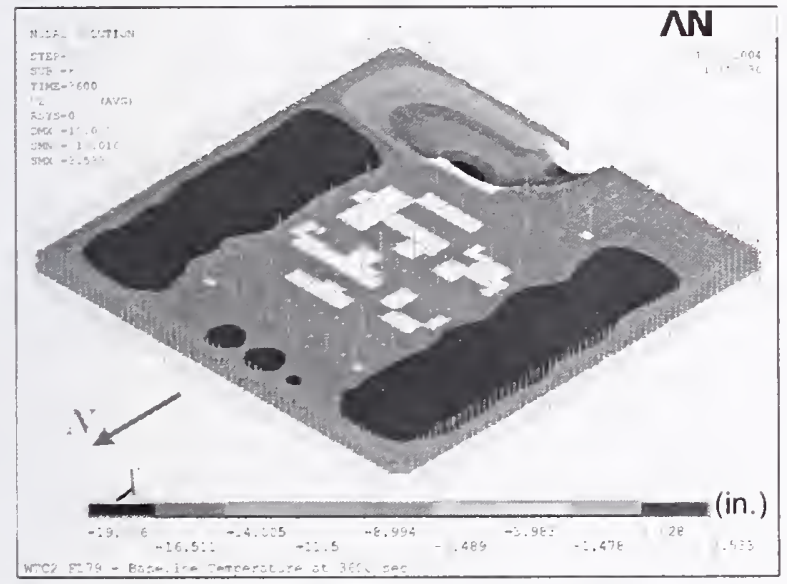

(a) Entire model

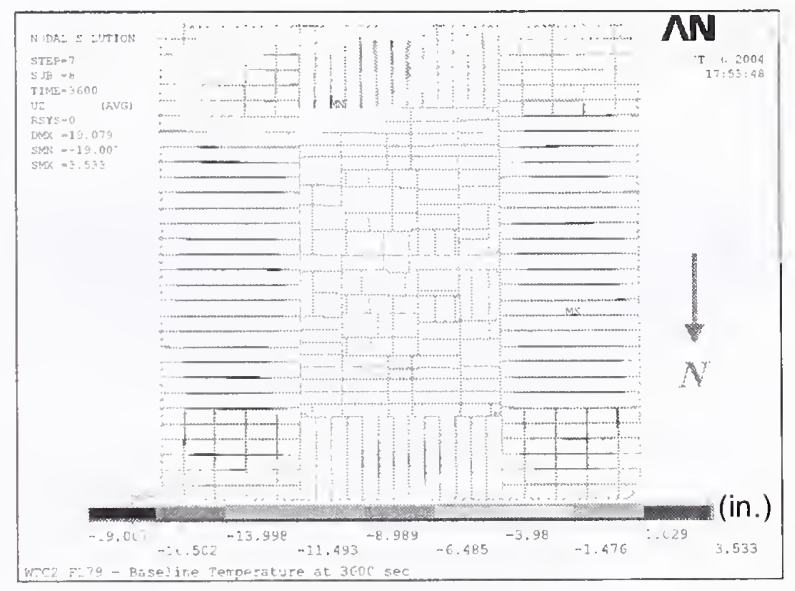

(b) Top view without slab

Figure 5-98. Vertical displacement of WTC 2 Floor 79 for Case $C_{i}$ temperature condition at $60 \mathrm{~min}$ (downward displacement is negative; $5 x$ displacement magnification). 


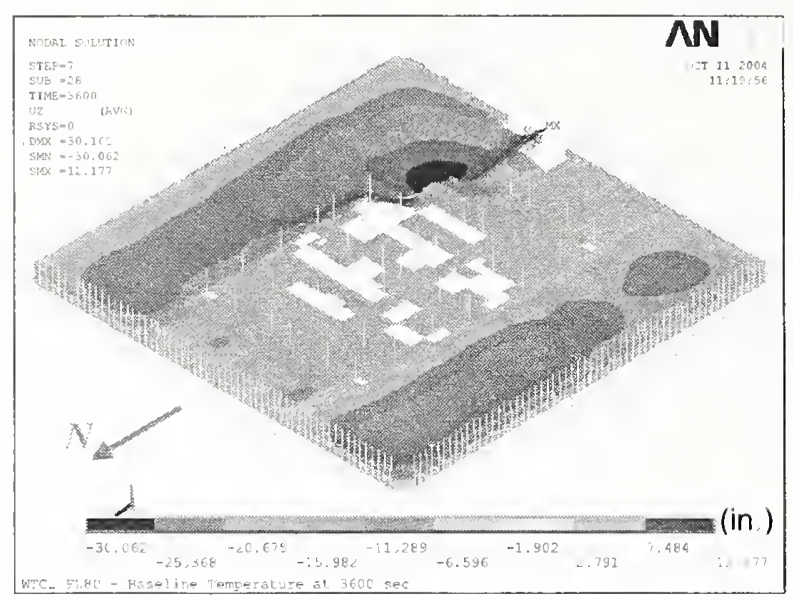

(a) Entire model

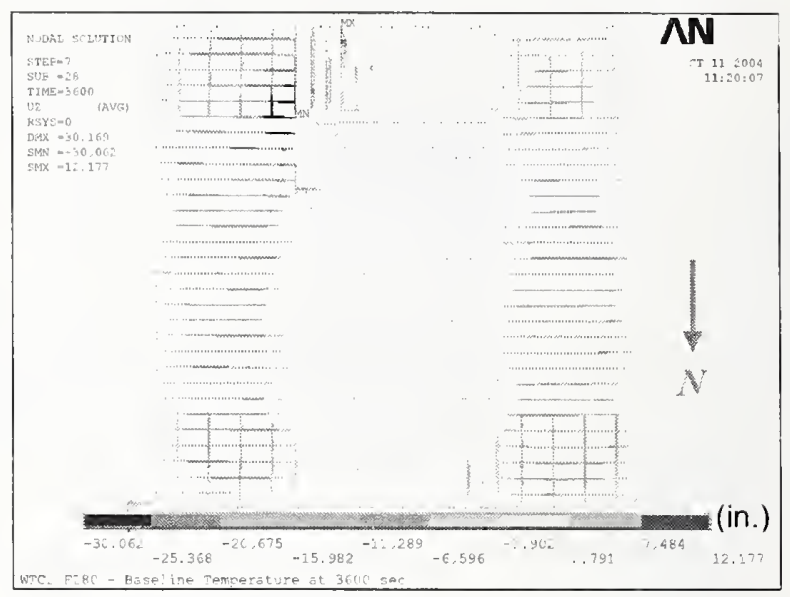

(b) Top view without slab

Figure 5-99. Vertical displacement of WTC 2 Floor 80 for Case $C_{i}$ temperature condition at $60 \mathrm{~min}$ (downward displacement is negative; $5 x$ displacement magnification).

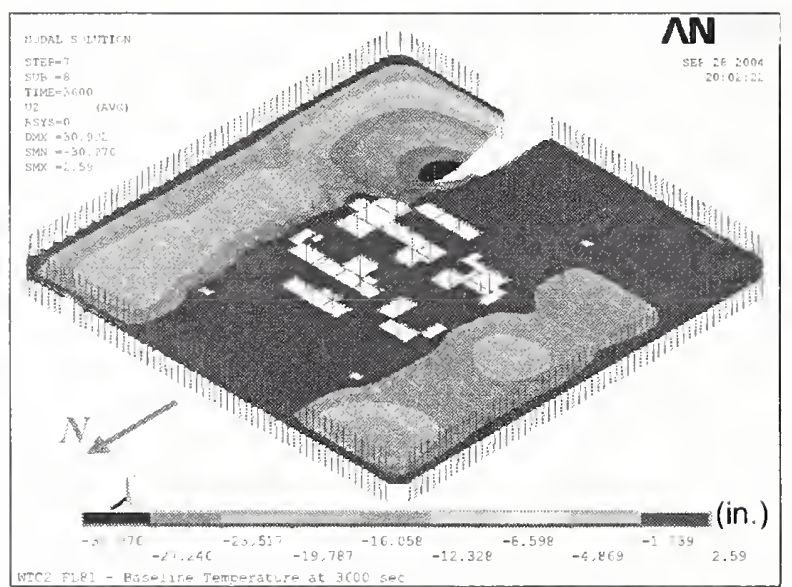

(a) Entire model

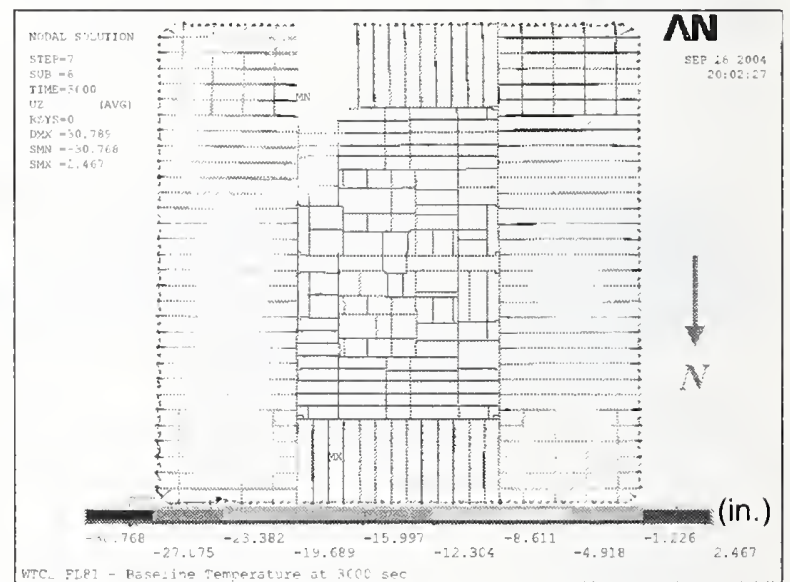

(b) Top view without slab

Figure 5-100. Vertical displacement of WTC 2 Floor 81 for Case $C_{i}$ temperature condition at $60 \mathrm{~min}$ (downward displacement is negative; $5 x$ displacement magnification). 


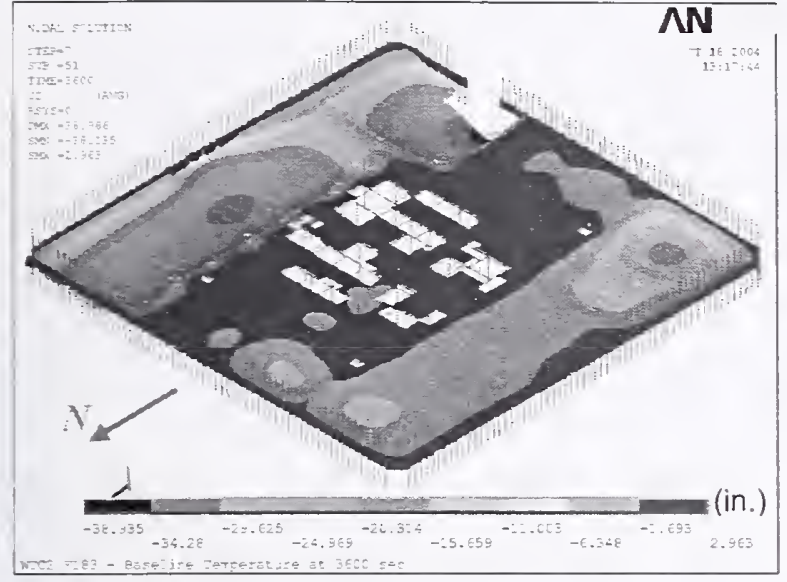

(a) Entire model

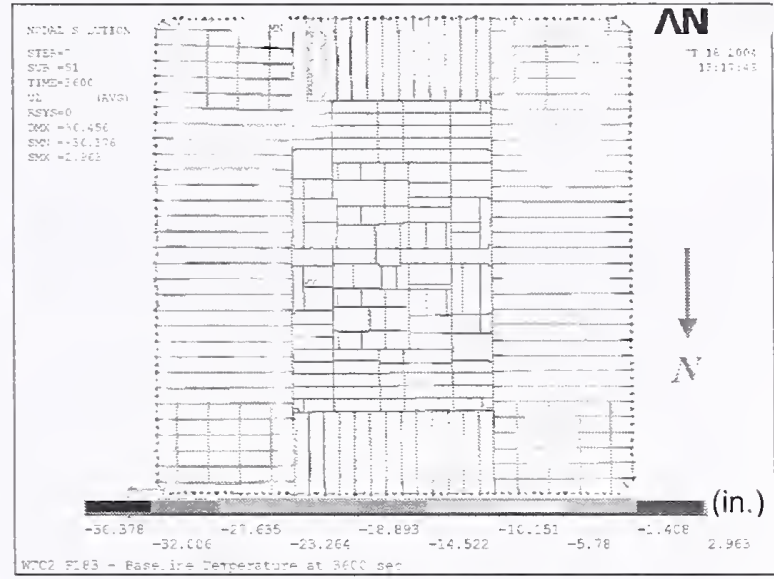

(b) Top view without slab

Figure 5-101. Vertical displacement of WTC 2 Floor 83 for Case $C_{i}$ temperature condition at $60 \mathrm{~min}$ (downward displacement is negative; $5 x$ displacement magnification).

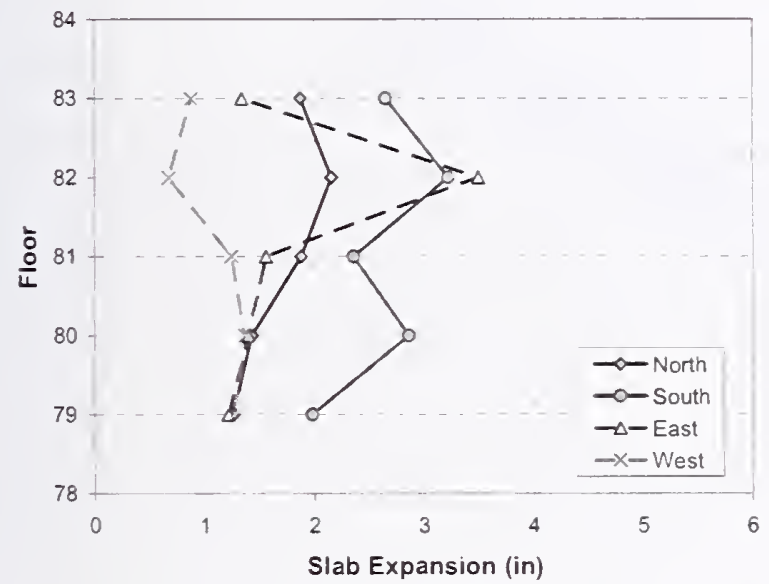

(a) Average displacement of each face

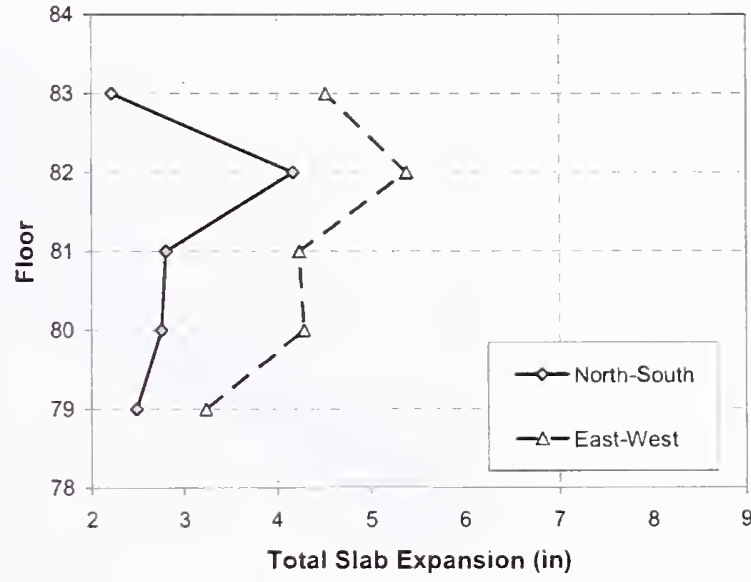

(b) Average slab expansion in each direction

Figure 5-102. Average thermal expansion of WTC 2 floors at 60 min under Case $C_{i}$ temperature condition. 


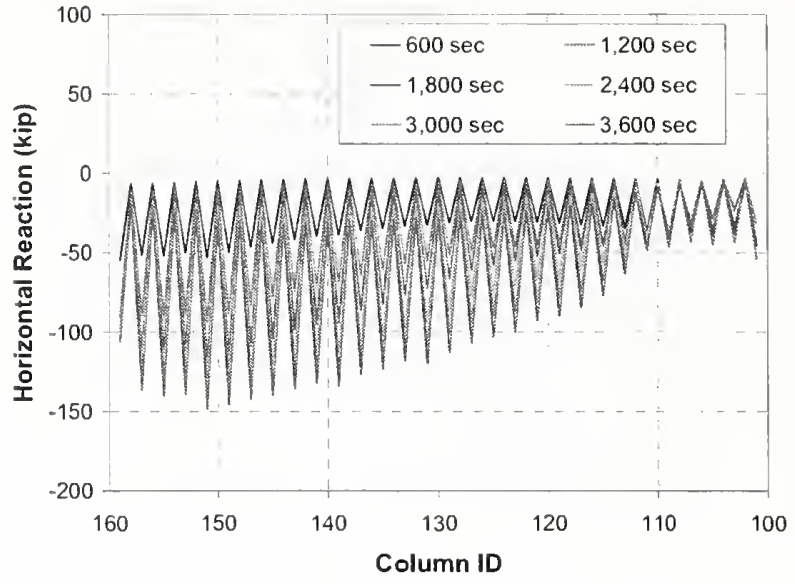

(a) West face

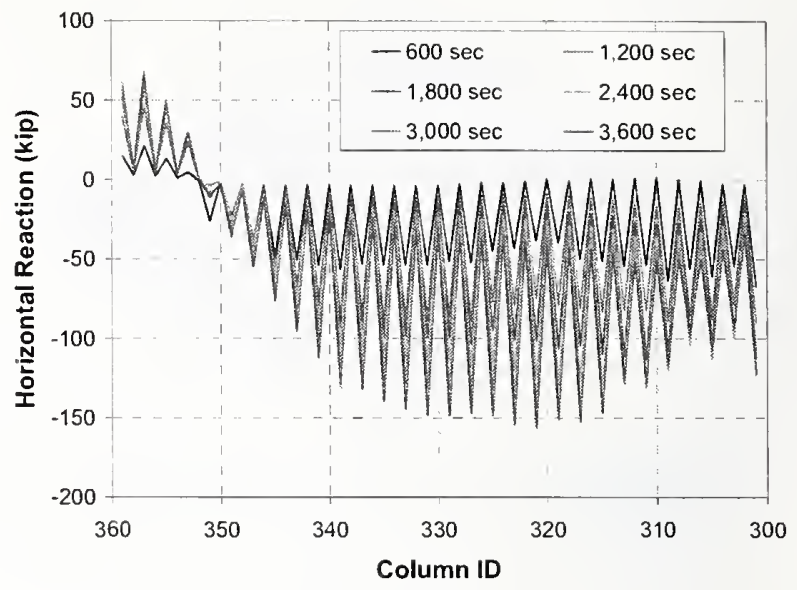

(b) East face

Figure 5-103. Horizontal reaction force per column of WTC 2 Floor 81 for Case $C_{i}$ temperature condition.

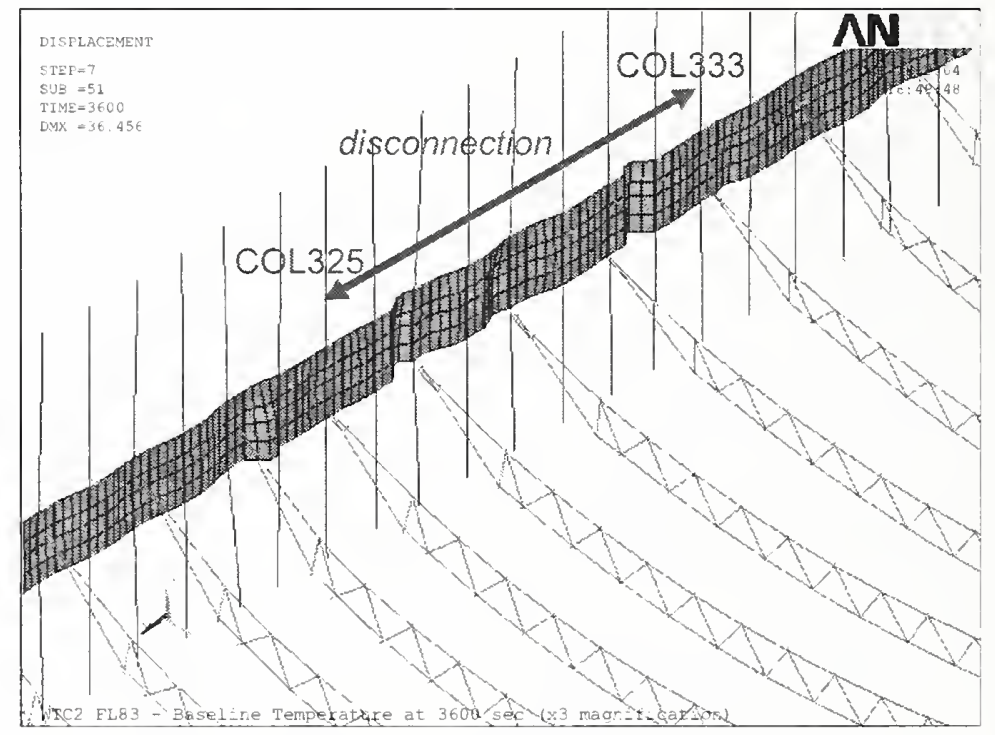

Figure 5-104. Loss of vertical supports in Floor 83 of WTC 2 for Case $C_{i}$ temperature condition at $60 \mathrm{~min}$ ( $3 \mathrm{X}$ displacement magnification).

\subsubsection{Results from WTC 2 Floors under Case $D_{i}$ Temperature Condition}

Table 5-18 summarizes the maximum vertical displacement of WTC 2 floors under Case $D_{i}$ temperature condition, and Figs. 5-105 to 5-109 show the vertical displacements of WTC 2 floors when each floor experienced the maximum displacement. Due to the more extensive impact damage and higher temperatures than Case $\mathrm{C}_{\mathrm{i}}$ conditions, all floors had larger vertical displacement. Floor 80 and Floor 81 suffered impact damage to transfer trusses and many interior truss seats in the southeast area. Bridging trusses that had been removed in the analyses with Case $\mathrm{C}_{\mathrm{i}}$ conditions were replaced in these two floors to provide support to the primary trusses in the east office area after aircraft impact. A maximum vertical 
displacement of 97 in. occurred at Floor 81 near the impact damage at 50 min as shown in Fig. 5-107. Similar sagging of the floor was found in other floors.

Gusset plates and bolts at more than 75 percent of all the exterior seats of the east face of Floor 82 and Floor 83 failed due to horizontal shear force that was caused by the difference in the thermal expansion between the floor and the exterior wall in the direction transverse to primary trusses. The truss at Column 357 of Floor 81 was the only truss that lost its vertical support at the exterior truss seat among all floors. This truss walked off the truss seat.

Floor sagging caused pull-in forces. For instance, Column 101 to Column 111 on the west face and Column 347 to Column 359 on the east face were pulled in by the floor at $60 \mathrm{~min}$ on Floor 80 as shown in Fig. 5-110 because of the floor sagging occurring in the southeast area. Since core columns were not restrained in the horizontal directions, when the floor pulled in one face of exterior wall. the opposite face of the exterior wall was also pulled in. Columns at the southeast corner were pulled in by the floor at Floor 79 and Floor 81. Many columns of the west face of Floor 82 were pulled in. The reaction forces at many columns of the east face of Floor 82 were close to zero, as shown in Fig. 5-111 (b). The gusset plates and seat bolts failed at a number of trusses on the east face of Floor 82 . Since columns at these locations were not supported in the horizontal direction by the floor, the reaction force became close to zero at these columns.

Figure 5-112 shows the average thermal expansion of floors at $60 \mathrm{~min}$ of Case $\mathrm{D}_{\mathrm{i}}$ temperature condition. The average total floor expansion ranged from 1 in. to 5 in.

Table 5-18. Maximum vertical displacement of WTC 2 floors for Case $D_{i}$ temperature condition.

\begin{tabular}{|c|c|c|}
\hline Floor & $\begin{array}{c}\text { Max. Displacement } \\
\text { (in.) }\end{array}$ & $\begin{array}{c}\text { Time at the Maximum } \\
\text { (min) }\end{array}$ \\
\hline 79 & 35.8 & 60 \\
\hline 80 & 65.6 & 40 \\
\hline 81 & 96.7 & 50 \\
\hline 82 & 49.4 & 60 \\
\hline 83 & 44.6 & 60 \\
\hline
\end{tabular}




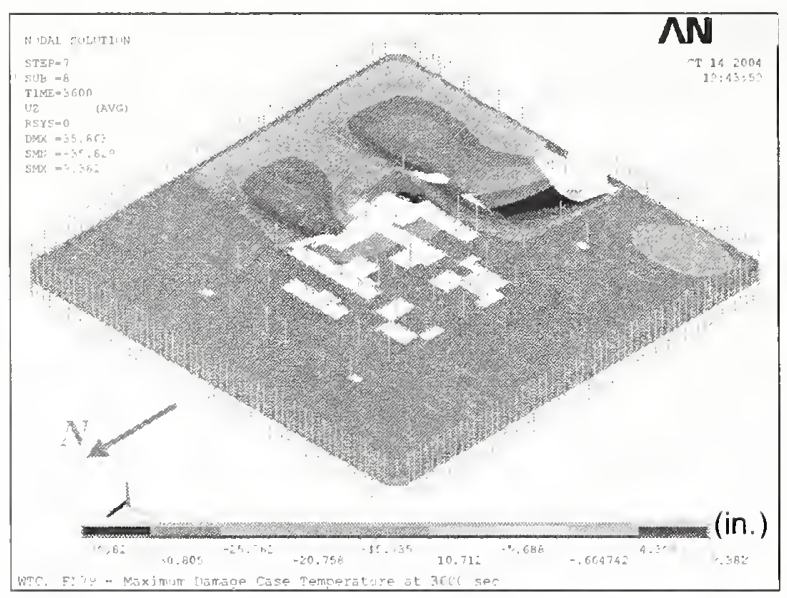

(a) Entire model

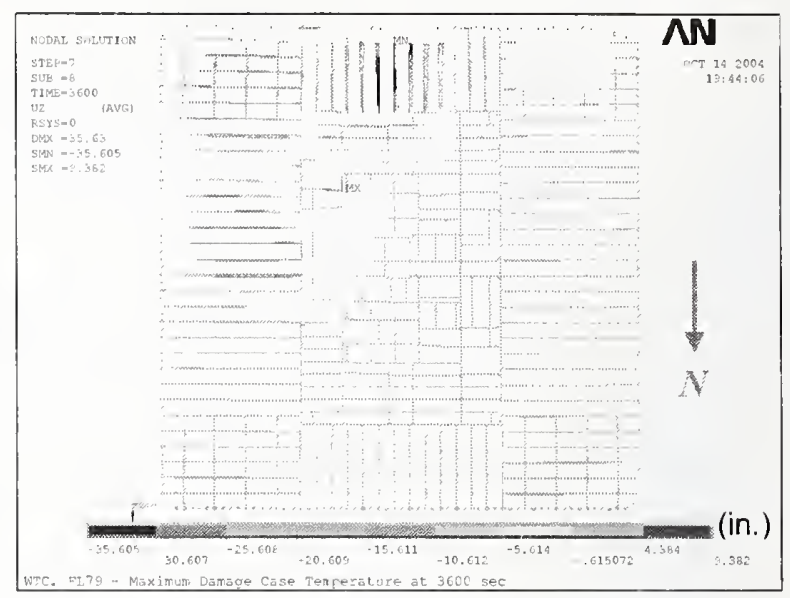

(b) Top view without slab

Figure 5-105. Vertical displacement of WTC 2 Floor 79 for Case $D_{i}$ temperature condition at $60 \mathrm{~min}$ (downward displacement is negative; 5x displacement magnification).

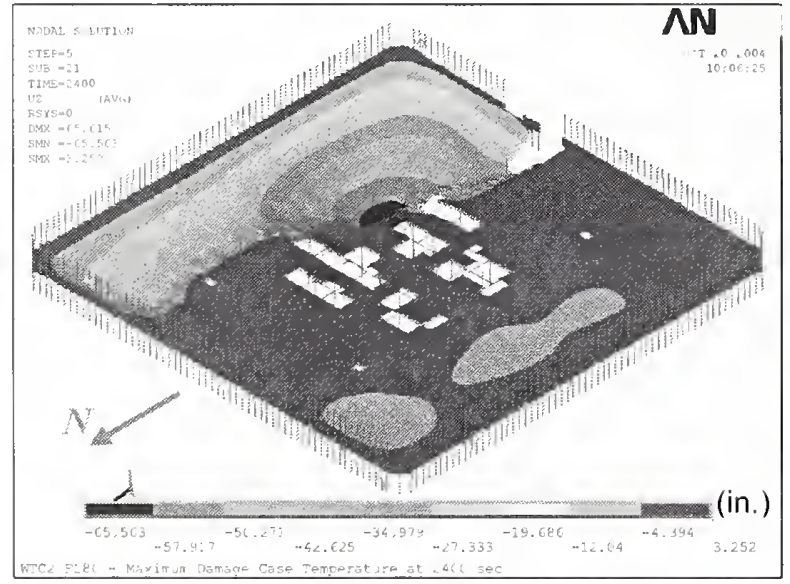

(a) Entire model

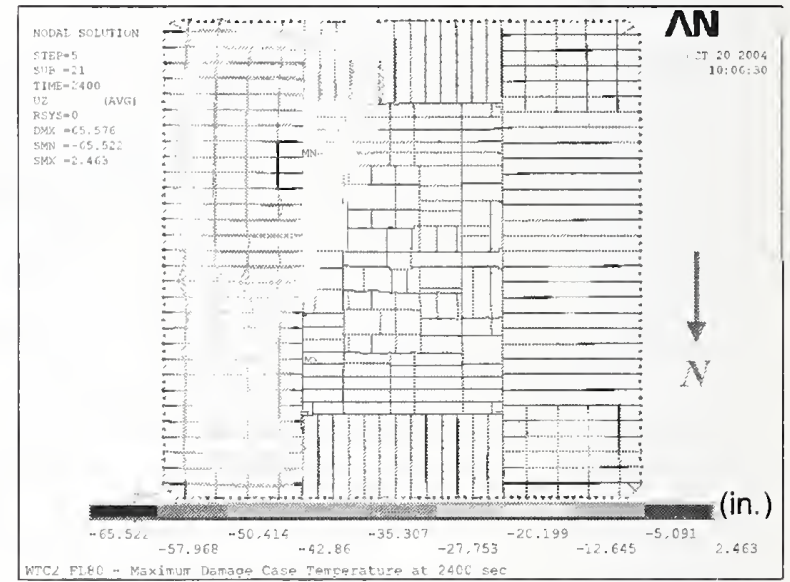

(b) Top view without slab

Figure 5-106. Vertical displacement of WTC 2 Floor 80 for Case $D_{i}$ temperature condition at $40 \mathrm{~min}$ (downward displacement is negative; $5 \mathrm{x}$ displacement magnification). 


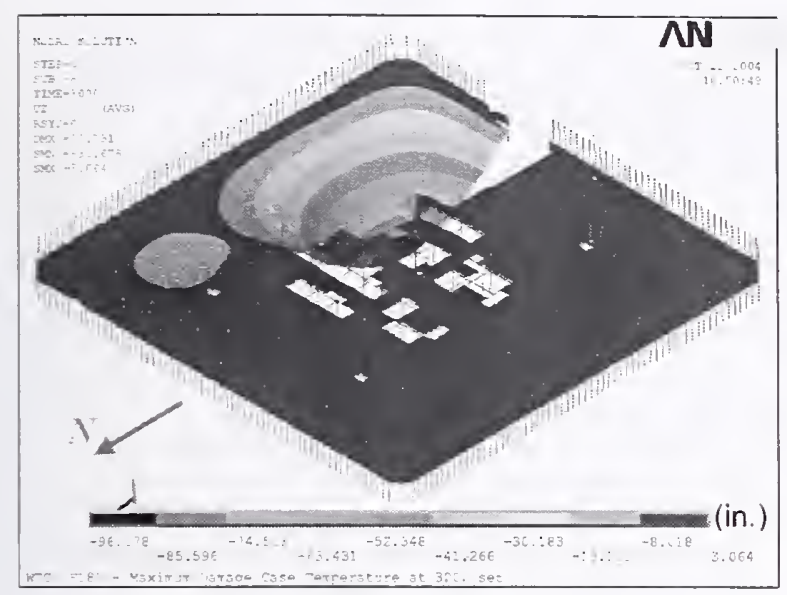

(a) Entire model

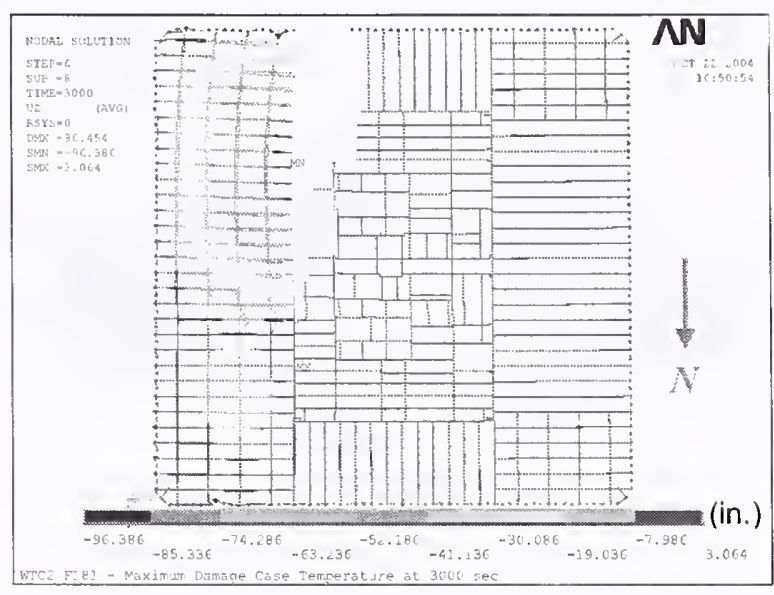

(b) Top view without slab

Figure 5-107. Vertical displacement of WTC 2 Floor 81 for Case $D_{i}$ temperature condition at $50 \mathrm{~min}$ (downward displacement is negative; $5 x$ displacement magnification).

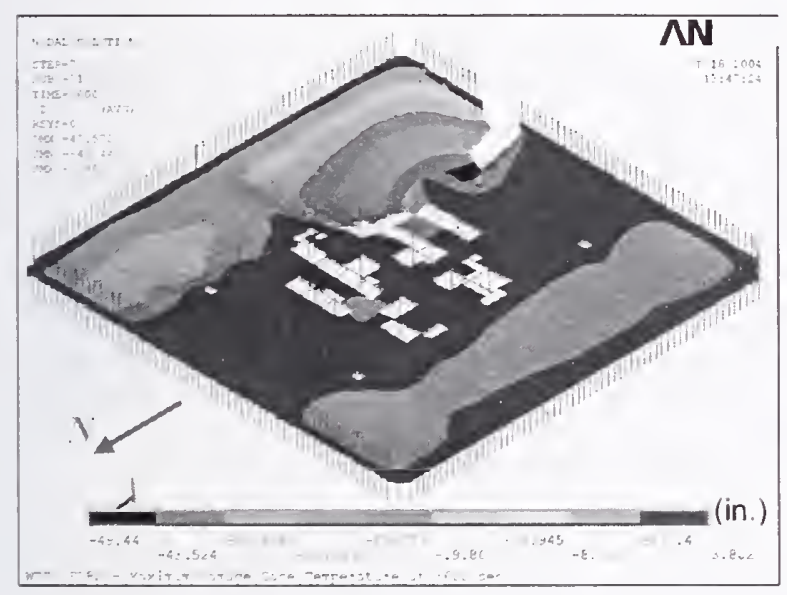

(a) Entire model

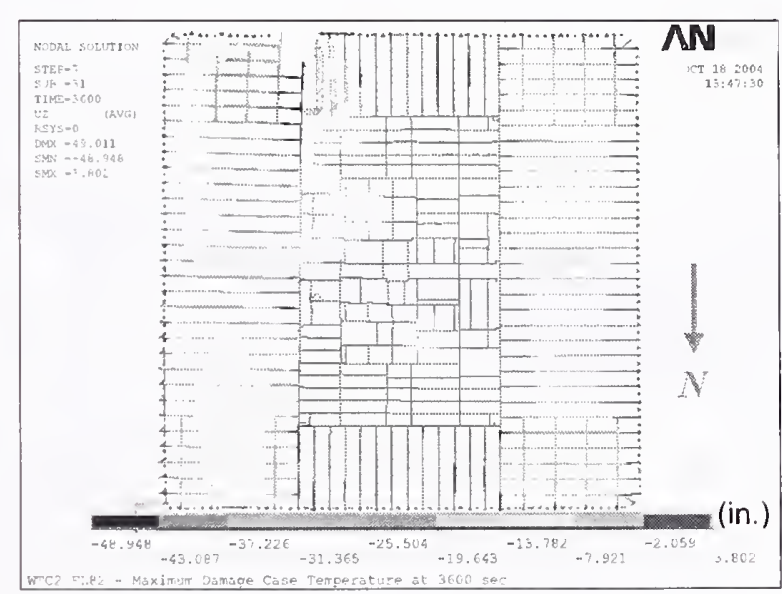

(b) Top view without slab

Figure 5-108. Vertical displacement of WTC 2 Floor 82 for Case $D_{i}$ temperature condition at $60 \mathrm{~min}$ (downward displacement is negative; $5 \mathrm{x}$ displacement magnification). 


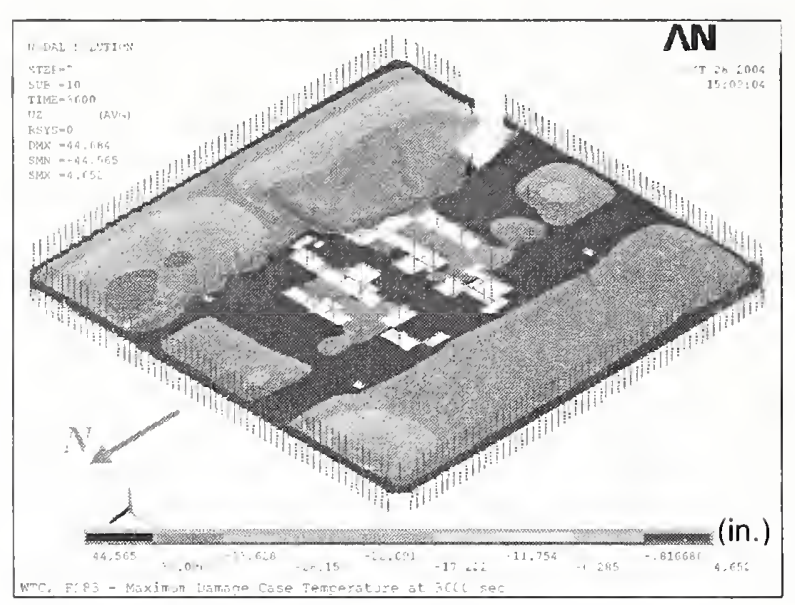

(a) Entire model

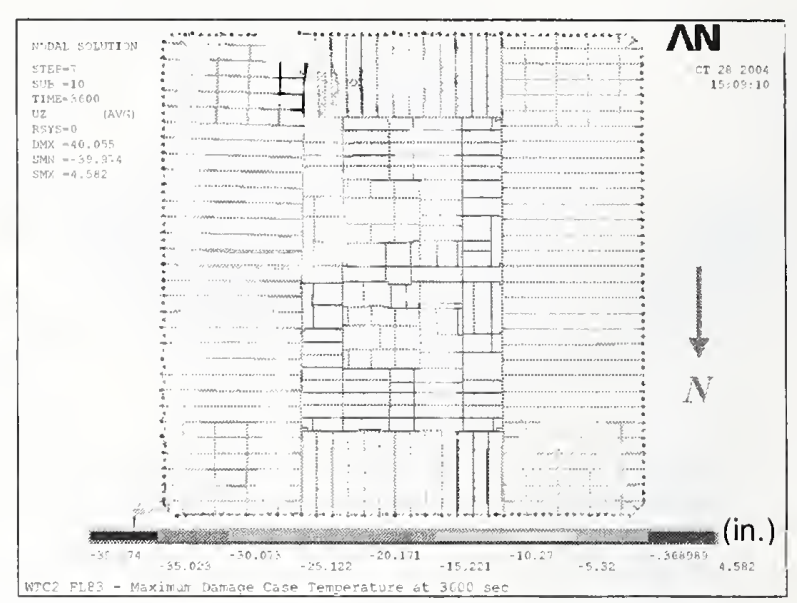

(b) Top view without slab

Figure 5-109. Vertical displacement of WTC 2 Floor 83 for Case $D_{i}$ temperature condition at $60 \mathrm{~min}$ (downward displacement is negative; $5 x$ displacement magnification).

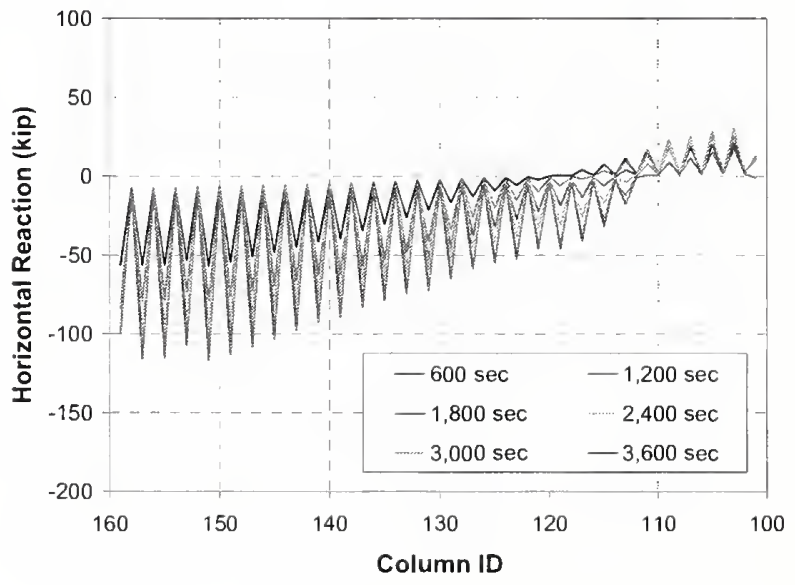

(a) West face

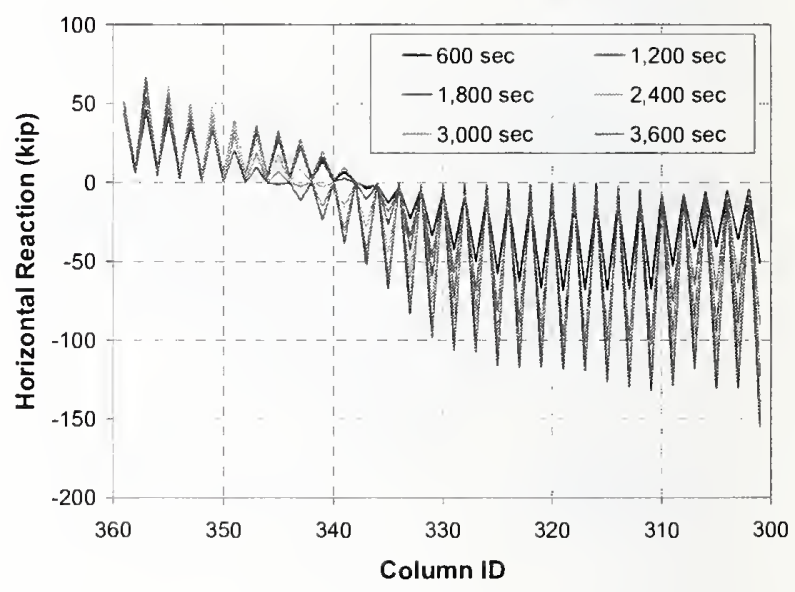

(b) East face

Figure 5-110. Horizontal reaction force per column of WTC 2 Floor 80 for Case $D_{i}$ temperature condition. 


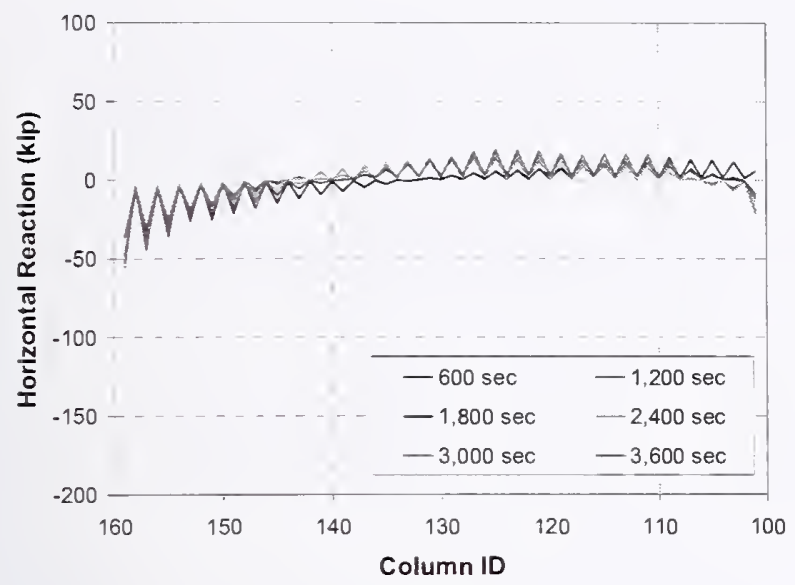

(a) West face

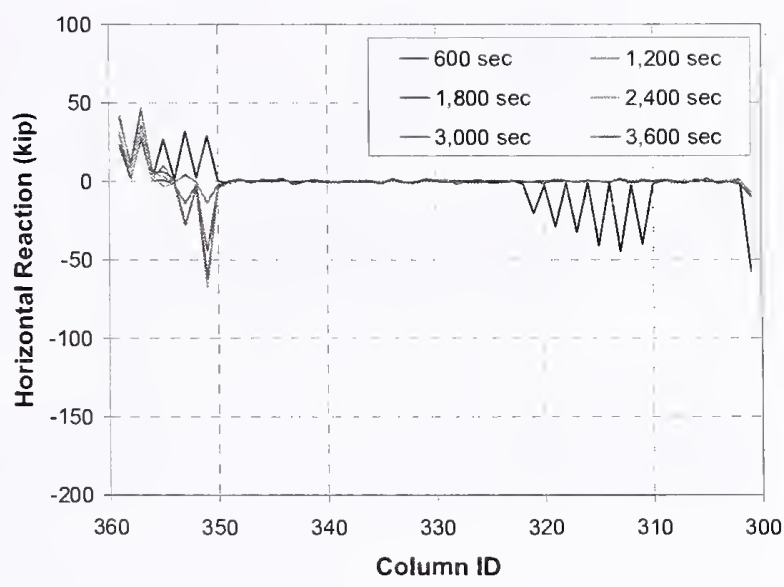

(b) East face

Figure 5-111. Horizontal reaction force per column of WTC 2 Floor 82 for Case $D_{i}$ temperature condition.

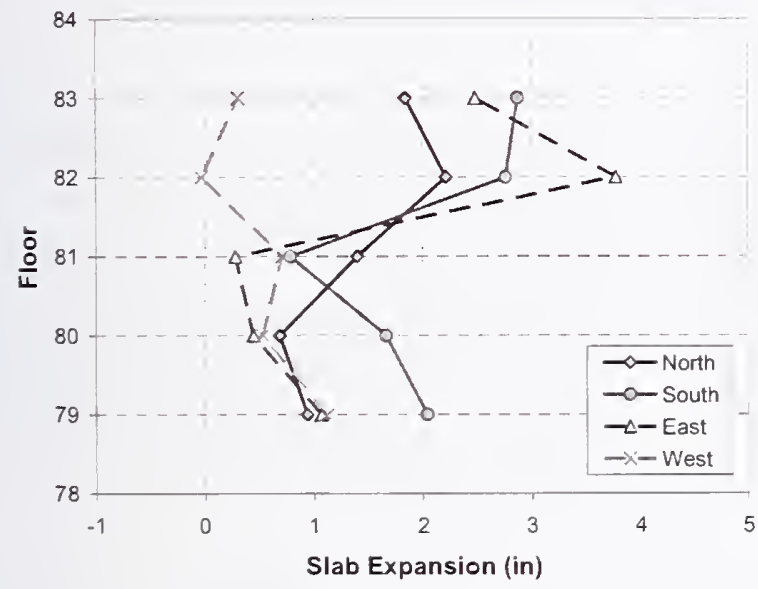

(a) Average displacement of each face

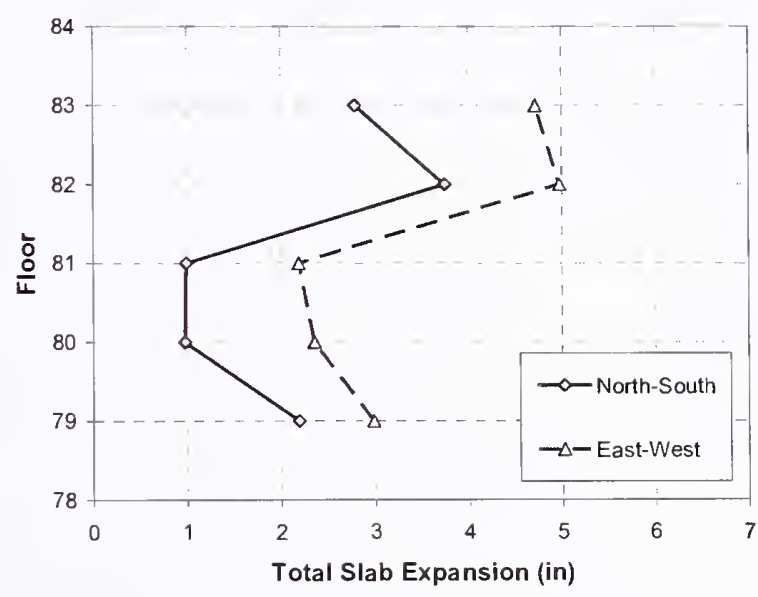

(b) Average slab expansion in each direction

Figure 5-112. Average thermal expansion of WTC 2 floors at $60 \mathrm{~min}$ for Case $D_{i}$ temperature condition. 


\subsubsection{Creep Effect}

Full floor models were not run with creep due to the inherent convergence problems of BEAM188/189 elements under thermal loadings with materials with temperature-dependent creep. To evaluate the effect of crecp, a simplified truss model at Column 333 of Floor 96 was extracted from the full floor model and was subjected to Case $B_{i}$ temperature condition. The model was analyzed with and without creep in the steel.

Vertical displacements at $40 \mathrm{~min}$ are shown in Fig. 5-113. The maximum displacements at 40 min were $44 \mathrm{in.} \mathrm{for} \mathrm{the} \mathrm{model} \mathrm{with} \mathrm{creep} \mathrm{and} 26 \mathrm{in}$. for the model without creep. After $40 \mathrm{~min}$, the model with creep walked off the exterior truss seat, while the model without creep did not walk off the exterior truss seat, and the vertical displacement increased with time and reached $31 \mathrm{in}$. at $100 \mathrm{~min}$. The maximum pull-in forces were $14 \mathrm{kip}$ for the model with creep and $8 \mathrm{kip}$ for the model without creep. The interfacc force between the exterior columns and the truss became compression in the model without creep after 37 min because the thermal expansion overcame the shortening caused by the sagging.

Based on this study of the simplified truss model, creep in steel would significantly increase the existing floor sag at high temperaturcs. Therefore, the sagging of floors was underestimated in the full floor model analyses performed without creep.

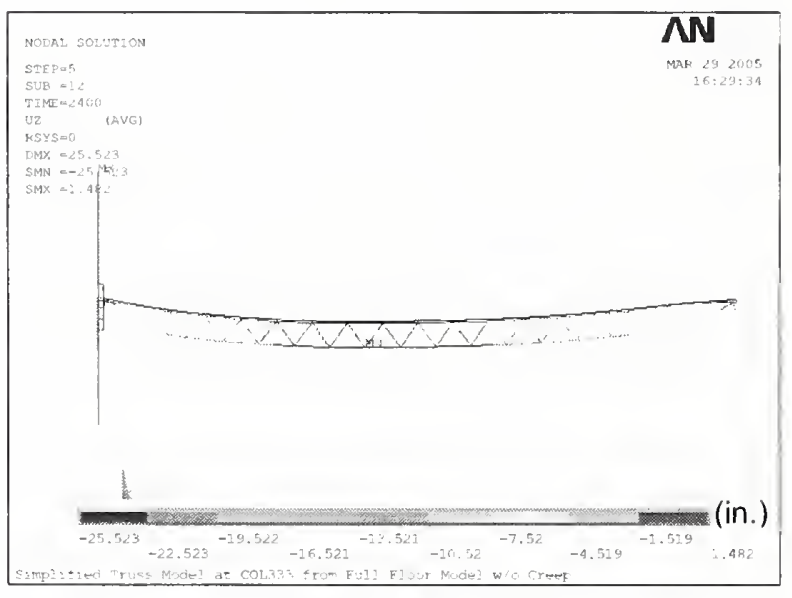

(a) Model without creep

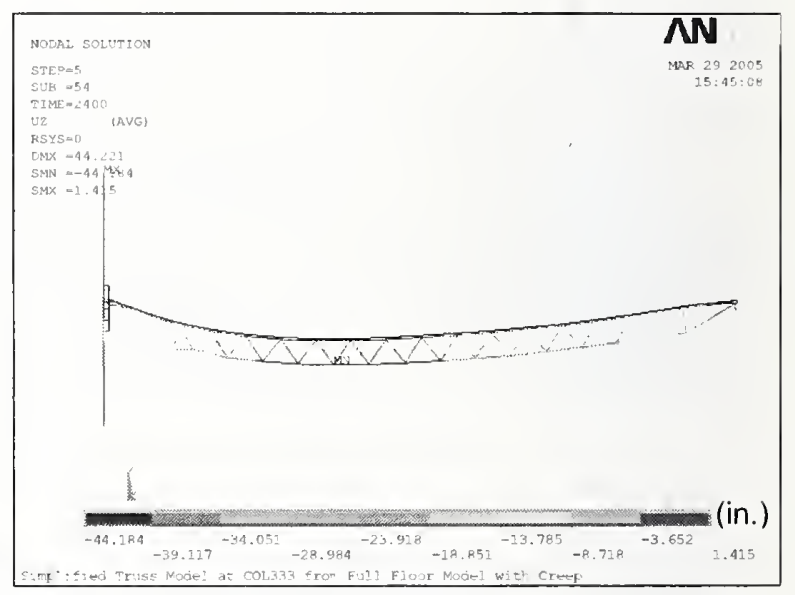

(b) Model with creep

Figure 5-113. Vertical displacement of a simplified truss model at Column 333 extracted from the full floor model of Floor 96 of WTC 1 under Case $B_{i}$ temperature condition at $40 \mathrm{~min}$ (downward displacement is negative).

\subsubsection{Effect of Column Boundary Conditions}

The boundary conditions at the ends of columns and column length affect the horizontal force between the floors and the exterior walls resulting from the thermal expansion of the floor. The fixcd boundary conditions and single story column length assumed in the floor analyses shown in this report represent a relatively high degree of lateral restraint. The effect of reducing the degree of lateral restraint was evaluated by performing nonlinear static finite element analysis with two story and three story column lengths.

The results showed that the reduced restraint did not significantly affect the overall structural performance of the floors although it decreased the vertical deflection of the floor by less than 20 percent and it 
decreased the magnitude of the lateral force by as much as 85 percent. (Note that this decrease in deflection compensates partially for the additional deflection expected due to creep, as discussed in Section 5.5.15.)

\subsubsection{Floor Subsystem in Global Models}

Floor: The floors in the global models were modeled by SHELL181 elements with temperaturedependent elastic properties to enhance computational efficiency. Their functions were to:

1. Simulate the diaphragm action of floors

2. Simulate the load transfer from the core to the exterior wall system when the core experiences significant downward displacement due to shortening of core columns

The membrane stiffness of shell elements for the office area was determined by calculating the longitudinal stiffness of the composite floor using the single truss model which included not only the stiffness of the truss but also the stiffness of the connections between the truss and the exterior wall.

Fire-Induced Damage: Floors modeled by shell elements could not capture failure modes of floors under elevated temperatures; therefore, key failure modes were implemented in the global models at appropriate points in time as fire-induced damage. Two different behaviors were considered based on conditions of connections between the floor and the exterior wall: 1) the floor sagged and pulled the exterior wall in and 2) the floor was disconnected from the exterior wall. The locations of floor/wall disconnections and the locations and magnitudes of pull-in forces in the sagging floor areas were determined using not only the full floor model results but also the actual observations from photographs and videos and the analyses performed on isolated exterior wall models, as discussed in Section 2.5 of NIST NCSTAR1-6D.

Results from the full floor model analyses are presented in Figs. 5-114 to 5-117 only at the end of time histories for the conditions of the connections between the exterior wall and the floors. The figures show the following conditions:

- Condition 1: gusset plate failure + seat failure due to vertical shear (loss of vertical support)

- Condition 2: gusset plate failure + seat bolt shear-off + truss walk-off (loss of vertical support)

- Condition 3: gusset plate failure + seat bolt shear-off + significant vertical displacement $(>25$ in.) of the floor in that area (floor remains vertically supported)

- Condition 4: tensile force between the exterior wall and the floor system (floor remains vertically connected, but exerts pull-in force on the exterior wall)

Conditions 1 and 2 were treated as the case of floor/wall disconnections. Conditions 3 and 4 were treated as the case where the floor pulled in the exterior wall. Owing to the failure of the gusset plate and seat bolts (Condition 3), the floor in this model cannot pull in the exterior wall at these connections. In reality, in addition to studs and diagonal strap anchors that may not have failed, there was friction between the truss bearing angles and the exterior truss seat angle. For these reasons, Condition 3 was treated as the case where the floor pulled in the exterior wall. More discussion on the pull-in force can be found in Section 2.5 of NIST NCSTAR 1-6D.

In the full floor model, every other exterior column was connected to the floor because spandrel studs and strap anchors were removed from the model. The four conditions above were defined for columns at primary trusses; however, they are shown in Figs. 5-114 to 5-117 for all columns because there were 
strap anchors connecting the floor to the columns located between primary trusses. When the same condition of the connection was found for two adjacent truss locations, the column between the two trusses was assumed to have the same condition as the adjacent columns in these figures. For example, failure of exterior seats (Condition 1) occurred at Columns 329 and 331 of Floor 98 of WTC 1 for Case $\mathrm{B}_{i}$ temperature condition. In Fig. 5-115, Column 330 is also indicated as Condition 1, although there was no truss located at Column 330. 

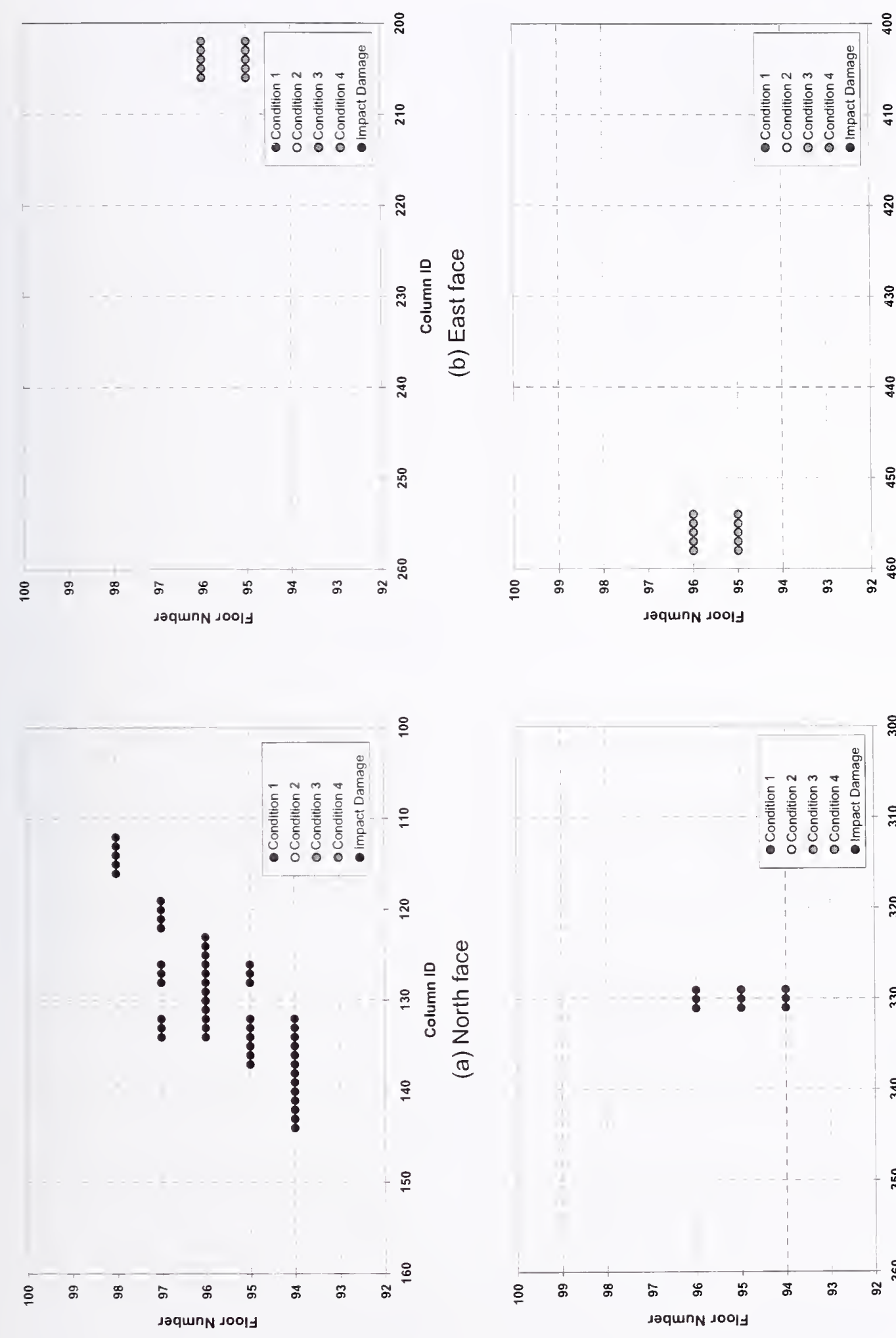

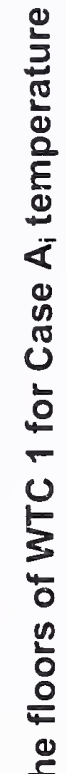

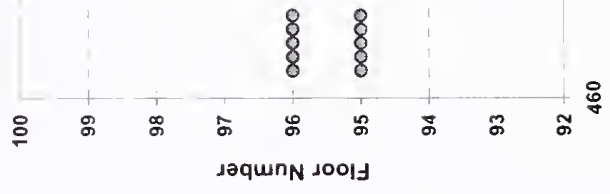

ริ

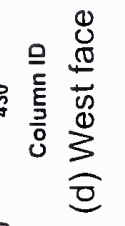

$-\frac{9}{3}$

㝵

F

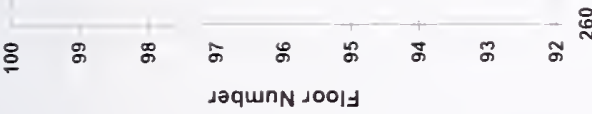

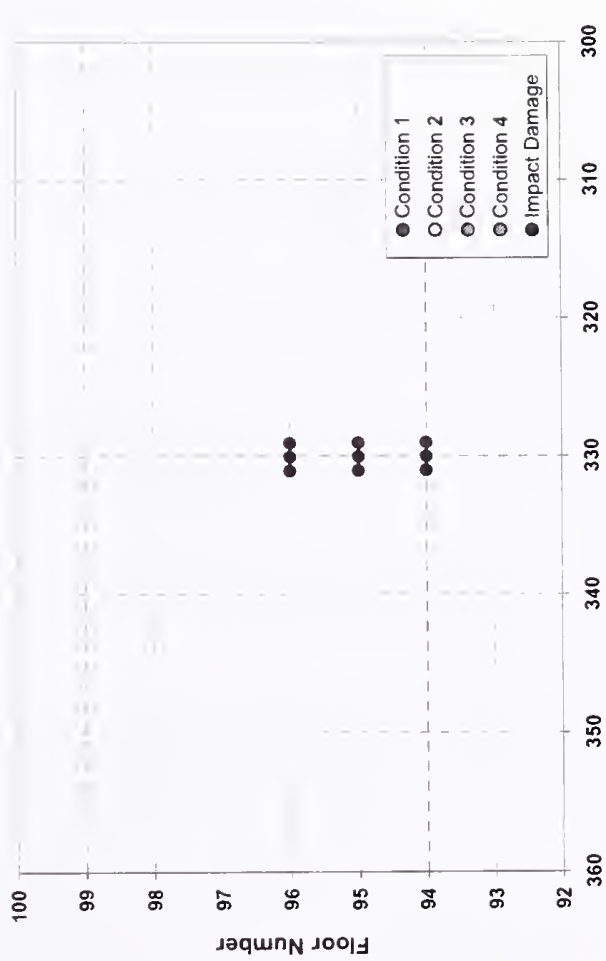

둥

耍

응응

훈

동

홍

동 응

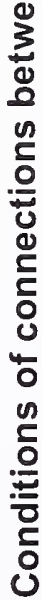

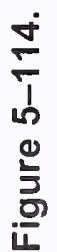



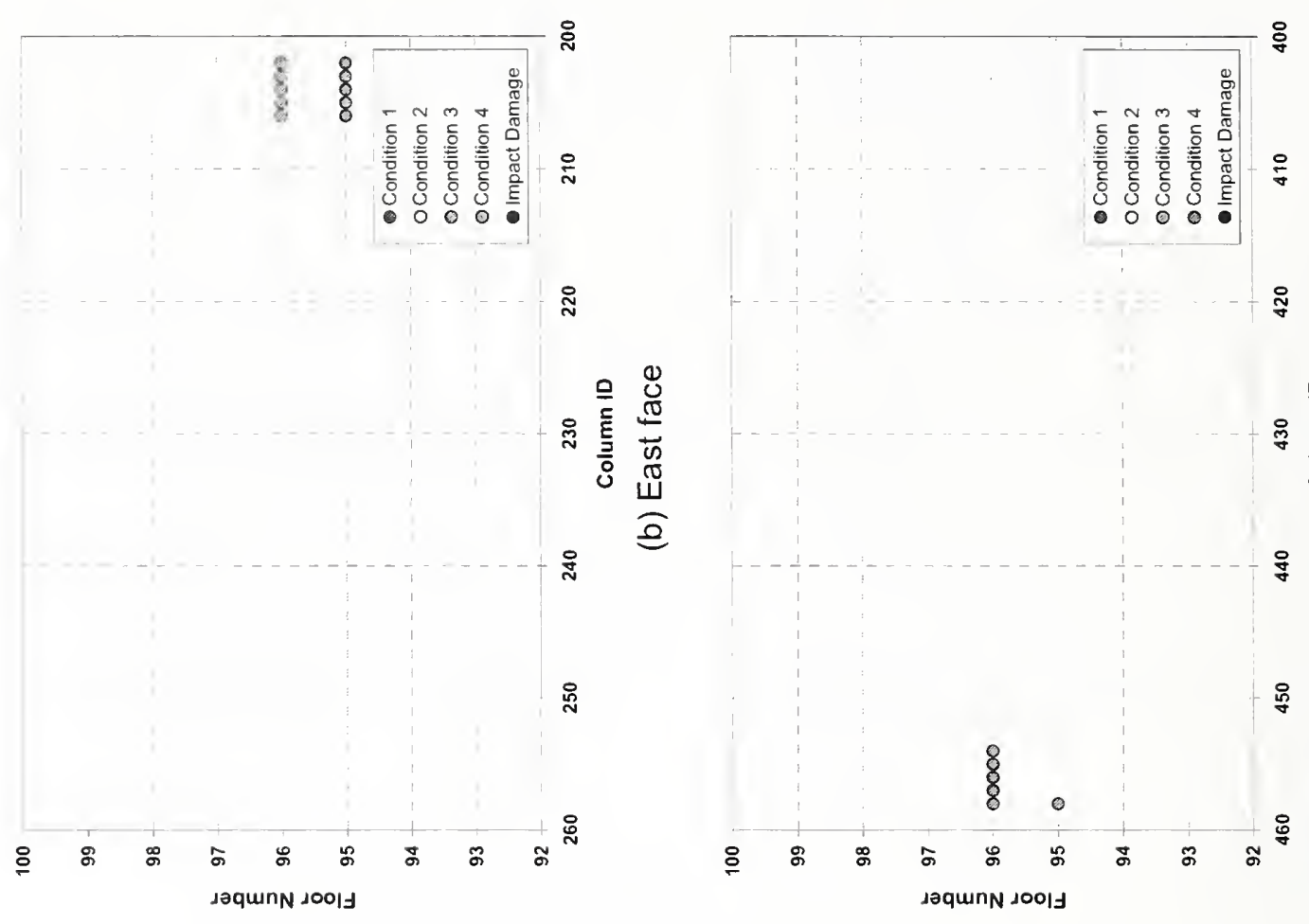

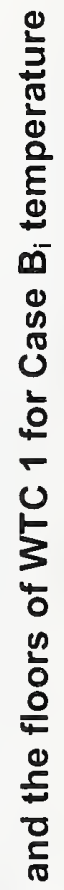
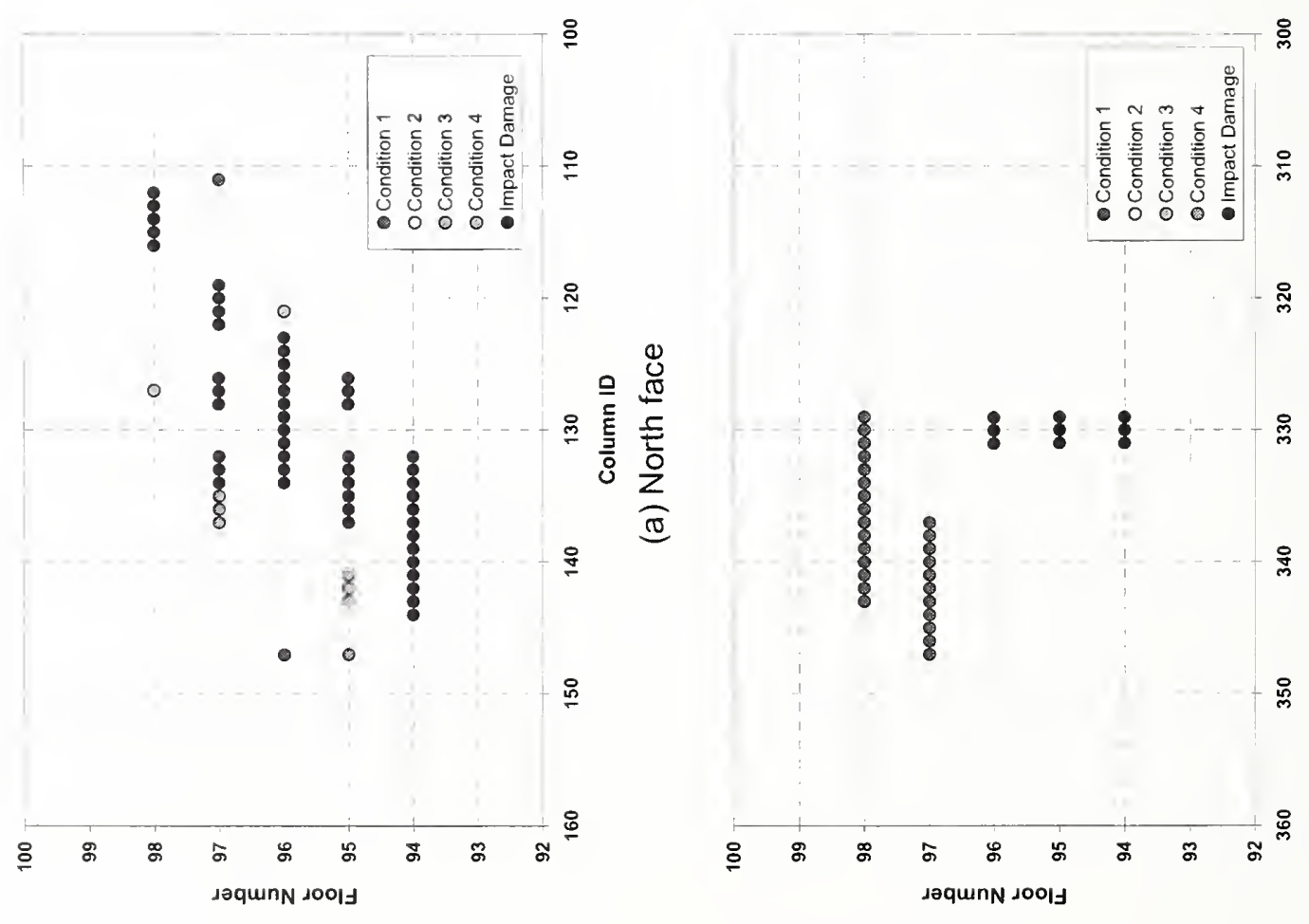

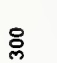

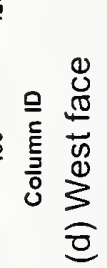

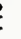

8

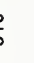

ฆ

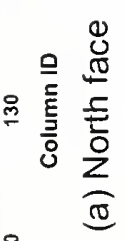

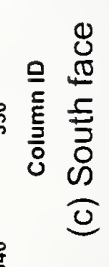

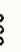

竞

응응

은

돈

ه

$\sum_{0}^{\infty}$

$\stackrel{n}{\frac{n}{5}}$

列

$\stackrel{8}{\circ}$

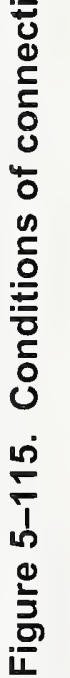



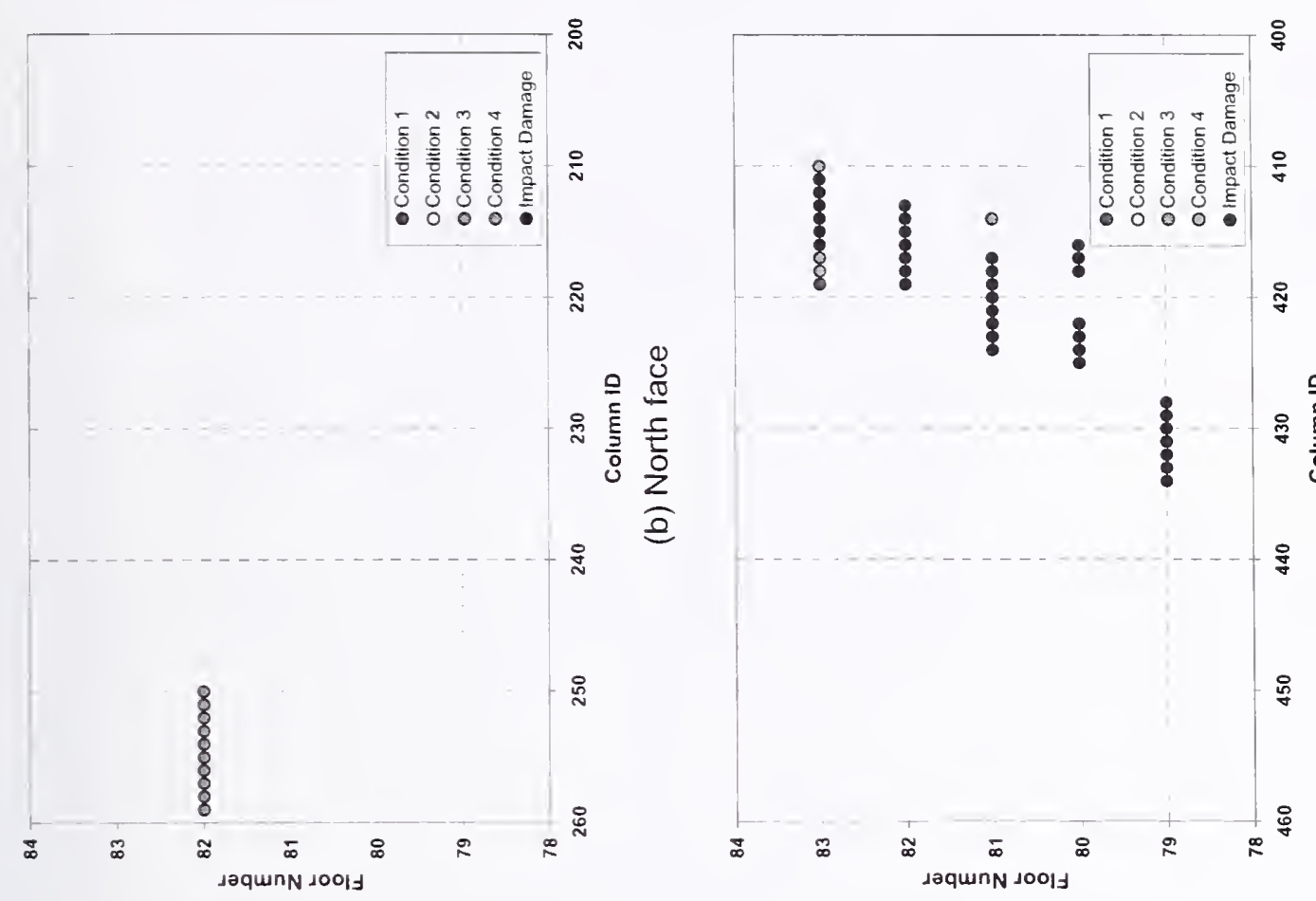


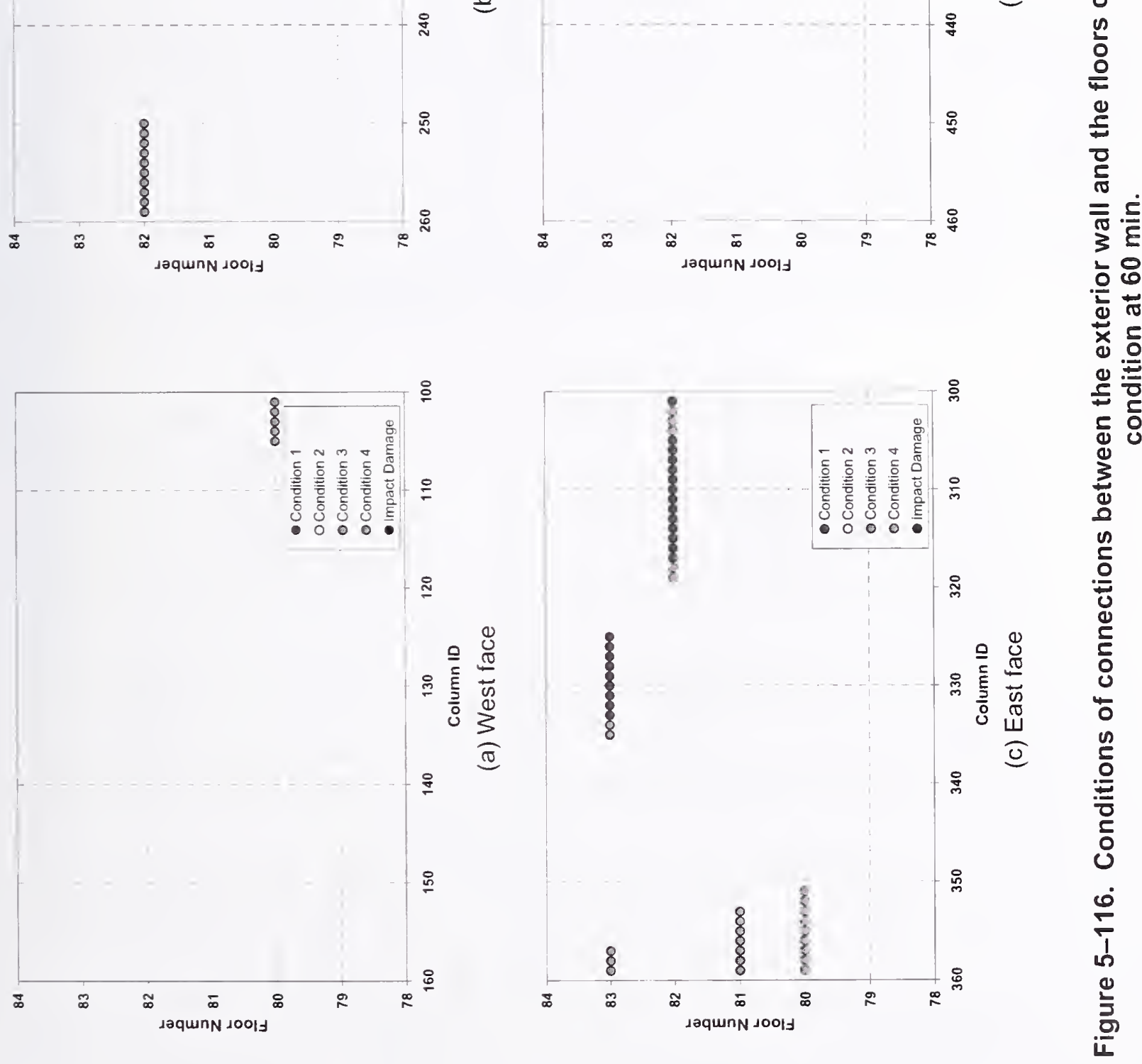

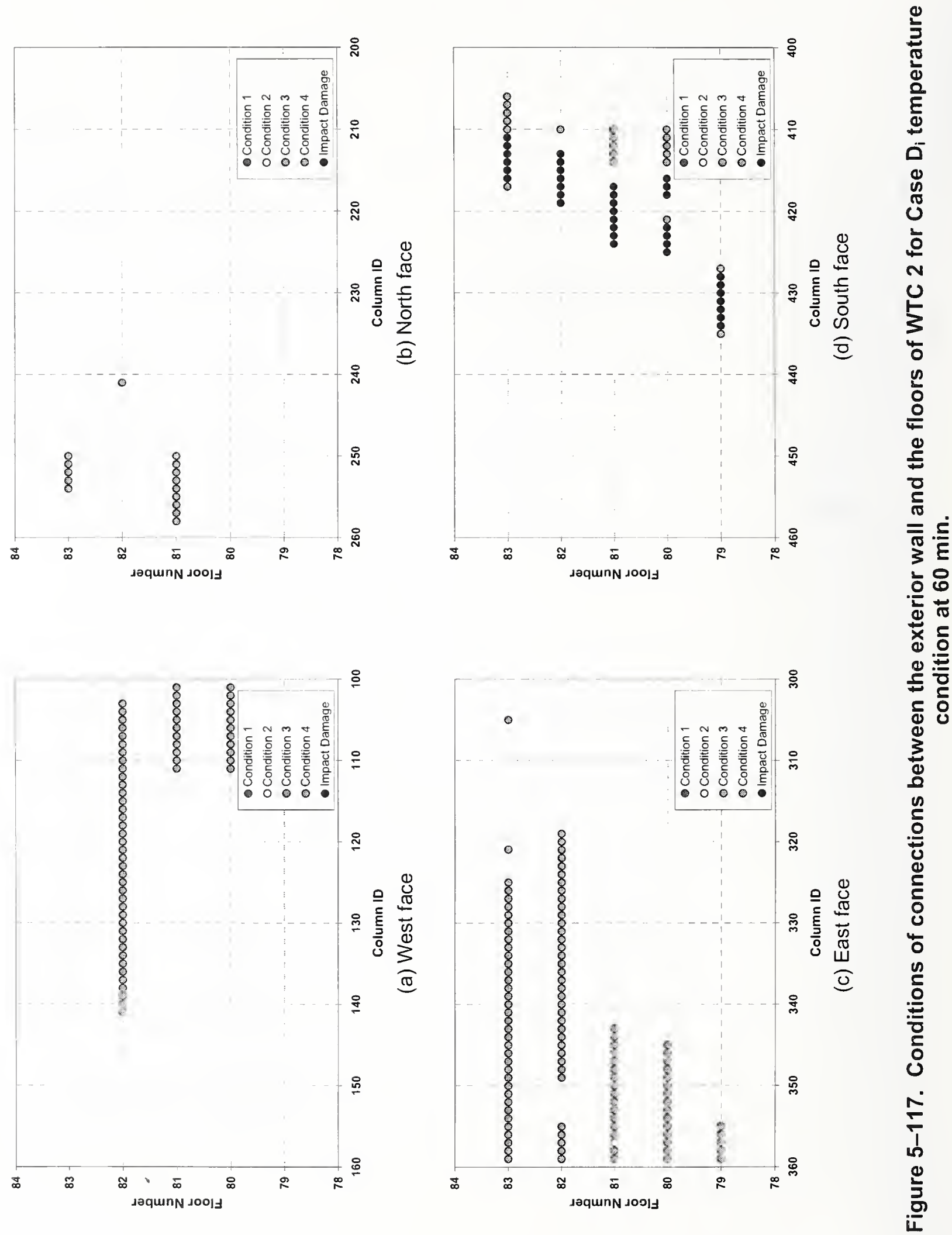


\subsubsection{Summary of Results and Discussion}

The behaviors of the floor system found in the full floor models subjected to impact damage and elevated temperatures from the fires can be summarized as follows:

Bridging trusses subjected to elevated temperatures buckled between primary trusses.

When significant differences in thermal expansion of the floors and exterior walls in the direction transverse to the axes of primary trusses occurred near the corners, studs, diagonal strap anchors, gusset plates, and seat bolts at exterior truss seats failed due to the lateral shear.

Web diagonals of floor trusses with damaged insulation buckled.

Floors sagged as they lost bending stiffness resulting from web diagonal buckling, and they pulled the exterior wall in.

Truss seats disconnected from the exterior walls.

Pull-in forces were expected to develop whenever the floor sagged. Although the floor sagging was captured by the floor models in the heated area, the pull-in force on the exterior columns was not captured in most of the full floor model analyses. To accurately calculate pull-in forces between the floors and the exterior columns in the full floor model, much more detailed modeling will be required. Such modeling includes accurate boundary conditions on columns, creep in steel, friction at the truss seats, accurate evaluation of failure of strap anchors and studs, and concrete cracking and spalling. In addition, temperature time histories that were used in the full floor model analyses may have been conservative estimates, which were derived from conservative estimates of impact damage to the insulation. Further discussion on the pull-in force can be found in Section 2.5.2 of NIST NCSTAR1-6D. 
This page intentionally left blank. 


\section{Chapter 6 \\ EXTERIOR WALL SUBSYSTEM}

\subsection{OBJECTIVE}

The objective of the exterior wall subsystem model was to study the performance of the exterior wall subjected to the combined effects of gravity and thermal loads for the following conditions:

- all floors provide lateral support,

- two adjacent floors do not provide lateral support,

- three adjacent floors do not provide lateral support,

- in addition to loss of lateral support at three floors, the exterior wall is subjected to pull-in forces by the sagging floors, and

- in addition to loss of lateral support at three floors, the exterior wall is subjected to additional gravity loads.

The following temperature-dependent nonlinearities and material properties were included in the extcrior wall model:

- Large deflections and buckling

- Material plasticity

- Creep

- Material failure

- Column splice failure

- Spandrel splice failure

\subsection{EXTERIOR WALL SUBSYSTEM DESCRIPTION}

The exterior walls of the towers were constructed with prefabricated wall panels, rcferred to hcreafter as panels. Typical panels contained three-column segments spanning three stories with three spandrcls extending one half-span past the outer columns. The panels werc arranged such that the spandrel splices between panels aligned vertically, and the column splices between panels were offsct by one story.

The modeled exterior wall subsystem was located on the north face of WTC 1 toward the east side and included nine columns, extending vertically from the column splice located below Floor 91 to the column splice above Floor 99, and nine spandrels extending horizontally from the spandrel splice betwecn

Columns 149 and 150 to the spandrel splice between Columns 158 and 159. This exterior wall subsystem model included seven full panels and portions of four other panels.

Figure 6-1 shows the subsystem pictorially. Figures 6-2 (a) and 6-2 (b) give the types and yicld strengths of the columns and spandrels and the types of column and spandrel splices. Figure 6-3 shows the column plate notation used. Tables 6-la through 6-1c give the geometry and material properties of the plates in the columns, the spandrels, and the column and spandrel splices. 


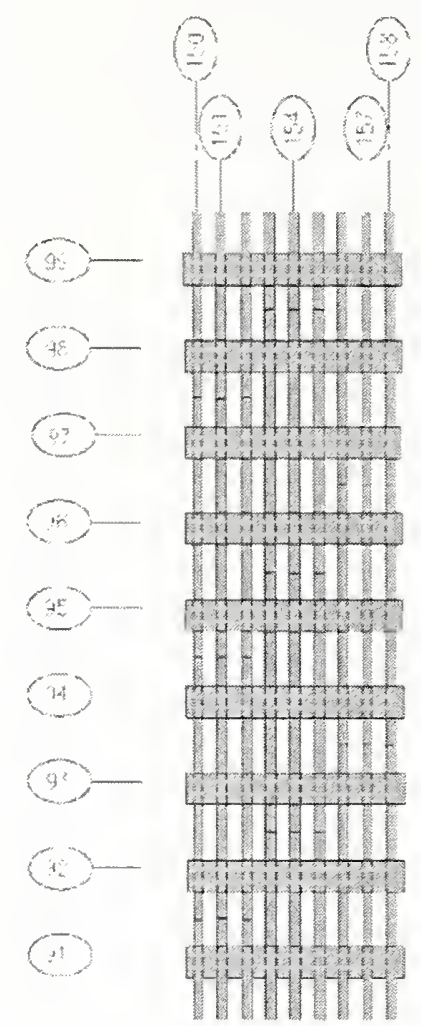

Figure 6-1. Exterior wall subsystem structure.

The odd-numbered columns supported the floor trusses. Pairs of strap anchors extended diagonally from the top chords of truss pairs to the even-numbered columns. The trusses and the strap anchors partially braced the columns both in-plane and out-of-plane of the exterior wall. 


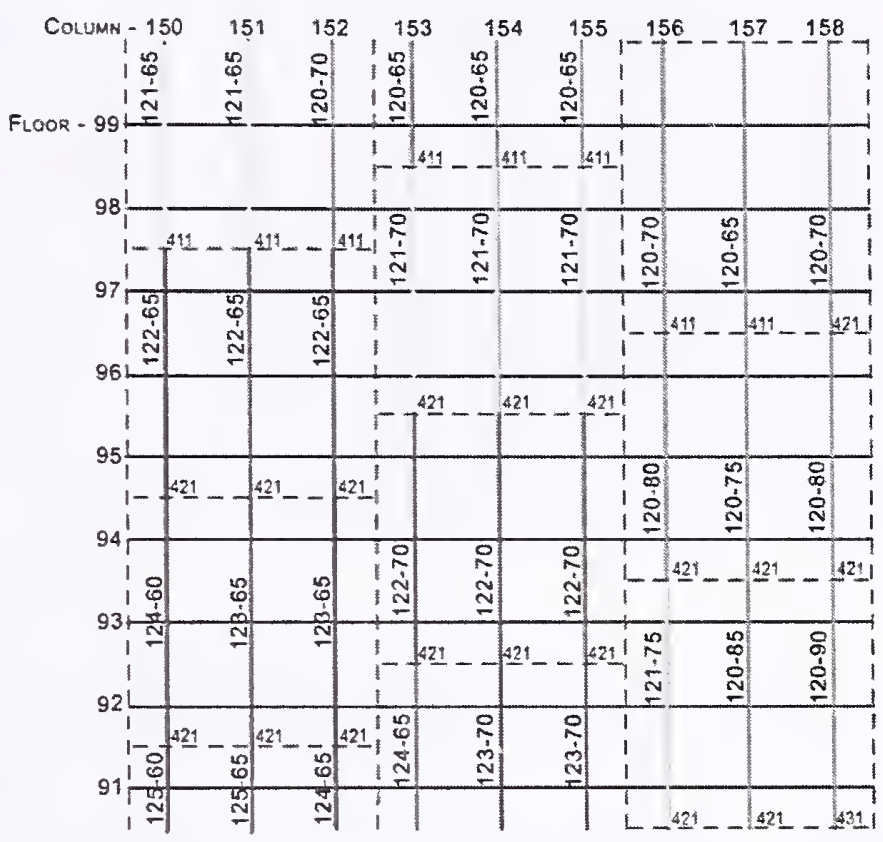

$X X X-X X$ indicates type and nominal yield strength of column (ksi) $x x x$ indicates type of colum splice

(a) Columns and column splices

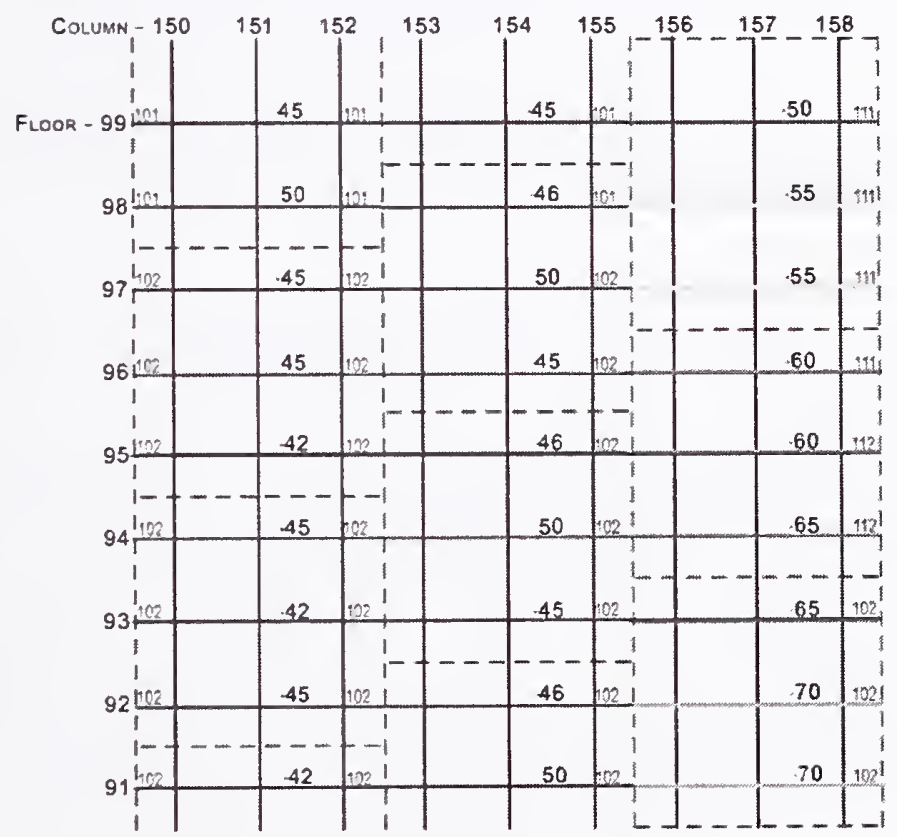

$X X$ indicates nominal yield strength of spandrel $(\mathrm{ksi})$ $x x x$ indicated type of spandrel splice Spandrel thickness is $3 / 8$ in.

(b) Spandrels and spandrel splices

Figure 6-2. Columns, spandrels, and splices: type and material assignments. 


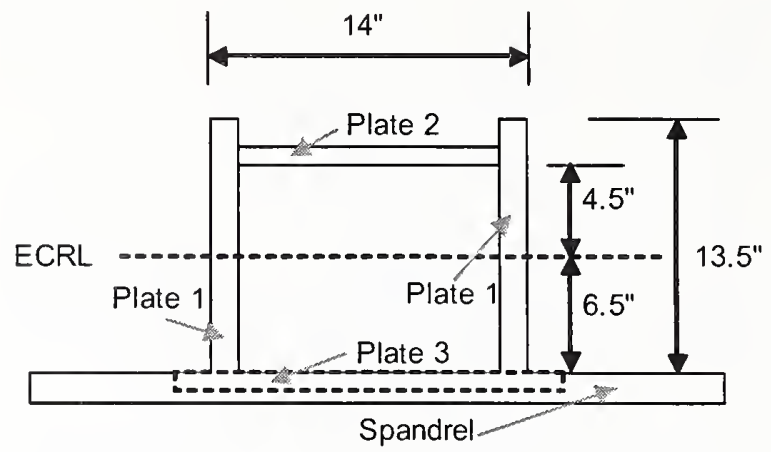

Figure 6-3. Schematic of column cross section.

Table 6-1a. Column sectional properties.

\begin{tabular}{|c|c|c|c|}
\hline $\begin{array}{c}\text { Column } \\
\text { Type }\end{array}$ & $\begin{array}{c}\text { Plate } \mathbf{1} \\
\mathbf{I} \text { t } \\
\text { (in. } \times \text { in.) }\end{array}$ & $\begin{array}{c}\text { Plate 2 } \\
\mathbf{I} \text { t } \\
\text { (in. } \times \text { in.) }\end{array}$ & $\begin{array}{c}\text { Plate 3. } \\
\mathbf{I} \times \mathbf{~ t ~} \\
\text { (in. } \times \text { in.) }\end{array}$ \\
\hline 120 & $13.5 \times 0.25$ & $13.5 \times 0.25$ & $15.75 \times 0.25$ \\
\hline 121 & $13.5 \times 0.3125$ & $13.375 \times 0.25$ & $15.75 \times 0.25$ \\
\hline 122 & $13.5 \times 0.375$ & $13.25 \times 0.25$ & $15.75 \times 0.25$ \\
\hline 123 & $13.5 \times 0.4375$ & $13.125 \times 0.25$ & $15.75 \times 0.25$ \\
\hline 124 & $13.5 \times 0.5$ & $13 \times 0.25$ & $15.75 \times 0.25$ \\
\hline 125 & $13.5 \times 0.5625$ & $12.875 \times 0.25$ & $15.75 \times 0.25$ \\
\hline
\end{tabular}

${ }^{1}$ All spandrels in model are 52 in. deep $\times 3 / 8$ in. thick.

Table 6-1b. Column splice details.

\begin{tabular}{|c|c|c|c|c|c|c|}
\hline $\begin{array}{c}\text { Column } \\
\text { Splice Type }\end{array}$ & $\begin{array}{c}\text { Butt Plate } \\
\text { Thickness } \\
\text { (in.) }\end{array}$ & $\begin{array}{c}\text { Number } \\
\text { of Bolts }\end{array}$ & $\begin{array}{c}\text { Bolt Diameter } \\
\text { (in.) }\end{array}$ & $\begin{array}{c}\text { Gage } \\
\text { (in.) }\end{array}$ & $\begin{array}{c}\text { Bolt Spacing } \\
\text { (in.) }\end{array}$ & $\begin{array}{c}\text { Column } \\
\text { Splice ID }\end{array}$ \\
\hline 411 & 1.375 & 4 & 0.875 & 3.5 & 6 & 411 \\
\hline 421 & 1.625 & 4 & 0.875 & 3.5 & 6 & 421 \\
\hline 431 & 1.875 & 4 & 1 & 3.5 & 6 & 431 \\
\hline
\end{tabular}

${ }^{1}$ Butt plates have specified yield strength of $50 \mathrm{ksi}$.

${ }^{2}$ Bolts are A325. 
Table 6-1c. Spandrel splice details.

\begin{tabular}{|c|c|c|c|c|c|c|c|c|}
\hline $\begin{array}{c}\text { Spandrel } \\
\text { Splice } \\
\text { Type }\end{array}$ & $\begin{array}{c}\text { Number } \\
\text { of } \\
\text { Bolts/Row }\end{array}$ & $\begin{array}{c}\text { Total } \\
\text { Number } \\
\text { of Rows }\end{array}$ & $\begin{array}{c}\text { Bolt } \\
\text { Spacing } \\
\text { (in.) }\end{array}$ & $\begin{array}{c}\text { Gage } \\
\text { (in.) }\end{array}$ & $\begin{array}{c}\text { Overall Splice } \\
\text { Plate } \\
\text { Dimensions } \\
\text { (in. } x \text { in. } x \text { in.) }\end{array}$ & $\begin{array}{c}\text { Bolt to } \\
\text { Centerline } \\
\text { of Splice } \\
\text { (in.) }\end{array}$ & $\begin{array}{c}\text { Gap B/W } \\
\text { Spandrels } \\
\text { (in.) }\end{array}$ & $\begin{array}{c}\text { Spandrel } \\
\text { Splice } \\
\text { ID }\end{array}$ \\
\hline 101 & 6 & 2 & $5 @ 9$ & & $49 \times 6.75 \times .25$ & 1.875 & 0.75 & 101 \\
\hline 102 & 8 & 2 & $3.6 .3 @ 9.6 .3$ & & $49 \times 6.75 \times .25$ & 1.875 & 0.75 & 102 \\
\hline 111 & 6 & 4 & $5 @ 9$ & 3 & $49 \times 12.75 \times .25$ & 1.875 & 0.75 & 111 \\
\hline 112 & 8 & 4 & $3,6,3 @ 9.6 .3$ & 3 & $49 \times 12.75 \times .25$ & 1.875 & 0.75 & 112 \\
\hline
\end{tabular}

${ }^{1}$ All spandrel splices use 7/8 in. A325 bolts; specified spandrel splice plate yield strength is $36 \mathrm{ksi}$.

${ }^{2}$ Holes in spandrel are 1/4 in. larger than bolts; holes in plates are bolt $+1 / 16$ in. or option to match spandrel holes.

\subsection{FAILURE MODES}

The exterior wall subsystem model can capture the following failure modes:

- Column buckling from large lateral deformations,

- Column buckling from loss of support at floor truss seats and strap anchors,

- Failure of column splice bolts, and

- Failure of spandrel splice bolts or tearing of spandrel or splice plates at bolt holes.

The model does not capture the local buckling of column plates or the formation of plastic hinges (kinking) from the interaction of local plate buckling and general stability of the column when subjected to combined axial load and bending moments.

Several of the later analyses did not include the effects of creep. Displacement control analysis in ANSYS did not function properly when strain rate effects of creep were included.

\subsection{MODEL VALIDATION}

\subsubsection{Description of Models}

Validation of the exterior wall model was performed by comparing the stiffness of an ANSYS model of a single exterior wall panel with beam and shell elements to a SAP2000 shell model of the same panel developed by Leslie E. Robertson Associates under a contract from NIST.

Figure 6-4 shows the SAP2000 shell model of a typical prefabricated panel at Floors 79 to 82 provided by NIST. The model was modified as follows:

1. Eliminated self-weight from loading conditions.

2. Provided a stiff member at the top of the columns.

3. Added out-of-plane wall supports (UY) at the top of the columns for stability under out-ofplane loading.

Figure 6-5 shows the ANSYS prefabricated panel model. BEAM189 elements modeled the columns, SHELL181 elements modeled the spandrels, and BEAM4 elements connected nodes on the axis of the columns to nodes located in the mid-plane of the spandrels. 
Figure 6-6 shows the various boundary conditions. Out of plane displacement (UY) was restrained at the tops of the columns. All three directions of translation were restrained at the bottoms of the columns. The spandrels were free at the boundaries of the model.

Both models were subjected to three loading cases at room temperature, as shown in Fig. 6-6:

1. A vertical force (FZ) at the top of one of the outside columns.

2. A horizontal force in the plane of the wall (FX) at the top of one of the outside columns. The stiff members described previously distributed this shear load evenly to the tops of all three columns.

3. A transverse force (FY) on the middle column at Floor 81 (middle floor).

The loads described above did not include self-weight.

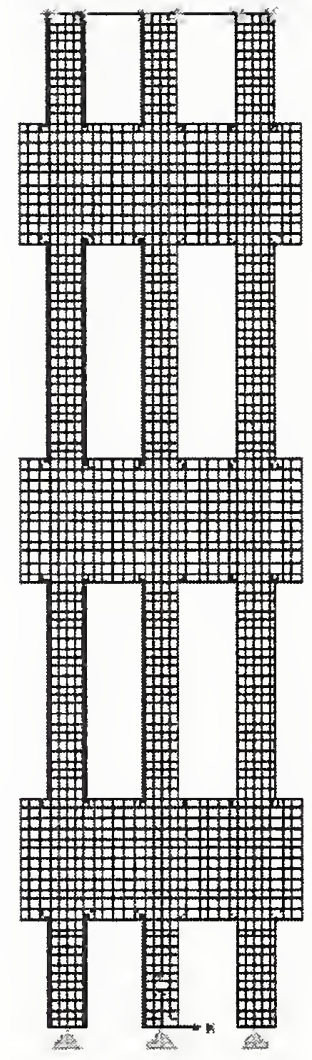

Figure 6-4. SAP2000 model of prefabricated panel. 


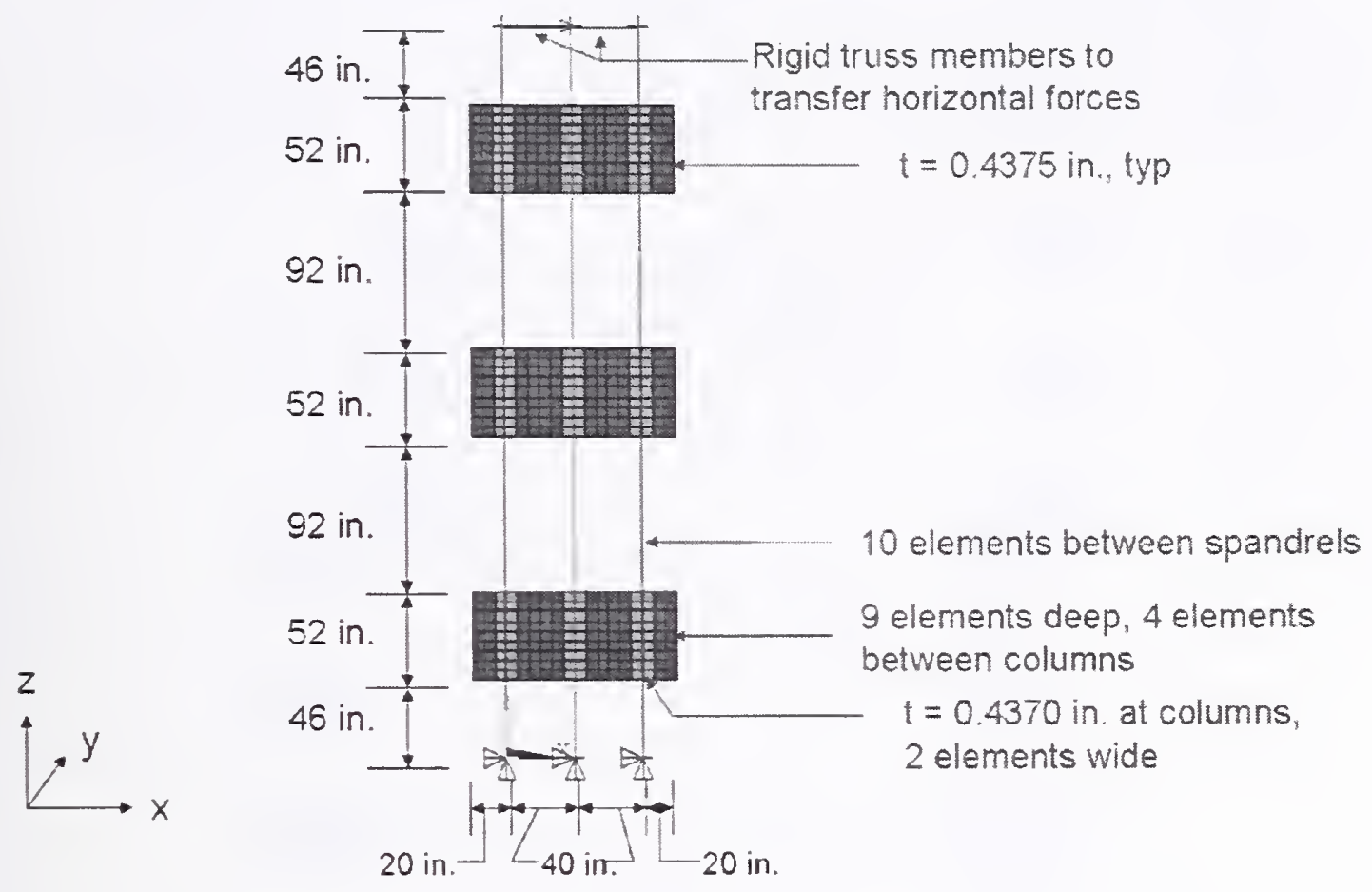

Figure 6-5. ANSYS model of prefabricated panel showing meshing.

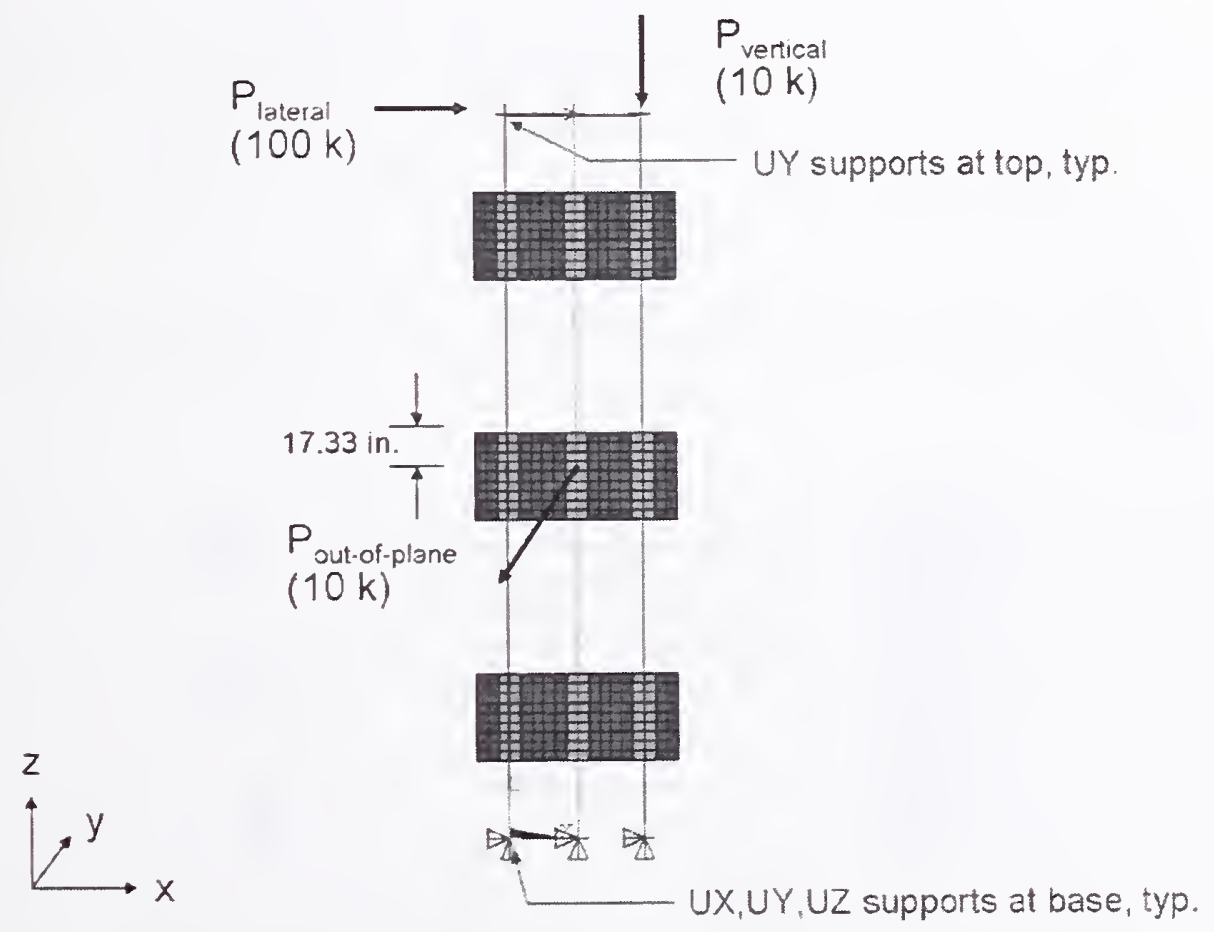

Figure 6-6. ANSYS model of prefabricated panel showing boundary conditions and loading (loads applied separately). 


\subsubsection{Validation Results}

Figures 6-7 through 6-9 show deflected shapes and indicate the displacement at the points of applied load for the SAP2000 and ANSYS models. Table 6-2 summarizes the differences in reactions and displacements between the SAP2000 and ANSYS models. The table indicates that these differences were small.

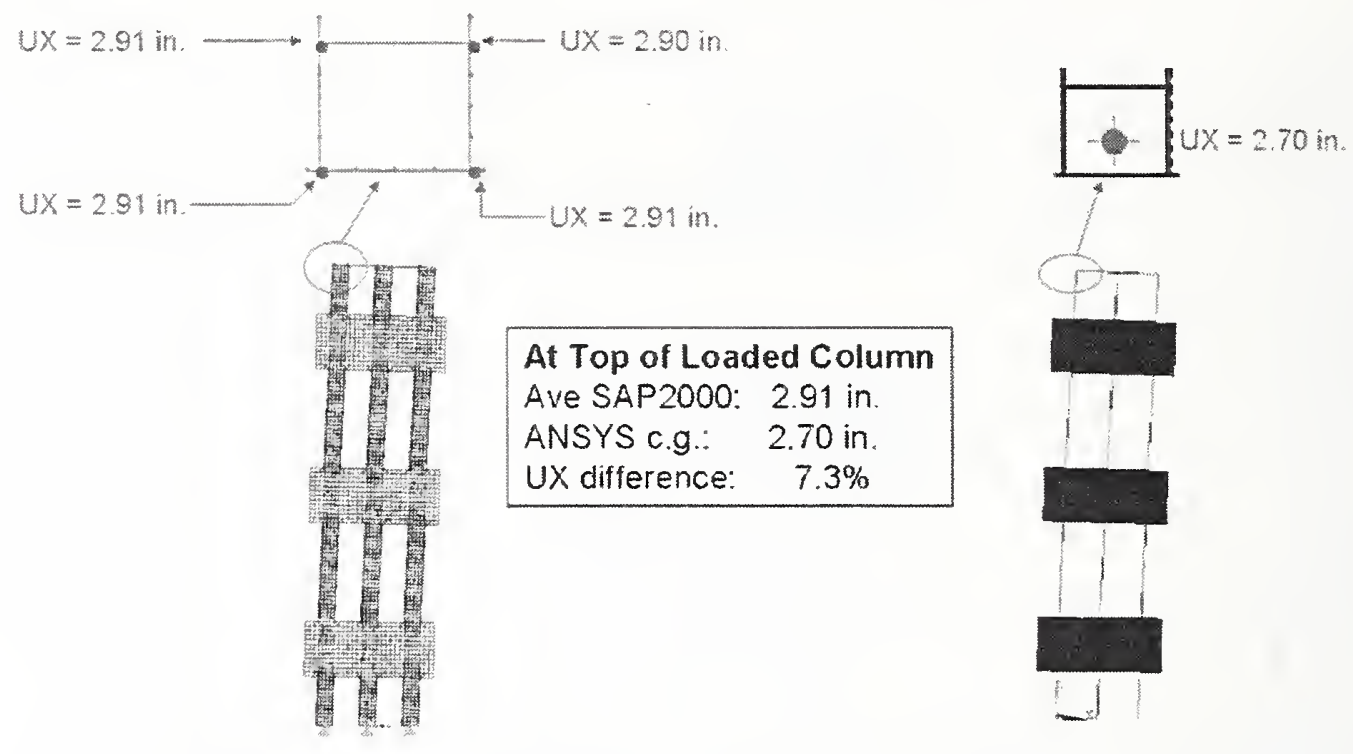

SAP2000 Deflected Shape

ANSYS Deflected Shape

Figure 6-7. Deflection of prefabricated panel under 100 kip lateral load.

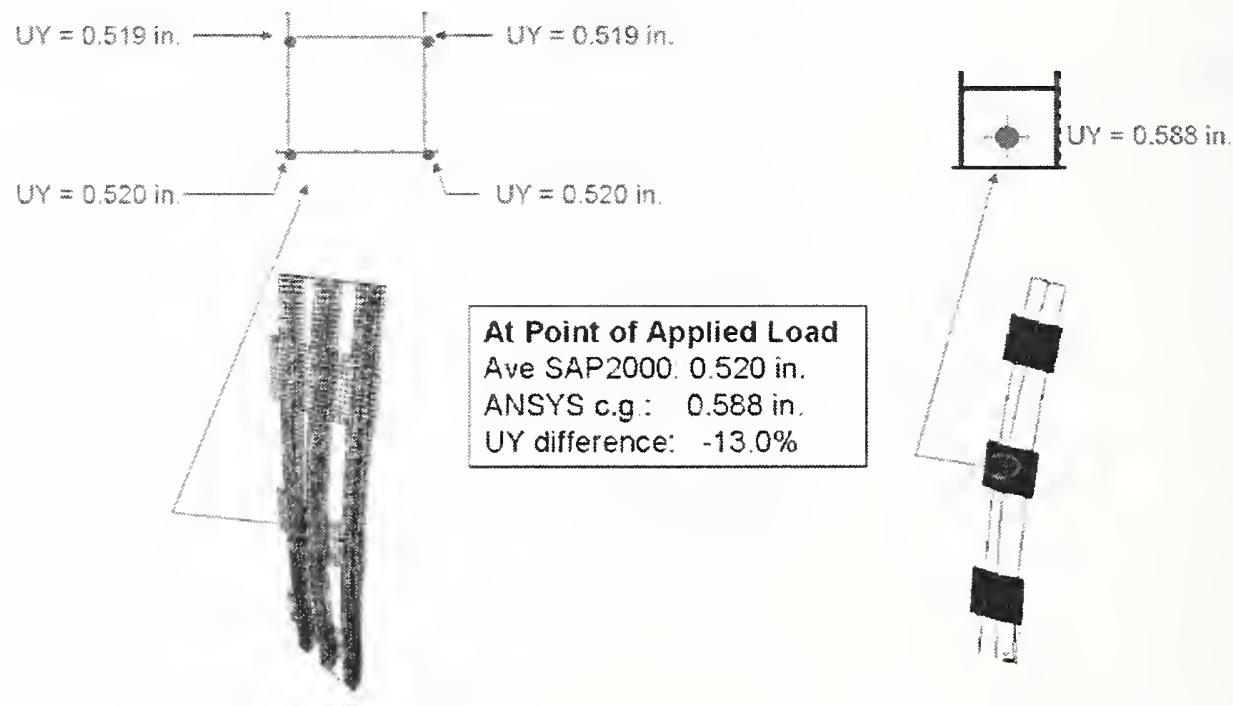

SAP2000 Deflected Shape

ANSYS Deflected Shape

Figure 6-8. Deflection of prefabricated panel under 100 kip transverse load. 


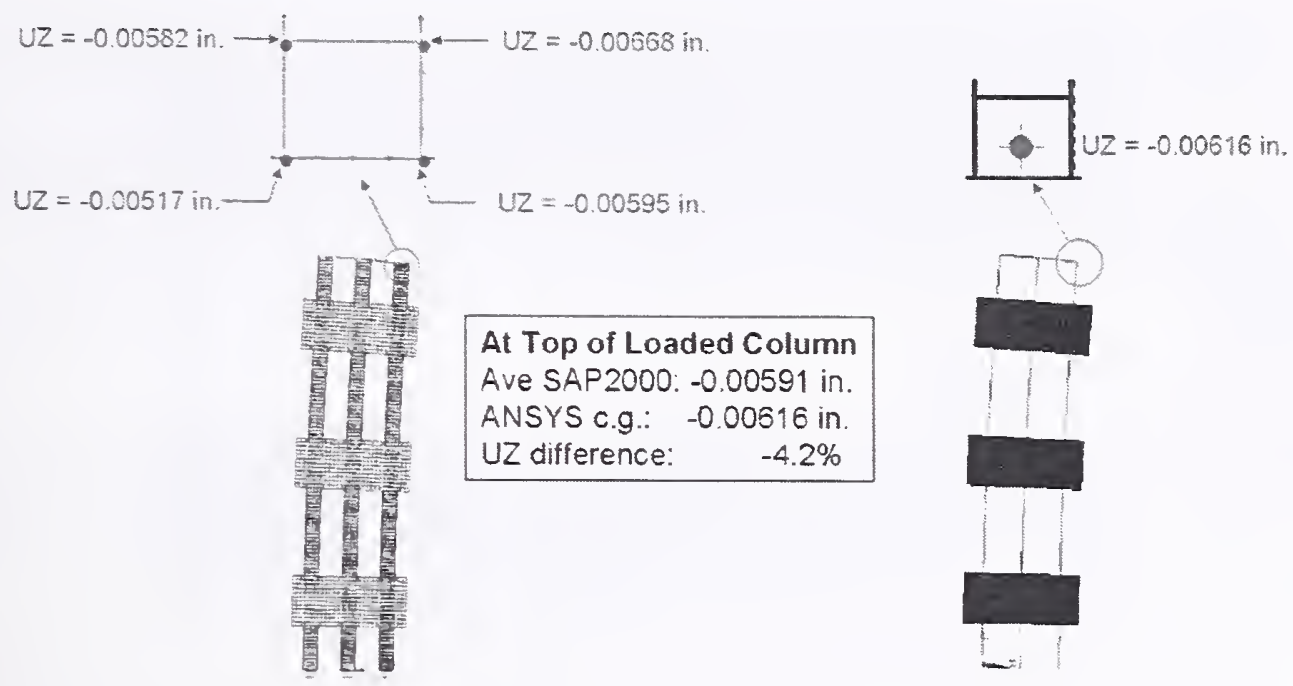

SAP2000 Deflected Shape

ANSYS Deflected Shape

Figure 6-9. Deflection of prefabricated panel under 10 kip vertical load.

Table 6-2. Prefabricated panel validation results.

\begin{tabular}{|c|c|c|}
\hline \multirow{2}{*}{ Loading Condition } & \multicolumn{2}{|c|}{ SAP2000/ANSYS Difference Range } \\
\cline { 2 - 3 } & Reactions $^{1}$ & Displacements \\
\hline Lateral FX & RX: $-2 \%$ to $+1 \%$ & UX: $7 \%$ \\
\hline Transverse FY & RY: $-6 \%$ to $+7 \%$ & UY: $-13 \%$ \\
\hline Vertical FZ & RZ: $-1 \%$ to $+2 \%$ & UZ: $-7 \%$ \\
\hline
\end{tabular}

${ }^{1}$ Range considers maximum disparities between results for all support reactions.

${ }^{2}$ Displacements considered at tops of columns for FX and FZ, and at points of load application for FY.

\subsection{FINITE-ELEMENT MODEL OF EXTERIOR WALL SUBSYSTEM}

\subsubsection{Elements and Meshing}

Figure 6-10 shows the model in elevation. BEAM189 elements modeled the columns. Above and below spandrels, BEAM189 elements modeled the complete cross sections of the columns. At spandrels, BEAM189 elements modeled cross sections where the interior plate thickness of the column was reduced to $0.005 \mathrm{in}$. to maintain a closed section yet allowed for a continuous spandrel. Since neutral axis location of column shifted in the column elements in the spandrel zone, MPC184 rigid elements were used to connect the neutral axes of column elements where this shift occurred. SHELL181 elements modeled the spandrels. Figure 6-11 shows the number of elements used to model columns and spandrels. BEAM4 elements connected nodes on the axis of the columns to nodes located in the mid-plane of the spandrels. Figure 6-12 shows this use of the BEAM4 elements.

BEAM4 elements are two-node Euler (elastic) elements with large deflection capability. BEAM189 elements are three-node (quadratic) Timoshenko beam elements with large deflection, plasticity, and creep capabilities. SHELL181 elements are four-node multi-layer elements with large deflection, 
plasticity, and creep capabilities. MPC184 elements are multipoint constraint elements that implement kinematic constraints using Lagrange multipliers. These element types and their features are summarized in Table 4-1.

Material IDs, as described in Chapter 3, were assigned to the elements. The properties (e.g. stiffness) and behavior (e.g. plasticity) of the elements vary with temperature as the assigned material properties vary with temperature.

\subsubsection{Boundary Conditions}

The bottoms of all columns in the model were restrained in the vertical direction. The top and the bottom of all columns in the model were restrained in the direction normal to the wall. In addition, the bottom of central Column 154 was restrained in the in-plane horizontal direction. Symmetry boundary conditions were imposed on the spandrels at the boundaries of the model, except that the spandrels were free to expand in the plane of the wall. Motion out of the plane of the wall was restrained at all floor truss seats and strap anchors. In several analyses, such restraints were removed at two or three floors (either Floors 95 and 96 or Floors 95, 96, and 97) to investigate the effect of floor sagging and floor/wall disconnection on stability of the exterior wall system.

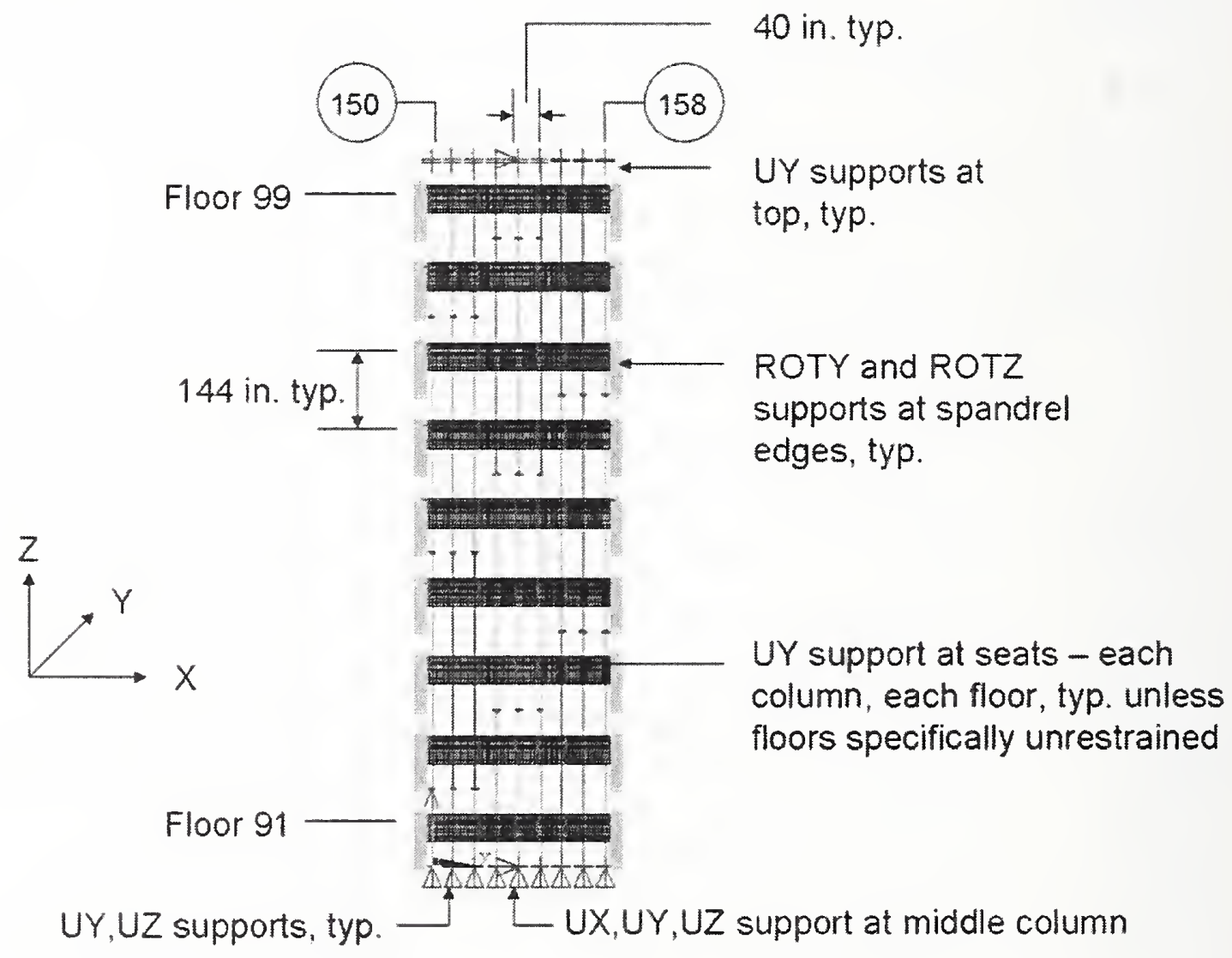

Figure 6-10. Exterior wall subsystem model with boundary conditions. 


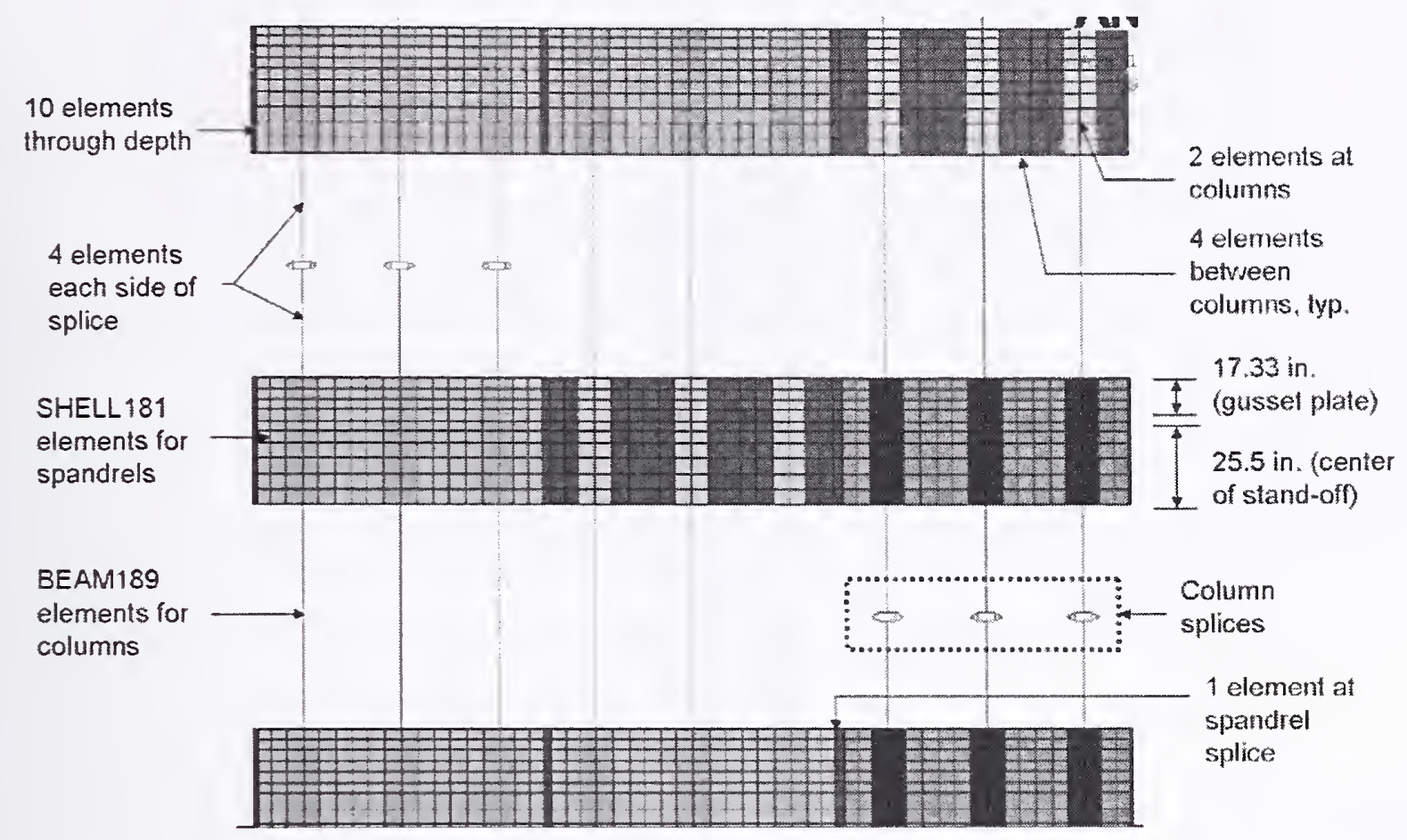

Figure 6-11. Typical meshing of exterior wall model components.
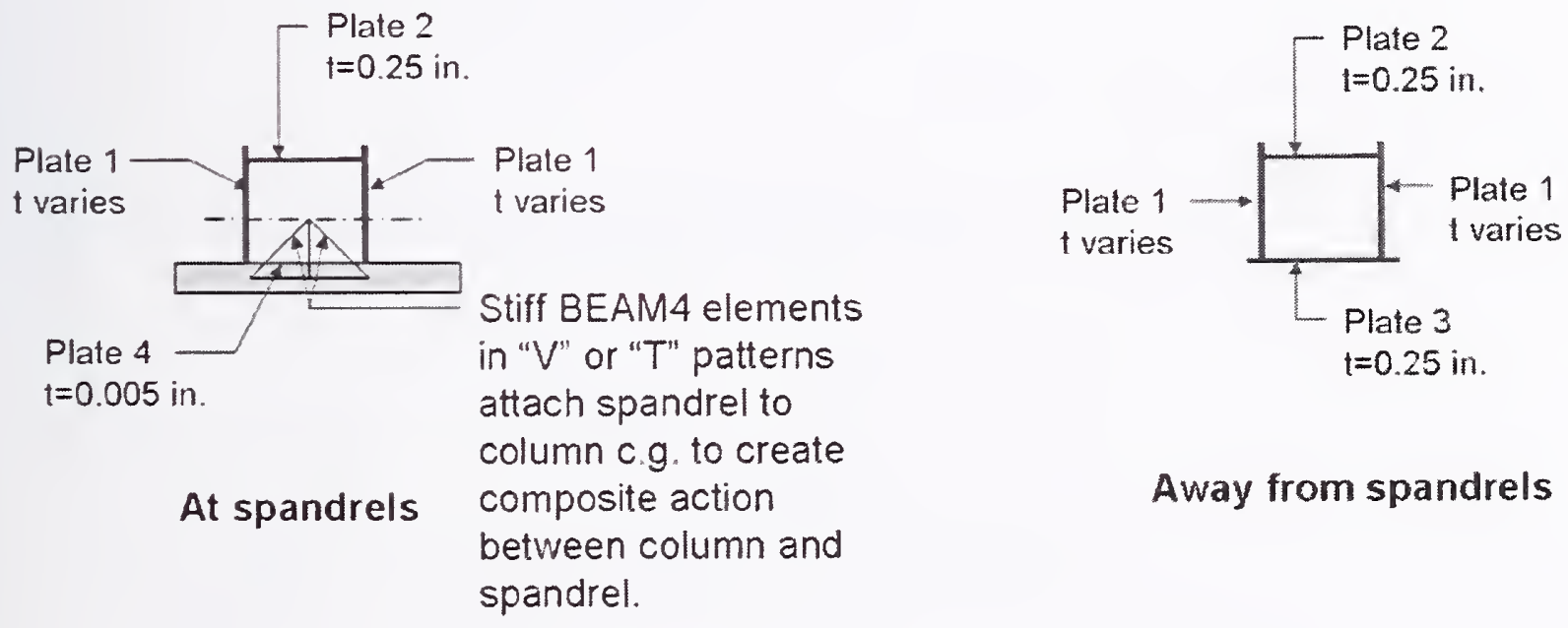

Figure 6-12. Schematic representation of columns used in the exterior wall model. 


\subsubsection{One-, Two-, and Three-Story High Columns}

Figure 6-13 shows the model of a one-story high exterior column. The model included a one-story high portion of Column 151 extending from Floor 95 to Floor 96 and portions of spandrels at Floor 95 and Floor 96. The model also represented Column 151 from Floor 96 to Floor 97 since the dimensions, plate thicknesses, and material properties were identical to those of Column 151 from Floor 95 to 96.

SHELL1 81 plate elements modeled the plates of columns and spandrels. CERIG rigid elements connected the center of gravity of the column to its component plates and to the spandrel at both the top and the bottom of the model. The column was pinned at the bottom and restrained in the two horizontal directions at the top. Axial displacement was applied incrementally at the top of the model.

Figure 6-14 shows the variation of axial load with the imposed axial displacement and the resulting lateral deflection at room temperature (RT) and $700{ }^{\circ} \mathrm{C}$. This figure also shows the hand calculated theoretical column load levels at room temperature (RT) and $700{ }^{\circ} \mathrm{C}$ for:

1. Local buckling of Plate 2 and Plate 3.

2. Uniform yielding of the column.

3. Axial load demand due to gravity dead and live loads at Floor 96.

Figure 6-15 shows the local bucking deformation of Plate 2 and Plate 3 at the maximum load at room temperature. Figure 6-16 shows a plastic hinge at mid-height of the column for an imposed axial displacement of 2 in. Figure 6-17 shows local buckling in Plate 2 and Plate 3 at maximum load at $700{ }^{\circ} \mathrm{C}$.

Figure 6-14 shows that at room temperature Plate 2 and Plate 3 buckle locally at a load that is less than the maximum column load, but at $700{ }^{\circ} \mathrm{C}$ the column yields before it buckles locally. This figure also shows that the expected column demand load of $175 \mathrm{kip}$ is substantially lower than the local buckling load at room temperature and the column yield load at $700{ }^{\circ} \mathrm{C}$.

At room temperature, the load-carrying capacity in the post-buckling regime decreased rapidly; however, it decreased much more gradually at $700{ }^{\circ} \mathrm{C}$.

Axial load-displacement behaviors of two- and three-story models were also examined, and the results are shown in Fig. 6-14. As the unsupported length became longer and the temperature became higher, the negative slope of the axial load-deflection curve in the post-buckling regime became less steep. 


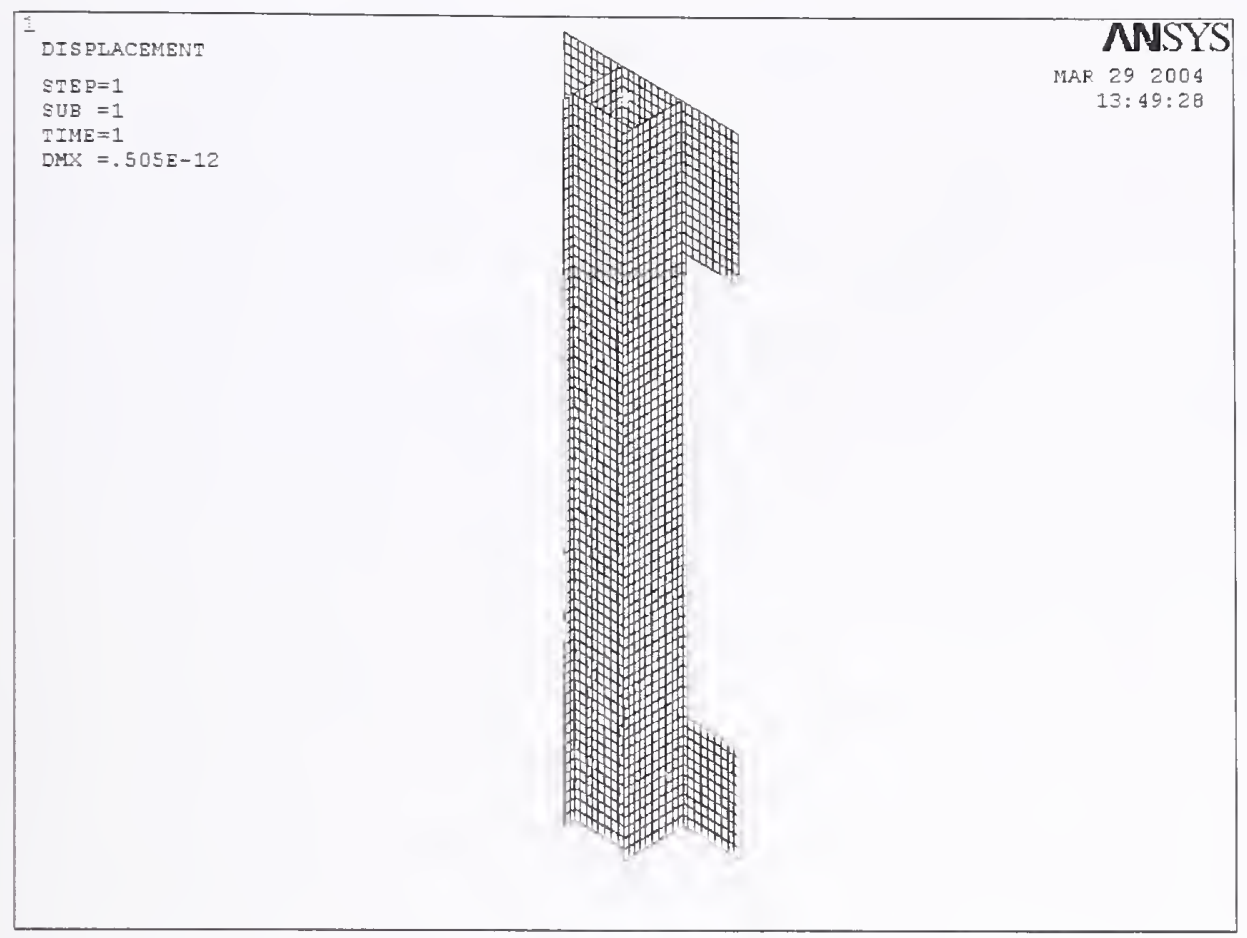

Figure 6-13. One-story exterior column model.

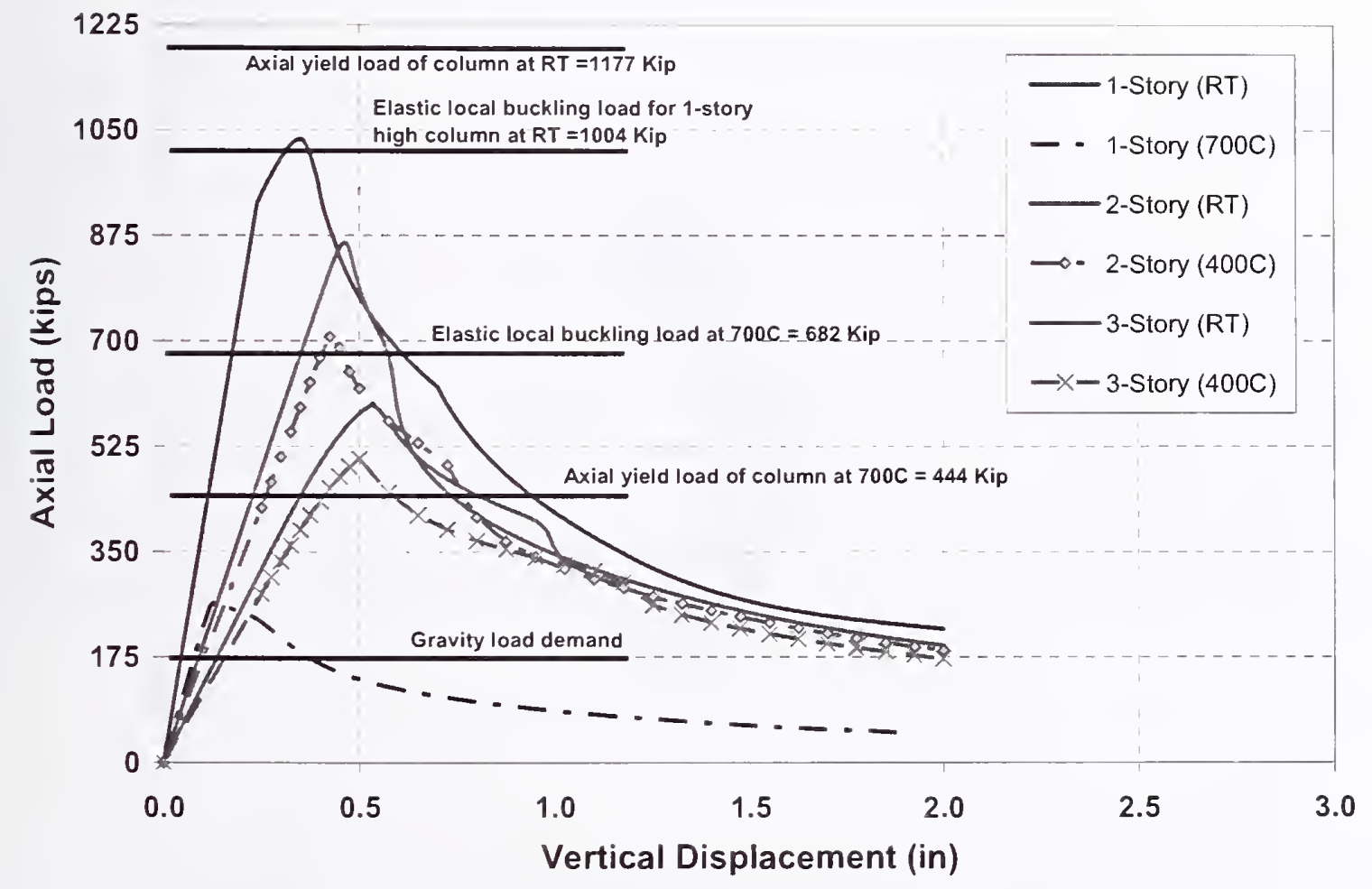

Figure 6-14. Load-deflection of column at room temperature and $700{ }^{\circ} \mathrm{C}$. 


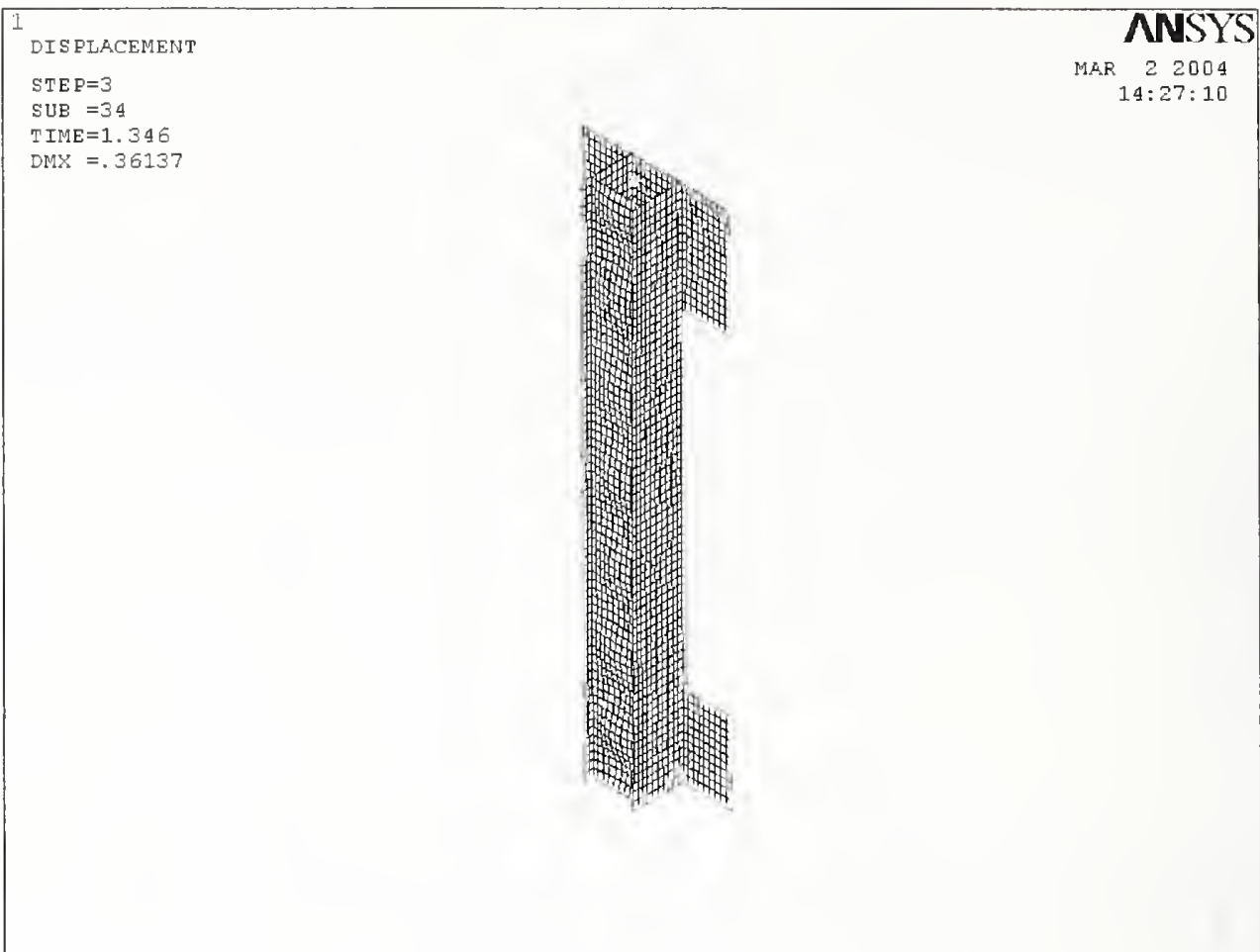

Figure 6-15. Local buckling of column at room temperature.

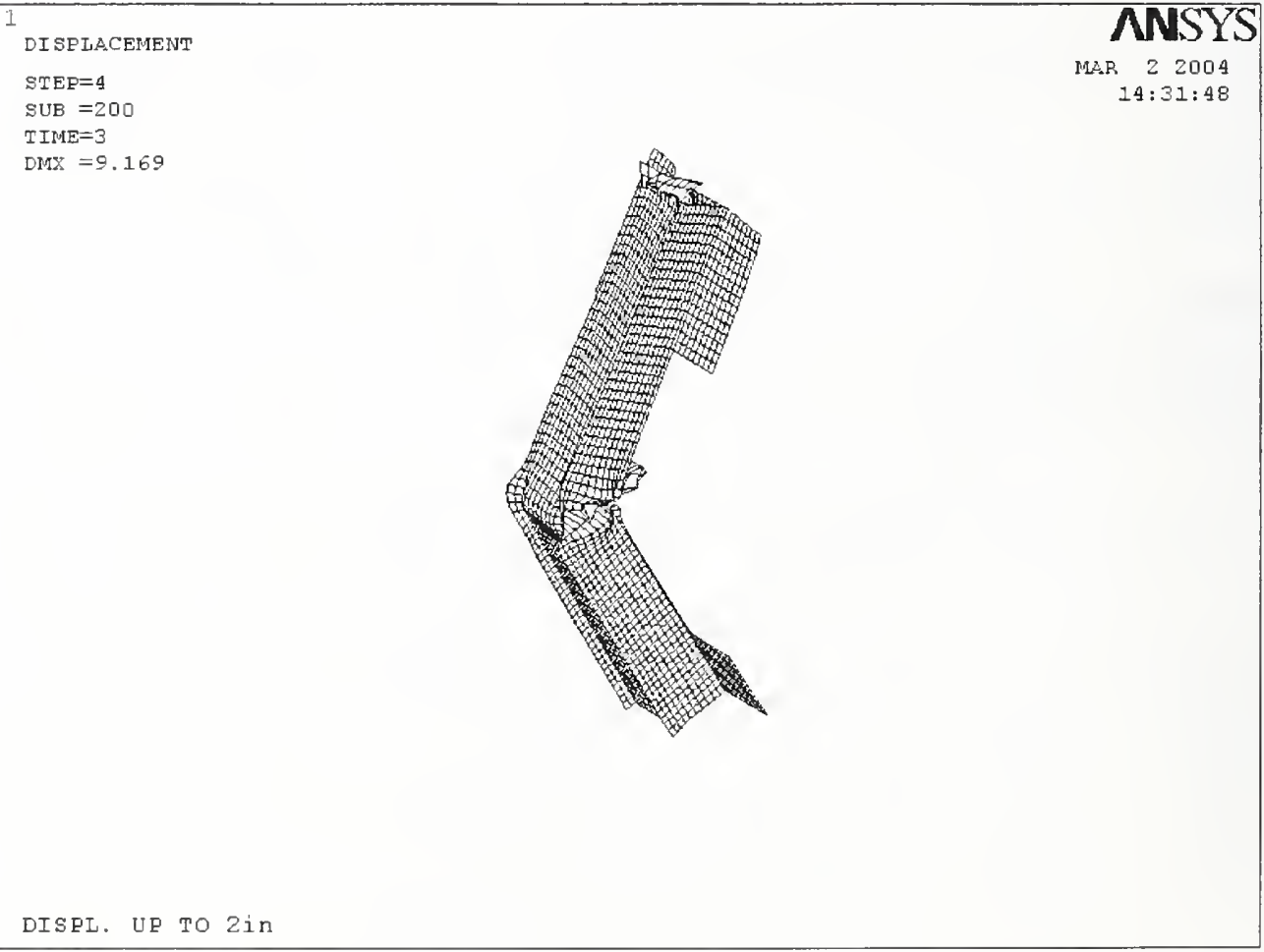

Figure 6-16. Plastic hinge in column at room temperature. 


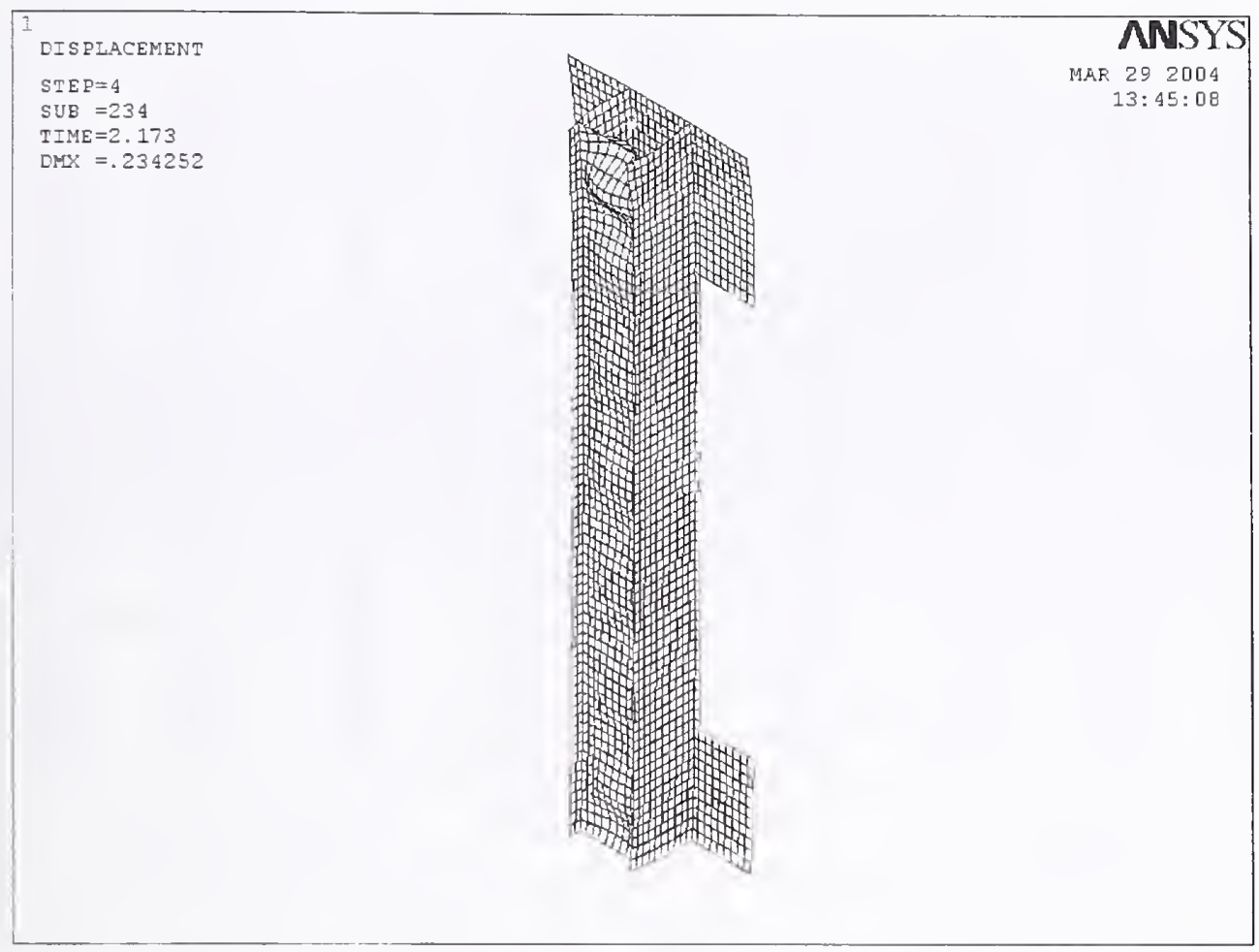

Figure 6-17. Deformed shape of column at maximum axial load at $700^{\circ} \mathrm{C}$.

\subsubsection{Spandrel Splices}

Figure 6-18 shows the typical layout of the spandrel splices in the model. User-defined break clcments were used to model the interior spandrel splice connections, and nodal couples were used to model the exterior spandrel splice connections. An interior spandrel splice occurs between Columns 150 and 158, and an exterior spandrel splice occurs at the edges of the model outside of Columns 150 and 158. Figure 6-19 shows the modeling of an interior spandrel splice. User-defined break elements at each node through the depth of a spandrel allowed the model to capture connection failure modes including (1) bolt shear, (2) tearing of the spandrel plate, and (3) tearing of the splice plates at the bolt holes. The exterior wall model contains 18 interior spandrel splices with 11 break elements at each splicc for a total of 198 spandrel splice break elements. With initial and failure stiffness values and temperature-dependent capacities defined by the user, the user-defined break elements transfer forces and moments bctwcen nodes according to the initial stiffness values until the element reaches its capacity in one direction. Upon reaching the capacity in one direction, the stiffness of the element in all directions changes to the corresponding failure stiffness, and the element sheds load to other load paths. The models uscd userdefined break elements that had the capability to fail in translation or rotation. 


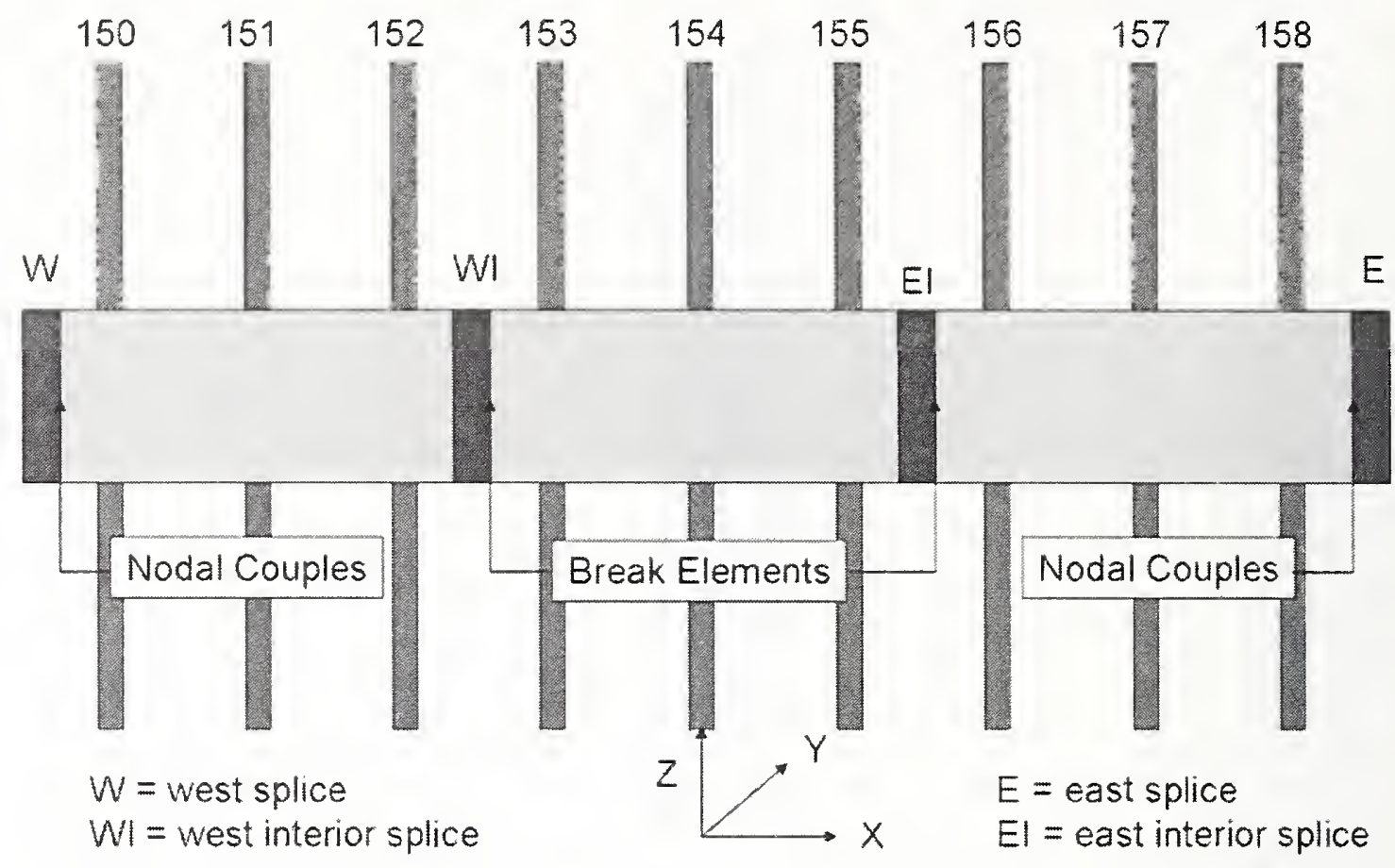

Figure 6-18. Typical spandrel splice layout for exterior wall subsystem.

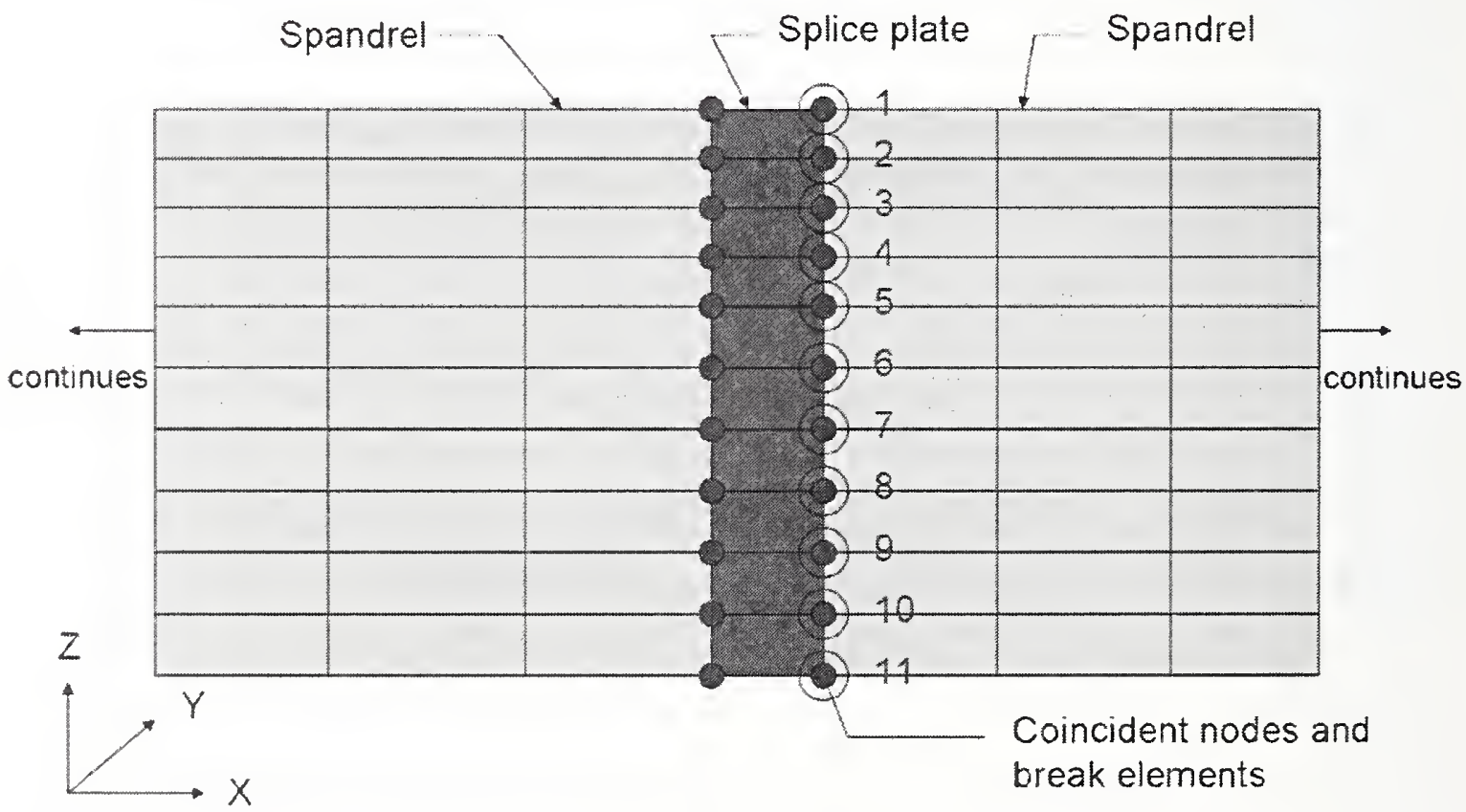

Figure 6-19. Modeling of a typical interior spandrel splice in the exterior wall model. 


\subsubsection{Column Splices}

Two BEAM189 elements for each of the four bolts, four pairs of CONTA178 contact elements at the faying (contact) surfaces, and stiff BEAM4 elements connecting the tops of the bolts to the CONTA178 contact elements were used to model the column splice. COMBIN37 elements modeled the fracture of the column splice bolts based on data from bolt tests provided by NIST and on shear failure of the splice. Figure 6-20 shows a schematic view of the column splice. A coefficient of friction of 0.35 was used for the contact elements. The $7 / 8 \mathrm{in}$. diameter column splice bolts were preloaded to $36.05 \mathrm{kip}$ at $20{ }^{\circ} \mathrm{C}$ (AISC 1964).

The column splice model cannot fail in compression. In tension, the bolts and, therefore, the entire splice will disconnect at $0.18 \mathrm{in}$. deflection beyond the ultimate capacity of the bolts. In shear, the column splice will disconnect after 1.1 in. deflection. The shear capacity is the summation of bolt shear capacity and splice friction. In bending, the capacity is controlled by bolt tension. The peak moment capacity occurs prior to failure of the first set of bolts with some capacity remaining on the second set of bolts.

The column splice model was verified by subjecting it to three displacement controlled load cases under two temperature conditions and comparing the results with hand calculated maximum capacities for each case. The load cases examined were: axial extension, to determine a maximum tensile load; applied rotation with $175 \mathrm{kip}$ axial compression, to determine a maximum moment; and applied lateral displacement with $175 \mathrm{kip}$ axial compression, to determine a maximum shear. Each load case was performed at $20^{\circ} \mathrm{C}$ and $300{ }^{\circ} \mathrm{C}$. The maximum difference between the finite element model and calculated capacities was 4 percent under the tensile load case. All other cases showed agreement to within 2.5 percent. The load-displacement response of the splice model to cach load case was in agreement with the predicted behavior.

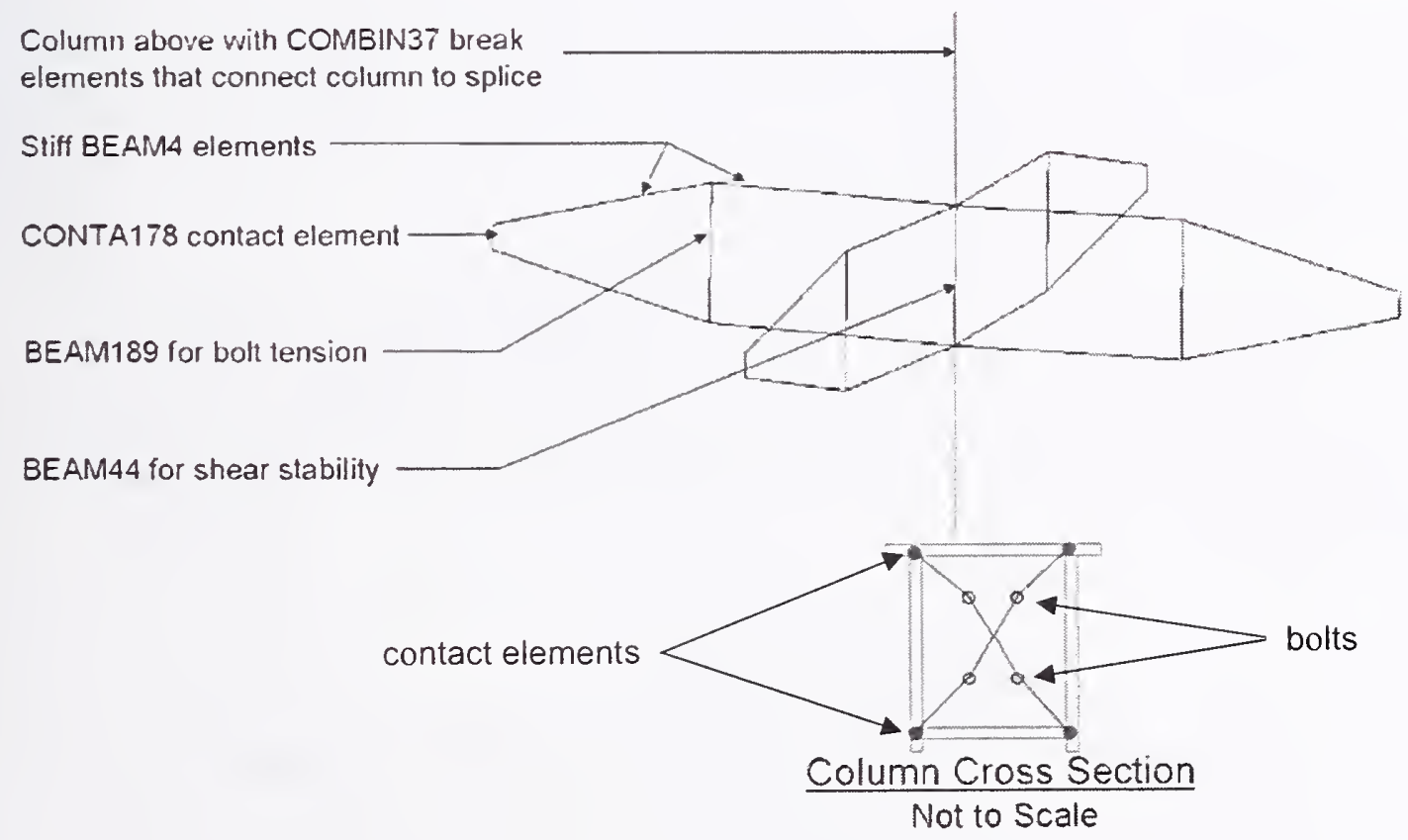

Figure 6-20. Column splice model used in exterior wall model. 


\subsubsection{Loads}

The loads on the model were applied sequentially in the following order:

- Self weight of the exterior wall components,

- Column splice bolt preload,

- Gravity dead and live loads of the floor system,

- Temperature time histories provided by NIST, and

- Transverse pull-in force from sagging floors or additional vertical load from a potential redistribution of gravity loads to this portion of the exterior wall

\section{Gravity Loads}

Gravity loading was obtained from two sources: the LERA SAP2000 global model and the LERA SAP2000 floor model. To capture the gravity load effects from upper floors (those above Floor 99), internal forces and moments at midheight of the columns between Floors 99 and 100 in the LERA SAP2000 global model, caused by dead plus 25 percent of design live load, were applied as loads at the tops of the corresponding columns in the exterior wall model at the center of gravity of the columns. To capture the gravity load effects from individual floors, floor loads were extracted from the LERA SAP2000 floor model and applied to each column. Also, a moment about the plane of the wall, based on the vertical force from the floor and the eccentricity of the truss seats, was applied to each odd-numbered column at the mid-plane of the spandrel.

\section{Thermal Loads}

To represent a range of thermal conditions expected in the WTC towers, NIST provided five thermal load conditions based upon fire conditions in the towers. These were labeled D, DBARE, E, E1 19, and F, and are described in Table 6-3. These load conditions differed in fire behavior, intensity, location in the towers, and time. Thermal load DBARE assumed steel without thermal insulation. Thermal load E119 corresponded to the standard ASTM-E1 19 fire load. Figure 6-21 shows how the maximum temperature in each thermal loading condition varied with time.

For columns that were modeled by BEAM189 elements, temperatures were provided for nodes at the center of gravity of the column, and their linear gradients transverse to the exterior wall were also provided. Gradients parallel to the wall were found to be negligible. Temperatures for SHELL181 elements were provided at each node. NIST did not always provide temperatures for the bolts at column splices. When bolt temperatures were provided, they matched temperatures at the nearest interior or exterior tips of columns. 
Table 6-3. Thermal loading conditions used in the exterior wall model.

\begin{tabular}{|c|c|c|c|c|c|c|}
\hline $\begin{array}{l}\text { Thermal } \\
\text { Loading } \\
\text { Condition }\end{array}$ & $\begin{array}{l}\text { Building and } \\
\text { Location }\end{array}$ & Columns & Floors & $\begin{array}{l}\text { Thermal } \\
\text { insulation }\end{array}$ & $\begin{array}{c}\text { Time } \\
\text { Duration }\end{array}$ & $\begin{array}{c}\text { Maximum } \\
\text { Temperature }{ }^{\circ} \mathrm{C}\end{array}$ \\
\hline D & $\begin{array}{c}\text { WTC } 1 \\
\text { South face } \\
\text { towards West }\end{array}$ & $340-348$ & $91-99$ & as specified & $90 \mathrm{~min}$ & $537^{\circ} \mathrm{C}$ \\
\hline DBARE & $\begin{array}{c}\text { WTC } 1 \\
\text { Same as D }\end{array}$ & $340-348$ & $91-99$ & $\begin{array}{l}\text { none - bare } \\
\text { steel }\end{array}$ & $90 \mathrm{~min}$ & $598^{\circ} \mathrm{C}$ \\
\hline $\mathrm{E}$ & $\begin{array}{c}\text { WTC } 1 \\
\text { East face } \\
\text { towards North }\end{array}$ & $221-229$ & $91-99$ & as specified & $90 \mathrm{~min}$ & $871^{\circ} \mathrm{C}$ \\
\hline E119 & WTC 1 & & & as specified & $90 \mathrm{~min}$ & $418^{\circ} \mathrm{C}$ \\
\hline F & $\begin{array}{l}\text { WTC } 2 \\
\text { North face } \\
\text { East corner }\end{array}$ & $250-258$ & $76-84$ & as specified & $60 \mathrm{~min}$ & $382^{\circ} \mathrm{C}$ \\
\hline
\end{tabular}

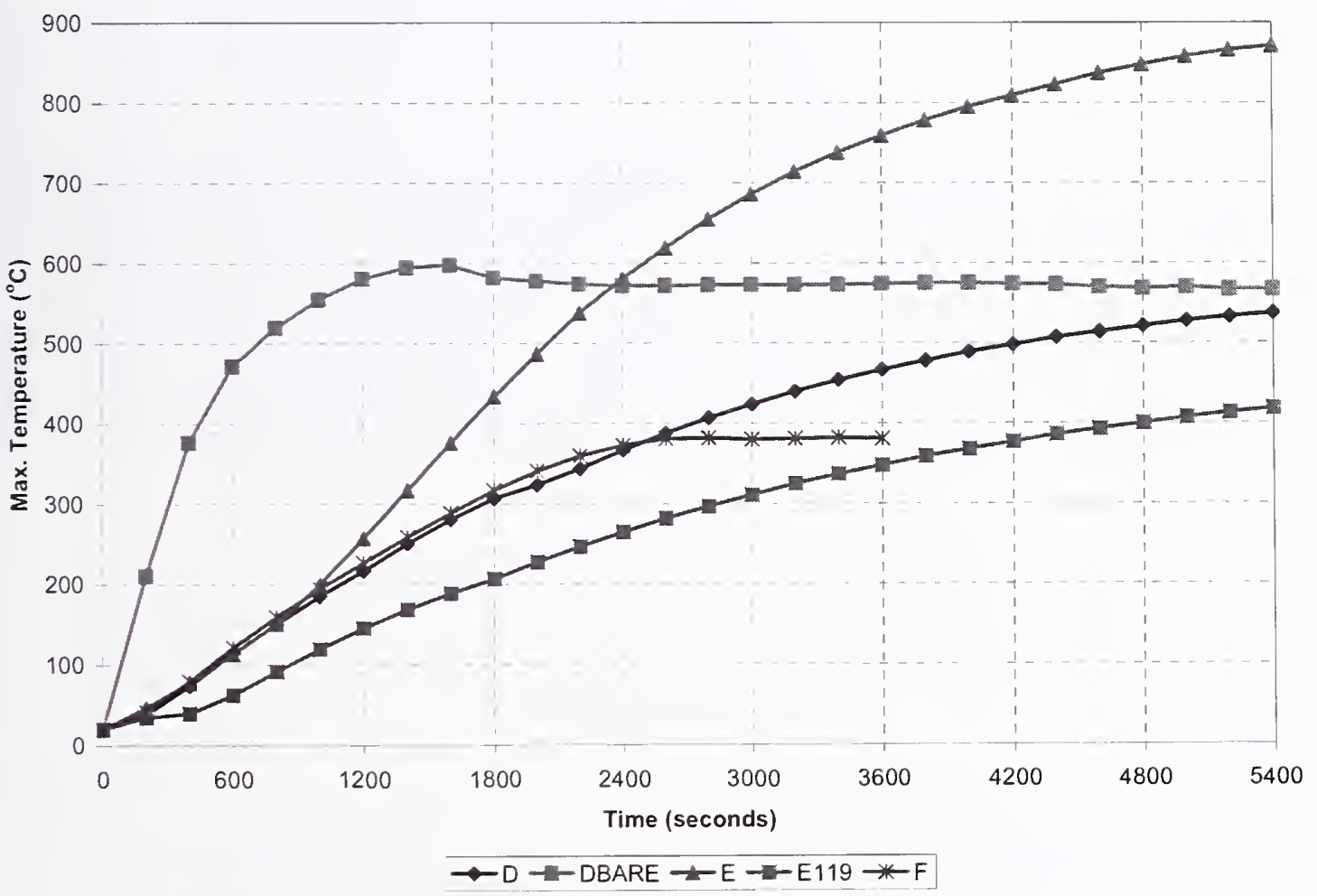

Figure 6-21. Exterior wall model temperature time-histories. 


\section{Transverse Pull at Disconnected Floors}

When floors sag, they begin to pull in the columns. The results of truss component analyses indicated approximately $14 \mathrm{kip}$ of pull-in force per truss. Strap anchors distributed this pull to the columns that did not support trusses. A $15 \mathrm{kip}$ pull-in force was applied to each column of laterally-unsupported floors to model the effect of the sagging floor.

\section{Push-down Loading}

Exterior wall columns were subjected to additional gravity loads that were redistributed due to weakening of other exterior walls and/or the core by the aircraft impact or temperature effects through the hat truss and spandrels. To simulate a redistribution of gravity loads, equal vertical displacements were imposed at the top of each column to push the model down. The imposed vertical displacements induced additional gravity loads in the columns.

\subsection{ANALYSIS CASES}

The loading sequence described in Section 6.5.6 is the same for all exterior wall analyses. Table 6-4 summarizes the different loadings and boundary conditions of the exterior wall subsystem.

As shown in Table 6-4, Case 6 and Case 7 used thermal condition DBARE with two and three floors not bracing the exterior wall system. Case 8 used DBARE, where the columns were not braced at three floors, and transverse loads (pull-in forces) were applied. Case 9 used DBARE, where the columns were not braced at three floors and vertical displacement was applied to the top of each column until unloading of the columns and instability was detected.

The analyses of Case 1, Case 5, and Case 6 through Case 9 were completed for the entire temperature time history of each case provided by NIST. The analysis of Case 2 was inadvertently stopped at 83 min of its temperature history; the temperature time history at 83 min was flat, and no significant change in the results was expected. Case 3 , at $70 \mathrm{~min}$ of its temperature history, reached a temperature of $800{ }^{\circ} \mathrm{C}$, beyond which material properties were not defined, and the computation was terminated. Case 4 could not be advanced past $83 \mathrm{~min}$ of its temperature time history, because the creep algorithm failed. The temperature difference between the temperatures at $83 \mathrm{~min}$ and $90 \mathrm{~min}$ was not significant for this case. 
Table 6-4. Analysis cases for exterior wall subsystem model.

\begin{tabular}{|c|c|c|c|c|c|c|}
\hline $\begin{array}{c}\text { Analysis } \\
\text { Case }\end{array}$ & $\begin{array}{c}\text { Thermal } \\
\text { Loading }\end{array}$ & $\begin{array}{c}\text { Bolt } \\
\text { Temperatures }\end{array}$ & $\begin{array}{c}\text { Creep } \\
\text { Effects }\end{array}$ & Floor Supports & $\begin{array}{c}\text { Pull-in } \\
\text { Force }\end{array}$ & $\begin{array}{c}\text { Push } \\
\text { Down }\end{array}$ \\
\hline 1 & D & No & Yes & All & & \\
\hline 2 & DBARE & No & Yes & All & & \\
\hline 3 & E & Yes & Yes & All & & \\
\hline 4 & E119 & No & Yes & All & & \\
\hline 5 & F & No & Yes & All & & \\
\hline 6 & DBARE & Yes & Yes & All but 95 and 96 & & \\
\hline 7 & DBARE & Yes & No & $\begin{array}{c}\text { All but } 95,96, \\
\text { and } 97\end{array}$ & & \\
\hline 8 & DBARE & Yes & No & $\begin{array}{c}\text { All but } 95,96, \\
\text { and } 97\end{array}$ & X & \\
\hline 9 & DBARE & Yes & No & $\begin{array}{c}\text { All but } 95,96, \\
\text { and } 97\end{array}$ & & X \\
\hline
\end{tabular}

\subsection{ANALYSIS RESULTS}

\subsubsection{Columns Braced at All Floors}

This group of analyses includes Analysis Case 1 through Case 5.

Analysis Case 1 (Fire Scenario D) Figures 6-22 (a) through 6-22 (c) show the total displacement, von Mises stress, and plastic strain, respectively, for the entire model. Figure 6-22 (a) shows that the maximum displacement of 1.53 in. occurred at Floor 98 near Column 158. Figure 6-22 (b) shows that the maximum von Mises stress in the spandrels of $49 \mathrm{ksi}$ occurred at Floor 95 and Column 156. Figure 6-22 (c) shows that plasticity in the spandrels was confined to Floors 95 and 96 , with the highest plastic strain occurring at Floor 96 near Column 155. Figure 6-22 (d) shows the deformation of the spandrel at Floor 94 . Table 6-5 summarizes the status of the spandrel splice break elements. All failed break elements indicated tearing failure. 


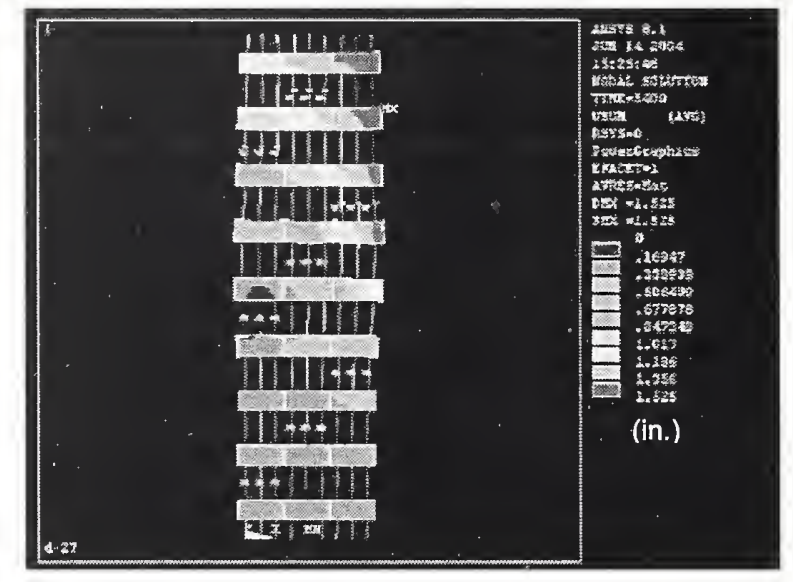

(a) Total deflection

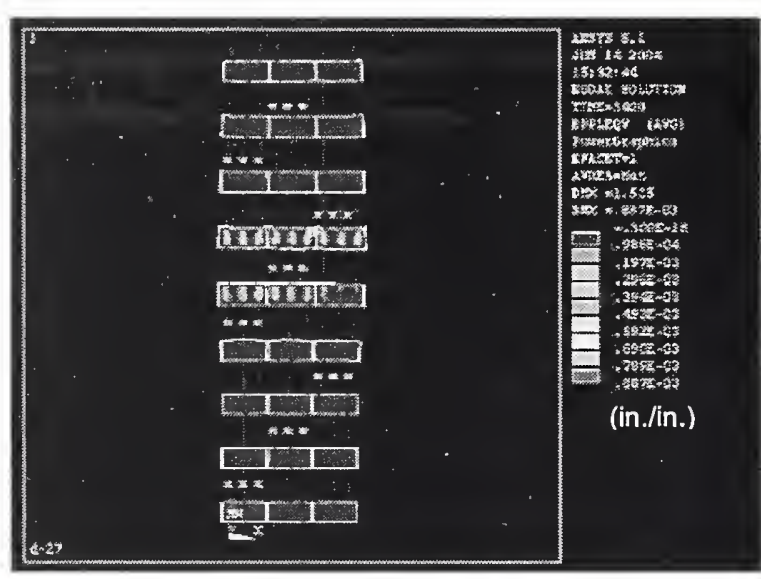

(c) Plastic strain

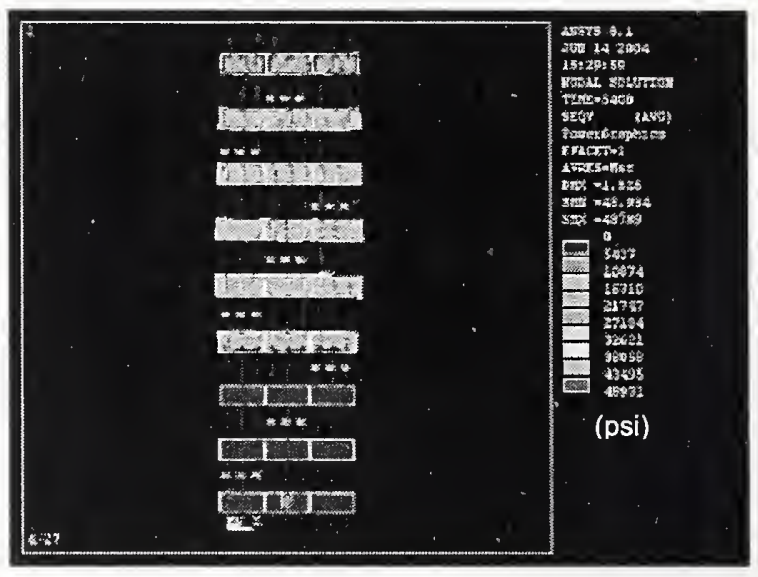

(b) von Mises stress

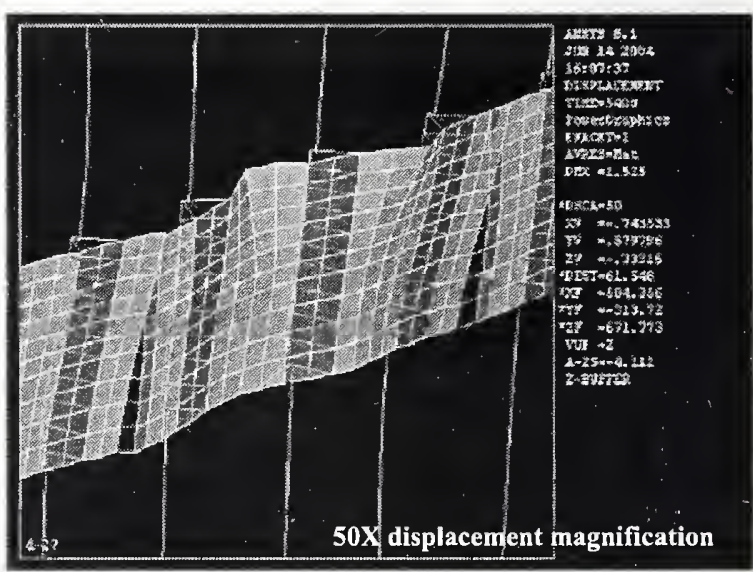

(d) Spandrel deformation at Floor 94

Figure 6-22. Structural response for temperature time history D with all floors supported.

Table 6-5. Summary of spandrel splice break elements for temperature time history D with all floors supported.

\begin{tabular}{|c|c|c|}
\hline & \multicolumn{2}{|c|}{ Number of failed elements } \\
\hline Floor & West Interior Splice & East Interior Splice \\
\hline 99 & 3 & 3 \\
\hline 98 & 0 & 0 \\
\hline 97 & 2 & 1 \\
\hline 96 & 1 & 2 \\
\hline 95 & 0 & 0 \\
\hline 94 & 0 & 0 \\
\hline 93 & 0 & 0 \\
\hline 92 & 0 & 0 \\
\hline 91 & 0 & 0 \\
\hline Total & 6 & 6 \\
\hline
\end{tabular}


Analysis Case 2 (Fire Scenario DBARE) Figures 6-23 (a) through 6-23 (c) shows the total displacement, von Mises stress, and plastic strain, respectively, for the entire model. Figure 6-23 (a) indicates the maximum displacement of 3.74 in. occurred at the top of Column 158. Figure 6-23 (b) shows that the maximum von Mises stress in the spandrels of $49 \mathrm{ksi}$ occurred at Floor 94 and Column 156. Figure 6-23 (c) shows plastic strain in spandrels at Floors 94 through 98, with the highest value at Floor 95 and Column 152.

Table 6-6 summarizes the status of the spandrel splice break elements. All failed break elements indicated tearing failure.

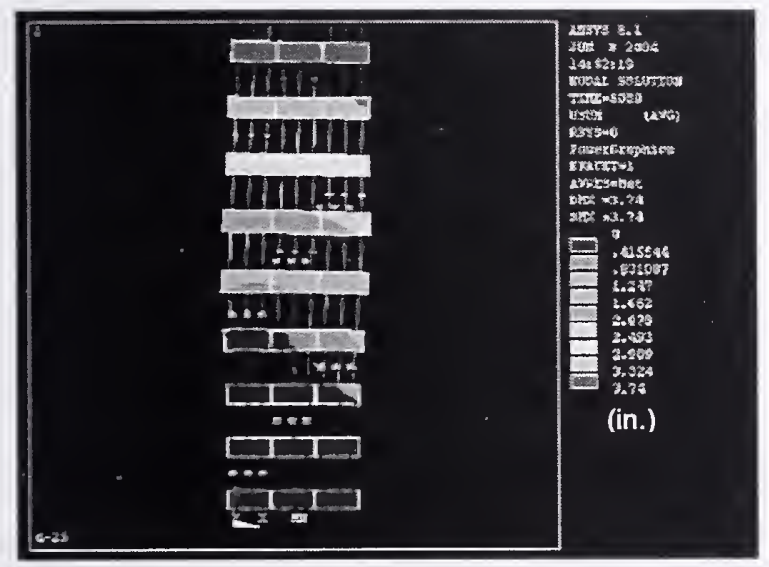

(a) Total deflection

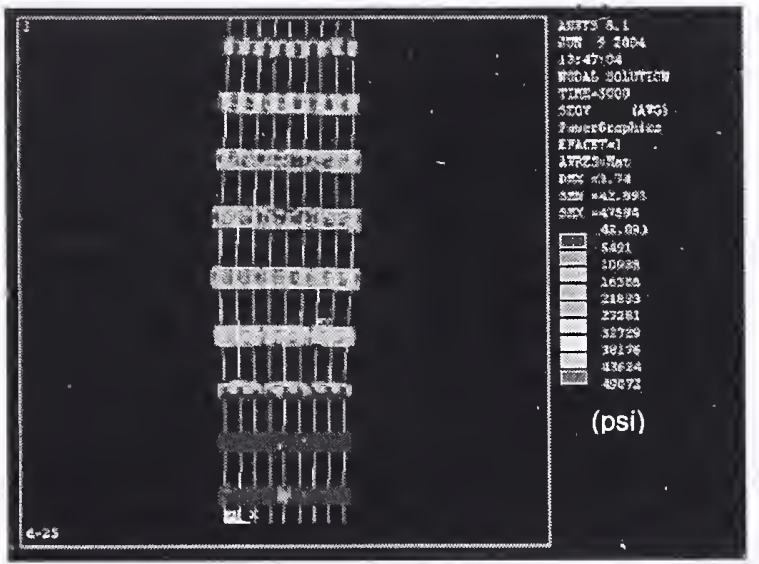

(b) von Mises stress

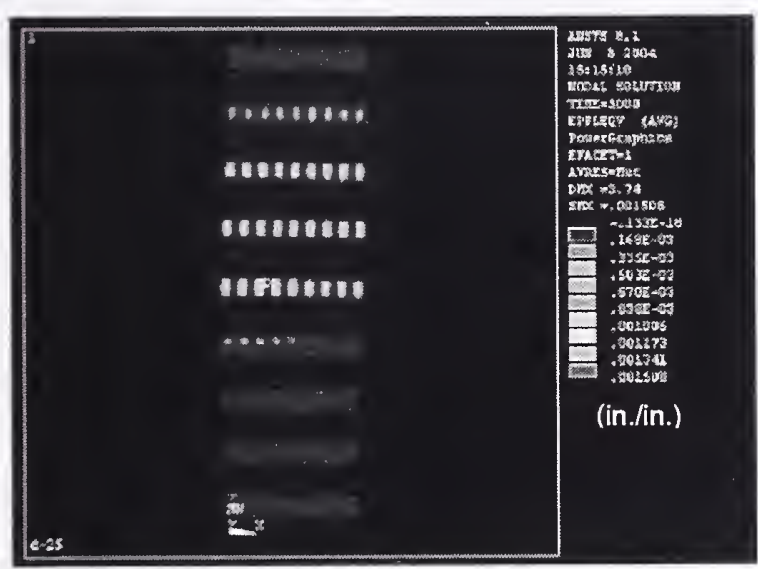

(c) Plastic strain

Figure 6-23. Structural response for temperature time history DBARE with all floors supported. 
Table 6-6. Summary of spandrel splice break elements for temperature time history

DBARE with all floors supported.

\begin{tabular}{|c|c|c|}
\hline & \multicolumn{2}{|c|}{ Number of failed elements } \\
\hline Floor & West Interior Splice & East Interior Splice \\
\hline 99 & 0 & 3 \\
\hline 98 & 3 & 3 \\
\hline 97 & 1 & 1 \\
\hline 96 & 0 & 0 \\
\hline 95 & 0 & 0 \\
\hline 94 & 0 & 0 \\
\hline 93 & 0 & 0 \\
\hline 92 & 0 & 0 \\
\hline 91 & 0 & 0 \\
\hline Total & 4 & 7 \\
\hline
\end{tabular}

Analysis Case 3 (Fire Scenario E) Figures 6-24 (a) through 6-24 (c) show the total displacement, von Mises stress, and plastic strain, respectively, for the entire model. Figure 6-24 (a) shows that the maximum displacement of 1.87 in. occurred at Floor 99 near Column 158. Figure 6-24 (b) indicates that the maximum von Mises stress in the spandrels of $57 \mathrm{ksi}$ occurred at Floor 94 between Columns 156 and 157. Figure 6-24 (c) shows that plastic strain occurred in spandrels at Floors 94 through 96, with the highest value occurring at Floor 94 between Columns 154 and 155. Figure 6-24 (d) shows the deformation of the spandrel at Floors 94, 95, and 96. Table 6-7 summarizes the status of the spandrel splice break elements. The nature of the break element failures indicated tearing failure at Floors 97 and above, bolt shear failure at Floors 95 and below, and a combination of tearing and bolt shear failure at Floor 96. 


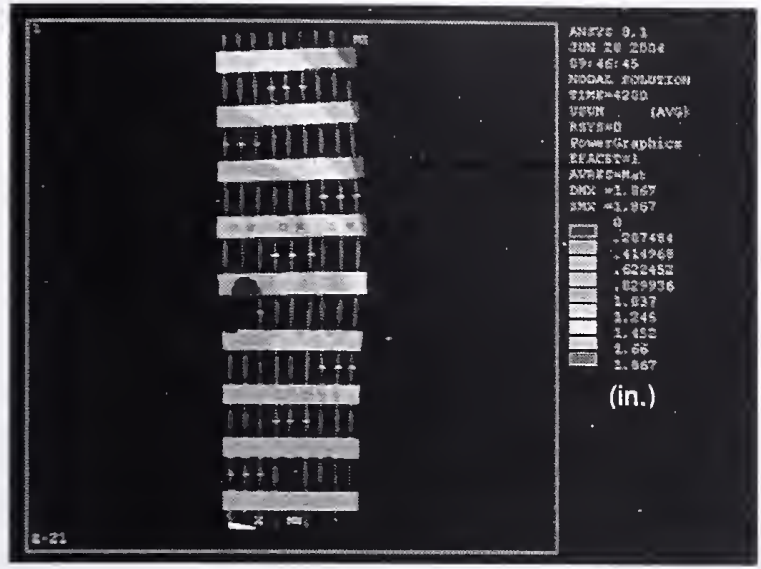

(a) Total deflection

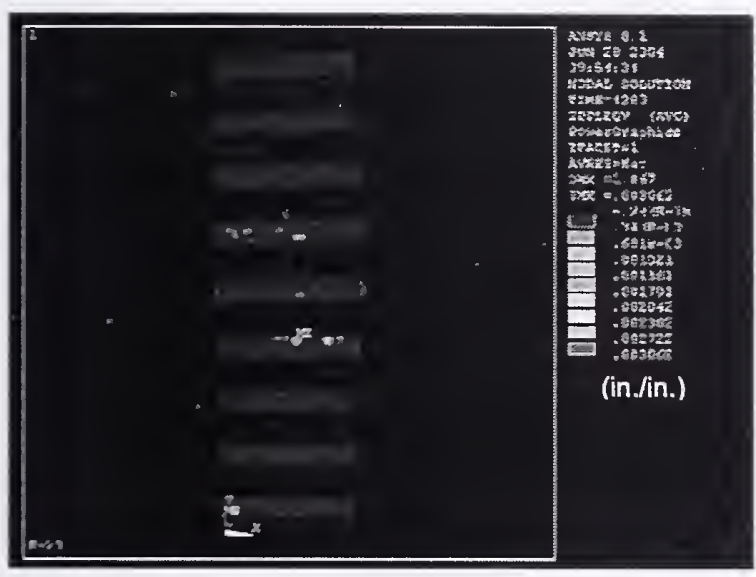

(c) Plastic strain

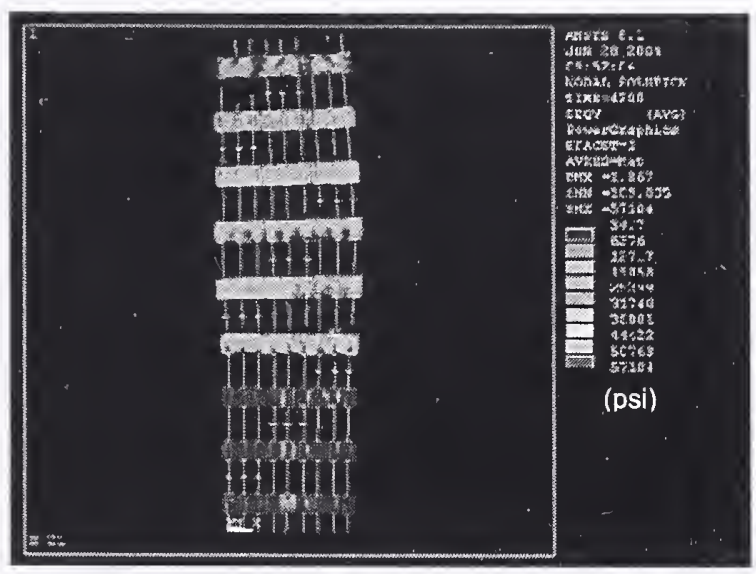

(b) von Mises stress

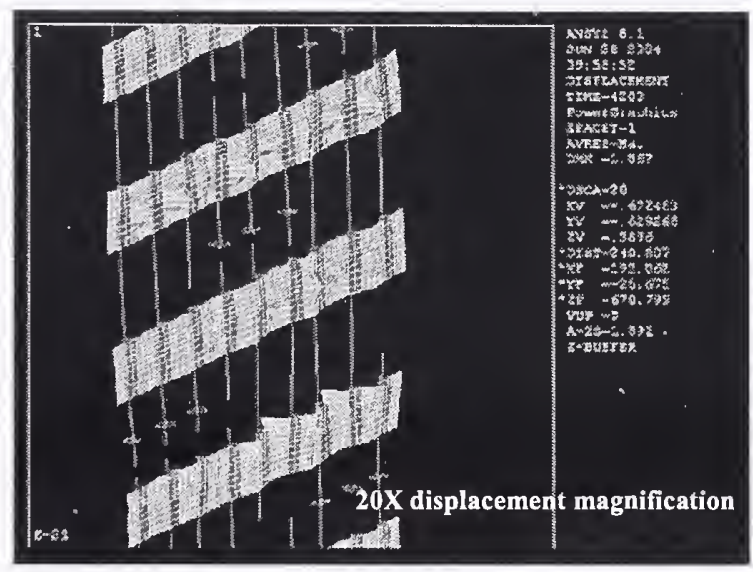

(d) Spandrel deformation at Floors 94 through 96

Figure 6-24. Structural response for temperature time history $E$ (hot bolts) with all floors supported.

Table 6-7. Summary of spandrel splice break elements for temperature time-history $E$ (hot bolts) with all floors supported.

\begin{tabular}{|c|c|c|}
\hline & \multicolumn{2}{|c|}{ Number of failed elements } \\
\hline Floor & West Interior & East Interior Splice \\
\hline 99 & 3 & 3 \\
\hline 98 & 3 & 3 \\
\hline 97 & 2 & 2 \\
\hline 96 & 8 & 8 \\
\hline 95 & 2 & 11 \\
\hline 94 & 1 & 2 \\
\hline 93 & 0 & 0 \\
\hline 92 & 0 & 0 \\
\hline 91 & 0 & 0 \\
\hline Total & 19 & 29 \\
\hline
\end{tabular}


Analysis Case 4 (Fire Scenario E119) Figure 6-25 (a) through 6-25 (c) show the total displacement, von Mises stress, and plastic strain, respectively, for the entire model. Figure 6-25 (a) shows that the maximum displacement of 2.07 in. occurred at Floor 99 near Column 158. Figure 6-25 (b) indicates that maximum von Mises stress in the spandrels of $53 \mathrm{ksi}$ occurred at Floor 94 and Column 158. Figure 6-25 (c) shows plastic strain in spandrels between Floors 93 through 99, with the highest value occurring at Floor 93 between Columns 154 and 155. Figure 6-25 (d) shows the deformation of the spandrel at Floor 93. Table 6-8 summarizes the status of the spandrel splice break elements. All failed break elements indicated tearing failure.

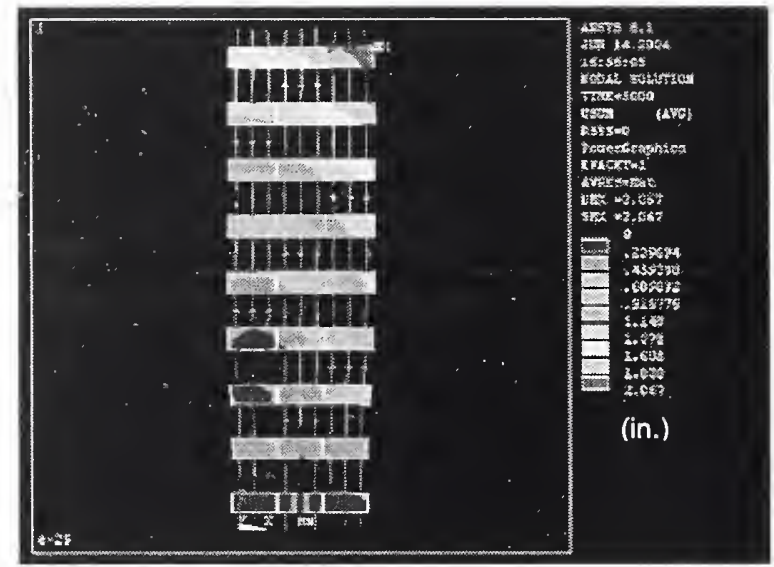

(a) Total deflection

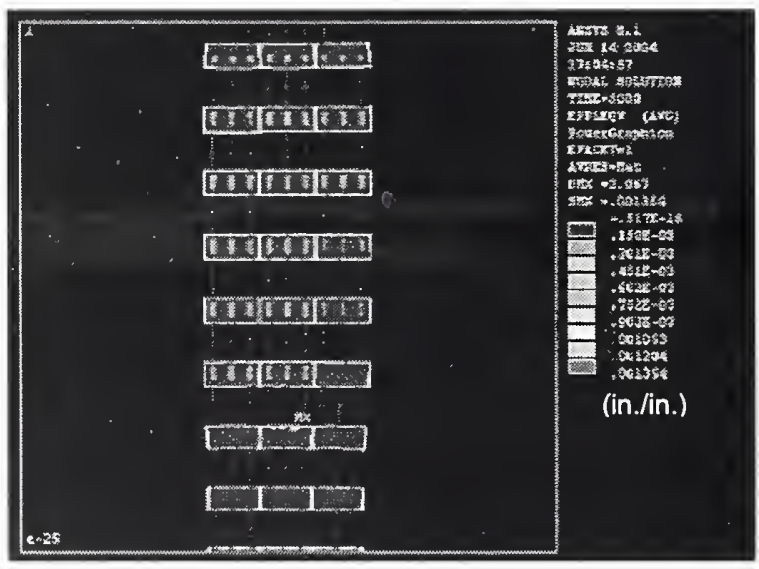

(c) Plastic strain

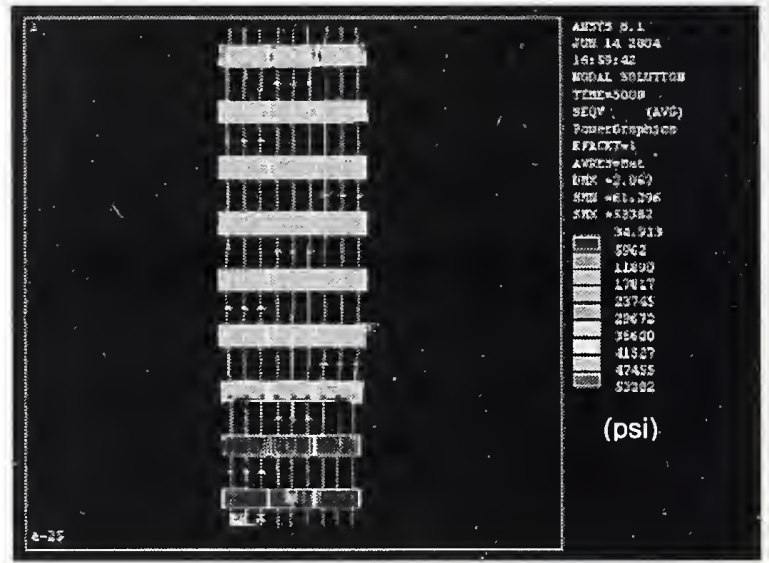

(b) von Mises stress

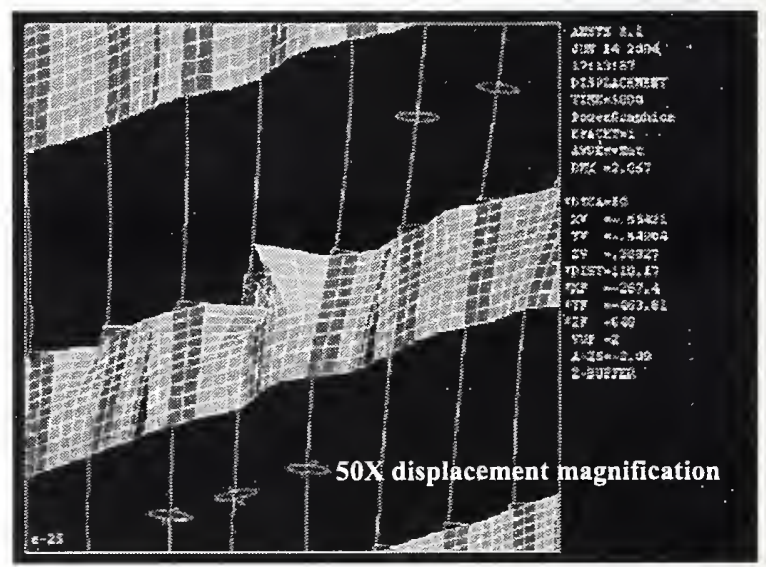

(d) Spandrel deformation at Floor 93

Figure 6-25. Structural response for temperature time history E119 with all floors supported. 


Table 6-8. Summary of spandrel splice break elements for
temperature time history E119 with all floors supported.
\begin{tabular}{|c|c|c|}
\hline & Number of failed elements \\
\hline Floor & West Interior & East Interior Splice \\
\hline 99 & 3 & 3 \\
\hline 98 & 0 & 0 \\
\hline 97 & 0 & 0 \\
\hline 96 & 0 & 0 \\
\hline 95 & 0 & 0 \\
\hline 94 & 0 & 0 \\
\hline 93 & 0 & 0 \\
\hline 92 & 0 & 0 \\
\hline 91 & 0 & 0 \\
\hline Total & 3 & 3 \\
\hline
\end{tabular}

Analysis Case 5 (Fire Scenario F) Figures 6-26 (a) through 6-26 (c) show the total displacement, von Mises stress, and plastic strain, respectively, for the entire model. Figure 6-26 (a) shows that the maximum displacement of 1.57 in. occurred at Floor 99 near Column 158. Figure 6-26 (b) indicates that the maximum von Mises stress in the spandrels of 46 ksi occurred at Floor 96 and Column 158. Figure 6-26 (c) shows plastic strain in spandrels between Floors 96 through 99 with the highest value occurring at Floor 97 at Column 151. Figure 6-26 (d) shows the deformation of the spandrel at Floor 99. Table 69 summarizes the status of the spandrel splice break elements. All failed break elements indicated tearing failure. 


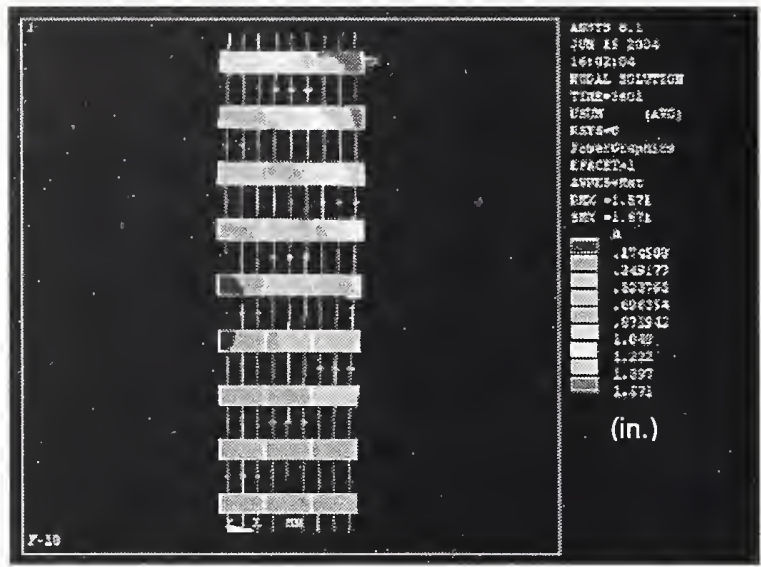

(a) Total deflection

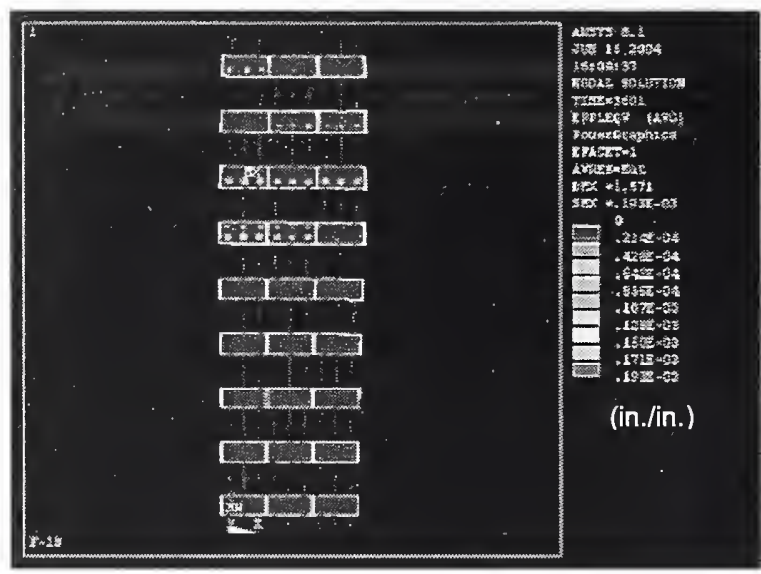

(c) Plastic strain

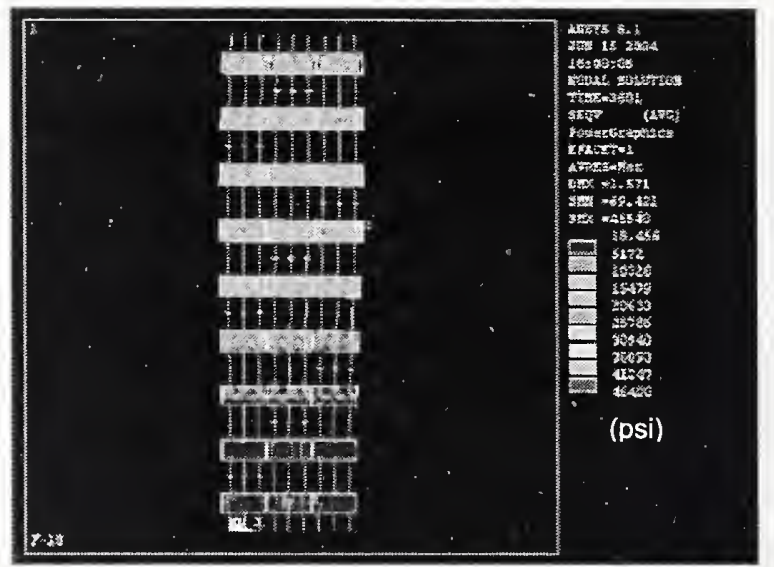

(b) von Mises stress

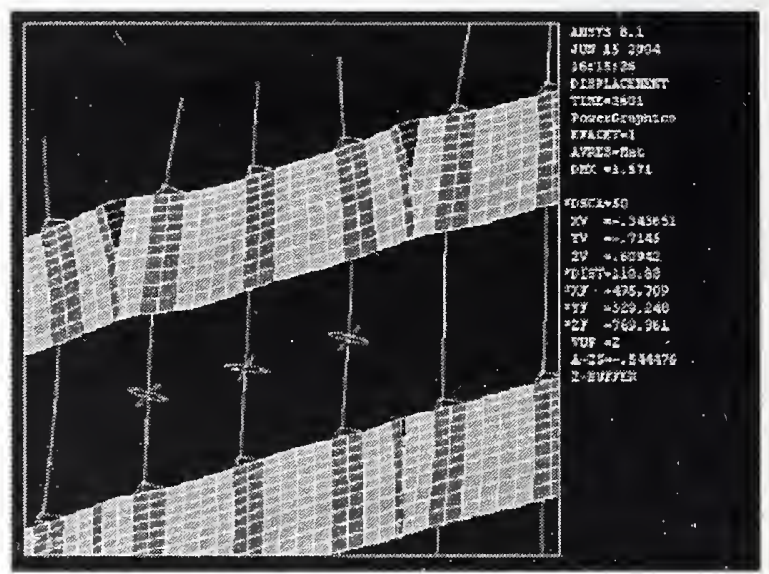

(d) Spandrel deformation at Floor 99

Figure 6-26. Structural response for temperature time history $F$ with all floors supported.

Table 6-9. Summary of spandrel splice break elements for temperature time history $F$ with all floors supported.

\begin{tabular}{|c|c|c|}
\hline & \multicolumn{2}{|c|}{ Number of failed elements } \\
\hline Floor & West Interior & East Interior Splice \\
\hline 99 & 3 & 3 \\
\hline 98 & 0 & 0 \\
\hline 97 & 0 & 0 \\
\hline 96 & 0 & 0 \\
\hline 95 & 0 & 0 \\
\hline 94 & 0 & 0 \\
\hline 93 & 0 & 0 \\
\hline 92 & 0 & 0 \\
\hline 91 & 0 & 0 \\
\hline Total & 3 & 3 \\
\hline
\end{tabular}




\subsubsection{Columns Not Braced at Floors 95 and 96}

Analysis Case 6 (Fire Scenario DBARE) Figures 6-27 (a) and 6-27 (b) show the total displacement and von Mises stress, respectively, for the entire model. Figure 6-27 (a) shows that the maximum displacement of 3.76 in. occurred above Floor 99. Figure 6-27 (b) indicates that the maximum von Mises stress in the spandrels of 23 ksi occurred at Floor 94 between Columns 154 and 155. Figure 6-27 (c) shows normal (transverse to the plane of the wall) displacement of the entire model. This figure shows a maximum outward displacement of 0.34 in. at Floor 96 and Column 154 and a maximum inward displacement of 0.45 in. at Floor 95 and Column 158. Table 6-10 summarizes the status of the spandrel splice break elements. Failed break elements at Floors 97 through 99 indicated tearing failure, and failed break elements at Floors 96 and below indicated bolt shear failure.

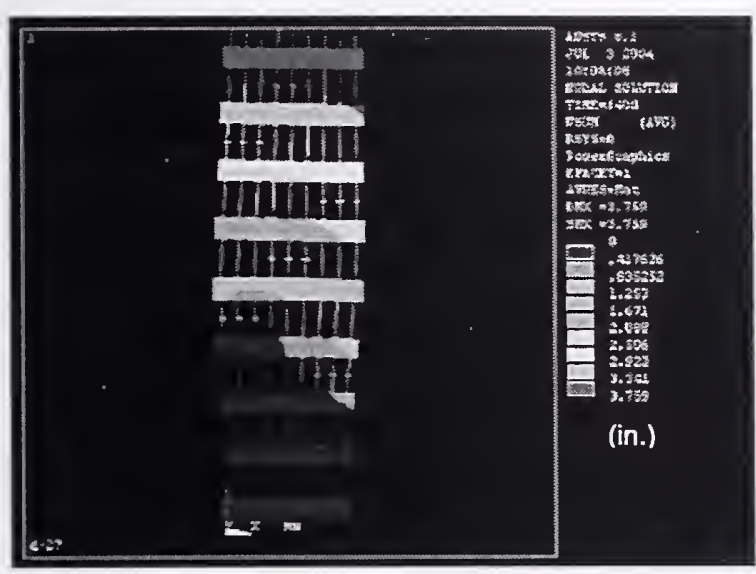

(a) Total deflection

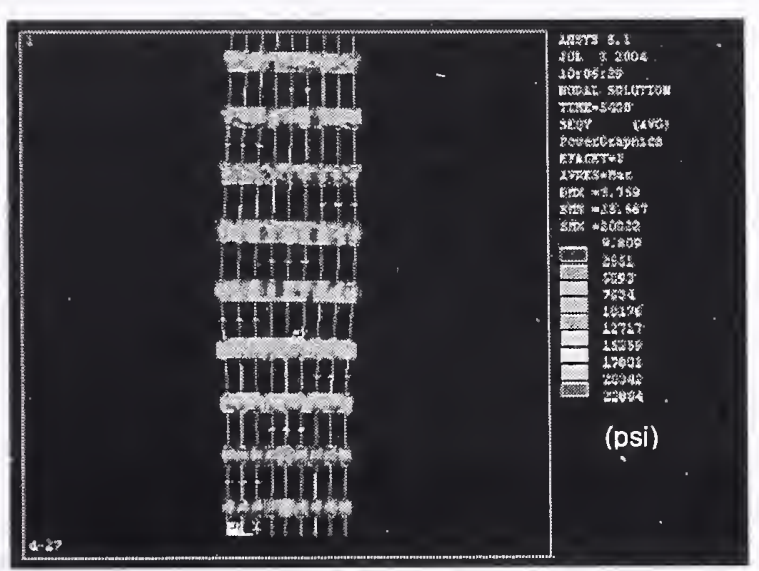

(b) von Mises stress

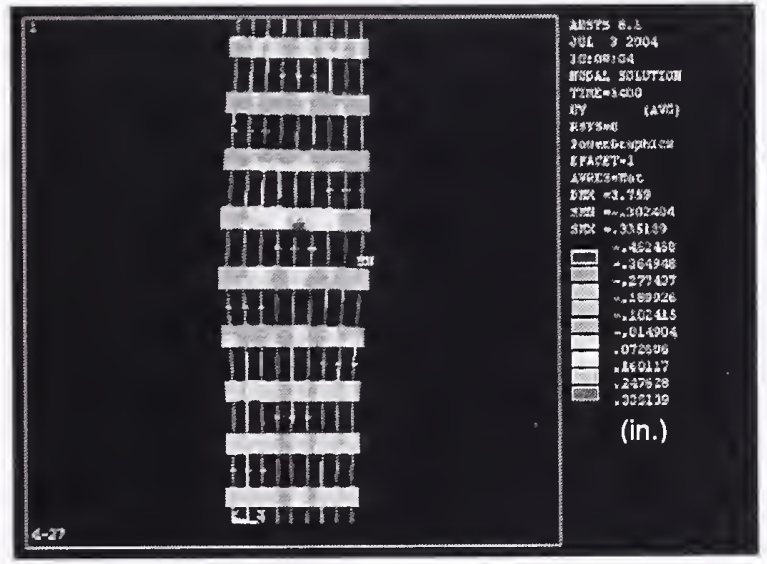

(c) Transverse displacement (outward displacement is positive)

Figure 6-27. Structural response for temperature time history DBARE with two unbraced floors. 
Table 6-10. Summary of spandrel splice break elements for temperature time history DBARE with 2 unbraced floors.

\begin{tabular}{|c|c|c|}
\hline & \multicolumn{2}{|c|}{ Number of failed elements } \\
\hline Floor & West Interior & East Interior Splice \\
\hline 99 & 1 & 3 \\
\hline 98 & 3 & 3 \\
\hline 97 & 1 & 0 \\
\hline 96 & 1 & 1 \\
\hline 95 & 1 & 0 \\
\hline 94 & 0 & 0 \\
\hline 93 & 0 & 0 \\
\hline 92 & 0 & 0 \\
\hline 91 & 0 & 0 \\
\hline total & 7 & 7 \\
\hline
\end{tabular}

\subsubsection{Columns Not Braced at Floors 95, 96, and 97}

Analysis Case 7 (Fire Scenario DBARE) Figures 6-28 (a) and 6-28 (b) show the total displacement and von Mises stress, respectively, for the entire model. Figure 6-28 (a) shows that the maximum displacement of 3.79 in. occurred above Floor 99. Figure 6-28 (b) indicates that the maximum von Mises stress in the spandrels of 23 ksi occurred at Floor 94 between Columns 154 and 155. Figure 6-28 (c) shows transverse to the plane of the wall displacement of the entire model. This figure shows a maximum outward displacement of 0.21 in. at Floor 96 betwcen Columns 154 and 155 and a maximum inward displacement of $0.96 \mathrm{in}$. at Floor 96 and Column 158. Table 6-11 summarizes the status of the spandrel splice break elements. Failed break elements at Floors 97 through 99 indicated tearing failure, and failed break elements at Floors 96 and below indicated bolt shear failure. 


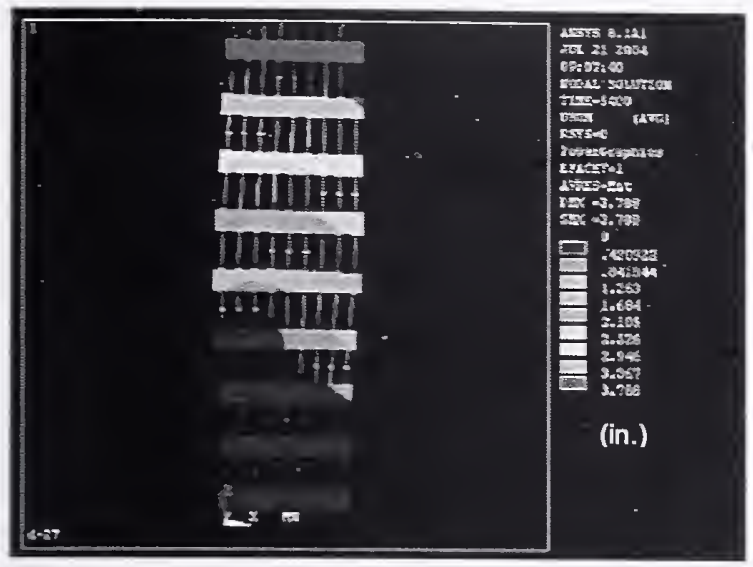

(a) Total deflection

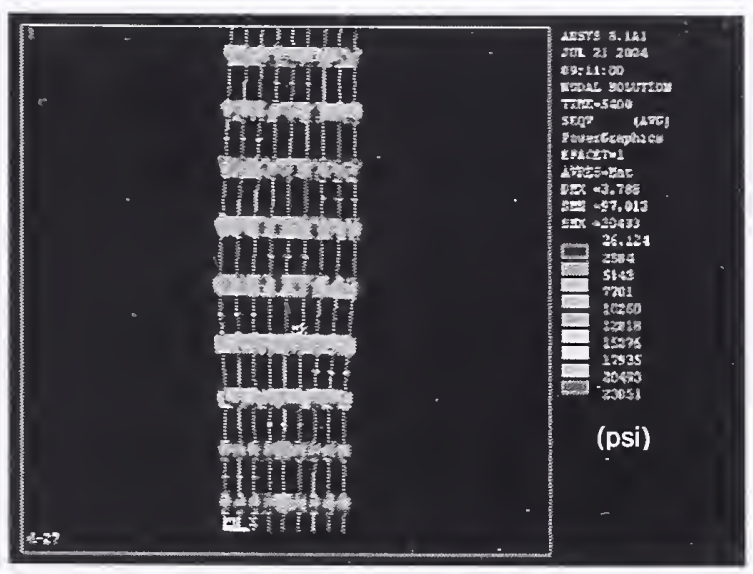

(b) von Mises stress

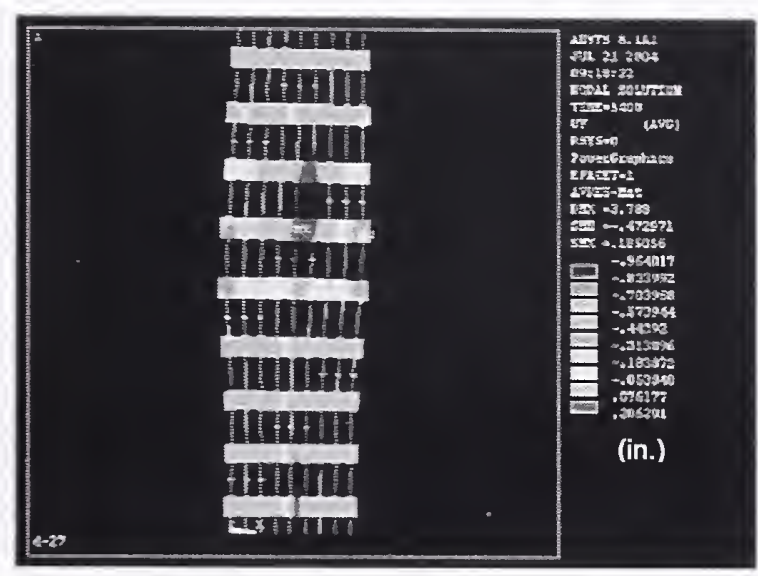

(c) Transverse displacement

(outward displacement is positive)

Figure 6-28. Structural response for time history DBARE with three unbraced floors.

Table 6-11. Spandrel splice break elements for temperature time history DBARE with 3 unbraced floors.

\begin{tabular}{|c|c|c|}
\hline & \multicolumn{2}{|c|}{ Number of failed elements } \\
\hline Floor & West Interior Splice & East Interior Splice \\
\hline 99 & 1 & 3 \\
\hline 98 & 3 & 3 \\
\hline 97 & 1 & 0 \\
\hline 96 & 1 & 1 \\
\hline 95 & 1 & 1 \\
\hline 94 & 0 & 0 \\
\hline 93 & 0 & 0 \\
\hline 92 & 0 & 0 \\
\hline 91 & 0 & 0 \\
\hline Total & 7 & 8 \\
\hline
\end{tabular}




\subsubsection{Columns Not Braced and Pulled at Unbraced Floors 95, 96, and 97}

Analysis Case 8 (Fire Scenario DBARE) Figures 6-29 (a) through 6-29 (d) show the total displacement, von Mises stress, and plastic strain, respectively, for the entire model. Figure 6-29 (a) shows that the maximum displacement of 10.4 in. occurred at Floor 96. Figures 6-29 (b) through 6-29 (c) indicate that the maximum von Mises stress occurred at Floor 94 and Column 156. Figure 6-29 (d) shows that plastic strain is limited to the portion of the spandrel at Floor 96 and Column 152. Figure 6-29 (e) shows transverse (to the plane of the wall) displacement of the entire model. This figure shows a maximum inward displacement of $10.2 \mathrm{in}$. at Floor 96. Figure 6-30 shows the maximum column splice bolt stresses, which occurred between Floors 96 and 97 at Columns 156 through 158. Figure 6-31 shows column splice contact status for those column splices occurring between Floors 94 and 97 . This figure indicates that column splices had opened or nearly opened at eight of the nine columns within this group of floors. 


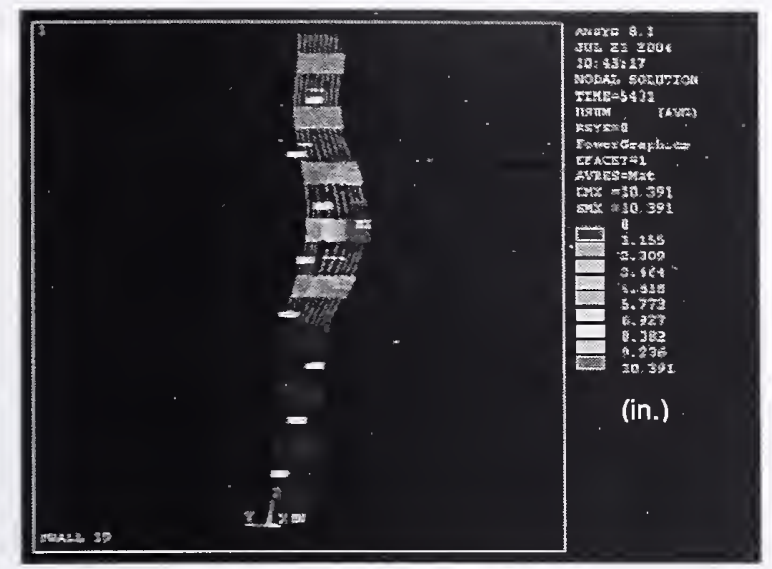

(a) Total deflection

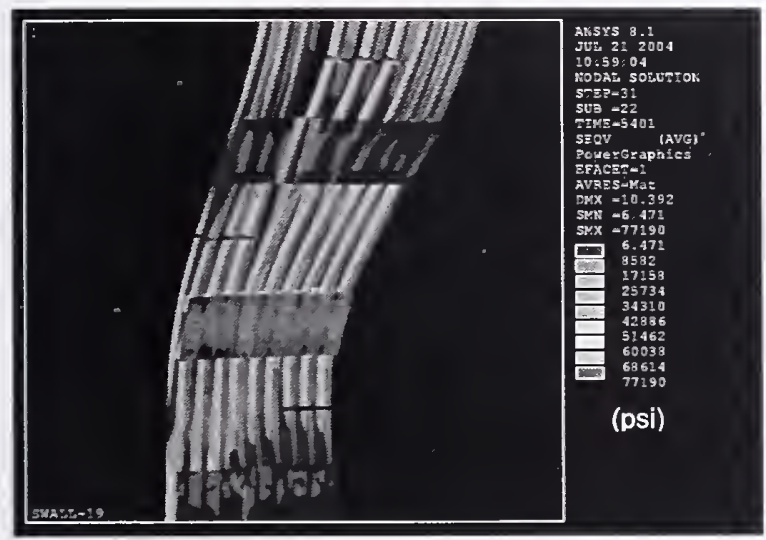

(c) von Mises stress

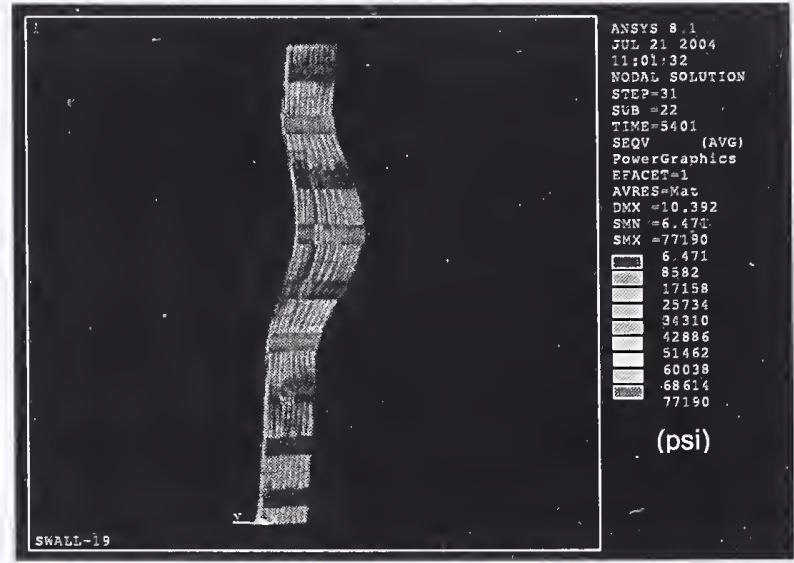

(b) von Mises stress

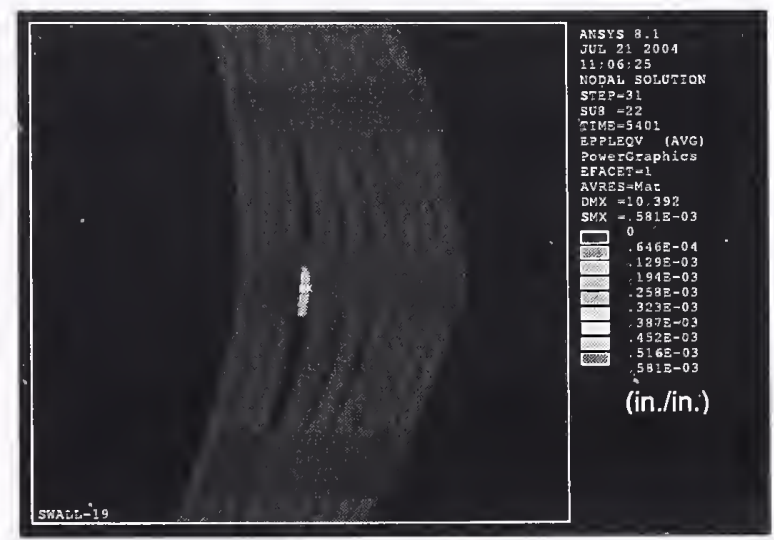

(d) Plastic strain

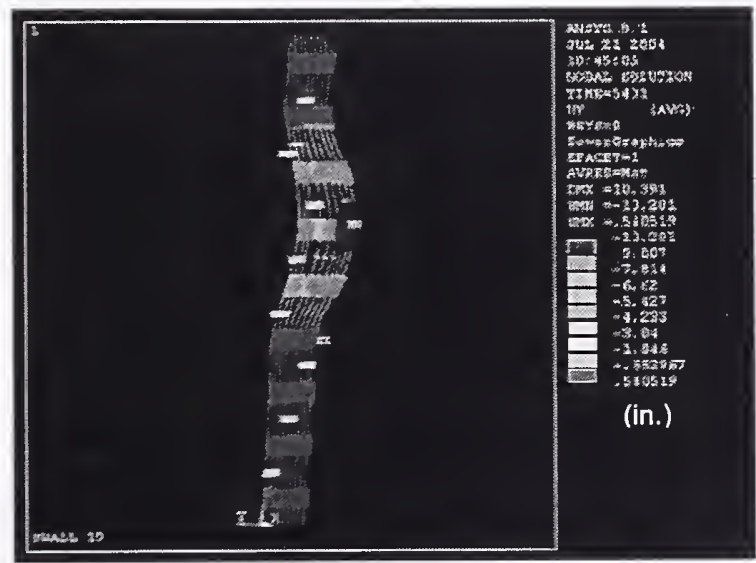

(e) Transverse displacement (outward displacement is positive)

Figure 6-29. Structural response for temperature time history DBARE with pull-in forces at three floors (10X displacement magnification). 


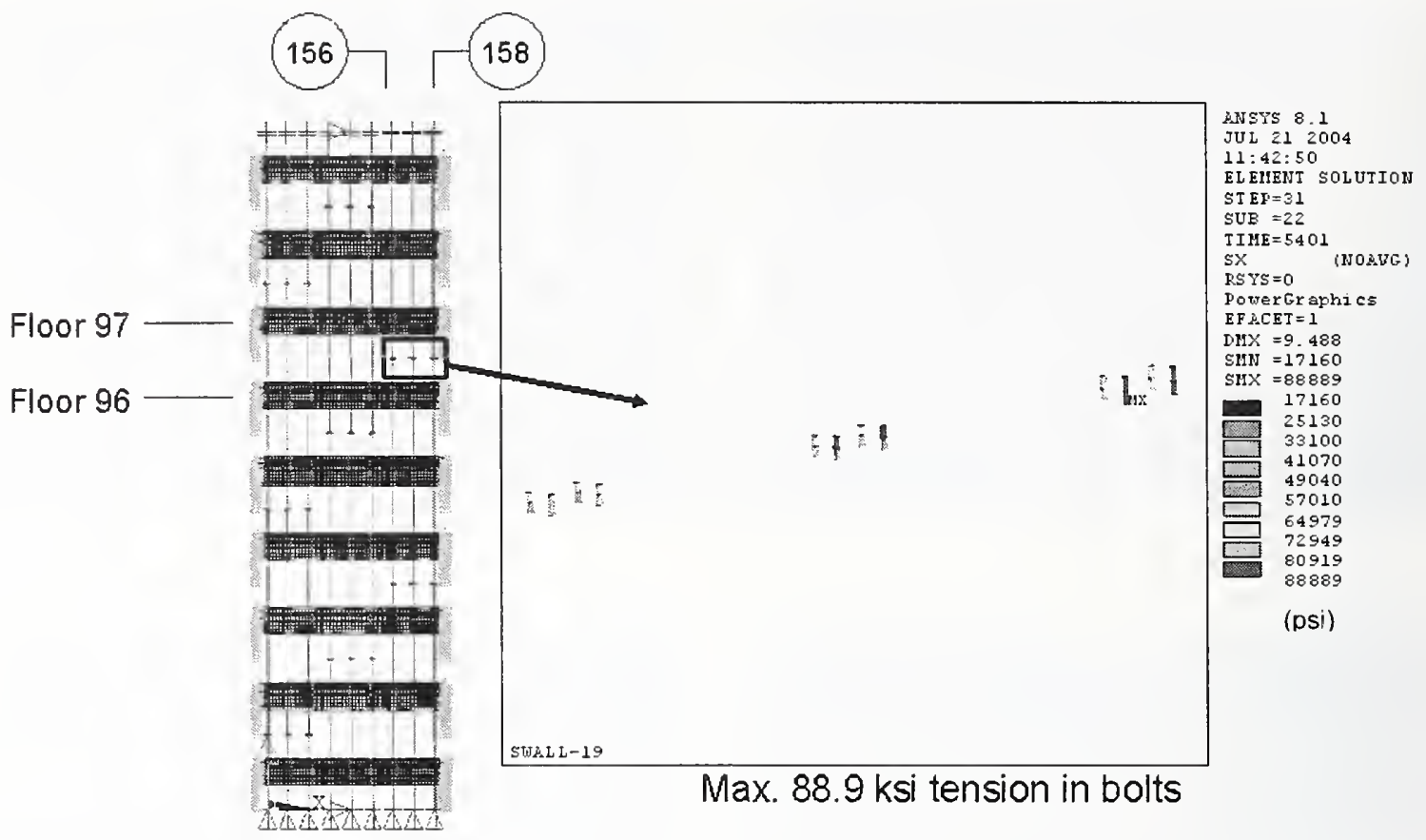

Figure 6-30. Column splice bolt stresses for temperature time history and DBARE with pull-in forces at three floors.

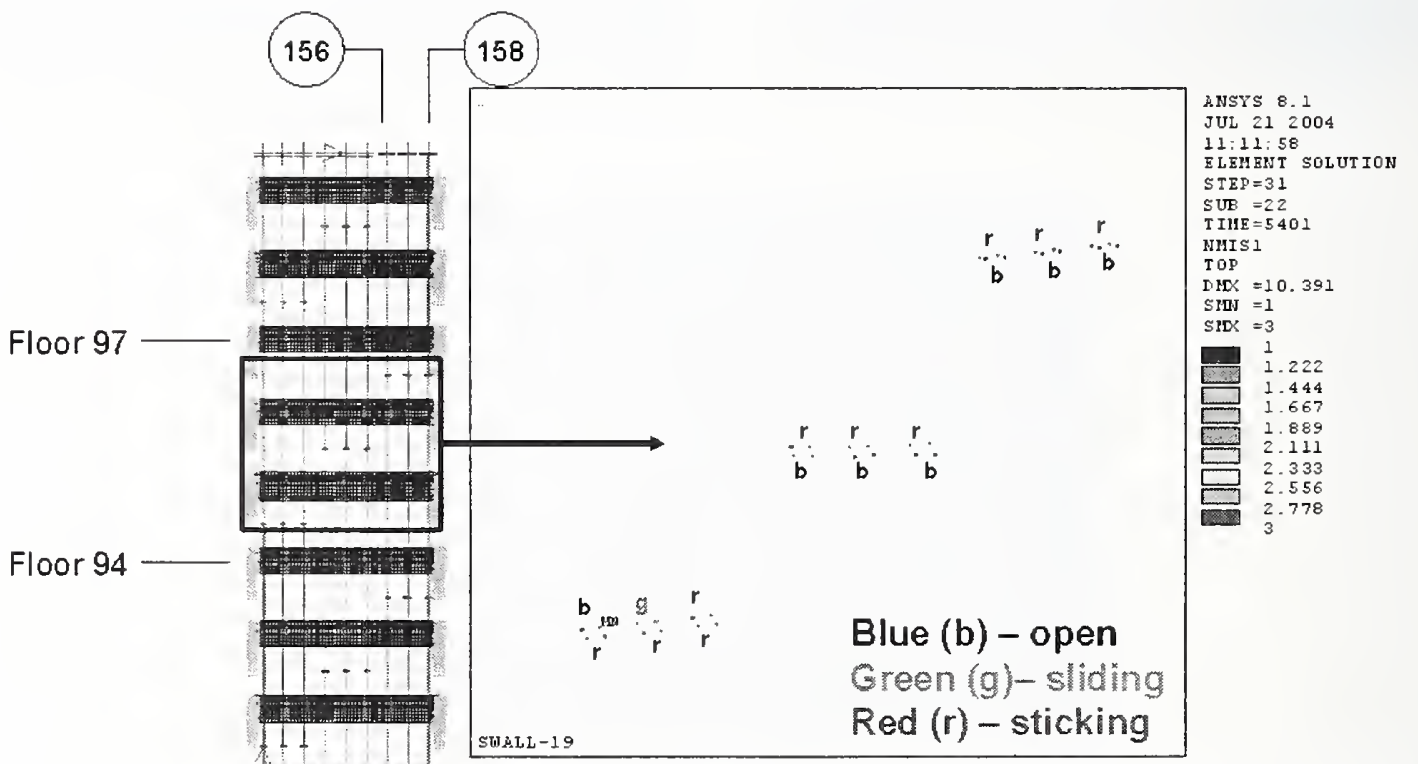

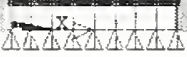

Note: 1 contact element pair also sliding at Col. 155 b/w Floors 98 and 99

Figure 6-31. Column splice contact element status for temperature time history and DBARE with pull-in forces at three floors. 


\subsubsection{Columns Not Braced at Floors 95, 96, and 97 and Pushed Down at Top}

Analysis Case 9 (Fire Scenario DBARE) Figure 6-32 (a) shows that the maximum total displacement of 14.8 in. occurred at Floor 96 . Figure 6-32 (b) indicates that the maximum von Mises stress of $69 \mathrm{ksi}$ occurred in Column 158 at Floor 96. Figure 6-32 (c) shows the von Mises stress in the spandrels and indicates that the maximum stress of $32 \mathrm{ksi}$ occurred at Floor 96 between Columns 151 and 152. Figures 6-33 (a) and 6-33 (b) show the column splice bolt stresses and column splice contact status, respectively. The maximum column splice bolt stress of $72 \mathrm{ksi}$ occurred between Floors 94 and 95 . Also, between Floors 94 and 95 at Columns 150 through 152, one contact element had opened and five others were sliding by the end of the analysis. Figures 6-34 and 6-35 show the sum of total vertical reaction forces at base and the sum of additional vertical reaction force at base induced by push-down, respectively. Figure 6-34 shows that instability occurred at a vertical displacement of 1.2 in., and columns unload beyond the point of instability to the end of analysis. Figures 6-36 through 6-38 show the total vertical reaction force, the additional vertical reaction force induced by push-down, and the difference between the additional vertical reaction at the base and the additional vertical force applied to the top for each column. Figure 6-38 shows that forces redistributed among the various columns throughout the pushdown loading. Figure 6-39 shows the transverse displacement at Column 154 with induced vertical displacement.

All deformations, partial separations of spandrel splices, stresses, and strains presented above are at the termination of the analyses after application of gravity loads, temperature time histories, and the imposed vertical displacement of $2.0 \mathrm{in}$. and not at the point of instability with a vertical displacement of $1.2 \mathrm{in}$. 


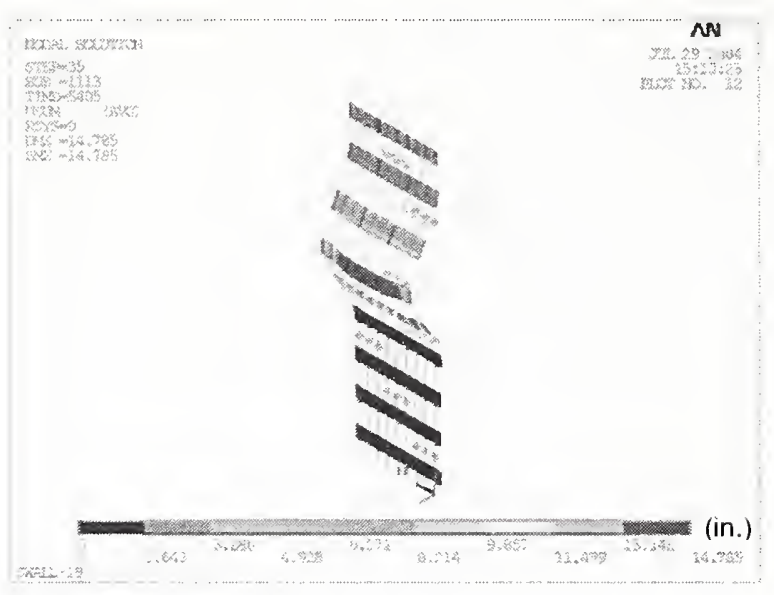

(a) Total deflection

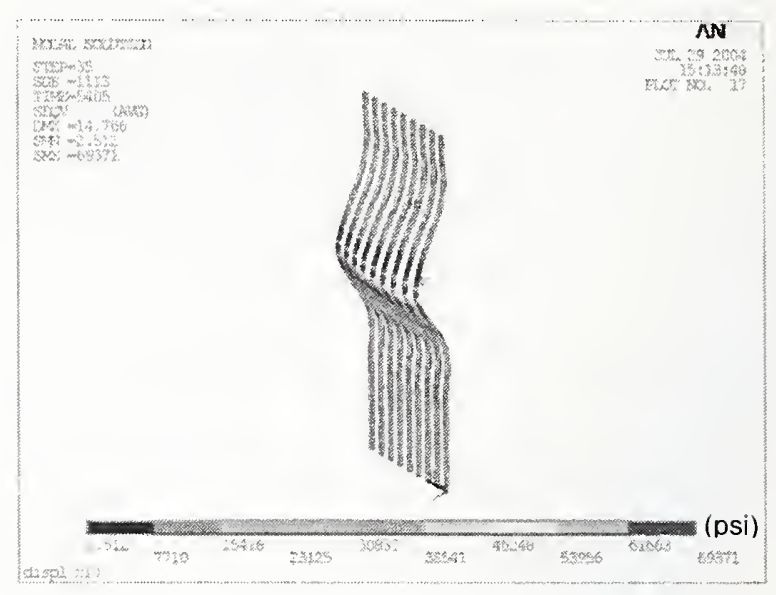

(b) von Mises stress in columns

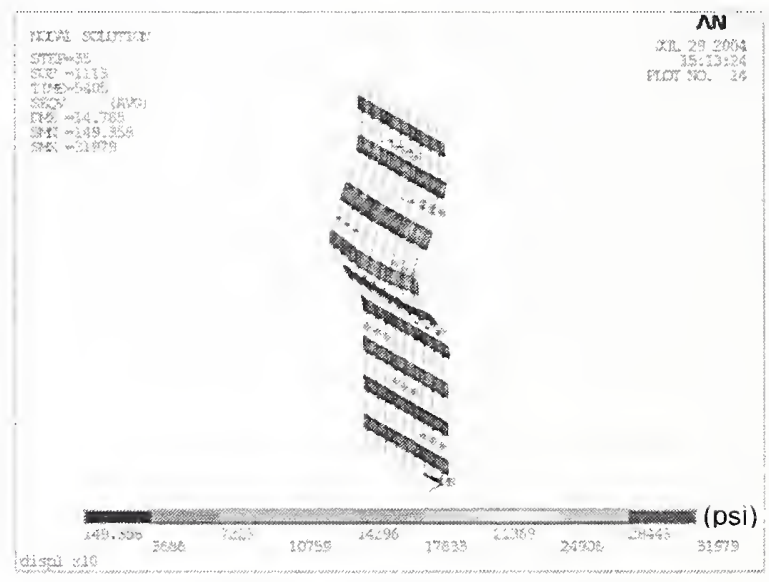

(c) von Mises stress in spandrels

Figure 6-32. Structural response for temperature time history DBARE and push-down with three unbraced floors (10X displacement magnification).

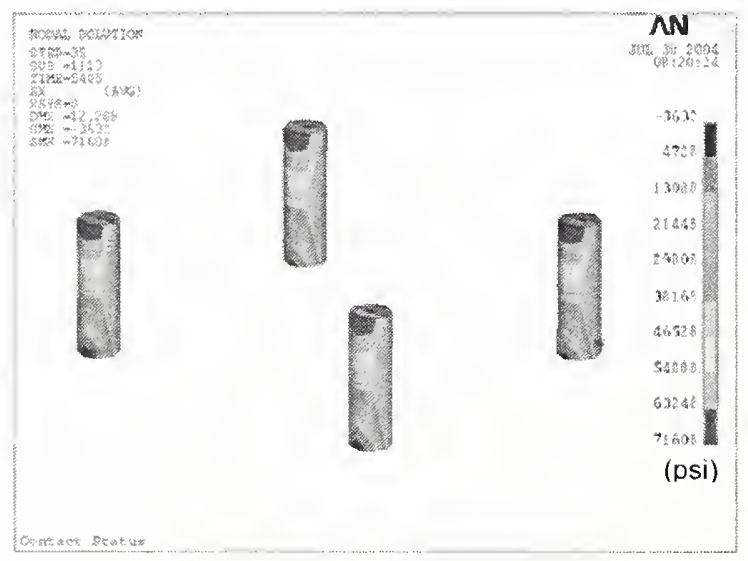

(a) Maximum longitudinal stress in bolts

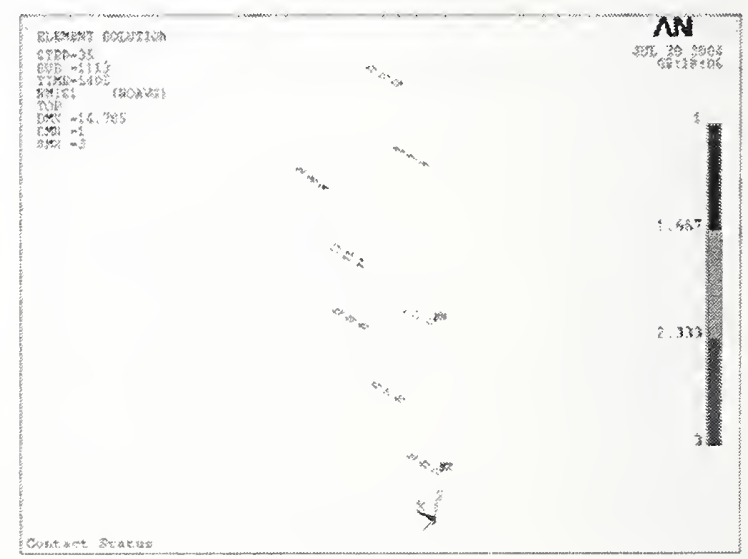

(b) Column splice contact element status

Figure 6-33. Column splice response for temperature time history DBARE and pushdown with three unbraced floors. 


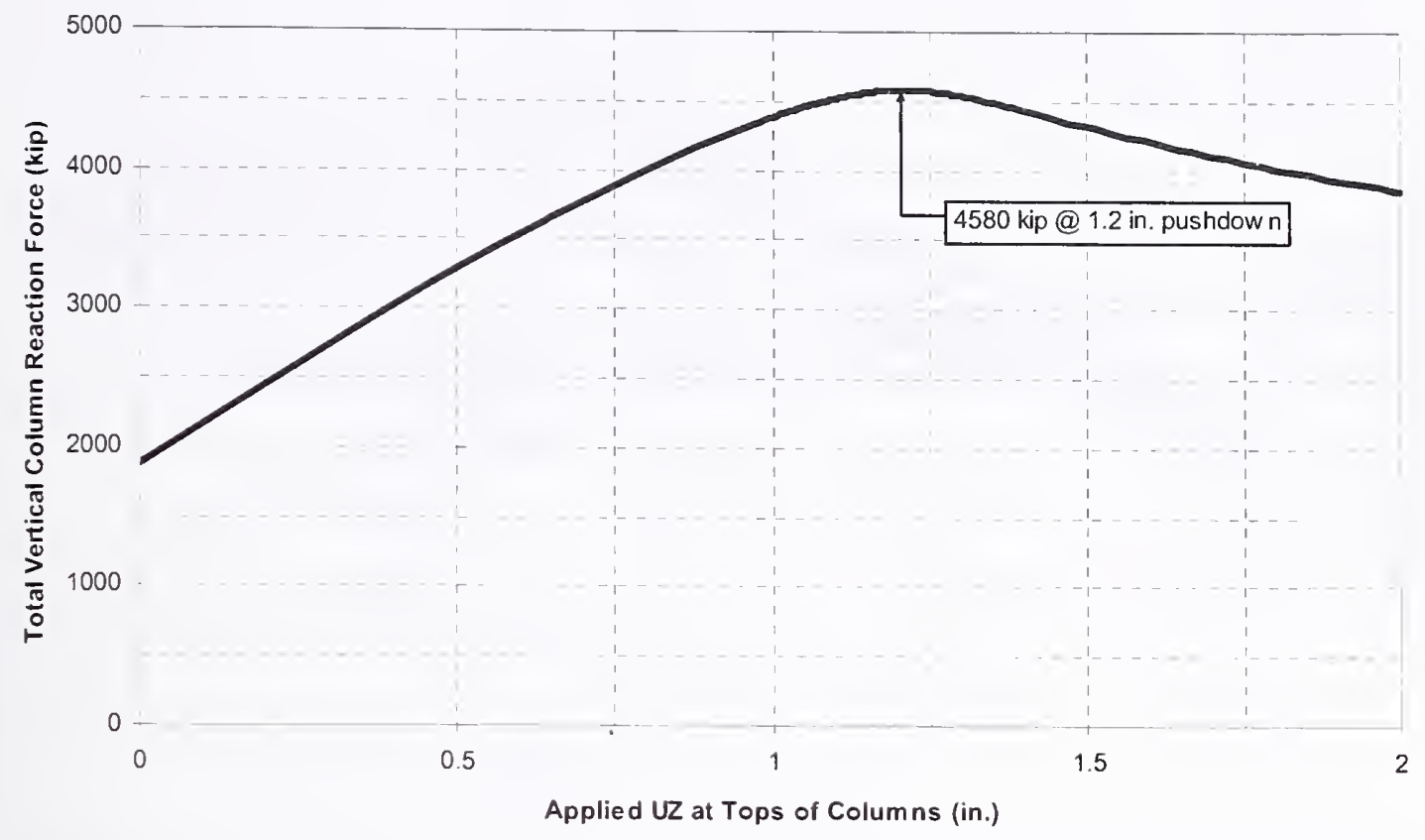

Figure 6-34. Sum of total column reaction forces at base during push-down after application of temperature DBARE with three unbraced floors.

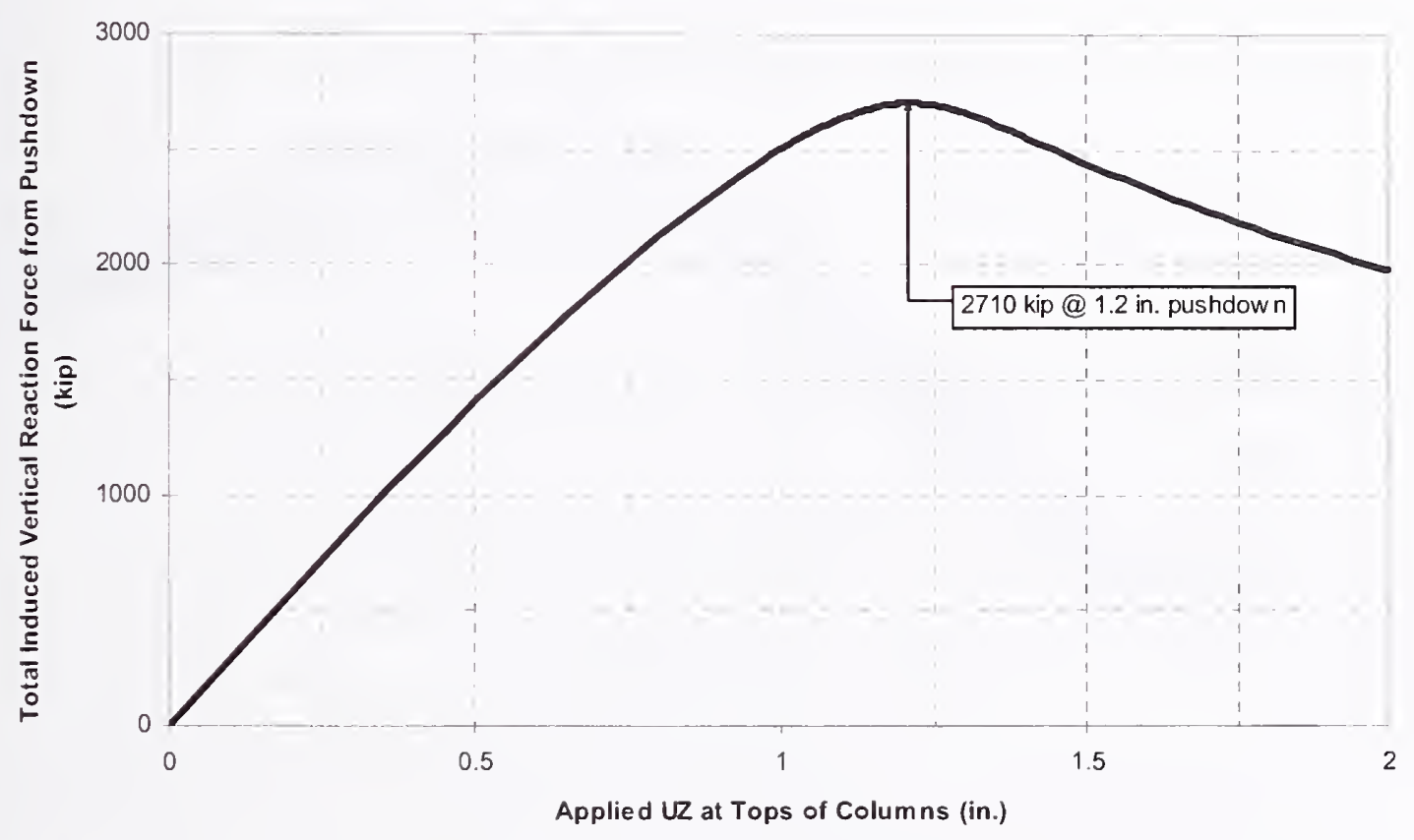

Figure 6-35. Sum of additional vertical reaction forces at base induced by imposed displacement during push-down after application of temperature DBARE with three unbraced floors. 


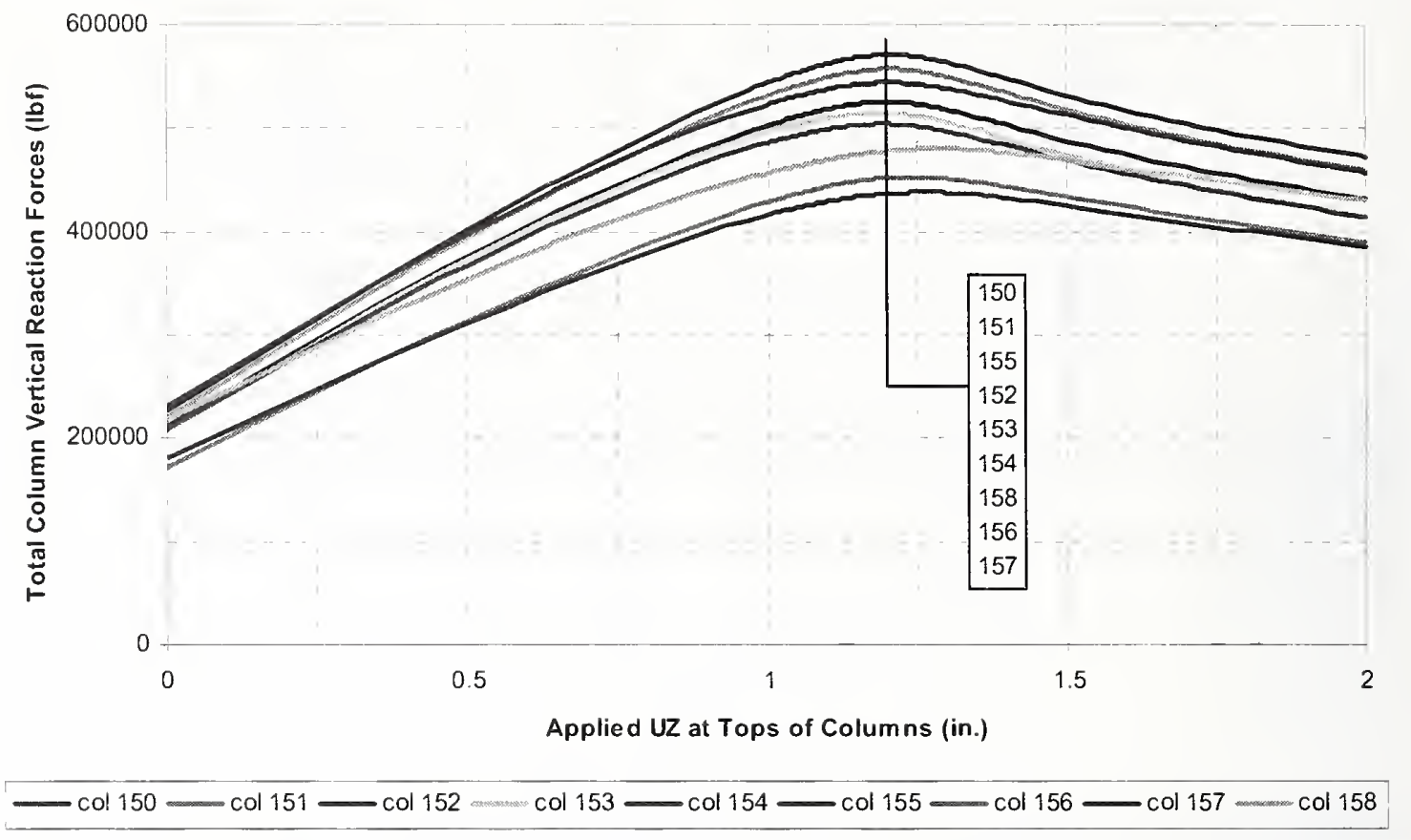

Figure 6-36. Individual total column reaction forces at base during push-down after application of temperature DBARE with three unbraced floors.

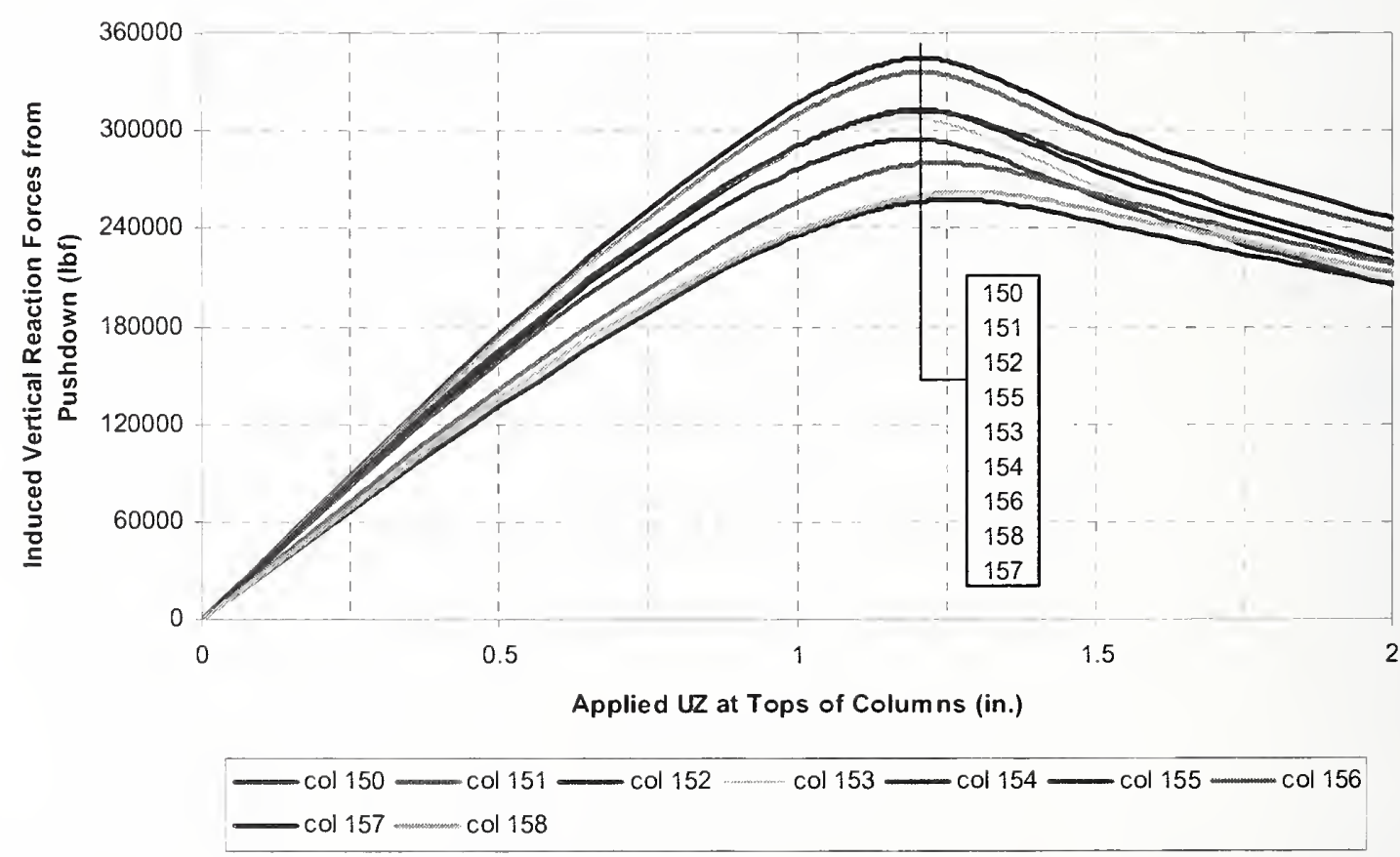

Figure 6-37. Individual additional column reaction forces at base induced by imposed vertical displacement during push-down after application of temperature DBARE with three unbraced floors. 


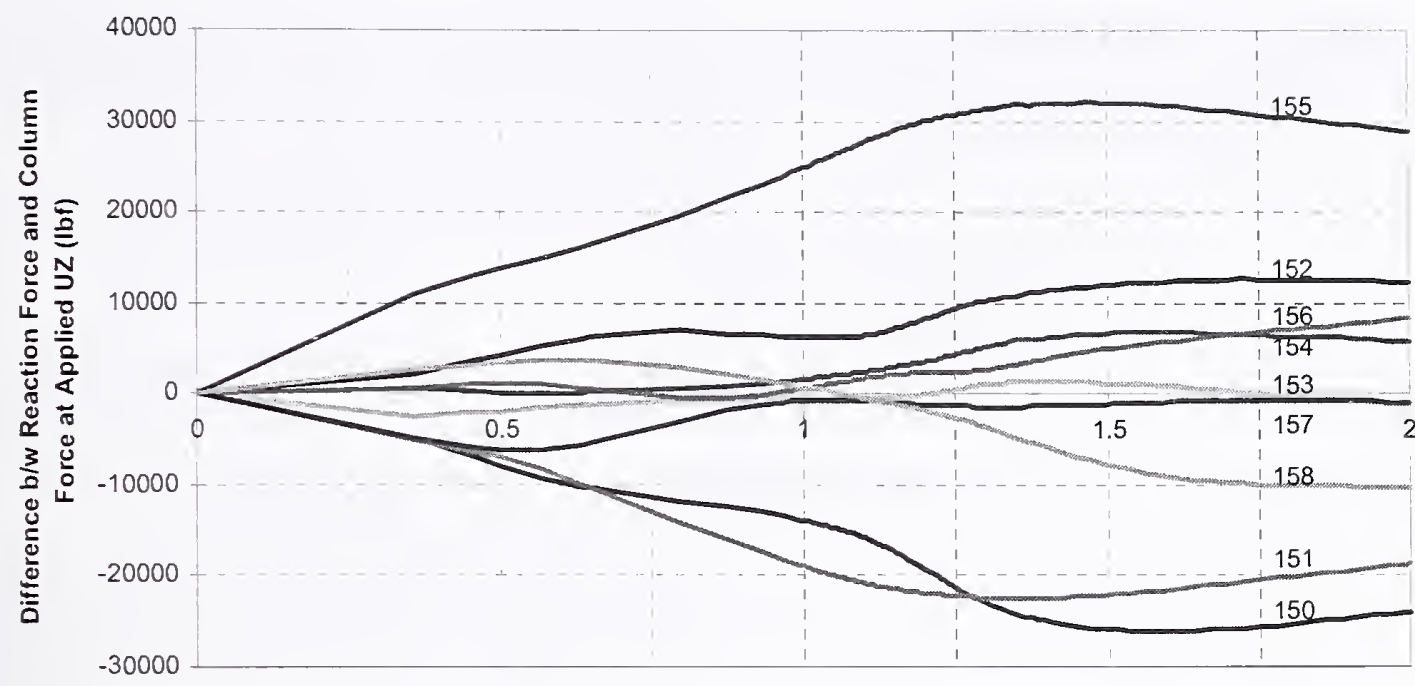

Applied UZ at Tops of Columns (in.)

$-\operatorname{col} 150-\operatorname{col} 151-\operatorname{col} 152=\operatorname{col} 153-\operatorname{col} 154-\operatorname{col} 155-\operatorname{col} 156$
$-\operatorname{col} 157-\operatorname{col} 158$

Figure 6-38. Difference between the additional individual column reaction forces at base and the vertical force applied at the top of each column during push-down after application of temperature DBARE with three unbraced floors.

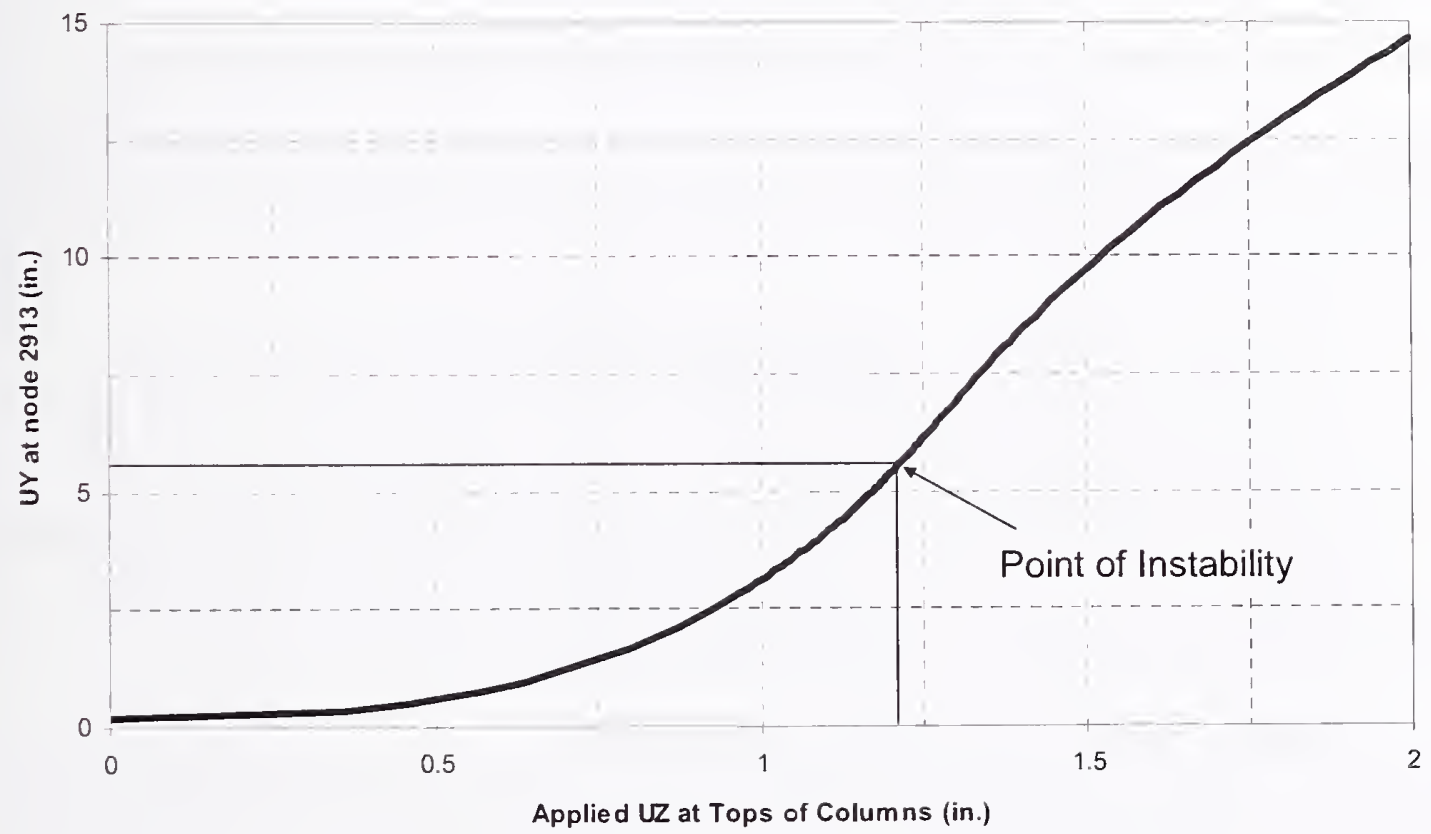

Figure 6-39. Transverse deflection during push-down after application of temperature DBARE with three unbraced floors. 


\subsection{SUMMARY AND DISCUSSION OF EXTERIOR WALL ANALYSIS RESULTS}

\subsubsection{Columns Braced at All Floors}

The analysis results presented above for the exterior wall subsystem with columns braced at all floors, Analysis Case 1 through Case 5, indicate the following:

1. Spandrels had the maximum stress in each Case.

2. The maximum spandrel stresses were at the columns.

3. The maximum spandrel strains were plastic.

4. Spandrels experienced large lateral distortions, indicative of lateral buckling.

5. Spandrel splices partially separated, but no spandrel splice separated completely in any of the five Cases. Partial failure of spandrel splices typically indicated tearing failures at Floor 97 and above and bolt shear failures at Floor 96 and below.

6. Lateral deflections of columns did not exceed $1 \mathrm{in.}$

7. The principal contributor to the total vertical deflection of the columns was the unrestrained vertical expansion due to thermal effects.

8. General instability of the exterior wall did not occur.

The model was unrestrained against in-plane deflection at both edges. In-plane deflection restraint from the remaining wall can further increase the lateral distortions, possibly buckle the spandrels, and fail additional spandrel splices from thermal expansion effects.

\subsubsection{Columns Not Braced at Floors 95 and 96}

The analysis results for the exterior wall subsystem with columns not braced at Floors 95 and 96 , Analysis Case 6, indicate the following:

1. Lateral deflections of the columns were less than $1 \mathrm{in.}$

2. There was no plastic strain in the columns and spandrels.

3. All column-splice contacts remained closed.

4. There was additional partial spandrel splice separation at Floors 95, 96, 97, and 99.

5. No spandrel splice separated completely. Partial failure of spandrel splices indicated tearing failures at Floor 97 and above and bolt shear failures at Floor 96 and below.

6. General instability of the exterior wall did not occur.

\subsubsection{Columns Not Braced at Floors 95, 96, and 97}

The analysis results for the exterior wall subsystem with columns not braced at Floors 95, 96, and 97, Analysis Case 7, indicate the following:

1. Lateral deflections of the columns were less than 1 in.

2. There was no plastic strain in the columns and spandrels.

3. All column-splice contacts remained closed. 
4. There was additional partial spandrel splice separation at Floors 95, 96, 97, and 99.

5. No spandrel splice separated completely. Partial failure of spandrel splices indicated tearing failures at Floor 97 and above and bolt shear failures at Floor 96 and below.

6. General instability of the exterior wall did not occur.

\subsubsection{Columns Not Braced and Pulled in at Floors 95, 96, and 97}

The analysis results for the exterior wall subsystem with columns not braced at Floors 95, 96, and 97 and subjected to pull-in force after DBARE temperature condition, Analysis Case 8, indicate the following:

1. A converged solution could not be obtained at the point of instability with a pull-in force greater than 12.6 kip.

2. At $12.6 \mathrm{kip}$ pull-in force, the inward bowing of the exterior wall was $10.2 \mathrm{in}$.

3. The maximum column stress of $77.2 \mathrm{ksi}$ was at Floor 94

4. Column-splice contacts slid or opened at several columns.

5. No column splice bolts fractured.

6. There were local plastic strains in the spandrel at Floor 94.

7. There was additional partial spandrel splice plate separation at Floor 99, but no spandrel splice separated completely.

8. Instability of the exterior wall with 12.6 kip pull-in force was likely for the temperature condition at the end of DBARE temperature.

\subsubsection{Columns Not Braced at Floors 95, 96, and 97 and Columns Pushed Down at Top}

The analysis results for the exterior wall subsystem with columns not braced at Floors 95, 96, and 97 and subjected to push-down displacement after DBARE tempcrature condition, Analysis Case 9, indicate the following:

1. The maximum sum of total reaction forces resulting from self weight, column and floor loads, and push-down force and was 4,580 kip, for nine columns.

2. The maximum individual total column reaction force was approximately $570 \mathrm{kip}$.

3. The maximum sum of additional column reaction force induced from push-down was 2,710 kip for nine columns.

4. The maximum individual additional column reaction force induced from push-down was approximately $350 \mathrm{kip}$.

5. Point of general instability, i.e. the maximum sum of column reaction forces was obtained at a push-down vertical deflection of 1.2 in.

6. The lateral deflection at point of instability was $5.2 \mathrm{in}$.

7. At an imposed downward vertical displacement of 2.0 in. (i.e., at the end of the push-down analysis), the sum of additional vertical reaction forces was reduced from 2,710 kip to approximately $2,000 \mathrm{kip}$. 
8. At an imposed downward vertical displacement of $2.0 \mathrm{in}$., the lateral deflection increased from $5.2 \mathrm{in.}$ at the maximum load to deflection $14.7 \mathrm{in}$.

9. Instability of the exterior wall was reached at a downward deflection of 1.2 in. when the push-down force was approximately about 150 percent of the initial gravity dead and live loads.

\subsubsection{Summary of Analysis Results}

Table 6-12 provides a brief summary of the exterior wall model analysis results.

Table 6-12. Summary of exterior wall model results.

\begin{tabular}{|c|c|c|c|c|c|}
\hline $\begin{array}{c}\text { Analysis } \\
\text { Case }\end{array}$ & $\begin{array}{c}\text { Total Deflection } \\
\text { (in.) }\end{array}$ & $\begin{array}{c}\text { Maximum } \\
\text { Stress } \\
\text { (ksi) }\end{array}$ & Plastic Strain? & $\begin{array}{c}\text { Number of } \\
\text { Spandrel Splice } \\
\text { Break Element } \\
\text { Failures }\end{array}$ & $\begin{array}{c}\text { Spandrel Splice } \\
\text { Failure Type }\end{array}$ \\
\hline 1 & 1.53 & 49 & YES & 12 & Tearing \\
\hline 2 & 3.74 & 49 & YES & 11 & Tearing \\
\hline 3 & 1.87 & 57 & YES & 48 & $\begin{array}{c}\text { Tearing and Bolt } \\
\text { Shear }\end{array}$ \\
\hline 4 & 2.07 & 53 & YES & 6 & Tearing \\
\hline 5 & 1.57 & 46 & YES & 6 & Tearing \\
\hline 6 & 3.76 & 23 & NO & 14 & $\begin{array}{c}\text { Tearing and Bolt } \\
\text { Shear }\end{array}$ \\
\hline 7 & 3.79 & 23 & NO & 15 & $\begin{array}{c}\text { Tearing and Bolt } \\
\text { Shear }\end{array}$ \\
\hline 8 & 10.4 & 77 & YES & - & - \\
\hline 9 & 14.8 & 69 & YES & - & - \\
\hline
\end{tabular}

${ }^{1} 198$ total possible break element failures

\subsection{SUMMARY OF RESULTS}

The analyses of the exterior wall model support the following conclusions for modeling the towers:

1. Large inelastic deformations of the spandrels and buckling at elevated temperatures can be expected, but they do not significantly affect the stability of the exterior columns and need not be accurately modeled for the global analyses.

2. Partial separations of the spandrel splices can be expected at elevated temperatures, but they do not significantly affect the stability of the exterior columns and need not be accurately modeled for the global analyses.

3. Exterior column splices can be expected to fail by sliding or opening at elevated temperatures and increased vertical loading. However, failure of column splices is expected only in the final phases of collapse sequence and need not be accurately modeled for global analyses.

4. Instability of exterior wall subsystem is expected when at least three floors are unbraced and the exterior wall subsystem is subjected to additional vertical load or pull-in forces. 
5. Plastic buckling by kinking with rapid reduction of load capacity in the post-buckling regime of exterior columns is expected at high column loads and at low temperatures. At lower loads and at high temperatures, plastic buckling with some reduction of load-carrying capacity as expected by P-delta effect occurs. Hence, the kinking-type plastic buckling need not be accurately modeled for global models. 
This page intentionally left blank. 


\section{Chapter 7 \\ MOdELING DeTAILS FOR SUBSYSTEMS IN GLOBAL MOdELS}

Structural analyses performed for components, connections, and subsystems revealed their key structural responses and failure modes. The results of analyses performed on the exterior wall subsystem showed that when the exterior wall subsystem was subjected to fires it would become unstable either when three or more floors were disconnected from the exterior wall and the exterior wall was subjected to additional vertical loads or when sagging floors exerted pull-in forces on the exterior wall. The results of the full floor subsystem analyses showed that the floor disconnected from the exterior wall when the sagging floor walked off the truss seat or the exterior truss seat failed under the combined action of vertical gravity loads and high temperatures.

Based on the results of the finite-element analyses performed on components, connections, and subsystems, a decision was made to use the following modeling details for the subsystems in the global models to enhance numerical efficiency.

\section{Floor Subsystem}

Floors in the global model were modeled by shell elements, which have their membrane stiffness equal to that of the full floor system. Floors in the global model function as diaphragms and transfer load between the exterior wall system and the core.

The global model cannot be constructed with the same level of detail in all floors subjected to thermal loading as the full floor model developed in this report. It was not practical, or in some cases not possible, to create computationally efficient global models that included all details of the floor system. The BEAM188/189 elements used in the full floor model caused sevcre convergence problems when creep was included and those elements experience thermally-induced buckling. Also, the extent of pull-in forces from sagging floors in the full floor models was less than estimated from the observed bowing of the exterior walls in photographs and videos because the aircraft impact damage to thermal insulation of the floors was conservatively estimated by limiting the dislodged thermal insulation to regions of direct debris impact.

To enhance computational efficiency and perform the computations in a reasonable time span, it was decided to model the pull-in forces and disconnections of floors from the exterior walls in the global models as "fire-induced damage" at appropriate times. Since the full floor models did not accurately estimate the pull-in forces at floor/wall connections, the fire-induced damage obtained from the full floor model analyses were modified by "actual observations" obtained from the examination of photographs and videos performed by NIST (NIST NCSTAR 1-5A).

\section{Exterior Wall Subsystem}

The exterior and interior columns were modeled with fidelity of their inelastic buckling behavior. To capture the premature buckling of the single span exterior columns at low temperatures, which would occur at the onset of plate buckling and results in kinking of the cross section, a fine mesh was needed. However, observations of photographs and videos showed that bowing was extended over several floors 
and column temperatures were not low. Therefore, kink-type buckling of the exterior columns was neglected, and was not modeled.

Exterior column splices were not modeled in the global models as failure of columns splices did not occur in the exterior wall subsystem analyses and was not observed in either tower prior to collapse initiation.

Spandrels were modeled by beam elements capable of resisting shear and bending moment. The spandrel splices were not modeled in the global analyses as complete separation of spandrel splices did not occur in the exterior wall studies and was not observed in either tower prior to collapse initiation. 


\section{Chapter 8 \\ REFERENCES}

ACI Committee 209 (1992), "Prediction of Creep, Shrinkage, and Temperature Effects in Concrete Structures," ACI 209R-92, ACI.

ACI Committee 318 (2002), "Building Code Requirements for Structural Concrete and Commentary," ACI 318-02, ACI.

American Institute for Steel Construction (2003), Mannal of Steel Constrinction, Load and Resistance Factor Design, 3rd Edition, AISC.

American Institute for Steel Construction (2001), Manural of Steel Construction, Load and Resistance Factor Design, 2nd Edition, AISC.

American Institute for Steel Construction (1964), Manual of Steel Construction, Allowable Stress Design, 6th Edition, AISC.

ANSYS, Inc. 2004. ANSYS Release 8.1 Docimentation. ANSYS, Inc., Canonsburg, PA.

ANSYS, Inc. 2004. Theory Reference, ANSYS, Inc.

Bartlett, F. M. and MacGregor, J. G. (1996), "Statistical Analysis of the Compressive Strength of Concrete in Structures," ACI Materials Jonmal, March-April, pp. 158-168.

Fields, B. A. and Fields, R. J. (1991), The Prediction of Elevated Temperature Deformation of Strnctural Steel Under Anisothermal Conditions, NIST.

LERA (2003), Development of Structural Databases and Baseline Models for the World Trade Center (WTC) Towers - Progress Report \#4: Structural Analysis Computer Models.

Livermore Software Technology Corporation. 2003. LS-DYNA User's Mannal. Livermore Software Technology Corporation. Livermore, CA.

Phan, Long T. (1996), Fire Performance of High-Strength Concrete: A Report of the State-of-the-Art, NIST.

Seanz, L. P. (1964), "Discussion of Equation of the Stress-Strain Curve of Concrete by Desayi and Krishman," Jommal of the American Concrete Institute, Col. 61, No. 9, pp. 1229-1235.

Stevick, G. R. (1994), "Failure of Welds at Elevated Temperatures," Welded Research Council Bulletin 390, Welding Research Council, pp. 1-39. 
This page intentionally left blank. 


Federal Building and Fire Safety Investigation of the World Trade Center Disaster

\section{Component, Connection, and Subsystem Structural Analysis}

Mehdi S. Zarghamee,

Said Bolourchi

Daniel W. Eggers

Ömer O. Erbay

Frank W. Kan

Yasuo Kitane

Peter R. Barrett

John L. Gross

Therese P. McAllister

\author{
Atis A. Liepins \\ Michael Mudlock \\ Wassim I. Naguib \\ Rasko P. Ojdrovic \\ Andrew T. Sarawit
}


